\title{
Matjapat Songs \\ in Central and \\ West Java
}

\section{Margaret J. Kartomi}

Monash University in association with The Faculty of Asian Studies and the Australian National University Press

Canberra 1973 
This book was published by ANU Press between 1965-1991.

This republication is part of the digitisation project being carried out by Scholarly Information Services/Library and ANU Press.

This project aims to make past scholarly works published by The Australian National University available to a global audience under its open-access policy. 


\section{Faculty of Asian Studies \\ Oriental Monograph Series}

These monographs are a continuing series on the Ianguages, cultures, and history of China, Japan, India, Indonesia, and continental Southeast Asia.

1. A.H. Johns : The Gift Addressed to the Spirit of the Prophet (1965)

2. H.H. Dubs (compiled by Rafe de Crespigny) : Official Titles of the Former Hon Dynasty (1967)

3. H.H.E. Loofs : Elements of the Megalithic Complex in Southeast Asia : An annotated bibliography (1967)

4. A.I. Basham (ed.) : Papers on the Date of Kaniska (1969)

5. A. Yuyama : A Bibliography of the Sanskrit Texts of the Saddharmopundarikasütra (1970)

6. I. de Rachewiltz and M. Nakano : Index to Biogrophical Material in Chin and Yüon Literary Works (1970)

7. Miyoko Nakano : A Phonological Study in the 'Phags-pa Script and the Meng-ku Tzu-yion (1971)

8. K.H.J. Gardiner : The Early History of Korea (1969)

9. Rafe de Crespigny : The Last of the Han (1969)

10. Frances D.M. Dow : Mandarin Phonetics. 2nd Edition (1972)

11. Igor de Rachewiltz and May Wang : Index to Biogrophical Material in Chin and Yüan Literary Works, Second Series (1972)

12. D.N. Lorenzen : The Kōpālikas and Kälömikhas : Two Lost Saivite Sects (1972)

13. Margaret J. Kartomi: Matjopat Songs in Central and West Java (1973) 


\section{MATJAPAT SONGS \\ IN CENTRAL AND WEST JAVA}

\section{Margaret J. Kartomi}

Published in association with

Monash University

and

The Faculty of Asian Studies

The Australian National University

Australian National University Press

Canberra 1973 
First published in Australia 1973

Printed in Canberra for the Australian National University Press, Canberrs

North, South, and Central America: International Scholarly Book Services, Inc., Portland, Oregon

Southeast Asia: Angus \& Robertson (S.E. Asia) Pty Ltd, Singapore

Japan: United Publishers Services Ltd, Tokyo

C Margaret J. Kartomi

1973

This book is copyright. Apart from any fair dealing for the purposes of private study, research, criticism, or review, as permitted under the Copyright Act, no part may be reproduced by any process without written permission. Inquiries should be made to the publisher.

Registered in Australia for transmission by post as a book

ISBN

0708103553

Library of Congress Catalog Card No, $72-94035$ 


\section{Preface}

The uses, functions and degree of musical significance of the matjopat song genre in Javanese and Sundanese societies cannot adequately be compared with any one song genre of a Western society. Tembang matjopat is both 'folk' and 'art' song. It resembles Western folk-song in its relatively free and improvisatory performance practice and in that the composers and poets of matjopat songs remain, more often than not, anonymous. But unlike Western folk-song, which in feudal society belonged chiefly to the village populations of rural areas, songs in matjopat metres are found in both courts and villages, as well as in the various forms of commercialised and non-commercialised theatre in the cities, towns, villages, and courtly centres. The songs range from short, straight forward ditties to songs of a high degree of artistic complexity and refinement. Performed by unaccompanied solo singer or interpreted to the accompaniment of elaborate ensemble, tembang matjapat comprises love songs, religious songs, moral-didactic songs, songs for and by children, lullabies, songs paying respect to parents and superiors, ceremonial songs of court and village, and songs of dramatic intent.

An ethnomusicological study of such a widely significant and little investigated cultural medium as tembang matjopat cannot restrict itself to purely musical elements, but has to take into account the place of these songs in society, past and present. While Part I treats in a general fashion of social, historical and textual aspects, compiled partly from observations in the field work period and partly from secondary sources, Part II deals with the purely musical aspects. Chapter 3 , which gives an outline of the main developments of tembang matjopat in its historical context, refers to such questions as Indian-Javanese cultural contact, the impact of Islam and the rise of Western colonialism, all of which developments are reflected in the poetic content and structures and indirectly in the musical styles of tembang matjopat. 
Part II is based chiefly on analyses of musical sources, which consist of taped and disc-recorded performances of matjopat songs transcribed in Western notation. The songs were collected by my husband and myself, partly in Java in 1959 and partly from Javanese and Sundanese singers visiting Europe in 1965. Tape recordings from Radio Republik Indonesia and the Ethnomusicologisch Archief, Muserm voor de Tropen in Amsterdam were used as well as the Lokananta disc ALD-041 and notated melodies from songbooks published in Java.

The original plan of this work was to incorporate all the main areas in Indonesia where songs in matjopat metres are sung, namely Central Java, Sunda, East Java, Madura, and Bali. However, the size of such an undertaking has prevented this for the time being. The musical elements of Central Javanese matjopat alone may be regarded as an interminable study:

The scope of the work was therefore limited to matjopat in Central and West Java, based on a fairly large collection of taped performances of songs in both these areas. Sundanese musical styles are admittedly radically different from Central Javanese musical styles, especially in vocal techniques. But in a first study of matjapat, the additional breadth afforded by a comparison of songs in these two major stylistic areas seems advantageous, especially in view of the fact that some formal musical elements in both regions are similar and prosodic structures are basically the same.

Both Javanese and Sundanese admit that elements of Central Javanese culture have entered the realm of Sundanese culture over the centuries, chiefly by way of the courts. Powerful political rivalry has long existed between the Javanese and Sundanese, with the Javanese generally dominant. Despite this, the Sundanese certainly did not adopt elements of Javanese culture blindfold. Borrowed elements were not only highly selective but were radically 
changed to meet Sundanese stylistic preferences. Thus, tembang matjapat was admitted into Sundarese culture with prosodic elements unchanged but with poetic and musical styles transformed in their very essence. There are some indications, moreover, that Sundanese musical style has had some influence on the music of the Central Javanese area of Banjumas, especially in vocal and kendang performance styles.

The great majority of songs in this collection are unaccompanied. From the total collection of 250 songs or versions of songs, each of which was subjected to detailed musical analysis, 147 Central Javanese and 54 Sundanese transcriptions were selected.

A few singers who performed songs on tape wished to remain anonymous and were therefore given fictitious names.

Indonesian words are spelled according to official Indonesian orthography (as of 1972). As is often the case in recent publications using the Javanese language, especially Javanese song books, diacritical marks are omitted. For the sake of orthographic clarity, the singular and plural forms of Javanese, Sundanese, and Indonesian words are written identically, e.g. both the singular and plural of kidung are kidung.

The word 'Javanese' in its wider sence applies to the whole island of Java. In its narrow sense it applies only to the language and culture practised in Central and East Java, the West Javanese language and culture being covered by the word 'Sundanese'.

This work is a revised version of the author's doctoral thesis Matjapat Songs in the Culture Areas of Central and West Java. 


\section{ACKNOWLEDGMENTS}

To all the Central Javanese and Sundanese singers who allowed us to tape their performances of matjopat songs and freely gave information and opinions, and to Drs Ernst Heins of the Ethnomusicologisch Archief; Institutit voori de Tropen, Amsterdam, who allowed us to make copies of tapes, I wish to express deep appreciation.

Of those in the Musikwissenschaftliches Institut, Humboldt Universität, who contributed their help during the preparation of the thesis, I wish particularly to thank Professor Georg Knepler and Dr Jürgen Elsner for their valuable criticisms and suggestions and Dr Reiner Kluge, who suggested a method to measure change of melodic direction.

My husband Hidris, whose mother languages are Javanese and Sundanese, whose taped performances of songs are included in this collection, who helped collect and tape other performances and who bore most of the work of translating the song texts, has assisted and advanced the writing of this work in every way. 
Contents

Preface

Acknowledgements

viii

Abbreviations

ix

Part I Matjapat in Society and History

1 Tembang Matjapat in Society 3

2 Tembang Matjapat in History 16

3 Prosodic and Linguistic Aspects 38

4 Poetic Content 56

Part II The Music

5 Collection and Transcription of Songs 67

6 Musical Concepts and Methods used in the Analyses

$7 \quad$ Song Analyses 102

8 Melodic Classifications $\quad 137$

$\begin{array}{ll}\text { Notes } & 167\end{array}$

$\begin{array}{ll}\text { Glossary } & 187\end{array}$

Musical Terms 197

Bibliography 203

Appendix I Translations of Song Texts 211

Appendix II Transcriptions of Songs in Matjapat metres $\quad 249$

Appendix III Literature About the Music

$$
\text { of Java. } 523
$$

Appendix IV Number Scripts and Tone Names

in Javanese and Sundanese Songs 534

Index 537 


\section{ABBREVIATIONS}

L.J. Low Javanese

H.J. High Javanese

IPT First Pillar Tone

IIPT Second Pillar Tone

O.P. Original pitch of performance before transposition.

T.I. Time-length, duration of a song.

M.M. Mbombong Manah, books of Javanese songs, R. Tedjohadisumarto (collector) Djakarta, 1958.

G Gong

k ketuk

n-6 kenong on tone 6

pj kempjang

p kempul 
PART ONE

MATJAPAT in SOCIETY and HISTORY 
The dearth of scholarly writings on tembang matjapat in no way reflects upon its longevity, popularity and pervasiveness in Javanese society past and present, nor on its wide participation and significance in many of the other fields of Javanese art. Like every other branch of Javanese culture, tembang matjapat embodies many facets of the whole life and culture. The parcelling off of different art fields as distinct, separate entities did not take place in feudal Java, the arts of tembang, gonelan, wajang, sastra (literature), keris, batik etc., all forming an interactive unity of artistic styles, mythological content and visual, moral and aesthetic ideas. The art of wajang, as an obvious example of unity between Javanese art fields, combines the arts of theatre, literature, song, declamation, gamelon, and puppet design and craftsmanship, its play of shadows symbolising and reproducing the mythology, taboos, and mysticism of ancient Java. ${ }^{1}$

Unity in Javanese art is also exemplified by the animist symbolism in some matjapat song texts which correspond to the symbolic meaning of animal and nature design in Javanese visual arts. ${ }^{2}$ The musical term eluk used in tembang matjapat probably derives from the terminology of the sacred weapon keris. The foreign origin of tembang gede refers only to the metrical system of the poetry and not in any way to the musical aspects; indeed, the tembang gede melodies are as distinctly Javanese as any of the tembang matjapat or tengahan. Musically all three types of tembang form a unity of rocal style.

Between tembang matjapat and the other branches of Javanese art there exists, then, either a direct or a symbolic 
interrelationship which results from the great antiquity of Javanese art and social forms. Tembang matjapat is a direct participant in the arts of theatre and dance, ancient and modern, in belletristic and historical literature, in gending and in the field of lightly accompanied or unaccompanied solo and choral song. The symbolic roots of tembang matjapat (understood in its widest sense as being song in autochthon Javanese poetic metres), reflecting life in Java and the world views of its aristocracy and peasants, the historical events and the canonic development of art in Java's long contact with foreign ideas and cultures, reach back into the ancient myths, communal ceremonies, and traditions of early Java.

Hence, in matjapat songs we find reference to or expression of not only the old pagan animist ideas and symbolism but also those of Hinduism, Islam, and Christianity. We find matjapat texts dealing with ald indigenous mythical stories (such as those of the Pandji myth) as well as texts relating Javanised versions of the Indian epics Rämâyana and Mahābhärata. Not individualistic ideas but sense of values and moral attitudes are expressed, attitudes essential since earliest times for the survival of the complex traditional community organisations of rural Java.

Matjapat songs are an integral part of forms of Sendratari (Seni Drama Tari), as in the moonlight dancedrama performances of stories of the Rāmāyana in front of the Giwa temple at Prambanan, Central Java. At Prambanan the stories are told, in the absence of dialogue, by a group of singers in matjapat and gede metres to gamelan accompaniment. Matjapat songs are also used in forms of village theatre (such as Wajang Kulit, Wajang Orang, Sundanese Reog), courtly theatre (Wajang Kulit, Wajang Orang, Langendrijan, Langenasmara, Langenwanara) and 'town' theatre (Wajang Orang, Ludruk, Ketoprak, Sundanese Sandiwara etc.). 
Matjapat texts incorporate not only independent short poems expressing single ideas such as joy at the sight of a harvest, but also lengthy literary forms such as the babad (historical writings from the pasisir period onwards), the kidung (story-poems in matjapat and tengahan metres), parts of the lakon (wajang texts), and the suluk (mystic poems in matjapat metres). These literary forms relate perennially popular legends and romances of indigenous and foreign origin, the sources of the rich mythological characters and tales of Java. Indeed, most Javanese belletristic literature since pasisir times has been written in matjapat metres, and many old poems were re-written and adapted into matjapat poetry.

On the purely musical side, tembang matjapat is integrated stylistically with the body of Javanese music proper. The pelog and slendro tonalities and all that is implied by the concept of patet are equally characteristic of matjapat vocal melodies as they are of instrumental gamelan music. Most characteristically, in village and in court, matjapat singing is a rhythmically 'free', metrically irregular, unaccompanied vocal medium, in which rhythmic, melodic, ornamental, and intonational variability reach far beyond the stylistic limitations of idiophonic instrumental music. But matjapat songs are also frequently accompanied by full gamelan or lightly accompanied by the gender in Central Java or the katjapi in West Java. When accompanied, the vocal style of the Sinden, Dalang, or Wajang Orang soloist is restricted in its degree of musical variability by the requirements of ensemble performance, and even more stringently in the case of a choir (Gerongan). The greatest degree of freedom in the performance of matjapat songs is sometimes reached in the unaccompanied introductions to gamelan works.

Tembang, and particularly tembang matjapat, is indeed 
one of the most frequently practised and popular of Javanese traditional art forms, 'for it takes no capital to sing and not very much skill'. As Geertz reports from a village in Java, 'you cannot walk from one end of Modjokuto to the other after ten at night and not hear someone singing a tembang somewhere along the way'. 3

Matjapat song is both folk-song and professional song, belonging to the village, to the theatre, and to courtly ceremony. A mother may sing her child to sleep with a matjapat song; a famous Dalang or Wajang Orang performer may sing melodies in matjapat metres in their theatrical performances; a Surakarta Keraton Pradjurit facing the large door behind which, in olden times, the Susuhunans were wont to sleep, may sing all night matjapat songs in a style 'extremely surcharged with variations and fiorituri prescribed by tradition'. 4 It is possible that matjapat singing in Javanese courts may have been bound to regulations reflecting the hierarchy of courtly life in the manner that certain gending, batik, and keris designs are known to have. However, many traditional courtly customs extant before World War II have been irrecoverably lost, due to paucity of documentation. The practice of midnight singing in the courts is the only known and surviving practice of unaccompanied, ceremonial, courtly matjapat singing. And even this is no longer done in the keraton of the Sultan of Djogjakarta. 5 Only tembang gede is regarded as a fit medium in which to honour the Sultan in Ujon-ujon concerts given, for instance, on the birth days of the Sultan (honoured every 35 days). Musically, however, the style of singing tembang gede seems to resemble tembang matjapat closely.

Matjapat songs play certain functional roles within gending, some of which are entitled after matjapat metre names (e.g. Ketowang Midjil Sulastri, ${ }^{6}$ Gerong Gending 
Pangkur, ${ }^{7}$ Ladrang Pangkur, ${ }^{8}$ and Srepegan Dandanggula), in a similar fashion to the practice of naming some aristocratic batik designs after certain gending names. An accompanied or unaccompanied vocal introduction to a gending - a Bawa is sometimes based on a matjapat poem or the first line thereof. Intermezzo songs between theatrical acts (Uranuran) are often matjapat songs. ${ }^{9}$ One or more solo or choral songs within a gending often follow or alternate with songs in other metres. For instance, the Sinden in the Ladrang Pangkur ${ }^{10}$ sings her free melodic line over the strict quadruple beat of the gamelan to the Kinanti Djugag and Kinanti metres. Sometimes in the course of a gending the whole gamelan halts while a singer performs an unaccompanied, highly ornamented, relatively free-rhythmic song in a matjapat metre, contrasting strongly with the strict quadruple beat and mass of sound of the main body of idiophonic gamelan instruments. For instance, a male Wajang orang actor gives a powerful performance of an unaccompanied Midjil in the middle of the gamelan-accompanied Gatutkatja Gandming. II In this same example, a popular matjapat melody is repeated by the male singer within the piece, a contrasting female voice performing another melody between repeats (Kinanti, Transcriptions 45 and 46). ${ }^{12}$

The symbolical and magical meaning of certain matjapat songs was probably of deeper significance and more widely accepted in previous centuries than in modern rural Java, just as some batik designs generally believed to possess magic curing power to the wearer have to a large extent lost their magical meaning and are today mass-produced for general consumption. ${ }^{13}$ But animist views persist in many rural areas, as opposed to the cities and towns, which have acquired a new social order and outlook through foreign contact and Indonesian nationalism. Ancient pagan 
rites such as the Nini Towong rain-making ceremony in the Banjumas area still exist. The evergreen Wajang Kulit still preserves the spirit and imagery of Hindu-Javanese times. Song is still employed by some with intent to repel evil forces believed to cause illness and calamities of all sorts. In the villages, some people of the older generation still sing matjapat songs at home in order to calm themselves when in a state of fear or to avert illness or adversity. These are mostly taken from the Kidung, which are long story-poems or advice-poems in matjapat and tengahan metres. Satjadibrata even defines $k i d u n g$ in his Sundanese-Indonesian dictionary as tembang jang maksoednja oentoek menolak bahaja karena perboeatan hantoe, which translates as 'tembang (sung) in order to fight off the danger of actions by evil spirits'. 14

Outspoken expressions of the animist outlook are still to be found in modern Java, especially in times of crisis or stress. I have been told that in the Wonogiri area of Central Java, during the revolutionary struggle against the Dutch, guerilla fighters used to hold Kidung nights every Friday from late evening, sometimes until dawn. Participants sang magically powerful kidung (matjapat songs) in the belief that this might help to frighten the enemy away. It certainly helped to build up their self-confidence.

On the occasion of an ordinary Malam Kidungan (Kidung Night), the neighbours young and old gather together in the host's house and partake of specially prepared food. The women on such occasions mainly attend to the cooking and serving of food, after which they sit together in a back room of the house. The men sit in the front of the house, usually in an open-walled room called a pendapa, and sing from a Serat Kidungan (Kidung book), which may be a venerated old volume in Javanese script or, as is generally nowadays the case, a printed pamphlet of kidung in Latin script. 
Since these kidung poems are often very long, the performers tend to sing them in straightforward, simple lugu fashion, at a fairly fast rate and with a minimum of ornament, in order to finish performing the whole book in the one night. Women do not dare to sing these magically powerful songs partly because, I was told, the menses invite bad spirits. Women and children may sing only those matjapat songs which deal with themes from every-day life.

Matam Kidungan may be held on such occasions as moving into a new house, or celebrating the planting or harvesting of rice. One may be held on special ceremonial occasions such as the Tingkeban, a celebration held in honour of a seven-months pregnant woman, because she is about to enter the state of motherhood; or after a Tjukur Baji ceremony, when a new-born baby's hair is cut for the first time. Sometimes they are held simply because a host happens to have some extra funds.

However, Malom Kidungan are not as frequently held now as they were a half a century ago. This is especially the case in West Java, where matjapat singing is becoming more and more a professionalised activity or looked upon as belonging to the older generation. This tendency may also be observed in rural Central Java but to a much lesser extent. Some amateur radio stations (e.g. P2SC in Djakarta) broadcast a MaZam Kidungan every 35 days on Djumat Kliwon. ${ }^{15}$ Matjapat singers from various parts of Central Java gather in the studio late at night, sit sila (crosslegged) on the floor, sipping tea until dawn, singing excerpts from a Kidung book in Javanese script, or improvising texts on the spot. The national Radio Republik Indonesia also broadcasts matjapat singing in smaller quantities in Java.

In the popular ceremonial feasts named Slametan (held 
on occasions of birth, marriage, death etc.), ${ }^{16}$ or at school and other gatherings, the guests present are sometimes welcomed by a choir singing a Panembroma song in a matjapat metre (for examples see Transcriptions 111 and 121, entitled Kinanti Panembrama). Sometimes the more formal part of a Slametan; with its religious and other ceremonies relevant to the occasion, is followed by a Malon Kidungan, during which the host and guests relax with solo or community singing of well-known matjapat songs.

Advice to a bride is sometimes sung in tembang, in order to ensure long-lived happiness in wedded life. $D i$ Pradjia reports and gives textual examples of songs in Dangdanggula, Sinom and other metres, performed in honour of a Sundanese bride. ${ }^{17}$

In the Keraton Kasepuhan in Tjirebon, a special kidung singer is employed to sing at the ceremony to celebrate the first time a royal baby walks, at the age of seven months. This ceremony is called Upatjara Mudun Lemah (crown-touching ceremony). The baby is helped to walk through sadjen (offerings) from a bamboo cage up five golden steps to a throne and back. The five steps symbolise the five rules of Islam and the Moslem prayers which should be said five times a day. Several objects are placed in the cage and the parents watch to see which object the baby touches first. If he touches a gold object, it means he will be rich. If he touches rice, it means he will become a farmer, or at least have to do with the soil. If he touches a pen, it means he will become a scholar. This ceremony is also performed outside the keraton in the Tjirebon area, although it has been rarely performed since the forties.

A large number of matjapat songs play an educative 
role. Moral and religious teachings, albeit sometimes with a feudal tinge, are taught through the song texts. Many songs are intended for children and taught to them by rote at school and at home in order to instil social attitudes and expected behavioural patterns. As a result, the great majority of Javanese and Sundanese village dwellers and court functionaries as well as many city dwellers can sing matjapat songs; of course, the number of songs known and the standard of performance largely depends on the talent and musical experience of each singer. Few people born in a Javanese or Sundanese village are unable to sing a few tembang, although the more talented singers (in our experience) are usually much more ready to perform than the others.

With the development of 'popular' theatre and music in the last hundred years or so and the import of foreign, popular entertainment into the cities during the twentieth century, the role of classical tembang matjapat as a ceremonial adjunct, as a form of corporate, edifying entertainment, as a means of self-expression or as a means of inducing spiritual intervention may be observed to be diminishing in cities everywhere and especially in Sundanese cities. Some young city people who learnt matjapat songs during childhood no longer wish to sing them, regarding them as old-fashioned in style and superseded by songs of foreign import. Some reject the songs because of their feudal or their religious content, regarding them as the soporific antipathy of progressive ideas in the modern situation. Increasing numbers of middle-class city dwellers and Indonesians of foreign descent, having received a metropolitan Indonesian, European or a Chinese education, never have the chance to learn how to sing tembang either at school, at home or from the neighbours and are therefore 
usually not very appreciative of them.

In the villages, on the other hand, acculturation or simple adoption of Western or other foreign cultural elements does not yet seem to be of very great detriment to the indigenous culture, the people remaining proud of and fascinated by their own culture of ancient origins. The mythology and religious beliefs contained in their art are still reflected in their everyday life, moral codes, and inhibitions. The artistic leadership of the keraton continues to some extent to be respected, the wajang performances continue to fascinate, the gamelan and small ensembles continue to be played nightly and the tembang are sung and enjoyed by the old as well as the young on ceremonial occasions, at work and in times of relaxation. R. Tedjohadisumarto, wanting to express the universal value of singing tembang, writes (in 1958) ${ }^{18}$ that in his experience tembang is commonly sung when one wishes to express one's emotional state of happiness or sadness. At work one sings too, for instance in order to lighten the task of helping to lift a heavy weight. Young people, he says, on occasions when they happen to be together,; simply like to sing tembang. And tembang is of great disciplinary and intellectual value when learnt and sung properly in school by children.

In recent times, matjapat songs have been adapted to serve modern theatrical as well as social, political, and religious propaganda purposes and therefore cannot be regarded as belonging purely to the alus art forms in the sense put forward by Geertz. ${ }^{19}$ Geertz distinguishes three 'art clusters' in Java: i) the alus or 'refined' art complex (including wajang, gamelan, tembang etc.), which is popular among all social classes but finds its greatest strength among the prijaji; ii) the kasar or 'unrefined', 'rough' art complex (Ludruk, Dongeng etc.), which belongs to the 
classes with the abangan outlook, consisting chiefly of the peasantry; and iii) the modern 'national' art complex (popular songs, dance bands etc.). A fourth category to classify art forms like Wajang Orang and Ketoprak is termed 'popular' art.

These art clusters, oversimplified for purposes of classification, are by no means matually exclusive. Kasar elements are to be found in the alus art complex; for instance, the kasar Panakawan characters are an essential part of the notably alus art of Wajang. Alus elements are to be found in the so-called kasar art forms; even the performances of the transvestite singers in Iudmuk theatre contain some elements of alus art styles. ${ }^{20}$ Both kasar and alus elements are to be found in the 'national' art complex and in 'popular' art. The modern Indonesian popular song may use not only classical prosodic rules but may also include references of a kasar nature and humorous content in its text.

The three 'cluster' classifications certainly overlap in the case of tembang matjapat. True, its traditional calmness of rendition, its highly ornamental, 'free'-rhythmic melodic line and its classical text composed to strict prosodic rules classify it as an alus art form alongside the alus arts of gamelan and wajang. Contradictions between alus and kasar elements as found in most Javanese theatrical productions are by no means excluded from matjapat texts; witness for example the conversations between the kasar giants and the alus knight in Durma (Transcription 3) and Sinom (Transcription 11). Musical styles have expanded; they feature not only alus and kasar elements but also 'national' and 'popular' characteristics. Religious and political gatherings have included the singing of tembang of suitable content. ${ }^{21}$ Especially since the 1945 Revolution, 
matjapat songs in modern, everyday language have been created, using old or new melodies and popularising social, political, and religious ideas, the aim being to modernise traditional theatre, literature, and song without losing the 'cultural identity' of the respective Indonesian region. The Javanese Transcription 51 (Durma) and the Sundanese Transcription 52 (Durma) express political ideas in the times of Soekarno, whereas many matjapat song texts listed in Sinau Tembang Djawa combine old Javanese melodies with relatively new texts dealing with biblical themes. Geertz. (The Religion of Java p.343) reports tembang singing in the meditation meetings of the Sumarah religious sect in East Java. Matjapat has been borrowed by art forms described as kasar, as in the case of Ludruk, or 'nationalist', as in the case of political songs of the Soekarno era. Modern theatrical forms such as the Javanese Ketoprak and the Sundanese Sandiwara also adopted matjapat textual regulations for many of their songs, while Langendrijan and the other classical theatrical forms continued as always to use the matjapat prosodic system in their Zakon.

Tembang matjapat, then, belongs essentially but not entirely to the art complex described as alus; an art complex which should be regarded as having had wide and ancient social origins, which has been stylistically refined and elaborated to fit courtly requirements and taste, but which is indeed most ubiquitously practised and enjoyed outside the courts. The role of the courts in the stylistic development of matjapat songs is very significant, but the sources of musical and poetic vigour and spontaneity as well as much of the poetic content, folklore, and spiritual depth must be accredited to the village populations of rural Java, to whom the majority of matjapat texts and melodies belong. 
The roles of matjapat in recent times raise the question as to the probable extent of future changes in musical style, to correspond with the textual modifications and its expanded use for purposes of political, social, and religious publicity. Some modern matjapat songs have adopted what Indonesians would call 'international' (Western) or 'semi-international' musical styles. But political, social, and religious organisations have adopted a gradualist, not a radical policy of cultural change. Instead of abandoning the old songs entirely, they have adapted old melodies to texts with a new content, or they have used new musical styles and poetic content expressed in texts based on the old prosodic regulations.

Apart from these policy considerations, it is unlikely in any case that in the near future the traditional matjapat styles will be entirely superseded by new musical styles, given the absence of any strong trend toward social change in rural villages. Villagers have not outgrown the need to express moral-didactic, spiritual, emotional, humorous and other ideas and experience in tembang matjapat.

Some degree of stylistic change is, we should admit, necessary if matjapat is to retain its vigour and vitality as a creative art form. But it is likely that the forces of change will co-exist with an active preservation of the old songs, as long as there is a social and artistic need for them. 
Tembang Matjapat in History

Unfortunately, since the earllest Javanese musical notation systems were developed in the midale of the nineteenth century and there was therefore no tangible way of preserving the melodic lines or other musical elements of matjapat songs, the long-term history of matjapat melody must remain unrecorded. ${ }^{l}$ However, since all poetry in Javanese metres is intended to be sung (it is, indeed, never read aloud), the history of matjapat poetry (or what can be reconstructed thereof) is at the same time the history of matjapat song. Some tangible sources exist in the form of literary texts, which by intimation, omission, or direct reference give some clue as to the main historical developments in literature and art. ${ }^{2}$ Ever since Javanese courts adopted the art of writing from India in the early centuries of our era, texts have been written and preserved on lontar leaves or engraved on stone or copper or other metallic plates, some of which heve been deciphered and translated.

Pigeaud has given some indications of the history of matjapat poetry in his Literature of Java. Wherees unwritten matjapat poetry belongs to a very old layer of Javanese culture, it is probable that written matjapat poetry first appeared in kidung form in the latter part of the East Javanese period (thirteenth and fourteenth centuries A.D.). This development of courtly literature in indigenous metres followed the disintegration of the old Indian metric system of the kakawin. Autochthon poetic metres played an increasing role in literature of the ensuing pasisir period. ${ }^{3}$ Eighteenth-and nineteenth-century pudjangga are notable not 
only for their revived interest in the classical prosody of the kakawin but also for their strong interest in poetic techniques and prosody in general. The pudjangga made a distinction between foreign and autochthon prosodies and wrote large amounts both of kakawin and kidung poetry. Possibly in this 'renaissance' period, 4 tembang matjapat acquired the hard and fast prosodic regulations and complex poetic techniques that are in use today. The poetic content of the kidung, babad, suluk and other literary forms kept expanding to include larger amounts of folklore and mythology as well as tales of foreign origin; this broadening of content has continued until the present day to include more recent and topical events and ideas in matjapat poetry.

In West Java, matjapat prosody (which in its modern form originated in the Central Javanese keraton) and even some Javanese melodies and poems were probably imported by Sundanese keraton or the people or both, or by the mixing of the people of both areas, 5 after which the tembang went through a process of Sundanisation in musical style and language. Matjapat repertoires in present day use in West, Central, and East Java each have a common source.

\section{HINDU-JAVANESE PERIOD}

The role played by tembang matjapat in Javanese literature is related to the whole question of Indian-Javanese culture contact. For the Javanese distinguish two basic types in their poetry, divisions based not on poetic content or literary length but on whether a poem's metrical system is of autochthon or fareign (Indian) origin. The metrical system of the former is nowadays termed tembang matjapat and tembang tengahan while the latter is termed tembang gede. The main literary form of the autochthon metres is the kidung while that of the Indian metres is the kakcavin. Both are large poetic forms, often hundreds of verses in 
length.

Iconographical, architectural, literary, legal, and religious sources discovered in the last few centuries indicate that a period of extensive culture contact took place from the first centuries A.D. between the island of Jave (and beyond) and the southern part of the sub-continent of India. ${ }^{6}$ Whether this contact took place through intermarriage, trade, invasion, colonisation, royal invitation, by a combination of ways or by symbiotic interchange is not finally agreed upon, due to the paucity of evidence. But possibly during the first thirteen hundred years or so A.D. when Brahmanism (in its Shivaite form), then Buddhism (Hinajanaist and Mahajanist) and again Brahmanism (chiefly Vishnuite) became state religions in Java, and IndianJavanese trading activities were relatively highly developed, Javanese courts consciously imbibed (and probably promoted) Indian culture-religion, the priests of which were renowned throughout Asia for the 'magical, sacral legitimation of dynastic interests and the domestication of subjects and probably for the organisation of the ruler's territory into a state'. 7 The autochthon animist religion, the basis of which existed in the villages from ancient times, and widespread remnants of which survive today in song texts and other folklore, was probably of too amorphous a character, too much linked with peasant psychological needs to serve as a very effective instrument of feudal control over the masses. Despite or perhaps because of this, it has withstood the test of time better than the various foreign religions which have been promoted by, and for a long time were the exclusive property of, emerging upper class groups, and which in the course of time were remoulded and amalgamated with the old pagan beliefs, which remained because they answered the necessities of peasant life. The mystically sensitive 
Javanese peasants, for whom 'rites connected with ancient indigenous myths, ancestor-worship and cults of local spirits of mountains, sources and rivers probably were sufficient religious bindings with the Unseen', 8 merged mystical elements of the Hindu, Buddhist, and (later) Islamic religions with their own Agama Djawa (Javanese religion).

The gifts from India bestowed upon the field of Javanese culture - the art of writing, the epic poems and imagery of the Mâhabhärata and Rāmāyana (translated into old Javanese at royal command), the prosody of the kakawin, Sanskrit additions to Old Javanese vocabulary, technical knowledge and Hindu-Buddhist religious teachings etc. - must have wrought widespread changes in Javanese court life and the ability of the feudal classes to consolidate their supremacy among the peasant masses through the patronage of foreign religious cults and cultural and technical skills. Elements of Indian culture left an indelible mark on classical Javanese culture as we know it today, although a Javanisation has occurred of whatever foreign elements were found amenable to and acceptable into the field of Javanese culture. Indian influence on Javanese court culture and eventually among the people was mainly that of stimulation and enrichment of a culture already highly developed. ${ }^{9}$

Despite the paucity of reference in literary and other sources to the existence of any Javanese artistic practices outside the courts, there can be no doubt that two or more layers of artistic activity co-existed in the Hindu-Buddhist-Javanese periods. Since the art of writing and other cultural skills were the property of the aristocratic and cultural élite, surviving sources of the times are entirely of court origin. But assumably there always existed a simultaneous and interactive stream of village 
culture and possibly even several other layers of artistic activity within monastic or other religious or social groups. 10 The most stable elements throughout the tumults of feudal power change in the history of Java's upper social strata remained the largely autonomous organisations of the villages.

Mechanically to split up components of a culture which is, and from earliest times was always an organic whole, can be misleading. But, functionallv, two main streams of culture may be distinguished in feudal Java: folk culture, dependent upon tradition and community practice, and court culture, largely dependent upon conscious cultivation and refinement, partly based on Javanese folk and foreign elements. Between these two streams, an exchange of material and stylistic qualities must always to a certain extent have taken place.

Assumably, early Javanese court culture was never purely under Indian influence. Peasant blood must at times have entered court art as the result of courtly patronage of artists from the villages and changes in feudal power, which was more than once taken over by the sons of peasants. ${ }^{11}$ Village elders, craftsmen, and merchants are known to have attended courtly festivities. And possibly certain artists, scholars, and priests of aristocratic origin who took interest in affairs outside the keraton used to take up. elements of folk art into the official, courtly art field. In court wajang, the dalang are known to have criticised 'topical events, sometimes even acts of the reigning prince', by 'performing certain lakons or by interspersing certain allusions in the course of a performance ... of some lakons it is known on what historical occasions they were performed and to what historical events they allude'. 12 
The great Central Javanese period began in the latter part of the seventh century after the decay of power in the early Brahmanist period. The Buddhist Sriwidjaja empire arose with its centre in Palembang, its power having already spread by the eighth century to Central Java where the Cailendra dynasty had expanded its power. No doubt Central Javanese court culture at this time was of a very high order, as witnessed by the famous Barabudur temple, but all written records of the period were lost. Temple reliefs give evidence of a high musical and dance culture at the time.

The epic Rämāyana was possibly translated into old Javanese from the Sanskrit even before the famous Rāmäyana reliefs were sculptured on the Central Javanese temple at Prambanan in the ninth century. This epic relates the many adventures of Prince Rama as he seeks, with the help of the white monkey Anoman, his captured bride Sinta. Poetry in the Central Javanese period was primarily in Indian metres.

The fascinating medium of wajang, in the modern lakon of which songs in matjapat metres alternate with narrated dialogue and songs in gede and other metres, is an art form of uncertain age. According to Rassers, wajang (and, incidentally, the keris) already 'existed in the Middle Javanese period, but ... their function in this culture probably was not very important'. 13 The oldest documentary report of wajang performance is in the eleventh century kakawin entitled Ardjunowiwaha, ${ }^{14}$ but assumably this already developed art form of ancient spiritual and technical origins, the repertoire of which at this time was expanded to include adapted Indian epics, was the possession of the people of Java long before that.

A new centre of power arose at the end of the tenth century in East Java. Although this period is noted for its 
turbulent nature, intrigues, and bids for power, the great kingdoms of Kediri, Singasari and Madjapahit became famous creative centres of 01d Javanese literature. The Mahäbhärata, dealing with the tragic conflict between the five 'right' Pandawa brothers and the ninety-nine 'left' Kurawa brothers, the Bharata Yuddha, dealing with the tragic last war of the Bharata, and the Ardjuna Wiwaha, wedding of Ardjuna, are among the famous Indian epics translated at royal command from Sanskrit into Javanese kakowin verse or prose, as well as many religious and moral texts. Foreign Indian cultural elements may have dominated court culture until the middle of the East Javanese period, but the pudjangga's knowledge of Sanskrit prosody was at this juncture growing ambiguous and kakowin verse more stilted. The kakowin remained important in literature of the fourteenth century and much longer but their rules of metric quantity, which are foreign to the languages of Java, eventually reached a degenerate state in their poetic application.

In Pigeaud's opinion, the rise of Javanese verse in autochthon (matjapat) metres probably took place during the latter part of the East Javanese period. This rise took place not only because of the degeneration of the court's secondhand knowledge of Indian prosody but also by the growth of Javanese feudal power, self-respect, and stability in the greatest empires Java has ever known - the Singasari and Madjapahit. The religious and mythical syncretic process continued, and popular myths, legends, and romances such as the Pandji and Domar Whian cycles expanded the literary repertoire. The romantic adventures of the hero Pandji, who is said to have lived in the Kediri period (1045-1222), are caused, according to the myth, by the abduction of his lovely bride on their wedding night. The handsome young Damar Wulan, born a prince but working as a servant at the court of 
Madjapahit (1294-1478), finally wins the hand of the queen and control of the kingdom after numerous amorous and dangerous episodes.

By the end of the Madjapahit period, the kidung had begun to push the kakowin, which, however, were still being created by the pudjangga, into the background. Kidung written since the East Javanese period have perhaps 'exercised a decisive influence on the development of native Javanese metrics, so-called maçapat metres'. 15

Songs of various poetic content are known to have played an important functional role in court life during Madjapahit, and to have been closely related to dance, theatre, and religious ritual. The kakowin Nagarakertagoma and other fourteenth-century literary works mentioned both instrumental and vocal music (including the singing of kidung $)^{16}$ in the courts. There were songs about rice cultivation, religious offerings and religious and moral didactic subjects. Folk song in native Javanese metres (later called matjapat and tengahan) assumably always coexisted alongside courtly sekar in Indian metres, although the autochthon metres may have taken a quite different form from those in use today. Doubtless, songs in matjapat (autochthon) poetry were sung in the villages from the earliest times, although there are no sources to prove it. Many of the old mythical, historical, and legendary stories of Javanese or foreign origin were sooner or later written down and sung in kidung form. ${ }^{17}$

\section{PASISIR LITERARY PERIOD}

The kidung, wajang, gamelan and other autochthon art forms imbued with overt Javanese mysticism and mythology are the links connecting the Hindu-Javanese world view and culture with the ensuing Islamic period, the authorities of which 
found it necessary to sanction non-Islamic but popular art forms and customs.

The expansion of the Islamic religion in Java from the fourteenth century had, like Hinduism-Buddhism, a stimulating impact upon Javanese culture and was accompanied by Important changes in the socio-political order. Islam, like Hinduism, was spread by a new ruling class, in this case the Pasisir merchant-kings and religious leaders (the Wali). It coincided with the emergence of an expanding middle class of north coastal traders and city artisans, anxious to gain power in order to expand and protect its home and international trade.

As political tensions between the Moslems and the Hindu nobility of Madjapahit grew, the Wali, some of whom were already unorthodox Moslem and under the strong influence of old Javanese religious concepts, helped to spread the Moslem religion and merchant-king political power among the people by making use of the old Javanese cultural forms as missionary media. In spite of the fact that the new religion banned artistic images of man and animals, the ancient wajang theatre and the accompanying gamelan and Javanese songs were widely performed and possibly more extensively spread in this period than ever before, the puppets being made with elongated, unanatomical proportions. This art of wajang, so deeply implented in the imaginative consciousness of the people of Java, survived all periods of religio-cultural change.

In contrast to the Hindu-Javanese period, during which court poetry was written in Indian metres (tembang gede), most historic and belletristic literature in the Pasisir period was written in matjapat metres.

The Wali wrote poems in matjapat metres, according to M. Ng. Mangunwidjaja, ${ }^{18} \mathrm{R}$. Hardjawiraga ${ }^{19}$ and other 
Javanese writers. Mangunwidjaja mentions that Sunan Giri was the first Moslem leader to write matjapat songs, followed by the other Wali. This is according to some documents inherited from the past but containing no exact reference to the source of information. The songs by the Wali include Asmarandana and Sinom by Sunan Giri, Durma by Sunan Bonang, Putjung by Sunan Gunungdjati, Dandanggula by Sunan Kalidjaga, Midjil by Sunan Geseng, Pangkur by Sunan Murjapada, Kinanti by Sunan Padjang and Maskumambang by Sunan Madjaagung. They also wrote tembang tengahan, such as Gambuh, Megatruh, Balabak, Wirangrong and Djurudemung.

The oldest surviving kidung and suluk texts (the latter of which are mystic poems amalgamating Islamic and pre-Islamic concepts in the matjapat poetic idiom date from the early Pasisir period. 'Probably historical romances and ballads, and some Muslim religious didactic poems are among the first texts written in native Javanese metres, called temba $\eta$ maçapat ... It is not unlikely that the first ballads were already put in writing at the end of the Majapahit period, still in Java'. ${ }^{20}$ Although a large amount of Moslem Javanese literature (such as law books and religious text books) was intended for the prijaji class and religious men, popular babad and heroic legendary stories, such as the Amir Hamzah cycle, were spread ubiquitously among the people who sang them to popular matjapat melodies. Amir Hamzah, believed to be the uncle of the prophet Mohammed, is a legendary prince whose adventures are related to the Javanese literary work Serat Menak.

Islamic influence on Javanese music, however, was very slight, and was possibly limited to the introduction of a few new instruments. ${ }^{21}$ Koran recitations and Islamic incantations remained the property of orthodox religion, having no apparent 
influence on classical Javanese song apart from the texts, some of which incorporated Islamic religious and moral concepts and Arabic words in the general vocabulary.

CENTRAL JAVANESE KERATON FROM THE EIGHTEENTH CENTURY Pasisir art declined in the seventeenth and eighteenth centuries as the coastal kingdoms were overcome by the great inland Mataram empire. Apart from the writing of historical dynastic accounts (babad), conditions for court art development were not very favourable. Trends in the folk art of the time, apart from myths and legends, have not survived in distinct form.

After defeating the Mataram sultanate in 1749, the Dutch were able finally to establish a firm basis for their colonial power. Between 1755 and 1757, they divided Mataram into three principalities or vassal states - Surakarta, Mangkunegaran and Djogjakarta - the kings of which were glven nominal power only. This was of considerable importance to the future course of Javanese art, especially in music, drama, and dance, distinctive forms and styles of which developed in each keraton.

In 1813 , a fourth principality was created under. Raffles near the Djogjakarta keraton of the Hamengku Buwana; this keraton was the seat of the Paku Alam. Each keraton carried on a rich and somewhat independent cultural life. An exhaustive comparative study of the musical and other artistic styles and their history in each keraton is yet to be made. Though each keraton has its own history of styles and forms of art, each has influenced the other. Generalisations are difficult to make. Some hold that the Mangkunegaran (home of Langendrijan theatre) and the Paku Alaman tended to conform somewhat to the Djogjakarta (Kasultanan or Hamengku Buwana) style. A view is also held 
that the gentleness, softness, and refined classicism of Surakarta music and dance is closer to the prijaji ideal than the more robust and powerful style of Djogjakarta. Both claim a degree of artistic innovation.

Unlike the keraton in Djogjakarta, the Surakarta keraton of the Paku Buwana used its long period of unbroken peace in the second half of the eighteenth century to develop court art activity. To the Prince of Surakarta, Paku Buwana IV (1788-1820), is accredited the creation of large amounts of matjapat poetry which are still famous and frequently sung today among the Javanese. 22 The other main Central Javanese keraton in DJogjakarta, however, was hindered in its cultural development by three quarters of a century of unrest after its foundation in 1755. Not until after the peasant uprising led by Prince Dipa Negara from 1825 to 1830 did the Djogjakarta aristocracy in the Kasultonan finally succumb to Dutch power, after which court art began to flourish there too.

In the Surakarta courts, the official chroniclers and maintainers of the adat - the pudjangga - and some members of the aristocracy took a revived interest in old Javanese belletristic literature. This activity reflected the pride of Javanese aristocracy in their cultural glory and power in the past. Besides writing lengthy kidung and verses of historical, didactic, and encyclopaedic content reflecting the Hindu-Islamic-Javanese world view, new versions of the old kakawin came into fashion. ${ }^{23}$ Keraton interest in music, dance, drama, and literature increased during colonial times. While Javanese aristocratic political power became more and more limited, royal wealth and cultural power needed to be displayed on festive occasions. Traditional song and dance, gamelan and wajang were highly patronised in the courts, 
underwent further processes of refinement to please courtly taste and were standardised in set forms and elaborate variations of them. Dalang art spread from the Central Javanese keraton all over Java as the model of good taste and refinement in theatre and was generally imitated both among the prijaji and the peasants. In the villages, wajang, gamelan, tembang, and tarian (dance) remained chiefly communal, not professional art forms, and mostly in a less elaborate form than was usual in the keraton, continued to be popular sources of artistic expression.

In this 'renaissance' period of classical literature, old folk tales, traditions, and myths were probably collected for the first time and written down in matjapat and other metres. Renaissance pudjangga experimented with and elaborated the available poetic techniques. The matjapat prosodic rules in use in present-day Java were probably fixed in the eighteenth century: the matjapat poetry accredited to Paku Buwana IV was already based upon perfected and elaborated poetic techniques.

Most literature since the creation of the four Central Javanese keraton has been written in tembang tjilik (matjapat). Many old poems such as the Serat Pararaton ${ }^{24}$ were rewritten in kidung form. Central Javanese poets of the nineteenth century distinguished two types of autochthon metres (the tembang matjapat and tengahan) from the metres of foreign origin (the tembang gede). ${ }^{25}$ Matjapat poems in their strict metrical forms were composed in the courts and the villages and were very widely spread and sung within and without the courts. Matjapat song, alongside other ancient Javanese art forms, acted as a form of psychological refuge from the demoralising effect of political and economic control by colonial power. 
Since the courts possessed the best means of preserving their poetry in writing, tembang matjapat surviving today often expresses the courtly world view. Tembang matjapat served, whether by intention or not, as an instrument to instil mystic and religious ideas and a degree of feudal submission among the people, by whom the songs were so widely sung. Many matjapat songs of popular content about love, nature, war, etc. have also survived, alongside the perennially fascinating wajang and folklore songs, and tales of foreign origin which syncretised into Javanese art as a whole. One of the most famous pudjangga was Rangga Warsita of the nineteenth-century Mangku Negara IV court, who created a much imitated poetic style and wrote a large amount of poetry in matjapat metres. Although originally a court poet, tradition has it that he had sympathetic contacts with the people and their art, adopted an anti-feudal outlook and lived in a village outside court walls. His songs, one of which foretold troubled times in the future, are still popularly sung today in Java.

The two layers of court and folk art have certainly not yet merged, but the ages of interactive contact and exchange of ideas between the two cannot but have brought them close together. Court culture had always drawn on the rich folklore, vigour and spontaneity of the people whereas folk culture had benefited from the foreign contacts, intellectual pursuits and systematic refinement of the courts. Some courtly art forms, such as the serimpi dance, were adopted by the villages where they were practised in a less alus form, whereas some artistic elements of village associations and origin, such as the peasant manner of the comic Panakcowan characters, ${ }^{26}$ became an integral part of refined courtly wajang performance. Matjapat song, similarly, probably adopted different functions and degrees of elaboration in 
the courts and the villages, although the elaborate styles are nowadays performed by talented singers of both.cultural backgrounds.

\section{THE DEVELOPMENT OF 'POPULAR' ART}

While tembang, gamelan, wajang and other traditional art continued to be practised in the courts and the villages, new developments in popular art took place in the last hundred years or more. ${ }^{27}$ New popular serio-comic theatre developed, with travelling troupes of players. Matjapat songs and other artistic elements of ancient origins were adopted by the new theatrical forms, the realistic acting and more topical themes of which reflected a more down-toearth period, contrasting with the stylised refinement of classical court theatre.

House theatricals called Langendrijan and Wajang Orang developed (or, perhaps, redeveloped) ${ }^{28}$ in the Mangkunegaran and Djogjakarta keraton, in the second half of the nineteenth century. Langendrijan is a musical play, the dialogue of which is sung by all-women dancers 'in machapatmeasures ... accompanied by the gamelan-sléndro', 29 the texts being adaptations of the Damar Wulan romance. Its techniques were perfected in the Mangkunegaran keraton. Wajang orang is an elaborate musical play in which human actors play the parts of the Wajang Kulit, with dancing, singing, prose dialogue, tembang, and gending providing introductory, interludary, and accompanying music. In this century it has spread all over Java in the courts and the towns and has become very popular. The lakon deal mainly with the traditional wajang repertoire, but in recent times certain organisations have tried to topicalise it a little by inserting modern social and political references into the main dialogue. 30 
The other two main types of popular theatre are played only in non-courtly circles, dealing more with popular topics and current events. Ludruk originated in East Java, with its centre in Surabaja; it consists of spoken dialogue, dances, and songs (kidungan) in matjapat and other metres and is accompanied by a special gamelan ensemble. ${ }^{31}$ The origins of the musical and dance styles are clearly traditional but they are much less stylised, and more dynamic and modern in form. Ludruk has often been used for the propagation of new ideas. The texts have included moral and political instruction, the humorous treatment of topical subjects like finding employment and, until 1965, the struggle against landlordism.

Ketoprak (in East and Central Java) and Sandiwara (in West Java) also consists of dance, dialogue, and song in matjapat metres accompanied by a gamelan ensemble. The texts deal with Islamic, pre-Islamic, and contemporary times as well as Persian-Arabic stories.

\section{THE TWENTIETH CENTURY}

Twentieth century developments in tembang matjapat may seem minor and insignificant in comparison with the great continuity of Javanese song, symbolism, and mythology in Java's long history of cultural retentiveness. But new developments have taken place which may portend more widespread changes for the future. These modern developments in tembang matjapat parallel the changes in the other arts and reflect the movements, consciousness, and events of the times. Indeed the momentous socio-political changes that occurred in twentieth-century Indonesia have been more rapid and probably further-reaching than changes during the last few centuries. It is therefore not surprising that efforts have been made since the Revolution, especially by cultural 
bodies, to adapt the poetic and musical aspects of matjapat songs into an idiom able to express problems and ideas relevant to modern times, just as new forms of Wajang kulit have appeared to meet modern requirement ${ }^{3}$ and topical references to events and ideas of contemporary times were inserted into performances of live theatre such as Ludruk and Ketoprak.

In the villages, those largely autonomous and most stable units of a not yet stable modern Indonesian state, the old matjapat songs continue to be sung by individuals or groups, in private or on ceremonial occasions, within theatrical performances, in gending or in solo unaccompanied form; and the old courtly tembang pendapa practice of midnight singing by a court official continues to honour the reigning prince in the Kasuhunan, Surakarta. But as has been mentioned, some matjapat songs have been modernised in content. Songs were created in the old prosodic regulations to texts with topical interest and an 'international' diatonic musical style, or they retained both the old matjapat prosodic regulations and musical style and merely modernised the poetic content. This was a reflection of the need felt by Indonesians to reintegrate traditional cultural elements with new ideas reflecting modern Indonesian society, a reflection of the efforts to develop a national Indonesian culture.

Decades before Indonesia became a sovereign country in 1950, in conditions of deep unrest, armed struggle and finally war, the search for a national Indonesian style or 'identity' had begun; and although pride in past cultural glory was very strong, the forms and content of traditional art which Indonesian political leaders wanted it to express were found insufficient for the expression of modern problems 
and emotions. 33 Western art had been present in the archipelago for centuries, but the mystic, symbolic aura of the ancient indigenous culture resisted for a long time the impact of Western artistic ideas, which were in general found inharmonious in a context of traditional Javanese culture. But the struggle for Independence and the new political and social ideas germinating since before the twenties changed the outlook and hopes of millions of Java's inhabitants, including eventually their outlook upon the West. 34

After Independence, while the movement to preserve traditional culture continued, the nostalgic, collectivist artistic attitudes of artists and art lovers during the authoritarian colonial period began to be replaced by attitudes allowing the artistic expression of individual experience and the responsibility of individuals and groups to the nation. The 1945 Revolution and attainment of Independence gave new spirit to some of the arts; this was most clearly reflected in the upsurge of high-quality modern Indonesian literature and painting after the Revolution. Experiments were made in Western and mixed Western-Indonesian styles of music, as well as the other arts. Defensive measures were also taken to preserve the various regional cultures from Western influences from early in this century till well into the post-revolutionary period as part of the political opposition to Western culture and colonialism. 35

Several political groups after Independence demanded that art works be closely related to the political, social, and moral order of the time. The pationalists set the last principle of Manipol Usdek (proclaimed by Soekarno in 1959) as the artistic guideline, i.e. the attainment of national 
identity. Forms of literature which characteristically relate stories in which inner and outer conflicts between the 'right' and 'left' parties almost always end with victory for the 'right' party, were found favourable for adaptation into a modern context for propaganda motives, especially those of the lationalists and communists. Cultural organisations such as B.M.K.N., ${ }^{36}$ L.K.N. 37 and Lekra ${ }^{38}$ encouraged the creation of songs, paintings, and theatrical productions etc. which dealt with contemporary political and social problems. Lekra also employed people to collect traditional songs in certain areas, to compose new songs or texts of songs serving mainly political purposes and to distribute them among local performing groups. These collections were presumably lost in the anti-Communist turmofl following the political upheaval in October 1965. The Ministry of Education and L.K.N. spread both traditional and modern diatonic songs with a nationalist content (for instance, the Javanese Transcription 51 in this collection). Theatre, song, literature, painting, and other arts in their modern form, reflecting topical ideas and events, made up an artistic stratum which distinctly contrasted with Westernstyle entertainment on the one hand and classical art of the courts and villages on the other.

But the anti-feudal, nationalist and socialist art trends in the post-revolutionary towns and villages of Java were not always as vigorous and successful as they might have been. Lacking somewhat in clarity of direction in a period in which some of the revolutionary spirit of the late forties was petering out, their potentialities were frustrated by delays in the Revolution and fulfilment of its promises. 'The cultural disintegration is ... closely connected with the disintegrated state of society in 
particular. Nor have the revolutionary processes produced a harmonious cultural interaction between the cities and the countryside'. ${ }^{39}$ In the cities, the growing social disintegration and lack of harmonious contact between rural and urban areas resulted, despite efforts to prevent it, in the widespread consumption of Western or 'Western-Indonesian' art. Some Western entertainment such as rock-n'-roll and 'pop' music groups like the Beatles were banned under Soekarno's government, ostensibly with the aim of defending traditional culture and encouraging new styles in tune with the Indonesian 'identity'. Since the October 1965 coup d'etat, consumption of Western or copy-of-the-West entertainment has been unconstrained, on the whole, and left-wing cultural organisations and radical-left content in art have been banned. Despite efforts to prevent it, the keraton have been selling or losing their art treasures for years now. As the wealth and prestige of the upper feudal order gradually lessen, so does the need for the continual cultivation of formalised courtly art and ceremony. The stalwarts of cultural stability remain as always the villages, in which the old tembang, lakon, and gending remain actual expressions of the still semi-feudal social organisation and world view of rural Java.

Java's artistic future will possibly be as stable or unstable and progressive or regressive as its social and political future. The musical problem is part of the wider, unresolved economic, social, and cultural problem felt at almost all levels of society, 'that of the confrontation of traditional Indonesian society with the modern world, a crisis of adjustment that began in the colonial period and is still far from solution'. 40

The assimilation of certain foreign artistic ideas 
and elements through city composers and traditional musicians working professionally will probably continue, along with the hope that these elements may help solve the problem. But in the villages, according to observations in various parts of Java, especially the Banfumas area, the mural populations are not likely to lose their enormous pride in and respect for their own culture in the near future. There is no serious foreign rival to the traditional culture in. the villages, yet. Conditions of rural poverty generally seem to induce the tendency to conserve what good things one has rather than to submit to foreign values. Most Javanese viljagers are as ethnocentric as rural villagers elsewhere; to them Western music, whether 'classical' or 'pop', is lacking in delicacy and refinement.

On a national level, the search for national unity in art is 'not basically a question of inter-regional homogenisation but one of spiritual unity between mental universes ${ }^{41}$ and is likely to continue alongside the practice of transformation of old art styles and works to meet modern ideas. The enormous wealth of purely artistic ideas from the different regional cultures and maral areas in Indonesia has been as yet only shallowly tapped. Old feudal, moral, and religious ideas, as expressed for instance in the content of some matjapat texts, which were considered to hinder the social and political developments in modern Indonesia, will, perhaps, continue to be replaced by new ideas reflecting the character and needs of various strata of the present social structure, without necessarily destroying the traditional artistic styles. Stylistic and technical changes In music, while still based on traditional artistic values, are not necessarily a negative process and indeed are bound to happen, despite ones' regret at the gradual passing of 
the old styles and communalness of art-making from the artistic limelight.

Artistic material and ideas in Indonesia for future development are present in abundance, only artistic motivation and clarity of artistic direction seem to be wanting. Obviously, artistic needs of the contemporary situation in Indonesia can no longer be answered by escapism into the past nor by imitation of foreign styles nor by the creation of art for an élite alone.

Tembang, gamelan, wajang and other traditional art forms which reflect Javanese character, achievements, and cultural antiquity, having already perhaps reached the heights of artistic perfection, may ultimately serve, alongside art forms of other regional cultures in Indonesia, chiefly as a means of inspiration and stylistic guldance for new movements in Indonesian art. But who knows whether the artistic genius of the people of Java cannot reflect modern needs by further direct developments of exactly those old tembang, gending and lakon which are still constantly performed by and fascinate the people of Java. 
Prosodic and Linguistic Aspects

Tembang matjapat is distinguishable from other songs in the area neither by the place and nature of performance, the class background of its singers nor even its musical style, but primarily by its poetic construction. Tembang matjapat is melody set to texts of widely varied content to the strict regulations of the matjapat poetic system. Like much folksong and unlike European 'art' song, one matjapat melody may be used in stretched or compressed form to fit a number of different texts, as long as they conform metrically to a given verse form. Many a well-known melody is sung in different areas or even the same area to several different texts $^{1}$ and occasionally one text is sung to two or more melodies. 2

Although the birth of tembang matjapat in its modern prosodic sense occurred in the Central Javanese keraton, this did not prevent the spread of the matjapat prosodic rules to West Java, where there is a separate repertoire of Sundanese melodies sung to texts in matjapat metres in the sundanese language. Matjapat metres were also imported long ago to Bali, where there is a large repertoire of songs about everyday Balinese events, moral and educational issues and other subjects. Balinese songs in matjapat metres are extensively used in ardja theatre, in which the songs are called tembang ardja. $^{3}$ In the island of Madura and in the extreme eastern part of Java, matjapat songs are sung in the Madurese language. There are also scattered areas in other islands such as western Lombok, the Kisaran and Metro areas of Sumatra, and southern Kalimantan (Bandjarmasin) which have 
been in some way reached by Javanese culture, and where tembang matjapat are sung. The present song collection includes only Central Javanese and Sundanese songs, which have the matjapat prosodic system and some musical characteristics in common, but which differ strongly in many melodic aspects, style of singing, vocal timbre and, of course, language.

TEMBANG MATJAPAT IN THE FIELD OF CLASSICAL JAVANESE SONG Tembang (in Low Javanese) or sekar (in High Javanese, literally meaning 'flower') means 'song'. There are three main groups of tembang based on their poetic system:

i) tembang gede which are songs in 'big' (gede) Indian poetic metres, ii) tembang tengahan and iii) tembang matjapat, the latter two groups of which are songs in 'Iittle' ( $t$ jilik) autochthon metres. A sub-type of tembang is the tembang gending, which is a solo or choral song in any metrical form sung within a gending. Other groups of Javanese songs - the Zagu dolanan (songs for children) and lagu djondjang (children's game songs) - will not be considered here.

Tembang matjapat, then, in its widest historical sense may mean song in indigenous Javanese poetic metres, 4 and in its narrower, more exact sense, song in one of the ten or so poetic metres accepted today as belonging to tembang matjapat, in contrast to the tembang gede, which are in imported Indian metres and based on Sanskrit prosodic rules of metric quantity. Whereas the matjapat metres fit the Javanese language well, the tembang gede metres are, theoretically, in some ways not suited to the Javanese language, which does not distinguish between long and short syllables as in Sanskrit.

In the nineteenth century, Central Javanese court poets commonly distinguished two types of autochthon metres: the matjapat, which consisted of about fifteen generally 
accepted metres, and the tengahan ('middle') metres. The tengahan metres were less widely known than the matjapat, and were supposed to occupy a middle position in age between the respected, 'oldest' tembang gede and the commonly used, 'youngest' tembang matjapat. However, the dividing line between tengahan and matjapat metres is not generally agreed upon. 5 For instance, the well-known Gombuh and Megatruh metres, which are often sung in kidung together with songs in matjapat metres, are regarded by some Javanese writers as belonging to the tengahan group. 6 However, $R$. Tedjohadisumarto ${ }^{7}$ writes that while these two metres in older times were part of the tembang tengahan group, in modern times they are generally regarded as belonging to tembang matjapat. Jaap Kunst on the other hand writes that these two metres are 'nowadays usually being classed among the tengahan group'. 8

The list on page $41^{9}$ shows the metric structure of the ten generally accepted matjapat metres in common use in modern Java. ${ }^{10}$ Each poetic line (gatra) has a set number of syllables (Zampah) expressed by the figures in the list; this rule is called the Gum Wilangan. ${ }^{11}$ Each line must end with a word containing a certain fixed vowel as prescribed in the list; this rule is called the Guru Lagu. ${ }^{12}$ Having chosen a suitable metre (or metres) for the subject of a poem, by obeying the above rules, a poet may construct a matjapat poem in any number of verses (pada).

According to one line of tradition, tembang matjapat was 'invented' by Prabu Bandfaransari of Sigaluh in the Javanese year 1012 and tembang gede, being the oldest, was 'invented' by Prabu Daniswara, king of Mendang Pramesan in the Javanese year 1010.13 According to Javanese-Islamic tradition, however, the matjapat metres were 'invented' by 
$+4$

$\stackrel{\leftrightarrow}{H}$

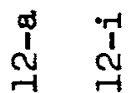

$\stackrel{H}{H}$

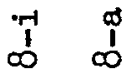

$\stackrel{H}{\lessgtr}$

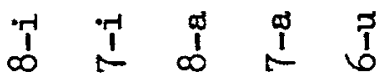

$\stackrel{H}{S}$

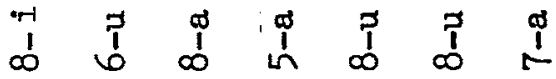

$>$

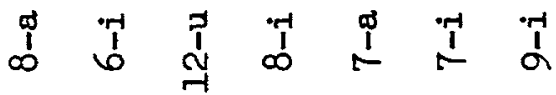

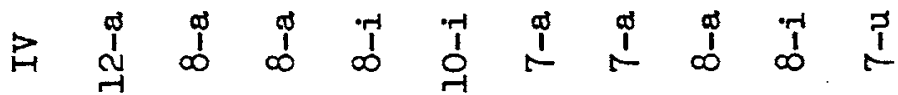

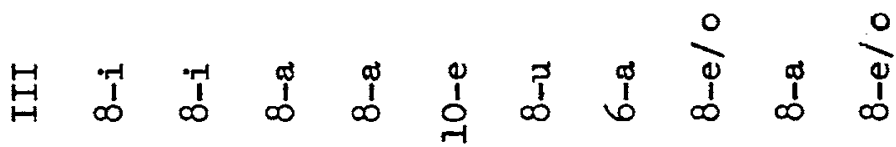

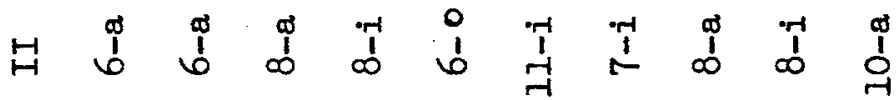

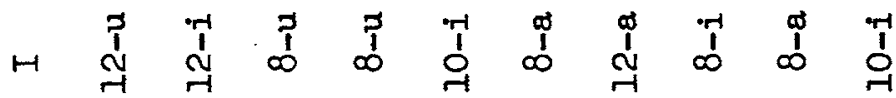

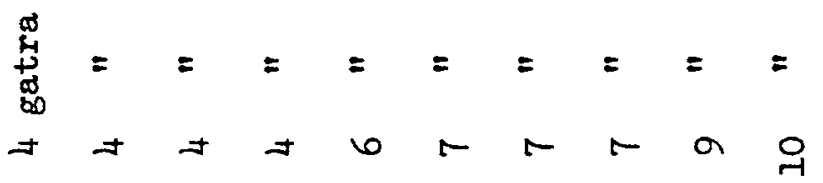

焉

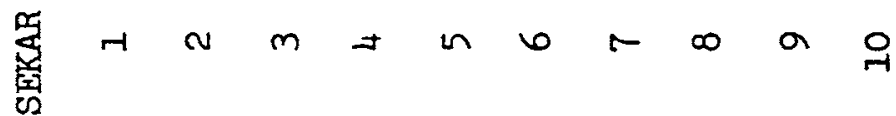


the Wali (Moslem saints) in the early Moslem period ${ }^{14}$ and the tembang matjapat metres were believed to be the youngest. However, some modern scholars are of the opinion that tembang matjapat have the oldest origins since they are autochthon, whereas the imported Indian metres of tembang gede assumably first appeared in Java during the Hindu-Javanese period. 'The macapat metres, ... are to be considered as consolidated forms of verse belonging to the mass of indigenous popular Javanese poetry, which for a long time remained amorphous and uncultivated'. ${ }^{15}$ The fixed matjapat prosody in use today has, possibly, different poetic forms and regulations from those used in olden times. 'In the pre-Islamic period', possibly, 'maçapat metres were not yet fully developed and differentiated by strict prosodic rules from the mass of indigenous popular Javanese verse'. 16

TEMBANG MATJAPAT IN THE FIELD OF CLASSICAL SUNDANESE SONG Tembang matjapat constitutes an important part of the Sundanese song repertoire. This song tradition is also of ancient origins, but the prosodic rules used in Sundanese matjapat song are identical with their Javanese counterparts. Each of the already mentioned matjapat metres is used in West Java, the only difference being that the Sundanese spelling of the longest metre is Dangdanggula. The word matjapat is, moreover not well known in West Java; only the names of the matjapat metres themselves are generally known.

As in Central and East Java, a distinction is made in West Java between songs performed in free metre (tembang, sekar, or mamaos) and songs performed to fit the strict quadruple metre of the gamelan accompaniment. According to P. Djatikocesoema, the Pangeran (prince) of the keraton in Tyigugur near Kuningan, these songs in strict metre are called sekar tandak, and this use of the word tandak should 
not be confused with tarian tandak, which means a rather low-class dance with music quite unlike sekar tandak. An alternative term for sekar tandak is tembang gending or lagu gending. Sometimes the tembang gending are performed in strict metre as sekar tandak. In Sundanese areas, the older tembang buhun (which are mostly unaccompanied and used for the telling of stories and for festive occasions) contrast with the so-called modern tembang kaajeunaan (which are often accompanied by instrumental ensembles and consist of various regional styles). 17

Tembang matjapat and tengahan in West Java consist not only of indigenous' Sundanese songs (tembang asal) but also of borrowed Central Javanese tembang as well as originally Central Javanese tembang modified to suit Sundanese musical styles. ${ }^{18}$ The Sundanese song repertoire also includes pantun songs and children's songs (kakawihan barudak).

\section{THE WORD MATJAPAT}

The meaning of the word matjapat is, according to several of my Surakarta informants, 'reading in fours' (matja means 'to read' and pat means 'four'). 19 That is, when people read or sing aloud old stories in matjapat metres (kidung), as a general rule they should try to breathe or make breaks only after each fourth syliable of a line. This popular explanation fits in somewhat with the generally accepted pedotan (caesura) rules, which favour divisions of four syllables for all line lengths. The Kinanti metre is the best example of this 'division into fours' idea, since each of its six lines contains eight syllables.

Several of my informants said they believe the term matjapat means 'simple', that is, it has the same meaning as lugu and bares, which adjectives along with matjapat are 
sometimes used in matjapat song titles. Thus, Transcription 12 was called Pangkur Lugu or Pangkur Matjapat by the singer; that is, the title means 'a simple Pangkur melody'. Kunst also wrote that tembang matjapat are the 'simplest songs', 20 to be compared with 'the classical lyrical-epic sekar ageng (L.J.: tembang gedé)'. However, there do not seem to be any strong grounds to support this explanation of the meaning or the use of the word matjapat; the melodies and the musical style of matjapat singing are certainly not simpler than the tembang gede or tembang tengahan, indeed they are mostly melodically complex and are often more highly ornamented.

Perhaps the explanation for this supposed simplicity of tembang matjapat is the Javanese belief in the 'inferiority' of their autochthon verse in comparison with poetry in tembang gede, with its long lines, Sanskrit prosody, obsolete words and courtly origin. ${ }^{21}$ or it could refer to the practice of singing Kidung in 'simple', unornamented melodic fashion in a Malam Kidungan, in order to finish performing a long book in a reasonable time.

\section{S. Prawiroatmodjo's Javanese-Indonesian dictionary} defines the word 'matjapat' as 'empat desa dikanan kiri desanja' (i.e. four villages to the right and left of one's village); here he is referring to the theory about an ancient Javanese custom of arranging matjapat or mantjapat ${ }^{22}$ village units, whereby the head village in the middle was surrounded by four 'outside' sub-villages situated as if on the points of a square..$^{29}$ Pigeaud's explanation of the word is as follows: ${ }^{24}$ 'Macapat and mañcapat, meaning "four fellows", are expressions referring to a group of closely-related units, located on the corners of a square, in accordance with cosmic order. To the Javanese mind the word mancapat suggests safety and the wellknown order of the home district'. This explanation supports 
the theory of the essentially autochthon quality of matjapat metres. However, it is not generally known or accepted among the Javanese with whom I have come into contact.

\section{THE MATJAPAT METRE TITLES}

The origins of at least some of the matjapat metre names are probably very old. Unlike the Sanskrit names of the tembang gede metres, the matjapat metres have, with the exception of Asmarandana, Javanese names, the original meanings of which are mostly unknown or unclear. Even less clear is the connection between the metre titles and the character of the metres themselves. One possibility is, as Pigeaud suggests, ${ }^{25}$ that some metre names derived from the first word or words of some early, exemplary poems in the corresponding metres.

\section{Dandanggula}

As mentioned in the Pararaton, King Kertadjaja of Kediri, after being defeated by Radjasa (probably a synonym for Ken Angrok), was known in the decades after 1222 A.D. by the derogatory name of Dandang Gendis, which probably means 'brown crow' and which is a synonym for Dandang Gula. ${ }^{26}$ There are many traditional stories in literary works of the period about Kertadjaja's abortive end, for instance, that he retired to a remote hermitage, or that he disappeared from his seat on an elephant in the battlefield into the air by means of yoga, or that he 'retired from the field of battle and sought refuge in the abode of the gods, which floated in the sky'. ${ }^{27}$ King Kertadjaja was the scholarly king of Kediri during the period of her literary glory. It could be that the Dandanggula metre was popularised in the period after the king's fall, or at a later time of retrospection about Kertadjaja's fall.

\section{Sinom}

According to Tedjohadisumarto, ${ }^{28}$ Sinom is related to words 
meaning 'young', 'young blood', 'bud'. 'Sinoman' means 'a group of young people'. 'Probably the ancient rural custom of ordering boys and young men, relatives of the host and the guests, to serve up the food at community meals prevailed too at the Majapahit court'. 29 This custom is mentioned in the poem Nāgarakertāgama (canto 89, stanza 4), probably written about 1350 . The Sinom song metre could be a survival of these festive occasions.

\section{Durma}

'Durma is the name of a hero, a demi-god; an epic poem is called after him. ${ }^{30}$ Perhaps the metre title derives from this poem. According to Tedjohadisumarto, Durma is related to words meaning 'go back', 'retreat', 'tell a lie'. 31 The Kawi syllable dur, generally meaning 'evil', may or may not have a relation to the violent, warlike, passionate content of many poems in this metre.

\section{Pangkur}

This name could be the remnant of kidung incantations chanted by a Pangkur officiant as part of his office. 'The enigmatic Pangkur, Tawan, Tirip ${ }^{32}$ are mentioned in the Kalasan Charter of 778 A.D., described as being armed district superintendents with probable spiritual influence. 'Perhaps in the tenth century in the reign of Sindok, Pangkur, Tawan and Timip were title names of officials' who collected fees from rural communities. 33 The name Pangkur was also used in a Balinese-Javanese Pandji romance as a name for Togog (a member of the clown-servant Panakawan group of wajang characters), thereby associating Pangkur with the Panakawan, who originally belonged to the field of ancient Javanese religious rites. 34 According to Pigeaud, Pangkur was probably an officiant of religious rites. 
words meaning 'war' and 'to look back', which fit the general characterisation of Pangkour poems in use today.

Asmarandana or Asmaradana

This is the only matjapat metre with a Sanskrit name; abmara means 'love' and dana means 'charity' or 'gifts'. According to Pigeaud, ${ }^{35}$ it could be connected with the Smara Dahana kakawin of twelfth century Kediri origin.

Midjiz

Midjit literally means 'appears' and is related to the word meaning 'born'. 36

Kinanti

Kinanti means 'walking hand in hand'. Like Asmarandana, Kinanti poems are often love poems.

Maskumambang

Mas is a title of endearment, or it can mean 'gold' or (connected with Permas) it could refer to 'an officiant in some shamanistic rites in Balinese popular religion'. 37 Kumambang, meaning 'floating', could as Pigeaud suggests refer to 'a characteristic feature of a shaman's psychic experience'. Or it could refer to a general psychic experience of dreaming unreality, characteristic of some poetry in this metre, which often expresses feelings of longing and homesickness.

\section{Putjung}

The word Putjung means a young nut or a soldier beetle; according to Tedjohadisumarto, its meaning is also related to kaluwak (a spice). In Madura it is also the name of a musical instrument (cleft drum) used by patrols during night watches. ${ }^{38}$ Perhaps it was originally the answer to a puzzle. Many poems in this metre are puzzles. 
MATJAPAT MEIRE CHARACTERISATION, POETIC RULES AND POETIC TECHNIQUES

Metre Characterisation, Guru Lagu and Guru Wilangan

There are four main types of matjapat metres: i) the mainly lyrical (Kinanti, Asmarandana, Midjil), ii) the mainly narrative (Dandanggula, Sinom), iii) those often used to express violent happenings (Durma, Pangkur), and iv) the short, pungent metres (Maskumambang, Putjung). 39 Perhaps the characterisation of the different metres is relatively modern. 'It is dubious whether in olden times maçapat metres had special characters'. ${ }^{40}$ In fact, a great variety of content is expressed in the various metres; here we can only speak of general tendencies.

As already explained, the Guru Lagu and Guru Wilangan, which are the only rules by which matjapat poetry is tightly bound, fix the number of lines per verse, the number of syllables per line (Zampah) and the final vowel sound of each line.

The graphs on page 49, showing the variety of linelength in each metre, show at a glance the degree of each metre's symetry of Lampah, which together with the Guru Lagu influences to an extent the poets' choice of metre to express different types of poetic content.

Kinanti is the most regular, formalised metre, consisting only of even-numbered lampah; all its six lines have the same medium length of eight syllables. Besides that, there is alternate line rhyming of the final ' $i$ ' vowel. This metre is one of the most popular, especially in West Java, where it seems to be the most common of all metres. Its regularity and relative shortness suit the expression of love, happiness, graciousness, welcome to guests, the beauty of nature, moral advice, and the beginning of a story. 
Graphs of Matjapat metres

showing variety of LAMPAH

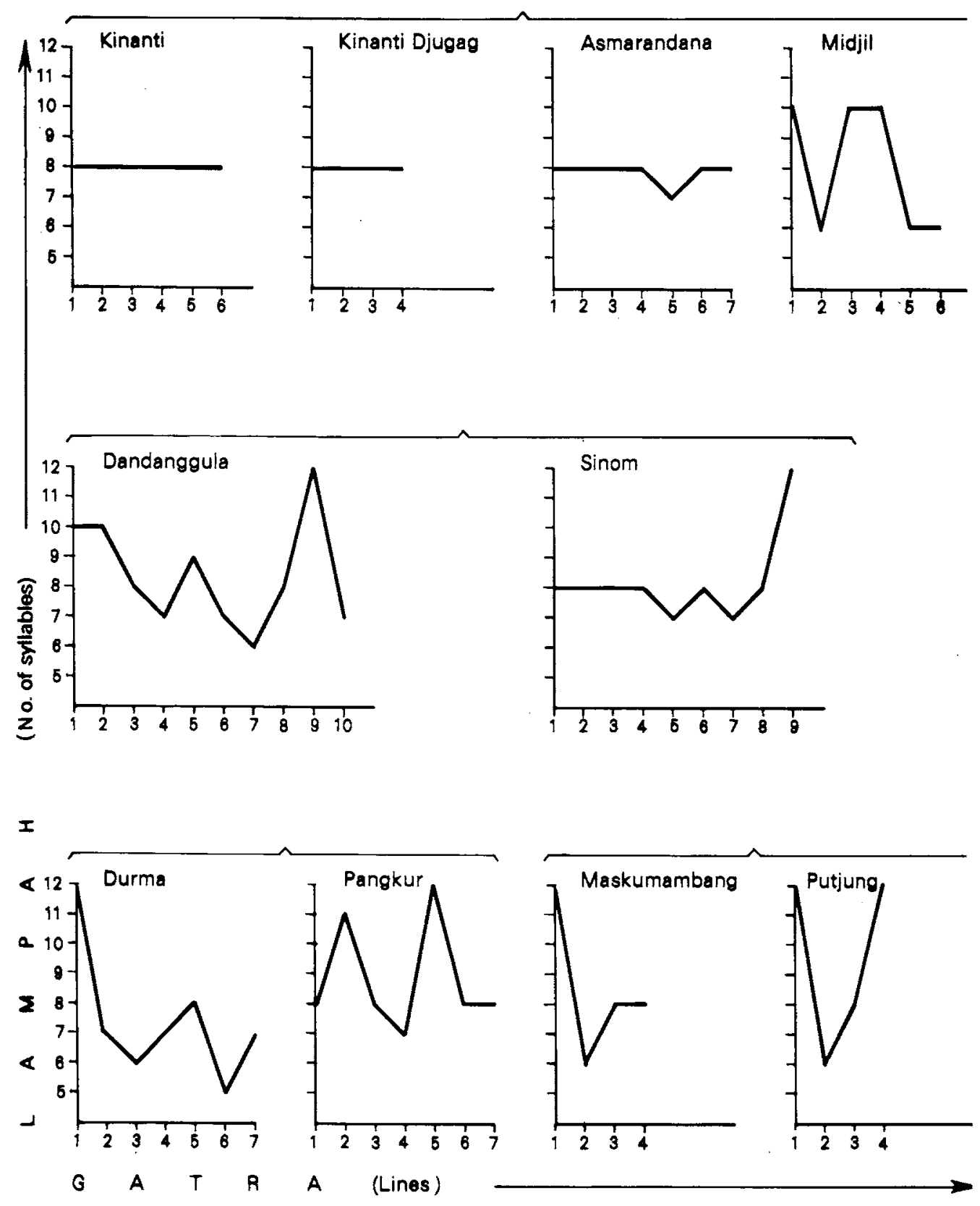


The Kinanti Djugag metre differs from the usual Kinanti metre in its relative shortness, but its lampah, Guru Iagu and poetic character are similar. The Asmarandana metre also possesses a high degree of regularity, but its less regular rhyming system, its 7 -lined pada and its one oddnumbered lampah (of 7 syllables) make it appear a relatively free verse form. Poems in this metre are mostly of a lyrical, romantic, or pastoral character, but one also finds, among other things, puzzles and prayers in the Kinanti metre. According to Tedjohadisumarto, 'the sadness of love' is often expressed in this metre.

Another metre characteristically used to express pastoral, lyrical, and religious content is Midjil, which in its metrical construction occupies a midale place between the lyrical and narrative types. Consisting of six lines like Kinanti, it has only two types of Zampah, of 6 and 10 syllables respectively. There are no odd-numbered Zampah. The three long lines are sultable for descriptive or narrative purposes. Moreover there is a comparatively wide choice of final vowel and there is no regular rhyming. The Midjil metre, besides being used for lyrical topics and moral advice, is often used to describe nature. According to Tedjohadisumarto, Midjil sometimes describes 'positive sadness', the intention to better one's lot, and hope for the future.

The second type of metre is characterised by Dandanggula and Sinom, the long verses and irregular Zampah of which are especially suitable for lengthy narrative didactic poems and poetry on other serious subjects. Dandanggula is, together with Kinanti the most often used of the metres; many long poems begin and end in this metre. ${ }^{41}$ The poems in this metre vary widely in content, from moral advice, fokes, miracles and political events to love and 
nature. With its ten gatra (lines), which vary greatly in length but are predominantly long, it has the most extended verse form of all matjapat metres. All possible vowel sounds are used in the final syllables of the lines. Except in the fourth line, it has alternate rhyming.

Sinom, on the other hand, has a smoother Zompah sequence. Consisting mainly of lompah divisible by four, it has no very short lines and has a long line at the end of the verse. Sinom poems show, like Dandanggula, a great variety of content; the Sinom metre is used, for instance, to begin a story, to give advice and for dramatic conversations in the theatre.

The third metre type consists of Durma and Pangkur, which, with their very irregular metrical forms and medium pada length (both metres have seven lines each), have been found suitable for the expression of conflict, war, death, violent passions, and love. However, riddles and the giving of advice are also expressed. In these two metres. Both metres have irregular rhyming and a mixture of odd and even numbered Zampah. The restricted choice of final vowels contributes to the directness of impact. The Pangkur metre contains the only instance of an eleven-syllable line, while Durma's seven lines include three seven-syllable lines and one five-syllable line. No other metre has such a variety of line length as Durma, the Zampah of which vary between five and twelve syllables.

Maskumambang and Putjung constitute the fourth type of metre; they are characterised by their shortness (both metres have four lines each), their regularity of rhyme, the contrast of short (six-syllable) and long (twelvesyllable) lines, their even-numbered lampah and their restricted choice of final vowel. The metres are 
used to express anything simple and direct, such as a pungent riddle or advice to children. Maskumambang is also often used to express a clear-cut feeling of pain, longing for parents, or homesickness. Putjung poems on the other hand are rarely melancholy.

\section{Pedotan and Andegan Rules}

The following poetic rules were popularised by Javanese pudjangga in the eighteenth and nineteenth centuries in order to elaborate poetic techniques; they are, unlike the Gume Lagu and Gumu Wilangan, by no means essential, especially in non-courtly matjapat poetry.

Pedotan is the caesura ruling; musically it means the proper time space between one breath and another during the singing of a tembang. According to the Pedotan rules, in a line of between six and twelve syllables, a singer should if possible take any necessary breath after each fourth syllable. If, however, this would result in the arbitrary breaking up of a word, one should divide the line into groups of two and three syllables. Thus, for instance, a seven syllable line should be divided up into groups of four and three syllables, or, if this is impossible, into groups of three and four syllables, or groups of two and three and two syllables. A line with five syllables, if it must be broken up, should be sung in groups of three and two syllables. If the punctuation breaks happen to occur in the midale of a word, or they do not coincide with the sense units, the singer should use one of the other possible pedotan arrangements; otherwise it is kaken, it results in poetic 'stiffness'. 42

Andegan means 'sense-unit'. Andegan Ageng means a large sense-unit, which usually means the sense-unit of a whole verse, while Andegan Alit means subordinate senseunits within a verse. The Andegan Ageng is preferably 
limited to the length of one verse, although sometimes in longer poems the sense is carried over into a succeeding verse (e.g. in Transcription 113). Dandanggula, for instance, has four Andegan Alit, i.e. lines 1-3, 4-5, 6-7, $8-10.43$

\section{Purwakanti}

Purwakanti Swara means assonance or rhyme within a line, such as in the senggakan in Transcription 70 (Sinom):

'Pudangane bajung, gadangane wulung'.

Puwakanti Sastra means alliteration throughout a line or a verse, such as in Transcription 12 (Pangkur Palaran), where the consonants 'ng' and ' $k$ ' are used alliteratively: Mingkar-mingkur ing angkara.

Puwakanti Tembang is a poetic trick of ending a line and beginning the next with the same word, e.g. (in the Sinom metre): ... batine kudu den isi ... the soul must be filled Ingisi kawruh njang ngelmu Filled with knowledge Ngelmu kang nora scomar ... Knowledge which is not vague 44

Wangsazan

Wangsatan is allusion, pun, word hinting ${ }^{45}$. The allusory words or lines can be freely inserted within or at the end of a song. They are incomprehensible unless the context of the word hinting is known. Wangsalan are sometimes used by Dalang as clues for singers or gomelan players to indicate the name of the next piece to be performed in Wajang. Pigeaud notes ${ }^{46}$ that the word mundur ('backwards') was used in this way as a clue for the song Pangkur, because mundur suggests mungkur ('to turn one's back'), which sounds like Pangkur. Similarly, wangsatan are sometimes used by poets of kidung to forewarn kidung singers of a change of poetic metre and, therefore, melody. 
Such a clue or keyword is inserted into the last line of the last stanza of a canto. A list of such keywords, alluding to metre names, is given by Pigeaud. 47

Sandiasma

If a poet desires discreetly to include his name in a poem, each line can be constructed so as to include a syllable from his name; this usually occurs at the beginning of a gatra or pedotan. The device is called Sandiasma.

\section{Sengkalan}

In order to avoid long, unpoetic, vernacular number-words, year-dates are often replaced by word symbols or chronograms. Thus, 'one' may be replaced by word expressing the idea of importance, such as Pati (king). This would constitute a Sengkazan.

\section{Senggakan}

Senggakan (Javanese) or Senggak (Sundanese) is as much a musical as a poetic custom. It is an extra melodic line or phrase inserted in a tembang, melodically and poetically free. For instance, the Sundanese tembang Transcription 48 (Asmarandana Madenda) has three Senggak, two of which merely mean 'Oh, forgive me'. The Javanese tembang Transeription 24 (Midjiz Ketoprak), Transcription 70 (Sinom) and Transcription 136 (Kinanti Djugag metre) each contain Senggakan (e.g. 'Manggo stones, hurrah, hurrah.'). If the song is accompanied by gamelan, a Senggakan can serve to fill a rhythmic gap between one line and the next. Several types of senggakan are mentioned by Kunst. ${ }^{48}$ They include explanatory, commentary or nonsense-syllable interjections within songs. 
Poetic style

Tedjohadisumarto ${ }^{49}$ advises Javanese poets not to neglect the following when composing a new tembang. The Guru Lagu and Curu Wilangan should be chosen according to the poetic idea. Beautiful but difficult words should not be sought out to replace simpler, more easily understood words. Only a few well-known Kawi ${ }^{50}$ words should be used; on the other hand, a tembang is tjemplang ('not complete') unless some are present. Certain words can be shortened, lengthened or appear in crabwise order. A Pedotan should always finish at the end of a line (that is, the syllables of one word should not be carried over from one line to the next). An Andegan Ageng should be of verse length. If a song begins in Kroma, ${ }^{51}$ it should not be mixed with Ngoko words. Finally, it is good style to use instances of Sandiasma, Sengkalan and the three types of Pumakanti in a tembang. 
THE CENTRAL JAVANESE TEMBANG MATJAPAT

'An account of Javanese literature is curious, and even important, as it tends to throw light on the history of society in general ... but if the reader expects to find in the literature of Java any merit worthy of the attention of the European scholar, he will be utterly disappointed. He w1ll discover in it neither sublimity, pathos, tenderness, nor humour, but, on the contrary, bombast, puerility, or utter inanity, in literature, the very stanmering of infancy without its interest or amusement. I

Certainly matjapat poetry, perhaps the most widely familiar: section of Javanese literature among the people, is 'important' for an understanding not only of Javanese history but also present-day Javanese life. Matjapat poems, being mostly folk song, do not pretend to specialise in sublimity, mostly leaving that quality for other forms of literature. Infant stammering and utter inanity may be the reaction to Javanese poetry of someone entirely unacquainted with the Javanese language or the poetry in translation. The fact remains that the complex matjapat prosodic system has been found by the Javanese to be one of the most adequate and expressive forms in which to relate their experiences and ideas. The present collection, containing only a small part of the total matjapat literature, which includes the whole field of the kidung, can give only a slight impression of the wide range of subject matter and attitudes, the sense of fun and humour, the emotional qualities, the moral ideas and the quality and complexity of poetic 
technique in the matjapat medium.

Of the 147 transcriptions of Central Javanese songs in this collection, there are 96 different poem texts; that is, some well-known song texts are sung by one singer or by different singers to the same or a different tune.

Many of the verses in this collection are incomplete since they are the beginnings or parts of longer poems, such as stories from the Rämäyana and Damar Wulan cycles. However, most verses express a single complete thought or action, because of the Javanese preference that the Andegan Ageng should be of verse length.

Dramatic conversations as in Transcription 99 (Dandanggula Palaran) and Transcription II (Sinom, a conversation between Damar Wulan and the giant Menakdjingga), are often expressed in the longer verse forms. The metric forms of narrative verses are chosen according to subject matter. For instance, Transcription 14 (Kinanti Sandung) describes Anoman's discovery of the thin, beautiful, captured Princess Sinta, wife of Rama; the description of the princess is, appropriately, in the Kinanti metre. On the other hand, Transcription 15, which describes the confused retreat of the giants after a war with the monkeys. (led by Anoman), is in one of the two metres reserved for war and death, Durma.

Descriptions of nature are almost always in the Midjiz metre, whether it be the description of the beauty of the land of Java, a rocky landscape, a river course, a path into the jungle, or a starry, moonlit night. But sometimes the Kinanti, Sinom, and Dandanggula metres are also used for descriptions of nature. Poems in Dandanggula sometimes contain a description of sunrise and the beginning of the day (e.g. Transcriptions $I$ and 100), or of the moon at night 
(Transcription 98). On the other hand, the pretty verse about a lovely lily in a pond (Transcription 140), is in the Pangkur metre.

Expressions of emotion, such as foy at the sight of a rice harvest (e.g. Transcription 123 (Asmarandana) and Transcription 142 (Kinanti)), or love to a beautiful girl (e.g. Transcription 69 (Dandanggula TLutur), Transcription 47 (Dandanggula) and Transcription 136 (Kinanti)), are most commonly in the Kinanti, Asmarandana and Dandanggula verseforms .

Poems referring to war and death are almost always in the Durma or Pangkur metres (e.g. Transcriptions 3, 15, 107, all in Durma, and Transcription 126 in Pangkur (Perang). Even the tjangkriman (puzzle) in Transcription 33, to which the solution is kupat (pressed rice wrapped in coconut leaves cut into squares), one of the clues to which is death by torture, is in the Durma metre. Transcription 109, which describes the hurling of the fire and brimstone onto sodom and Gomorrah and Transcription 3, a conversation about war, are also in Durma.

Poems of a political nature are mostly in Dandanggula and Sinom, excepting those of modern political content like the Javanese Transcription 51, which is about political ideas in Soekarno's time; modern political poems are usually in the Durma metre. Transcription 87, describing the prosperous order of the nation is in the Sinom metre. Praise of the wisdom of a Prime Minister as in Transcription 16 and Transcription 71 is expressed in the Dandanggula and Sinom metres respectively. Transcription 2 (Sinom) and Transcription 70 (Sinom) use the second longest metre. The 'time of madness' (djaman edan) in Transcription 70, mentioned in a poem by the court poet Rangga Warsita, has 
been interpreted as being a forecast of future events, for instance a forecast of the latter violent period of colonial times. Transcription 2 describes the destruction and disorder of Java and the sadness of its inhabitants. Transcription 36 tells of terrible miracles happening, and signs of unrest in Central and East Java.

A large proportion of the songs has a moral content, some intended for children and some for adults, mainly in the shorter Kinanti and Putjung metres. Descriptions of evil and aimless behaviour are in Sinom (e.g. Transcription 130, telling of a child blinded as a punishment of his wickedness), and Pangkur (e.g. Transcription 141). Some poems express moral values desired of the peasantry by the feudal class. For instance in Transcription 23 (Midjiz), the poet advises humility, the bowing of the head when one is reprimanded, and keeping out of the way of one's master in time of trouble. Laziness, day-dreaming, pleasureseeking and greediness are often censured, as in Transcriptions 117 (Kinanti), 92 (Putjung), 85 (Durma), 76 (Kinanti) and 13 (Pangkur). The poem in Transcription 117 states that day-dreaming causes sadness, sadness causes iliness, and illness causes death. Transcription 85 contains advice to lessen one's desire for food, sleep, and pleasure, and to be prepared to stand suffering. The poems in Transcriptions 76 and 77 similarly advise hard work and are against mere eating and sleeping; moreover, a lazy or luxurious manner of living is said to reduce one's capacity to think. Transcription 132 (Dandanggula) contains advice to work hard and avoid interruptions.

Several Putjung poems (e.g. Transcriptions 73, 75, and 144) express the collective outlook, the value of sharing one's opinions with relatives. Respect for the advice and 
guidance of parents and grandparents is mentioned in Transcriptions 89 (Maskumambang), 48 (Kinanti), 73

(Putjung), and 101 (Putjung). Advice to children to study hard is given, for instance, in Transcriptions 110 (Kinanti) and 125 (Pangkur). Calls for help to one's parents are always expressed in the Maskumambang metre, for instance Transcriptions 10 and 124. Advice to noble heroes (as in Transcription 5, Midjil) and general behavioural guidance are given, for example, in Transcriptions 5, 16 (Dandanggula) and 72 (Pangkur); the desired qualities include courage, humility, kindness, politeness, good manners, the following of customs, and a clear knowledge of good and evil.

Religious poems containing Moslem teachings are usually sung in Arabic chant, not in tembang. But Transcription 53 is based on a poem about the Moslem duty to pray regularly at the prescribed times. This collection includes some matjapat melodies set to Christian texts. Stories taken directly from the Bible are contained, for instance, in Transcription 113 (Kinanti), Transcription 120 (Kinanti), Transcription 126 (Pangkur) and Transcription 131 (Sinom). God's creation of the universe in six days is expressed in the Midjil 'nature' metre (in Transcription 103). In Transcription 104 (Midjil), hope for a way out of poverty and hardship is placed in serving God.

Besides the educative and moral songs for children there are the tjangkriman (puzzles) in matjapat metres. Tjangkriman are usually in the short, pungent Putjung metre (e.g. Transcriptions $7,8,102$ ), but the tjangkriman in Transcription 42 is in Pangkur, Transcription 105 in Midjiz and Transcription 136 in Kinanti Djugag. Mostly a puzzle in a poem is posed by listing a few clues to the answer. For instance, in the very well-known song, Transcription 7 , 
the object to be guessed (called meanwhile by the name Bapak Putjung), is said to be neither a rock nor a mountain (implying, however, that he is large); he is said to be a knight from Palembang where he is a pet of the Governor (that is, he is not found in Java but only in Sumatra); moreover he sways his nose when he walks. ${ }^{2}$

In Transcription 136, the name of Prince Prijambada is to be guessed. Some of the clues given in the poem are the Prince's other name, Sang Marabangun, the name of the river Oja in Djogjakarta, and the use of the word Prija in the poem (suggesting part of the Prince's name).

Transcription 105, which is in the Midjil metre (since the poem is about nature), plays on the names of stars. Like Transcription 136 , it is incomprehensible if one is not acquainted with the context, which is, in this case, the Javanese star names. The Javanese predeliction for subtle allusions, hidden meaning in puns, metaphors, onomatopoeia, and chronograms etc. is well known. Subtle allusion to human character developing through suffering is made in Midjil (Transcription 78) through references to leaves and other attributes of trees. Dandanggula (Transcriptions 36 and 38) tell of the troubles of Kartasura royalty, not by mentioning any names or even status, but by symbolising kingly power through references to tigers and elephants.

There are also poems containing descriptions of animals, for instance, Transcription 127 (Pangkur), Transcription 138 (Pangkur), and Transcription 133 (Dandanggula), the last of which describes an army of animals.

The songs of welcome sung by choirs at feasts and other ceremonies - i.e. the Panembrama songs - are exemplified by Transcriptions 111 and 121 (both in the Kinanti metre). 
The Sundanese Tembang Matjapat

The present collection of Sundanese tembang, being much smaller than the Javanese collection (of 54 song transcriptions there are only 22 different poems), shows much less variety of poetic content. There are, for instance, no directly religious poems, no poems reporting social disorder or even joy at the sight of the harvest. This does not mean Sundanese poems on these and many other subjects are not in existence, but it is partly a reflection of the fact that matjapat songs in West Java are dying out quicker than in Central and East Java, just as a Sundanese Malam Kidungan is today a rarer occurrence than it was thirty or forty years ago. The most well-known Sundanese matjapat songs are for children, songs which are remembered throughout adult life. Thus, in this collection, nine of the singers chose to sing the children's puzzle Budak leutik bisa ngapung (Kinanti) in two melodies, and six singers happened to sing, all in the same tune, Eh bamudak (Maskumambang), a song about the debt to one's parents. In Sundanese tembang for adults, keen personal emotion seems to be more often expressed than in Javanese tembang. The Sundanese matjapat poetic style is often very lyrical and has strong symbolic features.

Kinanti and Asmarandana, the two most regular metres, are the favourite verse-forms. The metre-characterisation trends in Central Javanese matjapat poetry are also generally followed in West Java.

Many Sundanese stories and kidung in matjapat metres exist. A few songs in this collection are taken from longer stories, for instance the dramatic conversation as in Transcription 12 (Durma) and the narrative poems like Transcription 4 (Midjil) and Transcription 7 (Sinom, 
written by the Sundanese author Hadji Hasan Mustafa). The Rōmāyana, Mahābharata and the Pandji myths are not as deeply imprinted on the culture of the sundanese as in the more easterly parts of the island.

Sentimental love is expressed in Transcription 20 (Kinanti), containing allusions to symbolic and ceremonial objects such as coconut flowers and a wedding house. The love song Transcription 47 (Asmarandana Madenda) also contains flower symbolism. Transcription 49 (Pupuh Sinom) is the outpouring of someone trying to recover from lovesickness.

As in Javanese tembang, Sundanese songs in the Pangkur and Durma metres are mostly reserved for violent actions or implications of violence. The only Sundanese Pangkur text here tells of a meeting with the robber-chief Djaja Pati (Transcription 1). In Transcription 12 (Durma), a royal personage boasts of his bravery in war. Transcription 35 (Durma) mentions ominous signs of death such as the appearance of blood in the water and a squawing black crow. Transcription 52 (Durma) is a modern poem about the duty to defend the flag of the Indonesian Republic. The preparedness to die for one's country is also expressed in the Dangdanggula metre, Transcription 50, where patriotic selfsacrifice is compared with flowers and trees bending in the wind.

A common theme, as in the Central Javanese poems, is duty to one's parents, for instance, in Transcription 5 (Dangdanggula), which exhorts children to keep their parents free from worry and distress. Transcription 3 (Asmarandana) tells children to look after their clothes. Transcription 46 (Asmarandana) relates the value of the Sundanese Gandasari book, which contains mainly feudal moral teachings 
and was read in the elementary schools during colonial times.

The one Sundanese poem here in the Maskumambang metre, in keeping with its usual character of appealing to or being dutiful to one's parents, reminds children of their lifelong indebtedness (Transcription 15) to their parents. But the appeal for maternal help against the ill-treatment of a step-mother in Transcription 9 is in the Kinanti verse-form.

Matjapat Tatarutjingan (puzzles), especially children's animal puzzles, are also popular in West Java. This collection includes an animal puzzle in the Kinanti metre (e.g. Transcription 43). 
PART TWO

\section{THE MUSIC}


Collection and Transcription of Songs

Notated and recorded sources of matjapat songs are very few. Since Javanese and Sundanese musical notation systems are comparatively recent, only in latter times have notated matjapat songs in skeletal melodic form been printed in Java for popular use. A few musicologists have occasionally transcribed outlines of some song tunes. ${ }^{1}$ There are various recordings of songs in matjapat metres sung within longer gamelan works, but sources of unaccompanied matjapat songs on disc are very scarce.

The present collection of matjapat songs, performed by singers from the Central Javanese ${ }^{2}$ and Sundanese culture areas, ${ }^{3}$ was made in Java in 1959 and in Europe in 1965-6. It also includes songs from a disc recording, the tape collections in the Ethnomusicologisch Archïef, in Amsterdam, Radio Republik Indonesia and various Javanese songbooks. The tapes made in Europe consist of songs performed by singers born in Central and West Java who had recently arrived in Europe. 4 The tapes made in Java consist chiefly of recordings by village-born performers, willing to sing on tape to texts which they knew from memory. Singers who had studied Western singing, who were performers of Western music or who had lived a long time abroad or in the metropolitan city of Djakarta, were generally excluded because of possible foreign influence on their style. Of course, all the performers could also sing some modern Indonesian songs, which are based on Western intonation. But it is apparent that the two fields of song are isolated from each 
other in the performers' musical consciousness. The timbre, singing style, and intonation of a performer singing a Javanese or Sundanese song are kept quite separate from the timbre, the singing style, and the intonation used when singing a song in Western intonation. The two styles belong to different worlds. Intonational influence of the one upon the other is apparently so small as to be negligible. The roots of the classical Javanese and Sundanese musical styles after the intensive enculturation of childhood remain strong and unviolated.

One singer with Javanese parents who as a child lived in a Sundanese area (Bandjar) has a large repertoire of both Javanese and Sundanese songs. There is, however, no sign that his Sundanese way of singing is influenced by his Javanese or vice versa. It seems, under certain circumstances, not only can a child simultaneously learn two languages perfectly, but also two stylistically separate song repertoires.

Although the home towns of the singers are fairly well distributed over the thickly populated areas of Central and West Java, a wider area of distribution and a much greater number of songs are necessary for an adequate comparison of regional styles. Moreover, some regional styles may already have lost some of their individuality, influenced as they have been by the Djogjakarta, and even more strongly in some areas, the Surakarta stylistic prototypes. For instance, the northern part of the Banjumas region is influenced to some degree by Djogjakarta, whereas the Wonogiri area is strongly influenced by Surakarta.

The number of performances by professional singers in this collection is heavily outweighed by the number of amateur performances. The professional performances include 
four songs (Transcriptions 43-46) performed by the great Wajang Orang actor Rusman of Surakarta, who sings in a powerful, vigorous style the part of the strong, manly figure of Gatotkatja. They include the two songs performed by Srikandi of the Mangkunegaran (Transcriptions 80-81), one by the Sinden Rubinem of DJogjakarta (Transcription 83), and the performance (Transcription 78) by Sumardjo of an unaccompanied matjapat song in traditional kidung fashion. In the Sundanese collection, only Sopandi is a truly professional singer (Transcriptions 44-54), although Sjamsuddin (Transcriptions 33-40) has had some professional experience.

However, the difference in level of musicianship between amateur and professional matjapat performance in Java is not by any means as great as in Western societies. One is just as likely to hear fine matjapat performances in an out-of-the-way village as on the occasion of a keraton festivity or as sung by a professional singer on the radio. Most amateur performers of songs in this collection display a high level of musicianship. Performances such as those of Sabar (Transcriptions 1-17) are certainly no less elaborate and virtuoso than the tembang gede performances I have heard during Ujon-ujon in the keraton of the Sultan of Djogjakarta and the keraton of the Sultan Paku Alam. A more elaborate style than Purwaredja-born Sabar's performance of Durma (Transcription 3) would hardly seem desirable in the Javanese stylistic context, whether in a court or a village. Vocal styles of other amateur singers such as Trisno and Imam are as highly expressive, fluent, imaginative and, sometimes, as virtuoso as the best of professional matjapat styles heard today on the radio. 
tembang matjapat performances in any of the keraton. K.R.T. Madukusuma, director of musical affairs in the keraton of the Sultan of Djogjakarta informed me early in 1970 that tembang matjapat is no longer performed in the Djogjakarta keraton but that the style of tembang gede we heard there resembles keraton performance style of tembang matjapat. The tembang gede singing I heard was especially composed to honour a birth day of the sultan. It was sung in a calm, decorative, melismatic style with ample eluk (melodically decorated final syllable of lines), long sustained melodic phrases and a wide tonal range. The only real difference between this and a good village performance of tembang matjapat was the wonderful echoing effect of the song in the marble-floored pendapa of the keraton.

From the many possible subjects we met, the best singers were naturally the most willing to sing on tape. Men and women with less than average voices or talent generally did not offer their services.

Most of the singers chosen have had a variety of musical experience and come from inland towns and villages. Many of the Javanese singers come from the cultural centre of Surakarta/Mangkunegaran and the surrounding regions. Some are or were professional musicians and dancers, having studied Javanese and/or Sundanese music and dancing in the Konservatori Karawitan (Kokar) of Surakarta or Bandung. Some of them sing in the polished styles of the courts and high theatre, but most sing in the relatively relaxed, unconstrained manner which is most common with unaccompanied tembang. Many of the performers took part in village or town gomelan playing and were genuinely integrated with community musical life. They vary between 20 and 40 years of age. 
In several cases, twofold or multiple versions of a melody were given by a singer, not always with the same text or tempo. These variants of songs were useful in assessing the degree of melodic variability. Some singers sang in relatively strict time as if with gamelan accompaniment or as if in the rhythmically straightforward Gerongan (choral) style. Background information about the songs from singer-informants was valuable but limited to nontechnical aspects.

The four songs sung by Rusman I have transcribed from the performance of the Gending Beksan Gatutkatja Gandmung on the Lokananta record AID-041 (1964). The latter part of the Javanese collection contains matjapat songs from popular songbooks ${ }^{5}$ and stencilled gending parts from the Prambanan Ballet Ramajana; these songs I have transcribed from the Javanese number script commonly used into European notation. They include Sinden (e.8. Transcription 134) and Gerongan (e.g. Transeription 136) performances of the songs.

\section{TRANSCRIPTION}

'The transcriptions of recordings of folk music should be as true as possible. It should be realised however that an absolutely true notation of music (as well as spoken words) is impossible because of the lack of adequate signs in our current system of notation'. 6 Despite the lack of adequate notational signs, the unsuitable suggestivity and the other imperfections of the Western notational system when applied to non-Western music, Western notation is nevertheless used here because it is the only system complex enough and sufficiently widely understood to form the basis of detailed transcription work. The Javanese cipher (number) and checkered scripts, ${ }^{7}$ while sufficient for notating outlines of vocal melodies and nuclear themes of gamelan works to 


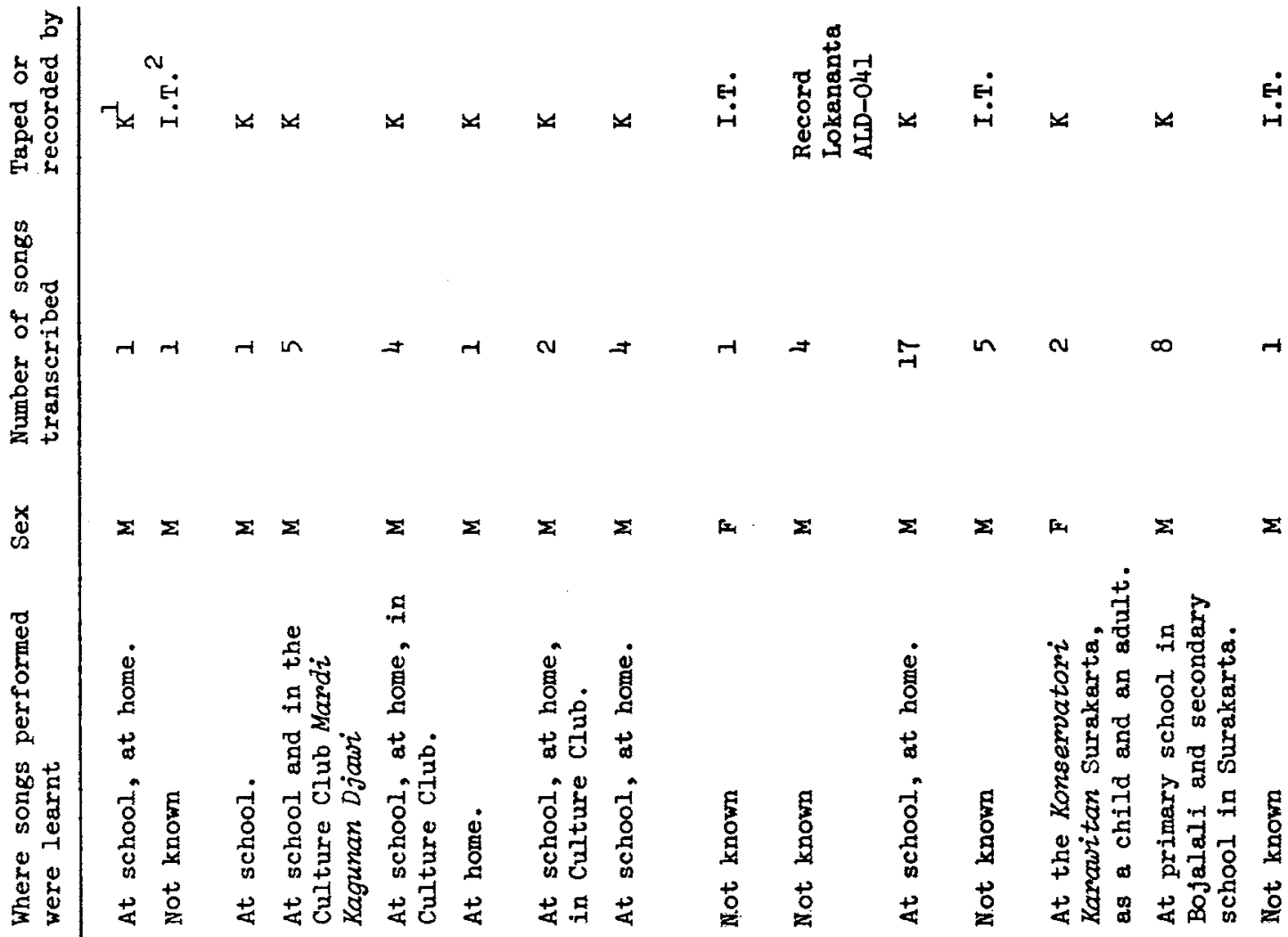

居

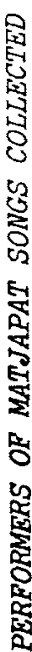

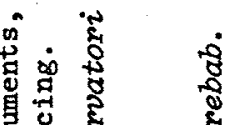

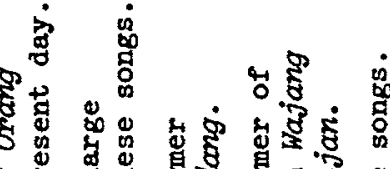

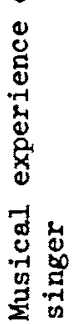
(1) 空

(1)

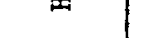

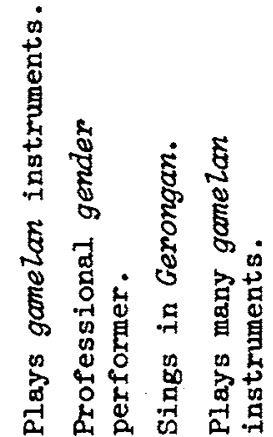

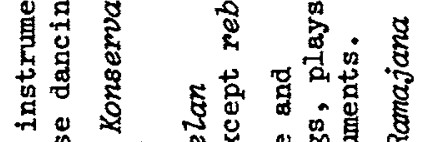

है

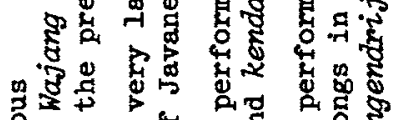

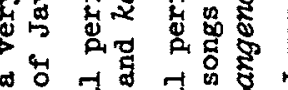

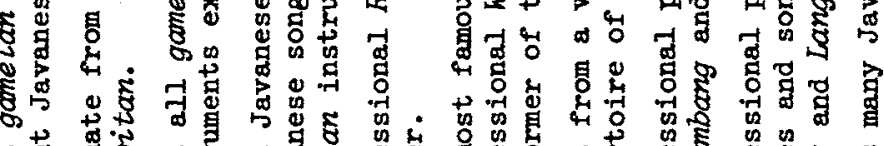

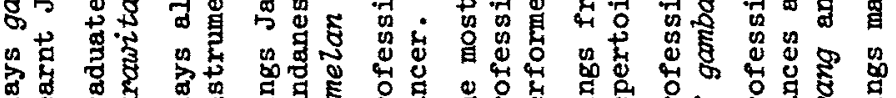

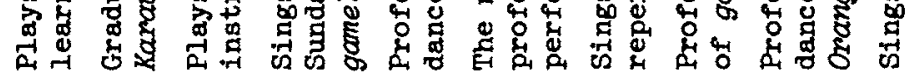

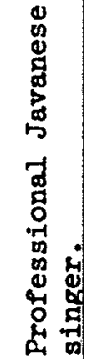

9 政

$\stackrel{\mathscr{g}}{\mathscr{E}}$

总

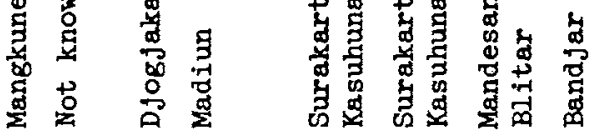

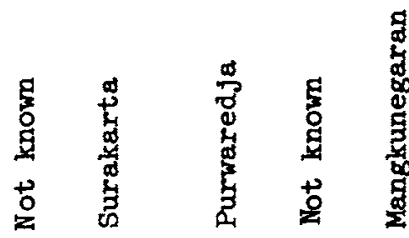

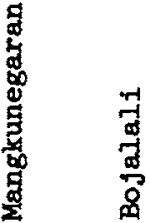

站

政

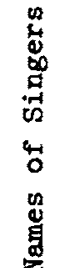

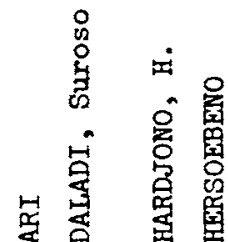

至

营
范
㤐

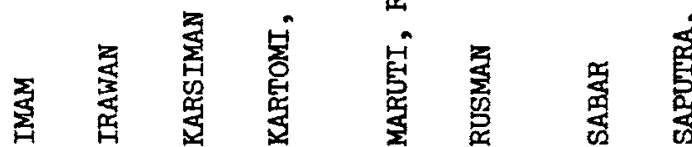

崖管

鱼 
initiate performers into a knowledge of new works or simply to aid their memory, do not allow one to make a detailed transcription of rhythmic, melodic, ornamental and intonational aspects of an actual performance, which usually differs from all other performances of the one work. The aim of the transcriptions in the present instance is obviously not to provide the basis for future performance. Probably, even an exceptionally talented musician would be unable to give a stylistically adequate performance of these songs in any case, unless he had lived since childhood in Java. A Javanese or Sundanese-born performer needs only a number-script notation to learn the outlines of new songs or to remember old ones, after which he can give a unique, ornamented rendition of each song. The present transcriptions are Nachschrifte, transcriptions made after a unique performance of a song; they attempt to portray some of the high degree of musical detail in performance, for purposes of musical analysis.

The possibility of employing one of the aleatoric compositional methods of notation was also considered. The principle of this method would have been to place notes in their approximate pitch positions with some graph-like standard in mind, and with the notes showing their relative rhythmic distance from each other. The advantage of this system would have been that the factors of free pitch and rhythm in the performances would have been depicted. However, this method was unsuitable for reasons similar to the reasons against using Javanese or Sundanese notational methods. Aleatoric notation is more suitable for use in a free performance of a composed musical idea than in the accurate transcription of such a free performance. The purpose of transcription here is to describe the details 
Distribution of hometowns of singers in the Central Javanese and the Sundanese cultural areas (taken from Map 9b of Java in Atlas van Tropisch Nederland, Batavia, 1938).

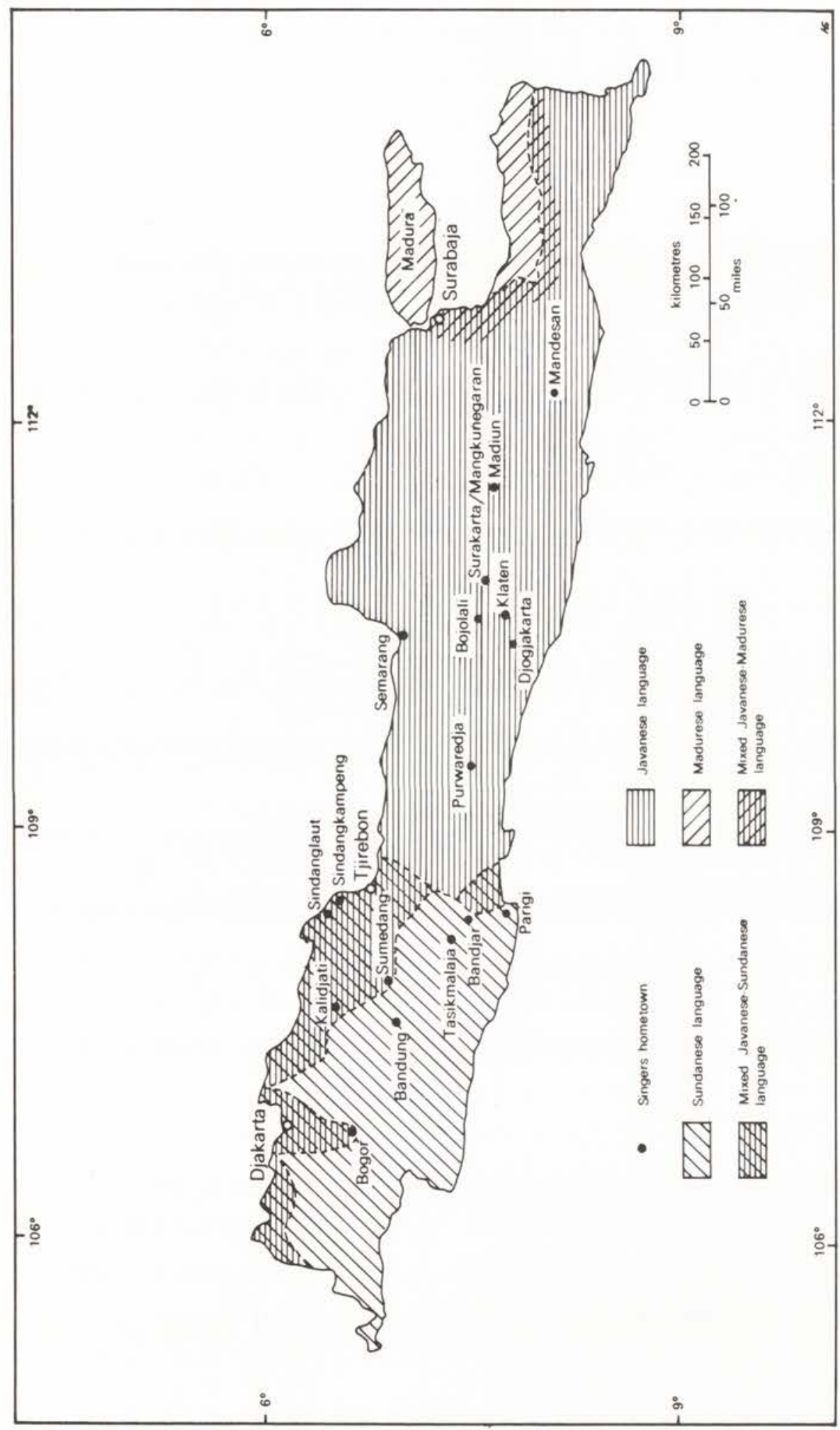


of a single performance of a musical model which exists in the performer's mind, not to make future performance possible. ${ }^{8}$ Moreover, the performer's freedom is not as unlimited as it might seem, bound as it is by traditional stylistic tendencies, the requirements of patet and text and the limits of intonational and other types of variability. Even if a typical performance of a song could be selected or worked out and notated aleatorically or in simplified number script, it would still be incapable of reflecting variability in performance, and would be unsuitable for detailed analysis. However, for some songs a quasi-aleatoric notational method is used, as in Transcription 136 in which the rhythmically 'free' line of the Sinden floats above the strict quadruple-metric beat of the gamelan. Thus A (taken from the Javanese number-script) is transcribed as in $B$ : $A^{9}$

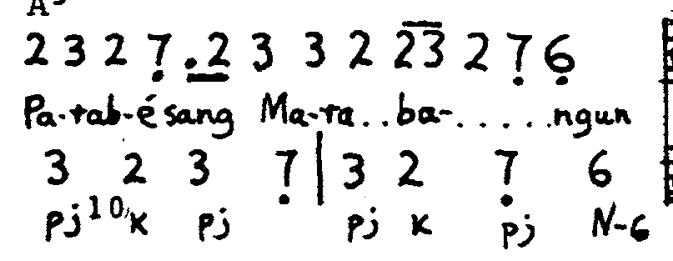

where the numbers represent the approximate pitch of the

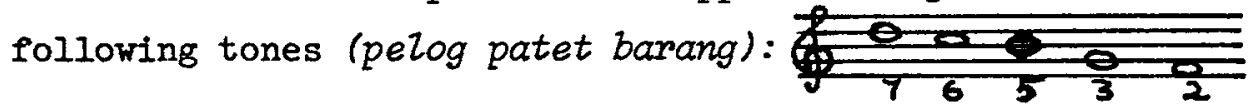

The purpose of this method of transcription is simply to attempt to reflect the irregular metre and free rhythmic continuity of the Sinden line, in contrast to the quadruple metre of the gamelan accompaniment. It is not possible to transcribe the rhythm of the sinden part literally since the time values of the cipher-notated Sinden tones do not correspond with the barred time values of the balungan line. The tones placed far apart in $B$ are to be read as relatively long tones, those close together as relatively short. The purpose of these spatial relationships in the sinden transcriptions is to portray the rhythmic continuity and 
irregular metre of the Sinden line.

It may be that the detailed transcriptions of this collection put too great a demend on a reader who is not used to highly ornamented, relatively free-rhythmical music. For this reason, a minimum of transcription signs is used, melodic passages on one syllable are phrased together to allow quick perception of the melisma, and the end of each poetic/musical line (usually followed by rests) is shown by underlining the last syllable. Simplified transcriptions, which would destroy the real character of the melodies, were not contemplated. The transcriptions could not be matters of extensive compromise since they were of crucial importance to the validity of the musical analyses. '(Es) ist nicht in Abrede zu stellen, dasz die mehr ins Detail gehende Notation effektiv ein sehr viel zutreffenderes Bild vom Gesamthabitus und von den Stileigentümlichkeiten ein.es: Stückes bietet trotz der Begrenztheit des menschlichen Wahrnehmungsvermögens und trotz der Begrenztheit des Notensystems, in dem diese Wahrnehmungen schriftlich niedergelegt werden. 11

\section{The Rhytrm}

Despite the fact that the songs were transcribed and retranscribed several times in order to increase their reliability, and abundant use of a stop-watch, metronome, and slow-speed tape rotation were made, absolute rhythmic accuracy in the transcriptions cannot be claimed. Matters were easier in the more metrically regular songs performed with gamelan accompaniment, but the uneven metrical structure of most of the unaccompanied songs sometimes allowed the perception only of approximate time values. However, the main aim was to show the degree of rhythmic freedom. A singer rarely performs tones one after the other in regular rhythm. Indeed, absolute accuracy in the 
rhythmic transcription, which in this case is unattainable by the ear alone, is of less analytical consequence than it may seem, since a singer never performs exactly the same rhythmic values in a second performance.

Since regularity of tempo even for a short passage rarely existed, it seemed impracticable continually to adjust metronome values throughout a song transcription. Periodically changing the metronome beat in a transcription would give the false impression that there exists in these songs several passages of momentarily fixed tempo, whereas in fact a singer rarely changes tempo suddenly and constantly for a given period.

In most songs, a short fundamental note-value could be heard throughout and was used as a basic time-unit in the transcriptions. An appropriate metronome beat was chosen for each song and the values of all notes estimated in proportion to this basic beat (mostly notated as $\boldsymbol{f}$ orf"). If the note-values in a song became too complicated, the metronome speed was changed within the transcription (as in Transcription 19), but this was rarely necessary. In order to improve the readability of the time-values, where possible the musical line was written in such a way, that the basic time-unit was apparent. Thus, the unusual but more quickly graspableff frwas written instead off ETin a song in which the basic time-unit was $P$.

The arbitrary metronome figure at the head of each transcription has no permanent function in performance, since the tempo differs each time a song is performed. The figure serves as the basis for note-values in the transcription process: for the reader it merely gives an approximate idea of the tempo and real time values. An impression of the tempo can also be gained by reading the 
time length of each poetic-musical line and of the whole song. This is given alongside the heading of the song to the nearest $1 / 100$ of a minute.

In the more strongly accentuated or regularly metrical melodies, dotted barlines are tentatively placed before the accentuated tones. However, most of the songs lack any accentuation pattern. In melodies of regular quadruple metre, triplets are common. ${ }^{12}$ In the free-rhythmical songs, however, $\sqrt{3}$ has not the ordinary meaning of triplets, but merely implies that three tones happen to be sung within the period between two arbitrarily fixed metronome beats.

The pause sign $\cap$ is not used. Accelerandi and ritardandi are always written out in the respective time values. Because of the deliberate instability of tempo in most unaccompanied matjapat performances, the only consistent and accurate way of expressing time values of notes and changes of impetus was to try and assess actual time values of notes, and not to resort to signs like ritardando and pause signs as in prescriptive notation.

The Pitch

More difficult still was the problem of pitch. Electroacoustic measurements of pitch-levels in an intonationally highly variable vocal style of music seem to be of little value in comparison with pitch measurements in a fixed-pitch, instrumental medium, and were therefore not attempted. But in order to facilitate aural comparisons of tones which varied in pitch throughout the performance of a song, the tones of similar pitch to each other were copied onto a tape one after the other and played back as a succession of isolated tones. The degree of pitch variability of tones performed by each singer could thus be assessed and indicated in the transcriptions. 
The performances by some singers vary in pitch much more than others. Sutamdio, for instance, sings with very free intonation, raising and lowering tones at will. Sujitno, on the other hand, has a much stricter attitude to pitch, varying the pitch of a given tone rarely. Hersoebeno, almost constantly in his pelog songs, sings tone 3 (dada) an approximate quarter tone lower than is usual for Sujitno. Perhaps Hersoebeno naturally sings close to the tuning of the gomelan which he is used to playing in his home town.

Mostly, tones are lowered or raised irregularly and inconsistently throughout a song. Sometimes a tone is raised in pitch for a line or two and then reverts to near original pitch. Pitch deviations in 'folk music' should, of course, be regarded as 'subconsciously intentional'. 13 When a singer alters the pitch of tones in these songs it does not mean he sings 'out of tune'; this pitch variability is an allowable aesthetic element which in some cases - e.g. in the tlutur style - is even expected to a high degree.

Since the use of the stave suggests associations with 'just' or 'tempered' pitch, Hood suggested that when reading his Western-notated nuclear themes of gending, the reader should "learn that "c" is not really " $c$ " but barang and that "d" is actually gulu etc. 14 The pitch-levels of these tones are not inviolably fixed but certainly differ from the pitch-levels implied by notes on the stave. Thus, for instance, when reading a pelog melody, the pitch of tones 2 (gulu) and 6 (nem) should be mentally adjusted approximately as follows: ${ }^{15}$

pelog

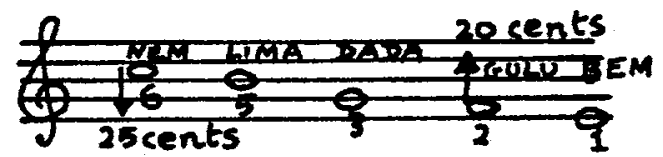


In slendro

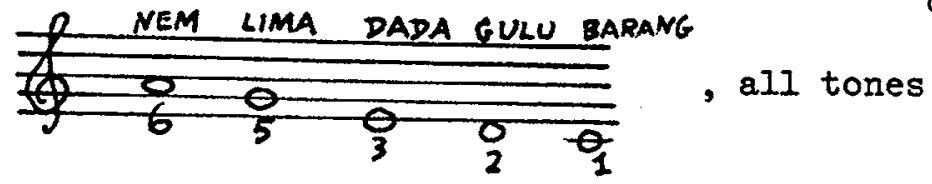

can vary very greatly in pitch, but especially tones 1

(barang) and 3 (dada), which may vary up to a tone or more above or below the stave tones as written above. ${ }^{16}$

The only practicable way of solving the pitch notation problem in the present instance seemed to be to resort to the system used by Bartók and others, which does not pretend to be more than a general pitch guide. If pitch deviation was strongly perceptible, i.e. about 50 cents (a quarter tone) or a little less above or below a 'tempered' pitch level, the plus or minus signs were written above or below the notes in the transcriptions. The possibility of using special signs for particular pitch-levels was not made use of, mainly because the pitch of the tones could not be accurately assessed, particularly beyond the quarter-tone level. It is well known that the human ear is prone to subjectivity in the hearing of microtones.

Signs used in the Transcriptions The clefs $\$$ for male and $\oint$ for female singers are employed. No key signatures or natural signs ( $h$ ) are used. If necessary, songs are transposed up or down from the original pitch in order to suit the staves used and to avoid accidentals, in which case the original pitch (O.P.) of the performance is shown above the transcription. Vibrato is shown by the sign:m. Medium to small vibrato amplitude is most common in these songs; heavy vibrato does not occur. But some singers perform with exceptionally slow or fast vibrato. Signs for trills and mordents are never used since they suggest an unwarranted similarity with European music; they are always written out. The signs for strong accents $\bar{l}$, weaker accents $\bar{l}$, vocal glottal stop $l \vec{l}$, non- 
tonal glottal stop $f^{\partial}$, short cut-off tones $l$, fast tones of uncertain pitch $\downarrow$ and various types of portamento, e.g.

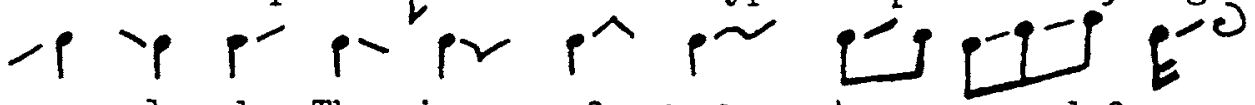
are employed. The signs $p, f,<,>$, etc. are used for showing dynamics, since the Javanese and Sundanese words for dymamics are not usually abbreviated nor generally understood outside Java.

\section{ORDER OF SONGS IN APPENDIX}

The collection of songs could have been arranged according to melos, degree of rhythmic freedom, poetic metre or patet. However, the systematisation was preferred whereby all songs sung by the one performer, in the order in which he or she chose to sing, are placed in consecutive order. This arrangement allows an apprehension of styles of performance by individual singers. The seemingly haphazard order of songs chosen by a singer may in some cases be significant. Mostly a singer who performed several songs chose to warm up on the songs he preferred and knew best.

Each of the following groups of transcriptions are, in my opinion, either closely or distantly related versions or variants of the one melody. Versions are understood here as renditions of the one melody by different performers, as opposed to variants, which are also renditions of the one melody, but performed by one and the same person; in both cases, musical variability occurs between renditions. Most of the following are versions: in the Central Javanese collection, Dandanggula (Turuzare) (Transcriptions) 1, 19, $36,38,47,54,55,58,64,90,132$; Dandanggula Tlutur 16, 69, 98; Sinom Paridjata 11, 60, 70, 131; Durma 22, 49, 109; Durma 33, 50, 56, 59, 65, 85, 107, 108; Pangkur 18, 34, 62, 68, 72, 126; Pangkur Palaran 13, 42, 81, 125; Asmarandana 21, 53, 57, 66; Midjil 5, 17, 23, 24; Midjil 44, 86; 
Kinanti 6, 41, 45, 46, 118; Kinanti Subokastowo (Panembrama) 31, 61, 111; Kinanti Gondomastuti 40, 48, 119; Kinanti 76, 77; Maskumambang 10, 32, 39, 52, 89, 124; Putjung 9, 26, 30, 50, 83, 93, 102; Putjung 73, 101. Some of these sets contain versions of a song in different tone systems and/or patet, for instance, Kinanti Transcription 76 is in pelog patet barang, and Kinanti Transcription 77 (a related melody), is in slendro patet sanga.

Sundanese sets of versions are: Dangdanggula 5, 6, 28; Sinom 7, 29, 34; Durma 12, 52; Pangkur 1, 11, 26, 33, 51; Asmarandana 3,14, 22, 30, 36, 46, 54; Midjil 4, 16, 25, 27 ; Kinanti $2,8,17,21,31,38,41,43,44$; Maskumambang 15, 24, 32, 40, 42, 53; Putjung 13, 39. 
Musical Concepts and Methods used in the Analyses

For a Western musician listening for the first time to a song, say, in the Dandanggula or Sinom metre, the most striking aspect may be the freely constructed, nonrepetitious continuity of the long melodic lines. Used to listening for the repetition, development, splicing and fusion of motives which are characteristic of Western melody, he finds that these elements are generally lacking in matjapat songs, but that despite this, the strong formal unity of each song cannot be denied.

Only in those songs with regular rhythm and predominantly short lines, many of which are intended to be accompanied by the quadruple measures of the gamelan, does the repetition of melodic phrases occur. Phrases approaching motivic significance, established by development or repetition, are very rare. ${ }^{I}$ In general, repetition is a minor formal element in these songs. Unity is achieved by such elements as recurring melodic formulae, the ornamental style, the ebbs and flows of the rhythmic motion, and the prevailing direction of melodic movement, which is nearly always descending.

A modern European may be struck by the melodic ornamentation and the free attitude to rhythm and intonation in matjapat song. However, this manner of singing, common in many parts of the world today such as the Arabic lands and South and South-east Asia, has been a common practice throughout world musical history, including European history. ${ }^{2}$ It is still to be found in parts of Europe today, 
such as in some villages in the Balkan areas. ${ }^{3}$

Musical concepts fundamental in the following analyses of matjapat songs will now be outlined. TONE SYSTEMS, VOCAL TONES, AND PATET Javanese music has two tone systems in common use - the 5-toned slendro and the 7-toned pelog. ${ }^{4}$ However, in practice, pelog has also a basically pentatonic nature, since five of the pelog tones are always selected as the Principal scale of the patet in which a piece or song is performed, the two remaining tones (sorogan or 'exchange tones') being subordinated to the tones of the patet's Principal scale. The essential difference between slendro and pelog is that the basic scale of the former is anhemitonic, while the basic scale of the latter incorporates both 'half' and 'whole' tones. In vocal practice, however, and in the music of instruments such as the rebab and suling, semitones and micro-tones are common in both tone systems.

\section{Slendro Tuning}

Since no slendro tuning standard exists, different slendro gamezan have widely different tunings. The opinions of Kunst, Sachs, Dewantara, and others that slendro is developing towards an equidistant tonal structure was objected to by Hood, ${ }^{5}$ who pointed out that the difference between the slendro patet depends on the non-equidistant tonal structure of slendro. Since the slendro patet concept does not seem to be disintegrating, the concept of stendro tonal equidistance needs to be abandoned. The great majority of gamelan slendro have two intervals tuned larger than the others. The alternation of large and small slendro intervals in vocal and instrumental music can vary between SISLS, ${ }^{6}$ SISSL and LSSLS, resembling the tones: 


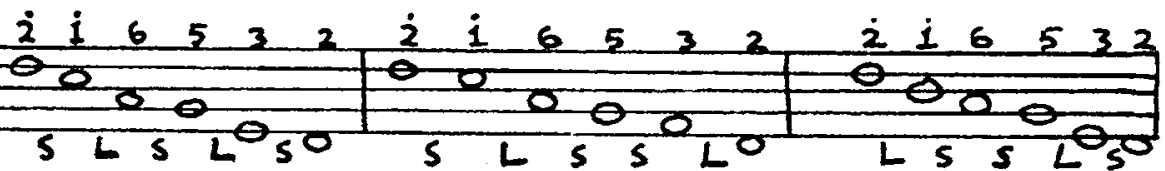

The Javanese describe gamelan tunings in which the intervals between tones 1 and 2 (barang and gulu) is very large (i.e. more than 240 cents) as sigrak, i.e. 'bright'; tunings in which this interval is small (less than 240 cents) as Zumh, i.e. 'soft', 'gentle'; and tunings in which this interval is about 240 cents (the 'equidistant' interval) as rata i.e. 'even', 'medium'.

In many of the slendro song performances in this collection, the slendro tones 1 and 3 are very unstable in pitch. Not one performance even approaches an equidistant slendro tonal structure. It is quite misleading to depict the slendro octave as having equidistant intervals of 240 cents each, as is still done in some of the most recent books about Javanese music. 'In modern practice, there is no true or standard slendro scale. ${ }^{8}$

\section{Pelog Tuning}

Although not as controversial as slendro, pelog tunings also vary from song to song, gamelan to gamelan. In the Konservatori Karawitan in Surakarta, the pelog scale tuning is given as:

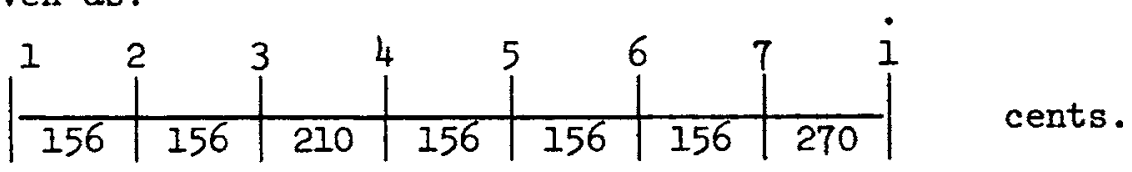

The pitch of the pelog scale tones may vary, and rocal tones may be inserted. ${ }^{9}$ As in slendro, if the interval between the pelog tones 1 and 2 (bem and gulu) is large (about 140 cents), it is believed to give a bright, energetic sound; if small (about 100 cents), a gentle sound; and if of 'average' size (about 120 cents), a sound of medium vitality. 10 


\section{Vocal Tones}

Javanese musical theory is based on music as played on idiophones which, unlike the voice, rebab and suling, cannot perform vocal tones. Vocal tones constantly deviating in pitch in a melody are called by the Javanese miring ('deviating') tones, whereas incidentally deviating tones are in Central Java called sliring ${ }^{11}$ and in West Java samaran. ${ }^{12}$ Tones which are so performed as to deviate slightly in pitch throughout their own time-length nay be called 'diphthong notes'.

Some Javanese rocal styles, especially those of the Sinden, resemble the rebab not only in timbre and kembangan types but also in the degree of intonational freedom. The Javanese attitude to pitch may be judged by a passage from the nineteenth century poem Tjentini, about a rebab playing with the gamelan: 'Every now and then there was a little deviation from the correct pitch so as to enhance the charm of the music'. ${ }^{13}$ The large number of incidental vocal tones in some songs, which are theoretically pentatonic or heptatonic, suggest that the relatively high degree of Javanese vocal pitch freedom has an aesthetic significance similar to that of 'incidental' melodic decoration. 14 The Javanese feel a distinct delight in performing 'pitch ornamentation', that is, performing songs consisting of theoretically nameable pitch levels in a highly variable, intonationally deviating way, in a similar way to ornamental techniques such as the glissando.

The degree of pitch ornamentation in a song varies like the degree of melodic ornamentation from singer to singer. Some occasionally perform sliring tones, some constantly alternate between two pitch-levels for the one theoretical tone, some prefer diphthong notes, and others 
constantly or incidentally introduce a large number of vocal tones.

Tones deviate in pitch to the highest degree in the tlutur songs, as in Transcriptions 2,16 , and 69, in which vocal tones are an expected part of the style. R.M.A. Koesoemadinata ${ }^{15}$ mentions the performance of a Sundanese slendro song containing 17 pitch-levels in the octave. A total of 21 tones could be heard by the naked ear in one of the Javanese tzutur songs of this collection (see p. 182).

Probably this free vocal style, with its fluid attitude to pitch and the large amount and many types of portamento, in which direction of melodic movement is often a more important element than the exact pitch of the tones themselves, is of ancient origins. In any case, it is presumably much older than song-styles based on relatively strict pentatonic pitch levels, which are obviously under the intonational influence of gamelan instruments. The evolutionary theory that 'complex' scales with many tones evolved from the relatively unvacillating pitch-levels of the tones of 'simple scales' with few tones, is hardly plausible. 16 It is likely that instrumental influence on vocal style in respect of pitch, rhythm and some types of vocal timbre, grew in Java with the development of the gomelan instruments and was always most strongly felt in songs performed with gamelan accompaniment as part of the gending repertoire.

Kunst suggested that the intervals and tone sequences of certain Javanese and Sundanese children's songs may be traced back to certain ancient miring and ringkung scales. 17 Tonal deviations in matjapat songs may also in fact be references in some cases to sequences of tones formerly accepted as norms, but this is almost impossible to trace. 
In these songs, tonal deviation is often an incidental and inconsistent ornamental feature.

Patet

In Central Java, the two tone systems slendro and pelog each consist of three commonly used patet. 18 The slendro patet comprise 5-toned scales; the pelog patet comprise systems of 5-toned scales consisting of a principal and two auxiliary scales each. The scales of each patet are pitched a conjunct fifth above or below the other scales or scale systems of the respective tone system, and each possesses its distinctive melodic characteristics and in some contexts social, theatrical, and mystical associations.

Each patet of the same tone system is distinguishable: i) by the tonal construction and/or pitch of its respective principal scale, which is one or two 5ths above or below the other principal scales of the same tone system; and in pelog by the respective patet' $s$ 'high auxiliary and low auxiliary scales, which are pitched a 5 th above or below the principal scale; ii) by its distinctive transposition ${ }^{19}$ and/or modulation ${ }^{20}$ practice from patet to patet, principal to auxiliary scale and vice versa, and tone system to tone system; iii) by its theoretical tone hierarchy, consisting (theoretically) of its three pillar tones around which the melody revolves according to specific melodic characteristics and two less important tones of which one sometimes acts as an 'enemy tone'; 21 iv) by its association (if in wajang performance) with one of the three periods of the wajang night.

The term pizzar tones (i.e. main tones of a patet) is preferred to the term gong tones first proposed by Kunst and consistently used by Hood. Gong tone is a colourful name but not as generally appropriate for both 
vocal and instrumental media as the term pillar tone. 22 Besides, the function of pillar tones is not limited to the coincidence of final tones with a stroke on a gong, as the term gong tone may seem to imply. Pillar tones have complex melodic and tonal hierarchical functions.

The term 'melodic formulae', denoting certain standard tone sequences, is also preferred to Hood's 'cadential formulae', since these formulae are used within the melodic line just as often as at cadential points; moreover, sometimes formulae occur within a line and are omitted or appear in incomplete form at cadential points. However, in many cases, a typical melodic formula occurs most prominently at the end of a melody. Hood's term cadential formulae also carries the meaning of melodic formulae, but the latter term, in my view, is clearer.

Kunst covered most of the aspects involved in the difficult patet concept without, however, attempting a 'genuine definition' 23 of it.

Hood made a study of the patet characteristics of nuclear themes in gending and presented a definition of patet. 24 The most valuable results of his investigation were an assessment of the relative functions of tones in each patet, and a set of two ascending and two corresponding descending formulae ${ }^{25}$ for each patet: 


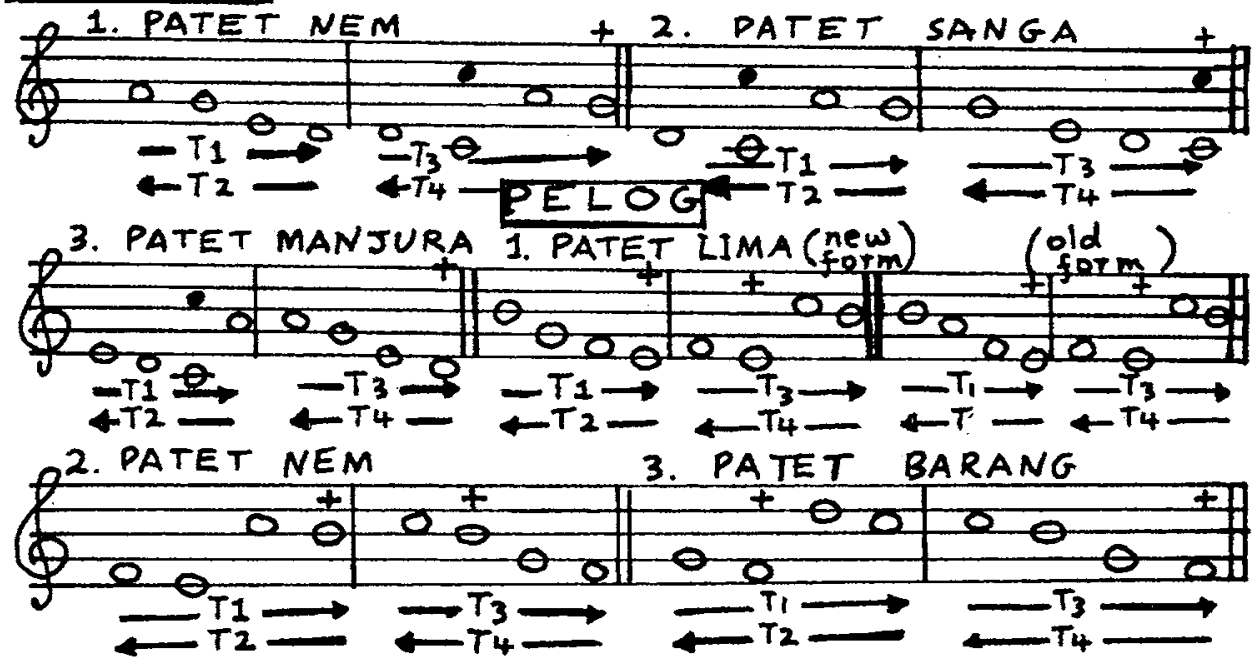

Typical melodic formulae of the Central Javanese patet, after Mantle Hood. 26

Wider research into the patet characteristics of the various instrumental and vocal media still remains to be done. Patet is not a concept reserved for gending alone, nor is it limited by genre or musical form. Moreover, regional musical differences in respect to patet, especially in West and East Javanese regions, are as yet hardiy investigated. The Javanese writer Tedjohadisumarto, in his book on Javanese tembang, confirms Hood's findings as to two of the typical melodic formulae for each of the three slendro patet, differing only in 'formula shape', i.e. the shape of T 1 (patet manjura) is according to Tedjohadisumarto: 27

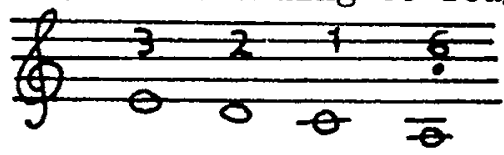

Formula shape, which is rigidly set in the case of the balungan instruments of the gamelan can in vocal music be very diverse.

The Slendro Patet. Theoretically, the three slendro patet each consist of the same tones (see p. 85), but each patet begins on a different pokok (starting note). The pillar 
tones are:

$\begin{array}{rcccc} & \text { IPT } & \text { IIPT } & \text { dasar } \\ \text { slendro patet nem } & \text { tone } & 2 & 5 & 6 \\ \text { sanga } & & 5 & 1 & 2 \\ \text { manjura } & 6 & 2 & 3\end{array}$

Patet nem and patet manjura resemble each other in their two common pillar tones and the $\mathrm{T} 1$ and $\mathrm{T} 2$ melodic formulae. Patet sanga, on the other hand, by far the most frequent patet of this song collection, has in general the clearest and most abundant patet characteristics.

The Pelog Patet. The tones of the principal and auxiliary scales of the three pelog patet are:

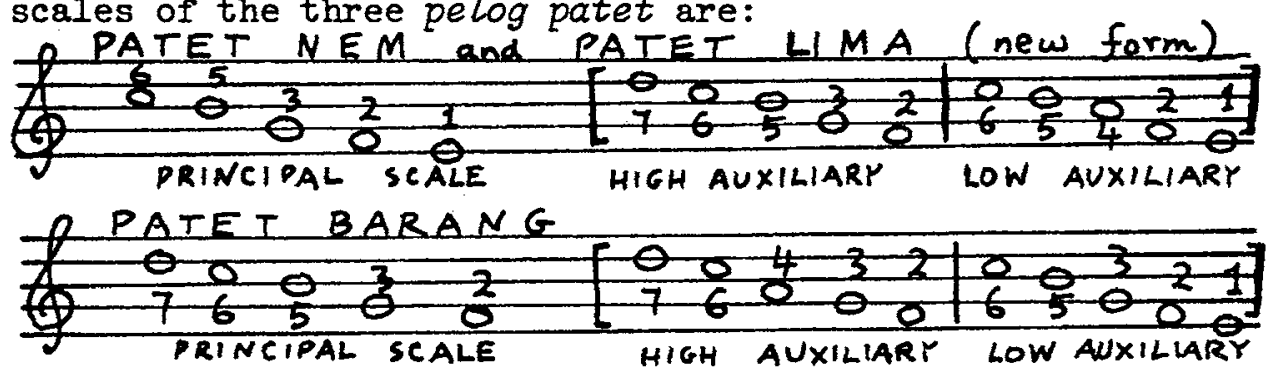

The pillar tones are:

$\begin{array}{rcccc} & & \text { IPT } & \text { IIPT } & \text { dasar } \\ \text { pelog patet lima } & \text { tone } & 5 & 1 & 2 \\ \text { nem } & 2 & 5 & 6 \\ \text { barang } & 6 & 2 & 3\end{array}$

The existence of a really independent pelog patet manjura has not yet been conclusively proved, despite Kunst's and Hood's belief that it is a separate but infrequently used patet. 28 Hood's analysis of a Ladrang as being in pelog patet manjura is questionable. ${ }^{29}$ The melodic formulae proposed by Hood for pelog patet manjura were found in these song analyses to be misleading. 30

The complex patet system of West Java, an important 
subject for future detailed research, cannot be discussed here. Its theoretical aspects have been outlined by Kunst. ${ }^{31}$ The Sundanese songs of this collection cannot provide the basis for an inquiry into the Sundanese patet system.

The main concepts such as the pillar tones are similar to Central Javanese patet, but theoretically there are a great many more possible patet in Sundanese music.

The reputed improvisatory freedom of performances of music in Java, even that of unaccompanied tembang matjapat, may not be as great as it first seems. No song or piece can be freely invented or 'composed'; conservative Javanese musical tradition lays down formulated or unformulated regulations in respect to patet (which literally means 'to restrain'), basic melodic progressions and vocal styles. Musical improvisation, as practised in Javanese vocal and instrumental music, is based on the deep, instinctive understanding of a musical system, which limits stylistic choice in such matters as the final tone of a piece and the appropriate melodic formulae constantly to be used for a given patet. 'A good nitaga from the Principalities immediately distinguishes one patet from another, without ever making a mistake; he is however, incapable of explaining how or why he does so. 32

\section{KEMBANGAN}

T'wo types of kembangan (melodic ornamentation) are distinguished in the song analyses: the purely ornamental, 'incidental' decorations such as glottal stops, glissandi, shakes and acciaccaturas on the one hand and the melisma on the other, generally consisting of statements or elaborations of the melodic formulae typical of the patet and other freely invented melodic phrases. The former type possesses minimal structural importance and is very much dependent 
upon the vocal style of the performer and the whim of the moment. The melismatic kembangan consists, in many cases, of memorable melodic phrases which should be regarded as being an integral part of the melodic construction. One cannot say unequirocally that the melisma are 'freely improvised' because in fact the melisma can often be shown to follow definite melodic tendencies which, since they frequently endorse the patet through quoting its typical melodic formulae, should be regarded as possessing formal significance of a high order.

Neither type of kembangan should be regarded as possessing a non-essential nature, but both types are often 'added' to a performance; i.e. one singer may perform an acciaccatura or a melismatic phrase in three different places or ways in three performances of the same song, due to such momentary details as syllable emphasis or the number of consonants in a word of the text; or he may omit an embellishment in one performance and add it in the next. True, some singers perform, for instance, matjapat children's songs in a syllabic, non-melismatic way and others omit the more incidental type of ornamentation. But performances lacking kembangan altogether are rare. Kembangan, albeit of a highly variable nature, should be regarded as an attribute of matjopat style in performance.

\section{ELUK}

A stylistic characteristic of matjapat songs is the decorative, melismatic passage which may be sung on the last syllable of a poetic line and termed eluk. In its widest sense, eluk means any ornamental feature or melismatic passage. But according to singer-informants who came from the Surakarta area, the word in its restricted sense means an ornamental melodic passage (tjengkok) sung on 
the last syllable of a line. It is in this latter sense that eluk will be used here. Thus, in the ten-lined Dandanggula, it is possible (but not always desirable), to sing a maximum of ten eluk. An eluk-ending to a line consists essentially of melismatic kembangan, but 'incidental', ornamental touches (such as acciaccaturas) are often added to some of the melismatic tones.

The musical term eluk is presumably taken from the terminology of the traditional, sacred, dagger-like weapon the keris - which is still carried today on certain ceremonial occasions and believed by some Javanese to be a mystical protection against adversity. According to tradition, the keris has a genetic relation to Javanese music and theatre. The same divine hero Pañji, who created the Javanese theatre and the gamezan orchestra - that forms an intrinsic part of it - is also said to have been the first kris-smith; he is the inventor and the first wearer of the kris." 33

The keris blade is of two main types, 'the straight (dapur bener) and the undulate form (dapur luq ...) ... the one form is associated with the idea of "rest", the other with that of "action". 34

In the musical sense, the Zuq or eluk is similarly characterised by its melodic activity; its melodic line 'undulates' back and forth in melisma like the undulating keris blade. The total number of undulations as well as each individual undulation are called eluk.

According to two Surakarta informants, the number of 'undulations' in a musical eluk, like the undulations of a keris blade, can be counted. 35 Thus, the long eluk in. Transcription 16 (Iine 7), drawn in a pitch-line as follows: 


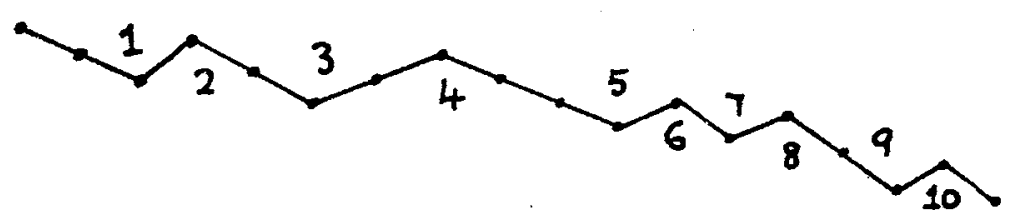

could be said to possess 10 eluk, or convexes.

However, the essential character of eluk in actual performance is the freedom on the part of the singer to include or omit an eluk as he chooses, and if he chooses to sing one, to perform as long or short an eluk as he wishes at the moment of performance. Certainly a singer never premeditates the number of melodic undulations he sings. Transcriptions 54 and 55 are sung to the same melody and text by the same singer; in Transcription 54 (line 5), the singer performs a long eluk, but in the corresponding place in Transcription 55, he omits the eluk entirely.

\section{METHODS USED IN THE ANALYSES}

\section{Mezos}

For purposes of analysis it was found useful to simplify the melodic line of each song into a melos, whereby all repeated tones were omitted, and the remainder written out in arhythmic form, with a line across the stave at the end of each poetic/musical line.

It is evident that the poetic line possesses structural musical significance. In performance, the singers generally think in terms of the line as a formal unit. In the majority of cases, rests occur and breaths are taken at the end of a poetic line. A melos is so constructed that repeated tones occur only if the final tone of a line and the first tone of the next line are of the same pitch. Tones with relatively long time-values, or the first tone of a string of repeated tones on one pitch 
(i.e. at least three repeated tones), are left white in the melos, whereas short single tones or tones repeated only once or twice are coloured black.

The melos shows the essential melodic structure of a song, unencumbered by tone repetition and rhythmic and ornamental detail.

Intervals

The intervals are designated as follows: ${ }^{36}$

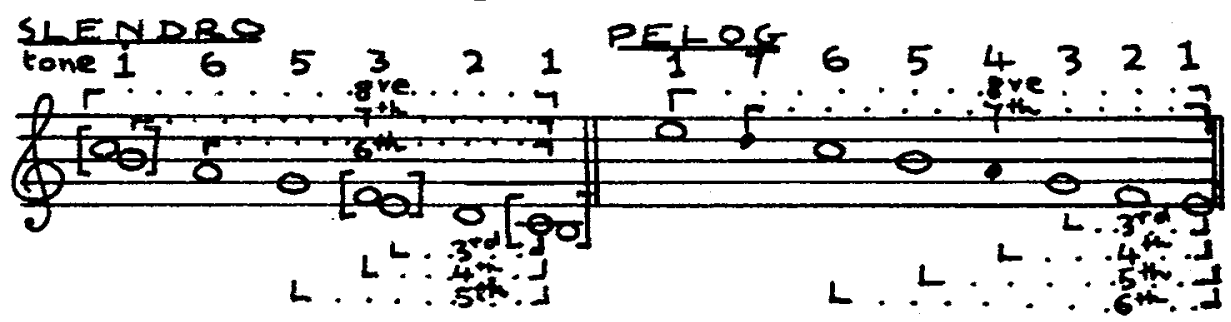

Intervals which approximate the minor or diminished and augmented intervals of Western music are here called 'small' and 'Iarge' intervals in order to avoid Western harmonic associations. Thus, is called a large 4th. The term 'slendro $3 \mathrm{rd}^{\prime}$ ' is used to mean the two small 3rds found in the slendro scales, tuned as notated on p. 86 ; 'pelog $3 r d s '$ is used to mean the 3rd, large 3rd, and small 3rd found in the pelog patet's principal and auxiliary scales.

Melodies based on the gapped structure of pentatonic scales in common use contain by their very nature more leap movement than scales with equally or nearly equallyspaced tones. However, in order to distinguish between normal pentatonic-scale $3 r d s$ and other melodic leaps, any pentatonic progression from one scale tone to the next will here be called stepwise motion. 'Slendro stepwise motion' means, then, any scalewise slendro progression, irrespective of whether it is a 2nd, 3rd, or small $3 \mathrm{rd}$, all of which 
intervals are contained in the slendro scale. 'Pelog stepwise motion' means any progression from one of the respective patets five principal scale tones to the next, including 2nds, 3rds, small 2nds and small 3rds. 37

\section{Tone Prominence}

In order to estimate the practical usage of each tone of the patet in each song, a method of estimating 'tone prominence' was devised, which also served in some cases to check patet analysis of songs. Indeed, the biggest problem of the analyses was to find as infallible a way as possible to determine the patet of each song. Based on the fact that the scales of each patet are structurally a tonal hierarchy (three tones are theoretically more important than the other two), the following method was devised to assess the characteristic usage of individual tones and to confirm patet analysis in a few ambiguous cases, after the tonal material had been investigated and the melodic formulae selected. Tone prominence was estimated for each tone of the melos of a song according to the respective tone's frequency of occurrence, its number of appearances (if any) as final tone of lines and as initial, final, highest, and lowest tone of the song, its relative time-length and its occurrence in repeated tone passages (the two latter cases of which are expressed by white tones in the melos). Each tone received one point for an appearance in the melos and an extra point if it was final tone of a line, if it was the initial, final, highest, or lowest tone of the song range, if it had a relatively long time-value ${ }^{38}$ or if it was repeated at least three times in succession. Final tones of lines were regarded as being in general more significant than initial tones of lines; the former consisted in many cases chiefly of pillar tones of the 
respective patet (e.g. Transcription 1) whereas the latter showed more tonal variety (using vocal tones as well as all scale tones, e.g. Transcription 47, line 1) and sometimes merely repeated the last tone of the previous line.

The two or three tones receiving the largest number of points were then called 'the most prominent' tones while the tone or tones with the least number of points were called 'enemy' tone(s). In many cases, but by no means in principle, the two or three most prominent tones of a song happened to be two or three of the pillar tones of a certain patet. $^{39}$ The enemy tone(s) often varied between songs in the same patet and in some of the more 'democratic' songs in which all five principal scale tones were of similar prominence, no tone was neglected enough to be able properly to be called an enemy tone.

\section{Level Shift}

The term 'level shift 40 was found useful in designating the degree of each melody's ascent or descent. The level shift statistics for the two groups of songs in this collection allow interesting generalisations. However, they may not be too Iiberally interpreted, since variability of initial and final tones and even the range of each song are matters of stylistic licence in matjapat singing.

Level shift is calculated on the basis of the relations between the initial, final, highest, and lowest tones of a song. 41 Despite the variability of these tones between different versions of the one melody, these four tones always possess some special degree of melodic significance. The initial tone is the point of reference to which all. following tones are automatically heard in relation, whereas the final tone gives the ultimate degree of melodic 
resolution. The highest and lowest tones, being the summits and the valleys of the melody, have considerable formal and melodic directional sighificance.

Degree of Melodic Direction Change

The above method of classifying the trend of melodic direction can usefully be combined with another method of calculating the exact amount of melodic direction change in a song, in order to describe the course of the melodic movement in more detail.

The tones of each song were represented by a series of dots, arranged to show the approximate level, rise or fall of each successive melos tone. Each change of direction was then indicated by an arrow. For instance the beginning of the Sundanese Transcription 25 (Midjil)

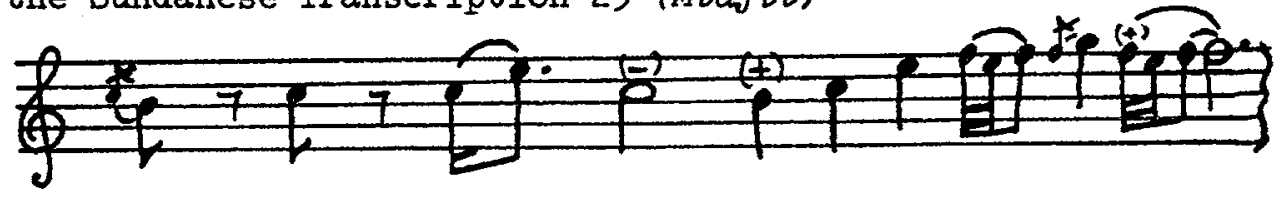

was represented diagramatically as:

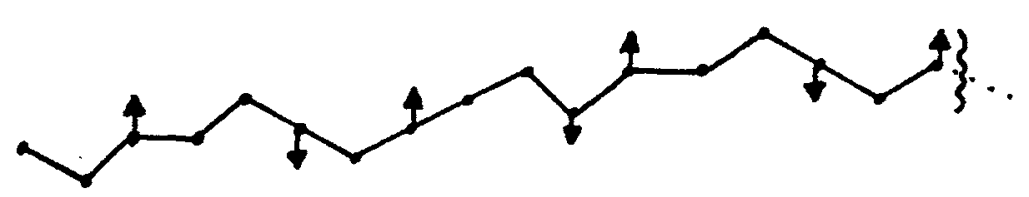

The number of arrows represents the number of direction changes. The percentage of direction changes in a song may then be calculated. 42

Since the main type of movement in these songs is either slendro or pelog stepwise motion, it is not of great consequence that this test fails to take size and direction of intervals into account. These matters were the subject of a separate investigation. The value of this test, in combination with the measurement of level shift and tone 
repetition, is in the light it throws on the relative amounts of melisma 43 and tone repetition, which are important stylistic factors in these songs.

Degree of Repetition of Adjacent Tones

The method outlined above allows a quick count not only of the total number of tones in a song but also the number of successive repeated tones. The percentage of tone repetition could then be calculated for each song. 44

The value of the above-mentioned tests lies in the stylistic generalisations they allow about each of the two song-groups of this collection. 
Since stylistic evaluations tend to be subjective, especially when attempted by foreigners, appraisals of 'value' and inclinations towards certain songs were avoided in the analyses. Song versions and variants showing typical, variable, or exceptional traits were selected for the following analyses. In order to avoid repetition, relatively detailed analysis of the first group of transcriptions is given, after which analyses are presented in progressively briefer form.

The first group was chosen because of its many typical features and because it constitutes the maximum of performances of any one song in this collection.

\section{CENTRAL JAVANESE SONGS}

Dandanggula Turulare ${ }^{1}$

of the twelve collected performances of this melody, eleven are in the slendro tone system and one (Transcription 38) in the pelog. They are sung to five different texts, dealing with early morning, the teachings of a king, prophecy of miracles, love for a beautiful girl, and advice to study. Transcriptions 90 and 132 were taken from the number script, and in their rhythmic and melodic simplifications of actual vocal practice contrast with the transcriptions of live performance. Transcriptions 54 and 55 are variants performed by Imam. All the others are versions of different performers. Melodic Movement. The melodic movement takes a moderately descending direction, and possesses a relatively high amount of both direction change and tone repetition. The level 
shifts of all but the first version are descending, ranging from $-9^{\circ}$ to $-36^{\circ}$, but there are no extreme level shifts. Average melodic direction change for the twelve song-versions is 35 per cent, with a maximum of 42 per cent (in Transcription 19). The average amount of tone repetition is 38 per cent, but in one version (Transcription 38), 47 per cent of the tones are adjacent repeated tones.

Since the melos of each version varies from the others to a considerable extent, one cannot speak of 'the basic melos' of this (or any other) matjapat song. The melos of Transcription I begins on a different tone (a vocal tone) from the melos of Transcription 47 (shown on p. 106). Iine 1 of the melos of Transcription 1 contains fewer tones by far than line 1 of Transcription 47, which contains a Iong eluk. Whereas line 2 of Transcription 47 consists of one pitch-level only, the same line in Transcription 1 contains a melodic curve. However, the range of these two versions is identical. As is common practice in matjapat songs, the highest tone appears in both versions only at the beginning of the song, while the lowest tone is reserved for the latter half of the descending melody, appearing twice in the melos of Transcription 1 and five times in the melos of Transcription 47.

Transcription 47 covers the same melodic ground in its first poetic line as the first two poetic lines of Transcription 1, restricting itself to repeated tones for the entirety of line 2. This overlapping of the melodic Iine across the poetic line in Transcription 47 is an exception in matjapat songs; it rarely occurs in the other songs of this collection. The tones of the melos of lines $4,5,6$, and 7 in the two versions are somewhat similar. But line 9 in Transcription 47 contains repeated tones and 
three-toned undulatory movement, while in Transcription I, the same line comprises a scalewise descending and ascending curve. The final line of both versions uses the lowest part of the range, but in Transcription 1 there are two leap movements, in contrast to Transcription $47^{\prime} \mathrm{s}$ undulating slendro motion. In a second performance of the melody in Transcription 1, the entire final line was sung to a different melodic progression, ending a fifth above the final tone of the previous performance. Although based on the same basic melody, the two versions differ considerably from each other.

Slendro stepwise motion predominates. Transcription 1 contains only 8 melodic leaps while Transcription 90 has the maximum number for this group of transcriptions, i.e. 11 leaps. Leaps occur twice as frequently between the end of one line and the next than within the poetic/musical line itself. By far the most common intervals are the ascending and descending 4 ths, but 5 ths and 3 rds are often found, and 6 ths and 7 ths occasionally occur. Small or large intervals in the slendro versions of the melody (e.g. the small third:

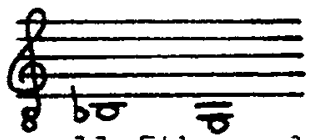

in Transcription 58) are rarely found, but small 5ths and 3 rds as well as 4 ths and 5 ths occur in the pelog version. Leaps are always preceded and followed by stepwise motion. A moderate amount of sliring tones occur, especially the lowered tones 3 (as in Transcriptions 1, 19, $36,54,55$ ) and 7 (as in Transcriptions 54, 55). In Transcription 47 , tone 3 is an almost stable approximation of the pitch level:

whereas tone 3 in Transcription 90 is always written: Only of the five following pitch-levels of the pentatonic 


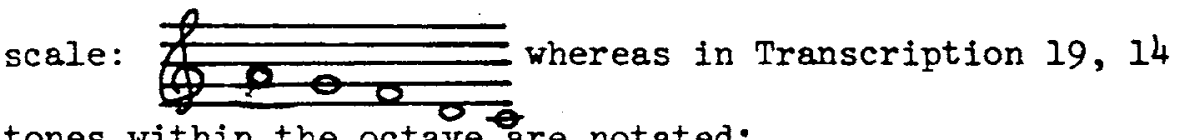

tones within the octave are notated:

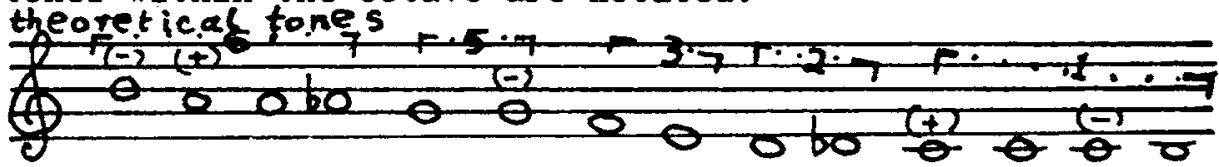

A minuter measurement of pitch would no doubt show a still

greater amount of tonal material. Many tones in versions of this song also deviate in pitch within their own timelength.

Patet. An analysis of the tonal and melodic formula structure of the melos of each version shows clear slendro patet sanga characteristics, except in the case of

Transcription 38, which shows pelog patet lima characteristics. The T 3 and $T 4$ patet sanga formulae were found in the melos of each slendro version; however, the $\mathrm{T} 1$ and $\mathrm{T} 2$ formulae were found to be absent.

In most of the slendro patet sanga and some patet manjura songs of this song collection, three very common 3-toned formulae were found, the descending forms of which will be entitled $Q 1, R I$, and $S 1$ and the corresponding ascending formulae $Q 2, R 2$, and $S 2$ :

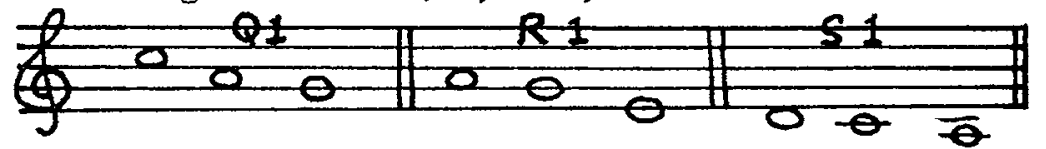

A variety of shapes for all formulae were found in these songs, the most common shape being the ascending or descending scalewise form. The 13 formula, for instance, most commonly takes the shape:

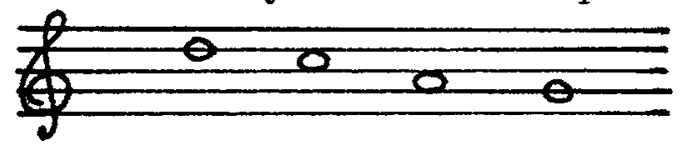

in this group of versions, not the shapes found by Hood as being typical for nuclear themes of gending as played on the saron:

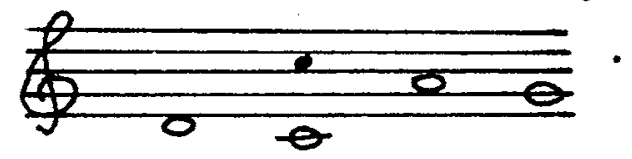




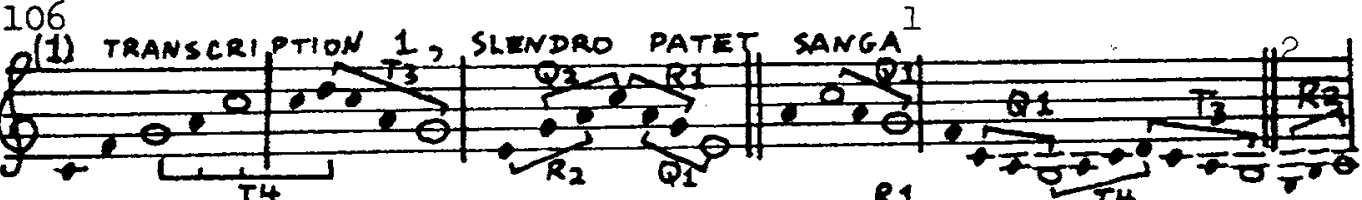
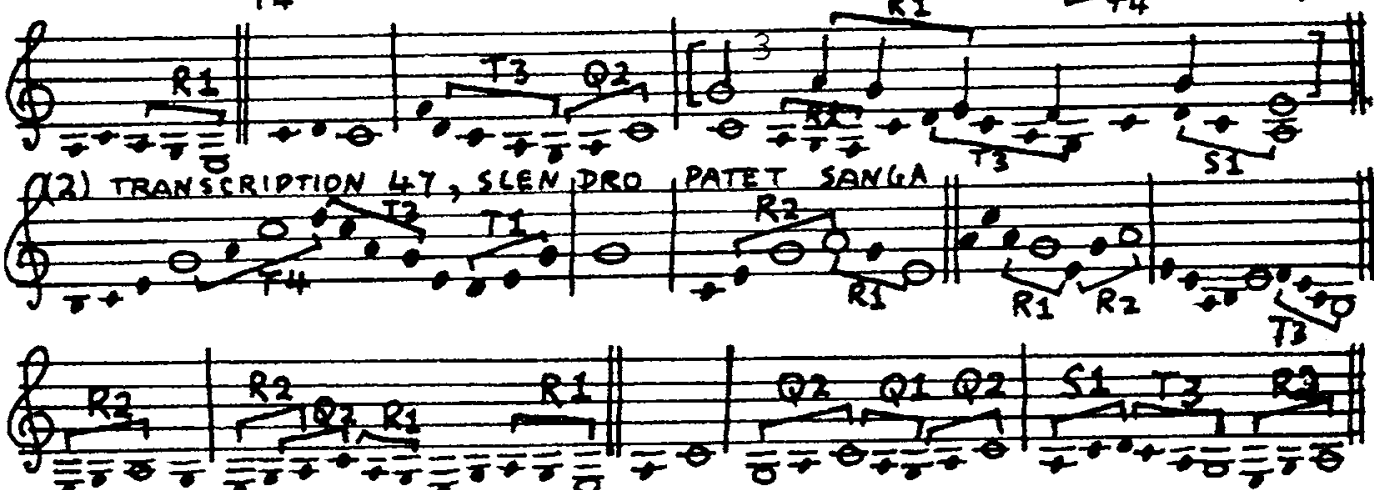

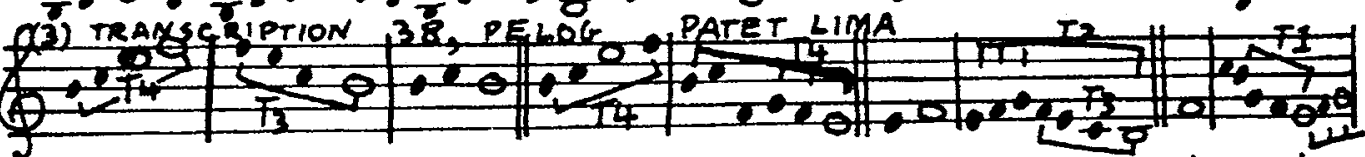
(4) Transcription 38, transposed from the pelog

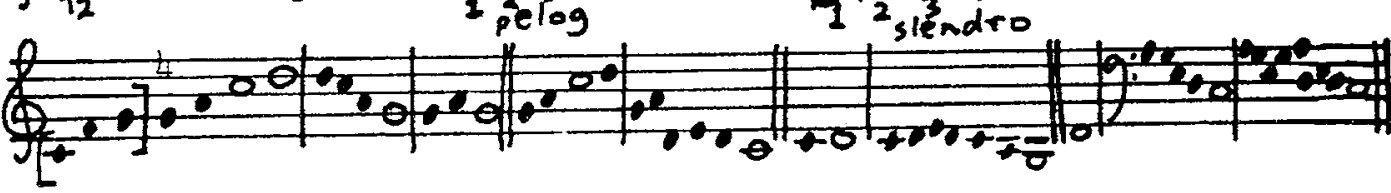

THREE MELOI and ONE TRANSPOSED MELOS of DANDANGGULA TURULARE.

1. Note: T 1 (type I) and $\mathrm{T} 3$ are the descending 4-toned formulae for the patet, $T 2$ and $T 1$ being the corresponding ascending or retrograde formulae (see p. 91). Q I, $R I$, and $S I$ are additional descending 3-toned formulae found typical of the versions of this song. $Q 2, R 2$, and $S 2$ are the corresponding ascending or retrograde formulae.

2. The double lines represent the Andegan divisions.

3. The ending of Transcription 1 was performed differently when repeated. The lower line of bar 10 above is the melos of the first performance; the upper line is the melos of the second.

4. These three tones are added in order to make the similarity of the transposed melody with the original slendro versions clearer. 
As might be expected, formula shape is more variable in vocal than in instrumental music, in view of the fact that the latter is often limited by the range of fixed-key instruments.

In the melos diagrams on p.106, the melodic formulae of Transcriptions 1, 47, and 38 are shown. The most prominent tones among the slendro versions are tones 5 (IPT), 1 (IIPT), and 6, but in Transcription 60, raised tone 3 was, exceptionally, a prominent tone. Tone 2 (the dasar) is less prominent even than tone 6 , except in Transcriptions 60 and 95 in which the dasar plays a prominent part. The least used tones in the slendro versions are either the dasar or tone 3 , but in Transcriptions 1, 19, and 38, tone 3 is conspicuous for its pitch variability. Repeated tone passages occur most often on the IPT, IIPT, and tone 6 . Similarly, melismatic passages begin most often on tones 5,1 , and 6 . These characteristics help to establish and endorse the patet.

The melos of Transcription 38 transposed on p. 106 into the slendro tone system shows clear similarities with the first three lines of Transcription 1, after which the melos deviates more strongly and finally descends to a lower level than in Transcription 1. But in respect to the text, the Andegan structure, its range of tones (19 semi-tones), the general direction of melodic movement, the appearance of the highest tone in the beginning and the lowest tone at the end of the song, its paucity of pitch-levels in lines 6 and 8 and its descending scalewise movement in line 7 , it resembles the slendro versions of the melody. All the four types of the pelog patet lima formulae appear, and the version ends on the most typical final tone for the patet (tone 1). The highest tone is the dasar (tone 2); and the most prominent tones are the three patet lima pillar tones (tones $5,1,2$ ). 
The patet is confirmed by the tone repetition passages, which mostly occur on the pillar tones 1, 2, and 5 (in order of frequency). The 'enemy tones' 3 and 6 occur relatively seldom and mostly at unimportant points. ${ }^{2}$ The Relation Between Speech Melody and Song Melody. In order to compare the melodic and rhythmic elements of the speaking and the singing voice, some of the matjapat song texts were spoken into a tape recorder by non-singers who were born in a Javanese or Sundanese village. The Javanese and Sundanese languages are not, like Thai or Chinese, tone languages with phonemic pitch inflections. But when spoken in normal, non-intellectual conversation, these languages are characterised by their exceedingly melodic nature. Indeed, some gramatical forms such as questions require a particular intonation to be understood as such. Degrees of politeness are also determined to an extent by speech intonation. It is therefore at least a reasonable hypothesis that free melodic styles have some relation to speech melody and rhythm in Java. ${ }^{3}$

The diagram on $p$. 110 is an attempt to transcribe by ear the speech melody of a Dandanggula stanza by a Central Javanese ex-villager. It is intended to show i) approximate pitch variations (each square note representing a relative pitch level); ii) the rhythmic speech pattern and; iii) the slightly emphasised syllables ${ }^{4}(\dot{p})$ of the text.

A comparison of the diagram with Transcription 1 shows i) a degree of correspondence in the phrasing and position of rests of the spoken and the sung versions; ii) the speech rhythm is much more regular than the song rhythm; iii) both the speech melody and the song melody rise in the first two words (Djago Kluruk), and they both descend in lanang wadon, and in sawetaning gunung, etc.; 
iv) the slight speech accentuation of the Javanese language has little relationship to the position of the melisma. In this example, a certain correspondence between the duration and melody of the spoken and the sung versions exists. This was, however, not always the case. ${ }^{6}$ Musical requirements often demand large-scale changes in the normal rhythmic and intonational speech patterns.

Rhython. Minutely detailed rhythmic analyses of songs which feature a very small degree of rhythmic regularity or repetition would seem to have little value. As a comparison of any two performances of this unaccompanied song by different singers will show, the individuality of the performer is at its greatest in matters of rhythm.

There are, however, certain rhythmic similarities even between performances by different singers, especially in the phrasing of words in the melody, and the position of long and short tones (e.g. in Transcriptions 1 and 19, the third tone of the melos, and the final tones of lines 2 and 3 are relatively long). Melisma and tones of relatively short time-value tend to occur on descending melodic lines, while ascending lines (as in the first line of Transcriptions 1,38 , etc.), often consist of longer tones. Repeated tone passages tend to be irregular in rhythm, the syllables with long consonants (as in 'scom-', '-nung') tending to have longer time-values than syllables with shorter consonants (as in 'Ne-te-pi'). Final tones of lines and rests, especially between lines, are of erratic length, as an inspection of any transcription of this group of versions will show. Long-held tones at the end of a poetic/musical line are common, as in lines $2,3,5,7,9,10$ of Transcription 1. Melisma containing tones of even timelength are rare, but an example of this is found in the eluk 
110

The speech melody

of a recitation of Dandanggula

as transcribed by ear

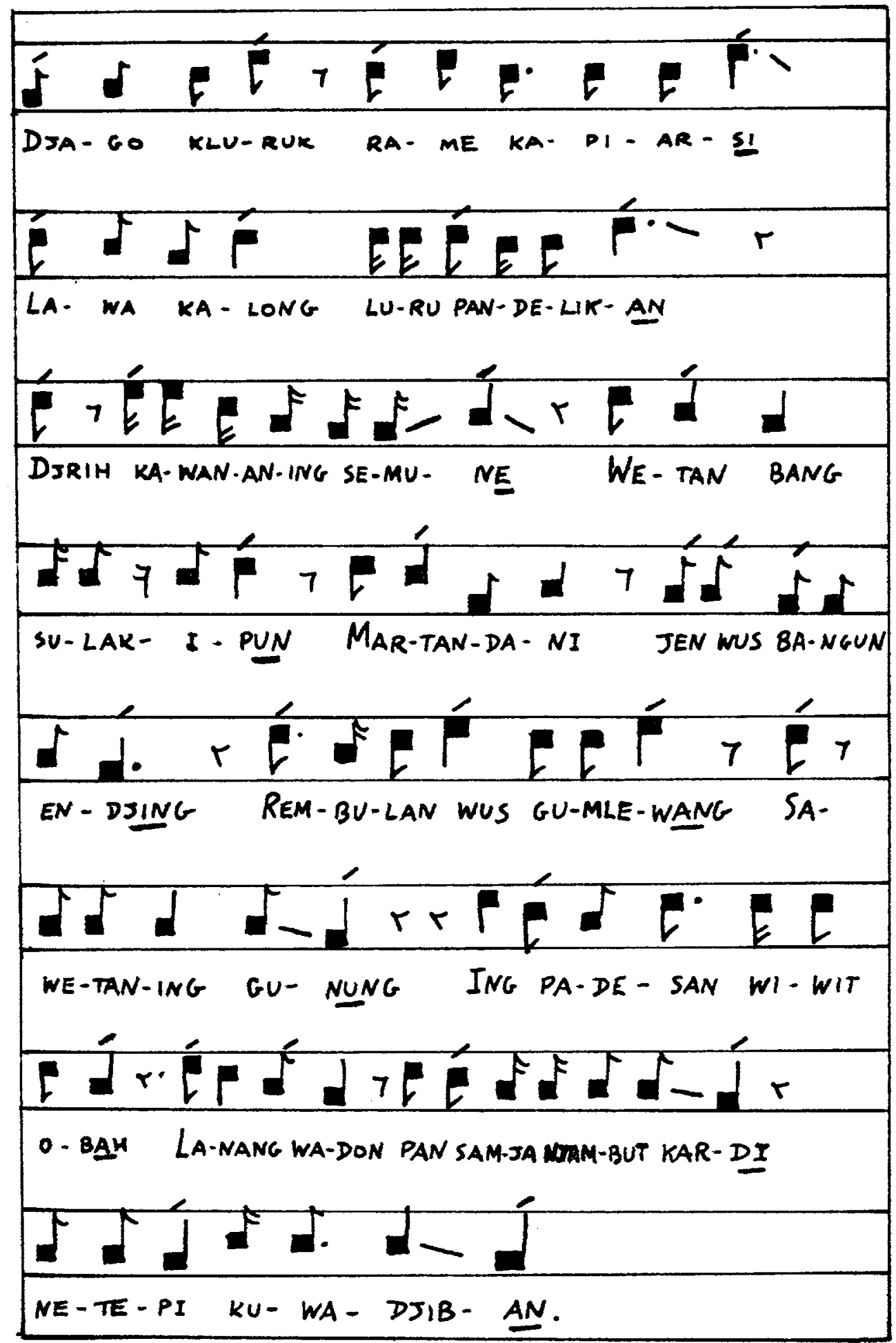


of line 1 of Transcription 47. Incidentally embellished tones (e.g. tones preceded by acciaccaturas or glissandi), are usually of fairly long duration and never shorter than a quaver in these transcriptions.

Andegan and Formal Structure. In Transcriptions 1, 47, and 90 , the longest final tones and rests between lines occur at the ends of lines 3,5, and 7. The musical breaks are identical with the theoretical Andegan divisions of the Dandanggula verse form. ${ }^{7}$ That is, there is a correspondence between the poetic and musical structure in these three versions. However, this rarely occurs in other songs.

The main musical elements of formal unity are the large degree of iterativeness of the typical melodic formulae and their elaborations, the kembangan (e.g. in Transcription 1, 90 per cent of the melisma begins on, and 94 per cent of the glissandi, glottal stops and acciaccaturas precede or follow one of the pillar tones), and the continual rhythmic mutations from melodic movement to rest. Imitation and repetition of melodic figures or motives are absent. Rhythmic and melodic variants of the $T 3$ formula occur for instance in Iines 2,5 , and 9 of Transcription 1 :

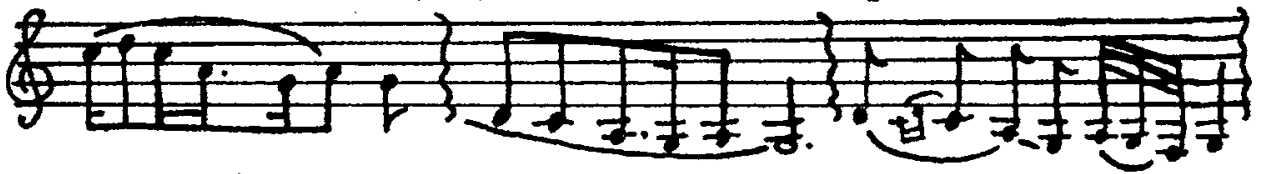

The poetic/musical line mostly functions as a melodic formal unit, after which long or short rests usually occur. Vocal Styles. Vibrato is light to medium in amplitude, and fairly liberally employed by some singers, especially on the last tones of lines, on the eluk and on long tones within a line which are followed by a melismatic passage. Some singers from the Surakarta area (Imam, Sunarto, Supardi etc.), sing with a very fast vibrato, and the others with a slow or 
medium vibrato (about 4 to 6 oscillations per second) of a slightly uneven character. Melismatic passages are generally sung without vibrato, or with alternating vibrato and nonvibrato. Repeated tone passages are also generally sung without vibrato, and sometimes with slight, rhythmicallyirregular stresses on certain syllables.

Degrees of dynamic contrast vary from singer to singer, but ascending melodic lines generally tend to be accompanied by crescendi and descending lines by diminuendi or by no change of dynamics. The slendro performances of this song constantly alternate between crescendi, diminuendi, and stable dynamics, with the loudest part in the first three lines, followed by a prevailing diminuendo trend until the end. The pelog version is, however, more subdued, containing little dynamic contrast.

Two diverse singing styles are those of Sujitno and Kartomi, the former singing quickly and a little excitedly, with little vibrato, few long-held tones, short melisma and a light timbre, the latter being characterised by its calmness, slowness of tempo, steady crescendi and diminuendi, liberal use of vibrato, long melismatic passages, and rhythmic contrast between the quick, irregular rhythm of the repeated tone passages and the long-held tones, especially at the ends of lines. Imam characteristically reserves his very fast vibrato for the long tones, the movement of the vibrato matching his correspondingly fast melodic figurations.

Some singers occasionally add the neutral syllables ('e') or ('a') between syllables of the text (e.g. Sabar, in Transcription 1). This practice is probably based on rhythmic reasons, on the need for movement in places where the text is of insufficient length for the melodic line; or in order to enable two successive consonants to be more 
easily pronounced, e.g., the ' $r$ ' and ' $s$ ' syllables in ' $\mathrm{Ka}$ piar-(e)-si' (Transcription I).

Kembangan. The most prevalent 'incidental' melodic decorations in this song are single, double, and triple acciaccaturas $4, X_{p}, x_{p}$, and the slow to medium, shakelike oscillations of tones a second or small third apart (e.g. see the eluk line 3, Transcription 47), often appearing in irregular rhythm. Rarer are such rhythmic-melodic sequences as: (in the eluk, Transcription 55, Iine 5 ).

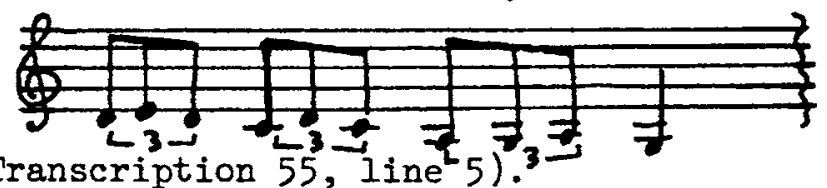

Particularly common are anticipatory tones (A) and turns (T) (e.g. in the eluk line 10, Transcription 1):

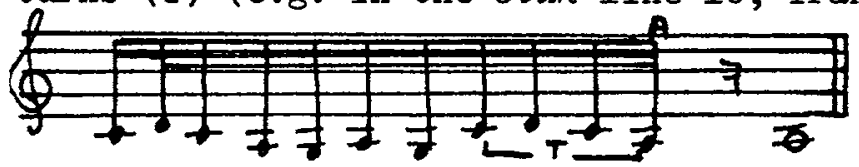

Glottal stops ( $D$ ) and vocal glottal stops ( $\mathcal{Q})$, produced by tightening the throat muscles in order abruptly to cut off the breath flow (e.g. in Transcriptions 1, 19, 47), are most perceptible and effective after a crescendo (e.g. the first line of Transcription 1). Portomenti of various types are very prevalent, usually occuring before or after scaletones, not vocal tones, and sometimes occuring several times in succession, as in Transcription 58, line 10:

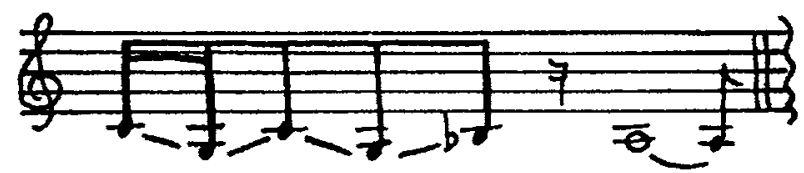

or in combined rising-falling fashion as in Transcription 55, line 10:

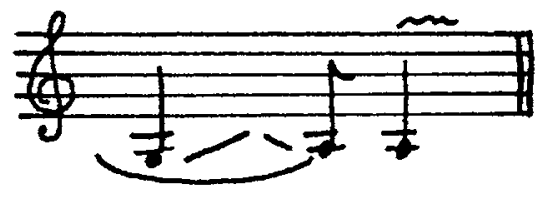

Fast glissando before a note $(\mathcal{F})$ sometimes almost reaches an 
acciaccatura effect.

The pitch levels used in incidental melodic decoration are very variable. Iterations of melismatic ornamental figures very rarely sound the same because they are generally sung in a differing rhythm and often in a differing intonation. Vocal tones are, however, not as common in this group of versions as in the group discussed on p.1I5ff. Types of incidental melodic decoration vary greatly from song to song, from performer to performer.

The melisma very often consists of elaborations of melodic formulae typical of the patet, especially in the eluk. In this group, Transcription 47 has the maximum amount of and most richly elaborated eluk, which occur at the end of the alternate lines $1,3,5,7,9$, and line 10 . The S-shaped scalewise movement of the eluk line $I$ is based on a combination of the patet sanga T 3 and $T 2$ (3-toned) formulae. This eluk has an important melodic function, since it begins on the sumit tone, which does not appear again in the song; after its curvaceous descent and ascent, it leads smoothly into line 2, which begins on the same tone as the final tone of the eluk. The eluk in line 3 is also based on the T 3 formula, containing sliring intonation. The eluk in Iine 5 consists of the $Q I$ and $Q .2$ formulae, whereas eluk 7 is made up of the $R I$ and $R 2$ formulae. Most eluk have an undulating but descending trend. The pelog Transcription 38 has the least number of eluk (one only in line 4), while the others have between 3 and 6 eluk each, mostly occurring on the odd-number lines $1,3,5$, and 7 .

Eluk and other melisma often begin on a pillar tone. In Transcription 47, three melismatic passages begin on the IIPT and two on the IPT. Most eluk consist of several tones, but some are merely 2-toned slurs, as in Transcription 
64 (line 4):

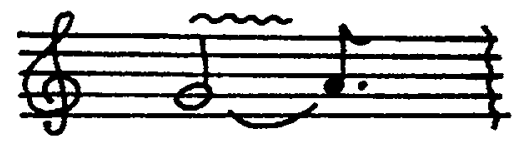

Mostly a singer's heaviest vibrato occurs throughout the eluk.

Perhaps because the Javanese and Sundanese languages are not characterised by strong accentuation, there seems to be little connection between the positioning of ornamentation and sy.llable-emphasis. ${ }^{8}$ The word lanang, for instance, is usually spoken with a very slight emphasis on $l a$, but in Transcription 1 , it is the nang syllable which is ornamented:

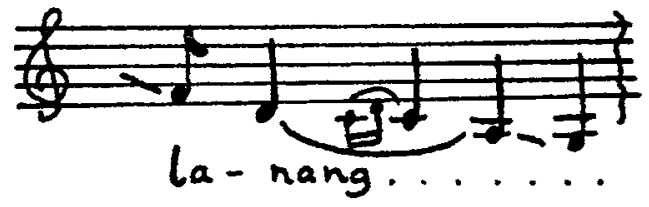

The word kiwadjiban is spoken with a slight emphasis on the second and fourth syllables. In the first performance of Transcription 1, the word is sung with melisma on the second and third syllables, and in the second performance, on all syllables except the last.

Dandanggula Tlutur

This long melody is sung to three texts about morality, love, and a moonlit night. Each version is entitled tlutur (Iiterally meaning 'sad'), which means the song should be sung in a style containing many tones of lowered pitch (mixing tones), which gives the melody an expressive, melancholy flavour.

All three versions have a rather steep descending Level Shift $\left(-42^{\circ}\right.$ in Transcription 16 , and $-63^{\circ}$ in Transcriptions 69 and 98). Melodic direction change varies between 34 per cent and 31 per cent. The range is about 19 semitones for all three versions. The melodic movement is 
mainly slendro stepwise movement, but there are a few leaps within and (especially in Transcription 16) between lines. Transcription 16 contains a descending small 9th and Transcription 69 an ascending 9th. Other intervals in order of prevalence are 4ths, 6ths, 5ths, and small 3 rds.

The meloi of Transcriptions 16 and 69 show strong slendro patet sanga elements in their use of the $T 3$, the $T 4$, and, less frequently, the $T I$ formulae, as well as their plentiful employment of the ascending and descending $\mathrm{R}$ and $\mathrm{S}$ formulae. The most prominent tones in Transcriptions 16 and 69 are the IPT and IIPT and tone 3, which often function as initial and final tones. In all three songs, the tones most often followed by melisma and repeated tone passages are the three pillar tones. Tone 3 assumes unusual importance for this patet in Transcriptions 16 and 69, carrying the main tlutur function, varying conspicuously in pitch throughout the two versions. In Transcriptions 16 and 69 , the highest tone is the dasar (tone 2). The lowest tone in Transcription 16 is the miring tone 3 , and in Transcription 69 it is the IPT (tone 5).

In Transcription 98, the range, the pillar tones and the final and the most prominent tones are one or two tones higher than in the patet sanga versions (e.g. the highest tone is tone 3 and the lowest tone is tone 6 ), this song showing clear slendro patet manura characteristics. Perhaps the reason why Tedjohadisumarto ${ }^{9}$ incorrectly wrote patet sanga by the title of this song is that its original patet, before transposition, was patet sanga, i.e. the same patet as this same melody is set in Transcriptions 16 and $69 . \mathrm{A}$ comparison of the melos of Transcription 98 transposed down one tone into patet sanga shows its close resemblance to the patet sanga melos of Transcriptions 16 and 69 (see p.119). 
A comparison of the meloi of the three versions shows a quite different sequence of melodic formulae in each. Matjapat songs clearly have no set formulae serving as the basis for performance (like the set harmonic formulae at the base of an improvised jazz performance).

A feature of all three versions is the extremely large amount of ornamentation. Every line of Transcription 16 ends with an eluk, mostly in long and complex form. Transcriptions 69 and 98 have nine long eluk each. The longest eluk of the whole song collection is in Transcription 16, line 7. This eluk has an undulating, descending trend, moving a total distance of a small 9 th, covering eight different pitch-levels, and including shake and turn-like ornaments, ending on an extremely long tone followed by a rest. It begins mezzo-forte and ends pianissimo.

Scalewise figurations are common in this group of versions. The tonal sequence:

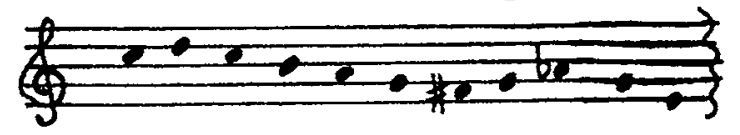

appears four times in Transcription 16, approaching the significance of a melodic motive. Such recurrence of melodic phrases is unusual in matjapat songs. But in this song, the iterativeness of the phrase contributes to its plaintive character, and in any case, each appearance of the phrase takes a different rhythmic shape.

The two live performances, Transcriptions 16 and 69, are sung with vibrato of medium amplitude and a wealth of portamenti, shakes, and turns. In Transcription 69 (Iine 9), there is an unusual instance of a glottally produced acciaccatura. Dynamic contrast in Transcription 16 varies between forte and piano, and in Transcription 69, between 
mezzo-forte and pianissimo. Besides that, continual crescendi and diminuendi occur.

Vocal tones are, as to be expected in the tlutur style, pre-eminent. In Transcription 16 , tones 1 and 3 are mostly sung with lowered intonation, whereas the pitch of tones 2 and 6 also varies, tone 5 being the most stable of all tones (it is the IPT). A total of 21 pitch levels may be heard. $1 \mathrm{C}$

Transcription 69 also has many miring tones, especially tones 6, 3, and 2. ${ }^{11}$ Since Transcription 98 (entitled Tlutur) is taken from the number-script, no vocal tones appear in the transcription.

Kinanti - A Tembang Gending 12

Unlike unaccompanied matjapat songs, tembang gending is restricted in its rhythmic and melodic movement, bound to regulations necessitated by the requirements of ensemble performance. These performances of a well-known Kinanti song have a high degree of rhythmic regularity, and contain repetition of melodic phrases. All three versions and two variants (Transcriptions 45 and 46) closely resemble each other. Transcriptions 45 and 46 are accompanied by gamelan, and the other performances of the song are sung as if with gamelan accompaniment. Most tembang gending (such as Kinanti Subokastowo ${ }^{13}$ and Kinanti Condomastuti ${ }^{14}$ ), possess a degree of formal regularity and are performed in quadruple or quasi-quadruple metre.

The main melodic direction trend of the 6 lines of each of the 5 versions of this group is remarkably similar, in comparison with the unaccompanied songs:
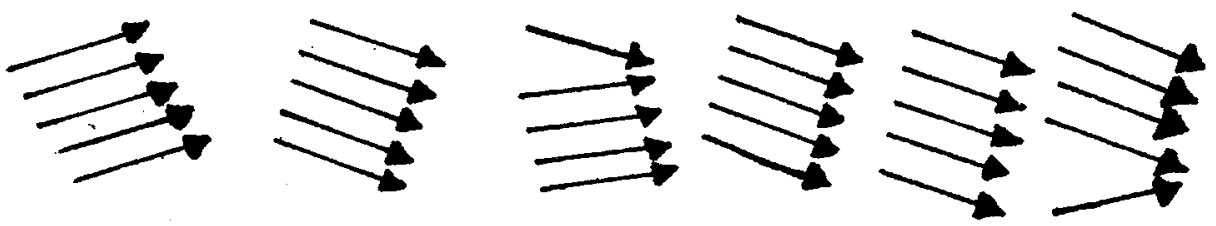
The meloi of three versions of Dandanggula Tlutur

1. TRANSCRIPTION 16, SLENDRO PATET SANGA.

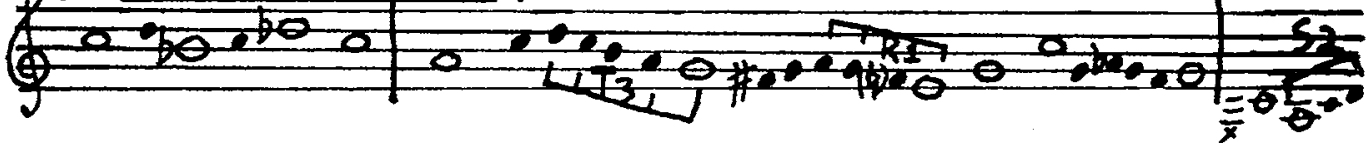

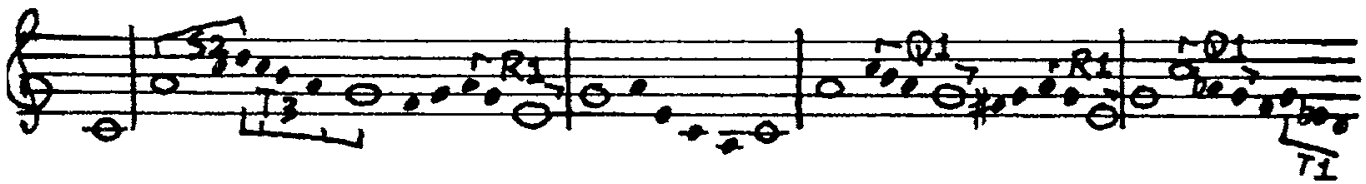

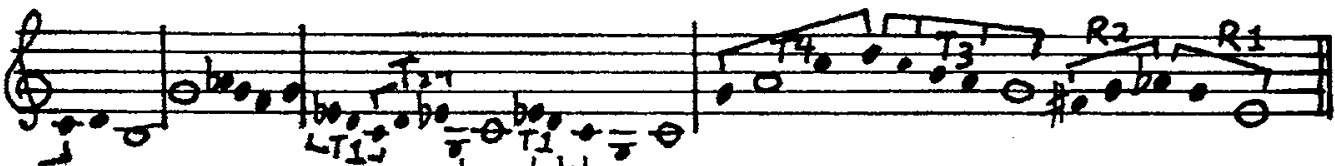

2. TRANSCRTPTION 69, SLENDRO PATET SANGA.

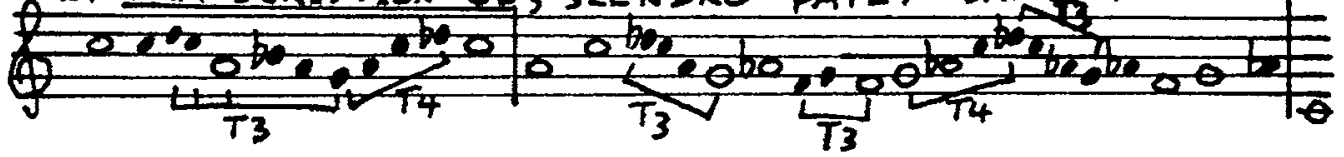

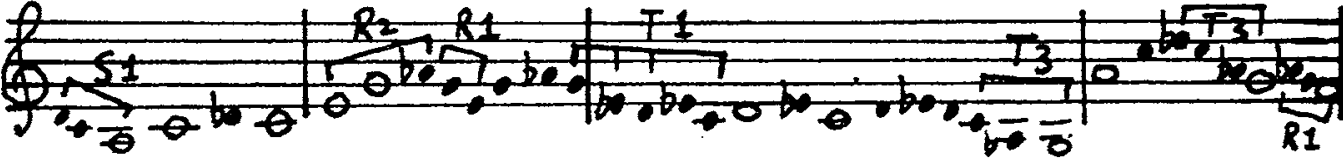

3. TRANSCRIPTION 98, SLENDRO PATET MANJURA.

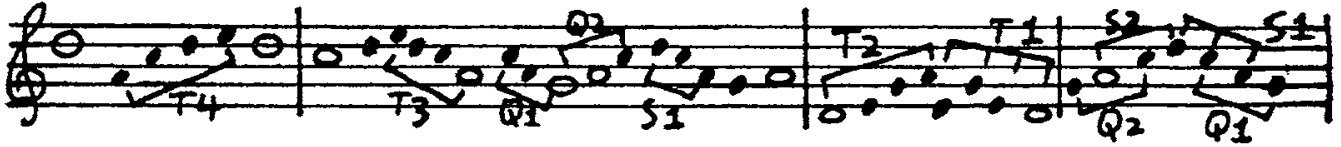

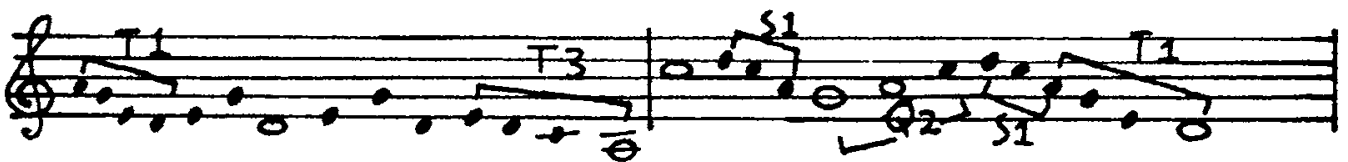

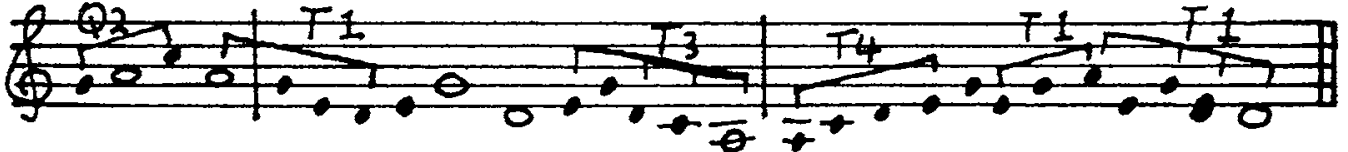

3a.TRANSCRIPTION 98, TRANSPOSED DOWN ONE SLENDRO TONE

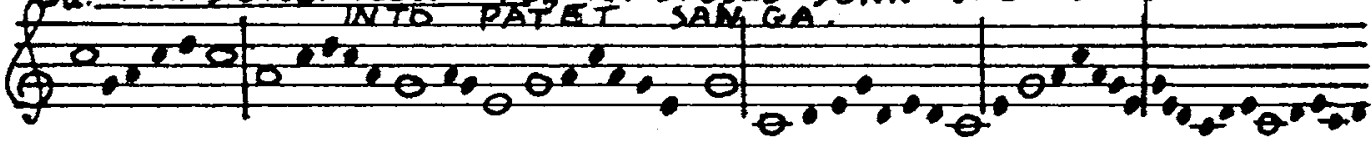

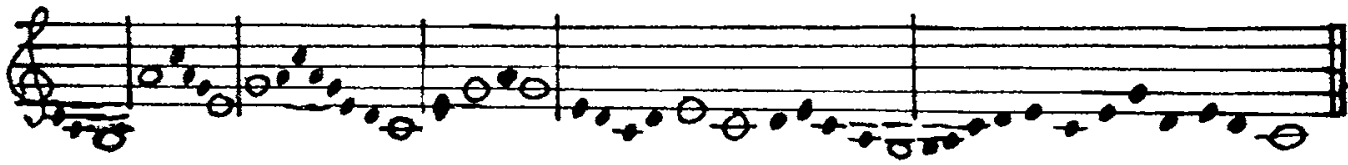


The formal structures of Transcriptions $41,45,46$, and 118 are very similar. In each, the tone-sequence and even the rhythmic structure of line 1 resembles that of line 3 . Lines 2 and 4 are also alike, but line 4 ends with an extension onto tone 2. Formally the song divides into 3 groups of 2 lines each (ABABCD). In Transcription 6, the recurrence of lines 1 and 2 is omitted, two extra melodic lines having been added in their place. Its first two lines resemble lines $I$ and 3 of the other versions and variants of this song. The limited melodic variability and relatively regular metre of the five performances of this song are typical of matjapat songs sung with gamelan accompaniment.

The Level Shifts are rather steep, between $-44^{\circ}$ and $27^{\circ}$, but in Transcription 118 the Level Shift is only $-19^{\circ}$. A high amount of change of melodic direction (average 46 per cent, maximum 52 per cent in Transcription 41), and a low degree of tone repetition (average 19 per cent, maximum 23 per cent in Transcription 46), characterise these performances. The range varies from 16 to 17 semitones.

The siendro patet sanga formulae T 1, T 2, T 3, T 4, $Q 1, Q 2, R I$, and $R 2$ are common in this song. In three cases, the final cadence is the T 3 formula, while Transcription 118 ends with the $T 3$ extended by the $Q 1$ formulae. In all cases except Transcription 118, the melody ends on the lowest degree of the range (i.e. the IIPT, tone I). The patet is confirmed by the melismatic and repeated tone passages, beginning mostly on tones I (IIPT), 5 (IPT), and 3. The highest tone in all versions or variants is tone 3 , the lowest tone either tone I (or lowered tone 1 ) or 3 .

Leaps between lines are most commonly descending 4 ths, but ascending 4ths, ascending and descending small 3rds, 
large 3rds, ascending 5ths and a rare descending 6th are also found. Within lines fewer leaps occur. They are predominantly pelog 3 rds and ascending 5ths and 4ths.

All the performers of this song tend to decorate the second last syllable of a line, not the last syllable as is usual in the unaccompanied songs. Fach performance contains one eluk, which mostly takes the form of a short, 2-toned slur. Glissandi, shakes, turns and acciaccaturas are found. 'Dotted note' shakes and anticipatory tones (A) are common e.g.

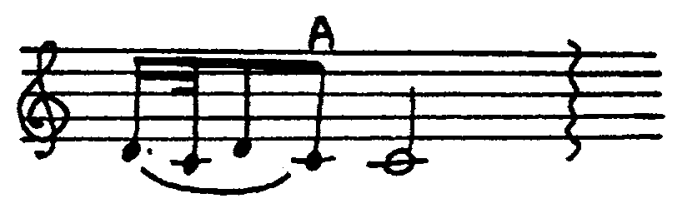

Line 1 in all cases except Transcription 178 has an anticipatory tone at the end of the first musical phrase.

Transcriptions 45 and 46, variants of Kinanti Pcaukir, are sung by the famous Rusman to gamelan accompaniment, and are based on an underlying, regular quadruple metre therefore. The strict metre of the gamelan proceeds inexorably forward while the singer, still retaining a degree of liberty in rhythm, pitch, and melisma, collaborates. The long pauses between lines are filled by the gamelan heterophony. At the end of Transcription 46, the vocalist and the gamelan make a large-scale ritardando as is usual at the end of a gending, with a final stroke on the sonorous gong ageng.

Rusman's voice has a full (ageng), resonant timbre, and his vibrato is of a small to medium amplitude in these two variants. His performances contain frequent, impressive, steadily expanding crescendi and abating diminuendi, the range of dynamics lying between forte and piano. His breath capacity is copious. In these variants, he consistently sings tone $I$ in a lowered pitch (as compared, for example, 
with Transcription 6). The pitch of tones 5 and 6 also varies.

The other versions of this song are sung with a slow tempo, a calm quality and with a greater amount of vibrato on the longer tones than is usual (especially in Transcription 6).

In Transcription 118 (taken from the number-script), the modern 'chromatic' touches in the melody are indications of a probable corruption of musical style due to influence by Western melody, e.g.:

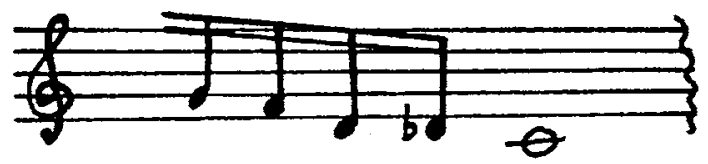

Such an example of Western influence was found, however, only in printed versions of matjapat songs, not in any live performance of this collection. The examples are all from the book Sinau Tembang Djawi, which includes several matjapat songs with Christian. texts.

A Putjung Slendro ${ }^{15}$ and a Putjung Pelog ${ }^{16}$

of these two extremely well-known melodies, some performances by different singers and even performances by the same singer (i.e. Transcriptions 7 and 8 ) vary greatly from each other. Although in other matjapat songs the most stable, unvariable melodic line is generally the first line, the opening phrase of this slendro Putjung (sung in most cases to the words Bapak Putjung), is different in every performance: 

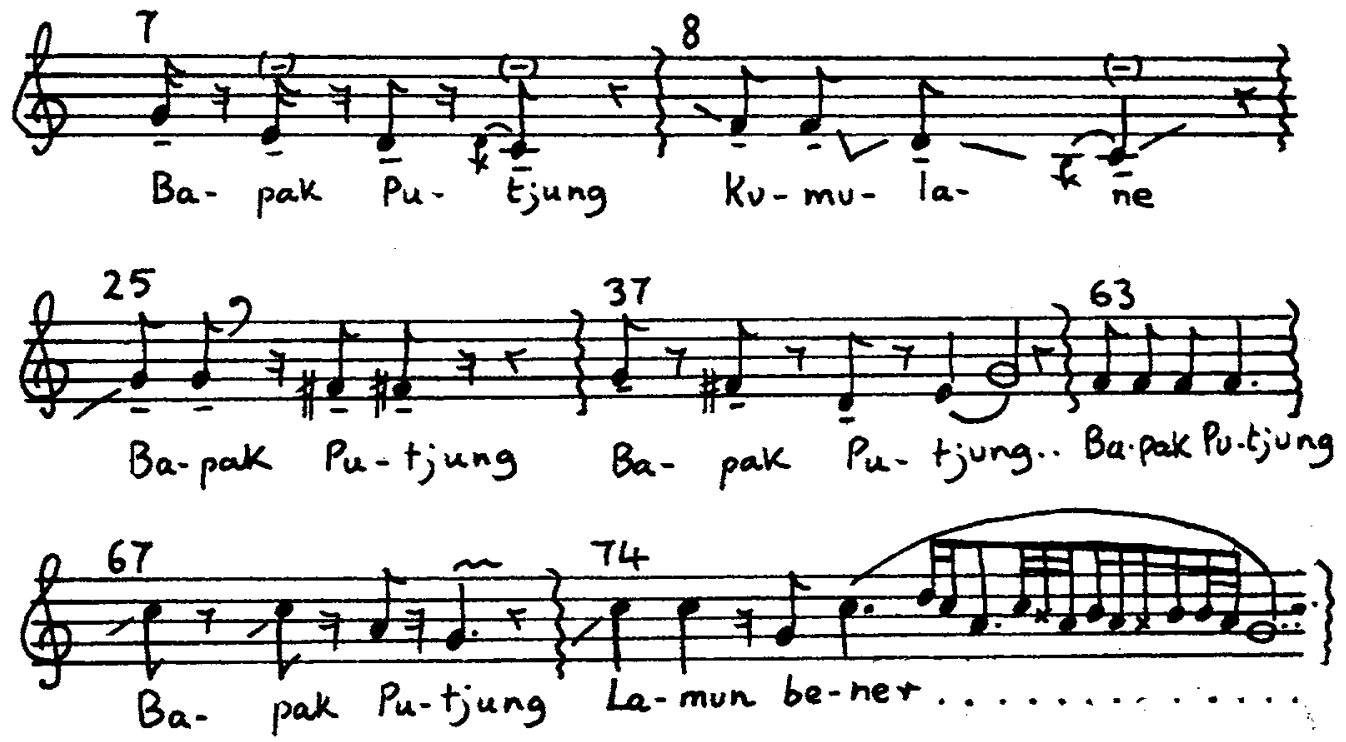

The most extreme differences in degrees of melisma exist between Transcriptions 7 and 74 . The former is not lacking in melisma, especially in the last line, but it does not approach the profusion of melisma in the latter.

The short texts are either puzzles, or about food or gaining knowledge.

The level shifts of the slendro performances are between $-63^{\circ}$ (Transcription 7 ) and $-18^{\circ}$ (Transcription 25), with an average of $-40^{\circ}$. The pelog versions contain two ascending (i.e. $21^{\circ}$ in Transcription 9 and $7^{\circ}$ in Transcription 50), and five moderately descending level shifts. On the average, the degree of melodic direction change is higher in the pelog ( 46 per cent) than the slendro (37 per cent) melody. The degree of tone repetition is small in the performances of both melodies (average 27 per cent in the slendro and 14 per cent in the pelog).

$T 1, T 3, T 2, Q 1, Q 2$, and $R I$ formulae are found in the slendro performances, which are in patet sanga. The characteristics of tone prominence, tone repetition, and melisma endorse the patet, since they mostly consist of 
or begin on the pillar tones. The pelog Transcriptions 83 and 93 are in patet barang, containing T 1, T 3, and T 4 patet barang formulae and ending on the final tones 2 or 3 , which are fairly typical for the patet.

The other pelog versions feature abundant T 4, T 3, and $T 1$ patet nem formulae. The most prominent tones are 2 (IPT) and 6 (dasar). Melisma occurs mostly after the IPT, IIPT and tones 1 and 3 , and repeated tone passages occur mostly after the dasar and tone 1. Final tones are mostly the dasar, IPT, or tone 3. The 'enemy' tone is tone 1.

In the pelog patet barang versions, leaps of pelog 3 rds, and (full-sized) 5ths, 6ths, 7ths, and 8ves occur within the lines; between lines, the leaps are mainly pelog 3 rds and 4ths. In the pelog patet nem versions, pelog 3rds, 5ths, 4ths, and 8ves are the most common intervals within the lines (in order of prevalence), while between lines, 4 ths, small 3 rds and 5 ths, and 3 rds are most common. In the slendro patet sanga versions and variants, ascending 5ths and small 3rds are common intervals.

There is not a great deal of melisma in the slendro performances, except in Transcription 74 , in which auxiliarytone sequences and repetitions of short three-toned phrases containing an auxiliary tone $(\mathrm{Au})$ are characteristic:

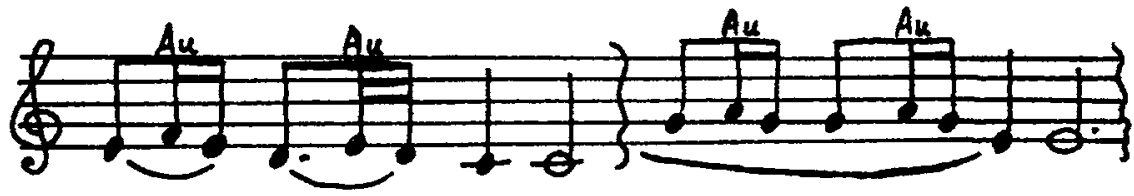

The turns, shakes and, melismatic passages usually include the theoretically non-existent tones ' 4 ' and/or ' 7 ' (i.e. the tones lying between the slendro tones 3 and 5 and 6 and 1). Anticipatory tones, acciaccaturas and other incidental decoration are common. 
The pelog versions contain more short melismatic passages than the slendro. Two-toned slurs are an established stylistic feature of Transcription 9, e.g.

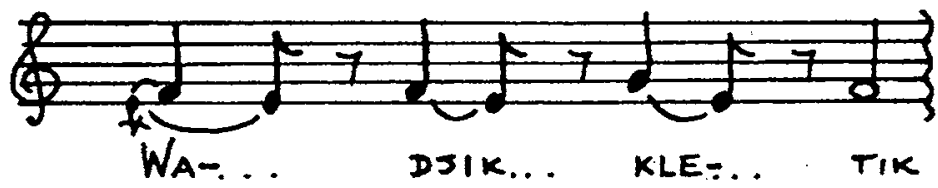

A few short eluk are to be found, and there are two long melismatic eluk in Transcription 74. Vibrato in Transcription 74 is sung on the long tones, which gives them movement to match the fast melodic decorations on most syllables. For contrast, however, some tones of medium length are sung without vibrato.

The slendro versions and variants are generally sung with a fast tempo, a vivacious, animated character, and a variety of articulation techniques. With very little vibrato, an even, quasi-quadruple metre, uneven stresses, a non-legato articulation and many rests, the song often sounds a little pompous. Transcription 8 , in particular, sounds gay and droll, containing many glissando effects, irregular accents and 'diphthong notes'. Transcription 7, characterised by its unsmooth articulation and stresses on short tones separated by rests, suddenly transforms itself in the final line to an extremely liquid legato.

Little dynamic contrast is found in the different versions and variants; the intensity is almost constantly mezzo-forte.

Two versions of another Putjung, in pelog and of a similar nature, are found in Transcriptions 73 and 101. Pangkur Palaran ${ }^{17}$

The texts are about morality and study. Level shift of Transcription 81 is equal to $0^{\circ}$. Transcriptions 13 
and 42 have level shifts of $-37^{\circ}$ and $-36^{\circ}$. Average melodic direction change is high, 45 per cent, and the average tone repetition is 28 per cent. The range of the versions varies between 16 and 2.2 half-tones.

Within the lines, wide leap movement occasionally occurs, especially 8ves, 6ths, 10ths, and 5ths. Between lines, the leaps are mostly 4 ths and small 3 rds, but also 9ths.

Transcription 81 is from a Petilan (section) of a Wajang Orang play, and is sung by a professional Sinden from the Mangkunegaran. The melodic line contains many elegant melodic turns with conventional Sinden-style rhythms, such as $P P$ and Pff. A triplet P Pather common in Sinden singing, occurs near the end of the song. She sings tones 1 and 3 with relatively free intonation. The singer's vocal timbre is characterised by its thin clarity and large percentage of high overtones and nasal resonance. It creates quite a false impression, however, to describe this timbre by the ambiguous word 'nasal'. The vocalist performs in the usual 'alus', refined, gentle Sinden style, with the special calm, 'inggil' thin timbre of Javanese female and high male voices in the theatres and courts, a somewhat instrumental timbre similar to the sound of the rebab. The thinness is compensated for by vibrato on most long tones. The breath capacity of the singer is copious, accompanied by an economical sound production. Articulation of the text is very clear. Dynamic contrast is small but the graduations are steadily controlled.

Transcription 13 is an interesting example of momentary slendro 'Scheinmodulation', which suggests that modulation in vocal practice does not occur in the pelog tonality alone. As already mentioned, ${ }^{18}$ modulation is 
theoretically impossible in slendro because of its variable pitch-levels. In practice, however, the two large intervals within a slendro scale can lie between different pitch levels. An inspection of the tonal material of Transcription 13 shows that tones 1 and 3, the pitch of which are generally the most unstable in slendro, deviate to a similar extent and for constant periods. This song may be said to be based on three slendro 'scales' made up of the following slendro pitch-levels (so arranged as to show the 5th interval between each 'scale'):

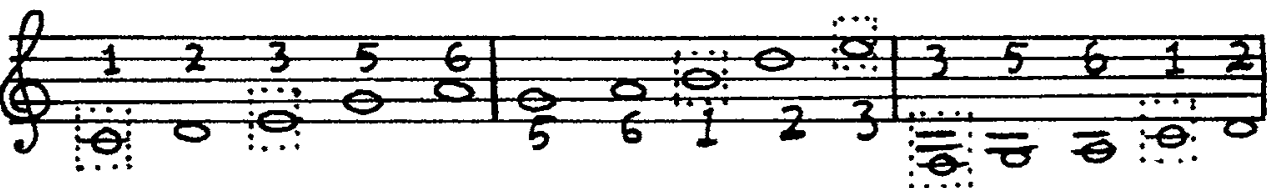

(Theoretical tones $: i:$ and $\dddot{3} 3:$ vary in pitch). The similarity of these hypothetical slendro scales to the pelog patet's theoretical Principal, High Auxiliary and Low Auxiliary scales, each of which have a modulatory function and are a distance of a 5 th apart from each other, is striking. 19

The 'modulatory' sequence of the melos of Transcription 13 is:
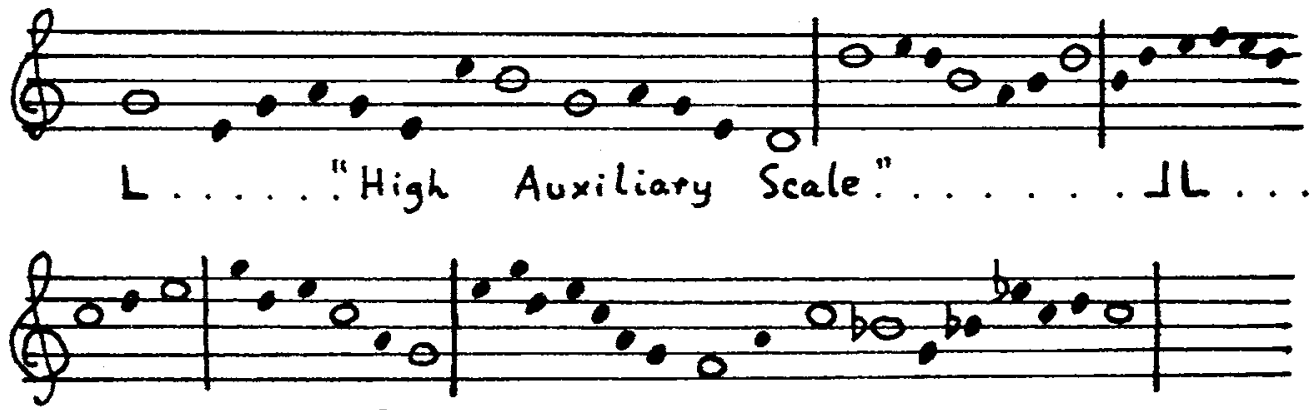
...Principal Scale.. JL..... Low Auxiliary...

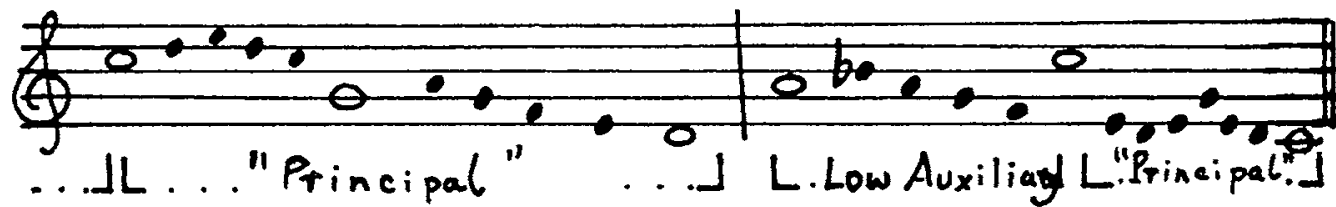


The melos seems to begin in the 'High Auxiliary Scale', after which it 'modulates' very temporarily to the 'Principal', the 'Low Auxiliary', the 'Principal', the 'Low Auxiliary' and finally the 'Principal Scale'.

This agile melody even features two successive 'triad' leaps at some points, which contribute to the temporary 'modulatory' effect (e.g. In line 5 of the melos

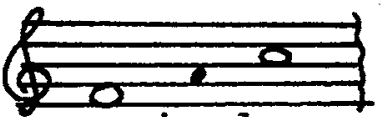
and

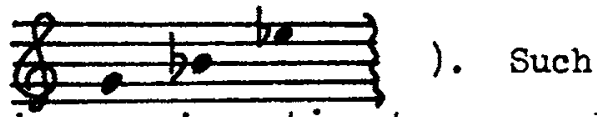
successive leap movement is rare in matjapat songs. Leaps are usually preceded and followed by stepwise motion.

Dandanggula Tlutur ${ }^{20}$

This is one of the few songs of this collection in slendro patet nem. All four typical 4-toned formulae of the patet (after Hood) occur in the melos as well as the $Q 2$ and 3toned formula to be termed $P 2$ (ascending form) and $P 1$ (descending):
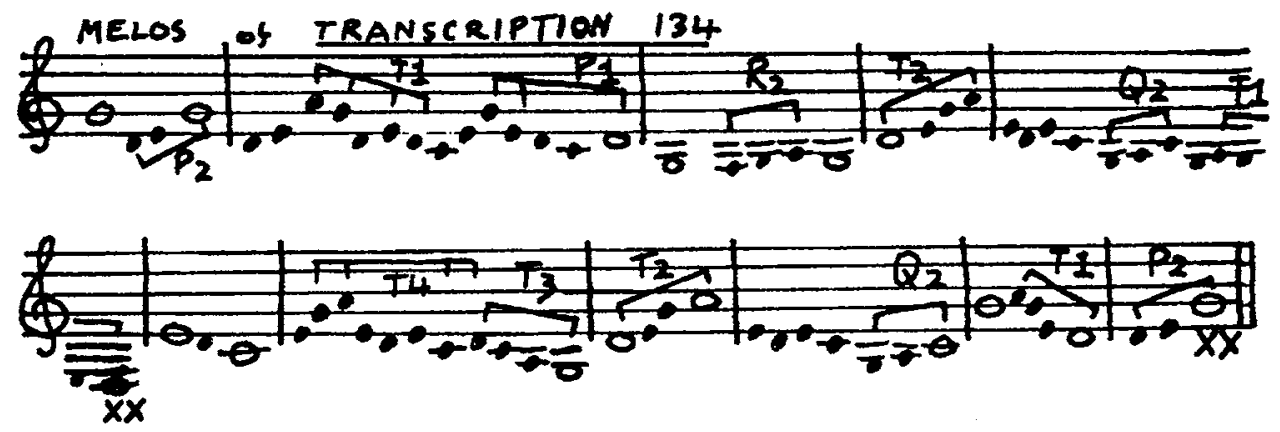

The First and Second pillar tones of slendro patet nem are the most prominent tones of the song. 21

Since this melody is transcribed from the number script, it contains, apart from raised tone 3 in line 3 , no instances of the rocal tones which one would expect in the performance of a song with the word tlutur in the title. 
Sundanese Songs

Midjiz. ${ }^{22}$ The versions of this song, all of which are sung to the same 'Nature' text about the Prince Gatotkatja flying in the clouds, are remarkable for their similarity to each other, their formal symmetry, their closeness to strict quadruple metre and their perfect pentatonicism. The versions are very smoothly, evenly, and calmly sung. Light vibrato is performed on the long-held tones. There is a gradual diminuendo trend, with little contrast of dynamics (mf - p.) The vocal style in this performance is Rantjag (simple, straightforward) as opposed to a Raehan, Pasieup or Dipasieup (ornamented, complex, free) style.

Two informants said this song is sometimes accompanied by gamelan and is therefore a lagu gending. Its musical characteristics support this claim. Its relative paucity of melodic ornamentation, its strict pentatonicism and its straightforward rhythmic and metrical character all suggest idiophonic instrumental influence on the vocal style. The performances of Midjil discussed here are without instrumental accompaniment and are therefore grouped under the second type of rhythmic movement (see p. 141).

The graph of the melos of Transcription 16 on p. 131 shows this song's curvaceous, symmetrical proportions. It consists of eight crests which top alternately small and large melodic curves. The two largest curves, containing sumit tone 3, occur in the early and the latter parts of the song, whereas the lowest tone is touched only once in the midale of the song.

The versions of the melody begin with a short, modest phrase of three or (in Transcription 25) four pitch-levels. The second half of the line begins with a splicing of the first phrase, which it then expands into a scalewise ascent 
and short descent which appears again in slightly altered form in the last line. Formally, the first part of the melody ends with line 2. The long melodic sweeps continue over line-lengths. Line 2 prepares its entry into line 3 by ending on the same pitch as line 3 begins. Line 3 stands relatively independent, ending on the lowest tone. Line 4 also stands alone, its melodic line revolving in the lower part of the range, and ending on the same pitch-level as the first tone of the final section of the song (lines 5 and 6). The steepest ascent and descent occur in the scalewise passages at the end of the song.

Melisma and ornamental shakes (mainly of a halftone or a 3rd), provide rhythmic contrast with the longer, relatively regular rhythmic tones which make up most of the melody. Double acciaccaturas are frequently found in the versions. The level shifts are rather strongly descending (between $-48^{\circ}$ and $-32^{\circ}$ ). The amount of melodic direction change varies between 47 per cent and 29 per cent (in Transcriptions 16 and 4 respectively). The degree of tone repetition is small, between 17 per cent and 6 per cent. The range of the song is, in every version, 19 semitones. There are few eluk; Transcription 16 has 2, Transcription 25 has 1, and Transcriptions 4 and 27 have no eluk. Transcription 25 has a more unconstrained rhythm and more incidental melodic decoration than the other versions. Vocal tones are very rarely used in all versions. The tonal material is almost entirely limited to the basic pentatonic pelog scale.

Kinanti Djemplang Titi $^{23}$

This song is sung twice to two successive verses of a lovepoem, performed by the most talented Sundanese singer of this collection, sudradjat. It is particularly interesting for its pasieup ornamental style and vocal timbre. Unlike 


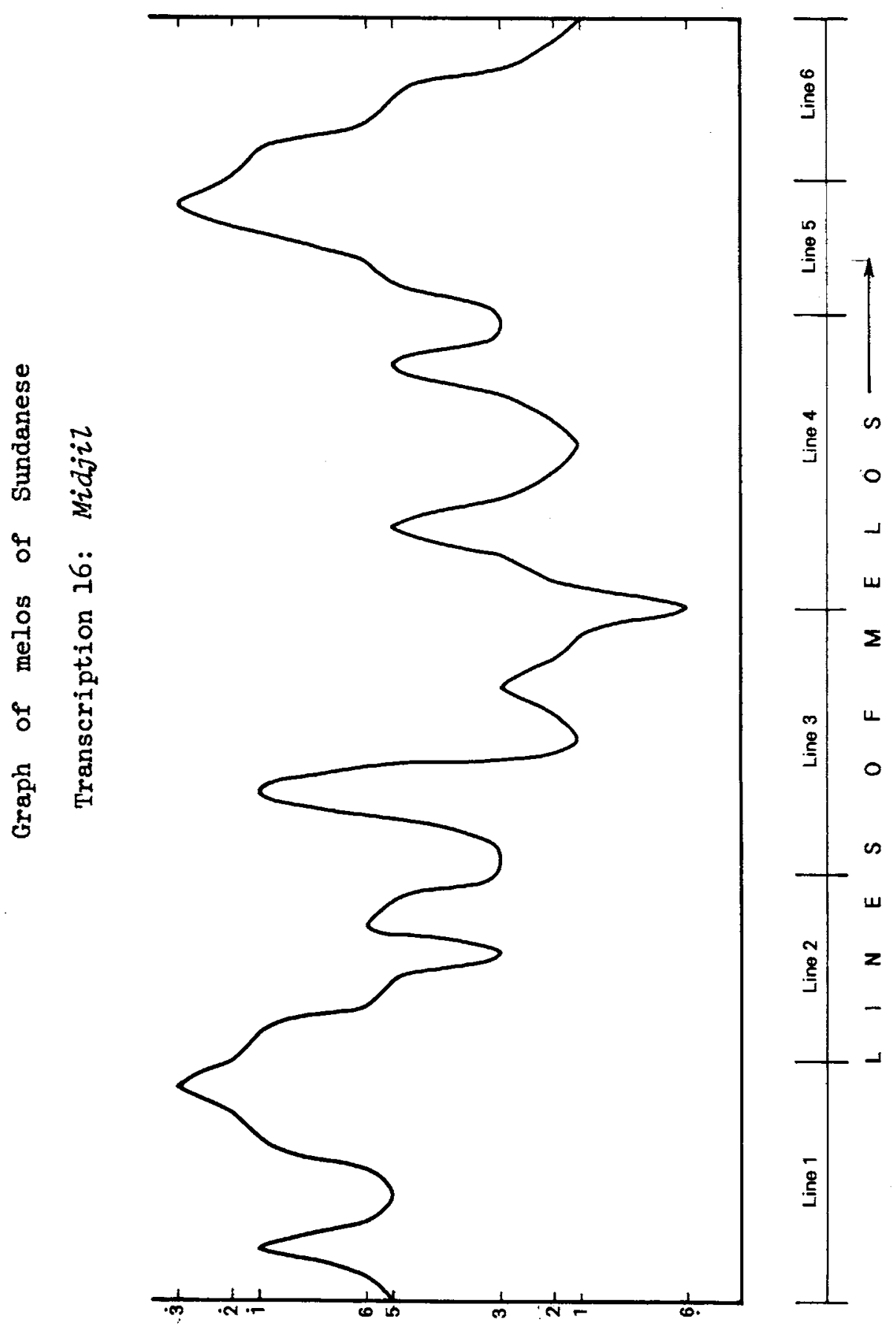


the Javanese singer Rusman, this singer's voice is not characterised by remarkable resonance or carrying power. The aim of the singer seems to be to achieve a continual change of dynamic level, which ranges in this performance between mezzo-forte and pianissimo. The enunciation of words is clearer than that of singers performing with an ageng timbre. The voice is 'placed' in the foremost, upper part of the head, which facilitates the performance of rapid crescendi. Breaths are taken fairly frequently.

The penetrating, short, rapid surges and abatements of dynamics occur on both long and short tones. For instance, in line 3 , three tones are sung with three changes of dynamics:

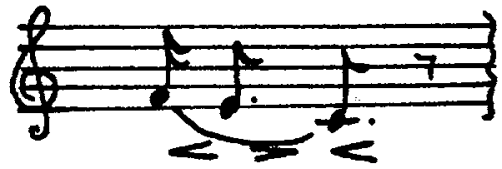

Very often, a sharp crescendo is suddenly cut off by a glottal stop, a rocal glottal stop, or a clean break. The fast vibrato of this singer is executed both on short and Iong tones in irregular sequence, as an ornamental feature. Long notes are sometimes adorned with vibrato and then blossom into a kembangan.

A great variety of ornamental types are to be found. Fast scalewise passages or turns between longer tones are found in several songs performed by this singer, e.g. Transcription 20, line 4:

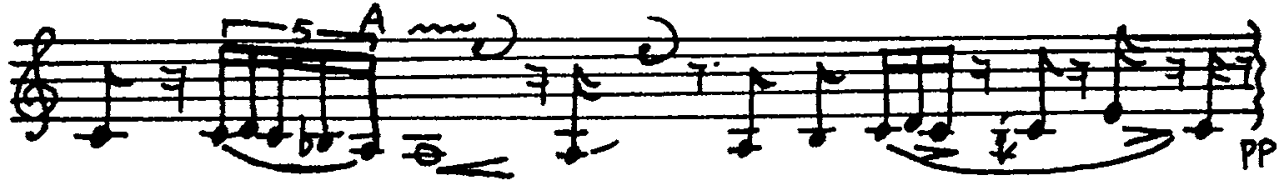

This quotation also shows an anticipatory (A) tone, two glottal stops, one of which cuts off a long tone sung with a sudden crescendo and relatively heavy vibrato, and the other of which cuts off a short tone followed by a quick 
ascending glissando. The latter part of the quotation shows the singer's typical practice of performing short tones isolated from each other ornamentally by brief rests, although the tones are all sung on the same syllable of the text; the isolated tones die away to pianissimo. Another type of break is:

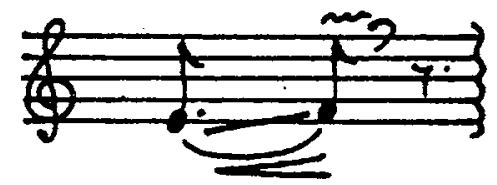

(line 1), in which the second of two slurred tones in a crescendo is sung with vibrato and then suddenly cut off. Single and double acciaccaturas are comnon. Repeated twotoned slurs, as in line 1 , are a feature of the ornamental style.

Various types of glissando occur, e.g.:

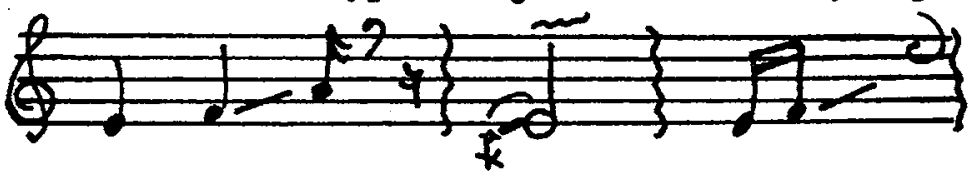

A glissando even occurs between repeated pitch-levels, e.g.:

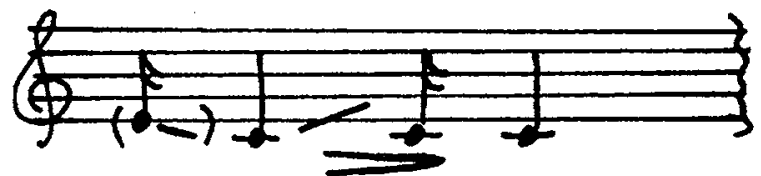

There are two eluk in verse 1 and three in verse 2, featuring the typical short auxiliary tone shakes and series of tones isolated by rests and turns.

Although the two verses sound quite different in performance because of the variety of ornamentation and melisma, the melos of each shows similar characteristics: 
Kinanti: Transcription 20

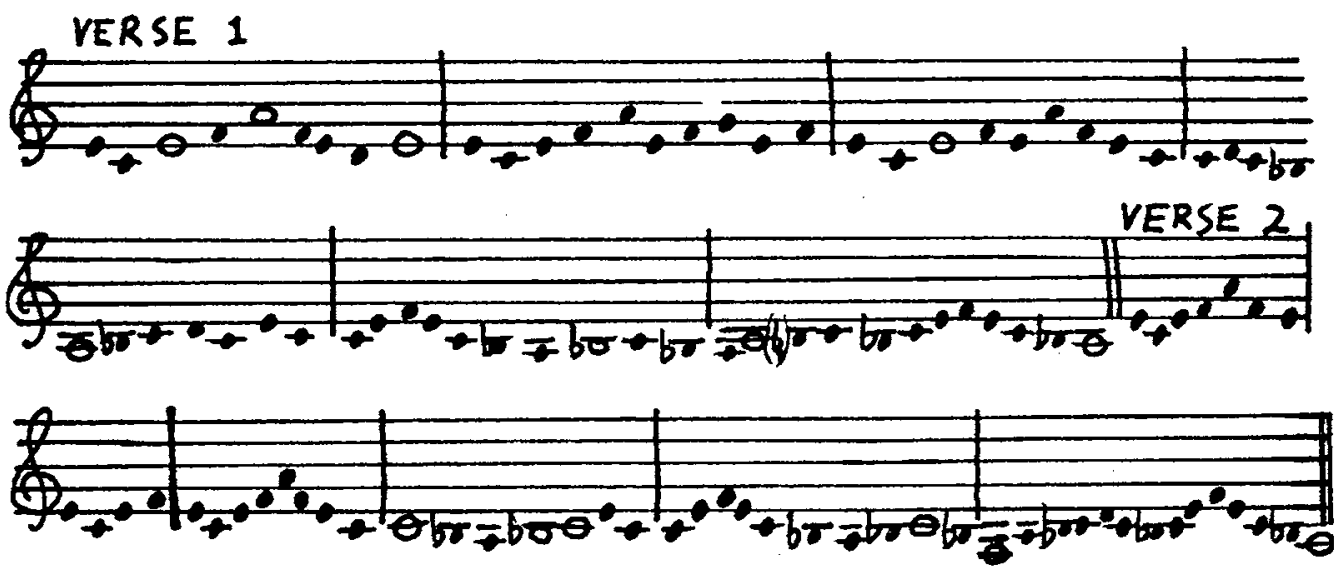

The first three lines resemble each other in both verses, revolving around tones $3,5,6$, and 1 , occasionally inserting the sorog tones 4 and 7 in verse 1 , after which there is a gradual descent to the lowest tone (6), which appears only once in each verse (in the final line). The highest tone (1) occurs in the first half of the melody only. The final tones of lines in both variants are the same (i.e. tones $5,6,3,3,2$, and 1 ). The most prominent tones are tones 3 and 5, while the least used tone is tone 2. The range of the song is 16 semitones. The pitch-levels of the tones do not differ from diatonic pitch-levels as much as the tones of some Javanese songs. Vocal tones are sparingly used; only tone 2 has a varying intonation. The level shift of the song is $-58^{\circ}$, the degree of melodic direction change 46 per cent, and tone repetition 21 per cent.

Maskumambang 24

All six versions of this short, well-known song are sung to the same text, about indebtedness to one's parents. The different versions vary little from each other except in rhythm and ornamentation. All versions of this song excepting 
Transcription 42 (the level shift of which is $-42^{\circ}$ ), begin and end on the same tone, i.e. their level shift is $0^{\circ}$. Melodic direction change varies among the versions from 52 per cent (in Transcription 53) to 31 per cent (in Transcription 42). Tone repetition reaches a maximum of 36 per cent (in Transcription 40) and a minimum of 21 per cent (in Transcription 15).

The tonal material of the different versions is as follows :

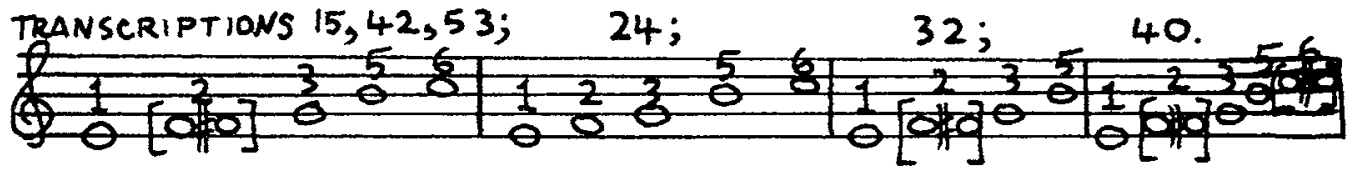

Transcription 24 is the only perfectly pentatonic version. Transcription 32 is in fact only four-toned, with a raised, vocal tone 2. Transcription 32 has the most limited tonal material of any song in the whole Sundanese and Javanese collections. In all versions except Transcription 24, tone 2 has a constantly variable pitch which has an ornamental melodic effect, e.g. Transcription 42, line 1:

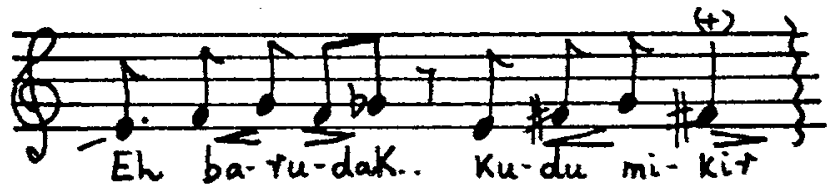

Raised tone 6 in Transcription 40 is used only once before the highest tone, lending it melodic colour and salience. Otherwise, this song is not rich in rocal tones. Glissandi occur sometimes.

The eluk in these versions do not carry an important function. Transcription 15 has 3 eluk, of which two are semitone shakes. Transcriptions 40 and 53 have also 2 eluk, two of which are (in both cases) merely two-toned slurs. The eluk Transcription 53 is a long, semitone shake. 
The final tones of lines are tones 5,1 , and 2. The highest tone is either tone 5 or 6 , and the lowest tone is 5 or 1 . Least used is tone 6 .

Dangdanggula Bajubud 25

This song is sung in free tembang rhythm (i.e. without regular accentuation), and contains the maximum number of eluk for the Sundanese collection. The 10 eluk contain mostly long shakes of a semitone amplitude, acciaccaturas, the characteristic Sundanese glottal stop (in eluk 4 and 5), and scalewise formulae. Although highly ornamented, there is less variety of ornamental types in this song than in the Sundanese songs sung by Sudradjat, and in the highly ornamented types of Javanese songs. Series of long shakes are the most common kembangan type, e.g., line 9:

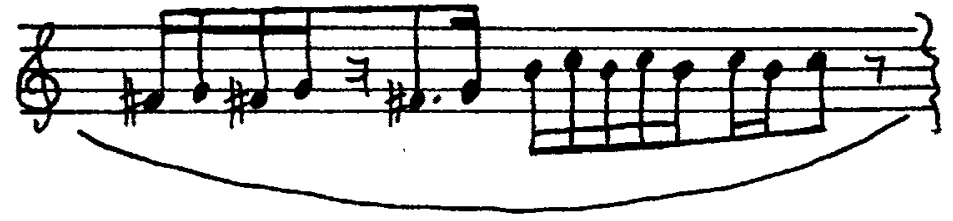

This song has the maximum range of the collection, i.e. two octaves. The tonal material is almost purely pentatonic. As is common in the performances of many Sundanese pelog songs, only tone 2 alternates in intonation between an upper and a lower level, e.g., line 10:

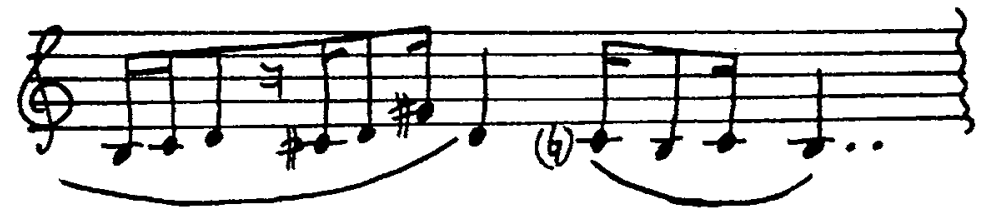

The song's level shift is $29^{\circ}$, the degree of melodic direction change 47 per cent, and the degree of tone repetition 23 per cent. 
Melodic Classifications

The melodies may be classified according to types of melodic movement, prevailing melodic direction, rhythmic motion, metrical and formal structure, tonal material, kembangan, variability in performance and rocal styles.

\section{Types of MeZodic Movement}

Three types of melodic movement may be distinguished according to the amount of melisma, degree of melodic direction change, and the degree of adjacent tone repetition.

The most prevalent type, found especially in the narrative and other longer melodies, consists of those song performances containing a relatively large amount not only of melodic direction change and melisma, but also of tone repetition (i.e. at least 30 per cent). These melodies usualiy contain numerous eluk and scalewise figurations. For example, the Javanese Transcription 47 (Dandanggula) contains six long eluk and other melismatic passages (with an average of six melismatic tones per line); it has 31 per cent melodic direction change and 39 per cent tone repetition. The Sundanese Transcription 29 (Sinom) contains 39 per cent melodic direction change and 39 per cent tone repetition. About half the Sundanese songs fit into this classification.

Another common type constitutes those songs with a high amount of melodic direction change and melisma, but a relatively low amount (less than 30 per cent) of tone repetition. The Javanese Transcription 31 (Kinanti Bares) averages between 3 and 8 melismatic tones per line, 41 per cent melodic direction change and 10 per cent tone repetition. 
The Sundanese Transcription 18 (Kinanti) has a high amount of melisma (an average of sixteen melismatic tones per line), 51 per cent melodic direction change and 8 per cent tone repetition. Versions and variants of these melodies often possess numerous eluk. Sometimes these melodies are slow, curvaceous, and smooth-flowing. Sometimes they are fast and agile, featuring scalewise figurations. About one-third of both the Central Javanese and Sundanese songs fit this classification. The Javanese melodies of this type are found in all metres, but the Sundanese ones are mostly in the Kinanti and Midjil metres.

The third type is rare, incorporating song performances with a high degree of tone repetition and a low degree of melodic direction change and melisma. These songs are the relatively short, rhythmically regular songs performed with little incidental melodic decoration, and with one syllable of the text fitting one tone of the melody or a short melismatic passage. An example is the Javanese Transcription 34 (Pangkur Matjapat), which contains two short melismatic passages, 28 per cent melodic direction change and 49 per cent tone repetition. Another example is the Javanese Transcription 2 (Sinom Iugu), with one or two melismatic passages per line, 30 per cent melodic direction change and 48 per cent tone repetition. This melody, however, is very expressive and melancholy, due partly to the reduction of melodic movement and the repetition of tones sung in lowered, miring pitch-levels. The melodic line as performed fits the dejected character of the poetic content.

OnIy 6 per cent of the Sundanese songs fit this type, e.g. Transcription 22 (Asmarandana), which has an average of 1.4 melismatic tones per line, 24 per cent melodic direction change and 61 per cent tone repetition. 
The Central Javanese songs have, as a group, a slightly higher degree of melodic direction change and a slightly lower degree of tone repetition than the Sundanese song-group. Of the Javanese songs, 85 per cent contain between 31 per cent and 50 per cent melodic direction change, whereas 83 per cent of the Sundanese songs contain between 21 per cent and 50 per cent. Of the Javanese songs, 74 per cent contain between 11 per cent and 40 per cent tone repetition, whereas 78 per cent of the Sundanese songs feature between 21 per cent and 50 per cent. That is, more Javanese songs contain a high amount of melodic direction change than the Sundanese, while more Sundanese songs feature a high amount of tone repetition than the Javanese. ${ }^{1}$

There is a slight tendency for pelog songs in both regions to have a higher degree of melodic direction change than the slendro songs, but all extremes are found in both tone systems.

Melodic movement is usually achieved by slendro or pelog stepwise motion. By far the most prevalent intervals are the 4ths, followed by 5 ths and non-slendro, non-pelog 3rds (small and large); but all possible small, large, and full-sized intervals up to the $12 \mathrm{th}^{2}$ are to be found within melodic lines and more especially between melodic/poetic Iines. Descending intervals predominate. Intervallic leaps are almost always preceded and followed by stepwise motion, two or more leaps in succession being extremely rare. But two successive 'triadic' leaps are occasionally found, for instance in the Javanese Transcription 13 and the strict-metrical, modern-style pelog melody of the Sundanese Transcription 23. 
Prevailing Melodic Direction

Less than 8 per cent of the Central Javanese songs have a prevailing ascending melodic movement. The most extreme upward level shift is a moderate $38^{\circ}$, in Transcription 65 (Durma), 10 per cent of the songs begin and end on the same tone (i.e. level shift $=0^{\circ}$ ). The great majority of songs have a moderately descending trend between $-69^{\circ}$ and $-29^{\circ}$, the average level shift for the Javanese songs being $-34^{\circ} .3$ Three of the Central Javanese songs begin on the highest tone of the range, and five begin on the lowest tone; 52 songs end on the lowest tone of their respective range.

In the Sundanese collection, 13 per cent of the songs have an ascending melodic direction, the most extreme ascent being $35^{\circ}$ in Transcription 35. Thirty-three per cent of the songs begin and end on the same tone. The average level shift is $-16^{\circ}$. That is, the Sundanese songs have a less steep descending trend than the Javanese collection. of the 54 Sundanese performances, two begin on the highest tone and two on the lowest tone of the range. Five songs end on the lowest tone of the range.

\section{RHYTHMIC MOVEMENT}

Since song performances by the same or different singers always vary rhythmically to a greater or lesser extent, only broad types of rhythmic movement can be mentioned.

Songs with a high degree of rhythmic freedom, i.e. unaccompanied tembang in additive rhythm, are the most frequently found type in this collection. The rhythmic features are to a certain extent related to the length of syllables of the text and the intonation, articulation, and stress tendencies of the language (see pp.108f. Melismatic passages in a version of one line of a text may occur as 
repeated tone passages in another version. A high degree of rhythmic variability occurs, although rhythmic similarities between versions of different singers, especially if they come from the same area, are found. Different versions and variants often, resemble each other in the position of long tones, the rests and the phrasing, but the details of the $e b b$ and flow of the rhythmic movement are different every time.

The rhythm of the repeated tone passages tends to be more irregular when sung than when it is spoken, and the melismatic passages have also generally a correspondingly irregular rhythmic movement. Long tones followed by rests, both of erratic length, are very common at the end of poetic-musical lines. Within the melodic line, the length of tones tends to increase proportionately to the degree of melodic ascent.

In most cases, a song is performed by different singers at a similar tempo, even if the performers come from widely different areas. For instance, the versions of the Sundanese Dangdanggula, Transcriptions 5, 6, and 28, featuring a high degree of rhythmic freedom, eluk and other melisma (especially in Transcription 6), have very slight tempo differences $(\boldsymbol{p}=125$ or 126$)$. It seems that certain degrees of tempo are related to certain songs. Small differences in tempo between different performances of a song almost always occur. But tempo is not a major element of variability in the songs of this collection.

Songs in purely additive rhythm usually feature a high amount of incidental ornamentation and melisma as well as rocal tones.

A second type of rhythmic movement is that of unaccompanied songs which are performed in almost purely 
additive rhythm but also occur or were originally conceived in strict divisive rhythm to gamelan accompaniment, e.g. Javanese Transcription 6 (Kinanti Lugu). The performers are only semi-consciously aware of the gamelan-accompanied form of the melody as they deliberately adapt it into a free rhythmic form. Since there is no regular time-unit throughout a song performed according to this type, the rhythmic movement cannot be described as elastic or mubato, although the semi-additive rhythm probably grew out of the rubato quality of the rocalist part of a tembang gending. These performances betray their divisive-rhythmic origin by their occasional quadruple or near-quadruple time units (especially at the beginning of a song), which occur alongside additive-rhythmic passages.

Another type of movement is the elastic, rubato, divisive-rhythmically based, melodic line performed by Sinden, Dalang, and Wajang Orang performers over the regular quadruple gamelan accompaniment. Whereas in the above-mentioned types no regular time-unit exists, the quadruple time-units of this type are the fixed base of the vocalist's melodic line. The singers, while adhering to the main tones of the melody and to the quadruple rhythmic base more closely than in the type mentioned on pp.140-1, retain a degree of freedom of movement, embroidering the basic melody with ornamental forms and irregular rhythmic structures, but co-ordinating with the beat of the gamelan line at certain points. An example is the Javanese Ladrang Pangkur (Transcription 136), in which the Sinden's melodic line rarely coincides with the exigent beat of the gamelan. The tempi of different versions of this type do not vary greatly, although Rusman's Kinanti performances (Transcriptions 45 and 46 ) have a rather slower tempo than the 
same melody (Kinanti Lugu, Transcription 6) sung by Sabar, the former containing more long tones and melisma than the latter. The tempo of Rusman's variant is strictly controlled by the accompanying gamelan, including the large-scale ritardando by the whole ensemble at the end (Transcription 46). Melisma containing 'dotted' or regular, evenly-spaced tones are quite frequent.

The fourth type incorporates songs performed in perfectly or almost perfectly strict quadruple metre, accompanied by the gamelan. Examples are the Gerongan songs, Pangkur Transcription 138 and Putjung Transcription 139. Lacking eluk and repeated tone passages and containing some 2-, 3-, or 4-toned melisma, Gerongan melodies have a high degree of melodic direction change. In pitch, melody and rhythm they are the type most strictly controlled by the gamelan.

\section{FORMAL STRUCTURE}

The poetic metrical structure of the different stanzas, with their set systems of line-length and number of lines per stanza, is mostly identical with the large melodic formal unit. That is, the Andegan Ageng mostly coincides with the melodic whole. The smaller formal unit of the musical line is also generally related to the poetic line, the two usually coinciding with each other in length and followed by rests. The stanza lines are melodic as well as poetic formal units. In most cases, the duration of the musical lines (which are generally separated from each other by rests) is strongly influenced in performance by the lengths (the number of syllables) of the poetic lines, despite the fact that a singer may insert melisma and accelerate or reduce the tempo at any point to counteract this influence. The number of textual lines in a given matjapat verse and the immutably set lengths of these lines determines in turn 
the formal musical structure of the whole melody to a large extent.

The formal character of Maskumambang melodies differs, for example, from the Kinanti Djugag songs, although both possess four lines. The former begins with a long 12syllable line, followed by three shorter lines, while the latter is made up of regular 8-syllable lines; this poetic form is naturally reflected in the musical form.

There are two main types of formal structure in the songs of this collection.

The heterogeneous, durch-komponierte or better, durch-konzipierte musical lines are typical of songs with a high degree of rhythmic freedom, i.e. the majority of the songs. Since repeats either of short or long phrases rarely occur, the element of repetition has little formal significance.

The tembang gending, on the other hand, occasionally contain a reiteration of the first and/or second lines or parts of lines in the middle or final sections of a song, as in Kinanti (Transcriptions 45 and 46). Melodies sung to the more regular Kinanti and Midjil as well as the Pangkur and Putjung metres are most typical of this practice. Formal, rhythmic and melodic similarities between different versions of a tembang gending are usually close (e.g. see p.118).

In both of these types, the melodic formulae are strong elements of formal unity. Exfoliations of a small number of typical formulae of the respective patet occur throughout each song, giving unity to cadential points as well as within the dissimilar course of most melodic lines. The melismatic Kembangan, in many cases based on these formulae, has not only a purely aesthetic but also a formal 
function. In its creation of melodic movement and the rhythmic ebbs and flows of the melody, and in its continual iterativeness of the essential melodic formulae, it is by no means an added, superfluous, purely decorative aspect, but an integral part of the melodic structure. Both incidental and melismatic Kembangan assist the recognition by the listener of the important tones of the scale, since the Kembangan occur or begin most often on the pillar tones.

The formal structure is also related to modulatory practices mentioned on pp. $147 \mathrm{fr}$.

\section{RELATIONSHIP BETWEEN POETRY AND TONAL MATERIAL} The matjapat metre groupings possess no fixed melodic types, but some general tendencies may be observed. Melodic direction change is at its highest in the metrically regular songs, which appear mostly in the Kinanti, Midjil, Putjung, and Pangkur metres. The two longest metres (Dandanggula and Sinom) are associated only with melodies featuring a high degree of rhythmic freedom. Long melismatic and repeated tone passages and scalewise figurations occur most frequently in the longer metres. Patet, tonality and level shift are elements largely independent of metre.

In the Central Javanese songs, texts about sadness, love, cries for help, and political turmoil are in the pelog tone system, whereas moral, descriptive texts, children's poems and puzzles are apt to be in slendro. The Sundanese texts about violence, death, patriotism, sadness, love, waiting, parents' desire and debts or requests to parents tend to be in pelog, whereas moral, educative, and animal poems are usually in slendro.

The relation between poetic content and melody is slight, since as in many folk-song traditions, new poems 
about a variety of subjects can be fitted to old melodies. TONAL MATERIAL

The tonal material of the songs may be classified according to the amount of vocal tones, the melodic range and the patet. Vocal tones are at their maximum in unaccompanied songs. Miring, Sliring, and Sorogan Tones; Modulation Practice Central Javanese Pelog Songs. About 15 per cent of the pelog songs are purely pentatonic, but this includes a large number of songs notated from the number script, which rarely show miring or sliring tones and are therefore not a reflection of real musical practice. Thirty-nine per cent of the songs contain incidental references to sorogan tone 4 (pelog), 37 per cent contain sorogan tone 7 (barang) and 8 per cent contain both sorogan tones. Eighteen per cent of the songs contain sliring intonations of tone 2, resembling the pitch-levels:

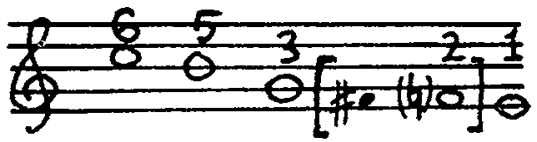

Other common sliping tones are (in order of frequency of occurrence) lowered tones 5, 4, 7 and 1 . One pelog song contains only four pitch-levels (Transcription 53, Asmarandana):

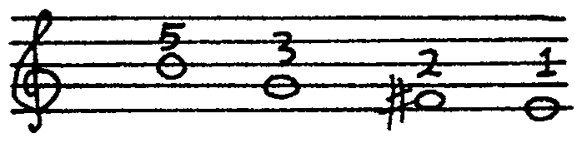

Transcription 3 (Durma) has the maximum number of thirteen notated pitch-levels within the octave, ${ }^{4}$ but some tones (e.g. lowered tone 2) appear only at the end of the melody. This flattening of tones near the end of the song was probably induced by the singer's strong awareness of the descending trend of the melodic direction. 
of the pelog patet barang songs, 43 per cent contain occasional incidence of the sorogan tone 4:

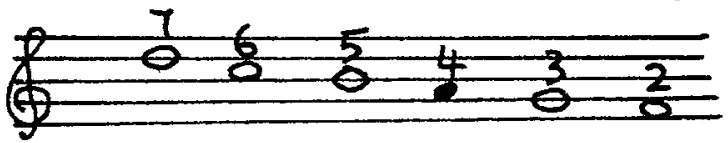

The rest are

either purely pentatonic or contain passing references to tone 1:

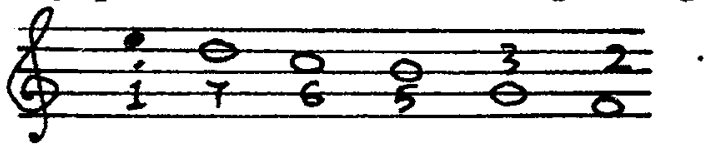

Occasional modulations by way of the two sorogan tones occur, e.g. in Transcription 78 (Midjiz), which begins in the principal scale and modulates in line 5 to the low auxiliary scale by way of tone 7 . Mostly, however, references to the modulatory tones occur incidentally, and are not sufficient to establish a real modulation. In Transcriptions 28, Sinom (Iines 3 to 9), and 49, Durma (Iines 2, 3,6), there is a touch of modulatory colour from the low auxiliary scale, but no real modulation.

Central Javanese Slendro Songs. Although the slendro scale system is theoretically much simpler than the pelog, the slendro performances in fact contain a much wider incidence of and variety of vocal tones. Only one live performance (Transcription 67, Putjung) is almost purely pentatonic (it contains lowered tone 1 ). AlI the others contain several instances of at least one rocal tone. Transcription 16 (Dandanggula Tlutur) has the maximum tonal material of 21 notated pitch-levels. 5

In six songs, tone 3 is constantly raised in pitch. Transcription 86 is in fact based on only four tones,

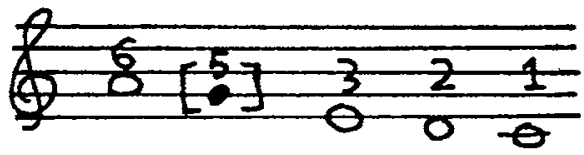


since tone 5 appears only once in an insignificant manner. In four songs, tone $I$ is constantly lowered in pitch, the main scale resembling the pitch-levels:

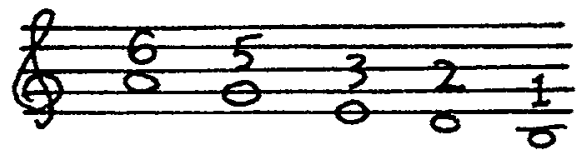

Tone ' 4 ' (i.e. raised theoretical tone 3) occurs in 27 versions: tone ' 7 ' (Iowered tone 1 ) in 25 versions, and both these pitch-levels in 10 versions. Other vocal tones are the lowered tones $3,6,2,5$, and the raised $6 \mathrm{th}$, each appearing in a variety of microtonal pitch-levels. Intonational irregularity is at its highest between the slendro tones 3 and 5 , and 6 and 1 .

The tonal material of these songs shows that in vocal practice, slendro is no more limited to pure pentatonicism than the heptatonic pelog scales (including the sorogan tones), and that there is certainly no tendency towards equidistant slendro pentatonicism. Tones ' 4 ' and ' 7 ' in slendro are used in a similar way to the tones ' 4 ' and ' 7 ' in pelog. Shifts of melodic centre and fleeting modulation occur in the vocal practice of both tone systems. 'Modulations' within slendro songs occur between scales pitched a conjunct fifth from each other, similar to the Principal, Low, and High Auxiliary scales of the pelog tone system. Examples occur in the Central Javanese Transcriptions 12, 13 (discussed on pp. I26ff. 42 and 81 .

Sundanese Pelog Songs. Of thirty pelog performances, only eight are purely pentatonic. Eleven versions contain references to the sorog tone ' 4 ' as a passing or modulatory tone, seven songs contain sorog tone ' 7 ' and one song contains both tones ' 4 ' and ' 7 '. Four songs contain a constantly raised tone 2 :

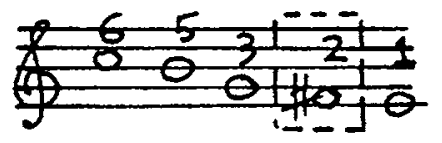


but in fourteen songs, performances of tone 2 alternate between a higher and lower pitch-level:

Other vocal tones are the raised tones 3 and 6 and the lowered tone 5 .

Transcription 18 (Kinanti) has the largest amount of tonal material of the Sundanese pelog performances, i.e. eight tones. 6 Transcription 49 (Pupuh Sinom) is one of the rare pelog modulatory songs. The tones: $\frac{43}{2-3}$ are used until the end of line 2, after which the melody modulates to a scale pitched a fifth lower, where it remains until the end of the song, i.e.

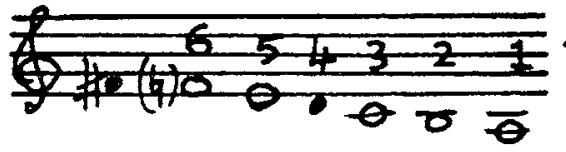

Sundanese Slendro Songs. of 24 slendro performances, 4 songs are purely pentatonic. Tone ' 4 ' appear in five songs and tone ' 7 ' in eleven songs. Tones ' 4 ' and ' 7 ' both appear in four songs.

'Modulation' in the Sundanese slendro songs is a relatively common occurrence. Eight songs begin in a scale containing rocal tones, and then modulate into a stable pentatonic or almost pentatonic scale. An example is Transcription 8 (Kinanti), which has the maximum tonal material for the Sundanese slendro songs ( 9 pitch-levels in the octave). At the end of the first two lines, which are based on the tones:

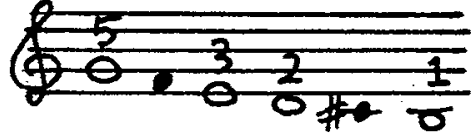

the melody 'modulates' to the pentatonic scale a 4th below (or a 5 th above), i.e.:

plus the two rocal tones:

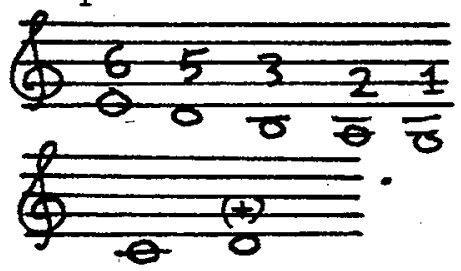


'Modulations' also occur in the slendro Transcriptions 8, 14, 17, 21, and there are touches of modulatory colour in Transcriptions 41 and 54.

None of the patet scales of the various Sundanese Surupan as listed by Kunst ${ }^{7}$ resemble the tonal material of any of the Sundanese songs of this collection. Possibly the raised tones 2 and 5 in Transcription 14 (Asmarandana) derive from a manangis scale, but it is equally possible that the singer performed these vocal tones incidentally, on the spur of the moment.

\section{Melodic Range}

The Central Javanese Songs. More than half of the performances have a range of $11 / 2$ octaves or more. A large range is found mostly in songs of the Dandanggula, Sinom, and Kinanti metres. The range of only two Dandanggula songs falls below the 1 I/2 octave mark. But the Maskumambang versions reach this width of range only once. Seven of the nine Maskumombang versions have a range of 15 semitones.

Seven songs have the maximum range of 22 semitones. The minimum of 12 semitones occurs only in three songs (Asmarandana and Kinanti). The average range is 17 semitones, the Dandanggula group having the highest and the Asmarandana and Maskumambang groups of songs the lowest average range. The widest melodic range is found in songs by unprofessional singers, in this collection. Rusman's songs are all within a range of 17 semitone pitch-levels, while the melodic ranges of the performances of the three Sinden vary in width between 19 and 21 semitones.

The Sundanese Songs. Eleven of the 54 Sundanese transcriptions have a range of $11 / 2$ octaves or more; these songs are in the Dangdanggula, Sinom, Kinanti, Midjil, Asmarandana, and Durma metres. The smallest range of 7 
pitch-levels a semitone apart is found in Transcription 22 (Asmarandana). Transcription 50 (Dangdanggula Bajubud) has the largest range of all the Sundanese and Central Javanese songs, of two octaves:

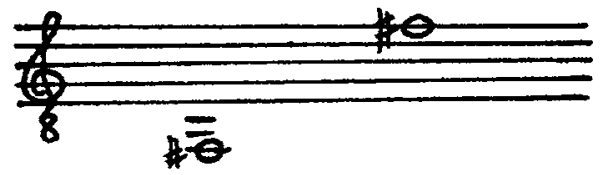

As a group, the Dangdanggula songs have the highest average range (20 semitones) and the Asmarandana and the Putjung the smallest average range ( 13 and 12 semitones respectively). A total of 13 songs have the relatively small range of 12 semitones. The Sundanese collection contains a greater variety of range but a slightly smaller average range than the Central Javanese collection.

\section{Patet}

The patet characteristics of the Central Javanese songs will be classified according to melodic formulae, tone prominence and transposition practice according to the analysis of the patet of each song in this collection.

Some songs show very clear patet attributes, containing many incidences of the typical melodic formulae and a strong tone hierarchy in favour of two or three of the pillar tones. Some other songs show dual or ambiguous patet characteristics or a democratic employment of each tone (i.e. each tone is approximately equal in degree of tone prominence). It was found helpful to use a combination of methods of patet analysis in ambiguous cases - i.e. analysing a melody's two or three most important tones (pillar tones of a patet); assessing the relative prominence or function of each tone (especially the initial, final, highest and lowest tones of a song); selecting the melodic formulae and other melodic phrases; comparing the melody with fts other versions and variants and (in songs from 
wajang) considering the textual content and time of performance in the wajang night.

Since details of the Central Javanese patet concept are not yet completely understood and it is possible that other patet criteria exist than are at present ascertained, the fallibility of the present patet analyses should be kept in mind in the following generalisations.

As previously mentioned, a detailed study of the little investigated patet system of West Java lies beyond the scope of the present study. Melodic formulae typical of Central Javanese patet, with a few exceptions (e.g. T I of slendro patet sanga, T $I$ and $T 3$ of pelog patet lima), are not typical of Sundanese songs. Recurrent melodic phrases and formulae occur, however.

Melodic Formulae. Although analysis of a much greater number of songs in each patet is needed before the relative frequency per patet of the 3-toned, slendro, $P, Q, R$, and $S$ formulae presented here can be assessed, the present analyses indicate that the $Q$ and $R$ are the most typical 3-toned formulae for slendro patet sanga, $R$ and $S$ for slendro patet manjura and $\mathrm{P}$ and $\mathrm{R}$ for slendro patet nem. However, these formulae (especially $Q, R$, and $S$ ) occur to a certain extent in songs in the other slendro patet. The 4-toned formulae, then, give much clearer indications of patet individuality than the 3-toned formulae.

Like the 4-toned formulae, there is an interval of a 4 th or 5 th (depending on formula shape) between the initial and final tones of the 3 -toned $P, Q, R$, and $S$ formulae. In songs of four of the six slendro and pelog patet, the most 
frequent of the cadential formulae in these songs begins on the dasar and ends with the IPT, whereas in the other two patet (i.e. pelog patet lima and slendro patet sanga), in which the most typical cadential formula begins with the IPT and ends with the IIPT, this formula comes a close second in frequency of occurrence. These analyses, then, support Hood's contention that the interval IPT-dasar is in general to be regarded as the 'principal fifth interval'.

of the total number of Central Javanese slendro songs in this collection, 49 per cent are basically 3-toned ${ }^{9}$ and 51 per cent are 4-toned. However, only 20 per cent of the pelog formulae are 3 -toned. ${ }^{10}$ The 4 -toned formulae play a much bigger role in the pelog songs than do the 3-toned formulae. Descending formulae make up $3 / 5$ of the total. The $T 1, T 2, P$, and $R$ formulae are most frequently encountered in the songs in slendro patet nem, but the $T 3$, $T 4, S$, and $Q$ also occur in this patet. The $T I$ and $T 3$ formulae are by far the most prevalent 4-toned formulae in the slendro patet sanga songs; the ascending T 2 and T 4 formulae occur with less than half the frequency of the descending formulae. Of the 3-toned formulae, $Q$ is by far the most common, but $R$ and $S$ also occur. The 3-toned formulae also occur more frequently in descending form.

The $T 3$ is the most frequent 4-toned formula in the slendro patet manjura songs, followed by the T 4, T I, and T 2. $R$ is the most typical 3-toned formula, but $S$ also nccurs quite frequently. $Q$ occurs sometimes, incidentally.

The pelog patet barang songs favour the T 3, T I, T 4, and $T 2$ formulae, in order of prevalence. The IIPT or the IPT are sometimes omitted from $T I$ and $T 2$ to form a 3-toned formula, and the IPT or the dasar are sometimes omitted from T 3 and $T 4$. 
The most common pelog patet nem formulae are $T 1, T 2$, $T 3$, and $T$. The IPT is sometimes omitted from the $T I$ and T 2 formulae, and the IPT or IIPT are sometimes excluded from the T 3 and T 4 formulae.

In pelog patet lima, the prevalent formulae (in order of frequency) are $T 1, T 4, T 3$, and $T 2$. The IPT is sometimes omitted from each of the four formulae to form 3-toned formulae.

In the pelog songs, the T 2 formula is the least used except in pelog patet nem, when it is second in frequency of occurrence.

Melodic shape varies considerably, but by far the most common shapes are the simple scalewise descending and ascending shapes. Besides the shapes mentioned by Hood, II the following examples are found in songs:

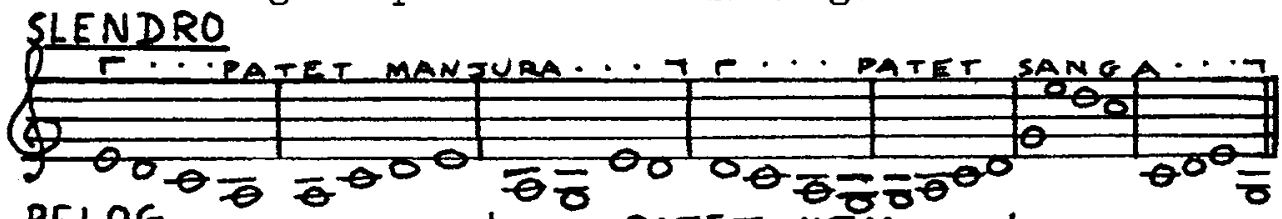
PELOG L... PATET NEM...J

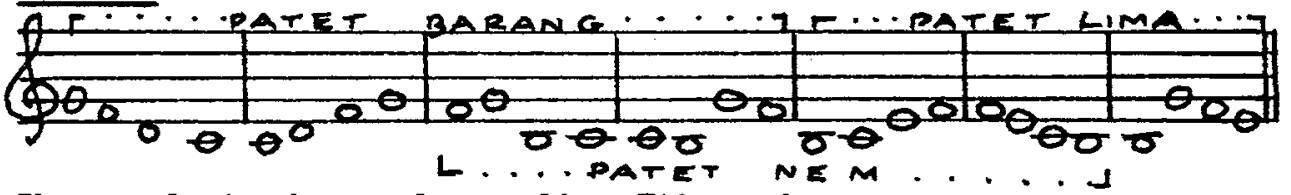
Shapes featuring a descending 7 th such as:

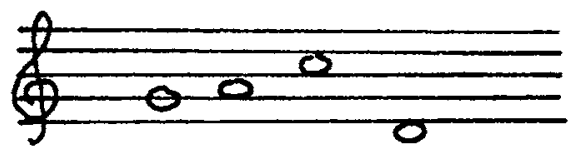

are rarely found in this collection. The formula shape featuring a descending 7 th is restricted by the range of the Saron. It is not typical of all the instrumental and vocal media.

Final cadences in the Central Javanese songs for the various patet are, in order of frequency of occurrence: 
slendro patet nem

sanga manjura

pelog patet barang

nem

Zima
T 1

T I, T 3, Q, T 4, R, S, T 2

T 3, T 1, S, T 4, Q

T $3, T 4, T 1$

T $1, T 3, T 2$

T $1, T 2$, T 3

Final cadences of the Sundanese songs are, in order of prevalence: 12
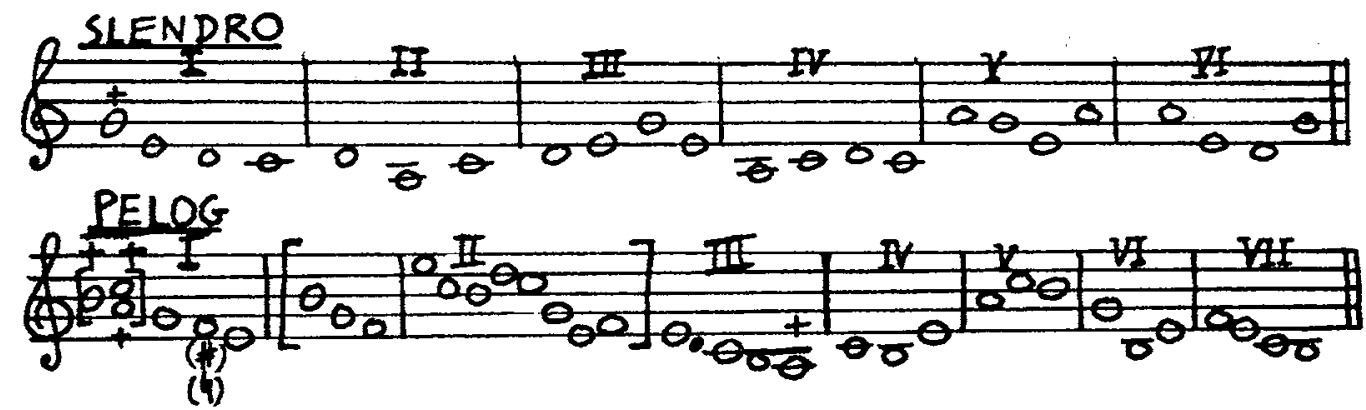

Unlike the Central Javanese songs, ascending, scalewise, final cadences do not occur. Scalewise descending, $\Lambda, V$ and $N$ shapes are found. The above pelog formula II is shown in its simple and in an elaborated form. The pelog formula VI is used in the modern melody of Transcription 23 (Durma), but such a formula is exceedingly rare in the traditional styles. The above cadences also occur within the melodic lines of the songs.

Elaborations and extensions of final cadences are common in the Central Javanese and, to a lesser extent, also the Sundanese songs, e.g. in the last line of the Javanese Transcription 98 (pelog patet barang):

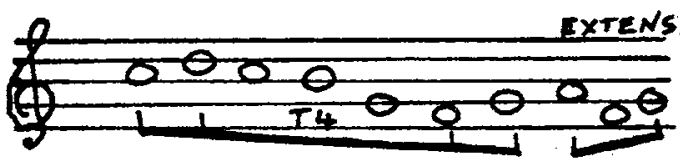

Extension of final cadences to one or more tones is particularly common among the Javanese songs in slendro patet sanga (48 per cent of the natet sanga songs have extended final cadences, which are mostly extended onto tones III or I) pelog patet nem ( 51 per cent of the songs) and pelog patet 
barang (50 per cent, generally extended onto tone II).

Tone prominence. The following is a summary of tone prominence for the Central Javanese songs in each patet:

slendro patet nem IIPT, IPT, tone 3, dasar, tone 1 sanga IPT, IIPT, dasar, tone 3 , tone 6 manjura IPT, tone 1, dasar

pelog patet barang IIPT, tone 5, IPT, tone 7, dasar nem IPT, IIPT, dasar, tone 3, tone 1 Iima IIPT, IPT, dasar, tone 3 , tone 6

The summary indicates i) that for songs in slendro patet sanga and the pelog patet nem and lima, the three pillar tones are the most prominent, that ii) the IIPT is the most prominent tone in slendro patet nem and the pelog patet barang and lima, and that iii) of the three pillar tones, the dasar is generally least prominent, especially in pelog patet barang. As Hood writes,', 'the three gong tones have a primary importance in all patet'. The prominence of the dasar in these songs is, however, smaller than one might have expected.

The final tones of songs are, in order of prevalence:

slendro patet nem

sanga manjura

pelog patet barang ${ }^{14}$

$$
\text { nem } 15
$$

$\begin{aligned} & \text { tones } 2,5,6 \\ & 1,6,5,3 \\ & 6,2,3,5,1 \\ & 7,3,5,2,1 \\ & 2,6,5,3,1 \\ & 1,5,3\end{aligned}$

The tones in italics are those most frequently used as the final tone of poetic lines. Any tone may be used for this purpose, but preference is given to the pillar tones of the respective patet.

Transposition. Transposition sometimes occurs in order to change the 'vitality-content'I7' of a song and to fit the range of a singer's voice. The following cases of transposition into different patet and/or tonalities were found 
in the songs:

I) slendro patet sanga - pelog patet lima 18

II) siendro patet sanga - slendro patet manjura 19

III) pelog patet nem - pelog patet barang.20

IV) slendro patet manjura - pelog patet nem 21

V) pelog patet nem

vI) pelog patet lima

- pelog patet lima - pelog patet
- pelog patet nem 23 barang

The 'robot' transposition method is used in I) and IV), despite Hood's assertion that this method is incorrect and never used by the Javanese. ${ }^{24}$ That is, the slendro tones:

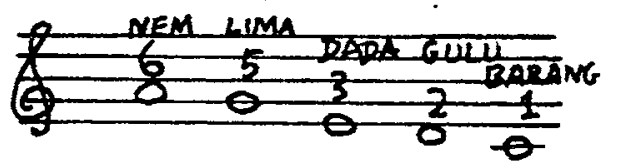

correspond with the numbers

of the pelog tones:

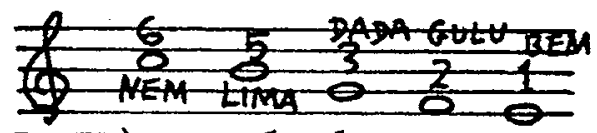

In II) the slendro patet sanga melody is transposed up one slendro tone into slendro patet manjura. That is,

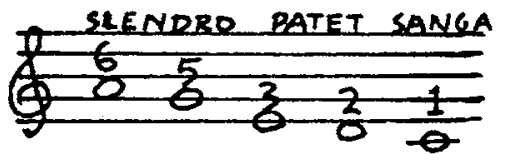

becomes

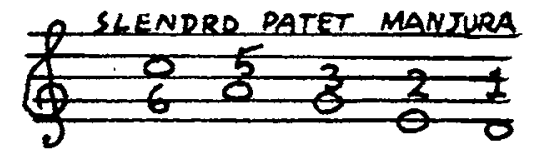

In III) and V), the pelog patet nem melody is transposed up a fifth into pelog patet barang. That is, 25

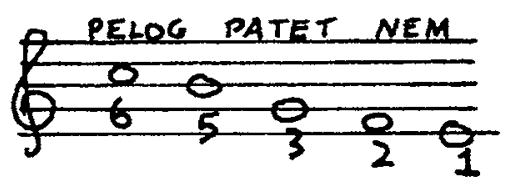

becomes

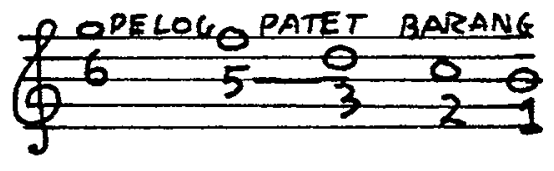

In V) and VI), the pelog patet nem and patet lima melodies have the same principal scale pitch-levels, differing only in the pillar tones, hierarchy of tone prominence and melodic formulae (i.e. the distinctive descending formulae 5321 in the songs in pelog patet lima and 6532 among the songs in pelog patet nem are used). 
KEMBANGAN, VARIANTS AND VOCAL STYLES

\section{Kembangan}

The specific kembangan types mentioned in Chapter 6 are not classifiable in relation to specific song groups, since they are general features of the whole vocal idiom and appear in highly variable forms. Certain songs, such as the Putjung slendro versions and variants discussed on pp. $122 \mathrm{ff}$ are generally performed with a relatively high degree of incidental melodic and a low degree of melismatic kembangan. However, one performer ( $P$. Saputra) sang this melody in a highly melismatic manner similar to his performances of other songs. It is evident that the amount and types of kembangan depend on the nature of the song and the style of the performer. It may also depend on the purpose of performance. Singers taking part in a Malam Kidungan may sing with relatively little melodic ornamentation in order to finish singing the kidung in a certain time span, whereas an unaccompanied matjapat song sung for pleasure or a vocal introduction to a gending may contain a large amount of Kembangan.

There are, however, four main types of kembangan preferences shown by different singers in most of their repertoires: those who perform i) a relatively high amount of incidental and a low amount of melismatic kembangan, $=. g . K$. Tobing; ii) a relatively high amount of melismatic and a low amount of incidental kembangan, e.g. P. Saputra; iii) a high degree of both incidental and melismatic kembangan, e.g. Sudradjat, and iv) a relatively high degree of pitch ornament, these performances usually being accompanied by a large amount of both incidental and melismatic kembangan, e.g. Sabar, Javanese Transcriptions 2 and 5 . 
Variability

The variability of the vocal line of different performances of a song is assumably caused partly by the personal style and taste of the singer, his vocal skill, his musical experience, the purpose and atmosphere of performance, and his cultural background. The part played by regional styles cannot be assessed here.

In most cases, singers in both Central and West Java perform relatively slight rhythmic, melodic, intonational, and ornamental variants in subsequent performances of songs, generally following rather fixed patterns of their own for each song. Often a second performance is ornamentally simpler and the melodic line shorter than the first performance, the range of the song or the frequency of occurrence of the highest or lowest tones of the range being reduced. In some cases, these changes are consciously made in order to cater for the demands of a different text. But the minor changes, especially those of rhythm, are assumably unconscious and spontaneous; the element of change is inherent in the variable nature of the style. However, the differences between versions of songs by different performers, whether they come from the same or a different home town, are sometimes very great. One cannot even say that in most unaccompanied tembang 'the nucleus is definitely fixed' 26 or that the singers 'keep to the melodic nucleus' of the song, since the range, the nature and amount of incidental and melismatic kembangan, the rhythmic structure, the intonations of certain tones, the number of summits and valleys in the melody, indeed any point of the melos itself, may vary. Since the songs are learnt by successive generations chiefly by imitation, and new texts are continually being fitted to old melodies, a virtue is made of a necessity: the quality of variability becomes an aesthetic licence, an element of the 
continual rejuvenation of a rich musical tradition.

Among the personal attributes of a singer's style are rocal techniques and ornamental, intonational, and rhythmic preferences. Some singers, for example, continually perform glottal stops, or double acciaccaturas, or pendular shakes, or incline towards long eluk, or sing certain tones with a flattened intonation, or prefer 'dotted' rhythms.

\section{Vocal Styles}

The three traditional types of vocal timbre ${ }^{27}$ are the ageng a sonorous, full, rich timbre, the tengah (middling) - a timbre with moderate volume, and the inggil - a high-pitched, thin vocal colour. All are to be found among the performances of the Central Javanese collection. The former is exemplified by Rusman's style of performance (described on p. I2l), the latter by the delicate, rebab-like vocal style of the three Sinden, Srikandi (whose vocal style is described on p.126), Retna Maruti, and Rubinem.

The tengah timbre is by far the most typical in this collection, which consists chiefly of 'folk', not professional performances; but there are many different types of timbre fitting into this tengah classification. Some vocal styles are typified by their relatively stable, moderate dynamics, their agility of movement, slight tenseness, quick breathing, rapid melisma and paucity of long-held tones, while others are characterised by their extreme calmness, continual controlled change of dynamics, copious capacity for breath control and preference for long-held tones. Most of the vocal styles feature a medium degree of slightly asymmetric vibrato of a small to moderate amplitude; often vibrato is of an ornamental nature and applied to long tones in order to give them movement, to match the faster melismatic and repeated tone passages which are generally performęd without 
vibrato. The usual dynamic range is between piano and mezso-forte. Intensity of dynamics tends to increase proportionately to the degree of melodic ascent. Articulation varies from legato to strongly stressed tones.

The Sundanese vocal timbres of this collection are all of a tengah quality, characterised by a moderate range of volume and a robust, vigorous quality which contrasts with the extremely calm quality of some Central Javanese singers (including the Sinden and several non-professional singers) and the ageng vocal quality of some professional male singers, especially from the theatre. A special vocal idiom which is very popular in Sundanese singing but also employed by Central Javanese singers, is the practice of ending a melodic line or phrase with a short, abruptly broken-off slurred tone: $\mathrm{f}^{7} \gamma$, like the flicking of a slendang (dance scarf) by a Javanese or Sundanese dancer.

Komariah Tobing's vocal style is an example of the bright, sturdy, vivacious 'folk' type in West Java, featuring strongly and unevenly stressed tones and a minimum of vibrato. Sudradjat's highly ornamental style, with its rapid dynamic surges and abatements, frequency of rests and fast vibrato is typical of professional Sundanese singing styles. But most Sundanese songs of this collection are performed with a normal speech-like vocal production plus varying degrees of melodic and glottal ornamentation.

CENTRAL AND WEST JAVANESE TEMBANG MATJAPAT COMPARED Although the differences between performances of Central and West Javanese singers in kembangan, professional vocal styles, textual characteristics and indeed the whole cultural background are strikingly apparent, the similarities between matjapat vocal styles in the two regions are greater than may be expected. Since Sundanese and Central Javanese 
matjapat prosody have a common source (the Central Javanese keraton), it is hardly surprising that some similarities exist between songs of the two areas, although each possesses its unique qualities and characteristic styles. 28

The typically more vigorous Sundanese professional vocal style, with its rapid, frequent changes of dynamics, wealth of incidental melodic ornamental types and vocal mannerisms, certainly contrasts with the characteristic Central Javanese professional style of the Sinden, with its alus, gentle, lelsured character, stereotyped melodic turns and other kembangan, steadily controlled stream of thin vocal sound and (mostly) steady change of dynamics. But gentle, 'refined' styles are also to be found in Sunda, and vigorous songs depicting strong emotions and violence in a round, full, ageng tone quality are an important part of the Central Javanese repertoire. The pelog and slendro tonal material, the amount and nature of the kembangan, the formal structure and the degree of rhythmic and pitch variability in performance indicate significant similarities between Sundanese and Central Javanese matjapat songs, alongside the structurel identity of the matjapat poetic system in both areas.

The non-professional matjapat singing styles, constituting, indeed, the true 'folk song' styles of both regions, resemble each other more strongly than the professional styles. 29 Especially apparent is the similarity in vocal production, which is of a normal, speech-like quality, plus a little vibrato on long-held tones and eluk. Long and short $e l u k$, frequently and infrequently applied $e l u k$, anticipatory tones and a high variability in kembangan are characteristic of both areas. Amounts of kembangan vary among singers in both areas from a profusion to almost none at all.

The melodic formulae, final tones, typical cadences 
and other aspects of the different patet systems of West and Central Java give the melodies of each area their distinctive melodic qualities. But variability of pitch levels (especially tones 1 and 3 in slendro and 2 in pelog) is extensive in both areas. Raised tone 2, giving a sigrak (bright) melodic quality is frequent in the Sundanese and occasional in the Javanese songs. Modulation occurs in both areas. Elaborations and extensions of final cadences as well as vocal tones are more frequent in the Javanese than in the Sundanese performances.

Descending intervals, indeed, a general descending movement throughout the songs, predominate in both areas. Intervalic leaps are almost always preceded and followed by stepwise motion. By far the most prevalent intervals in Central and West Java are the 4ths and 5ths, followed by 3 rds (large, medium, and small), but all small, medium, and largesize intervals up to a l2th occur. Fifty per cent of the Javanese and 20 per cent of the Sundanese songs have a wide range (of $11 / 2$ octaves or more).

In both areas, the most common type of rhythmic movement is the additive rhythmic movement typical of the unaccompanied songs, which are musically untrammelled by the requirements of ensemble work. The musical rhythm is often to some extent influenced by the speech rhythm. There is a certain correspondence in some songs of both regions between the duration pattern and melody of the spoken and sung versions of matjapat texts, but this is strictly limited by the musical requirements. Repeated tnne passages (partando) are generally in irregular rhythmic sequence. Tones embellished by acciaccaturas, glissandi etc. are usually of longer timevalue than unembellished tones. In general, ascending melodic lines specialise in longer tones and descending lines in shorter tones and melisma. 
The divisive rhythm of the gamelan strongly influences the vocal line of matjapat songs performed with gamelan accompaniment (tembang gending) in both areas. The gamelan's quadruple metric base and fixed idiophonic pitch levels restrict the vocalist's freedom of rhythm, melody, and pitch ornamentation. Moreover, versions or variants of a tembang gending resemble each other much more than the different versions or variants of the unaccompanied songs do. Tembang gending, as well as matjapat songs lightly accompanied by the gender in Central Java and the katjapi in West Java, retain a degree of rhythmic 'freedom' in their melodic line; they rarely coincide rhythmically with the beat of the gamelan but overlap, float along in collaboration with it, 'the triumph of freedom combined with lawfulness'. 30

Choral songs in both areas, on the other hand, are the type most strictly controlled in pitch, melody, and rhythm by the gamelan accompaniment.

Fast and slow vibrato is to be found in performances of both regions, the medium to slow vibrato being most typical of performances by non-professional singers of both regions, and slow vibrato being typical only of some of the Central Javanese performances. In both regions, vibrato is applied particularly on final tones of lines, eluk and long tones within lines which are followed by a melismatic passage. Melisma is often sung with alternating vibrato and nonvibrato while repeated tone passages are usually sung without vibrato.

Change of dynamics is more frequent and rapid in the Sundanese than the Javanese professional-type performances, the typical dynamic pattern of both being, however, a steady diminuendo trend from the beginning (i.e. the loudest part of the song) to the end (the quietest part). Some songs are sung at a fairly constant dynamic level throughout, 
whether at a subdued or at a loud level, and the slight changes of dynamics which do occur are not highly significant. Ascending lines tend in general to be accompanied by crescendo and descending lines by diminuendo or by no change of dynamics.

The formal structure of the music rarely coincides in Central Java or Sunda with the andegan regulations of the poetic formal structure, which implies that this concept is more a poetic than a musical one. The heterogeneous, nonrepetitious formal structure of unaccompanied song melody is most common in both Central and West Java. The tembang gending, on the other hand, feature a certain degree of repetition of musical phrases or even of poetic-melodic lines, a practice which is exceedingly rare in the unaccompanied songs. Formal unity of both Central Javanese and Sundanese vocal styles is achieved by the iterativeness of the melodic formulae (albeit different formulae in each region), the ornamentation, the eluk endings to lines, the rhythmic swellings and abatements of groups of notes and the generally descending melodic movement.

These two cultural regions of Central and West Java have been culturally interactive for many centuries, as the result of which many cultural similarities between them exist. Each of the two matjapat repertoires, however, while based upon collective attitudes, the same prosodic regulations, and similar musical qualities, retains its own unique musical idioms, distinctive standards of artistic taste, and diversity of styles. 


\section{Notes}

\section{CHAPTER 1}

1. See W.H. Rassers, Panji, the Culture Hero, The Hague, 1959, pp.95ff.

2. For instance, the tigers and elephants mentioned in Transcription 36 symbolise kingly power, just as kingly power is believed to be expressed by tiger and elephant design in exclusive, kingly batik of Tjirebon. 3. C. Geertz, The Religion of Jova, Glencoe, 1960, p.282. 4. See J. Kunst, Music in Java (hereafter referred to as $M J)$, p.126; this style is called tembang pendapa or tembang pringitan.

5. According to a verbal communication from K.R.T. Madukusuma of the Keraton Kasultanan, Djogjakarta.

6. See Transcription 137.

7. See Transcription 138.

8. See Transcription 136.

9. See Transcription 17 (Midjil Lugu) and Transcription 75 (Putjung).

10. See Transcription 136.

11. See Transcription 44.

12. The srepegan rambangan is a special Surakarta form of srepegan in which a matjapat melody is sung with a softly beaten gamelan (without saron and demung). The stanzas are often performed alternately by a man and a woman, and the kenong beats 'melt together in unison with the tones sung at any given moment' Kunst, MJ, p.310. Kunst also mentions (p.328) the (ka-)kowin in Djogjakarta which sometimes consists of a melody with a matjapat text. Kawin are sung by dalang at the appearance of a brave wajang figure. 
13. For instance, the Si Djuring batik design from Indramaju in West Java is still believed by some to possess the power to cure illness.

14. Kamoes Soenda - Indonesia, 1950, p.364.

15. That is, the day on which Friday (Djumat) of the international 7-day week coincides with Kliwon of the 5day Javanese week.

16. See Geertz, The Religion of Java, pp.llff., for details about Slametan.

17. R. Hassan Soema di Pradja, 'Ean en ander over gebruiken bij den Soendanees', Djoaid, Vol. 1, No. 1, 1921. 18. Mbombong Manah, Djakarta, 1958, Vol.I, p.vi. 19. The Religion of Java, pp.261-2. 20. See J.L. Peacock, Rites of Modernization. Symbolic and Social Aspects of Indonesian Proletarian Drama, Chicago, 1968. 21. The Javanese Transcription 51 (Durma) and the Sundanese Transcription 52 (Durma) express political ideas in the times of Soekarno, whereas many matjapat song texts listed in Sinau Tembang Djawa combine old Javanese melodies with relatively new texts dealing with biblical themes. Geertz, (The Religion of Java p.343) reports tembang singing in the meditation meetings of the Sumarah religious sect in East Java.

\section{CHAPTER 2}

1. Iconographical evidence from the Barabudur (eighth century), Tjandi Sari (c.750 A.D.), Prambanan (ninth century) and other temples give no intimation of past singing styles but show something of the wealth of musical instruments of the time, including saron, bonang, gambang, and gong, similar to modern gamelan instruments of the same names. They show a high level of musical activity at the time, both among the people (who assumably carved the reliefs) and in the courts (under whose command the temples were built). 
2. The oldest texts of literary value found date from the tenth century, but texts dealing with land gifts etc. date from the fifth century, see Pigeaud, Literature of Java, The Hague, 1967, Vol.I, P.52.

3. In ibid., the literature of the sixteenth and seventeenth century maritime kingdoms of Java 'is named after the Pasisir, the Coast districts' (p.13).

4. Ibid., p.7.

5. That an extensive exchange of musical elements has taken place between West and Central Java is illustrated by the fact that almost all the Central Javanese instmuments are to some extent known in West Java despite the utter dissimilarity of instrumental and ensemble style, see Kunst, $M J, p .358$.

6. The first known Hindu kingdom in Java is the Taruma Kingdom in West Java, of the fourth century. The late seventh century saw the rise of Budahism (Sailendra dynasty) and the Old Mataram Hindu kingdom came into existence c.870. 7. J.C. van Leur, Indonesian Trade and Society, The Hague, 1955, p.104.

8. Pigeaud, Literature of Java, Vol.I, p.47.

9. Javanese pre-Hindu culture was already of a very high order. In the Bronze-Iron Age, weapons and tools of bronze and iron were produced in large quantities and knowledge of the stars, navigation, a calendar and a complex irrigation system were in application, while Indonesian gold and silver craft and other products were objects of a thriving international trade in the first century A.D. and possibly earlier, see van Leur, Indonesian Trade, pp.92ff.

10. Mention is made by W.F. Wertheim, Indonesion Society in Transition, The Hague, 1959, p.84, of the Mandala (monastic estates) which tended to practise archaic artistic styles, religious forms and adat. 
11. For instance the ninth century rebellions against the Old Mataram monarchy and the thirteenth century rebellion led by the son of a peasant (Ken Angrok) against the Kediri monarchy.

12. B. Schrieke, Indonesian Sociological Studies, The Hague, 1957 , p.402.

13. Rassers, Pănji, p.220. 14. Ibid., p.99.

15. Pigeaud, Literature of Java, Vol.I. p.20.

16. See canto 91 , stanza 2.

17. One of the best known of the older kidung is the Kidung Sunda, which relates the tale, two centuries after the event, of the treacherous murder of the unsuspecting King of Sunda and his retinue after bringing his beautiful daughter in a festal fleet to marry Hajam Wuruk, king of Madjapahit; see C.C. Berg, 'Kidung Sunda: Inleiding, Tekst, Vertaling en Aanteekeningen', in Bijdragen tot de taal Kunde, Vol.83, 1927, pp.1-161.

18. In Serat Pumwakanti, Kediri, 1922, p.119.

19. In Patokaning Njekaraken, Djakarta, 1952, p.16. 20. Pigeaud, Literature of Java, Vol.I, p.125.

21. See Kunst, $M J$, pp.110, 220.

22. For examples of his verses, see Transcriptions 13, 47 , $83,86,89$ in Appendix II and the translations thereof in Appendix I.

23. Pigeaud, Literature of Java, Vol.I, pp.237-8.

24. See E.M. Uhlenbeck, A Critical Survey of Studies on the Languages of Java and Madura, The Hague, 1964, p.160, under Mangkoedimedja, R.M.

25. For further information about these distinctions see pp. 39 ff.

26. The Panakawan characters, led by the earthy-humorous clowngod Semar who can see more clearly in difficult situations than the heroes whom he serves, provide wise-humorous commentary 
26 (cont.) on the play, make satire on the rigid social norms and express social criticism. 27. 'Popular' art is used here in the sense of art in which old court and folk elements are merged with modern elements, that is, 1) art which is popular in towns, cities, and the courts (e.g. Wajang Orang) and 2) that which is popular in non-courtly circles in the cities, towns, and villages (e.g. Ludruk) . 28. According to Schrieke, Wajang Orang already existed in the eleventh century Mataram court; see 'Wajang Wong', Djäua, Vol.9, No. I, 1929 , pp. 5-6.

29. See Kunst, MJ, p.256.

30. According to A. Slamet, 'Drama Daerah dan Penggarapannja', Zaman Baru Vols, 10/11.

31. See R.A. Wongsosew̌ojo, 'Loedroek', Djöwå, Vol.10, No. 6, 1930. pp. 204-7.

32. For instance, Harsono Hadisoeseno's Wajang Pantjasila, in which the five Pandawa brothers of the Mahabhärata symbolise the five principles of the Indonesian state; and R.M. Sajid's Wajang Perdjuangan, which deals with guerilla warfare at the time of the Indonesian Revolution. 33. The attitude of some modern writers 'particularly in the early days', was 'to challenge their readers by announcing that they were deliberately ignoring the rules of good grammar, choice of words and conventional rhythms, because they wanted each work to be nothing more than "the direct outpourings of a full heart", S.T. Alisjahbana, Indonesia: Social and Cultural Revolution, oxford, 1966, p.37. 34. 'The ability to accept new influences and to add them to the existing diversity of elements in her culture lies, perhaps, at the core of the real Indonesian identity', J.D. Legge, Indonesia, Englewood Cliffs, N.J., 1964, p.173. 
35. As exemplified by the Taman Siswa schools initiated by

Ki Hadjar Dewantara, which specialise in the teaching of traditional culture.

36. Badan Musjowarat Kebudajaan Nasional, formed in 1952, subsidised by the government and consisting of various art organisations and individual members.

37. Lembaga Kebudajaan Nasional, formed in 1959 and affiliated to the Partai Nasionalis Indonesia.

38. Lembaga Kebudajaan Rakjat, formed in 1950 and affiliated to the Partai Kommunis Indonesia.

39. Wertheim, Indonesian Society, pp.309-10.

40. Ruth McVey (ed.), Indonesia, New Haven, 1967, preface, no page number.

41. Benedict Anderson, 'The Languages of Indonesian Politics', Indonesia, April 1966, p.91.

\section{CHAPTER 3}

1. For instance, of the eleven versions of one popular melody in this collection, Transcriptions 1, 55, 58, and 64 are set to a text beginning Djago Kluruk, 19 and 36 beginning Semut Ireng, 47 beginning Priwwaningreh, 54 beginning Hanjar kara, 90 beginning Pamedare and 132 beginning thus Zumahe.

2. For instance, the four different melodies of Transcriptions $12,13,18$, and 84 are each set to the same text beginning Mingkar-mingkur ing angkara.

3. See McPhee, Music in Bali, New Haven, London, 1966, pp.297303. For a collection of Balinese songs in matjapat metres (e.g. Ginanti, Sinom) written in Western musical notation, see Wajan D.jirne and Wajan Ruma (collectors), Taman Sami, Denpesar, 1968.

4. The word 'metre' is used here in the sense of the whole metrical structure of a verse.

5. It may be that the pudjangga employed the term tembang tengahan for theoretical, not prosodic reasons, i.e. if 
5. (cont.) tjilik (small) and gede (large) metres exist there should also be tengahan (middling) metres, just as gending are commonly divided into the gede, tengahan, and alit (tjilik) types.

6. See R.Ng. Ranggawarsita et al., Mardawa Lagu Djawa, Surakarta, 1957, pp. 35-8; Hardjawiraga, Patokaning Njĕkarkĕn, Djakarta, 1926; R.Ng. S. Probohardjono, Gending Djawi, Vol. LL, 1957 , p. 7.

7. Mbombong Manah, Vol. I, p. 5.

8. Kunst, $M J, p .125$.

9. The list is taken from Probohardjono, Gending Djawi, Vol. II,

p. 7

10. Many of the matjapat and tengahan metres listed in J. Kunst and A. Kunst-van Wely, De Toonkunst van Bati, Weltevreden, 1925, table XVI, are no longer in use.

11. Or Guru petungan or: Guru witjalan.

12. Or Dongding.

13. Tedjohadisumarto, Mbombong Manah, Vol. I, pp. 5-6

14. Pigeaud, Literature of Java, Vol. I, p. 20.

15. Tbid.

16. Ibid.

17. See Kunst, $M J$, p. 392

18. Ibid., p. 398.

19. This implies that tembang gede, which is sometimes called Matja-dji, means 'reading in ones', cf. Matja-ro: 'reading in twos' and Matja-lu: 'reading in threes'.

20. MJ, Vol. I, p.I22.

21. See Pigeaud, Literature of Java, p. 18.

22. Bausastra Djawa-Indonesia, 1957; matjapat, p. 292, mantjapat, p. 283.

23. Ngamantja can mean 'Iuar', out, outside; pat means 'four'. 24. Literature of Java, p. 20. 
25. Literature of Java, p.21.

26. Pigeaud, Java in the Fourteenth Century, Vol.IV, p.22.

27. Schrieke, 'Wajang Wong', p.11.

28. Mbombong Manah, Vol.I, p.12.

29. Pigeaud, Java in the Fourteenth Century, Vol.IV.

30. A written communication to the author from Pigeaud.

31. Mbombong Manah, Vol.I, p.Il.

32. Pigeaud, Java in the Fourteenth Century, Vol.IV, p. 405.

33. Ibid.

34. Ibid.

35. Literature of Java, Vol.I, p.22.

36. Tedjohadisumarto, Mbombong Manah, Vol.I, p.Il.

37. Pigeaud, Literature of Java, Vol.I, p.2l.

38. J.S. Brandts Buys and A. Brandts Buys-van Zijp, 'De

Toonkunst bij de Madoereezen', Djöwa., Vol.8, 1928, p.93.

39. 'No language, I believe, affords a parallel to this strange kind of measure'. 'A Javanese poem of any length does not uniformly consist of the same measure throughout, for the different measures are supposed to be the most appropriate to particular subjects', J. Crawfurd, History of the Indian Archipelago, Edinburgh, 1820, Vol.I, p.19-2l. 40. Pigeaud, Literature of Java, Vol.I, p.22. 41. Since the time of the pudjangga Jasadipura I, who was the grandfather of Rangga Warsita, Dandanggula has generally been used for the introductory section of a poem (see Kunst, MJ, p.125).

42. Tedjohadisumarto, Mbombong Manah, Vol.I, p.13.

43. Ibid., p.14.

44. Ibid., Vol.I, p.18.

45. Three types of wangsalan are mentioned in ibid., pp.19-23.

46. Literature of Java, Vol.I, p.22.

47. In his Literature of Java, Vol. III, pp.83-5.

48. MJ, pp.131-2.

49. Mbombong Manah, Vol.I, p.34. 
50. Kowi is old Javanese poetic language containing many words of Sanskrit origin.

51. Javanese language has four main levels used according to social status. Each level differs to some extent in vocabulary: Krama Inggil (the highest), Krama (high), Ngoko Madija (medium) and Ngoko (Low Javanese).

CHAPTER 4

1. Crawfurd, History of the Indian Archipelago, Vol.II, p.21.

2. In this poem, Bapak Putjung is an elephant.

\section{CHAPTER 5}

1. For instance, see Kunst, $M J$, appendixes $16,19,44,46$.

2. That is, the regions in Java influenced by Central Javanese culture, which are centred in Surakarta and Djogjakarta, and cover the province of Central Java and large parts of East Java.

3. That is, the parts of West Java where the Sundanese language is spoken.

4. The song-texts were mostly transcribed by ear, but occasionally, performers were able to dictate the texts of songs they performed.

5. Tedjohadisumarto, Mbombone Manah, Vols.III,V; D. Reksadarmadja, Sinau Tembang Djowa, Surakarta, 1956; K. Prawiradihardja, Serat Mardi-Laras, Surakarta, 1954, Vols.I,II; R. Ng. S. Probohardjono, Primbon Langen Swara, Surakarta, 1961. 6. Bela Bartōk and Albert B. Lord, Serbo-Croatian Folk Songs, New York, 1951, p.3.

7. Illustrated in Mantle Hood, The Nuclear Theme as a Determinant of Patet in Javanese Music, Groningen, 1954 , pp.318-19.: 
8. Transcription is 'descriptive', composition 'prescriptive'; see C. Seeger, 'Prescriptive and Descriptive Music-writing', The Musical Quarterly, Vol.44, 1958, pp.184-95.

9. A dot placed beneath or above a note means it is pitched an octave lower or higher respectively. Tones written e.g. $\overline{23}$ are quavers; $7 \cdot \overline{2}$ means: 10. These abbreviations are names of the colotomic instruments of the gamelan - i.e. pf = Kempjong, $\mathrm{k}=$ Ketuk, $\mathrm{N}-6=$ Kenong on tone 6 .

11. D. Stockmann, Das Problem der Transkription in der musikologischen Forschung, Berlin, 1966, p.235. Translation: 'It cannot be denfed that more detailed notations offer a much more complete picture of the whole nature and the stylistic characteristics of a piece, in spite of the limitations of human perception and the limitations of the notation system in which these perceived qualities are written down'.

12. Kunst also reports triplets in music played on the gambang, bonang, ketuk etc., see MJ, pp.188, 306-402. 13. Bartók and Iord, Serbo-Croation Folk Songs, p.4. 14. The Inuclear Theme, p.20.

15. This tuning generalisation is based on the idiophonic gender and is taken from ibid., p.I48.

16. Only the Central Javanese tone names are given here; see glossary for corresponding Sundanese terms.

\section{CHAPTER 6}

1. But they do occur, for example, in Transcription 16 (see p. 260).

2. See H.D. McKinney and W.R. Anderson, Music in History, New York, 1957, pp.36-7. During the time of the Hebrews' Babylonian captivity (586-538 B.C.), portions of the Scriptures were sung in the ancient Hebrew synagogues 
2(cont.) 'in free rhythm to traditional tunes of a highly decorated character (the process was called cantillation) in a manner strongly resembling the later practices of the Christians'. A characteristic of the style was 'elaborate musical exfoliations (melismata) on certain vowels'. 'The rhythm of the music depend[ed] on the rhythm of the prose'. Melismatic, free-rhythmic singing has been a constituent part of Christian and secular mic in Europe from the earliest times.

3. See D. Stockmann, W. Fiedler, and E. Stockmann, Albanische Volksmusik, Berlin, 1965.

4. 'Tone system' is understood as being the totality of tonal relationships in a given tonal material (e.g. the slendro tonal material).

5. The Nuclear Theme, pp. 138- 42 .

6. $S=$ small, $L=$ large.

7. See Kunst, MJ, p.252.

8. Hood, The Nuclear Theme, p.140.

9. Vocal tones are tones deviating in pitch from accepted pelog or slendro pitch norms, in vocal practice. 10. See Kunst, $M J$, p.252.

11. See Mantle Hood, Javanese Gamelan in the World of Music, Djogjakarta, 1958.

12. Kunst, $M J$, p. 69.

13. Ibid., p.59.

14. 'Incidental' melodic decoration includes glissandi and glottal stops; see further on pp.93ff.

15. In Ringǩ̌san Pangawikan Rinenggaswara, Djakarta, c.1950, p.17. However, these 17 rocal tones in the octave were theoretically arrived at and do not necessarily reflect vocal practice, resembling as they do the Western tones C C\# $D^{b} D$ D\# Eb E F F\# $G^{b} G G \# A^{b} A$ A\# $B^{b} B$. This theory was described in more detail in Koesoemadinata's Ilmu Seni Raras 
15 (cont.) Djakarta, 1969, and achieved concrete form in a new gamelan especially made to order and at present housed near the musicologist's home in Bandung (it was not yet completed in early 1970). Although Koesoemadinata claims that Sundanese, Javanese, Balinese, and Western music can all be played on this quarter-tone gamelan of compromise tuning, Javanese musicians in Djogjakarta said to me that the intonation of Javanese gending played on this gamelan sounds strange to their ears. In any case, Koesoemadinata's theory about Sundanese vocal tones seems to me to be mistaken, based as it is on the false assumption that tones in vocal practice are performed according to intonationally fixed laws. Javanese and Sundanese singers do not deliberately sing quarter-tones and are not restricted to 17 tones in the octave. The essence of their vocal styles lies in their relative freedom of intonation.

16. 'Die Melodiestrukturen der unbegleiten and von Instrumenten unbeeinflussen Gesangsmusik zeigen, dass gewisse Tonverhältnisse sich im Laufe der Entwicklung immer deutlicher ausprägen', R. Lachmann, Die Musik der auszereuropäischen Naturvölker, Potsdam, 1929, p.6. Translation: 'The melody structures of unaccompanied vocal music which is uninfluenced by instruments indicate that in the process of development, certain (unfixed) tonal relationships distinguish themselves from each other ever more distinctly'.

17. MJ, p.133.

18. The dual term pelog patet bem, used justifiably by some nijaga to imply mixed patet lima and patet nem characteristics, was not found necessary in the analysis of any songs in these patet, since elements of either patet lima or patet nem dominated the other to a greater or lesser extent in each case. 19. 'Transposition' is used in the special sense of transformation of a melody into another tone system or patet, i.e. it implies a new sequence of intervals, not only a change of pitch. 
20. 'Modulation' is used in the special sense of a change of tonal material from the respective patet's principal scale to an auxiliary scale (lying a fifth above or below the principal scale) or vice versa. 'Modulation' in slendro is theoretically impossible because of the variability of its pitch levels. However, it seems that slendro Schein-modulation (quasimodulation) does sometimes occur.

21. See Hood, The Nuclear Theme, p.245.

22. The three pillar tones are abbreviated hereafter as IPT (First Pillar Tone), IIPT (Second Pillar Tone) and dasar (= 'basic' tone), cf. ibid., p.7.

23. $M J$, p.72.

24. The Aructear Theme, p.248.

25. The term ascending formula is used here to mean those formulae containing two or three ascending intervals (cf. Hood's retrograde formula); descending formulae here mean those containing two or three descending intervals. 26. $T I=$ type 1 . The ascending or retrograde of $T I$ and T 3 are called $T 2$ and $T$ 4. The + sign means the tone may be omitted, resulting in a 3-toned formula. See Hood, The Nuclear Theme, pp.123, 224.

27. According to a comunication from Hood, this pattern cannot be played on a Djogjakarta saron since it does not have the pitch low-6, and would not be played on a Solonese (7-keyed) saron at cadential points for stylistic reasons. 28. Theoretically, this patet is the low auxiliary scale of pelog patet barang.

29. Hood gives an example of the Ladrang Wirogo (p.219) which he describes as being in pelog patet manjura, suggesting that the discrepancies in this patet analysis of the ladrang may be the result of the mistake of the scribe who transcribed it. There is, however, no need to infer a mistake by the scribe if one analyses this ladrang as being in pelog patet lima. 
29(cont.) The bubuka opaq-opaq of the ladrang contains no instance of the T 3 and $T 4$ patet manjura formulae which Hood proposed as the typical formula of this patet; the bubuka contains one T 3 and one three-toned T I formula of patet lima. Pelog patet lima characteristics are apparent throughout the Zadrang. 30. Since at least half the total number of Central Javanese songs was found to contain several instances of the proposed pelog patet manjura formulae proposed by Hood, and this patet is, as both Kunst and Hood mention, a rare one, it was obviously false to name every song of this collection as being in pelog patet manjura if it contained instances of the proposed formulae.

31. MJ, pp.70ff.

32. $M J$, p.73.

33. Rassers, Pänji, pp.220-1.

34. Ibid., p.230.

35. Rassers ventured the opinion that the number of undulations ( $(u q$ ) of a keris 'expresses the totality-character of the Kayon-serpent ... the number of $Z u q$ is always $O D D$, and it lies between the limits 3 and $13 \ldots$ there are, however, also krisses with a greater number of undulations, viz. up to 29, but always an odd number', ibid., p.235. 36. Kunst, $M J$, pp.101, 104, mentions some Javanese interval names, i.e. the second: Wilah, the fourth: Salah Gumun, the fifth: Kempyung and the octave: Sagembyangan. The Sundanese term for octave is Beulit. 37. A 3rd and a small 3rd occur in the principal scale of patet barang.

38. That is, at least three times the length of the commonest note value of a song. For instance, if the commonest note value vere $\boldsymbol{l}$, a tone of a value of $\boldsymbol{P}^{*}$ or more would receive an extra point in the calculation of 'tone prominence'. 
39. See examples of tone prominence statistics on pp. 181,183

40. The term 'level shift' was first used by M. Kolinski in 'The General Direction of Melodic Movement', Ethnomusicology, Vol.9, No.3, 1965, pp.240-64. 41. Level shift $=\frac{100(a-b)}{c}$ degrees, where ' $a$ ' is the interval between the lowest and the final tune, ' $b$ ' is the interval between the initial and the lowest tone, and ' $c$ ' is the range of the song (in semitones).

42. Melodic Direction Change $=\frac{100 x}{y}$ per cent where ' $x$ ' is the number of direction changes and ' $y$ ' is the total number of tones in a song. 43. 'Melisma' is used in the sense of at least two tones sung to one syllable of the text. The distinction, used in musicological writings about medieval European music, between neumatic and melismatic is not made here. 44. Tone Repetition $=\frac{100 z}{y}$ per cent where ' $z$ ' is the number of adjacent repeated tones in a song.

\section{CHAPTER 7}

1. See Javanese Transcriptions 1, 19, 36, 38, 47, 54, 55, $58,64,79,90,132$.

2. Cf. the 'tone prominence' statistics for Transcriptions 47 and 38: in Transcription 47, IPT: 31 points (i.e. 13 points for the black notes and $14(7 \times 2)$ for white note appearances in the melos and 4 points for being final tone of 4 lines), IIPT: 23 , dasar: 5, tone 6: 23, tone $3: 18$ (i.e. dasar is the avoided tone). In Transcription 38, IPT: 18, IIPT: 16, dasar: 20, tone 6: 9, tone 3: 8 (i.e. the three pillar tones ace by far the most 'prominent' tones in the song).

3. Cf. G. List, 'Speech Melody and Song Melody in Central Thailand', Ethnomusicology, Vol.5, No.1, p.36: 'In chant and song found in the traditional every day life of the 
3(cont.) people of Central Thailand, speech melody has played the most prominent role' (that is, in comparison with other song genres, especially the Western influenced genres). 4. The Javanese and Sundanese languages are characterised by their very weak syllabic emphasis. 5. Use of a spectograph would, of course, have given a mich more detailed and accurate graph of the speech melody. However, the ear seemed to be of sufficient aid for the present purpose, which is not to attempt a full-scale investigation of speech melody, but merely to indicate generally observable similarities and differences between speech and song melody.

6. This test has admittedly a rather artificial nature since matjapat poems are always sung, not recited.

7. See pp.52-53

8. R. Lach mentioned that melisma in early Gregorian chant occurred both on accentuated and non-accentuated syllables of the text, melisma and syllable-emphasis having little apparent relations. See Entwicklungsgeschichte der ormamentalen Melopoiea, Leipzig, 1913, p.26.

9. Mbombong Manah, p.27.

10. The pitch levels used in Transcription 16 are:

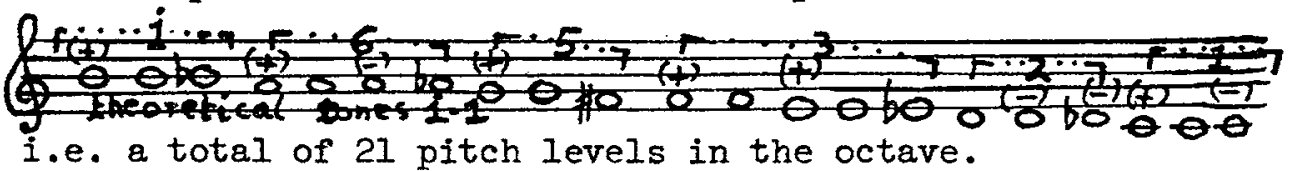

i.e. a total of 21 pitch levels in the octave.

11. According to Kunst, $M J, p .328$, tones dada and nem ( 3

and 6$)$ are commonly flattened in this patet.

12. See Transcriptions 6, 41, 45, 46, 118.

13. See Transcriptions $31,61,111$.

14. See Transcriptions 46, 48, 119.

15. See Transcriptions $7,8,25,37,40,63,67,74$.

16. See Transcriptions 9, 26, 30, 50, 83, 93, 102.

17. See Transcriptions $13,42,81,125$. 
18. See p. 89 and note 20 on p. 179 .

19. Hood, The Nuclear Theme, made a similar observation: "The ... gapped scale structures and the various "starting points" they represent in the basic sequence SSLSL are strikingly similar to the principal SCALE structures of the three PELOG patet.'

20. See Transcription 134.

21. The two pillar tones marked $X$ and $X X$ in the melos are each given 4 points in 'tone prominence': in the case of $X, 1$ point for its appearance in the melos, 1 for its relatively long time-length, $I$ for being lowest tone of song and $I$ for being final tone of line; in the case of $x X$, $I$ point for its appearance, I for its time-length, I for being final tone of line and I for being final tone of song. The first tone of the melos is given 3 points for its appearance, for its repetitiveness, and for its being initial tone of song. 'Tone prominence' statistics for the song are: IPT: 25 points, IIPT: 31, dasar: 14, tone 3: 20 and tone 6: 13.

22. See Sundanese Transcriptions 4, 16, 25, and 27. 23. See Sundanese Transcription 20. 24. See Sundanese Transcriptions 15, 24, 32, 40, 42 and 53. 25. See Sundanese Transcription 49.

CHAPTER 8

1. The above classification may remind one of the distinction in European opera between the recitativo parlando and embellished 'aria' melodic styles. Certainly some matjapat melodies are more lyrical and symmetrical than others, while some contain a high amount of tone repetition and other parlando-like features. Moreover, aria singers of Neapolitan opera were expected to improvise embellishments into the repeated sections of their arias. However, the 
I(cont.) similarities stop here. Apart from the unfitting associations the words 'recitative' and 'aria' have in a Javanese context, matjapat melodic types and their functions are quite heterogeneous.

2. A leap of a 12th occurs in Transcription 31 (Kinanti Bares), between lines 2 and 3 .

3. By comparison, M. Kolinski calculated a Level Shift of $-13^{\circ}$ for some Polish folk-songs, $-85^{\circ}$ for some Menominee Indian (Wisconsin) songs and an (upward) $44^{\circ}$ for a group of 100 Schubert songs. See 'The General Direction of Melodic Movement', Ethnomusicology, Vol.9, No.3, 1965, pp.240-64. 4. These pitch-levels are:

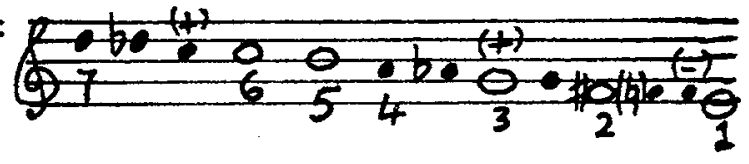

where the white notes are the principal scale tones or prominent miring tones and the black notes are the sliring tones.

5. See p. 182

6. These tones are

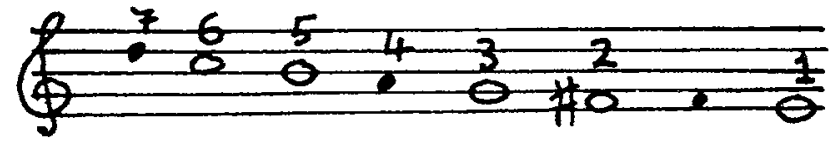

7. $M J, p p \cdot 542-5$.

8. The Nuclear Theme, p.237.

9. These 3-toned formulae include the $P, Q, R$, and $S$ formulae and the 3-toned formulae mentioned by Hood, which are formed by omitting a tone from the 4-toned formulae. See p. 91

10. These are the 3-toned formulae mentioned by Hood.

11. The Iuclear Theme, p.123.

12. Tones marked: + may be omitted from the cadences. The black note is occasionally included in the formulae. 13. The Nuclear Theme, p.236.

14. As Hood says (ibid., p.223), 'In patet barang the tone barang is the preferred final note'. 33 per cent of pelog patet barang songs end on tone 7 (barang). 
15. 57 per cent of the pelog patet nem songs end on tone 2 . 16. 71 per cent of the pelog patet 2 ima songs end on tone 1 . 17. Kunst, MJ, Vol.I, p.91.

18. See Dandanggula Turulare Transcription 38, in pelog patet lima. The other versions of this song group (see p. 18I) are in slendro patet sanga.

19. See the Dandanggula Tlutur group of versions, of which Transcription 98 is in slendro patet manjura and the rest are in slendro patet sanga. Another example is Pangkur Transcription 42 in slendro patet manjura, the rest of this group of versions being in slendro patet sanga (see pp. 125ff.) 20. See Transcription 96 in pelog patet barang, the other versions of the group being in pelog patet nem. 21. See Transcription 76 in slendro patet manjura and Transcription 77 in pelog patet nem. 22. See Transcription 15 in pelog patet nem, Transcription 85 in pelog patet barang and the rest of the group in pelog patet lima.

23. See Transcriptions 62 and 68 in pelog patet nem and the rest of the group in pelog patet lima.

24. The Nuclear Theme, p.244. In a written communication, Hood points out that after his dissertation was published, he too heard some examples of robot transposition in Java, but that he subsequently determined that these were incorrect, according to the best of professional musicians, and that the best of the keraton tradition does not allow for robot transposition.

25. This figuring of tones applies only to the transposition process. The numbers of the scale on the left become in the transposition the numbers of the scale on the right. 26. Kunst, $M J$, p. 126. 27. See Kunst, $M J, p .78$. 
28. All cultures operate under a countless number of foreign influences. Of essential significance, however, is the creation in the 'influenced' culture of new, unique art forms and styles, resulting from a synthesis of old, autochthon elements with new elements. 29. Vocal timbres and styles typical of professional Sundanese and Javanese performers are not, of course, exclusively reserved for professional performers. Professional and nonprofessional singing styles mutually influence each other to a certain extent. 30. Kunst, $M J$, p. 399 . 


\section{Glossary}

ABANGAN: outlook of the Javanese animist religious tradition, as opposed to the orthodox Moslem outlook of the Santri

ADAT: Traditional customs, including those based on mythical ideas AGENG, SWARA: a powerful, resonant vocal timbre

ALUS: refined, elegant

AMIR HAMZAH: hero of a cycle of legends from the Islamic period ANDEGAN AGENG: large poetic sense-unit (i.e. a whole verse) ANDEGAN ALIT: subordinate poetic sense unit within a verse ANGKLUNG: an instrument consisting of mobile bamboo tubes in a frame, performed by shaking

ASMARANDANA: a 7-lined matjopat metre

BABAD: 'historical' literature in verse, book on 'the past', especially the early Islamic period

BAJUBUD (Sundanese): Baju means 'wind' (song title)

BARANG: performance, mBarang means 'to perform' (song title)

BARES: simple (song title)

BAWA: a vocal introduction to a gending

BEDAJA: a dance performed by 9 young women, based on stories about

Njai Loro Kidul, accompanied by gamelon and pasinden (choir) BONANG: a goomelan instrument with small gongs on crossed cords in a wooden frame, played with 2 wooden haminers BUBUKA OPAQ-OPAQ: short introduction to a gending BUHUN (Sundanese): ancient (song title) CENTRAL JAVANESE CULTURAL AREA: the regions in Java influenced by Central Javanese culture, centred in Surakarta and Djogjakarta, and covering the province of Central Java and large parts of the province of East Java

DALANG: the puppet manipulator, narrator and leader of the gamelan in wajong performance, highly respected for his spiritual power and wide-ranging artistic ability and knowledge 
DAMAR WULAN: the hero of a popular cycle of stories from the time of Madjoxahit

DANDANGGUIA (Javanese), DANGDANGGULA (Sundanese): a 10-lined matjapat metre

DESA: village

DJILID: volume, book

DJOGJAKARTA: one of the two main Central Javanese cultural centres, containing the two keraton of the Hamengku Buwana and the Paku Alam

DOGDOG: the Sundanese name for a drum with a long-drawn shape; of various sizes

DONGENG: folk tales and legends for children

DURMA: a 7-lined matjapat metre

EIUK (or LUQ): (i) undulating keris blade; (ii) 'undulating' melismatic vocal passage sung on the last syllable of a poetic line, or on any syllable within the line

CAMBANG: a wooden xylophone with two padded hammers, used in the gomelan

GAMBUS: an Arabic pear-shaped lute, usually with seven double strings

GAMELAN: (from gamel, lit. to strike) Javanese or Balinese type of orchestra

GATRA: a poetic line in the tembang matjopat and tembang tengahan terminology

GENDING: a gamelon piece, of various possible formal structures and types

GERONGAN: a unison male choir which sings with gomelon; female Gerongan are also known in Djogjakarta in Wajang Orong, and Gerongan with both sexes occurs in modern practice 
GONDONALTUTI: lit. many praises (song title)

GONG AGENG: the great gong of the gomelon

GRAMBJANGAN: 'preluding', an instrumental or vocal introduction to

a gending

GURU LAGU: the regulation setting the final vowel of a poetic line

in tembang terminology

GURU WIIANGAN: the regulation setting the number of syllables in

a line

INGGIL, SWARA: a high, thin vocal timbre

KAKAWIHAN BARUDAK: Sundạnese children's songs

KAKAWIN: old Javanese epic poem in Indian metres on subjects drawn

from Indian epics (modelled on the Karya)

KASAR: unrefined, rough

KASMARAN: the word possibly derives from Asmara meaning 'love'

(song title)

KASATRIJAN, KSATRIJA: the moral code of noble warriors (song title)

KASEPUHAN: the name of the 'older' keraton in Tjirebon, cf. the

'younger' keraton Kanoman

KASUHUNAN: the name of the larger of the two keraton in the city of Surakarta, a cultural centre of central Java

KATJAPI (Sundanese), KETJAPI (Javanese): a zither-like instrument

played solo or in small ensemble

KAWI: Old Javanese, scholarly poetic language

KEMBANGAN: melodic ornamentation

KEMPJANG: a colotomic gamelan instrument generally consisting of

2 kettles struck simultaneously and giving a 'dissonant' sound KENDANG: the main two-headed, hand-played drum of the gomelan, the performer of which 'conducts' the orchestra and sets, maintains and leads changes in tempo 
KENONG: a colotomic gamelan instrument consisting of a single kettle resting on crossed cords in a box; it has a high-pitched sound when struck. Gomelan. have sets of Kenong tuned to the main, slendro and pelog tones.

KERATON: royal seat and cultural centre, consisting of a palace and surrounding area

KERIS: traditional dagger-like weapon with great spiritual significance and frequently kept as a sacred heirloom (pusaka) KETAWANG: a short, one-movement gending form KETOPRAK (Javanese): popular theatre with dialogue, dance, song (including song in matjopat metres) and gamelan

KETUK: a colotomic gamelan instrument consisting of a dull-sounding kettle resting on crossed cords in a box KIDUNG: (lit. song), a Javanese literary work in matjopat and/or tengahan metres, recited in singing form

KINANTI: a 6-lined matjapat metre KINANTI DJUGAG: a 4-lined matjapat metre

KRONTJONG: a semi-traditional type of music of mixed Indonesian and Portuguese origin, sometimes incorporating sentimental texts and melodies. It is usually performed by a mbato solo voice accompanied by bowed and plucked strings and, sometimes, a flute. Central Javanese Krontjong (cf. East Javanese, Indo and other types) retains strong elements of traditional Central Javanese $S$ inden and gomelan styles.

LADRANG: a short one-movement gending form

IAGU DOLANAN: Javanese songs for children (Zagu means 'song', dolan means 'game')

IAGU GENDING: the Sundanese name for gending with a vocal part IAGU SERIOSA: Westernised modern Indonesian 'serious' songs, usually with diatonic melodies for solo voice and accompanied by piano or Western orchestra. 
IAKON: the story upon which a Wajang or other theatrical episode is based

LAMPAH: (lit. walk, course, route), the number of syllables in a poetic line

LANGENDRTJAN: a musical play by women dancers who sing the dialogue in matjopat metres to gamelan accompaniment, with Zakon dealing with the Domar Wulan cycle. Langendrijan originated and is still performed in the Mangkumegaran

IIMRAH: simple (song title)

LUDRUK: popular theatre with dialogue, song, gamelan, and dance, the texts dealing often with humorous, modern stories and current affairs. Ludruk originated in Surabaja, East Java. LUGU: simple, ordinary (song title)

MADUMURII: madu means 'honey', murti means 'pure' (song title) MALAJU songs: songs in Surupan Malaju (i.e. a 7-toned scrle genus) MAIAM KIDUNGAN: a social gathering to sing Kidung, generally for a spiritual purpose, and often lasting for most of the night MANANGIS: a Sundanese set of scales in which the vocal tone panangis replaces the tone kenong

MANGKUNEGARAN: the name of one of the two keraton in the city of Surakarta, a cultural centre of Central Java

MASKUMAMBANG: a 4-lined mátjopat metre

MATJAPAT: (i) the term for songs set to a variety of autochthon Javanese poetic metres; (ii) part of a song title, e.g. Kinanti Matjopat

MELO.G: a Sundanese pelog tone gender

MIDJIL: a 6-lined matjopat metre

MIRING: (lit. slanting, sideways, insane) (i) tones constantly deviating in pitch from principal scale tone pitch-levels, found especially in tlutur songs; (ii) Sundanese Sumpan and scale genera 
NIJAGA (Javanese), NAJAGA (Sundanese): musician skilled in the performance of all the instruments of the gamezan

\section{NIRBAJA: brave (song title)}

OLD JAVANESE: the language extant in Central and East Java before the sixteenth century

PADA: stanza

PAKU ALAMAN: the name of one of the two keraton in the city of

Djogjakarta, a cultural centre of Central Java

PAKU BUWANA IV: Prince of Surakarta (1788-1820) who wrote a large amount of matjopat and other poetry

PALARAN: dipalar means 'taken', 'seized' (song title)

PANAKAWAN: wise-humorous clown-attendants, the chief of whom are

Semar, Petruk and Gareng

PANDJI: the divine hero of a Javanese legendary cycle

PANEMBRAMA: a song to welcome guests (song title)

PANGKUR: a 7-lined matjapat metre

PANGUKIR: ukir means carved, see Ukiran (song title)

PARIDJATA: type of rice, girl's name (song title)

PARIKENJO: maiden (song title)

PASIEUP or DIPASIEUP (Sundanese): complex, ornamented vocal style (cf. rantjag)

PASISIR: the north coast of Java between Surabaja and Tjirebon, a strongly Moslem area which developed aspects of its own culture in the early Moslem period

PATET: a concept similar to mode, maqam and raga, belonging to the slendro and the pelog tone systems, having to do with hierarchical tonal construction of scales, pitch, melodic formulae, 'transposition', 'modulation', and associated with periods of the Wajang Night PAWUKIR: see Ukiran (song title) 
PEDOTAN: caesura regulations in a poetic line

PELOG: (i) name of a tone system; (ii) name of the sorogan tone 4 PELOG TONES: ( $i$ ) in Javanese tembong: dji ( 1 ), ro (2), $\mathrm{lu}$ (3), pat (4), ma (5), nem (6), tu (7); (ii) in Javanese gending: bem (1), guiu (2), dada (3), pelog (4), lima (5), nem (6), barang (7); (iii) in Sundanese tembang: $d a$ (1), mi (2), na (3), ti (4), Za (5); (iv) in Sundanese gending: sunggul ( 1 ), galimer (2), panelu (3), liwung (4), kenong (5), barang (6), sorog (7). These numbers vary with the patet.

PITUTUR: advice (song title)

POKOK: starting note of a scale

PRAMBANAN BALLET RAMAJANA: name of a classical Javanese dance company, performing dances with Romoyana themes at night in the ninth century Prambanan temple (Djogjakarta), during the dry season

PRIJAJI: originally meant the hereditary aristocracy, but now implies the white-collar élite and gentlemanly class, not closely connected with orthodox Islam

PUDJANGGA: official court poet, chronicler, linguist, maintainer of the Adat

PUPUH (Sundanese): song (song title)

PURWAKANTI: poetic techniques (see p. 53)

PUT JUNG: a 4-toned matjopat metre

RAEHAI or PASIEUP (Sundanese): complex, ornamental vocal style (cf. RAVTJAG)

RAIGGA WARSITA: a famous late nineteenth-century Pudjangga of the court of Mangku Negara IV; he composed many poems in matjapat metres

RANGSAIV: to attack (song title)

RANGJAG (Sundanese): a simple, straightforward, not highly ornamented vocal style 
REBAB: a 2-stringed lute on a peg played with a loose-haired bow, an important solo instrument in the gamelan

RINGKUNG: an ancient Sundanese scale

SAMARAN: (lit. uncertain), the Sundanese name for incidentally deviating pitch-levels

SANDIASMA: a poetic technique (see p. 54)

SANDIWARA SUNDA: popular theatre in Sundanese language, with goomelon, song, dance and dialogue

SANDUNG: (lit, trip over), intermittent, between scenes (song title)

SARON: a gomelan instrument consisting of a set of bronze keys on a wooden frame, struck with a wooden hammer

SENGGAKAN (Javanese), SENGGAK (Sundanese): a free commentary or nonsense-syllable poetic/melodic phrase interjected within a song, especially where there is a long pause between vocal lines. SENGKALAN : chronogram

SERIMPI: a dance of keraton origin performed by 4 girls, accompanied by game Zan and sometimes Pasinden

SINDEN: female soloist who performs with gamelon

SINOM: a 9-lined matjopat metre

SLAMETAN: a ceremonial feast

SLENDRO: name of a tone system; Salendro in Sundanese. SLENDRO TONES: ( $i$ ) in Javanese tembang: dji (1), ro (2), $l u$ (3), ma (5), nem (6)(ii) in Javanese gending: barang (1), gulu (2), dada (3), lima (5), nem (6); (iii) in Sundanese tembang: da (1), $m i$ (2), na (3), ti (4), Za (5); (iv) in Sundanese gending: (among others) singgul ( 5 ), galimer (2), pane.lu (3), kenong (2), . barang (1). These numbers vary with the patet.

SIIRING TONES: tones incidentally deviating in pitch from the Principal Scale pitch-levels. Sliring is a common Javanese word used often by children to describe e.g. the curved path taken by a coin or stone when thrown with a twist 
SOROGAN (Javanese), SORONG (Sundanese): the two exchange tones in the pelog Principal Scale of each patet; these tones often carry a 'modulatory' function SUBOKASTOWO: honour and respect (song title) SULASTRI: lastri = evening, su = person; name of a girl (song title) SULING: the solo bamboo flute of the gamelan

SULUK: (i) mystic poems in matjapat metres; (ii) name of a group of song forms performed in wajang SUNDANESE CULTURAL AREA: the parts of West Java where the Sundanese language is spoken

SURAKARTA: one of the two main Central Javanese cultural centres, containing the keraton of the Kasuhunan and the keraton of the Mangkunegaran

SURUPAN (Sundanese): key, tuning note, general concept of tuning TEMBANG: song/poem

TEMBANG BUHUN: old Sundanese songs used for telling stories and for festive occasions

TEMBANG GEDE (LOW Javanese), SEKAR AGENG (High Javanese): 'great songs' in poetic metres of Indian origin

TEMBANG GENDING: songs sung within the performance of a gamelan work

TEMBANG KAAJEUNAAN: 'modern' Sundanese songs

TEMBANG MATJAPAT: songs in autochthon Javanese metres in modern

times using the strict prosodic rules mentioned on $\mathrm{p} \cdot 40-1$. TEMBANG TJILIK: songs in'small metres', i.e. matjapat and tengahan

TENGAH, SWARA: intermediate vocal timbre of moderate volume TERBANG: drum of Arabic origin

TJANGKRIMAN (Javanese), TATARUTJINGAN (Sundanese): puzzle in poetic form

TJENGOK: melodic style, ornamental melodic line 
TLUTUR: (lit. sad, sorrowful), a vocal style featuring many lowered miring tones and producing a melancholy musical effect to a Javanese

TURULARE: lullaby (song title)

UKIRAN: (i) carved object; (ii) omamented melodic line

URAN-URAN: any kind of singing, including songs performed in intervals between theatrical scenes

WAJANG: (lit. shadow), the name used to designate several forms of Javanese, Sundanese, and Balinese theatre

WAJANG KULIT: Javanese shadow theatre with flat leather puppets, led and played by a Dxlang, with dialogue, song, and gamelan. Wajang Purwa deals with the texts of the Mahäbiarata and Romayana, while Wajang Gedong deals with Pandji texts. It is of ancient origin

WAJANG ORANG/WONG: theatre in which human actors play the part of Wajong Kulit figures; it is popular in Central and East Java and Bali

WALI SANGA: the nine Mos lem-Javanese saints WANGSALAN : pun, word-puzzle WANTAH: simple (song title) 


\section{Musical Terms}

ADDITIVE RHYTHM: rhythm in which time values of notes and rests can freely be added to or subtracted from a musical line by the performer; rhythm in which time-lengths cannot be divided into regular bar lengths and are not limited by the need to fit into a regular pulsation (cf. synonyms 'free', 'quantitative' and 'synthetic' rhythm).

ANTICIPATORY TONE (A): the anticipation or melodic preparation of a tone of relatively long time-value by a tone of the same pitch and of shorter or equal.duration, most commonly occurring in matjapat songs at cadential points; it serves to slacken melodic movement and emphasise a particular tone.

AUXILIARY TONE: an unaccentuated tone of a melody a step higher or lower than the two tones of the same pitch between which it is inserted, e.g. comparatively inconsequential nature, achieves tonal emphasis through the reiteration of the preceding tone and is therefore 'auxiliary' or subordinate to the preceding tone.

CADENTIAL FORMULA: note patterm or melodic idiom frequently occurring at cadential points of a composition.

COLOTOMIC INSTRUMENT: instrument which divides or subdivides a gending by interpunctuation (e.g. gong, kenong, ketuk, kempul).

'DIPTHONG NOTE': a note which deviates in pitch throughout its own time-length.

DIVISIVE RHYTHM: rhythm with an accentual pattern dividing into bars of a regular number of beats (cf. synonyms 'accentual', 'analytical'). 
ENEMY TONE: the most avoided main tone of scale in performance, i.e. usually the least important tone of the respective patet tonal hierarchy (in some performances, however, no tone is treated as an enery tone while in others, two tones are avoided)'.

FREE RHYTHM: see Additive rhythm

GLISSANDO: ascending or descending gliding movement from one pitch to another without break of sound.

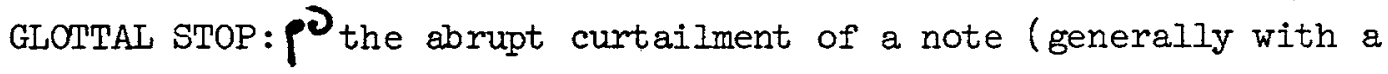
crescendo) performed by tightening the throat muscles to cut off the breath flow. Vocal glottal stop: ( $P$ ) glottal stop followed by a short, cut-off sound of rising pitch, produced at the back of the throat.

INCIDENTAL MELODIC DECORATION: ornamental melodic touches" of minimal structural significance (e.g. acciaccatura, glisscando), added to a performance according to the vocal style and whim of the performer.

INTERVALS: (a) smaIl: intervals approximating the minor or diminished intervals of Western musical terminology

(b) large: intervals approximating the augmented intervals of Western musical terminology.

INTONATION: (a) a standard of more or less accepted pitch norms in a given tone system

(b) a standard of pitch norms, some of which are lowered or raised in performance to create a miring, sliring, or tzutur intonation.

LEVEL SHIFT: a numerical designation of the degree of a melody's general ascent or descent (see p. 99). 
MELISMA: at least two tones sung to one syllable of a given text.

MELODIC DIRECTION CHANGE: the percentage of melodic changes of direction from a level course to an ascent or descent and an about-turn from an ascent to a descent and vice versa.

MELODIC FORMLA: tone patterns of various shapes continually recurring within a melodic line and at cadential points, thus established as being typical of a patet.

MELOS: a notated melodic line arranged in arhythmic form, omitting all adjacent repeated pitch levels and tautologies within lines and with a line drawn across the stave at the end of each poetic/musical line.

METRE: (i) the prosodic structure of a verse or line (poetic metre); (ii) accentual pattern of a musical line (musical metre).

MODULATION: change of tonal material from the Principal Scale of a patet to an Auxiliary Scale or vice versa; Scheinmodulation: hypothetical modulation, or modulatory colour, or change of tonal material with 'seeming' (not theoretically established) structural validity.

NUCLEAR THEME: the 'melodic core' of a gending, the 'widely-spaced' basic melodic tones as played on the 'saron group' of instruments (Hood, The Nuclear Theme, p.3), a concept roughly comparable to cantus firmus in early European polyphony.

ORNAMENTATION: melisma and incidental melodic decoration (kembangon).

PELOG INTERVAIS: intervals between the non-equidistant pelog scale tones of each patet. 
200

PELOG STEPWISE MOTION: any scalewise progression from one of the pelog patet scale tones to the next adjacent tone.

PILLAR TONES: the three most important tones of each patet's pentatonic scale(s), the tones being entitled First Pillar Tone (IPT), Second Pillar Tone (IIPT) and dasar.

PITCH DEVIATION: departure in performance from the various more or less aurally accepted pitch norms of the pelog and slendro tones.

PITCH LEVEL: the actual pitch of a tone in performance.

PITCH ORNAMENTATION: tones deviating in pitch (from whatever is accepted as the norm) in a sliring, decorative, incidental fashion

PORTAMENTO: $\quad$ see Glissando.

QUADRUPLE METRE: rhythm divisible into 4-beat accentual patterns or bars.

REPEATED TONE PASSAGES: passages of repeated tones of the same pit

SCALES: (a) principal scale: the main tone-series of a patet

(b) auxiliary scales: accessory scales lying a 5 th

above or below the Principal Scale of a patet, reached by modulation or merely touched upon in a piece to give modulatory colour.

SCALEWISE FIGURATION: melisma in which the successive tones lie scalewise intervals apart.

SHAKE: ornamental melodic oscillation between two pitch levels.

SLENDRO INTERVALS: all intervals between tones of a slendro scale.

SLENDRO STEPWISE MOTION: any slendro scalewise progression. 
'TONE PROMINENCE': an estimation of the relative prominence of each tone of a melos, according to the tone's frequency of occurrence, its number of appearances as final tone of lines and initial, final, highest, and lowest tone of song, its relative time-length and its occurrence in repeated tone passages; the purpose is to assess the usage of each tone of a song in relation to its patet and to confirm patet identity in ambiguous cases.

TONE REPETITION: successive repeated tones of the same pitch.

TONE SYSTEM: the totality of tonal relationships in a given tonal material (e.g. the slendro tonal material).

TRANSPOSITION: the transformation of a melody into another patet or tone system (e.g. pelog to slendro), resulting not only in a change of pitch but also a new sequence of intervals.

TURN : a melodic ornament consisting of 4 tones (plus, possibly, additional elaborating tones) moving in ascending and descending scalewise sťeps, e.g.

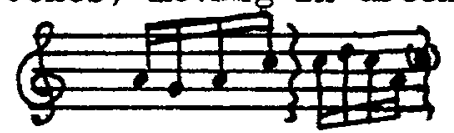

VARIABILITY: the incidence of rhythmic, intonational, melodic, and ornamental differences between performances of the one composition.

VARIANTS: variable renditions of one melody or musical work by one performer.

VERSIONS: variable renditions of one melody or musical work by different performers.

VOCAL STYLE: sum total of recurrent characteristics in the vocal performance of an individual, or common characteristics in the vocal performance of a geographical area, taking into account such qualities as vocal timbre, articulation, respiration, vibrato, pace of melodic movement, frequency of rests, dynamics, rhythmic and ornamental peculiarities, ratio between amounts of melisma and tone repetition, and song function. 
202

VOCAL TONES: tones deviating in pitch from and inserted by a vocalist between or in the place of the various accepted pelog or slendro pitch norms. 


\section{Biblography}

Alisjahbana, S. Takdir, Indonesia: Social and Cultural Revolution, Kuala Lumpur, 1966.

Anderson, Benedict R. O'G., Mythology and the Tolerance of the Javanese, Ithaca, N.Y.,1965.

- 'The Languages of Indonesian Politics', Indonesia, April 1966, pp. 89-116.

Anon., Tambahan Gending Ke: IV, Stencil Actief, Badan Penjelenggara Ballet Ramajana Prambanan, Prambanan, no date. Bandara-Bandarredja, I., 'Über Javanische Musik', Die Musik, Januar-Mai 1910, pp. 341-7.

Bartók, B. and Lord, Albert B., Serbo-Croati an Folk Songs, New York 1951.

Berg, C.C., 'Javanese Historiography - a Synopsis of its Evolution', in Hall, D.G.E. (ed.), Historians of Southeast Asia, London, 1961. Bosch, J.L.A., "Local Genius" en Oud-Javaanse Kunst', Mededelingen der Kon. Akad. von Wetenschoppen, Afdeling Letterkunde, Nievave Reeks, Vol. 15, No. I, 1952.

Brandts Buys, J.S., 'Beraads lagingen van de ontwikkelingsmogelijkheden van de muziek op Java' (introduction and debate) Djơwåa, Vol. 16, 1921, pp. 284-300.

- 'Over de Ontwikkelingsmogelijkheden van de muziek op Java', Djờå, Prae-adviezen II, Vol. I, 1921, pp. 1-90.

- and Brandts Buys-Van Zijp, A., 'De Toon-kunst bij de Madoereezen', Djow ${ }^{\circ}$, Vol. 8, 1928, pp. 3-290.

- and - 'Omtrent de Rebab', Djowá, Vol. 19, 1939, pp. 386-478. Bukofzer, M.E., 'The Evolution of Javanese Tone-Systems', Papers Read at the Intermational Congress of Musicology, New York, 1944, pp. 241-51.

Coomaraswany, A.K., History of Indian and Indonesian Art, New York, 1927. 
204

Crawfurd, J., History of the Indian Archipelago, 3 vols., Edinburgh, 1820.

Dewantara, Ki Hadjar, Sari Swara, Djakarta, 1964 .

Di Pradja, R. Hasan, 'Een en ander over gebruiken bij den Soendanees' Djơwå, Vol. 3, 1923.

Dittmer, K., 'Ethnologie und Musikethnologie', Bericht über den internationalen musikwissenschaftlichen Kongress, held at Hamburg, 1956, Hamburg, 1957.

Djåwa, Tijdschrift van het Java-Institut, Vols. 1-19, Kadipala, Soerakarta, 1921 to 1940.

Djirne, Wajan and Ruma, Wajan (Collectors), Tomom Sari, VoI. 3 Walmiki, den Pasar, 1968.

Ellis, A.J. (ass. by Hipkins, A.J.), 'Tonometrical Observations on some existing Non-harmonic Musical Scales', Proceedings of the Royal Society, London, 1884.

- 'Über die Tonleitern verschiedener Volker', Vortrag 25, März 1885, Gesellschaft für Kunst, Journal of Society of Arts, Vol. 33, No. $1688,1885$.

Endang, Mang, Pangadjaran Tembang Sunda, Bandung, 1968. Geertz, C., The Religion of Java, Glencoe, Illinois, 1960. Gonda, J., 'Some Notes on the Relations between Syntactic and Metrical Units in a Javanese Kidung', Bijdragen tot de Taalkunde, Nr. 114, 's-Gravenhage, 1958.

Hadiwidfana, 'De javaansche zang onder de regelen van de Westersche muziek-techniek', Djowå, Vol. 5, 1925, pp. 342-3. Hardjawiraga, M., Patokaning Njěkarakĕn, Djakarta, 1952. Heins, Ernst, 'Supplemental Note on a Recent Javanese Gamelan Record', Indonesia, April 1966, pp. 22-9.

- 'Music of the Serimpi Anglir Mendung', Indonesia, April, 1968, pp. 135-52.

H.0., 'De Onderdom van de Wajang Wong', Djơwà, Vol. 7, 1927, pp. 245-52. 
Holt, Claire, Art in Indonesia - Continuities and Change, Ithaca, N.Y.

Hood, Mantle, The Nuclear Theme as a Determinant of Patet in Javanese Music, Groningen, 1954.

- Training and Research Programe, Letter from Djogjakarta, Sept. 1957.

- Javanese Gomelan in the World of Music, DJogjakarta, 1958.

- 'The Javanese Rebab' in Music, Libraries and Instruments, London, 1961.

- 'Sléndro and Pélog Redefined', in Selected Reports, Institute of Ethnomusicology, University of California, Vol. 1, No. I, 1966, pp. $28 \mathrm{ff}$.

- 'Group Improvisation in the Javanese Gamelan's Ethnomusicology, Jan. 1967, pp. 107ff.

- 'The Enduring Tradition, Music and Theatre in Java and Bali', in McVey, Ruth (ed.), Indonesia, Southeast Asia Studies, New Haven, 1967 (2nd ed.).

Hooykaas, C., Proza en Poezie van oud-java, Batavia, 1933. Hornbostel, E.M. von, 'Über ein akustisches Kriterium für Kulturzusammenhänge', Zeitschrift für Ethnologie, 1911, pp. 60lff.

- and Abraham, O., 'Vorschläge für die Transkriptionen exotischer Melodien', Sammelbande der SIMG, Vol. 2, 1909, pp. Iff. H.S.A.P., 'Een en ander over gebruiken bij den Soendanees', Djäáa, Vol. 1, No. 3, 1921, pp. 157-84. Ifzerdraat, B., Rhythm and Dance in Java, Djakarta, 1959. Jay, R.R., Religion and Politics in Rural Central Java, Cultural Report Series No. 12, Southeast Asia Studies, New Haven, 1963. Jones, A.M., 'Towards an Assessment of the Javanese Pelog Scale', Ethomusicology, Vol. 7, No. 1, 1963, pp. 22-5. - Africa and Indonesia, Leiden, 1964. Koesoemadinata, R.M.A., Ringkĕsan Pangawikan Rinenggaswara, Djakarta, no date.

- IImu Seni Raras, Djakarta, 1969. 
Kolinski, M., 'The General Direction of Melodic Movement', Ethnomusicology, Vol. 9, No.3, 1965, pp. 240-64.

Kroef, J.M. van der, Indonesia in the Moderm World, Parts 1 and 2, Bandung, 1954, 1956.

- Indonesian Social Evolution - Some Psychological Considerations, Amsterdam, 1958.

- The Dialectic of Colonial Indonesian History, Amsterdam, 1963. Kunst, J., 'The Cultural Background of Indonesian Music', Journal of the International Folk Music Council, Vol. I, 1949.

- Music in Java - its history, its theory and its technique, 2nd revised and enlarged ed., translated from the Dutch by Emile van Loo, 2 vols., The Hague, 1949.

- Ethno-musicology - a study of its Nature, its Problems, Methods and Representative Personalities to which is added a Bibliogrophy, The Hague, 1959.

- Cultural Relations between the Balkons and Indonesia, and enlarged ed., Amsterdam, 1960.

- 'Sundanese Music', Indion Art and Letters, Vol. 22, No. 2.

- and Kunst van Wely, C.J.A., De Toonkunst van Bali, Weltevreden, 1925.

- and Wiranatakoes oema, R.T., 'Een en ander over soendaneesche muziek', Djò å, Vol. 1, 1921,pp. 235-52.

Lach, R., Entwicklungsgeschichte der ornamentalen Melopoiea, Leipzig, 1913.

Lachmann, R., Die Musik der auszereuropäischen Naturvölker, Potsdam, 1929.

Land, J.P.N., 'Über die Tonkunst der'Javaner', Vierteljahrschrift für Musikivissenschaft, 1889 .

Legge, J.D., Indonesia, Engelwood Cliffs, N.J., 1964. Leur, J.C. van, Indonesion Trade and Society, The Hague, 1955. 
List, G., 'Speech Melody and Song Melody in Central Thailand', Ethnomusicology, Vol. 5, No. 1, 1961, pp. 16-32.

McKinney, H.D. and Anderson, W.R., Music in History, New York, 1957. McPhee, C., Music in Bali. Form and Instrumental Organisation in

Balinese Orchestral Music, New Haven, London, 1966. McVey, Ruth (ed.), Indonesia, 2nd edition, New Haven, 1967. May, R. Le, The Cuiture of Southeast Asia: The Heritage of India, London, 1956.

Mellema, R.L. (transl. Hood, M.), Wayang Puppets, Carving, Colouring, Symbolism, Amsterdam, 1954.

Moerdowo, Reflection on Indonesian Arts and Culture, Sourabaja, 1958. Nettl, B., 'Change in Folk and Primitive Music: A Survey of Methods and Studies', Joumal of the American Musicological Society, Vol. 8, No. 2, 1955, pp. 101-9.

- Music in Primitive Culture, Cambridge, 1956.

- 'Transposition as a Composition Technique in Folk and Primitive Music' Ethnomusicology, Vol. 2, No. 2, 1958, p. 56.

- 'Some Historical Aspects of Ethnomusicology', Journal of International Folk Music Council, Vol. 11, 1959, pp. 200-1. Palmier, L.H., Social Status and Power in Java, London, 1960. Peacock, J.L., Rites of Modernisation. Symbolic and Social Aspects of Indonesian Proletarian Drama, Chicago, 1968. Pigeaud Th., 'Wayang-wong', Djöwà, Vol. 6, 1926, pp. 7-13.

- 'Over den huidigen Stand van de Tooneel - en Danskunst en de muziek-beoefening op Java', Djöwà, Vol. 12, 1932 , pp. 155-65.

- Jave in the Fourteenth Century - a Study in Cultural History, 5 vols., The Hague, 1960.

- Literature of Java, Vol. 1 - Synopsis of Javanese Literature 900-1900 AD, 3 vols., The Hague, 1967-9.

Prawiradihardja Ki., Serat Mardi-Laras, Vol. 2, Surakarta, 1954. Probohardjono, R. Ns. S., Gending Djowi, Surakarta, 1957.

- Primbon Langen Swara, Surakarta, 1961. 
Raffles, T.S., The History of Java, 2 vols., London, 1817, Kuala Lumpur, 1965.

Ramachandran, K.V., 'Hindu Origins of Javanese Music', Music Mirror, May 1958.

Ranggawarsita, R.Ng., Dewantara, K.H., and Najawirangka, R.Ng.,

Mardowa Lagu Djowa, Surakarta, 1957.

Rassers, W.H., Pănji, the Culture Hero, The Hague, 1959.

Reks adarmadja, C.S., Sinou Tembong Djowa, Surakarta, 1956.

Roberts, H.H., 'A Study of Folk Song Variants based on Field Work in

Jamaica', Joumal of American Folk-Zore, Vol. 38, pp. 149-216.

Sachs, C., Rhythm and Tempo, New York, 1953.

- The Commonsealth of Art, New York, 1946.

Sardj ana, H.A., Tembong Matjopat, Djogjakarta, 1968.

Sastrahadiprawira, R.M., 'Over de Waardeering der Soendaneesche

Literatuur', Djoàå, Vol. 9, 1929, pp. 16-21.

Satjadibrata, R., Komoes Soenda - Indonesia, Djakarta, 2 nd ed., 1950.

- Rasiah Tembang Sunda, Djakarta 1953.

Schrieke, B., 'Waj ang Wong', Djowià, 1929, pp. 5-6.

- Indonesion Sociological Studies, Selected Writings of B. Schrieke, The Hague, Part One: 1955, Part Two: 1957.

Sczabolesi, B., A History of Melody, New York, 1965.

Seeger, C., 'Professionalism and Amateurism in the Study of Folk

Music', Joumal of American Folklore, 1949, pp. 107-13.

- 'Prescriptive and Descriptive Music-Writing', The Musical Quarterly, Vol. 44, 1958, pp. 184-95.

SIamet, A., 'Drama Daerah dan Penggarapannja', Zaman Baru 10/11, 1962. Soedarsono, 'Classical Javanese Dance, History and Characterisation', Ethnomusicology, Vol. 13, No. 3, 1969, pp. 498-505. Soedjatmoko, E., Ali, M., Resink, G.J., and Kahin, G. McT., An Introduction to Indonesian Historiography, prepared under auspices of the Modern Indonesia Project, Southeast Asia Program, Cornell University, New York, 1965. 
Stockmann, D., 'Das Problem der Transkription in der musikethnologischen Forschung', Deutsches Jahrbuch für Volkskunde, Vol. 12, Jg. Teil II, Berlin, 1966, pp. 207-42.

- Fiedler, W., and Stockmann, E., Albanische Volksmusik, Berlin, 1965.

Stutterheim, M.W.F., 'Is Sléndro to be traced back to the

Çailendra's?', Actes du XVIIIe Congrès International des

Orientalistes, Leiden 1931, Leiden, 1932.

Tedjohadisumarto, R., Mbombong Manah, 5 vols. (in Javanese language),

Djakarta, 1958.

Tirtaamidjaja, N.S.H., 'A Bedaja Ketawang Dance Performance at the

Court of Surakarta', Indonesia, April 1968, pp. 31-61.

Uhlenbeck, E.M., A Critical Survey of Studies on the Languages of

Java and Madura, The Hague, 1964.

Vlekke, B.M.H., Nusantara, a History of Indonesia, The Hague,

Bandung, 1959.

Wagner, F.A., Indonesien - Die Kunst eines Inselreiches, Baden-Baden, 1959.

Wellesz, E. (ed.), Ancient and Oriental Music, London, 1957. Wertheim, W.F., Indonesian Society in Transition, The Hague, 1959.

- East-West Parallels, The Hague, 1964.

Wirjosuparto, R.M. Sutjipto, 'The Preservation of Javanese Vocal Music in Indonesia', Glimpses of the Cultural History of Indonesia, Djakarta, 1964.

Wojowasito, S., Sedjarah Kebudajaan Indonesia, Djakarta, 1957. Wongsosewojo, R.A., 'Loedroek', Djơ wå, Vol. 10, 1930, pp. 204-7. 
APPENDIX I

Translation of Song Texts

A. THE CENTRAL JAVANESE SONGS

Transcriptions

$1,55,58,64,79$

DANDANGGULA

Cocks crow noisily

Bats look for a hide-out

Daylight has come

The sun rises from the east

Morming is beginning

The moon is still shining

East of the mountain

In the village, life begins

Men and women begin their day's work

And carry out their duties.

2 SINOM

The destruction of the land of Java

Came with the arrival of a white spirit

Her weapon is a violet sugar-cane stalk

The Javanese are scattered and in disorder

Many villagers are sad

Captured under the spell

Pray to God

For a ray of light

A ray from the north-east.

$3,49,95$

DURMA

Menakdjingga: 'Damar Wulan, do not disillusion me in the affray (giant) You had better go home'

Damar Wulan: 'I will never retreat

You must die

I will strike you with holy keris' 


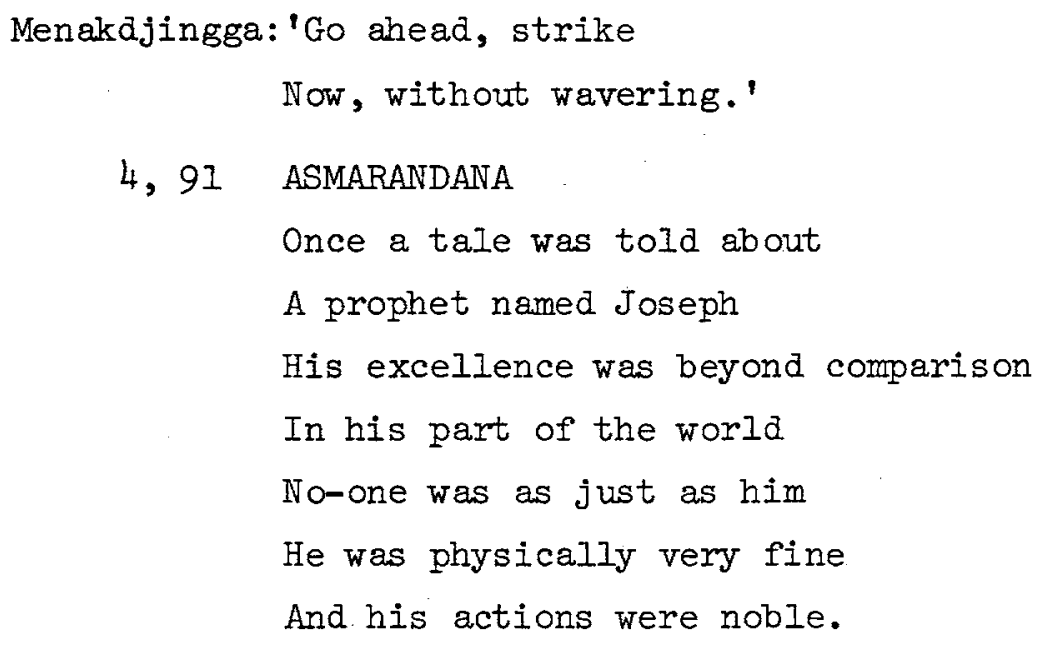

$5,35,86$

MIDJIL

You must all remember

The advice of wise men

Because you are noble heroes

You must behave kindly and politely

Always remaining calm and intelligent

In all your actions.

$6,20,76,88$

KINANTI

Training the mind

Is the sign of an attempt to gain wisdom

One continually needs to induce

Courage and humility and

To make the physical effort

of reducing eating and sleeping. 
$7,25,26,30,37,50,63,67$

PUTJUNG

Bapak Putjung is neither a rock nor a mountain

He can be found across the sea

[He can be found in Palembang] ${ }^{1}$

He is the pet of the Governor

When he walks he sways his nose.

8,83 PUPJUNG

There is a young kalzowak nut

Its two parts are one unit

It is also called Putjung

When it is ripe its two parts separate.

9 PUTJUNG

Bapak Putjung, dried rice-cakes in the food-stall

'Gunung'

Cigarettes with a Sendika trademark

Delicious coconut cakes from Kebalen

Sticky rice-cake, the favourite food of Prince Irasuman. $10,32,39,52$

MASKUMAMBANG

On where are you mother?

Quick, help me,

I am drowning in the river

I am almost gone, struggling in the water.

$11,28,29,80$

SINOM

Menakdjingga:' $E$ h, who are you?

You dare to enter the royal gardens

You are handsome

Where do you come from?

What is your name?

You had better tell me before

You die a meaningless death.

It is dangerous for you if you do not tell me.'

Damar Wulan: 'If you want to know, I am a demigod.' 
$12,13,18,34,62,68,81,84$ PANGKUR $^{3}$

Consider the following teaching (ukara)

The way a child can gain self-assurance

As expressed in this beautiful song

Which will be received happily and with an open heart

Is to control the passions by acquiring

spiritual knowledge

The people who live in Java

Should follow the religion of their king

$14,31,40,41,61,147$

KINANTI

Anoman sprang over

Onto the Nagasari tree

He saw down underneath

A beautiful but thin woman

Her hair was unpinned and unclean

Her ribs were showing. ${ }^{4}$

15 DURMA

The giants are all dead or retreating helter-skelter

The blood of the captured

Is flowing everywhere

Anoman waits a long time

But the enemy does not come

He then destroys

The Palace garden. 
$16,19,27$

DANDANGGULA

It is said, a soldier

Must give a good example

This story tells about

The trusted gentleman

Who rules Maospati

Whose name is Prime Minister Suwanda

He is known as the man

Who founded Three Maxims

Which are useful and to be seriously considered

And were borm of excellence.

17 MIDJIL

Vision and courage of mind (mean)

(Do)nothing unless (all aspects) are seen

Do not attack before the right moment

Courage is not (mere) daring

It is the child of the mind

Appearances are misleading.

20 KINANTI

Training the mind

Is a sign of the attempt to acquire wisdom

(There is) a continual need to induce

Courage and humility

To make the physical effort

To reduce eating and sleeping. 
21 ASMARANDANA

A sailing boat is visible

Moving with raised sails

Thrown about by the high waves

Right into the ocean

The crew is sinking

Luckily help is available

From a large ship.

22. DURMA

The man calls out: 'Friends, put down your hoes,

Look! There is a bird,

A very big one

Call the others too,

Let us have a closer look at it.'

But after seeing it close up

They see it is not a bird at all.

23, 24 MIDJIL

The way to success (magic power)

Is humility

He who makes concessions will win in the end

Lower your head when reprimanded

Avoid confronting your master

Retire in time of trouble.

$33,59,108$

DURMA

Uncle, uncle what is the news from the street?

On the street are many corpses

What is the cause of the death?

Death by torture

They were stabbed from the chest through the back

The souls are gone

The bodies are left rolling. 
36,38 DANDANGGULA

Of black ants calves are borm

An invalid buffalo swims across the river

Little snail's horns are as big as coconut leaves

Cucumbers have eight leaves

Surabaja is in terrible unrest

In deadly turmoil, chasing tigers

They are forced into a bamboo stalk

In Kartasura square elephants ${ }^{6}$ try to break away

Tied to a little sidoguri tree

They are killed by the scratch of a rooster.

42 PANGKUR

Guess the answers to my puzzles

Oh! there is a banana tree with nangka fruit on it There is a chicken with three heads

Sugar-cane stalks have no knots on them

The Dalang dies but he is not carried to the grave

A baby buffalo is feasting in the Sjura (fasting) month

A cricket has twenty-five horns. 7

43 PANGKUR

Let us make love

I would lose lovelost feeling if you were resting on ny arm

I would forget myself, drunis as I am with love

I would no longer feel dizzy through your absence

Please come to me

I want us to gaze into each others eyes. 
44 MIDJIL

Oh maiden of the mountain, queen of beauty,

You couzd quite dement me

How beautifully you are dressed

How can I possess you?

Ultimately you will call me $M a s^{8}$

Oh maiden of the mountain. 9

45 KINANTI

My beloved from the mountain is beautiful

As a rainbow needs to drink water

It is better for me to marry you, my relative

If people say we do not suit each other it does not matter

White tin is glinting, changing colour

I want you to become wife.

46 KINANTI

The happiness of heart, on beloved from the mount ain

Is like a cricket at night

I will not retreat, even if I have to close ny life

You are the only hope of ny heart

A black bird eats corpses

I want you to become my wife.

47, 54 DANDANGGULA

A sweet ray begins brightly to shine

A beautiful marriageable maiden

Has a fine sweet manner ${ }^{10}$ (1ives in Indonesia) ${ }^{11}$

(I am) deeply in love

Recovering patiently from serious illness

It seems from the distance

She would be very faithful

She is as bright as a Djohar star

Glittering and shining

It is right for me to serve her. 
48 KINANTI

Siti and Slamet behave very well

They do not have to be asked to help

Whenever their parents are working

They help as a matter of course

Siti sweeps the floor and tidies up

Slamet puts everything in order.

$51,56,65$

DURMA

Friends, beware, stand on guard

At grave moments

Do not be careless

About the actions of egoistic people

Who want to destroy the Three Commands 12

The Five Talismans 13

Which are the highest aims to be fulfilled.

$53,57,66$

\section{ASMARANDANA}

It is your duty to follow

The laws of religion

To protect your life, call to God

Pray regularly

Honour God

At the prescribed times

Honour Him until you are old. 
60 SINOM

Once it was said

A river flowed.

In the province of Central Java

Its source was in the Southeast

The Bengawan Solo flowed

From the Gadjah Mungkur road

Along the border of Patjitan

It flowed to the north

Through Baturetna, Wonogiri and Surakarta.

69 DANDANGGULA

Golden, golden, golden is the skin of a beautiful girl

Golden like a king's crown

People with golden skin speak very graciously

You are beautiful

I wish you were in my arms

Up there is a Kenowa bird

With red wings

Do not peck eyes

But peck this beautiful girl's body

So that she will soon become an adult.

TO SINOM

We have lived to see a time without order

In which everyone is confused in his mind

One cannot bear to join in the madness

But if he does not do so

He will not share in the spoils

And will starve as a result

It is God's wish

Happy are those who forget

Happier yet are those who remember and who have deep insight. 14 
71 SINOM

An exemplary character, a model

For the people of the land of Java

Is the great man of Mataram (called)

Panembahan Senopati

Study with concentration

Always try to reduce lust and desire (train the patience)

And meditate persistently

At all times make the effort

To achieve peace and happiness for all the people.

72 PANGKUR

Advice is sung in a Pangkur song

Advice to serve human life

What is good and evil

Should be known as clearly as possible

Customs should be learnt

As well as manners and politeness

Which should be observed day and night.

73 PUTJUNG

It is safer to have many relatives

It is good to compare (ideas)

If all opinions are united

The result is different from having no relatives.

74,145 PUTJUNG

If correctly and wisely guided

By those who are elderly

One naturally adopts

A patient attitude to one's fellow man. 
75 PUTJUNG

To have relatives makes both pleasure and difficulties

One does not worry if one is separated from them

But still feels close

But one is concerned when they need one's help.

77 KINANTI

Follow this conduct

Reduce eating and sleeping

Do not live luxuriously

Wear simple clothes

Self-indulgence is a sign of bad character

It reduces one's capacity of thinking.

78 MIDJIL

To forget, but one cannot forget

The longer one looks the more one can see

Just like a big tree

One prunes the branches and twigs and the tree does not die

But more shoots appear

And then the leaves become thicker. ${ }^{15}$

82,104 MIDJIL

Ever since I was a child

It was lot

To bear poverty and hardships

But what I have not yet done

Is to serve God

Who is the way. 
DURMA

Let us all be able to withstand suffering

To eat less and sleep less

Not to seek pleasure but

To lessen our excessive desires

With a calm soul

One can reach

One's eternal purpose.

87 SINOM

The following story is told until today

Once upon a time there was a country

Called Bandjarardja

It was peaceful and bountiful

Prosperity was widespread, even among the common people

Everyone enjoyed the bounty

Food and clothes were sufficient for all

Crime did not exist

Peace reigned, no country caused any disturbance.

89 MASKUMAMBANG

Grandparents' teachings

Five principles to which we pay homage

Each has an independent place

The five respected rules of life.

90 DANDANGGULA

The soul can be guided

By following the poet's advice

Be young in mind

But wise in your thinking

Know when to smile

And how to be kind

How not to hurt with your tongue

Follow good advice

Take care of all these matters

Which make life worthwhile. 
92 PUTJUNG

Knowledge can be obtained through experience Quicker still by Kas

Kas means how to attain a strong character Character capable of overcoming wickedness and greediness.

93 PUTJUNG

Although still a child ${ }^{16}$ (not yet able), hurriedly he dresses himself

And recites Arabic incantations

Like a descendant of the Prophet from Egypt

Each time, he adds to the welfare of mankind.

94 PANGKUR

If based on the highest wisdom

Your reason will remain strong

But when you are very old

If you are lacking in insight

You will be lonely and forceless, like a spent quid of betel,

When in the company of other people

You will (simply) try to draw attention to yourself by smiling.

96 MIDJII

Going into the forests, cautiously, into the fields Taking the path to a fertile valley

Walking on the thorny side

Joined by the edge of a passable cliff

Burnt black, sloping,

The rocks of the shallow valley. 
97 SINOM

Oh Damars as angka ${ }^{17}$

And your wife

Niken Rara Andjasmara

Are you both well?

If you are really

The son of my brother

Appear before me quickly

It is not necessary for me to open (the door for you)

'Yes, Your Excellency, as you wish.'

98 DANDANGGULA

It is very quiet in these surroundings

The moon rises, shining brightly

Not at all disappointing one's expectations

It shines the whole night through

It spreads over everything

Its rays light up the horizon

It looks so very far away

Yet it bathes the whole area in light

So many stars are spread in the heavens

That they cover the whole sky.

99 DANDANGGULA

Respected, beloved Prime Minister, I call you

I am letting you know

That I have news

From the great Godhead

That this war

Can only be solved

By a boy from the mountains

His name is Damarsasangka

Oh, dear Prime Minister, make the effort soon

Do not rest until he is found. 
100 DANDANGGULA

Suddenly the sun rises

The moon has almost sunk into the mountain

Curving to the west it no longer shines brightly

The cocks crow loudly

They all cry out

To good people who are late

So that they will not miss

Doing their worship duty

To honour the greatness of the power of God

Who rules all.

101 PUTJUNG

Children, it is your duty to heed

All that is taught you

By your father and mother

Who guide your lives.

102 PUTJUNG

Bapak Putjung, your mouth is in the air

You are playing by the well

You are resting on her left hip

When you come home you emit water from your mouth. ${ }^{18}$

103 MIDJIL

As to how the universe was created

It is the work of God

The first to the sixth day were completed

The Lord took a look

He was not disappointed

To see what was in existence. 
105 MIDJIL

Send a message to the 'Landjar Ngirim' (star)

The 'Leaning Hut' falls down

A royal 'Boat' is already in the midale of the river

A man with diseased eyes 'ploughs' his ricefield

The 'Bima Sekti'

Rides a black and white horse. 19

106 MIDJIL

The chief priests and elders

Advised the people

To choose only Barabbas

All the people agreed

Barabbas was chosen

The debt was paid.

107 DURMA

David goes straight into combat

He carries a sling

And a staff besides

He moves very deftly

He fights against the Philistine

Who is strong and mighty

Who is the champion.

109 DURMA

He has already entered the land of Zoar

After the sun rose

The Lord

Threw down brimstone

And fire out of heaven

He overthrew the whole land

of Sodom and Gomorrah. 
$110 \quad$ KINANTI

Oh students all

Keep your aim in view

This is how you are to study

With your teacher

Attend class every day

So that you will soon be filled with knowledge.

11 KINANTI (PANEMBRAMA)

With your permission

We all together

Present a choir to you

To you who have come

Willingly and with pleasure

Who desired to be present.

112 KINANTI

The land of Java

Is very beautiful

Its mountains are in rows

Bound up by the river courses

Like a snake in a field

It is unnecessary to seek proof (of Java's beauty).

113 KINANTI

The gift of a poor widow

Was two mites

Jesus called His disciples

And said to them all

I will teach you

About the gift of this poor widow. 
114 KINANTI

Follow the long path of prayer

We humble followers

Whose beliefs are united

All are joyful

On this holy day

of the birth of the holy Jesus.

\section{KINANTI}

The light of the moon and the meteors

And the various stars

All shine to brighten the universe

To give all creatures good cheer

Make them humble

And gladden the earth.

II6 KINANTI

Pray, remember

The counsel of a wise man

The Father is our teacher

Knowledge from God -

Its aim is to achieve calmness

One should always act in an intelligent way.

17 KINANTI

Do not sit and day dream

Or I will also be sad

Sadness is the flower of illness

And illness is the flower of death

A good solution is to work

Those who are industrious reach success. 
118 KINANTI

Wandering up and down the mountains

Going a cross a creek

Moving in and out of the fields

Not halting all day

It is very tiring

And(y) stomach is rumbling.

119 KINANTI

The night is bright

The sky is quite clear

Stars shine in the heavens

Bright as jewels

Their rays are dazzling

They make one feel joyful.

120 KINANTI

Once upon an evening

Abraham was sorrowful

Thinking about life

Because he had no offspring

Who could in the future

Carry on his work.

121 KINANTI (PANEMBRAMA)

The Kidung begins

A song of welcome sung by students

To all guests present

Who are happy and gay

At the wedding feast

Celebrating. 
122 ASMARANDANA

The nature of man

After birth from the womb

Is that Fate will make difficulties in his life

The world's contents

Have already been condemned

This applies to all men

Who live in the world.

123 ASMARANDANA

A long time ago there was a man

Who said to his offspring

'Look, my child,

Yellow rice fields

Make one content

That is a symbol of the love of God

The reward for our work.'

124 MASKUMAMBANG

Father, how shall I solve this problem?

Please take pity on me

Give me a blessing

Oh father.

125 PANGKUR

To go to school at seven

That is the duty of a school-child

To go there and back every morning

To the place where you can learn

To keep on the course of knowledge

To gain education

That is what you have to do. 
126 PANGKUR

Oh, it is all the same now

'Ah, Absalom, look at my weapon,

You must measure yourself alongside me!'

Spiritedly he takes action

With the strong anger of youth

'Now, take that!' (stabs him)

A spear ends his life.

127 PANGKUR

Menakdjingga sings

The crow is black and the gull has a white crest

The stork has a bald head

The tjangak bird has a long neck

The green canary takes a year to become black

The cygnet is the baby of a swan

Out of duck-eggs ducklings appear.

128 PANGKUR

Good behaviour

Should not be forgotten

It is a good weapon

It is not to be neglected

Whether getting up, sitting, standing or walking

Whether conversing, silent or asleep

Correctness of behaviour should not be disregarded.

129 SINOM

Everyone should realise

This universe

This large earth

Makes life joyful

Living things growing well

Make a pleasant sight

That is the power

of the Creator of the sky and earth

Who is to be worshipped by all men. 
130 SINOM

Pak Deduk as a child had a violent character Proud, wearing a catapult as a necklace

He was evil

Bi gheaded

Illmannered and reckless

Although small he was like a bully

He behaved destructively with other children

He pleased only the devil

Finally he was blinded.

131 SINOM

When the time came

The prophet Noah did as commanded

He was 600 years old

Then the earth was drowned

When God had locked

The door of the ark

The fountains of the deep were broken up

And the windows of heaven were opened

And then the rain fell.

132 DANDANGGULA

It is common nowadays

That people young and old

Study for knowledge

Study patiently

Anything of excellence

Written in books

And instructed by teachers

One should work hard

Avoid interruptions

And one's aim will be fulfilled. 
133 DANDANGGULA

A small mouse puts the line in order

A green frog is the Corporal

A grasshopper is the Sergeant

A crab is the Captain

Riding in a carriage around the building

A cricket is riding a horse

A spider leads the horse

Lizards are applauding

Chameleons are bravely watching the soldiers

Bugs are draining the sea.

134 DANDANGGULA

Three beats on the drum, it is not yet time to go to bed

With a bright moon shining in the yard

Sitting alone

Dew falling from above

My heart is growing sadder

(I) feel like an orphan

My body is prepared

There are no brothers, no relatives

In a Monastery, life is ascetic

Oh my soul, how can it be?

135 DANDANGGULA

Love requires sincerity

An angel declares

'Gabriel is my name

I come to Thee, oh God'

I whisper this to you:

Those who do not believe

Will be struck dumb

This will in time occur

Because my words to you

Are not believed. 
136 SONG FROM LADRANG PANGKUR

(in the Kinanti Djugag and Kinanti metres)

His name is Sang Marabangun

Sepat fish in the River Oja

One should not trifle with a man

Bigsepat. fish are dishonest ${ }^{20}$

After work go into the street

To watch a festival

The dance of a bamboo horse

Manggo stones, Hurrah, hurrah!

The build of her body is

Of medium height and slim

Her person is strong and perfect

Her manner is attractive

Her personality is pleasant

She is the worship of the earth

Sweet and friendly are her words

Her neatness charms the heart

Her manner is sparkling

She behaves like the Princess Sudarawerti

The big Kumjit flower has a shell

I wish to serve her.

137 MIDJIL

Moving fearlessly in the jungle

The path along the steep ravine is seen

A thorny bush on the edge

The thickly vegetated slope is almost impenetrable

The path is bumpy

The rocky valley is not very deep. 
138 GERONG GENDING PANGKUR (in Kinanti metre)

Very noisily, at night

A bat tries to $f l y$ around

To eat anything he can find

Guided correctly by the bushes and trees

(Such as) the Nangka, Djambu, Benda,

Randu and Bangkuang.

139 PUTJUNG

The war of the giant monkeys is interrupted

Halted by the arrival

of King Rama and his men

Quickly Anoman advances to meet him.

140 PANGKUR

The purpose of a lovely lily

Emerging from a verandah under water

Attacking the pond

Appearing on the water surface and blooming

Is only to spread its sweet fragrance

And watch the light of the moon

To delight mankind.

141 PANGKUR

Man should not as in present times

Behave under the control of his feelings

Knocking and pushing his way about

Without taking the purpose into account

The other way he interprets as a hindrance

Forgetting that he is a human being

The example of divine creation. 
142 KINANTI

It is really true

In the rice field one can rest

All the rice is divided

Under the control of the people on the land

To see it brings joy to the heart

And certainly sends luck.

143 KINANTI

The leaves are very thick

The crops in the fields

Are growing quickly and evenly

Sweetcorn, cassava, wi sweet potatoes,

Gembili sweet potatoes, and tales plant, each one Dark-bright, pure in colour and attractive.

144 PUTJUNG

Relatives, even distant relatives, must be in harmony with each other

In any instance they may not be separated

All their activities

If they are together will turn out well.

B. THE SUNDANESE SONGS

$1,11,26,33,51$

PANGKUR

They wandered about

Patrolling houses

Without any definite destination in view

And then were returning home

'Where are you three coming from in such a hurry?'

The robber chief answered:

'My name is Djaja Pati.' 
238,

$2,8,17,21,31,38,41,43,44,45$

KINANTI

A little child who can fly

Who flies usually at night

Hovers around

Looking for anything sweet

Any kind of fruit

Anything he can find.

In the daytime he hangs

Suspended from the branch of a tree

Chattering 'Kokotjeakan'

Think it over, Mimi

What is he called?

If you do not know, you are blind. ${ }^{21}$

$3,14,22,30,36$.

ASMARAIVDANA

Children, you should realise

You should keep clean and orderly

Look after your clothes

When they are dirty wash them straight away

When they are torn lose no time to repair them

You will need them even when they are old

So when they are new, care for them.

$4,16,25,27$

MIDJIL

Prince Pringgandani flies swiftly upwards

He is integrated with the clouds

The longer he flies the higher he goes

Seeking here and there, glancing down at the earth

Looking for his younger cousin

Pangeran Bimanju. 22 
$5,6,28$

DANDANGGULA

Parents invariably wish

Not to be given food

Or precious gifts

Their only desire is to be free from worry

From anything that would distress them

Cause trouble

Or make them sad

Parents wish to be happy

To have calm minds and contentment

To be joyful at heart and free from care.

$7,29,34$

SINOM

There are many kinds of fish in the pond

Many as big as a human thigh

Rolling along in layers on top of each other

Ratna Rangganis watches them

Observes the freshwater fish

Lalowak fish swimming swiftly

Sepat fish splashing in and out of the water

Djulung-djulung fish darting on the water surface

By the pond there is a Balingbing tree near a small pool.

$9,10,37$

KENANTI

Oh how is it mother?

You are living in happiness

But I am miserable

I am sending you a letter

I hope you will take interest

In what I say. 
240

12,23 DURMA

Rubbing his moustache he boasted

'Wait and see me

When $I$ am at war

It is my custom

To be heroic

To capture a king

I am not afraid to die.'

13 PUTJUNG

A monkey with a stub tail jumps over a barrier of tree stumps

A monkey with a freckled face

Jumps over a low fence

A yellow squirrel has a striped tail with thin hair.

$15,24,32,40,42,53$

MASKUMAMBANG

Ah children, remember from childhood on

That you are indebted

To your parents from the time of birth

Until now.

$18^{23}$

19 ASMARANDANA

I tire of listening for your arrival night and day Where shall I look?

If you come home alone

Do not flatter me

I do not regard you as a guest

I am not proud

I am even willing to accompany you. 
A butterfly coloured three depths of grey

I find a black one again

It flies up and alights on the wedding house

Hook the bud of a coconut flower with a coconut-leaf basket

A badoang bird

Swoops onto the Paku Hadji tree

Do not let such a trivial cause anger you

It will not be long before I come back

It is not because I do not want to come

The memory remains afterwards

Wait for me, wait for me

As long as my husband lives.

35 DURMA

Ah, so that is how it feels

At the time of departure

Strange incidents occur

It seems blood is in the water

And it is abnormal

That the black crow ${ }^{24}$ should squawk

Singing up above the water.

39 PUTJUNG

Bapak Putjung's favourite food is roasted pastry

Go and buy tobacco and Kowung leaf ${ }^{25}$

Go to the rice-stamper

And steal a squawking chicken. 
46 ASMARANDANA

The Gandasari ${ }^{26}$ is a favourite book

A book written for all of us

A book full of illustrations

It is a garden

A garden of multi-coloured flowers

Sweet-scented flowers

Which give one delight.

47 ASMARANDANA

Puring and Malati 27 flowers (Oh forgive me) 28

Wera and Malati flowers

The roses ask

Where my love is going (Oh forgive me)

A lovable suitor

Would normally walk around

Just to visit me.

48 SINOM

Indigo seeds from Rinuh flowers

A badoang bird on a badori plant

Settles on the holy KaIidjaga

The walet bird has strong wings

The kihkir bird sings at night

On the tundjung tree. Tell me,

What is to be done?

It is doubtful whether the mushrooms I planted will grow

The leaf of the bakung flower; pisiton is another name for kokoson. 29

49 SINOM

Oh pray, Moon, shine brightly

Please appear

Do not hide behind the clouds

Take pity on me

I who am sick at heart 
Who have been bewitched

Now desire to be glad again

I wander about to cool my mind

I hope I will be able to recover.

50 DANDANGGULA

The sekar maning (flower) is repeatedly blown by a soft breeze

And by a strong wind

The trees are all bending

As if they were putting their lives at stake

This vision makes the mind clear

And helps the determination

When trouble occurs

The tiger runs amok

Sincerely, unhesitatingly, loosen family ties, ready to die

To defend the homeland.

52 DURMA

Red and white is the flag of Indonesia

The red symbolises courage,

The white signifies purity

Braveness and determinedness to remain true

To serve the country with devotedness

For its dignity, fortune and prosperity

For its honour and wealth.

54 ASMARANDANA

Remember, always remember

That living on this earth

Is like a wajang show

The body is powerless

If one acts wrongly

The soul will regret it

But the body will be the one

That really suffers, 
244

NOTES:

The song texts were translated freely, the chief difficulties encountered being textual corruption, poetic obscurity, and obsolete idioms. My husband and, to a much lesser extent, I are responsible for the translations, with the help of several Javanese and Sundanese people, including Mr Poedijono of Wonogiri, teacher of Javanese gamelan at the Konservatori Karawitan Bali.

1. This line may be inserted instead of the previous line.

2. Answer to riddle: an elephant.

3. This text is from the Wedatama book. Here the poet expressed the feudal teaching that the religion of the king should be adopted by the adults and children of Java and used as a guideline for behaviour.

4. This poem refers to the captured Princess Dewi Sinta, wife of Rama, who is about to be rescued through the help of Anoman, the white Monkey King.

5. Answer to riddle: kupat (rice-cake wrapped in coconut leaves and cut into squares).

6. Tigers and elephants symbolise the power of the king.

7. This poem is a Tjangkriman in which each line poses a word puzzle. For instance, in line 3: 'Ana pitik ndase telu' the syllables 'tel' and 'lu' suggest the words 'dibuntel wulu', meaning 'covered with feathers'. The answer is: 'The chicken's head is covered with feathers'.

8. That is, you will marry me.

9. In these four poems (43 to 46), Gatotkatja addresses his future wife Dewi Pregiwa.

10. This line is sung in Transcription 47.

11. This line is sung in Transcription 54.

12. The three Commands are the Tri Sakti of President Soekarno. The commands are for Indonesia to achieve political and economic independence and cultural identity.

13. The five talismans (Pantja Azimat) are Nasakom, Pantjasila, Manipol, Tri Sakti, and Berdikari.

14. After the translation by Geertz., The Religion of Java, p.281.

15. Leaves symbolise qualities of human nature. 
16. A pescontren (Moslem school) pupil. Of such a school, Anderson, The Languages of Indonesian Politics, p. 92, writes: 'The pupils in the pesontren ... acquired their Koranic texts by rote, and the excelling pupil was the boy who could recite without mistakes, although he understood nothing of what he was saying.'

17. Peasant boy who became King of Madjapahit.

18. Answer: a flask.

19. This poem is a play on Javanese star-names; words in inverted commas refer to names of stars.

20. Answer to puzzle: Prince Prijambada (see p.61)

21. Answer: a bat. The second verse is sung in Transcription 43 only.

22. Son of Ardjuna. Prince Pringgandani is Gatotkatja.

23. This translation was not attempted due to the corruption of the text.

24. Ominous symbols of death.

25. Used to roll cigarettes.

26. A book previously read in Sundanese elementary schools.

27. Symbol of purity and weddings.

28. A Senggakan.

29. Pisitan and kokosan are words for the same type of fruit. 
Appendix II

Transcriptions of Songs in Matjapat Metres

The Japanese Transcriptions 

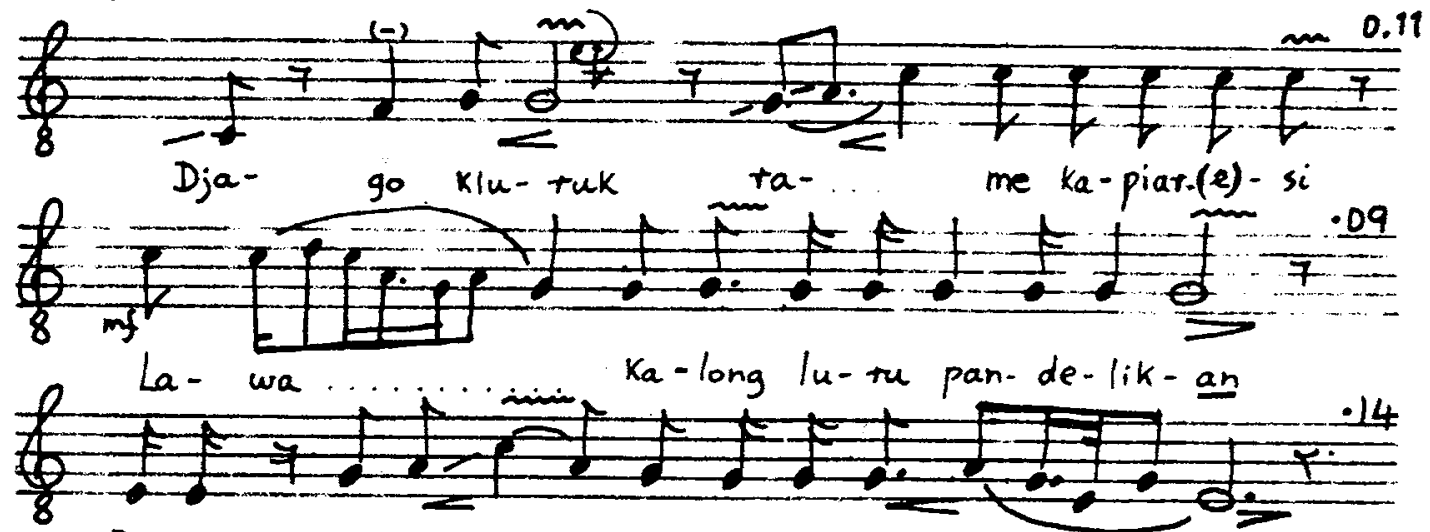

Dje-tih $k a-w a n-$ an. ing (e) se- mu-ne..........

$\exists$

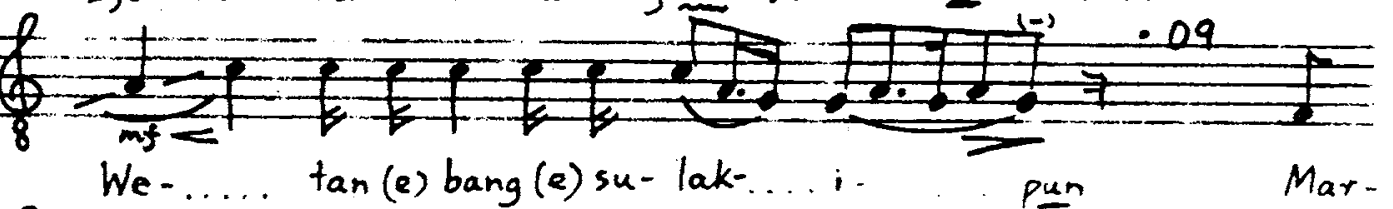

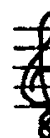

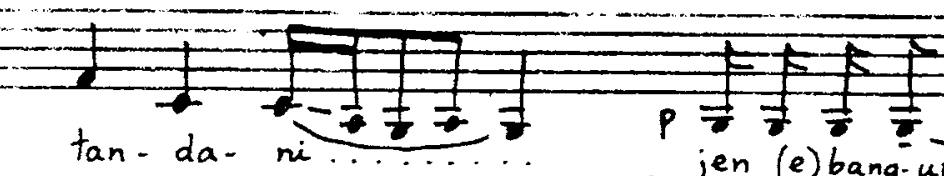

pun

Mar

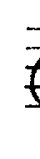

7

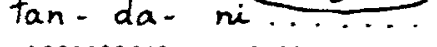
.18 jen (e) bang-un......
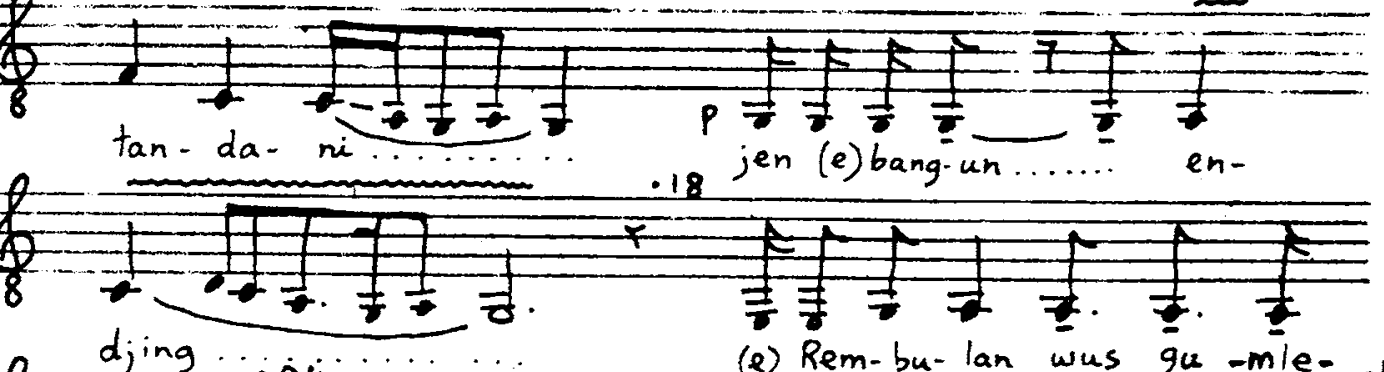

$\overline{7}$

djing $\cdots$

(e) Rem-bu-lan wus ga-mle- -12

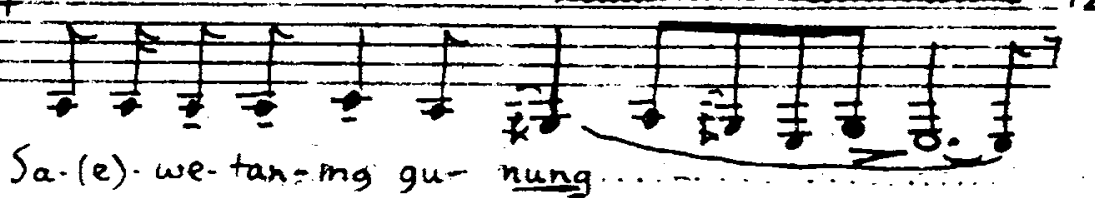

1) The last syllable of each poetic line is underlined.

2) The time-length of each poetic/melodic line is given to the nearest $1 / 100$ minute. 


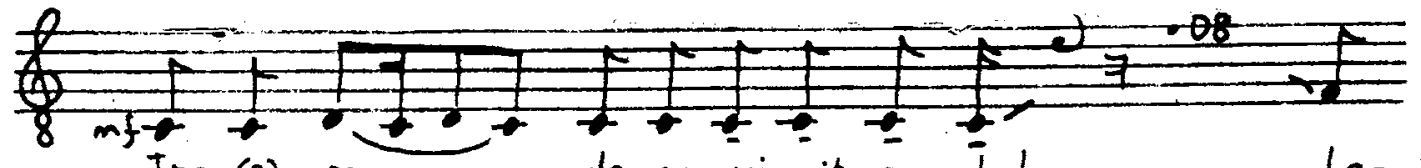

Ing (e) pa-..... de-san wi-wit o- bah La-
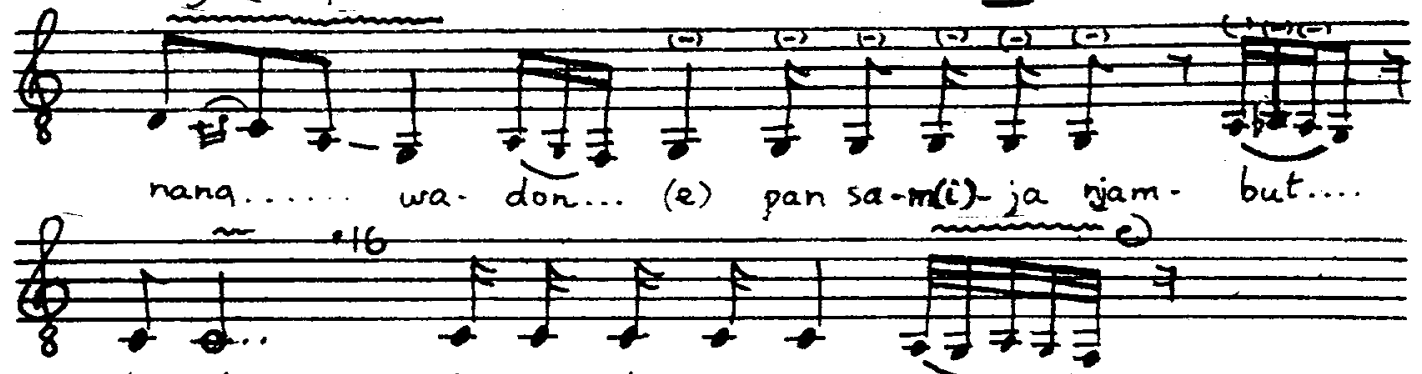

Kar-di A- He-te-pi ku-wa-...

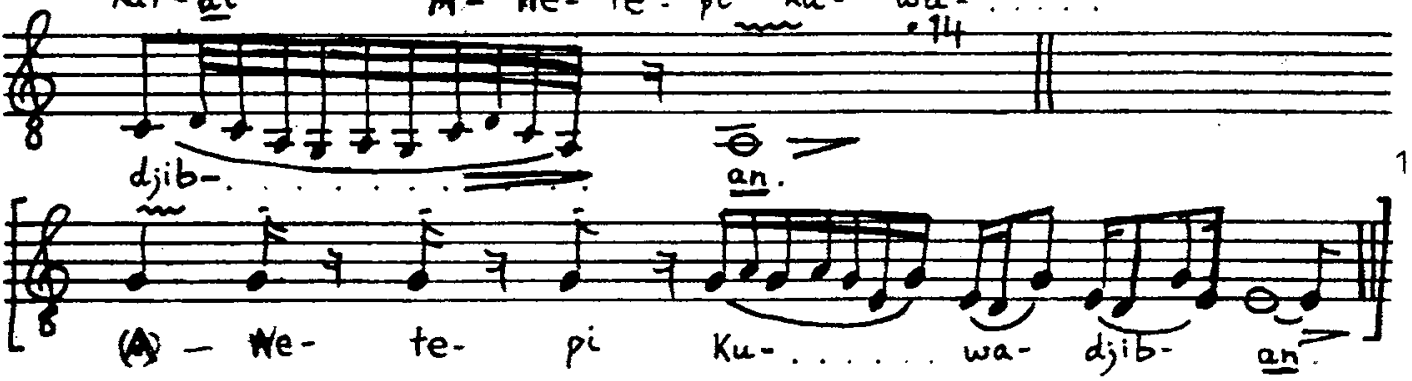

1) This song was performed twice by Sabar who radically changed the final line in the second performance (see bracketed stave above). 
2. SINOM LUGU

SINGER: SABAR

T.I.: $0.90 \mathrm{~min}$.

$0 . P_{\text {: }}$ I tone higher

$(J=104)$

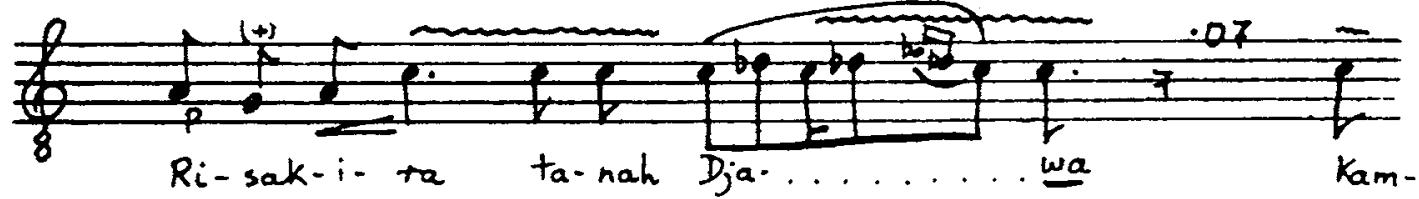

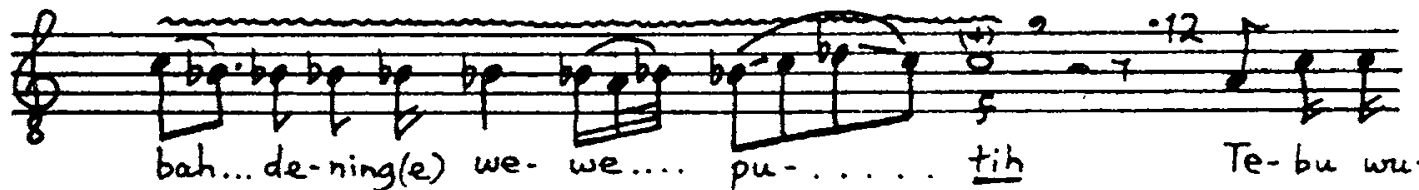
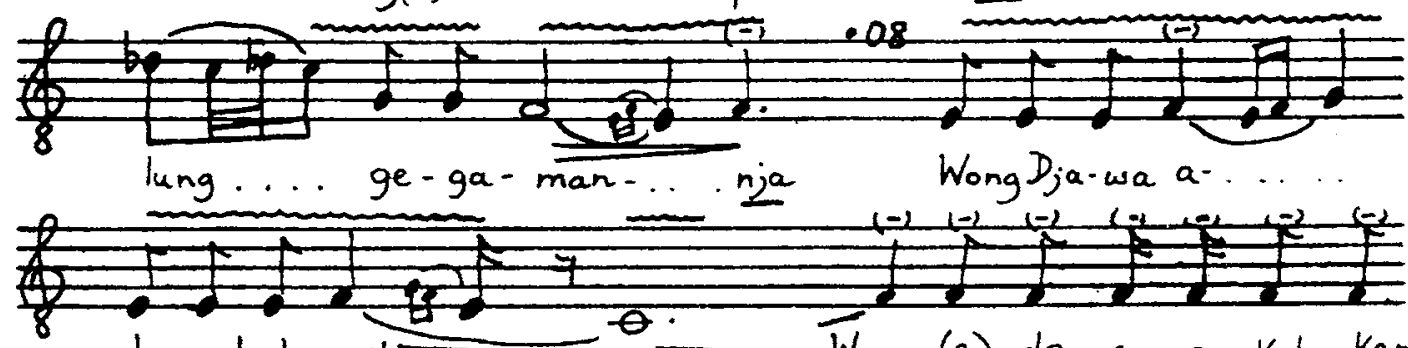

bo-sah-ba-sih Wong (e) de-sa a-keh kang

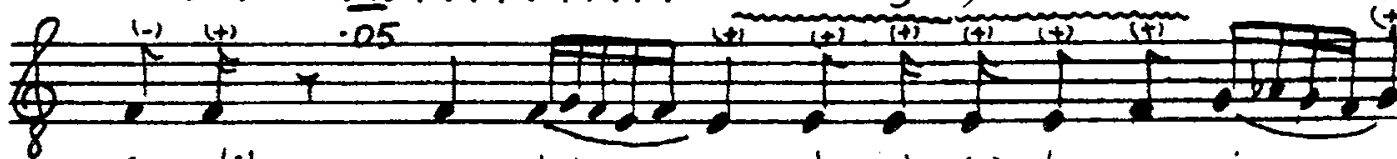

Se-dih ke. let..... de-ning (e) ba-war $i-\ldots$.

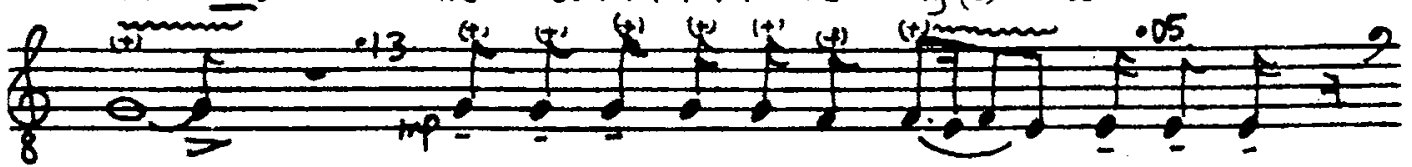

pun... Na-lang-sa mring(e) Dja-wa-...ta an-tuk

sihi-..... ra Hjang(e) Wi- di 


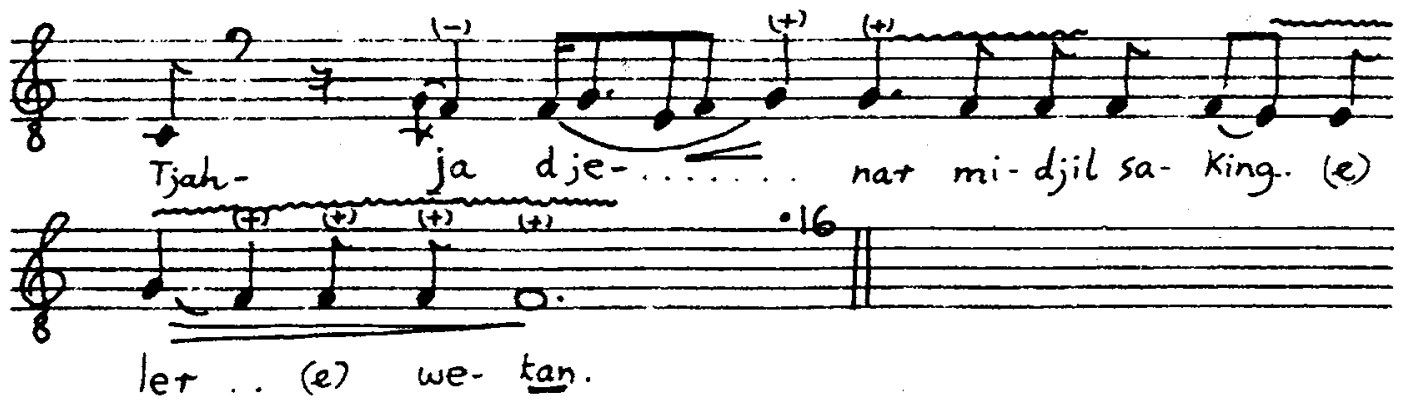


SINGER: SABAR

T.L.: $0.89 \mathrm{~min}$.

O.P.: 1 tone higher

$(\cdot=96)$

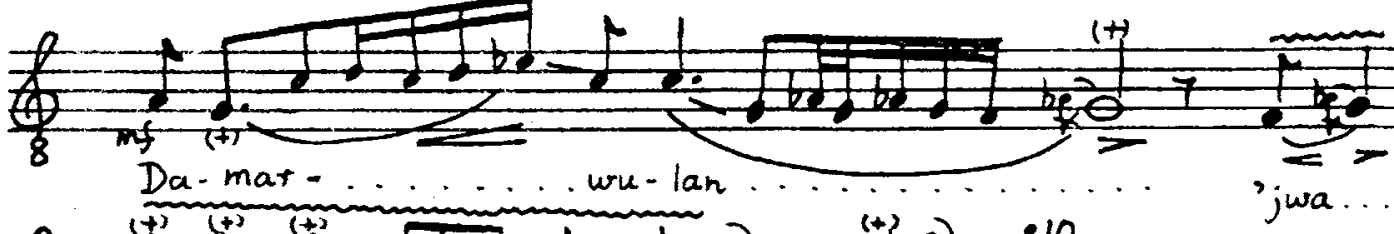

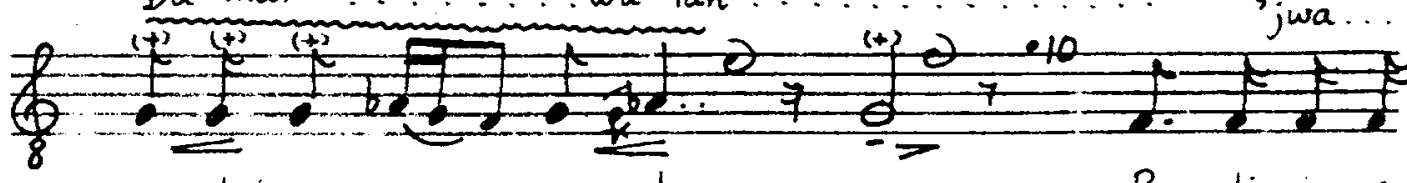

ngu-tji-rengnga- ju-da...... Ba- $\mathrm{l}_{i}$ ja sun

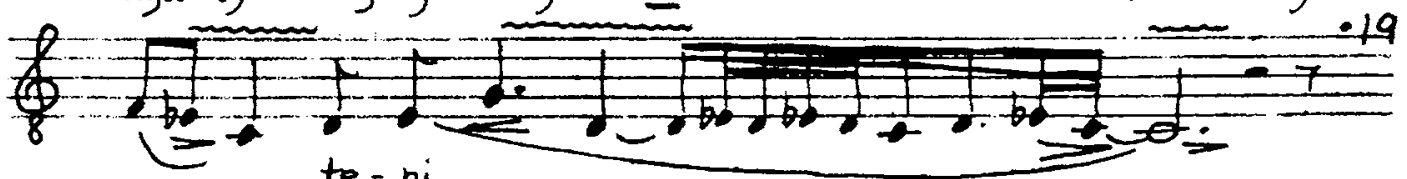

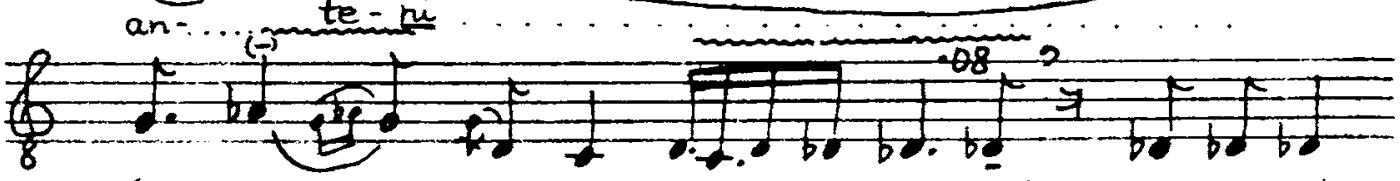
Sun mang- sa mun-dur-..... a Lah Bis-ma den

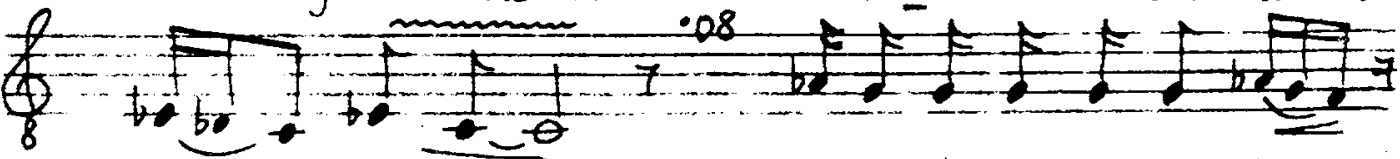
2. pra-im jit $\quad$ ka-t. ban (e) pu-sa.ka

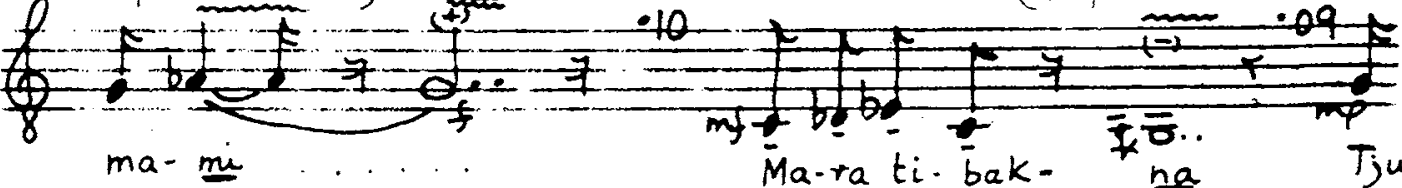

Ma-ra ti.bak- na Tju -

\& $1-1+1)+15$

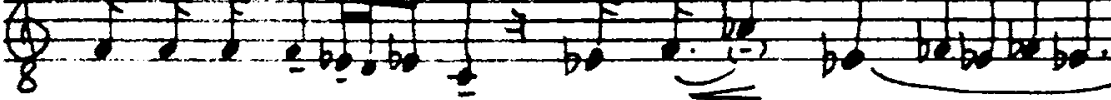
Ti-gan-i-ta

nu-li.. nu. $\frac{\underline{\underline{l i}}}{\underline{\underline{\underline{i}}}}$ 
4. ASMARANDANA

SINGER: SABAR

T.L.: $0.63 \mathrm{~min}$.

O.P.: $1 \frac{1}{2}$ tones higher

$(d=98)$

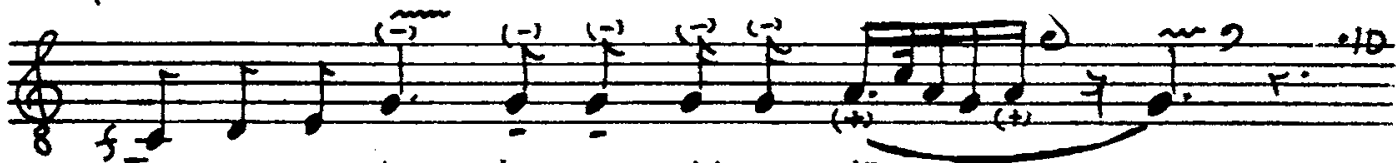

${ }^{f} T_{j i}-n a-t_{i}-t a \quad$ lang-kung (e) pe- Kik.

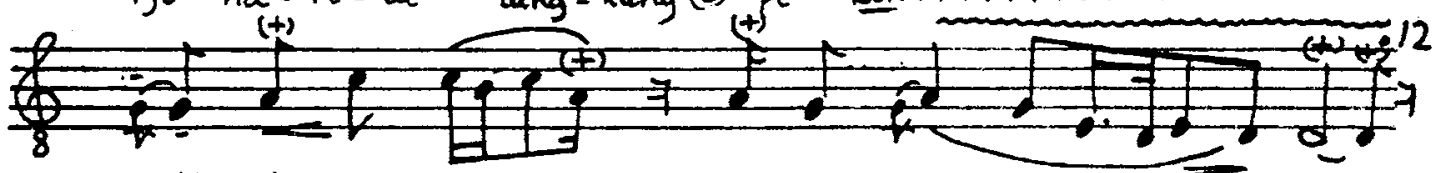

(e) $\mathrm{Na}-$ bi Ju-sup... na-ma-ni-....... na...

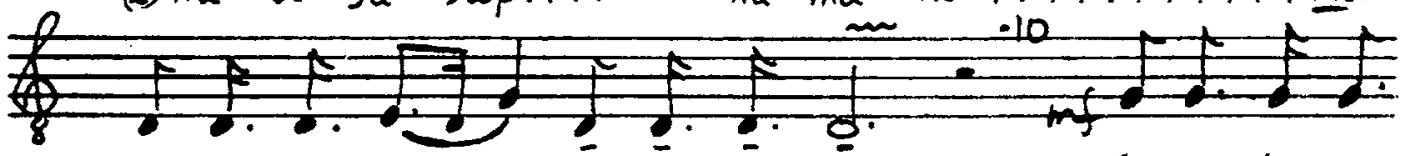
Tan-pa tan-ding-... an ba-gus-e
Sa-i-ter-ing

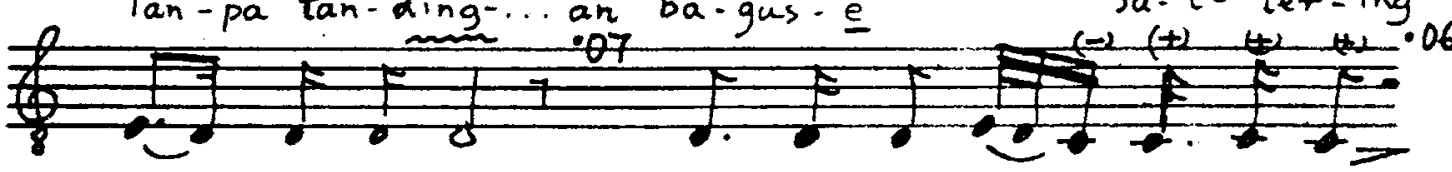

Kang.. bu-wa-na Tan won-ten Kang... Ku-tji-wa
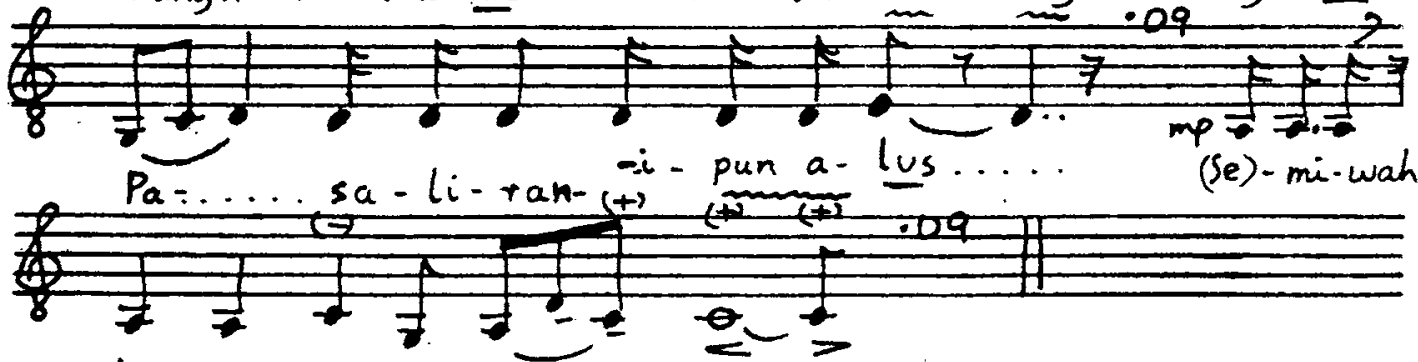

ing pa-kar.ti. ni..... $\sum_{\text {ra..... }}$ 
5. MIDJIL LUGU

SINGER: SABAR

T.L.: $1.0 \mathrm{~min}$.

O.P.: as below

$(d=67)$
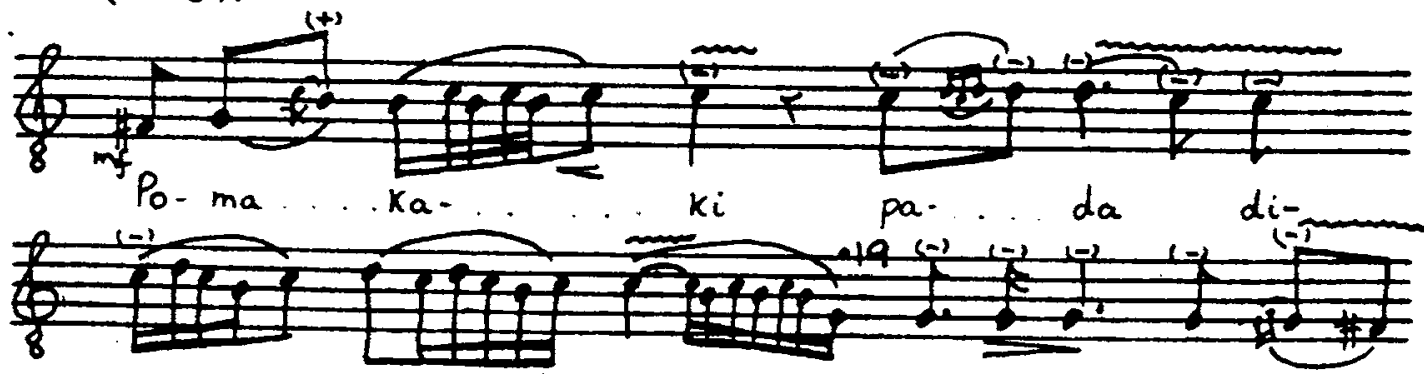

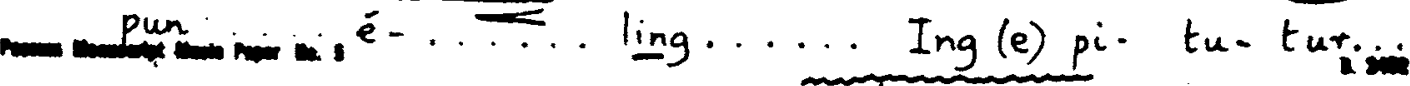

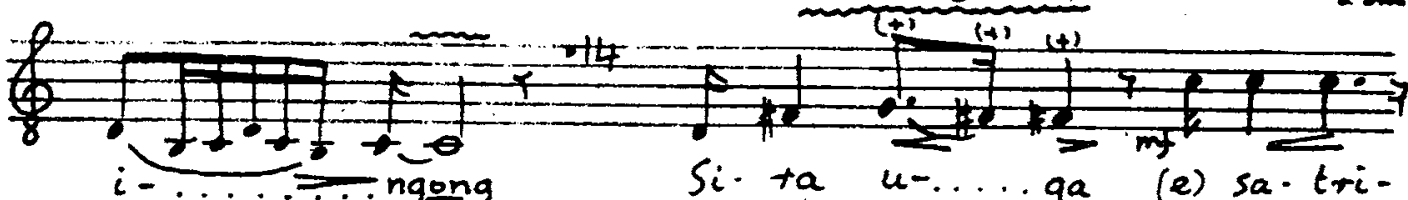

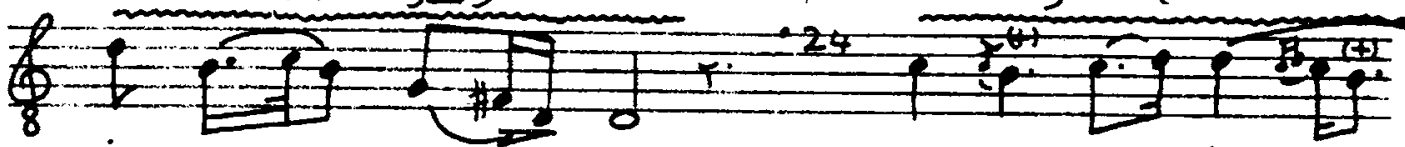
ja $a-\ldots . .+a-\ldots .$. ne $\quad K u$. du $a_{n} \ldots$ teng....

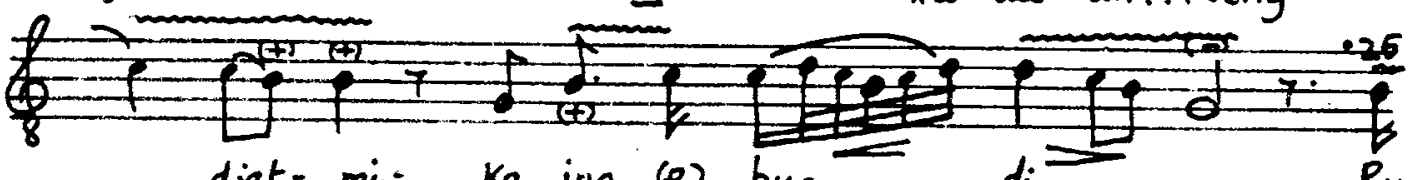
$\ldots$ djat...mi- $k_{a}$ ing (e) bu. .... di...... $R_{u}$

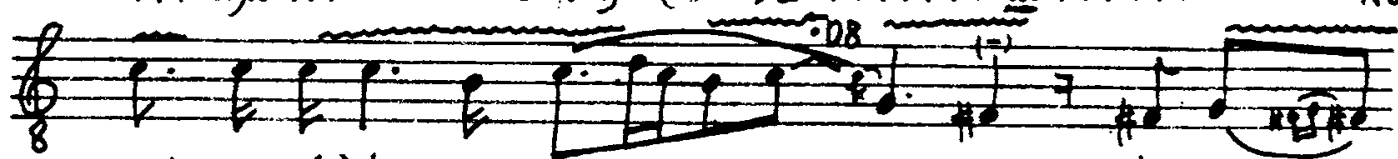
ruh sar-(e).ta wa- sis...... sa-mu- ba. rang-..

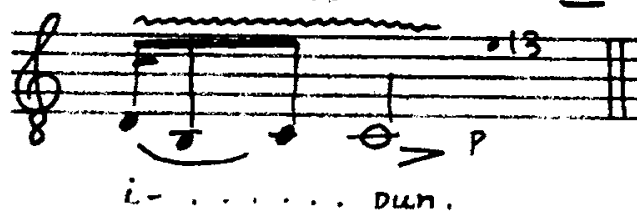




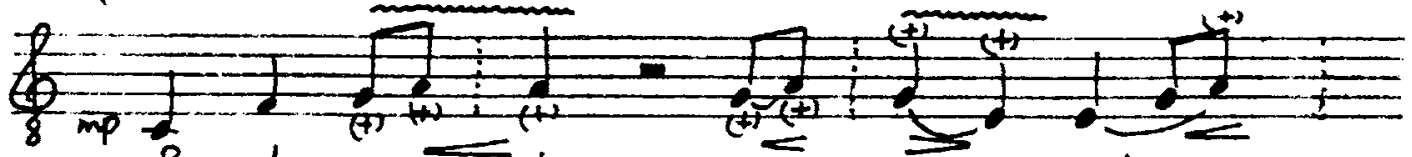

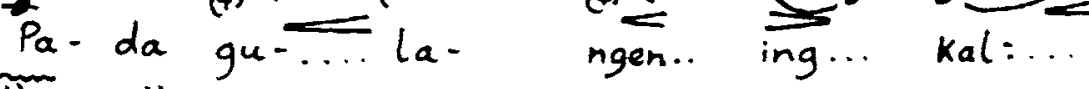

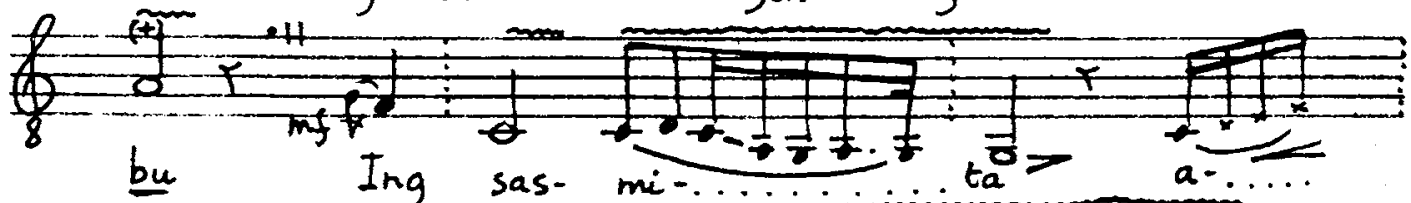

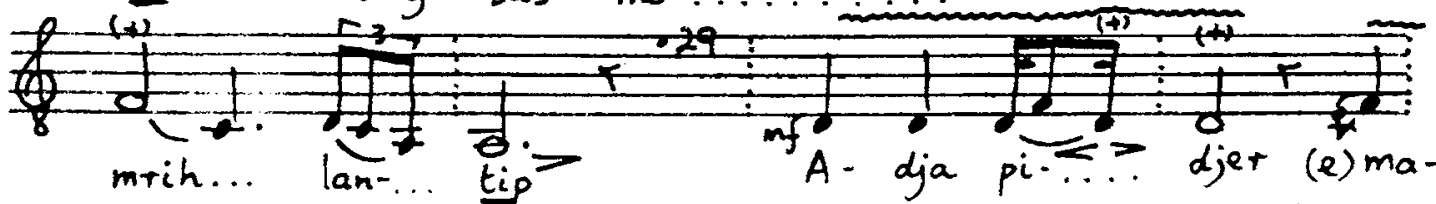

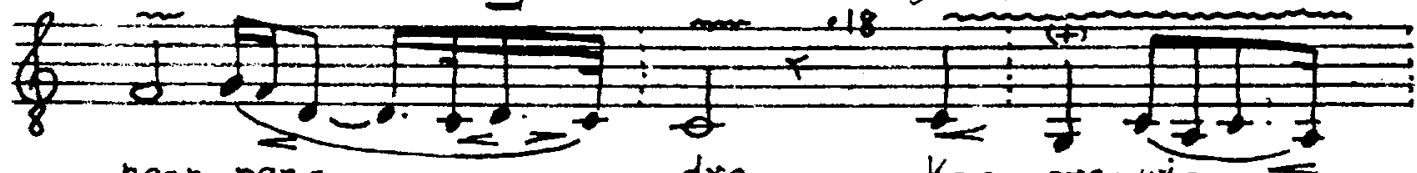
ngan nen -

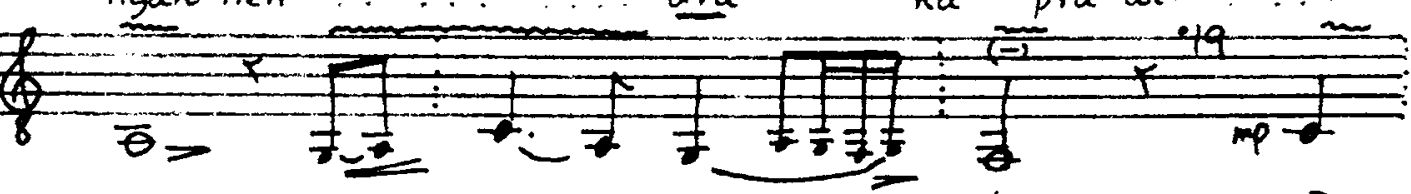
tan den... Ka....es .......ti Pe-

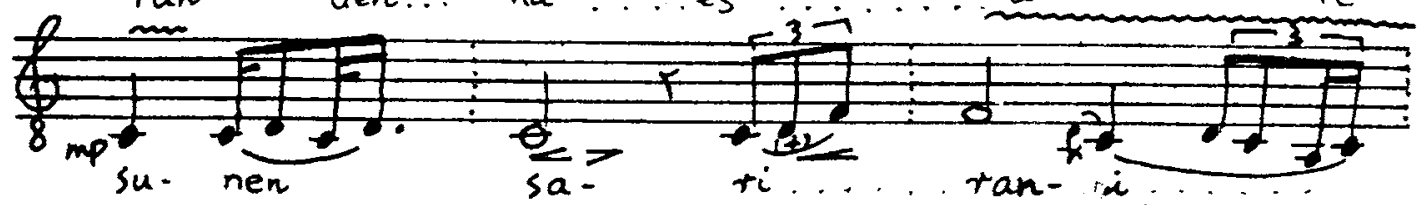

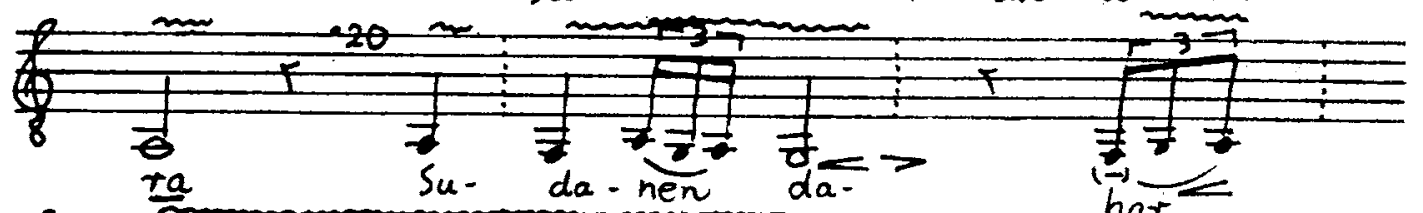

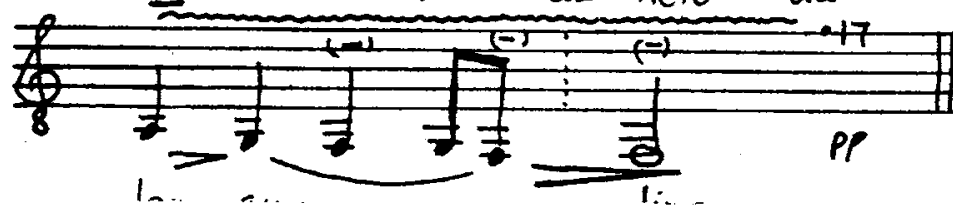


7. PUTJUNG

SINGER: SABAR

T.L.: $0.38 \mathrm{~min}$.

O.P.: $1 / 2$ tone higher

$(d=83)$

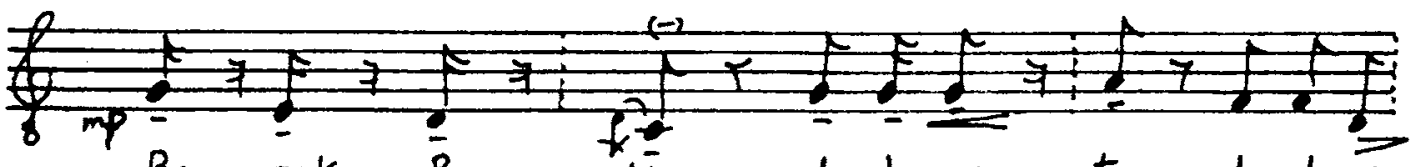

Ba. pak $\bar{P}_{u-}$ tjung du-du wa- tu $d u \cdot d u \overline{g u-}$
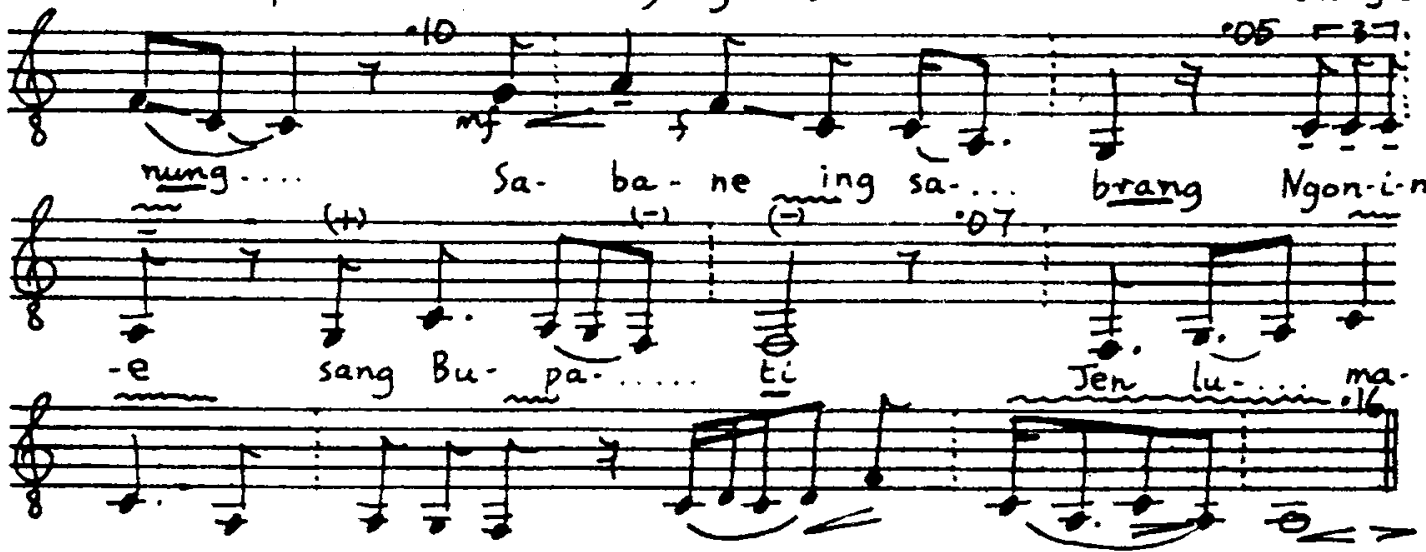

Ku si Pu-tjunglim- be $\ldots . .$. jan gra...... na 
8. PUTJUNG

SINGER: SABAR

T.L.: $0.35 \mathrm{~min}$.

O.P.: $\frac{1}{2}$ tone higher

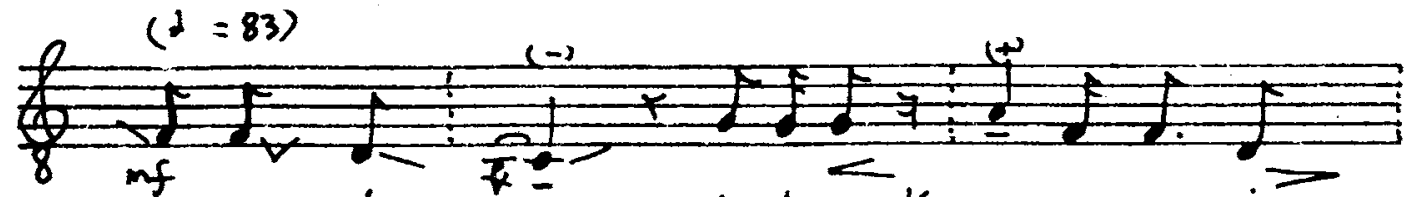

ka-mu. la. ne mo ka-lu-wak nom-nom-an-i=

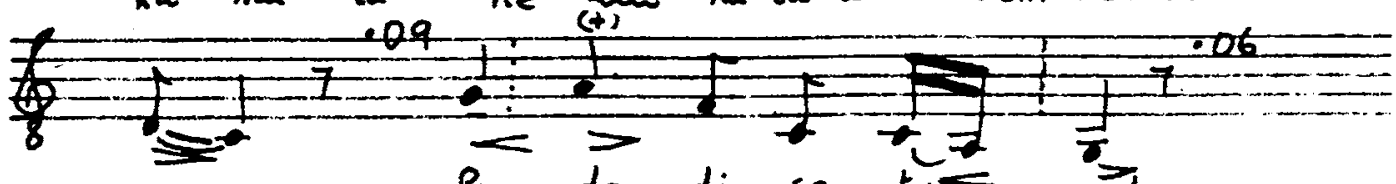

pun ...

Pan da. di sa. tung gal
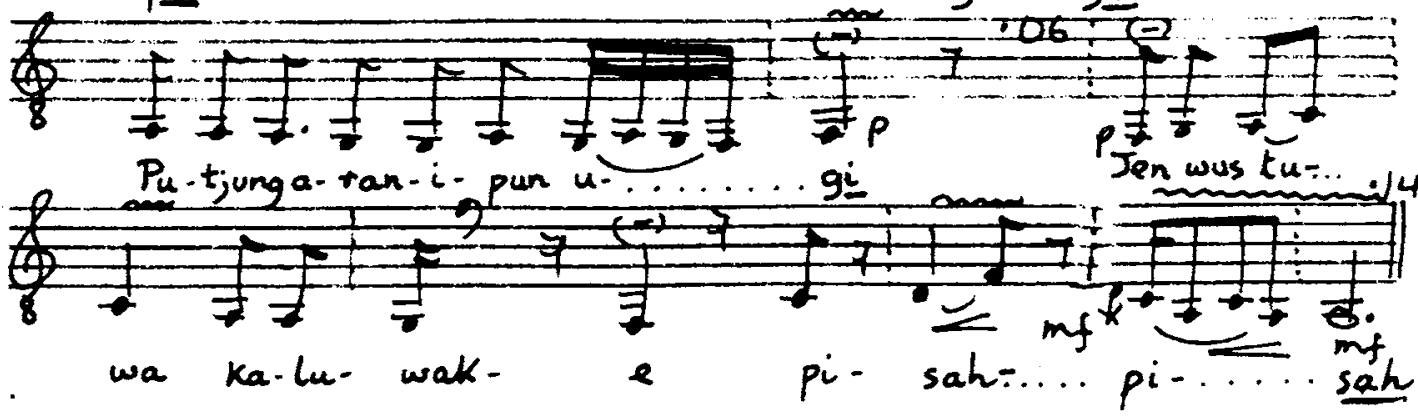

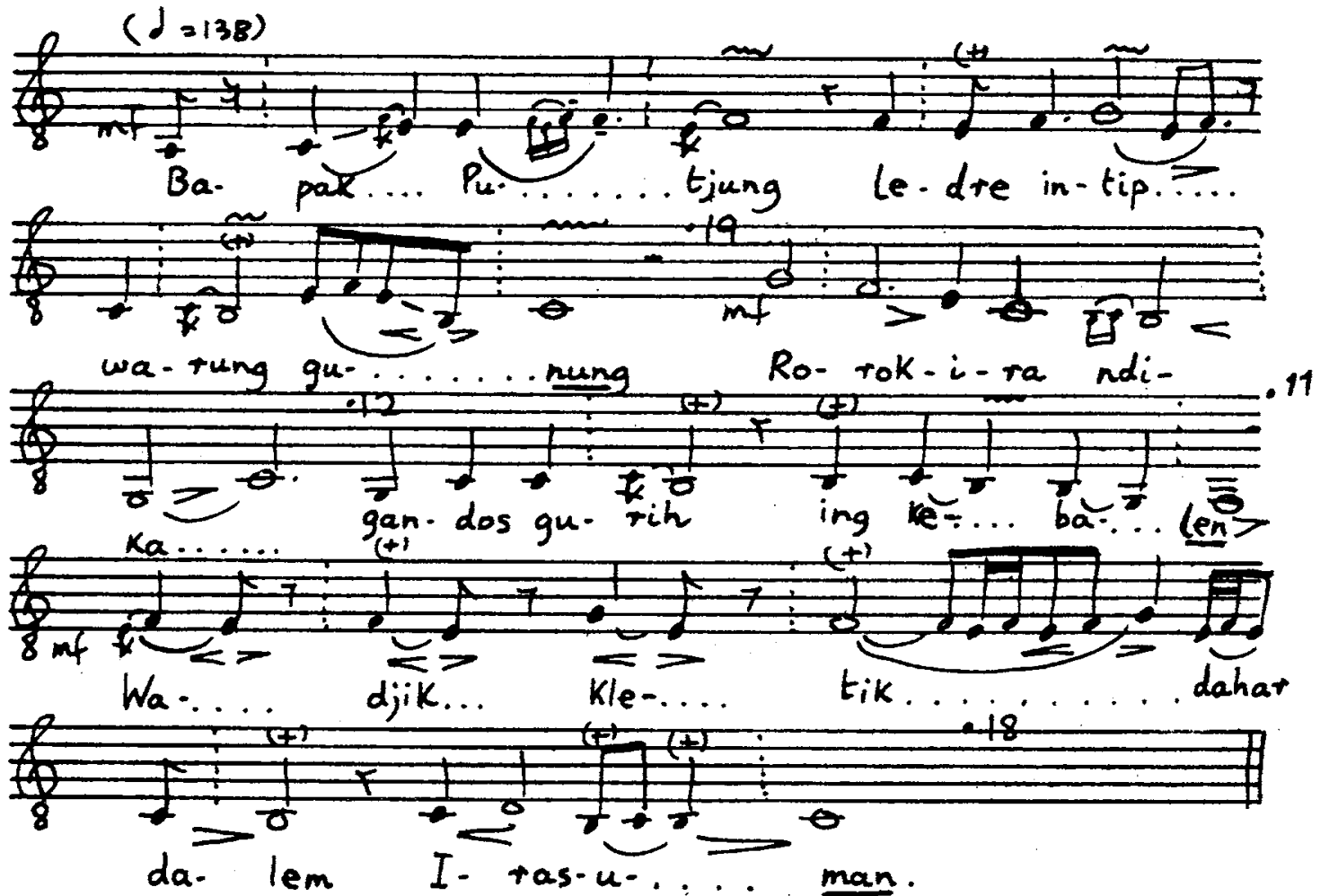


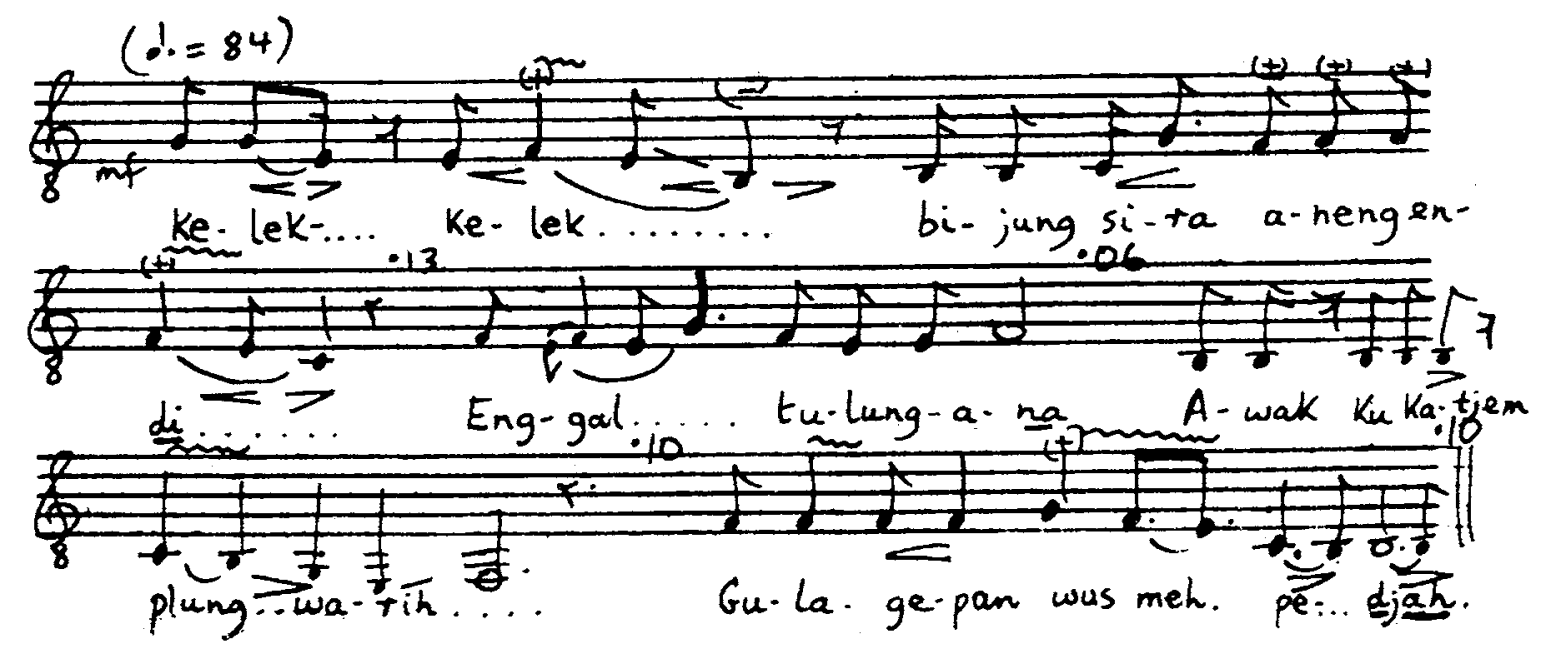


11. SINOM PARIDJATA

SINGER: SABAR

T.L.: $1.61 \mathrm{~min}$.

O.P.: as below
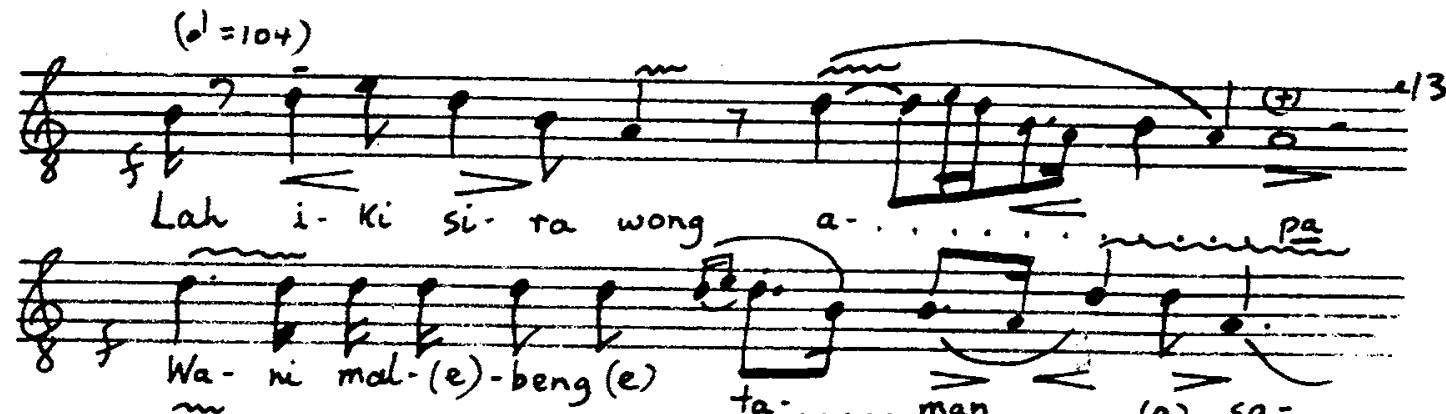

(t)

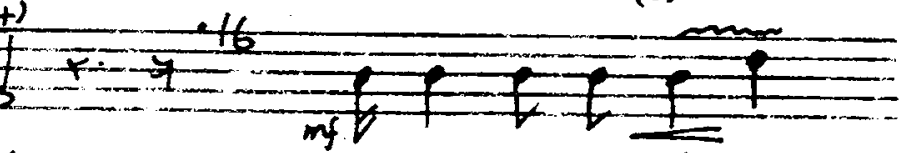

.............

(E) ru-pa-mu ba-gus

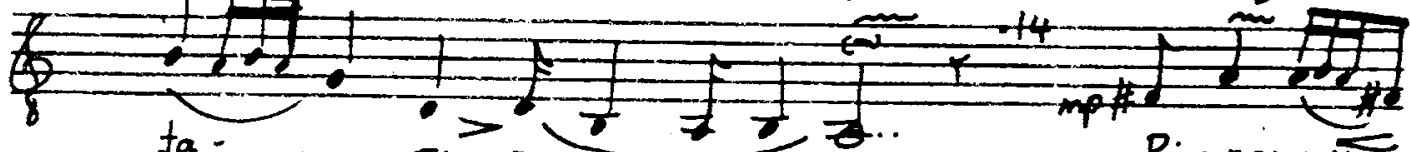

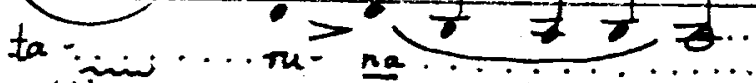

$P_{i}$ - nang $\overline{k a n}$

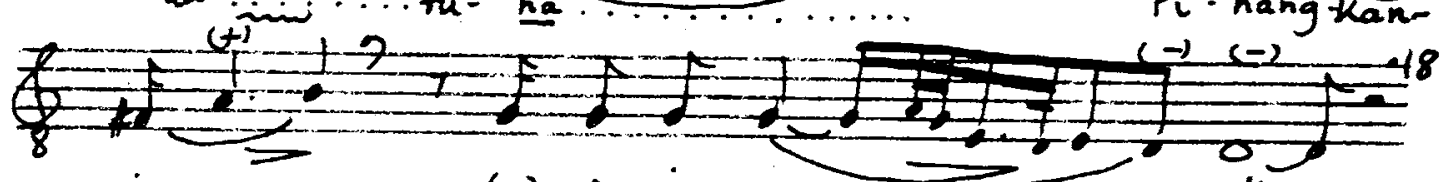

$i \ldots \ldots \ldots \quad$ (e) - ta ing $e_{n} \ldots \ldots$ di ...

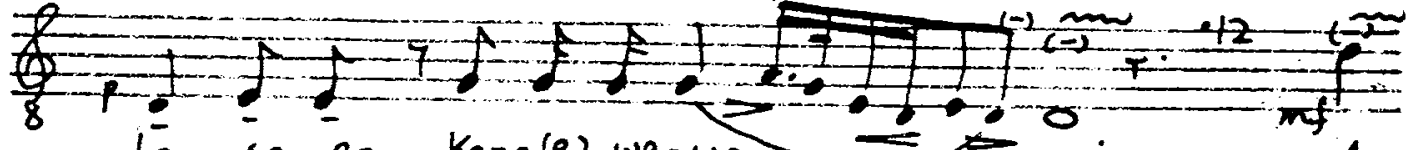

Lan sa-pa Kang (e) we-wa...ngi A-

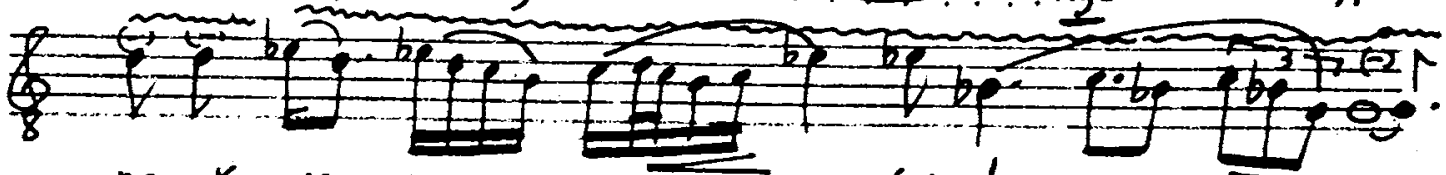

nga-Ku-wa.. mum =... pung ........ (e) du-........ rung

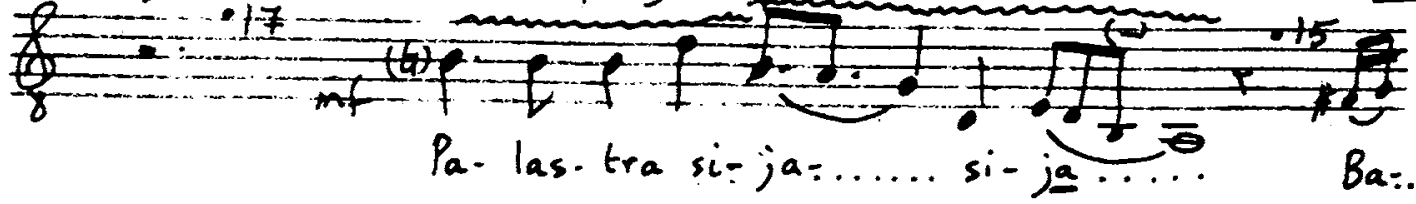



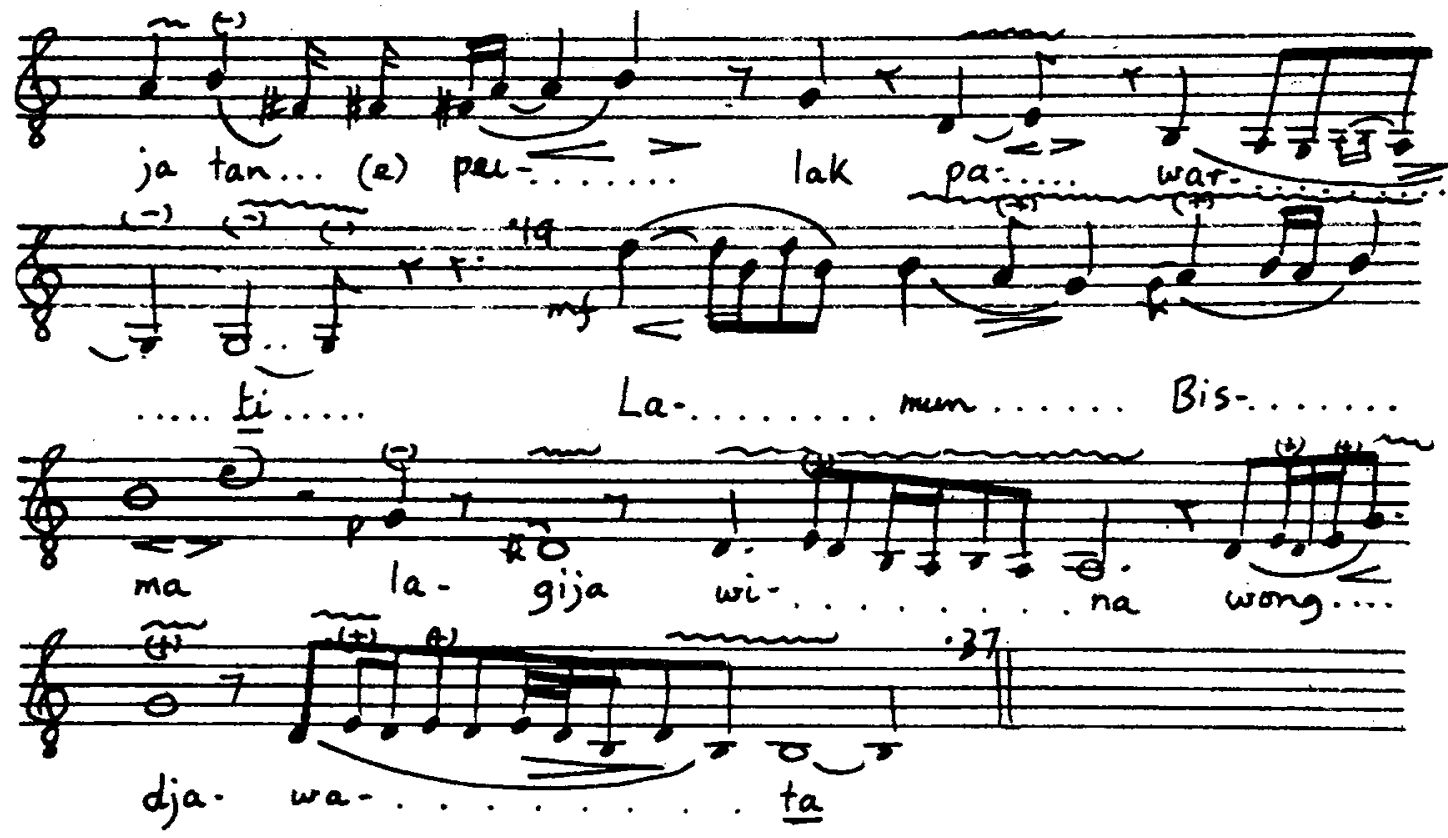
12. PANGKUR MATJAPAT (Lugu) STNGER: SABAR
T.L.: $0.98 \mathrm{~min}$.
O.P.: as below

(d. $=95)$

Ming-Kat-ming-Kur ing ang:F, Ka-

Af

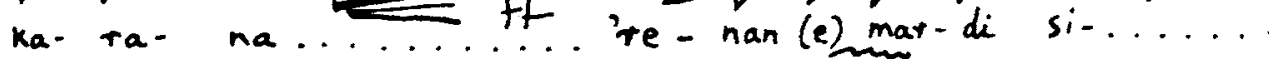
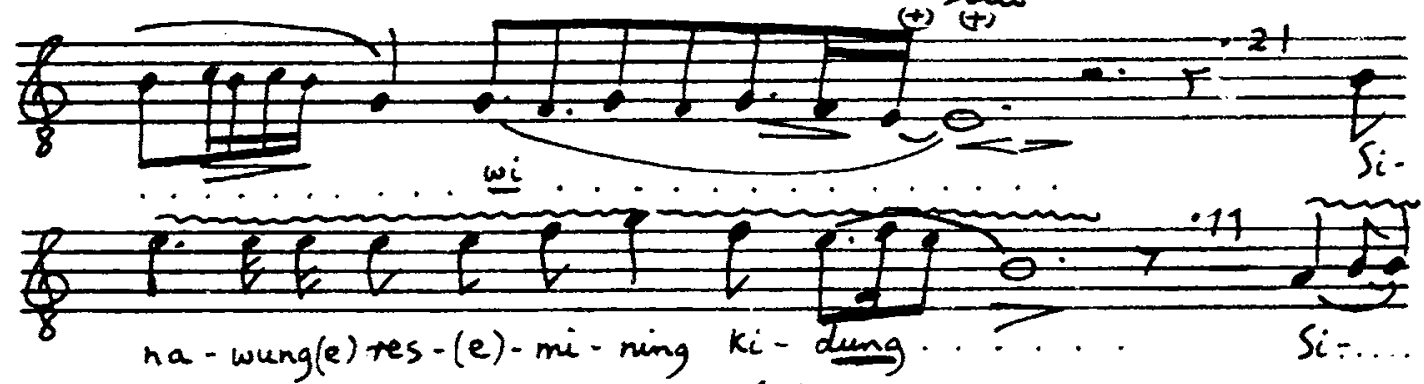

$x_{0}$

$m$ - ba $S_{i}-n_{u} \ldots . . k_{a r}$ ta $\quad M+i h \quad k r e-t a r=.$.

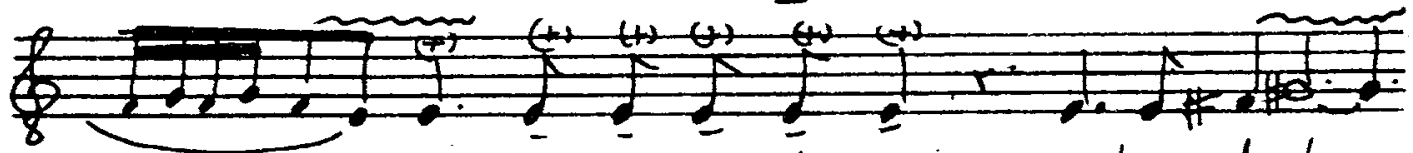

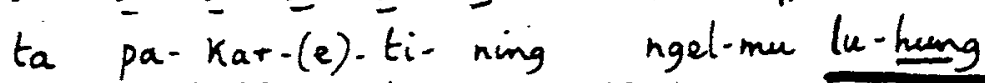

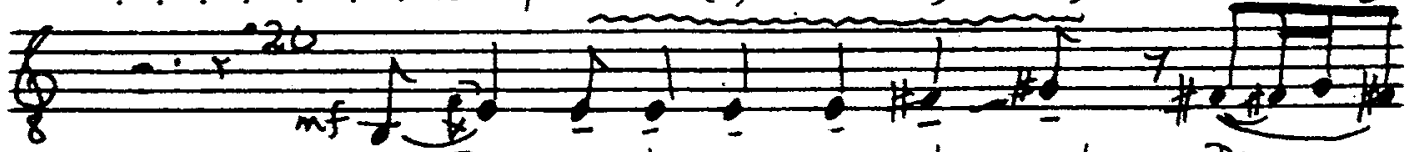

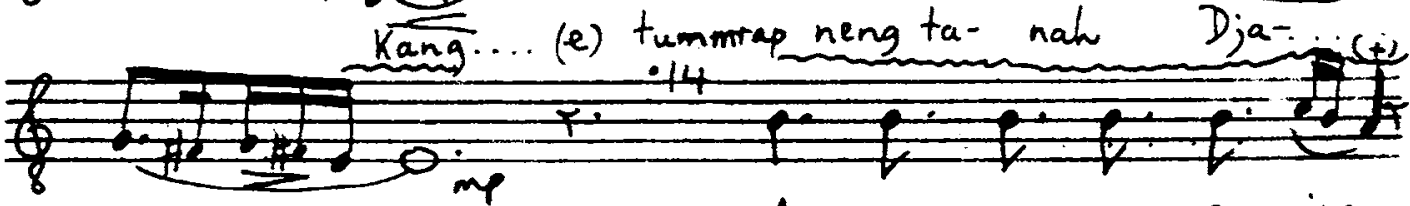

wa. A-ga- ma a-gem-ing..

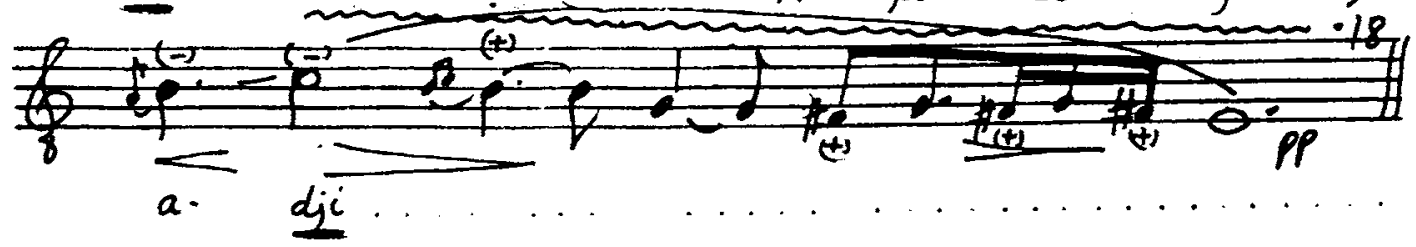


$(d=110)$

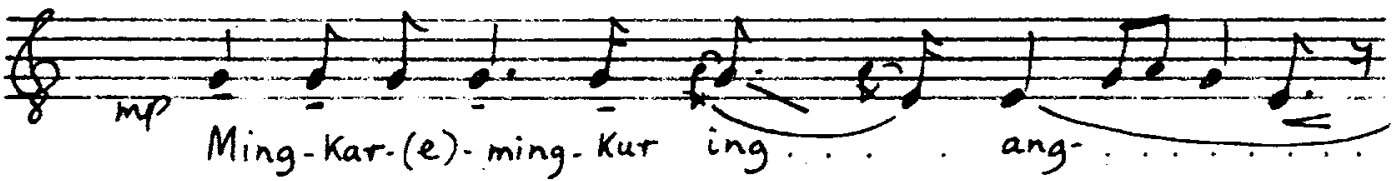

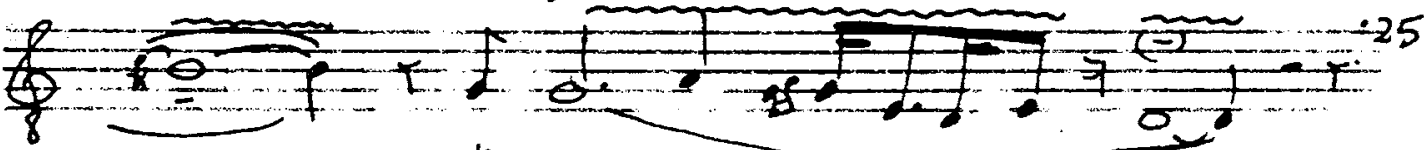
ka. ta

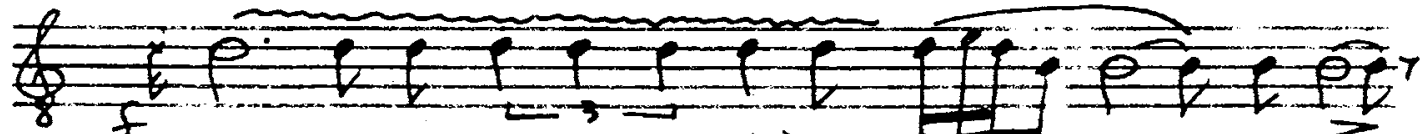

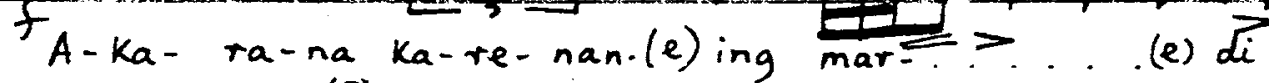

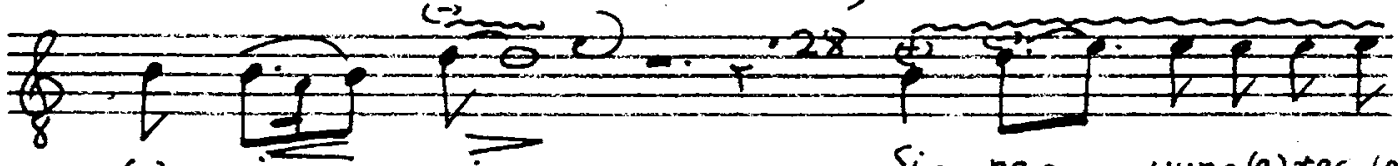
(e) si Si $_{i}$ na $\ldots$ wung $(e)$ res- $(e)$.

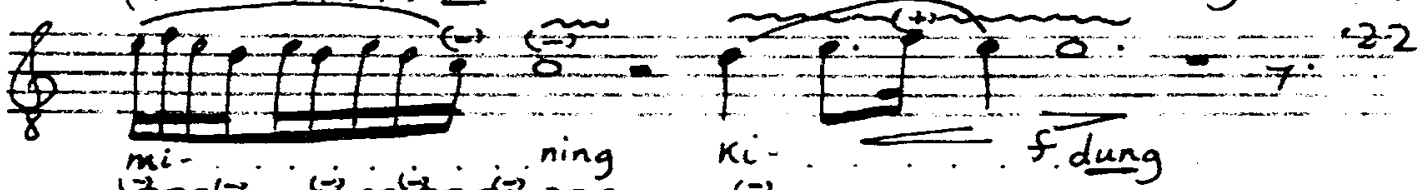

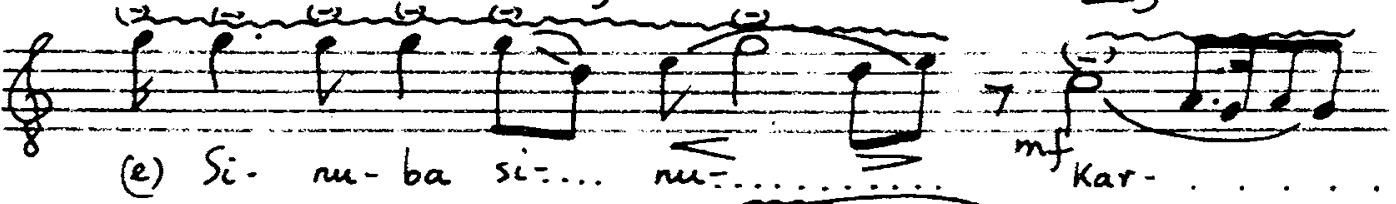
ta... M-rih Kre-

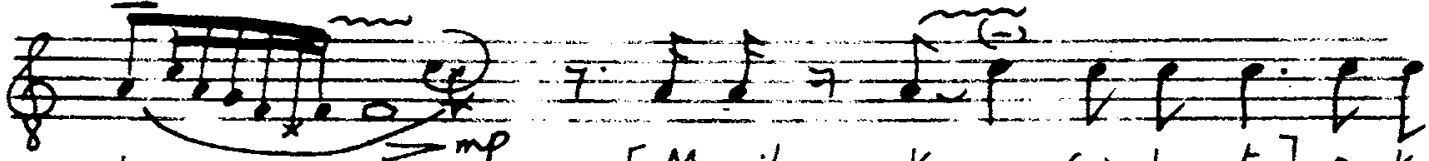
ta. [M.rih Kre-... (e) tar-ta] pa-kar- 


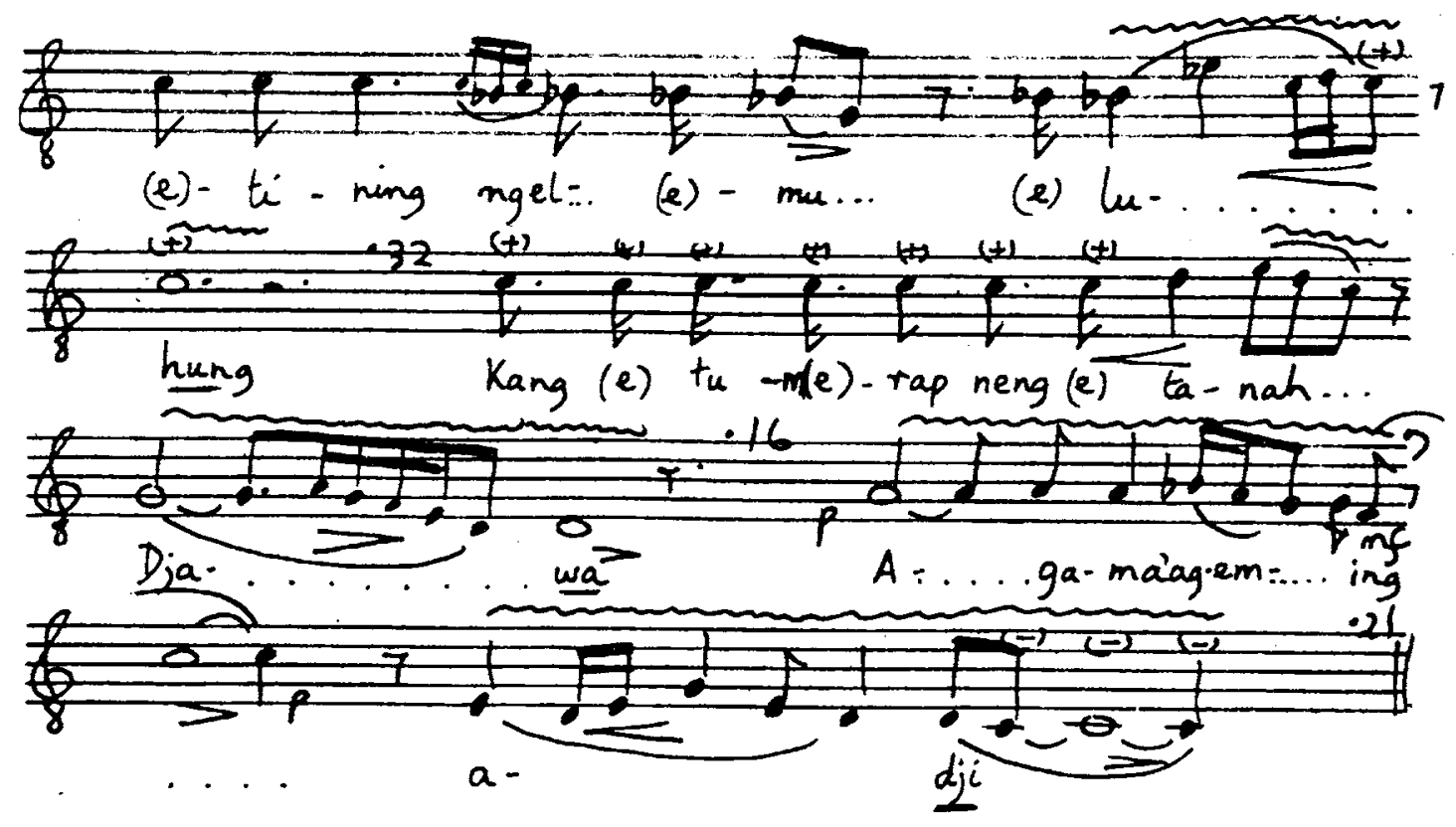


14. KINANTI SAINDUNG

SINGER: SABAR

T.L.: $0.63 \mathrm{~min}$.

O.P.: $\frac{1}{2}$ tone lower
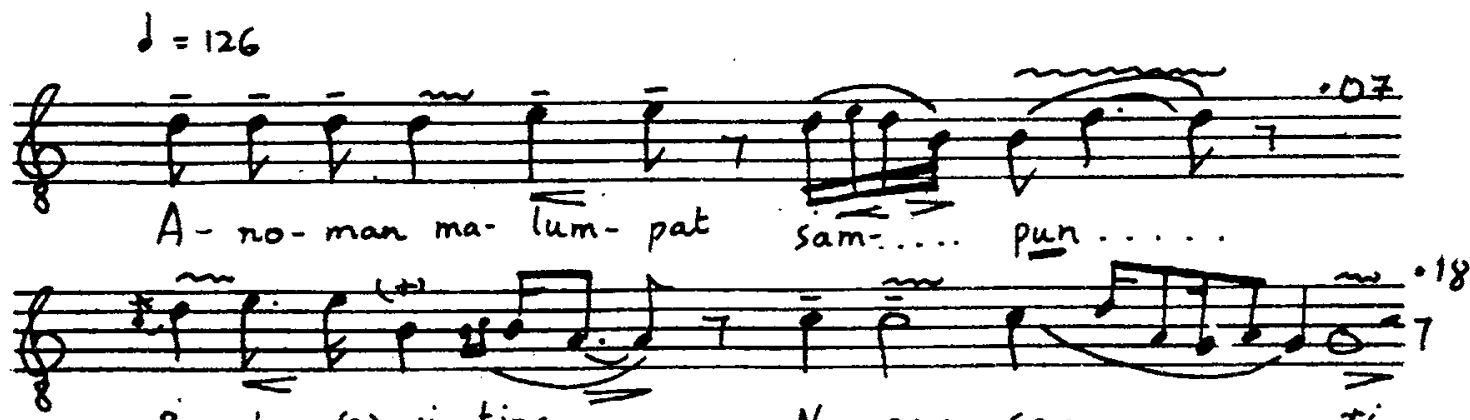

Prap-tengle wi-ting... $\mathrm{Na}$-ga- sa.......

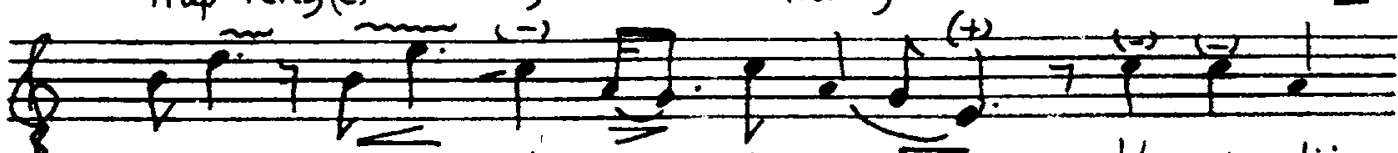

Mu-lat mang-an-dap $\overrightarrow{k a}: . . t i$-ngat... Wa-ma-dija
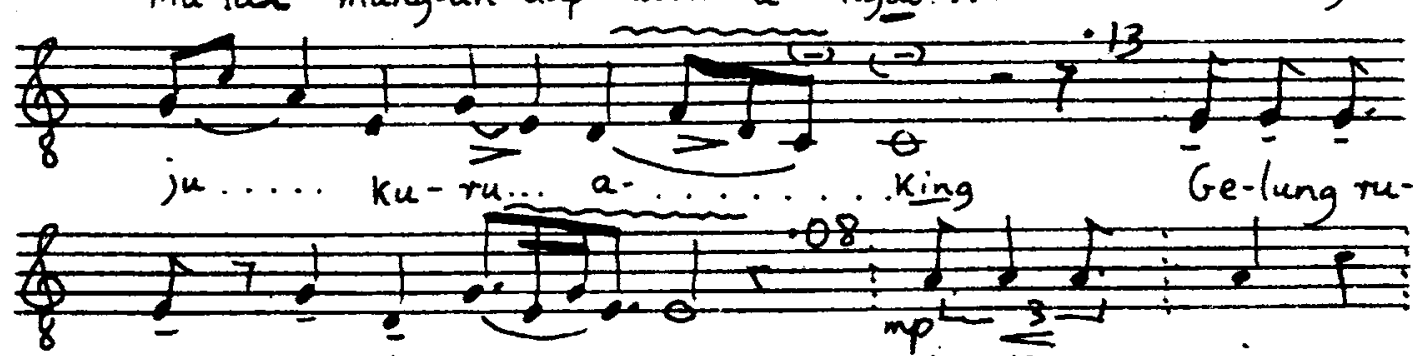

sak 'wor lan Kis-... ma kangi-ga- i-ga

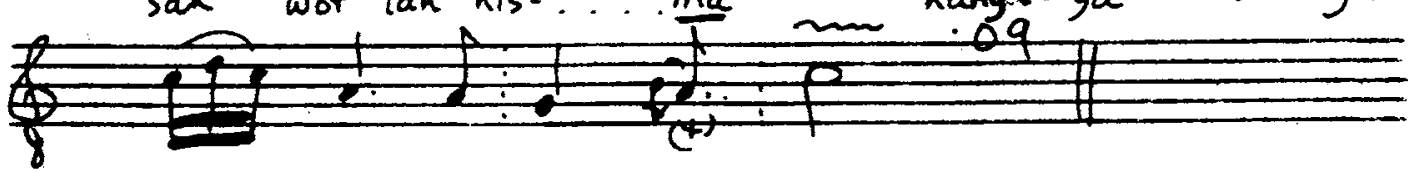

$\mathrm{Ka}$. ek (e) sc 
15. DURMA RANGSANG

SINGER: SABAR

T.L.: $0.67 \mathrm{~min}$.

O.P.: 1 tone lower

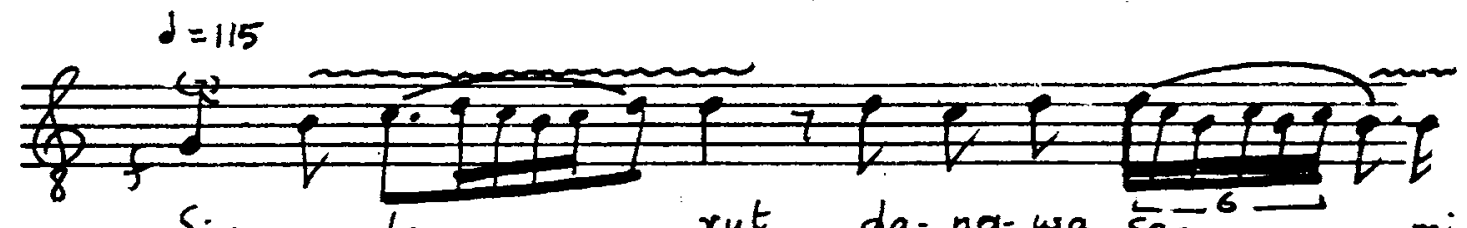

Sir-no la-..... rut da-na-wa sa- . . . mi(1)

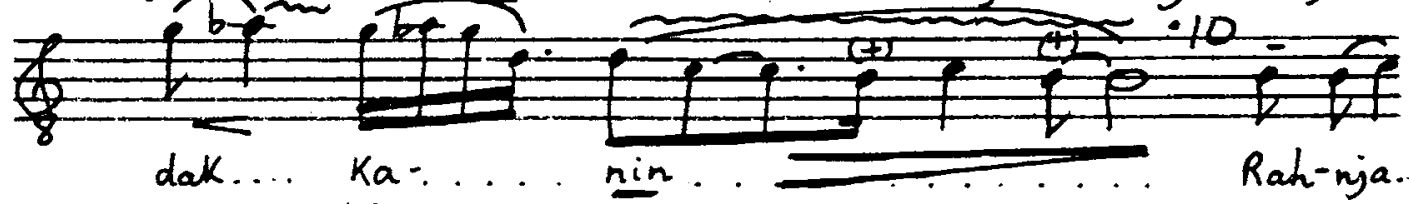
$\frac{(+)}{\text { bang be - la - bar }}$

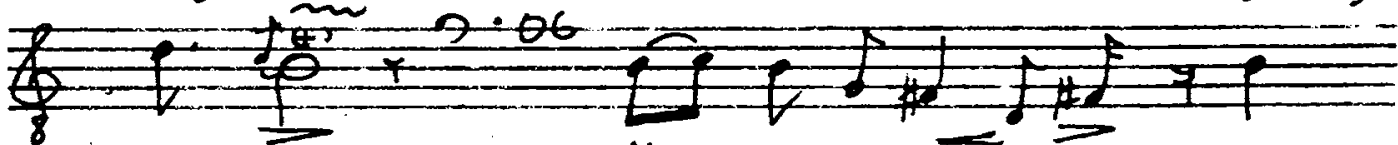
ti- ja Mu-..suh-nja $\tan a-m a$ prap-

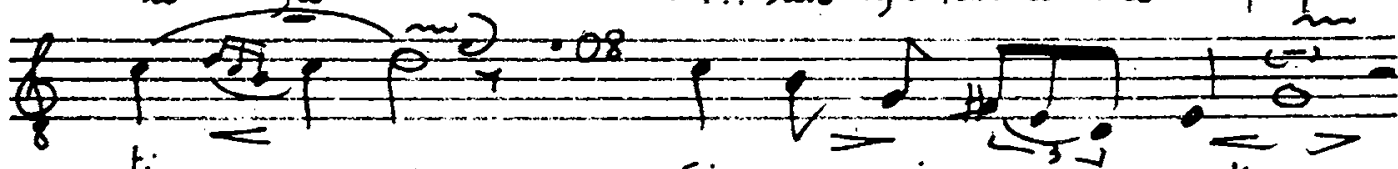
占. Si - gro ti- ne -... sak...

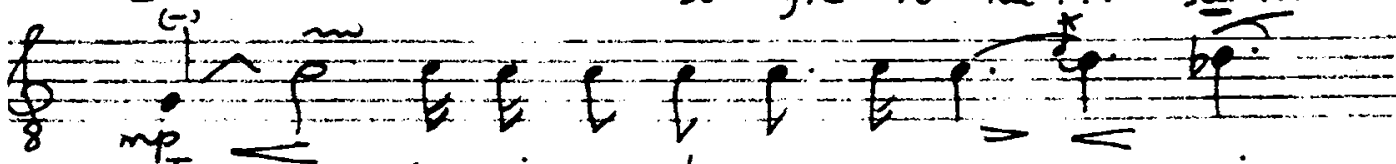
Ing $\ldots . .$. (e) si- ne ta. man (e) $s a-\ldots . .+i$ \& 

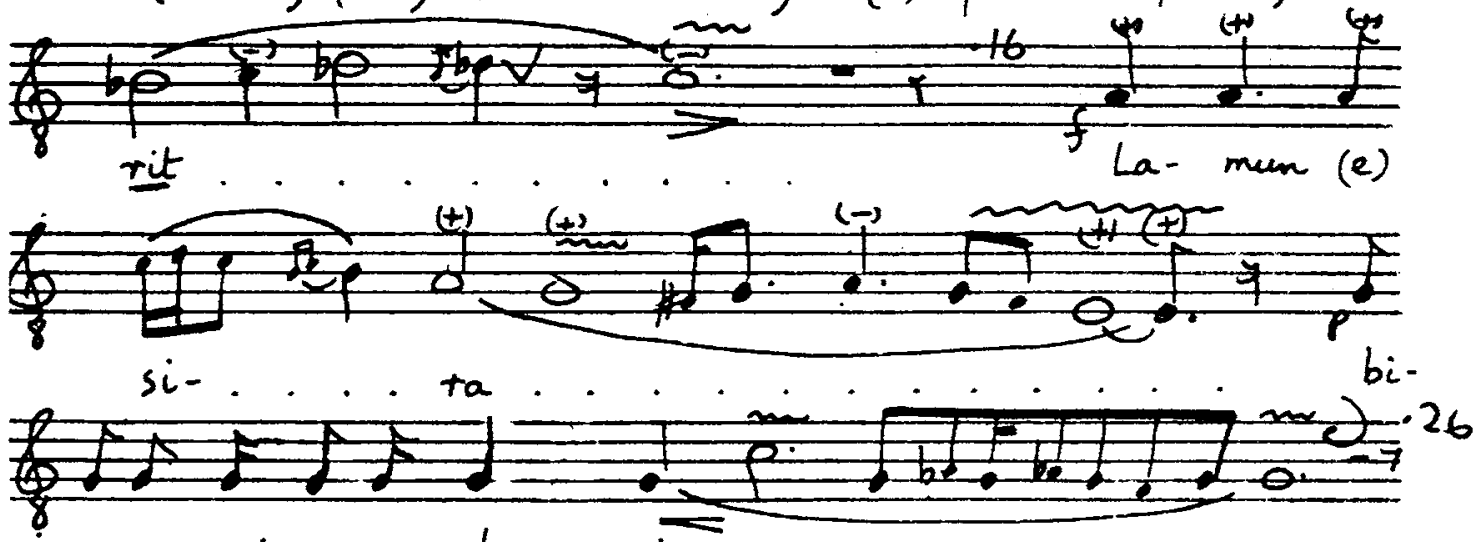

sa sa-mi a. nu-la-

da

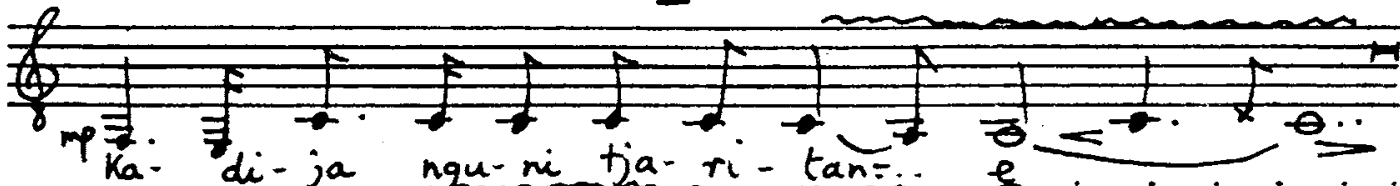

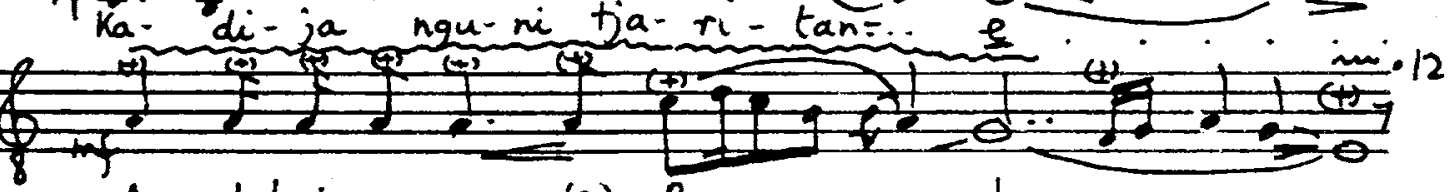

An-del-i ra sang (e) Pra-..... bu

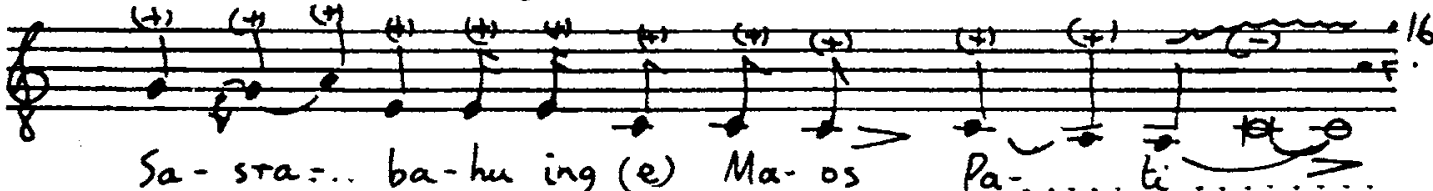

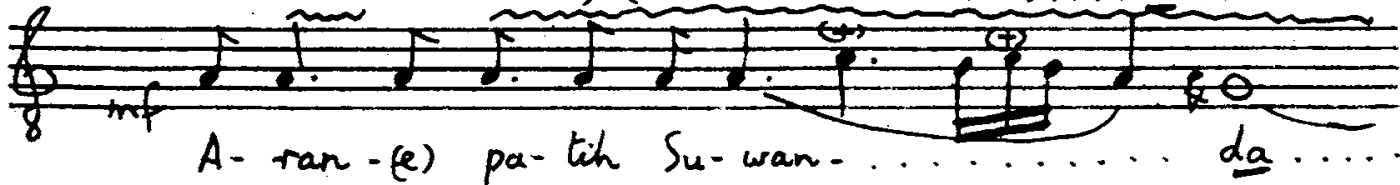




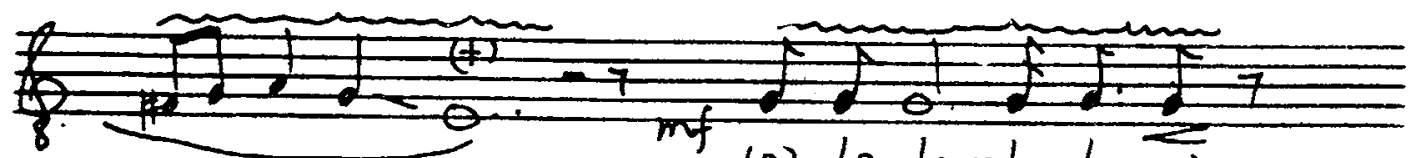

(e) Le -la-bu-han-i-
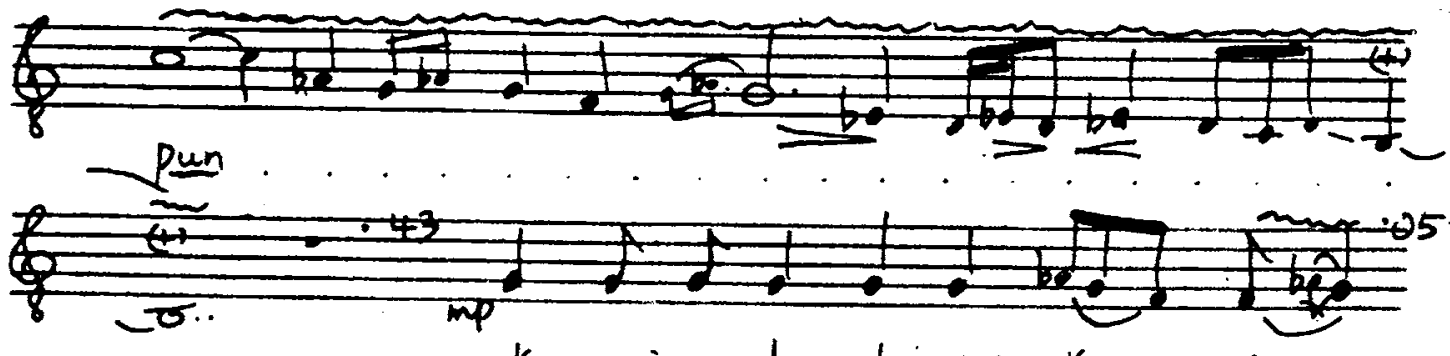

kang gi-ne-lung tri prea-ka $K_{a} .$. ra..

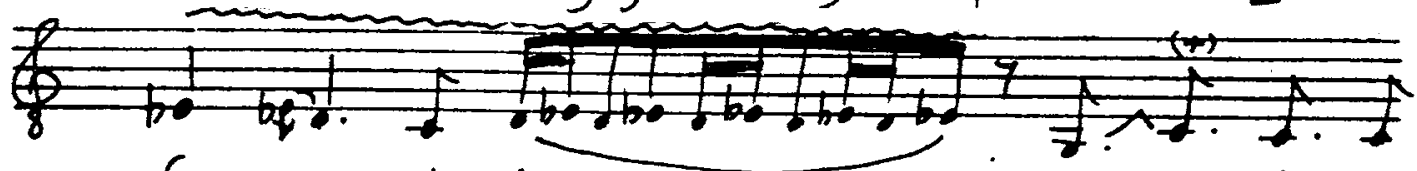

Gu. na ka-ja............ pu-run ing-kang

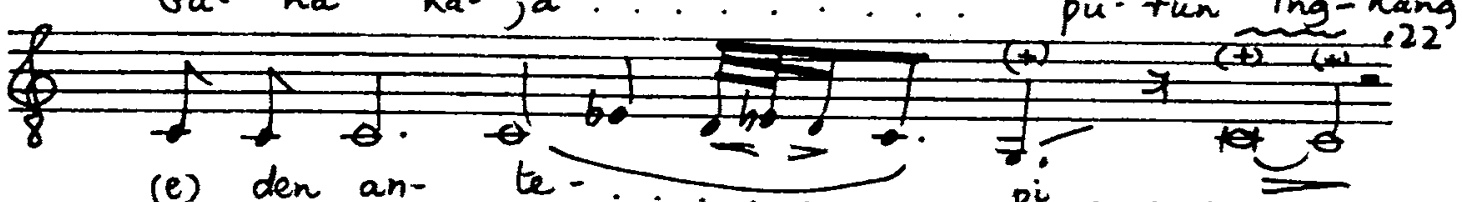

(e) den

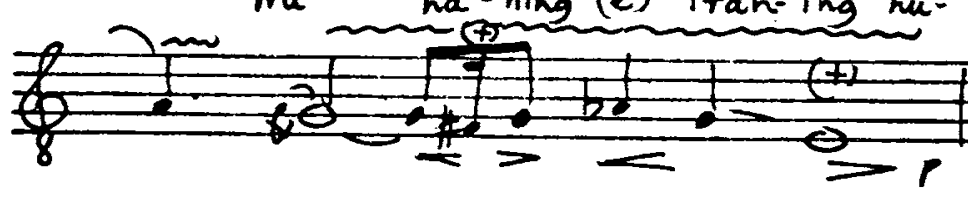




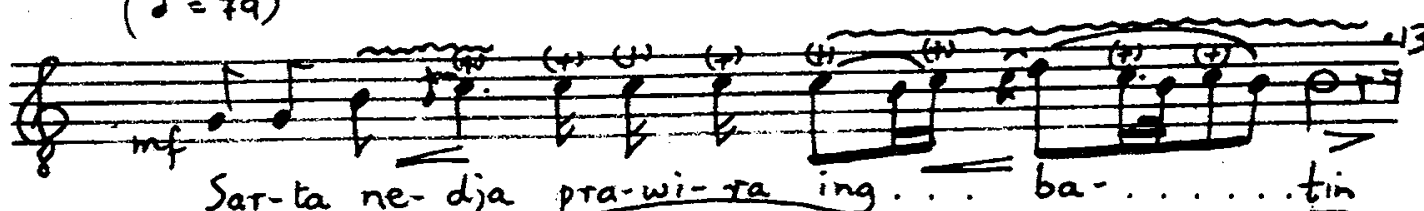

$$
\text { Sar-ta ne- dja pra-wi-ra ing. }=b_{a} \ldots \ldots \text { tim }
$$

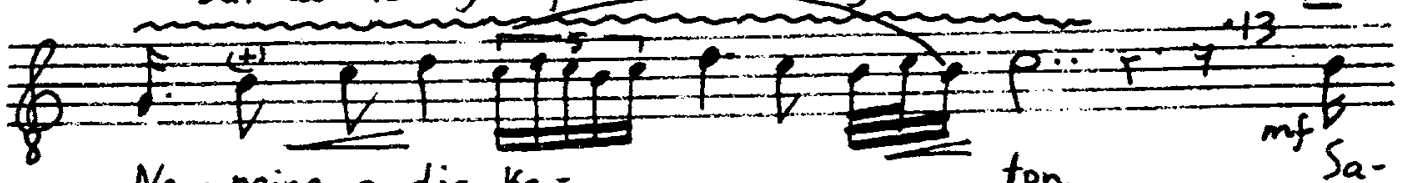

$\mathrm{Na}$. nging a-dja $\mathrm{Ka}-. . . . .2$ ton

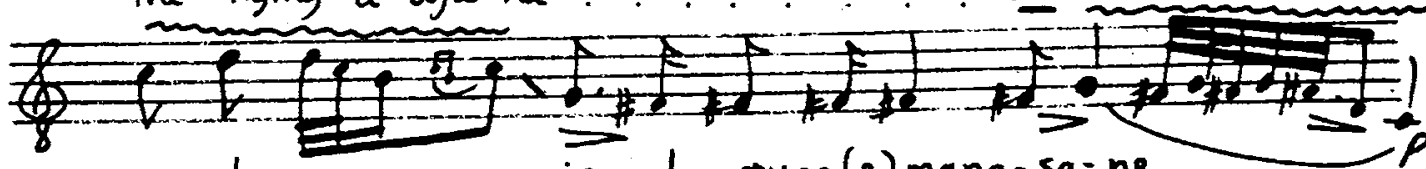

sa-ba-na.. jen du-rung (e)mang-sa-ne . P

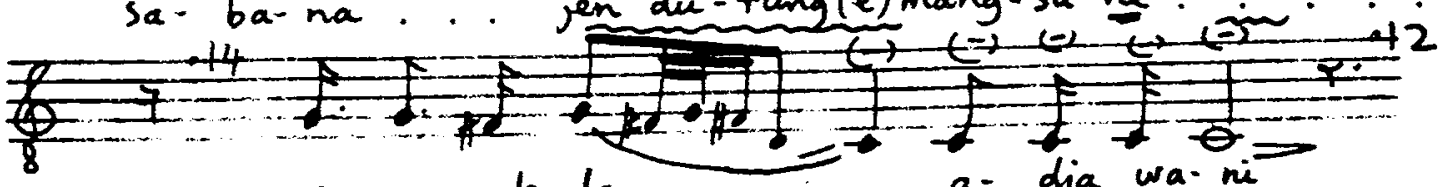

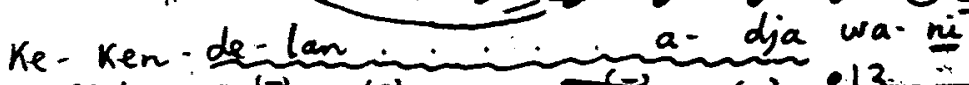
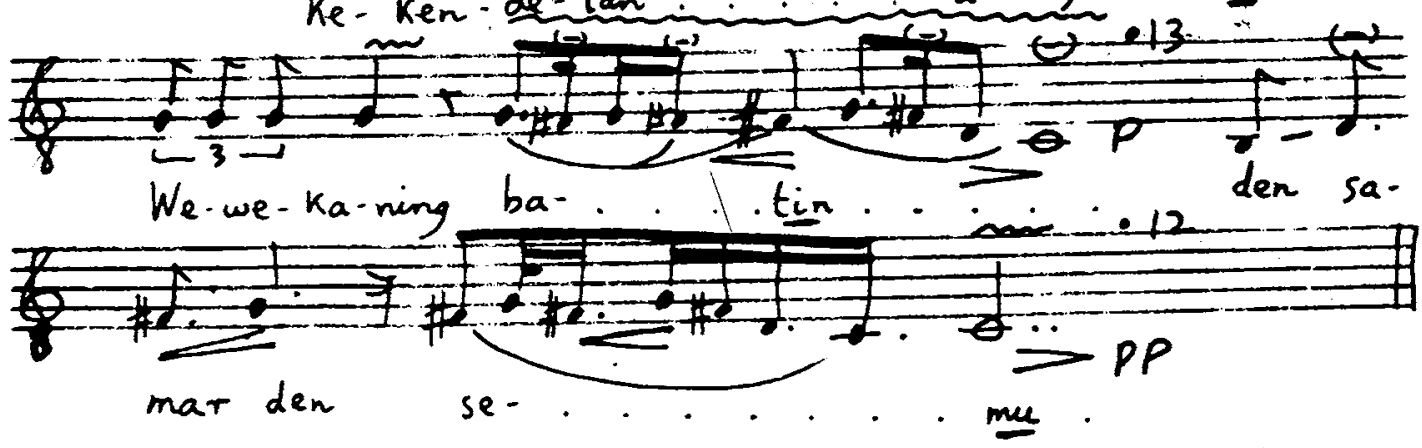
SINGER: SUTAMDIO

HOME TOWN: SURAKARTA/KASUHUHAN

T.L.: $1.62 \mathrm{~min}$.

O.P.: $\quad 1 \frac{1}{2}$ tones higher

(1. $=98)$

(m)

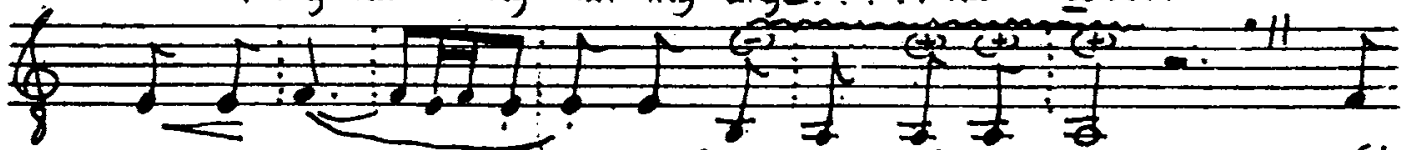

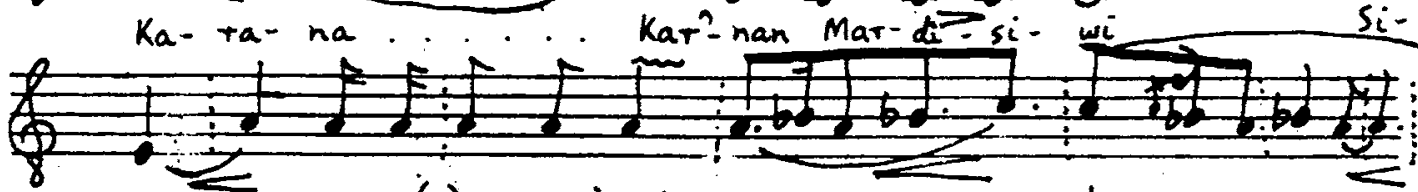

na... wung $(e)$ res-mi-ning $k_{i}-\ldots \ldots$ dung.

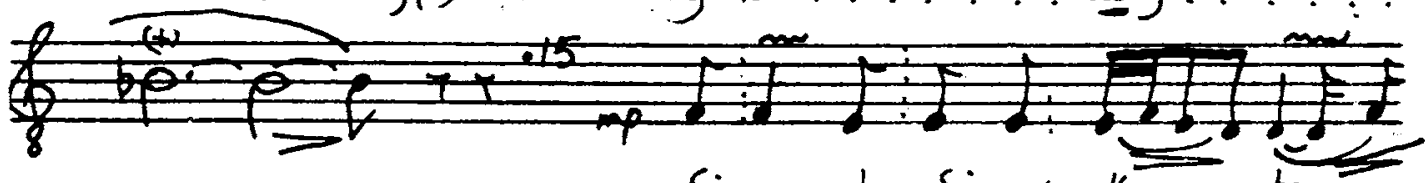

Si- nu-ba Sin- $u$ Kar- ta...

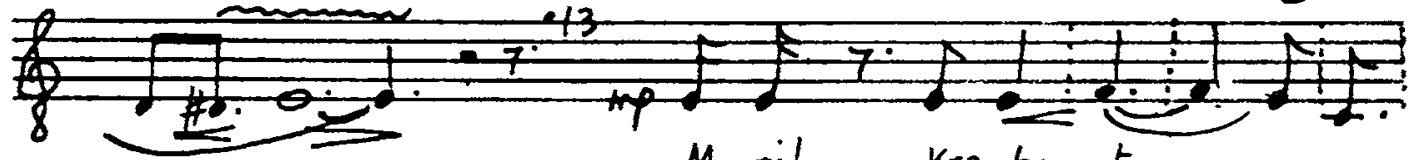

M-rih kre-tar.ta.... pa-

Kar-ti-ning ...

70 Kang

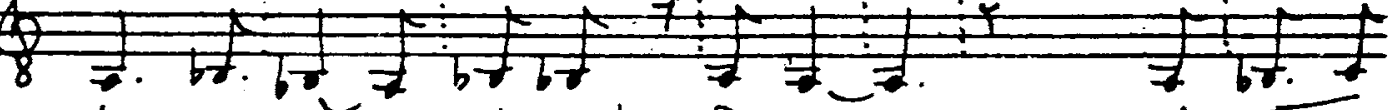

tum-mrap neng... ta-nah Dja-wa.. A- $\overline{-i=m}$

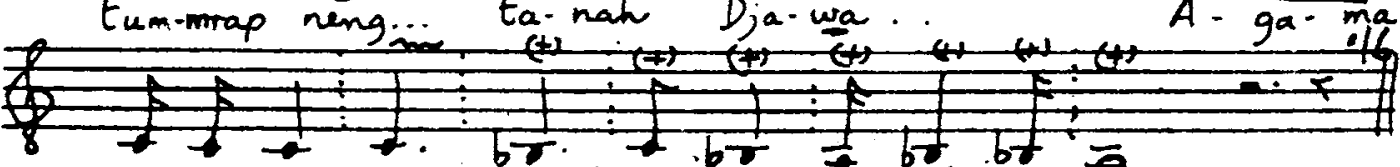

$a-g e-\operatorname{ming} a-b+d_{j i}=b+\frac{1}{\sigma}=$ 


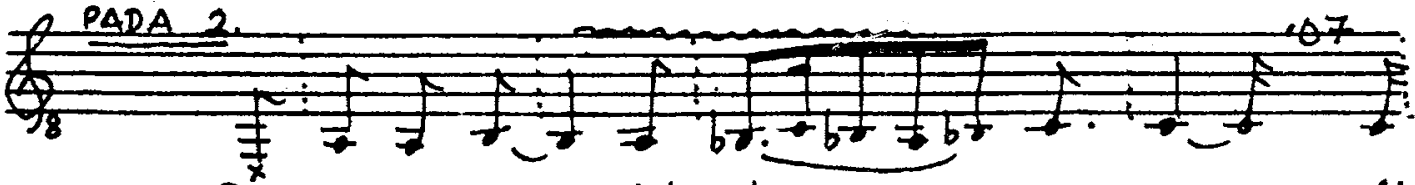

$D_{j i}^{*}$ ne-djer neng. We-da $\ldots$....ta $=$ ma... M.

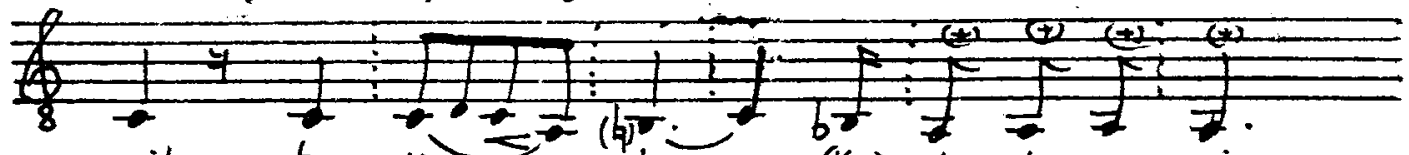
rih $\tan K e m=\ldots$ ba.... (Ke) Kem-beng-an sing

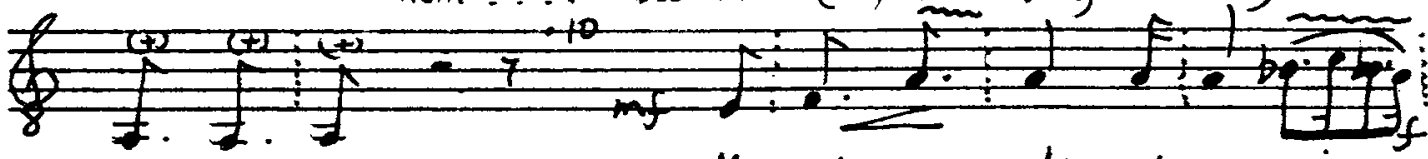

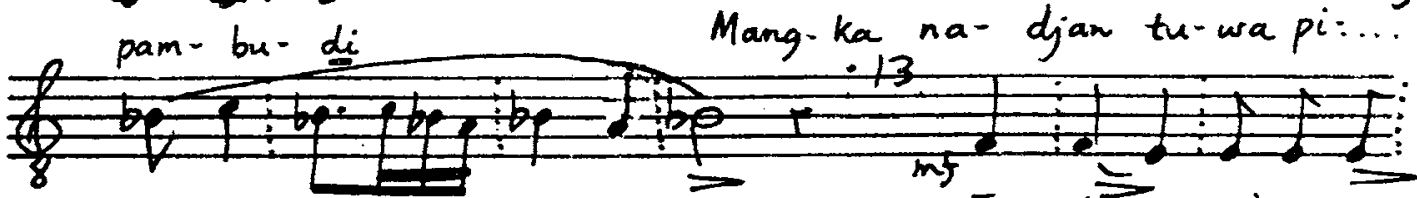

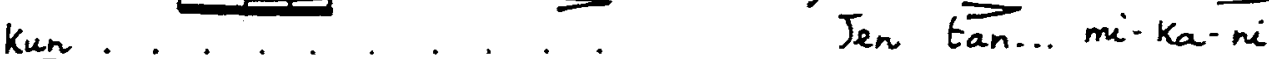
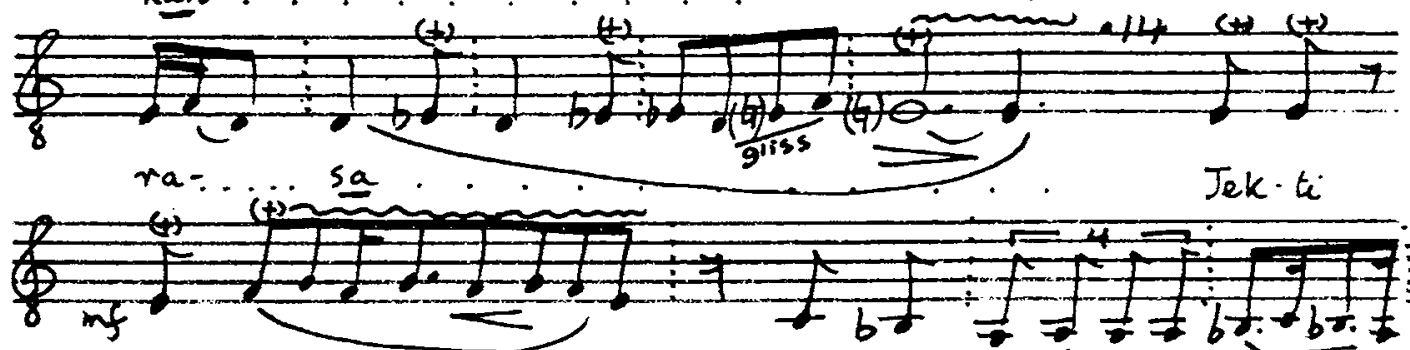

se-pi.a. a- se-palir (e) se-puc..

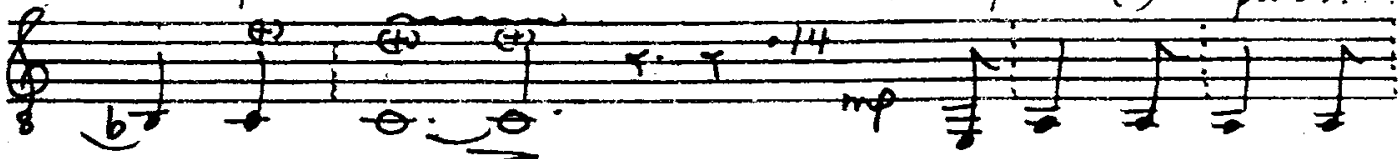

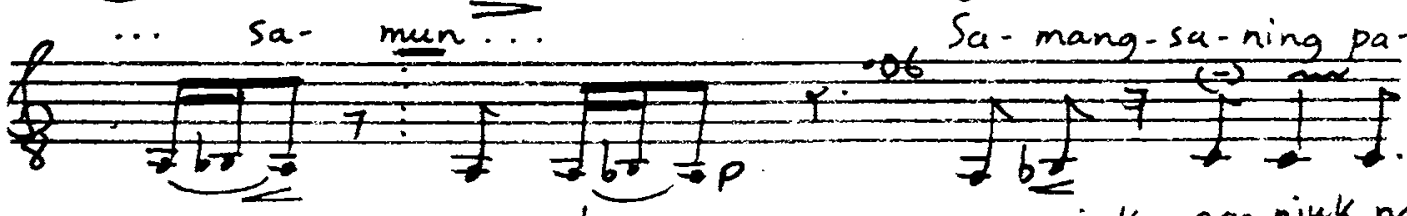

Kum-... pu-lan go-njak-ga.njuk ngle

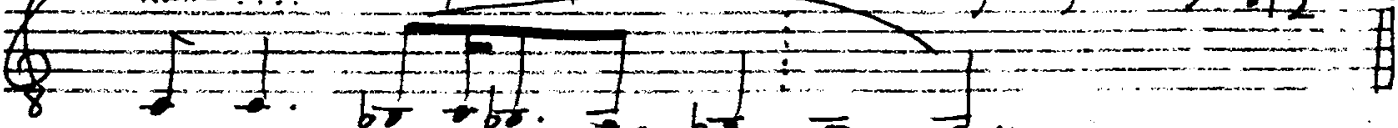
ling se - mi 
19. DANDANGGULA

SINGER: SUTAMDIO

T.L.: $1.17 \mathrm{~min}$.

O.P.: I tone higher
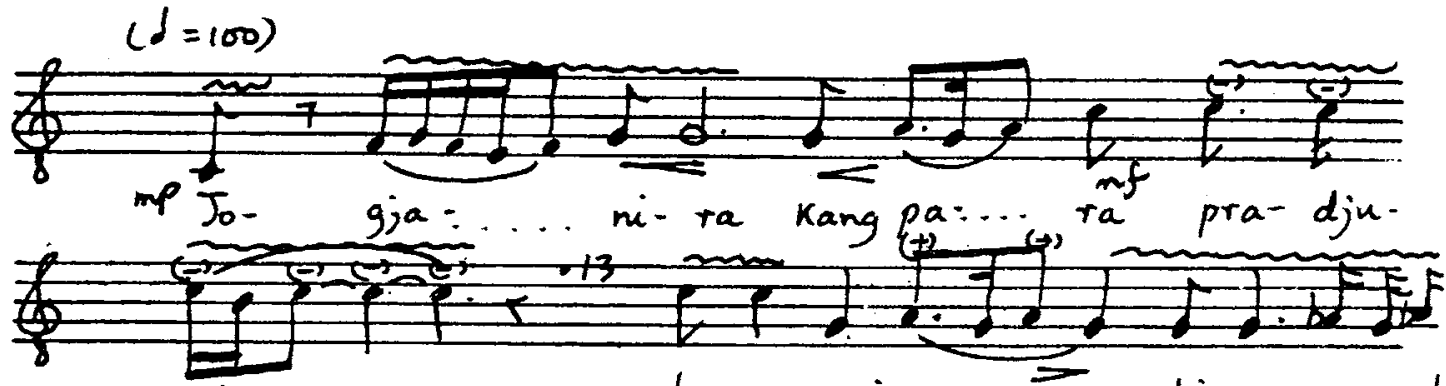

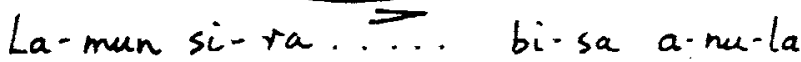

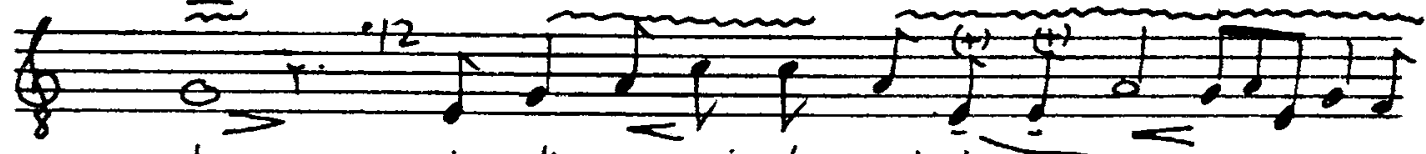

da $k a \cdot d i j a$ ngu-ni tja-ri-tan-

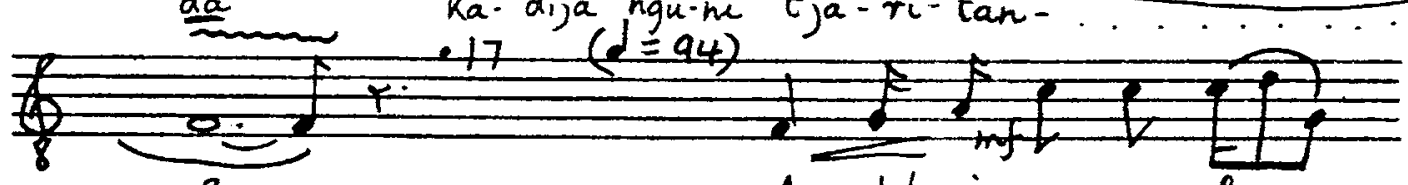

An-del-i- ra sang Pra =..
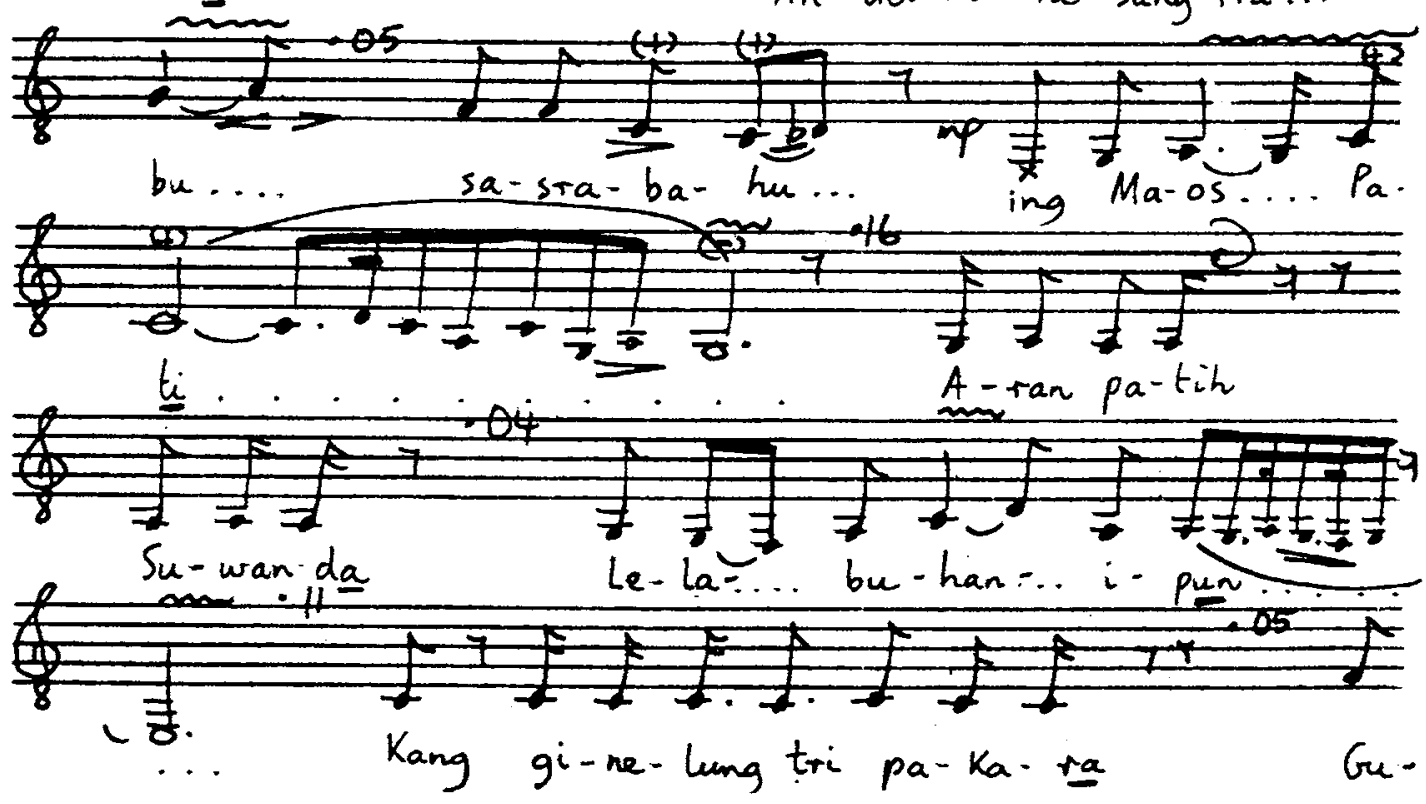


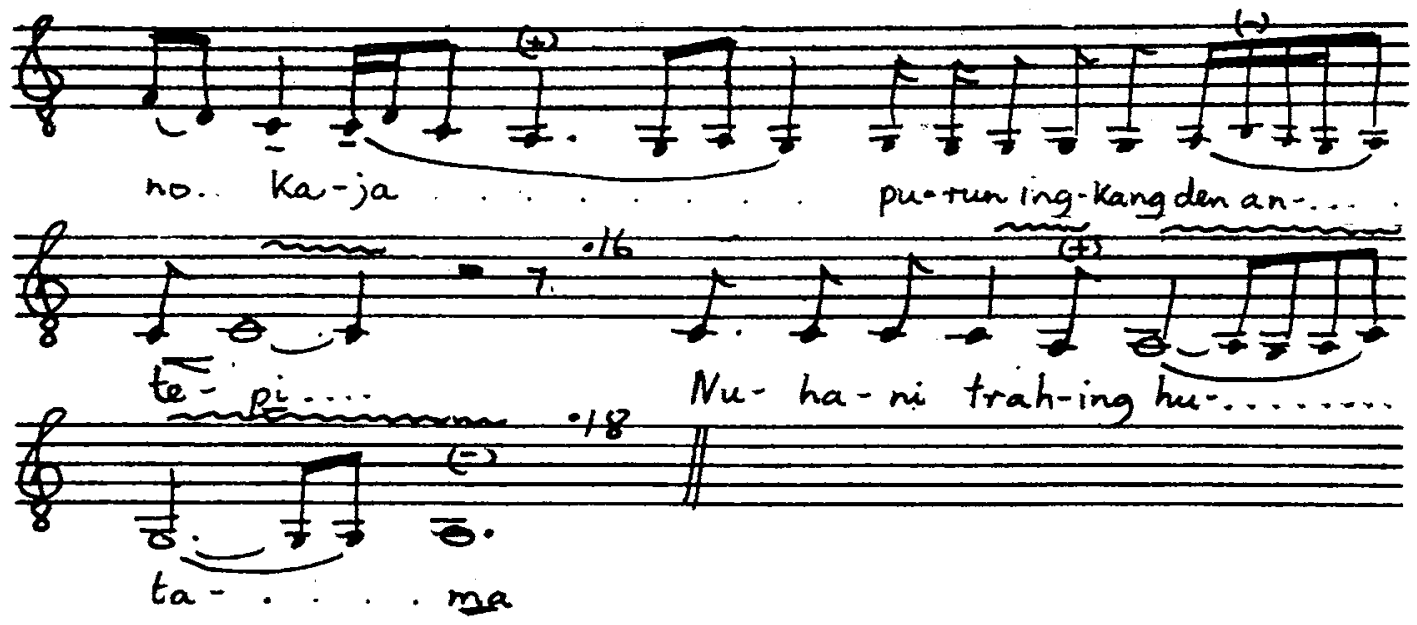


20. KINANTI MATJAPAT

SINGER: SUTAMDIO

T.I.: $1.01 \mathrm{~min}$.

O.P.: $\quad I \frac{1}{2}$ tones higher

$(d=111)$

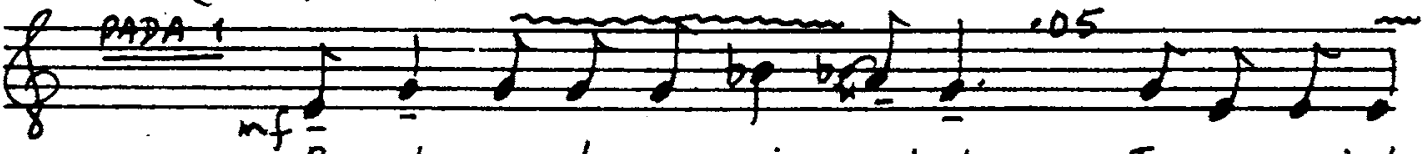
$\overrightarrow{P a}_{a}$ da gu-la-ngen ing Kal-bu Ing sas-mi-ta

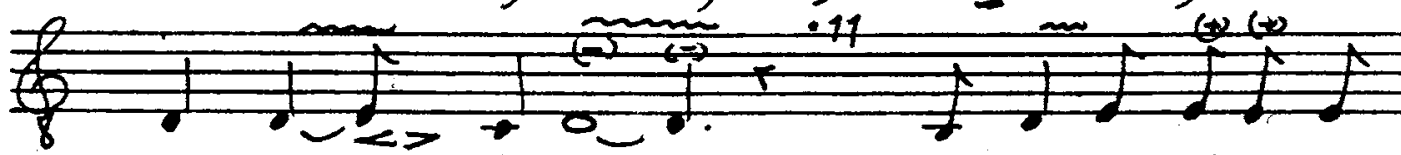
a- mrih... lan-tip... A A-dja pi-djer ma-ngan

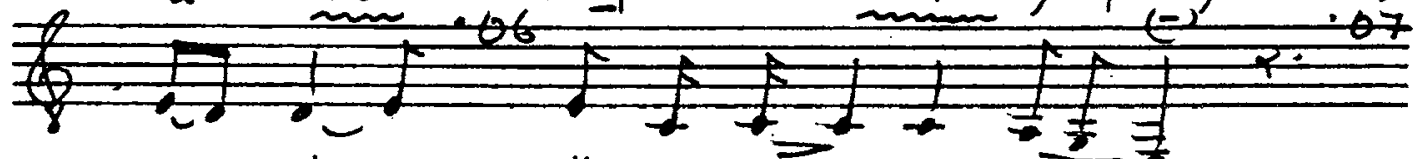
nen.. dra... $K_{a}$ pra - wi

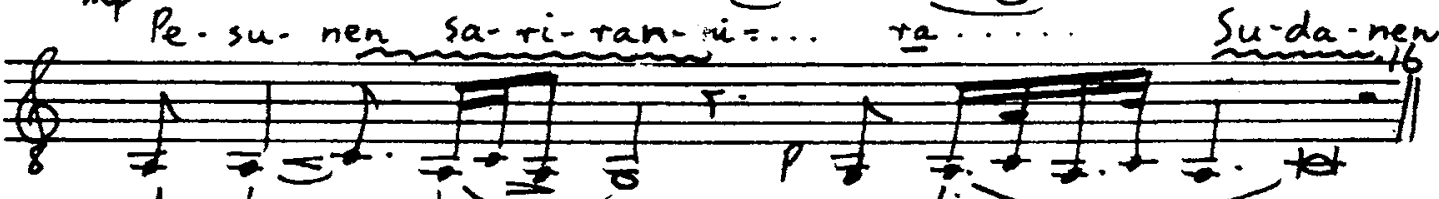
dathar.. $D_{a}-d_{i}-j a$ la-ku mi-... re- $k_{i} \ldots$ Tje-gahd'harla-

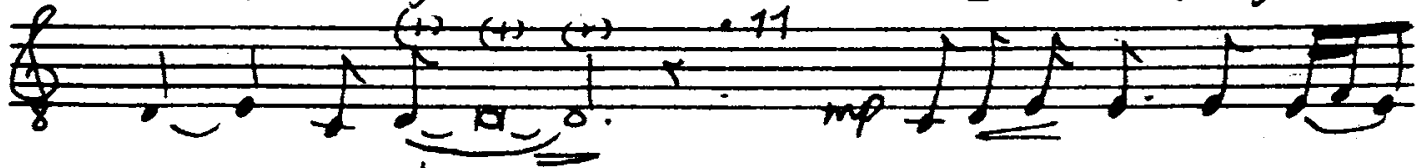
wan... gu. ling..

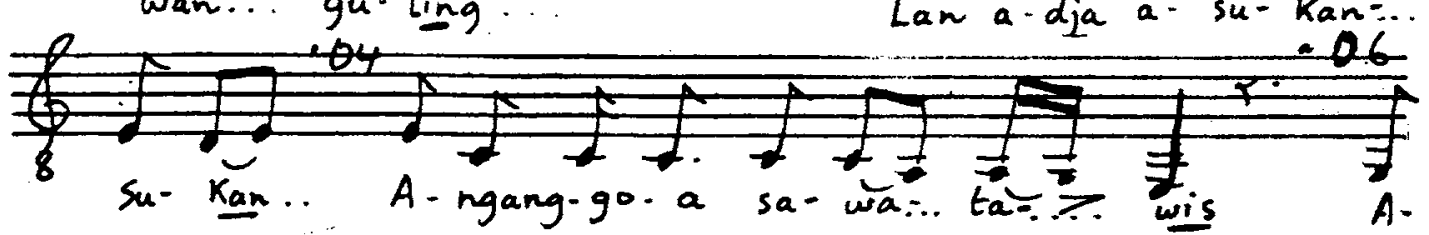




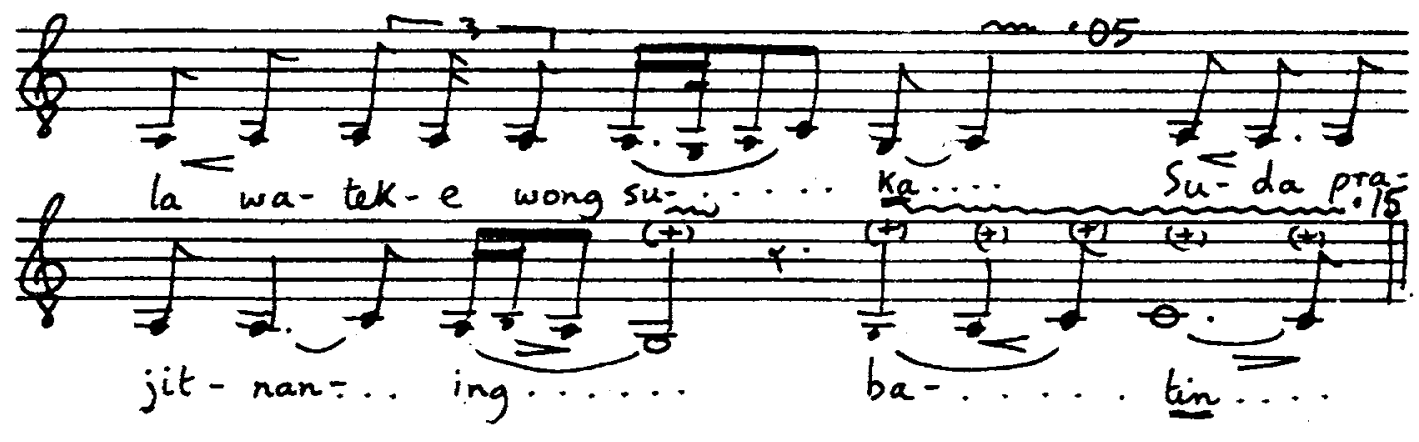


21. ASMARANDANA

SINGER: SUTAMDIO

T.L.: $0.49 \mathrm{~min}$.

O.P.: I tone higher

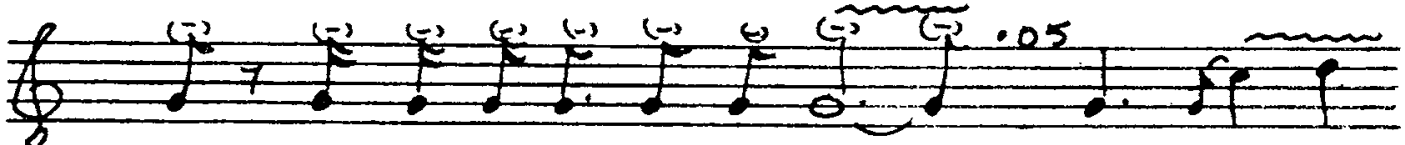
Kas - ma-ran duch a-ni-nga- $\underline{\mathrm{i}}$... Lam-pa-he

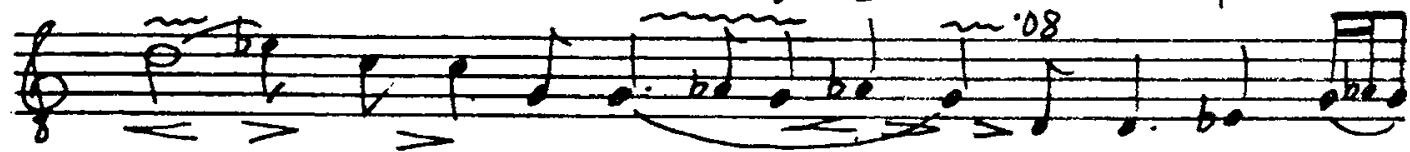
ka-...i- ta la-jat............ Ke-tem-puh pra:

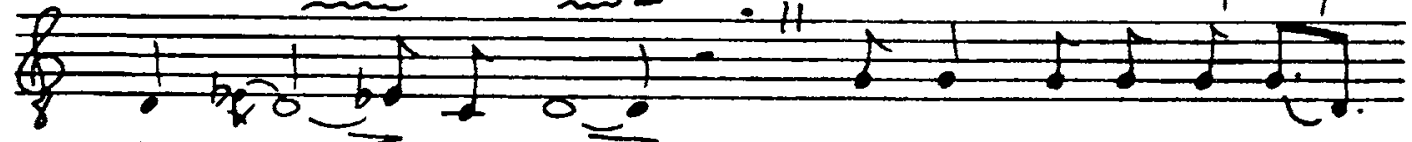
ha- $\operatorname{ra}_{05} \equiv$ ge-de $=$ Gu-ling-Kirmring sa-mu-..

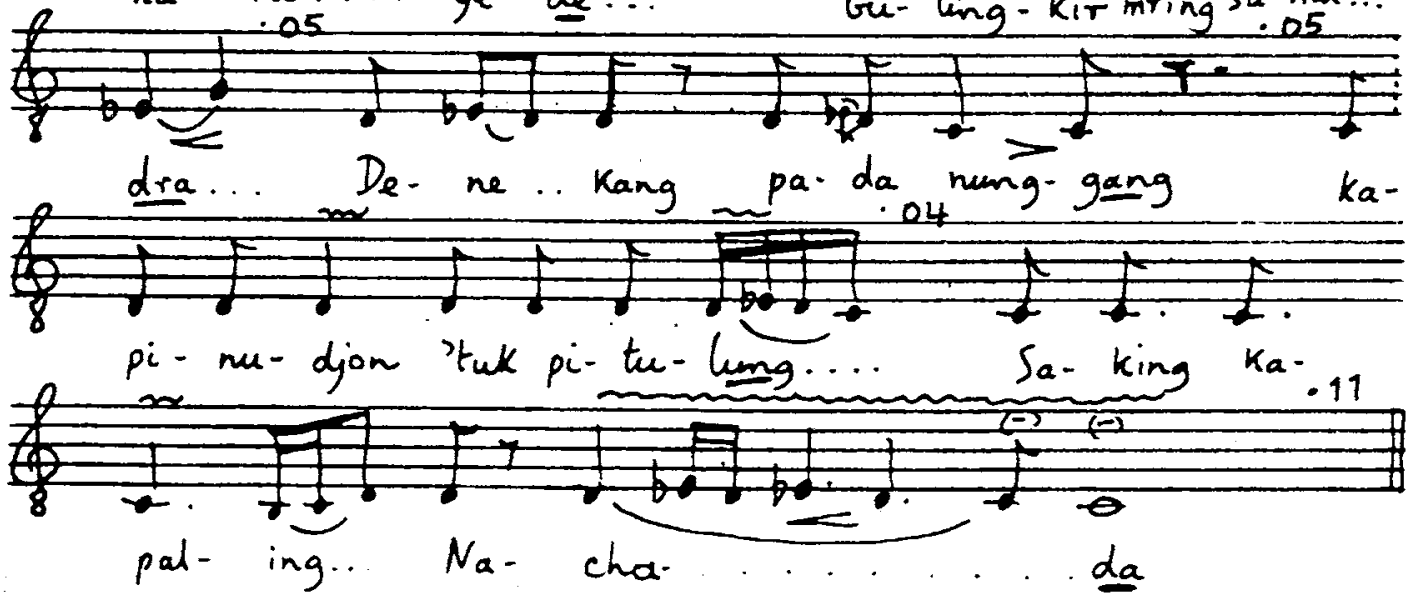


22. DURMA

SINGER: SUTAMDIO

T.L.: $0.90 \mathrm{~min}$.

O.P.: $\frac{1}{2}$ tone higher
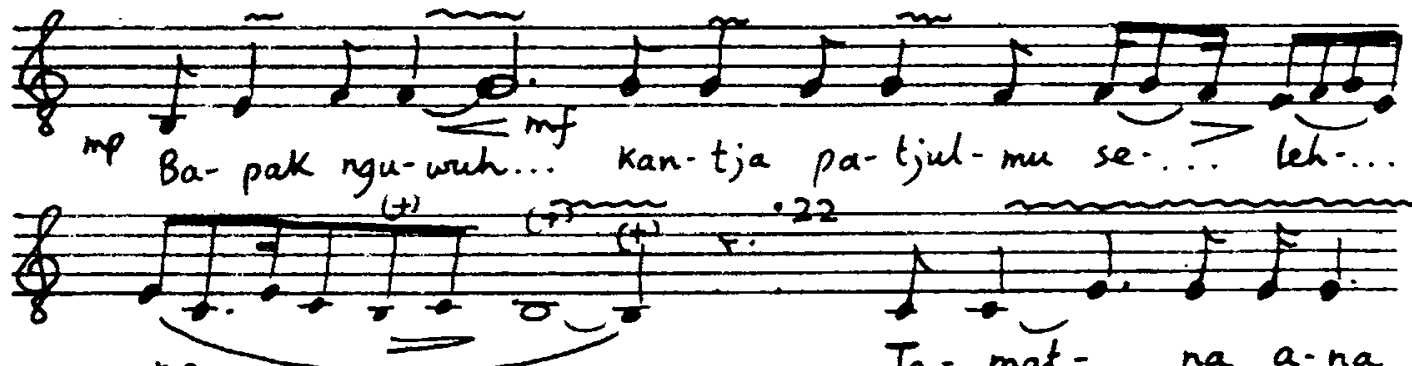

$T_{a}-\operatorname{mat}=\ldots$ na $a-n a$
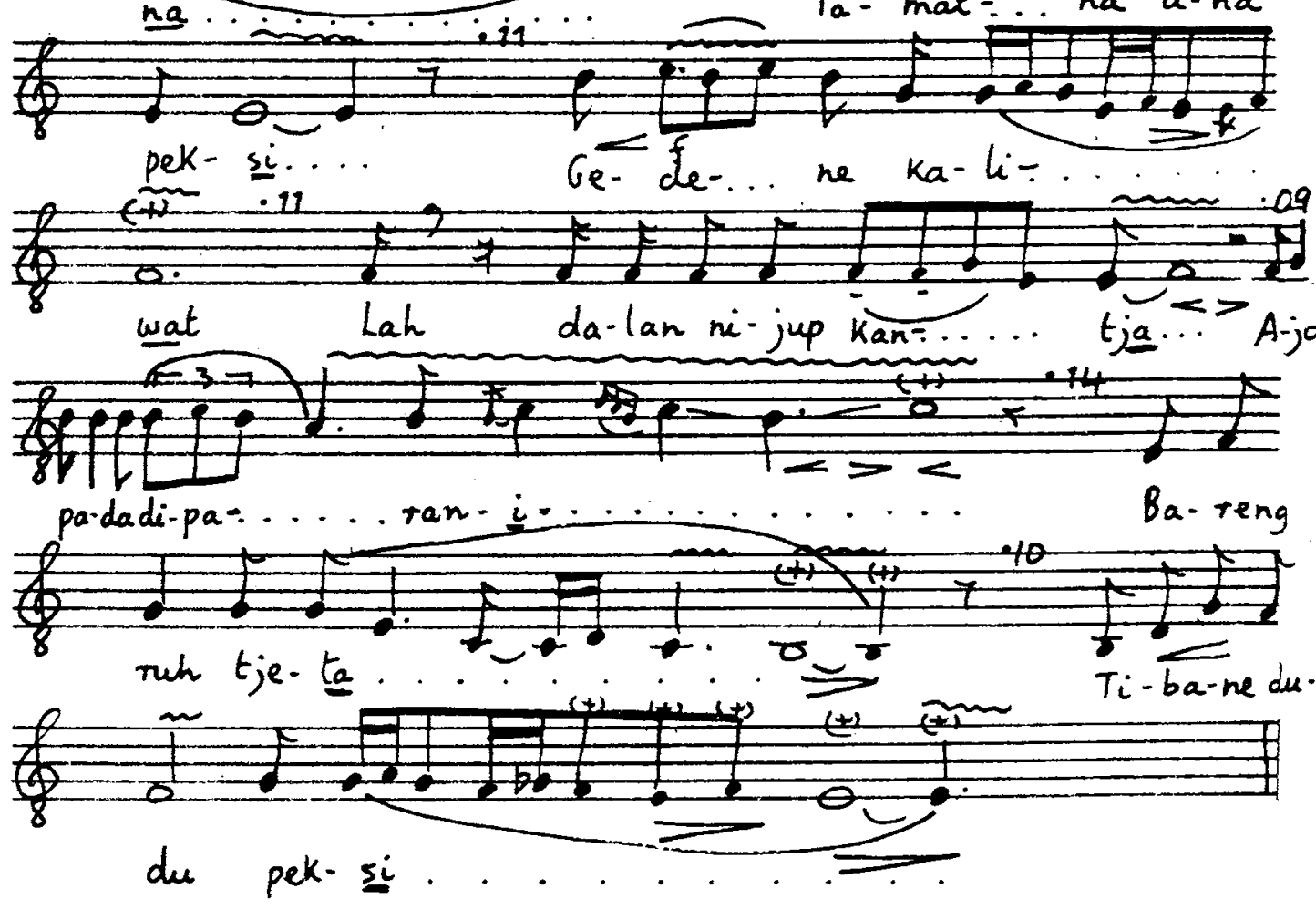
23. MIDJIL MATJAPAT

SINGER: SUTAMDIO

T.I.: $0.57 \mathrm{~min}$.

O.P.: $1 \frac{1}{2}$ tones higher

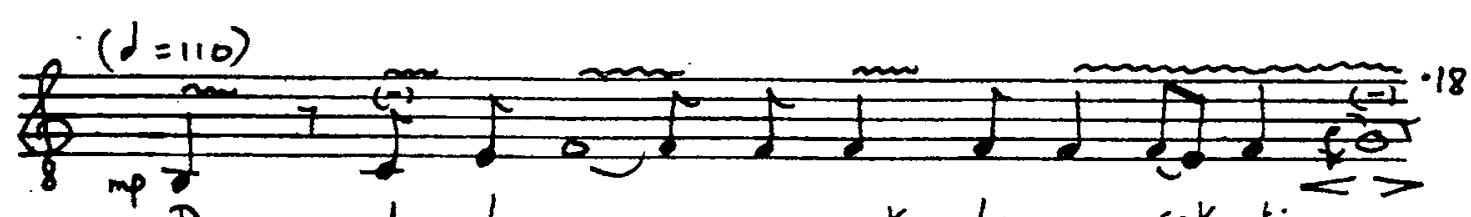

De- da- la-ne... gu- nok la-wan sek... ki. Ku-du an-dap a-.. sor $\quad$ Wa-ni nga-lah ....

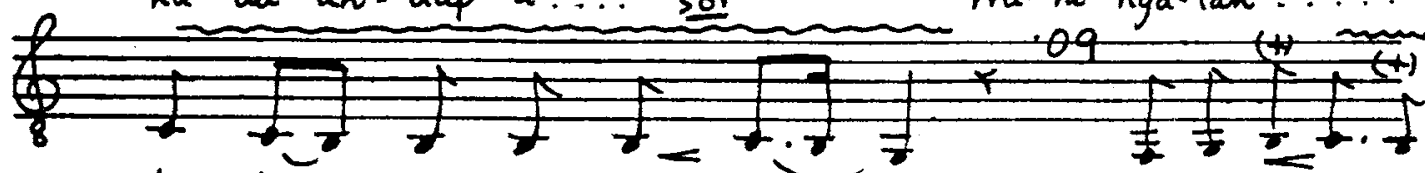
lu - hur... we - Ka- san- en $\cdots 07$ Tu-mung-Ku-la jen

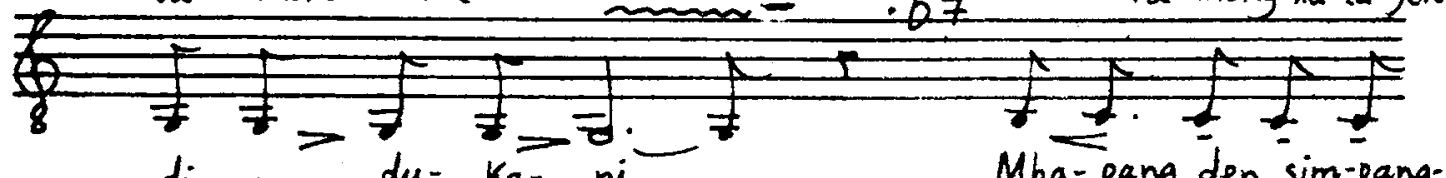

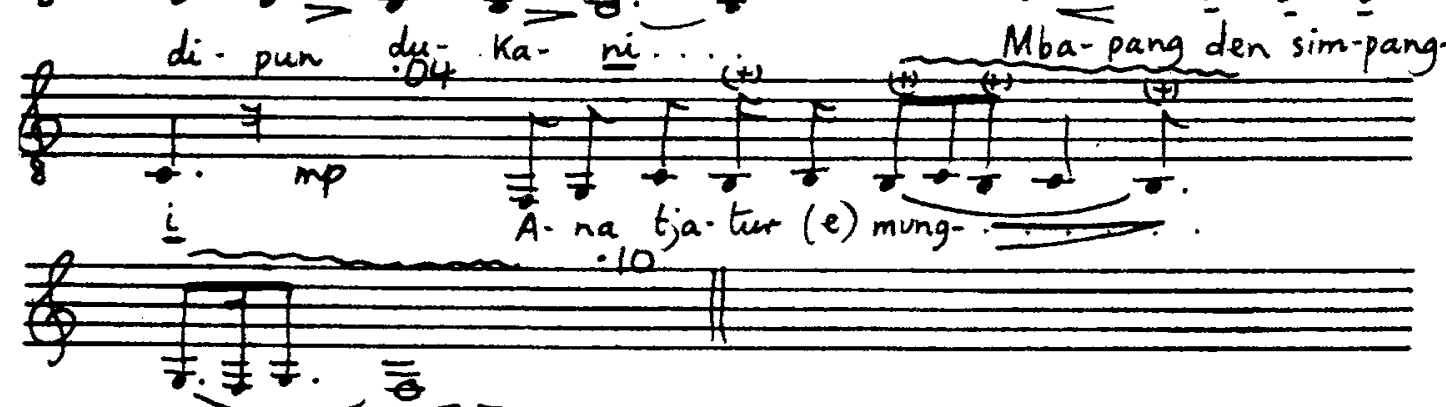
Kur.... $=$ 
24. MIDJIL KETOPRAK

SINGER: SUTAMDIO

T.L.: $1.18 \mathrm{~min}$.

O.P.: 3 tones higher

$(d=116)$

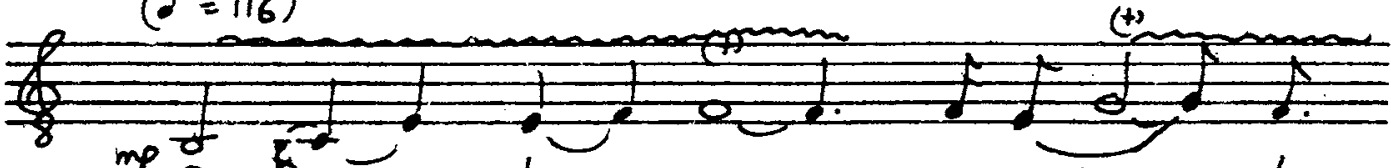

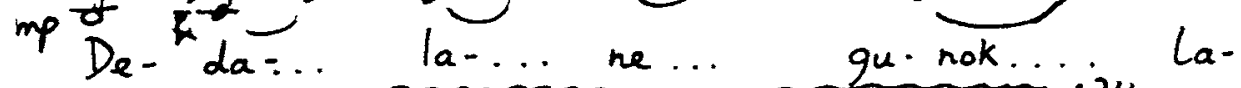
wan...

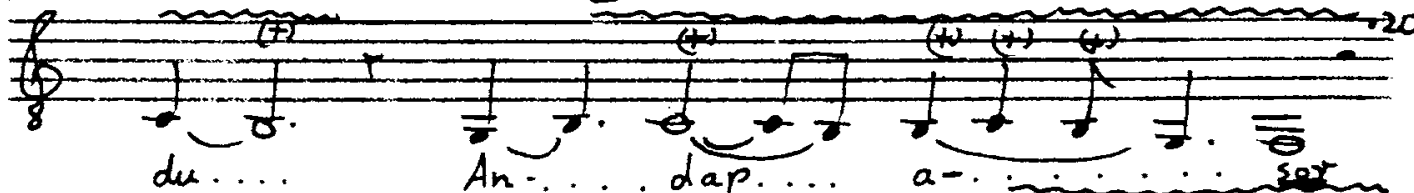

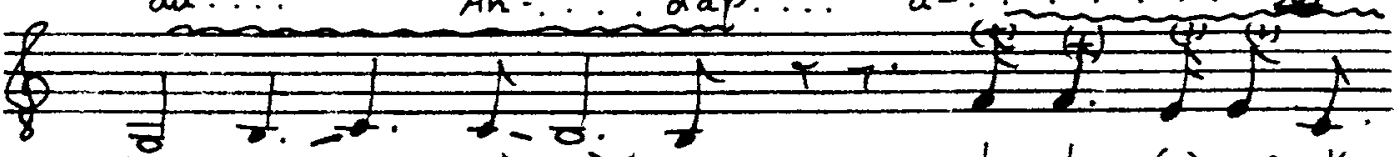
Wa- ni nga-lah- Lu-hur (e) we-Ka-

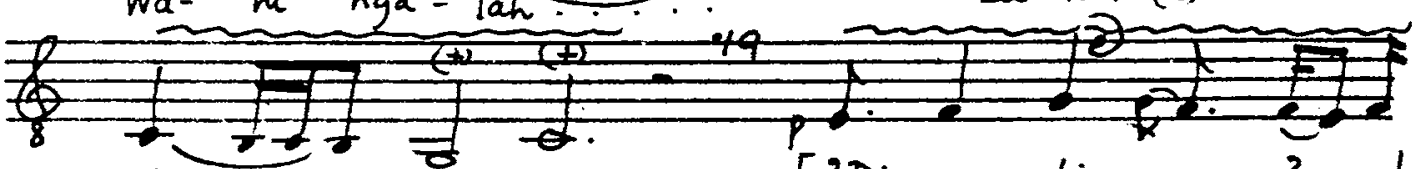
san-... ['Dja nge-tje wong 'ra.. du-

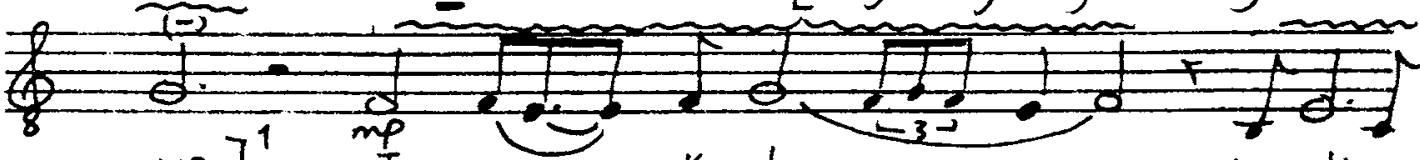
we $]^{1} T_{u}-\underbrace{\infty}_{\text {mung }} . . K_{u}-l_{a}$ 7...29 jen di-pun

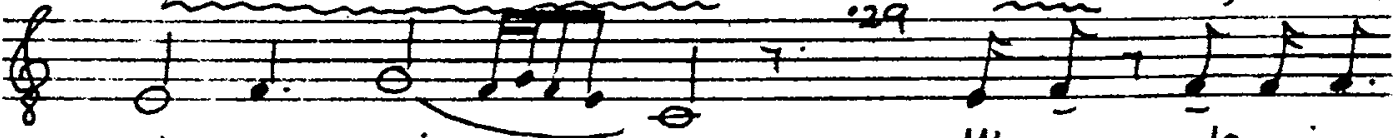
du - Ka-

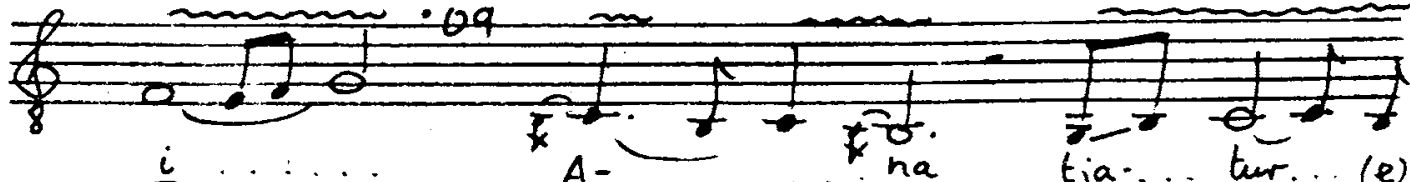

$\underline{i}$ $A-$. .17

tja... tur.

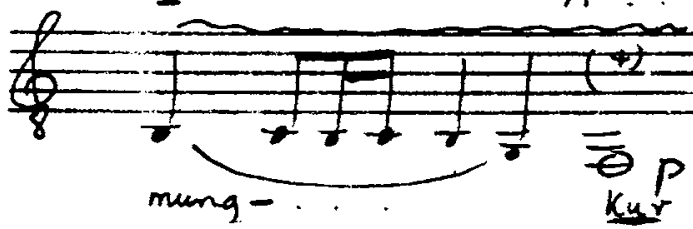




\section{$(d=9 a)$}
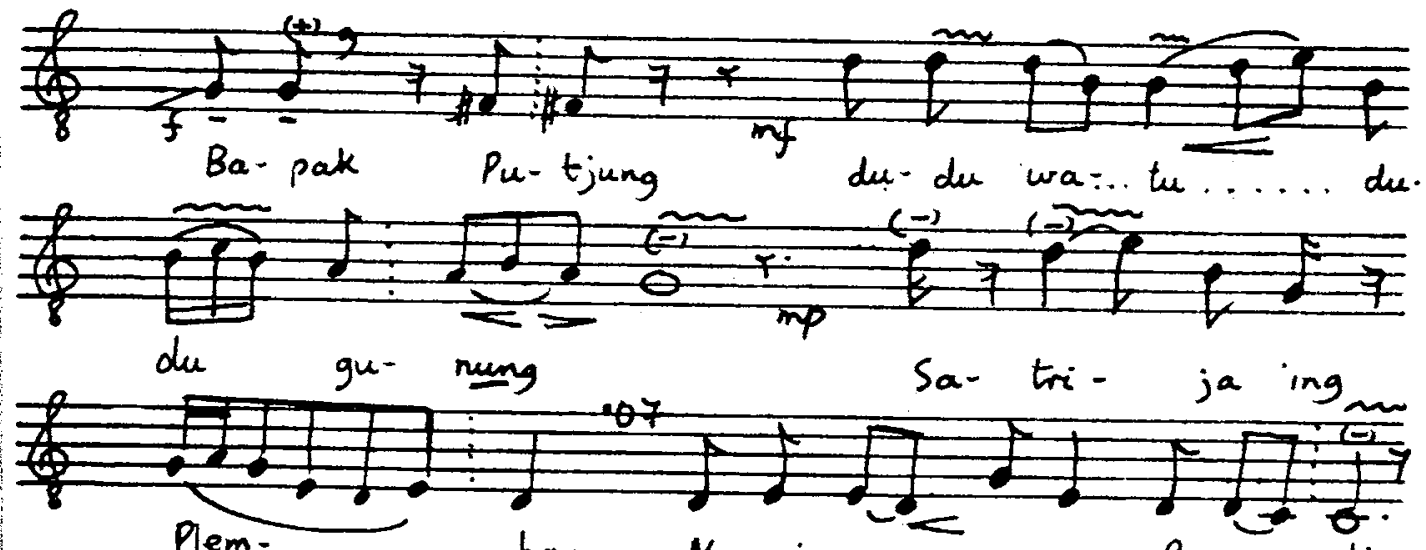

$$
\text { Plem- }
$$

$\overline{7}$

legato

bang Ngon-i-ngon:..e sang Bu-pa:.. ti 
26. PUTJUNG LUGU

SINGER: SUTAMDIO

T.L.: $0.45 \mathrm{~min}$.

O.P.: $\frac{1}{2}$ tone higher

$(d=108)$

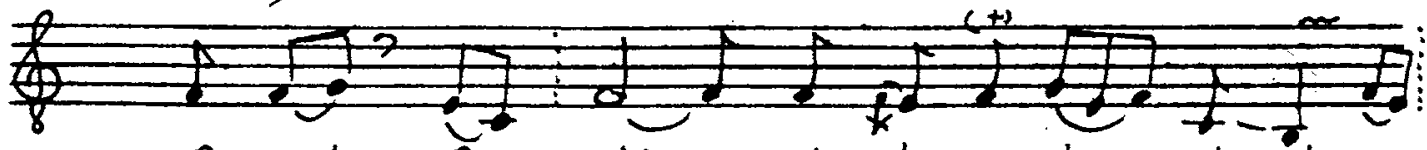

Ba-pak... Pu-.. tjung du-du wa-tu...du-du gu-

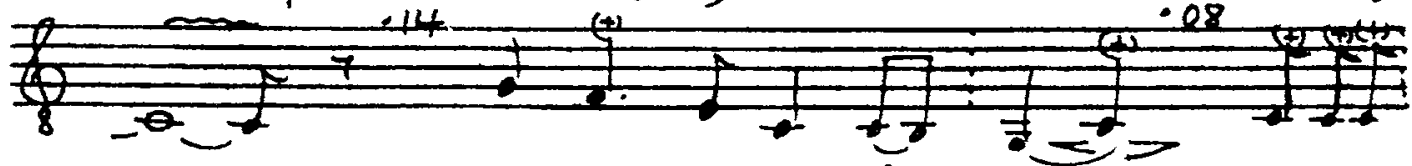

neung Sa-tri-ja ing Plemi.. bang... Ngon-i-ngan

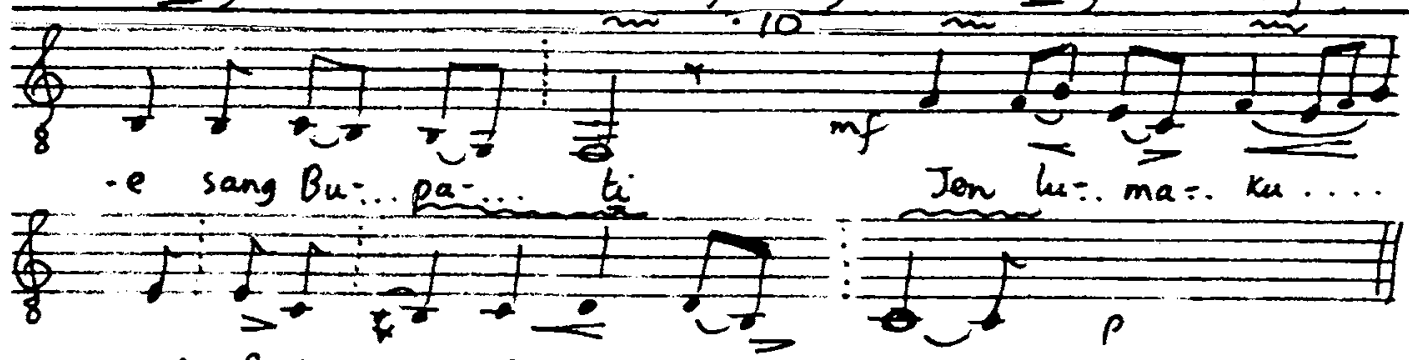

si Pk-tjung lim-be-jan Gra-. na.. 
27. DANDANGGULA LUGU

SINGER: SUJITNO

HOME TOWN: BOJOLALI

T.I.: $0.63 \mathrm{~min}$.

O.P.: $\frac{1}{2}$ tone lower

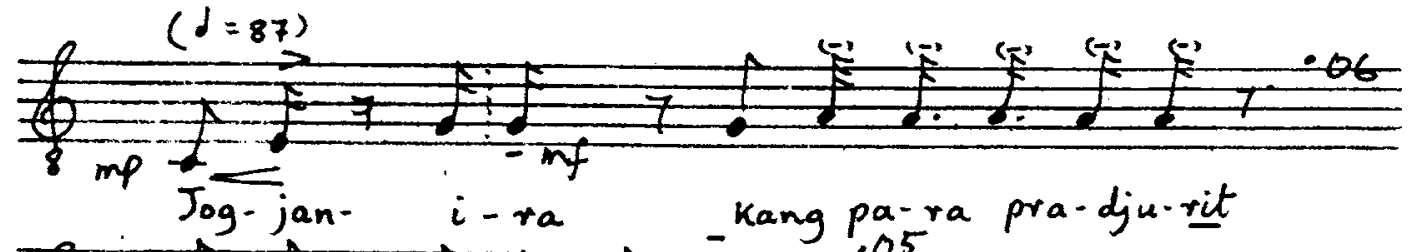

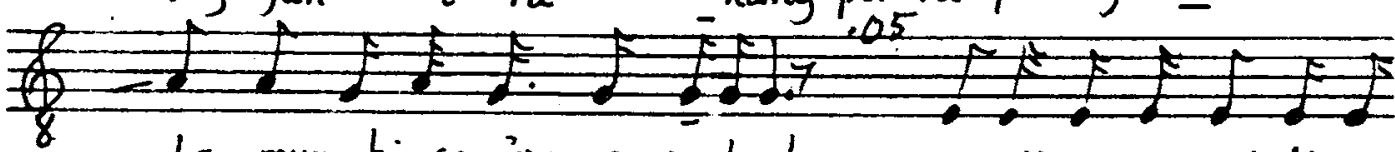

La-mun bi-sa 'ra a-rum-la-da Ka-di-ja ngu-ni jja-ri-

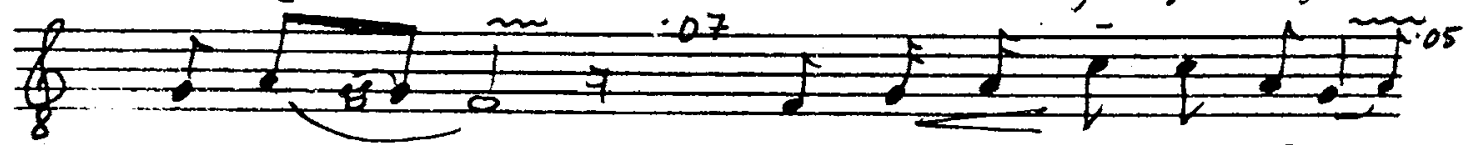

ta- ne $\equiv$. An - del-i. ra sang Pra-bu.

Sas -s+a-ba-hu ling Maros

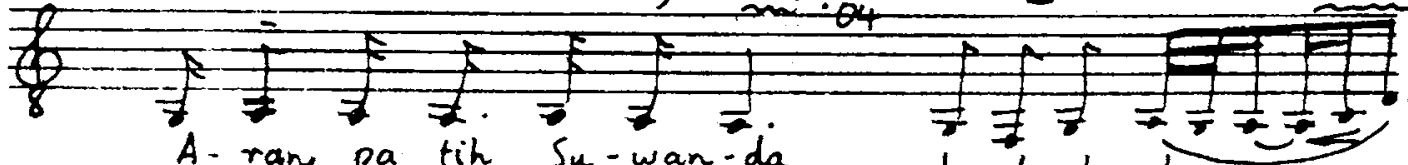

A-ran pa tih $S_{u}-$ wan-da

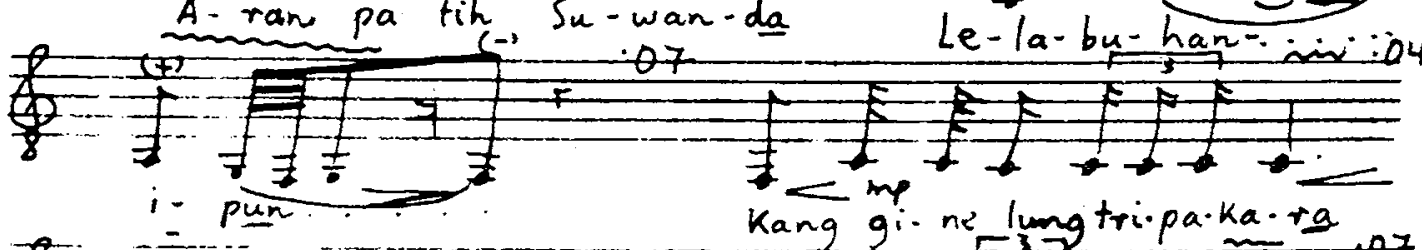

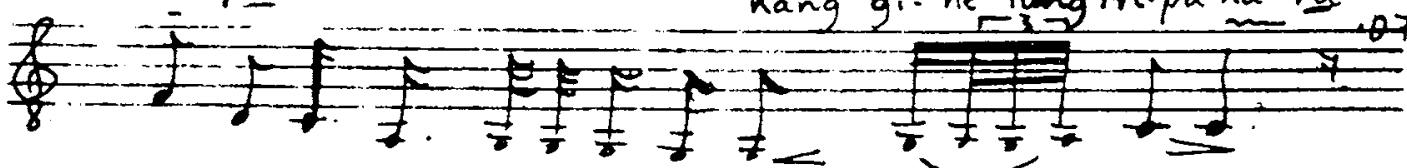

Gu-na ka-ja pu-runing-kangden an-... te-pi.

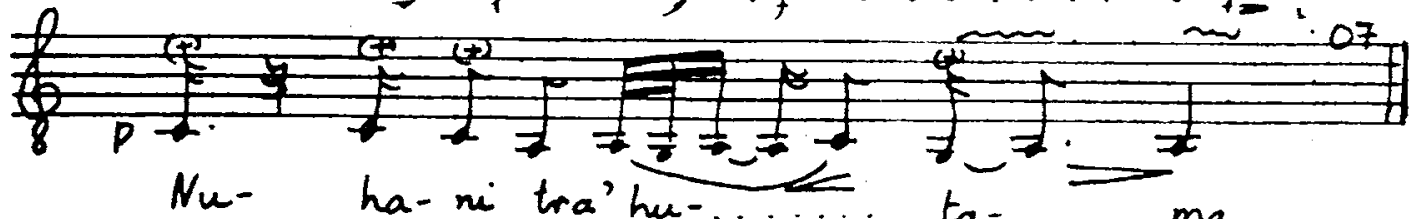

Nu- ha-ni tra'hu-.... ta t... ma 


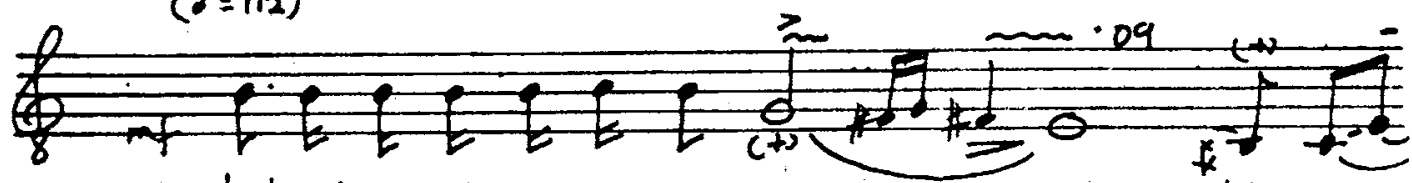

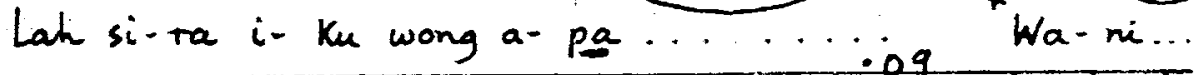

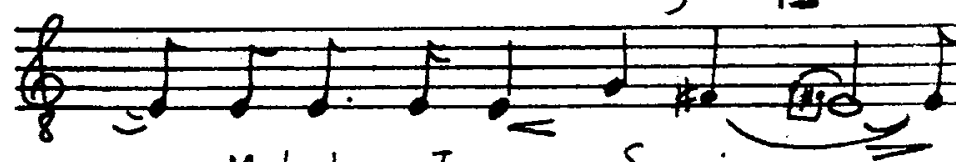
Mal-beng Ta-man Sa-i....

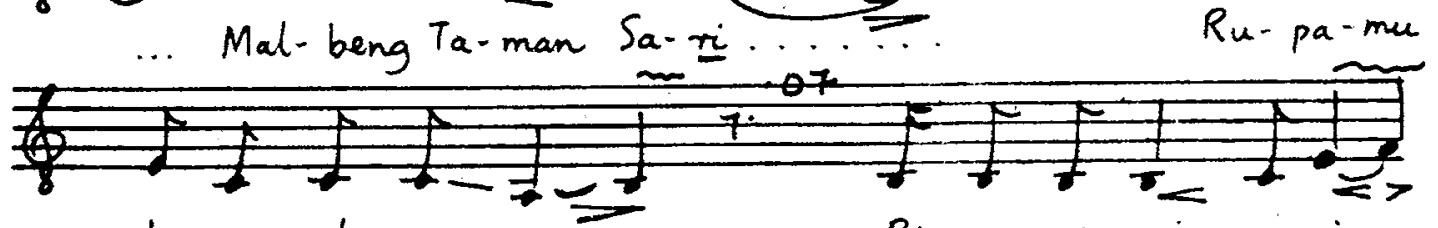
ba-gus ta-ru- na $\quad P_{i}$-nang-Kan-i-ra ing...

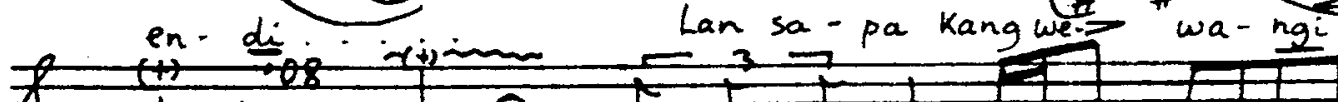

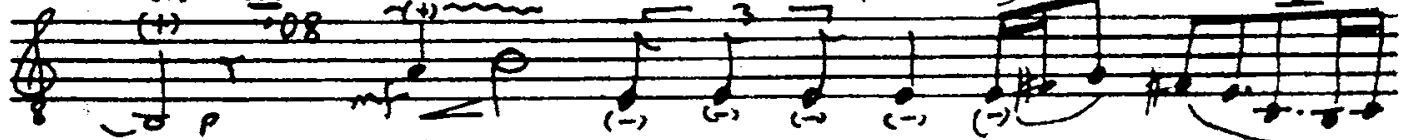
A - nga - Ku- wa mum-pung du=in rung

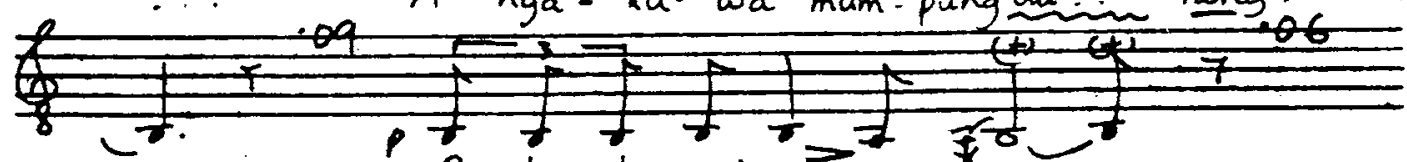
‥ Pa-las-tra si-ja- si- ja

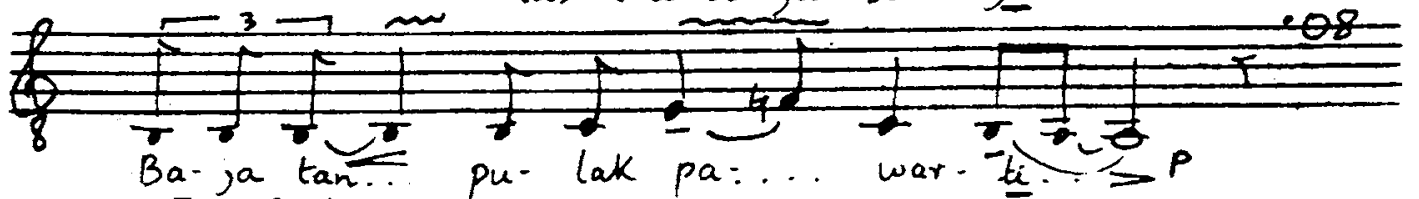
La mun

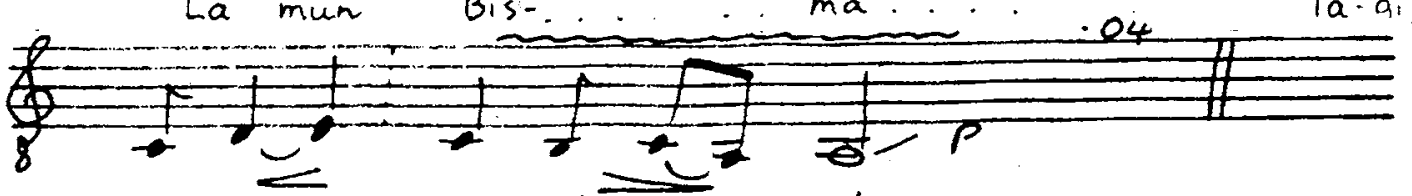
wi- $\overbrace{n a . .}$ wong $d_{j a-w a}$. $t_{a}$ 
29. SINOM PARIDJATA

\author{
SINGER: SUJITNO \\ T.L.: $1.22 \mathrm{~min}$. \\ O.P.: 2 tones lower
}

$\frac{t}{8} t_{m p}^{1}=92$ Lah si-ra... i- ku wong $a-\ldots . \cdots \cdot p^{p a}$

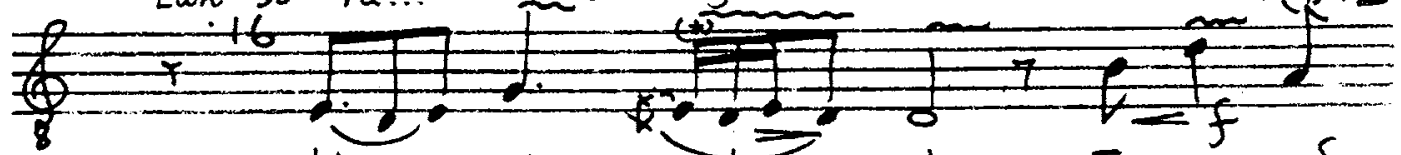
Wa... hi

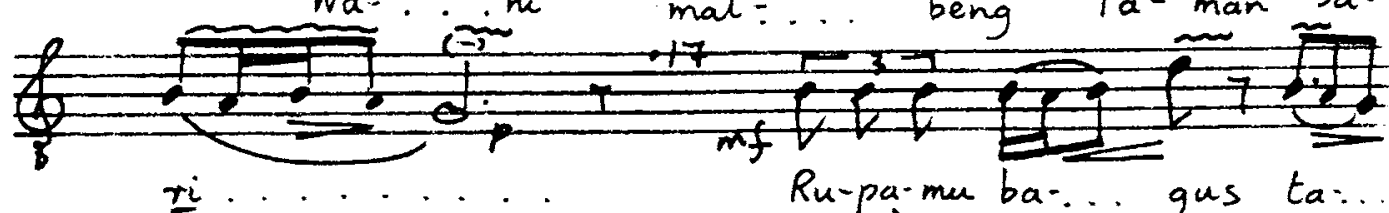

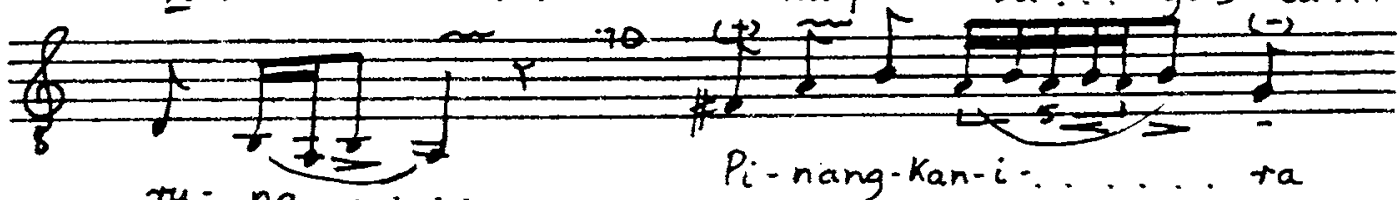

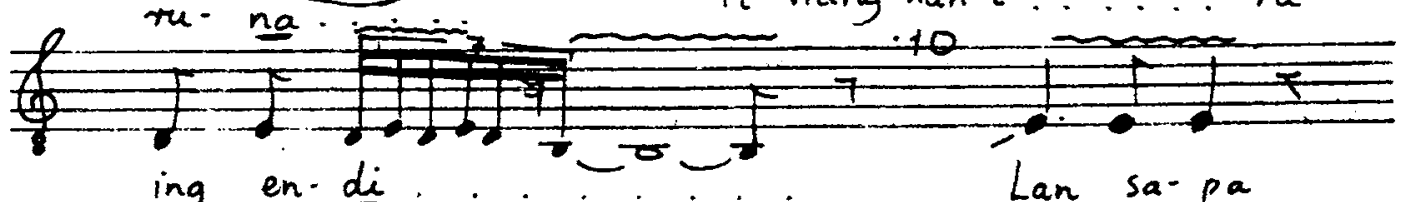
Kang ... we- wa$f_{8}=P_{m \in t}^{\infty}$

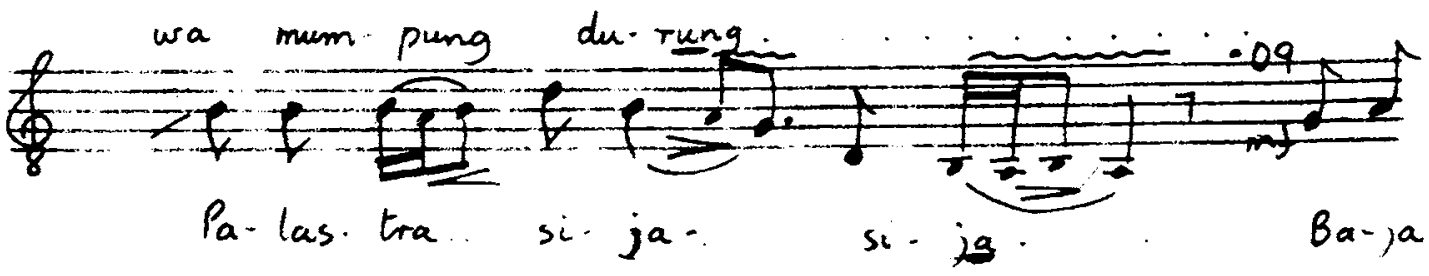




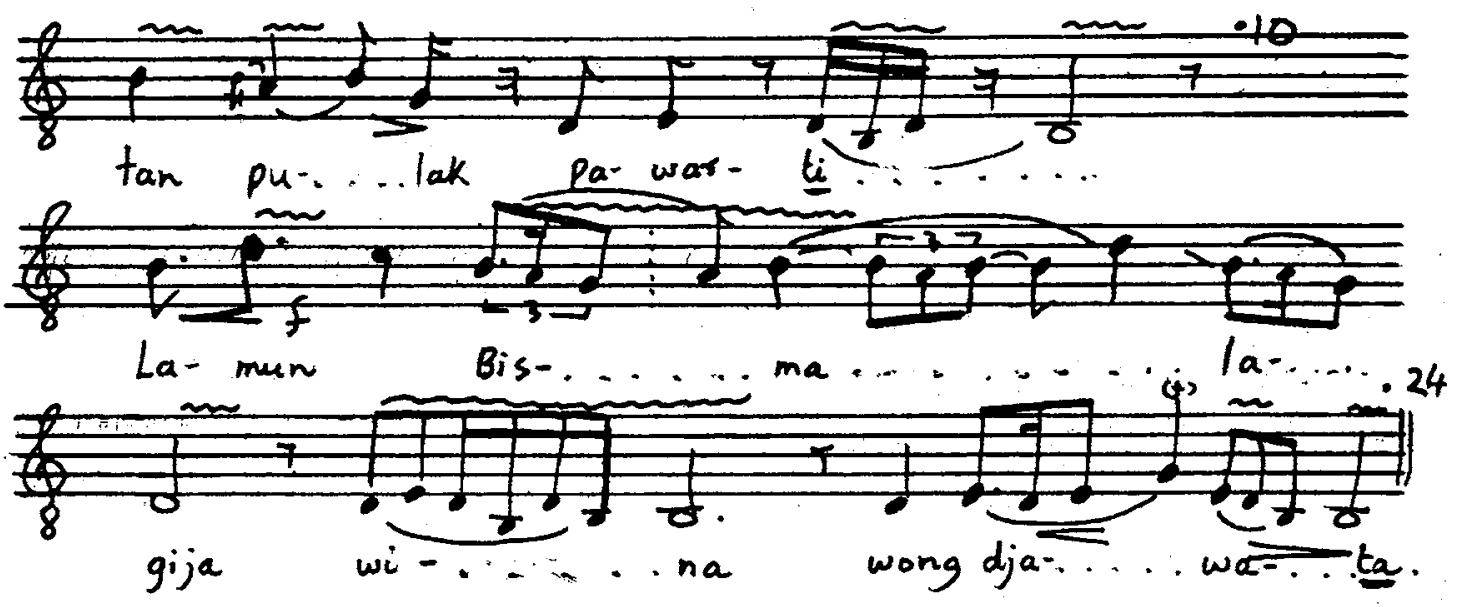


30. PUTJUNG LUGU

SINGER: SUJITNO

T.L. : $0.33 \mathrm{~min}$.

O.P.: I toneg higher

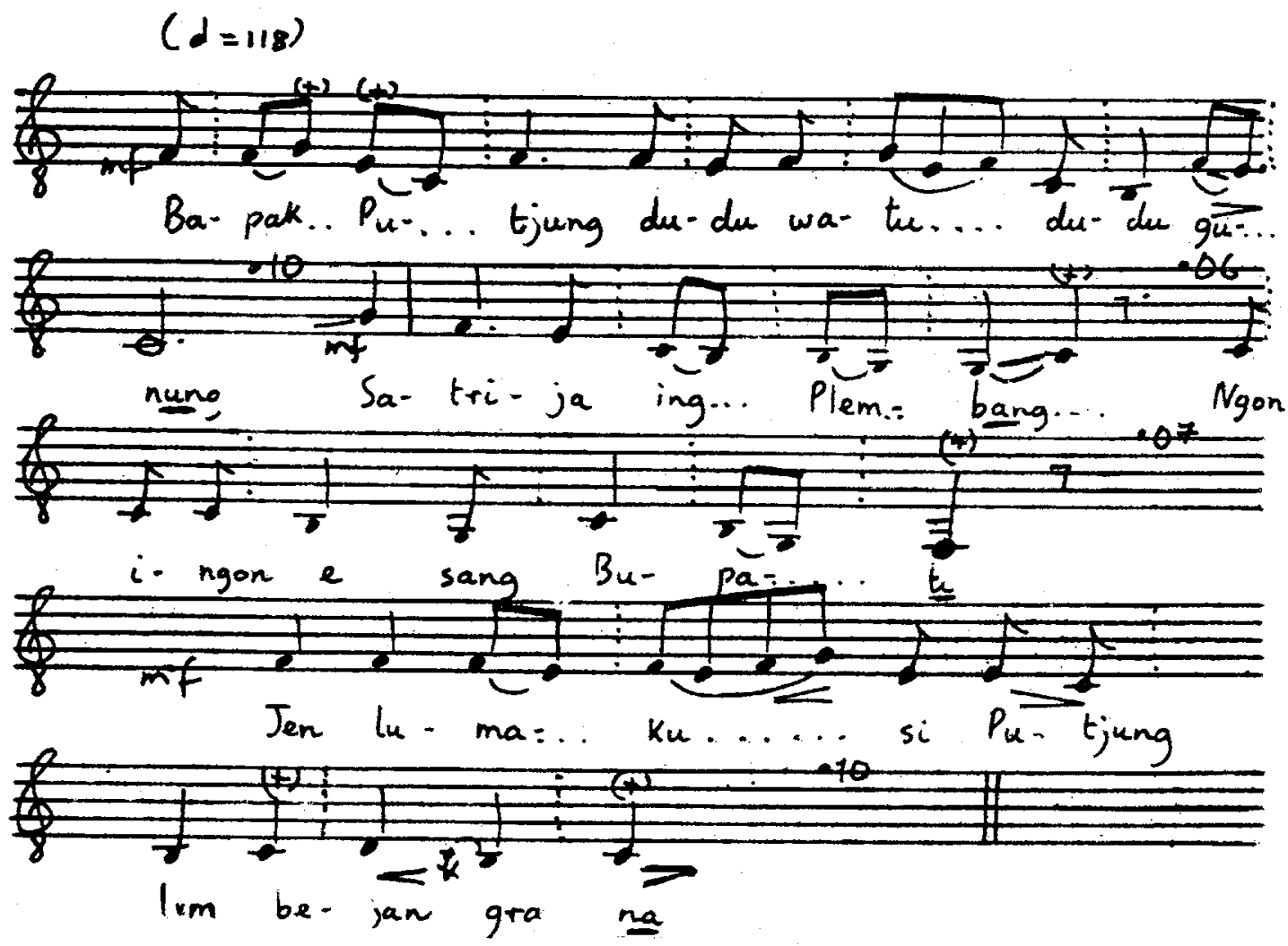


31. KINANTI BARES

SINGER: SUJITNO

T.L.: $0.77 \mathrm{~min}$.

O.P.: $\quad I \frac{1}{2}$ tones lower

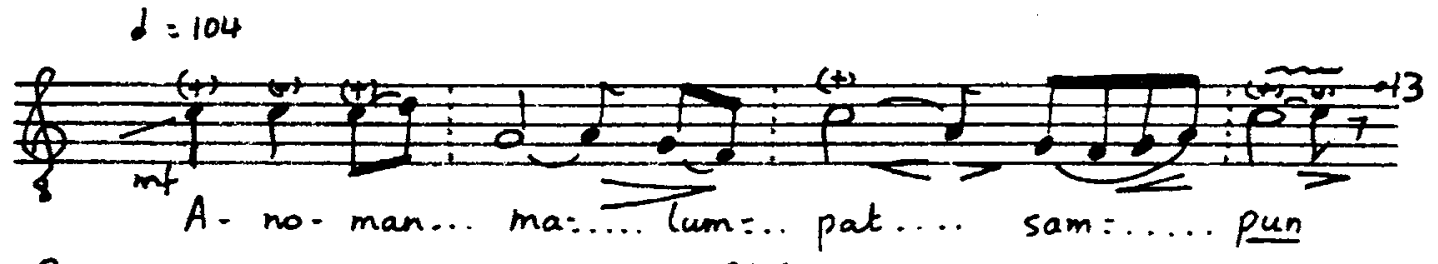

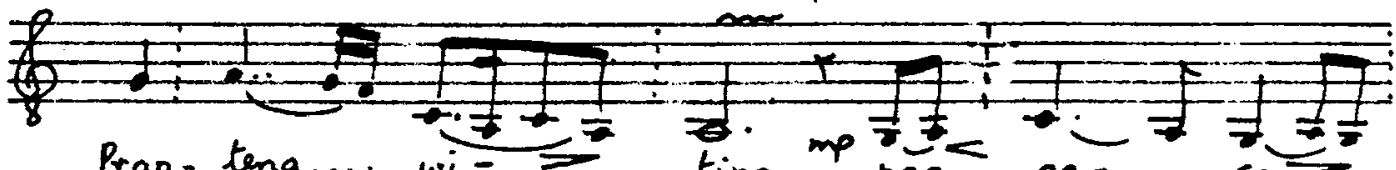

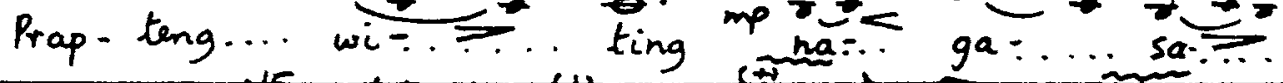

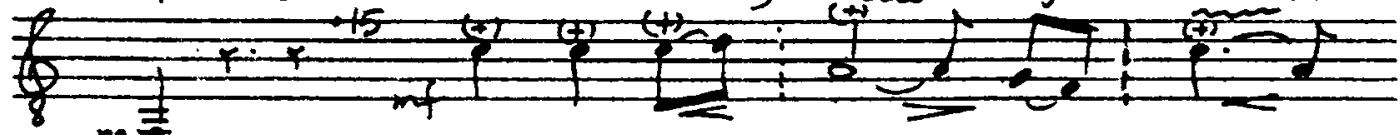

pp

Mu- lat ma... ngan- dap.. Ka ...
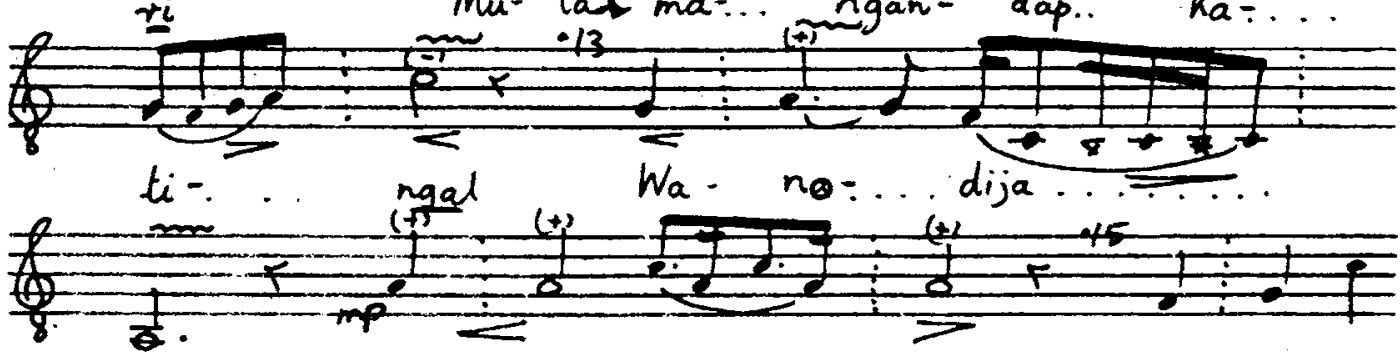

jue Ku- ru $a$-.i. King Ge-lung ru-

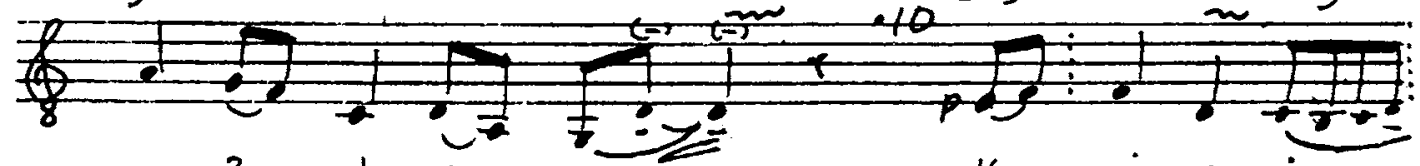

Sak wor.. lan Kis.. ma..... Kang $i$-ga. $i-\ldots$.

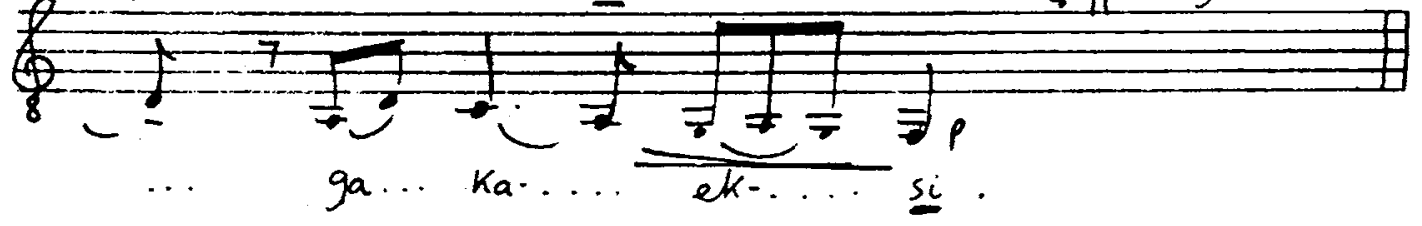


32. MASKUMAMBANG

SINGER: SUJITNO

T.L.: $0.30 \mathrm{~min}$.

O.P.: 2 tones higher

$(d=104)$

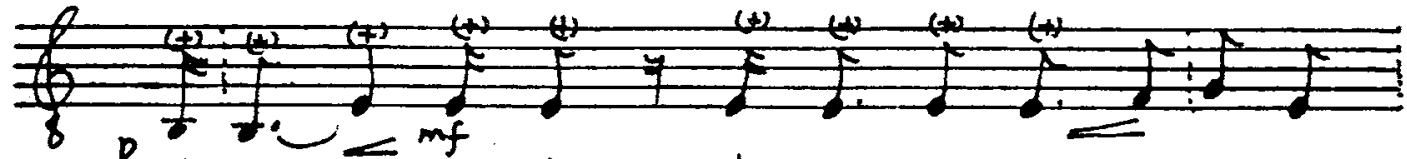

$p \sim m f$ -

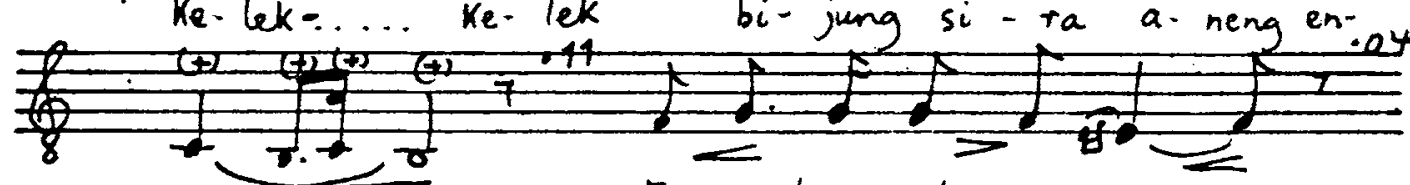

di

Eng-gal tu-kung-a-na...

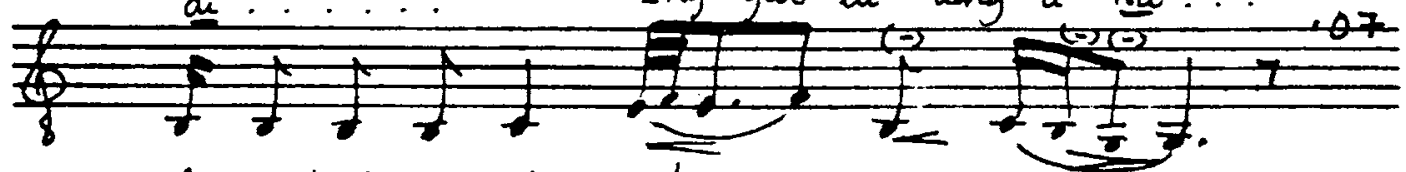

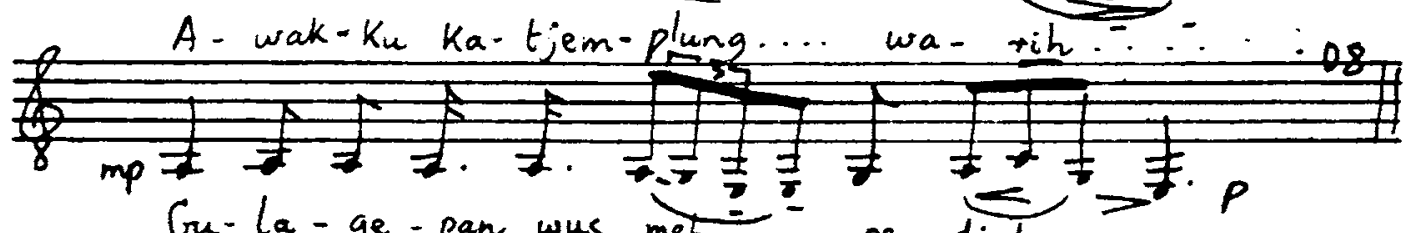

$G_{u}-l_{a}-g_{e}$ - pan wus meh … pe- djah.... 
33. DURMA ( $\mathrm{j} j$ angkriman)

SINGER: SUJITNO

T.L.: $0.38 \mathrm{~min}$.

O.P.: I tone higher
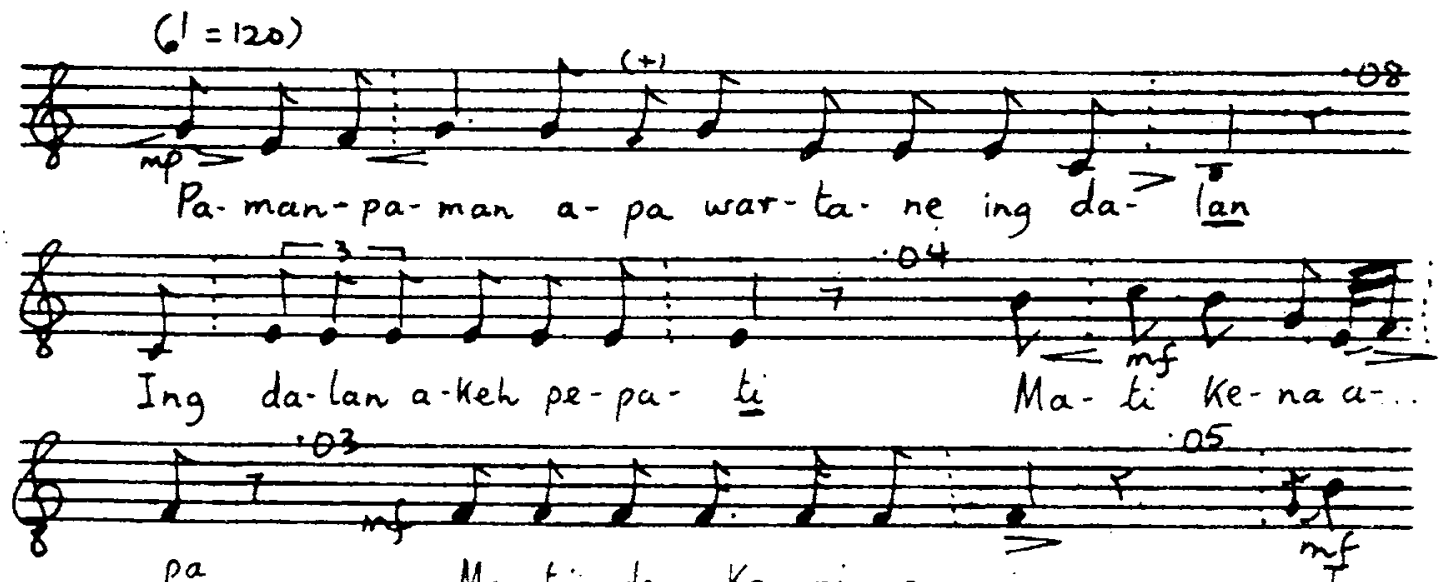

pa Ma ti den Ka ni.a. ja

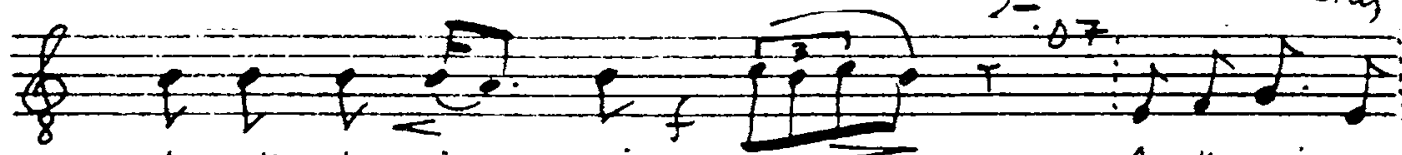

dja-dja trus ing... gi- gir... A-ka.ri ra-

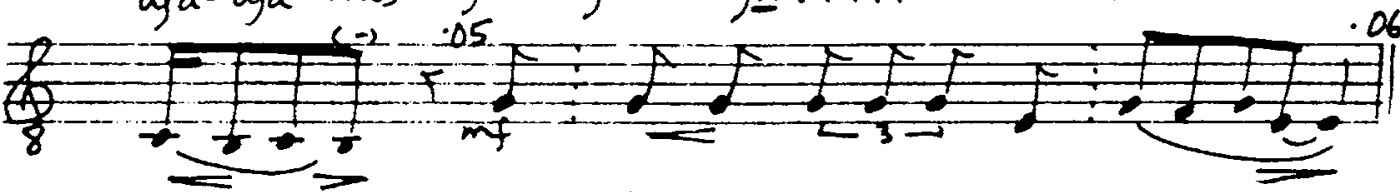

ga

Ba- dan-mja Ke-ti gumlin-ting 
34. PANGKUR MATJAPAT

SINGER: SUJITNO

T.I.: $0.35 \mathrm{~min}$.

O.P.: $\frac{1}{2}$ tone higher

$(!=126)$

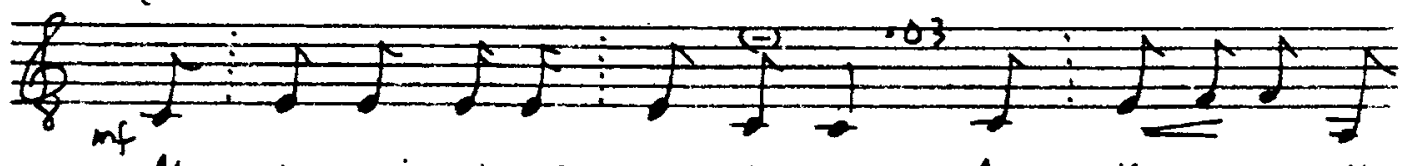

Ming-Kar-ming-Kur ing ang-Ka-ra A- Ka-ra-na Kar.
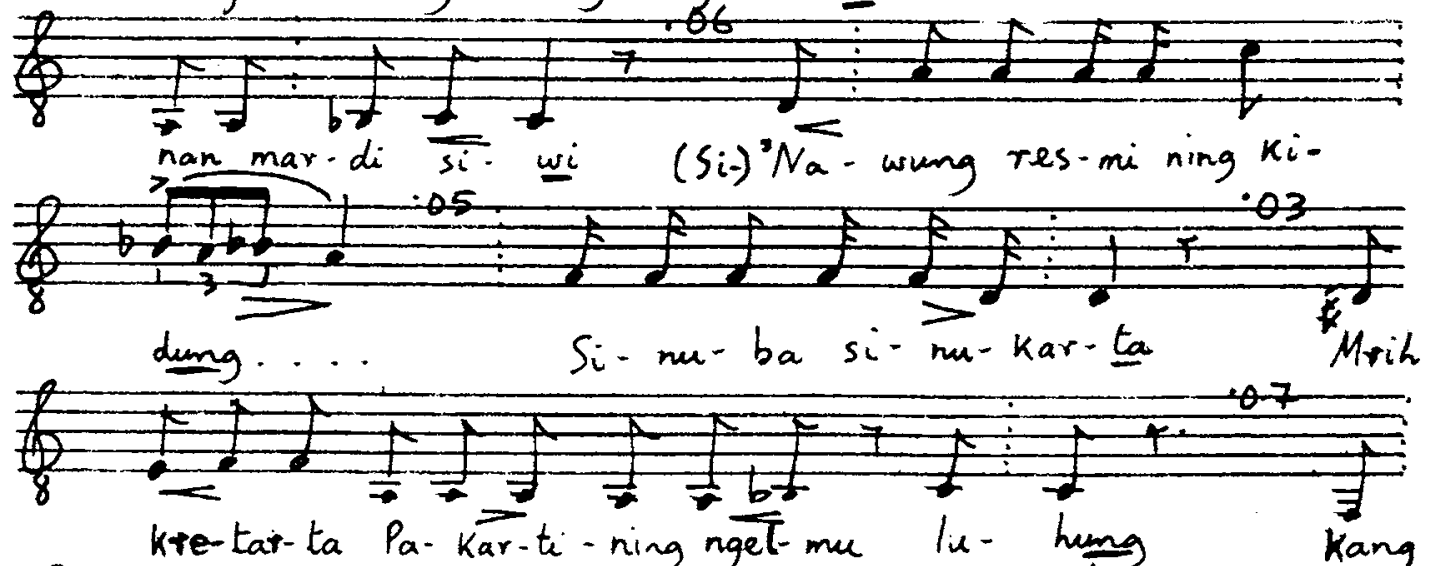

kre-tar-ta $\mathrm{Pa}-\mathrm{kar}-t_{i}$-ning nget-mu lie- hung Kang
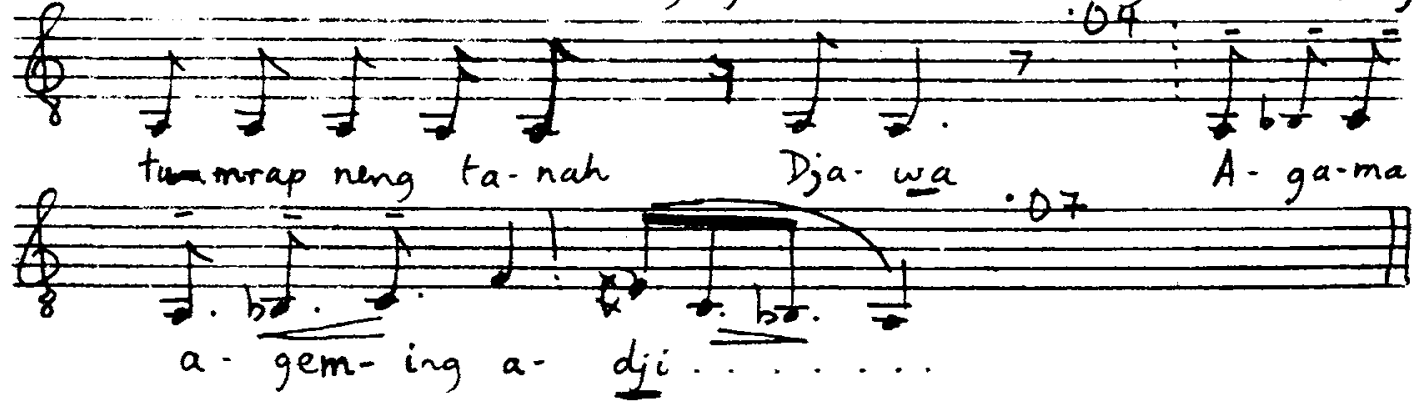
35. MIDJII

SINGER: SUJITNO

T.L.: $0.27 \mathrm{~min}$.

O.P.: 2 tones higher

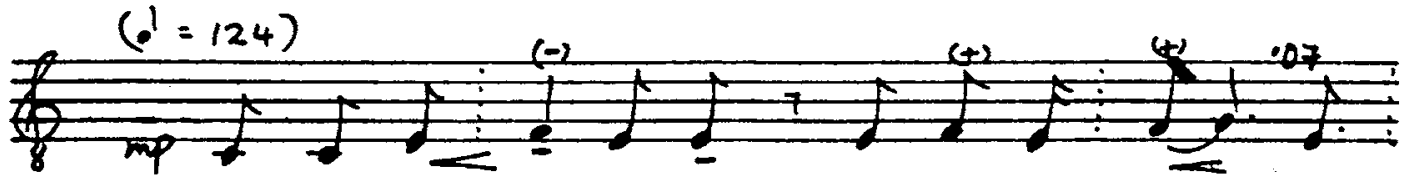

Po- ma-ka- Ki pa-da di-pun e-ling... Ing
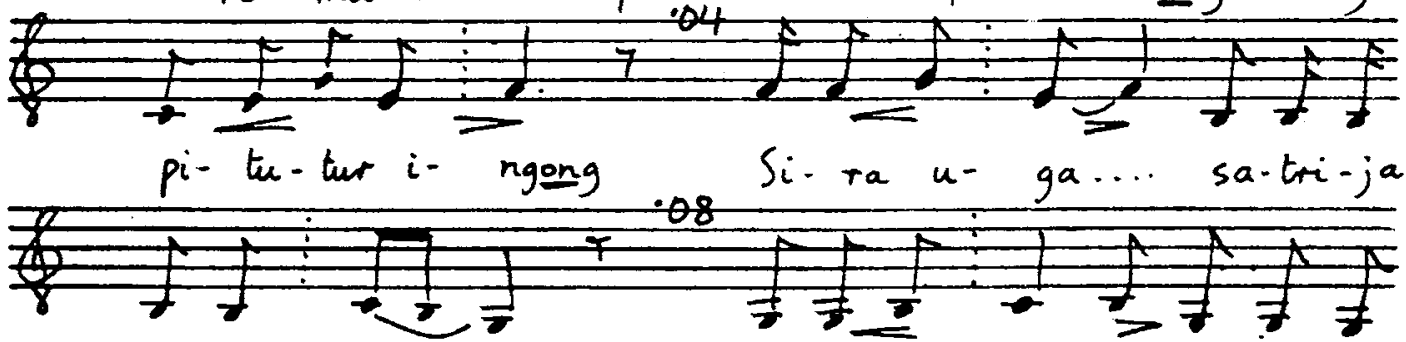

$a-\tan -e \ldots k u-d u$ an- teng djat-mi-ka ing
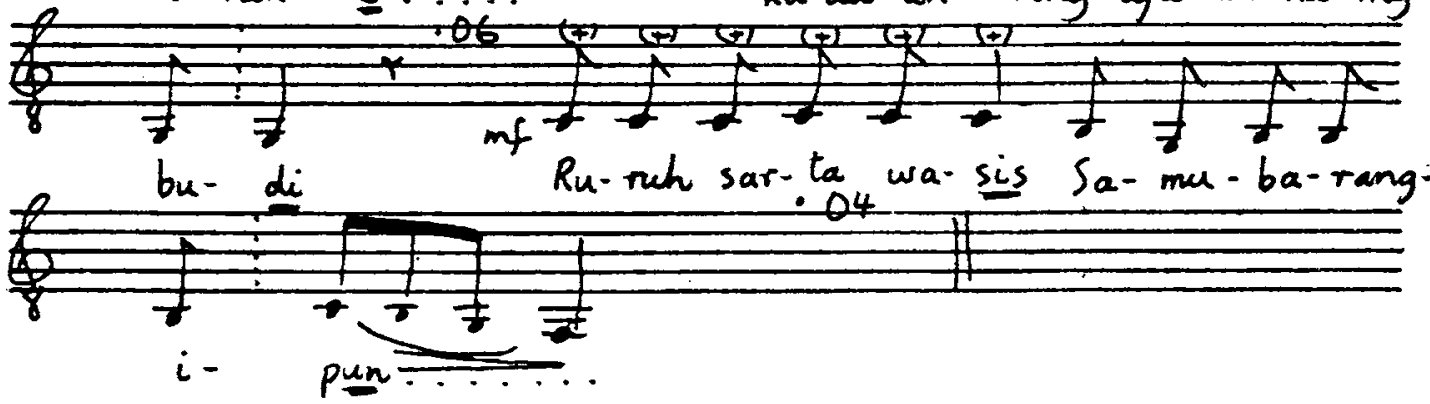
36. DANDANGGULA

SINGER: KARSTMAN

HOME TOWN: MANDESAN, near BLITAR

T.L.: 0.08 min.

O.P.: 1 tone higher

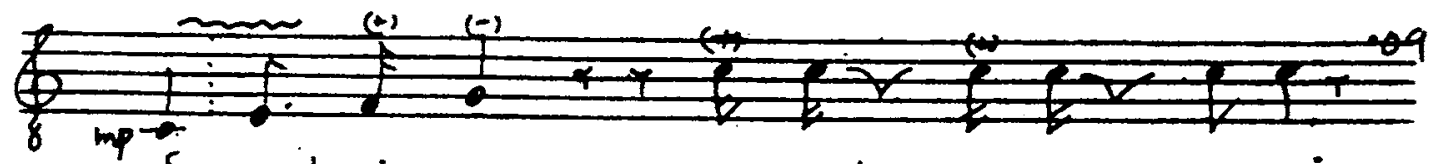
Se-mut $i$ - reng a-nak-a-nak sa-pi

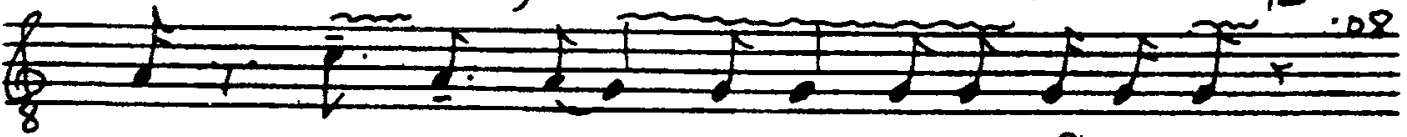
Ke - bo bong-Kang.. nja-brang Ka-li Be-nga-wan $\frac{1}{40+2}$ $k_{c}$ - jong gon-dang tjrak su-ngut - $s \ldots .$.

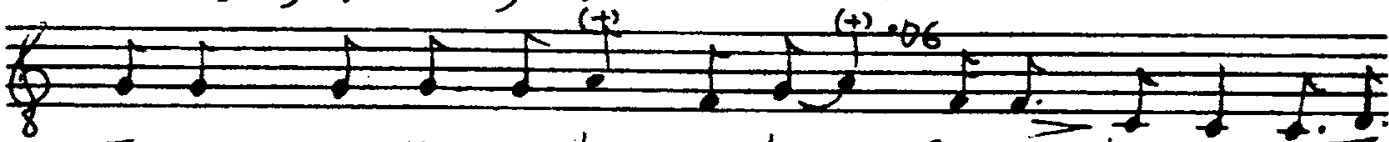
Ti-mean wu-ku go-dong wo-ku... Su-ra-ba-ja ge-ger $k_{e-p a-k_{i}}$

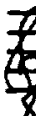
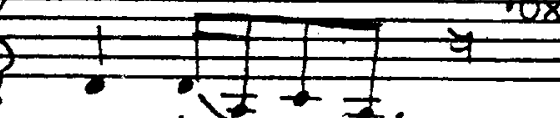

$+1+7$

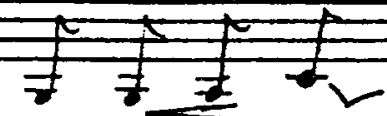
$m a-t j a n$

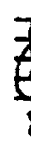

8
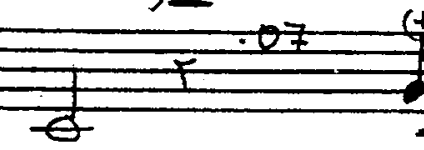

(+) (t) $T_{j i}-\overline{n a n-d} k$-den $w a-d a-h_{i}$

bumbun $\longrightarrow$

$=2$

A-lun-a-lun kar-ta-su-ra

$9 a-$

4

djah... me-ta

$1 \frac{1}{2-1}=09$

$\frac{1}{7} \frac{1}{\frac{1}{7}}$

Tii-nan-tjang wit 


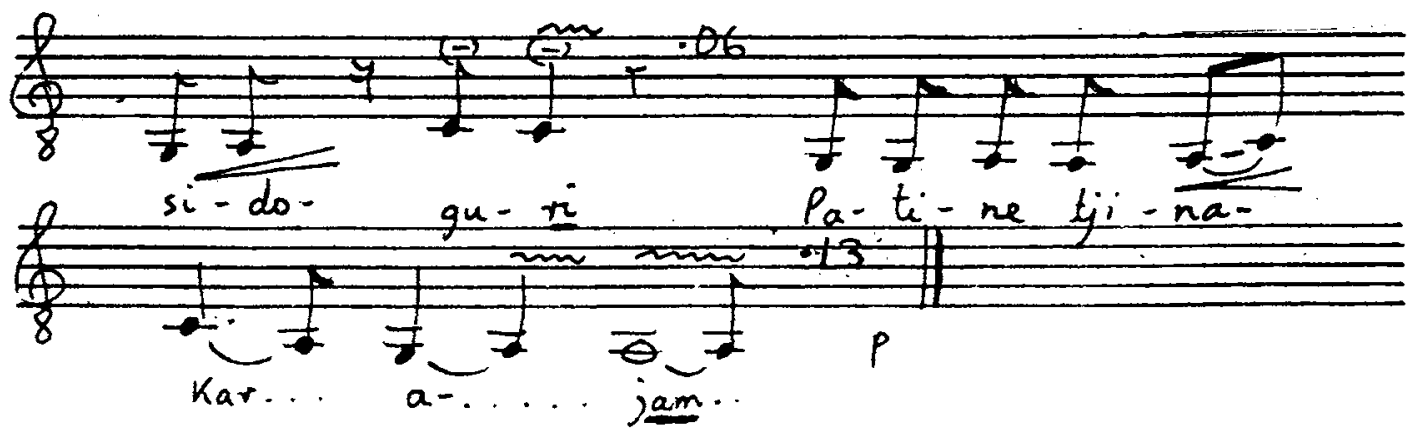


37. PUTJUNG

SINGER: KARSIMAN

T.L.: $0.42 \mathrm{~min}$.

O.P.: $\frac{1}{2}$ tone lower

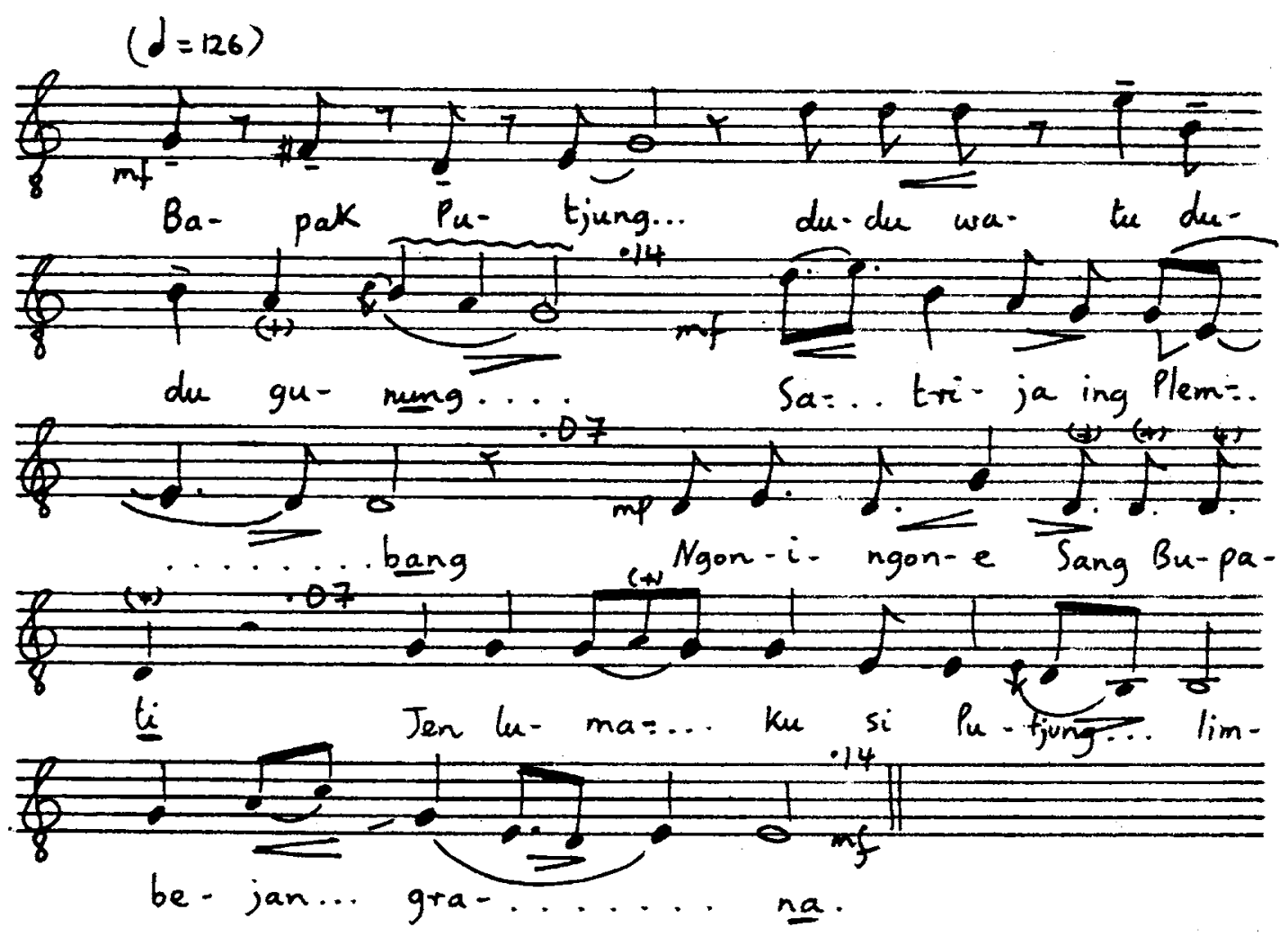


38. DANDANGGULA

SINGER: HERSOEBENO

HOME TOWN: MADIUN

T.I.: $0.72 \mathrm{~min}$.

O.P.: $I(t)$ tone higher

$(\cdot 1=124)$

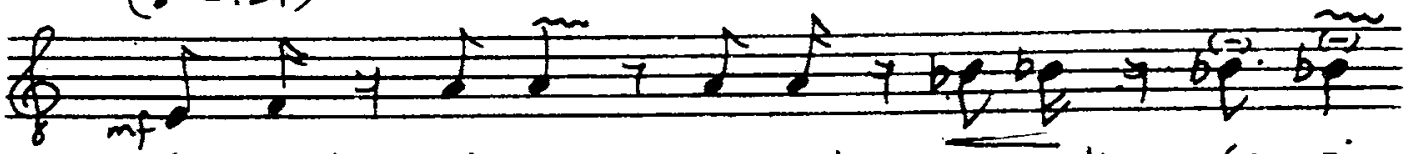

Se-mut $i$-reng a-nak- $a$-nak sa-pi

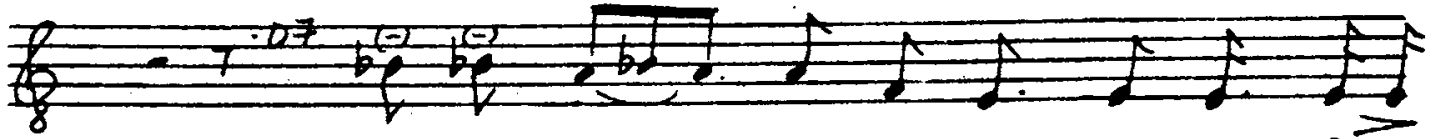

Ke-bo bong $=$... Kang nja-brang Ka-li Be-nga-

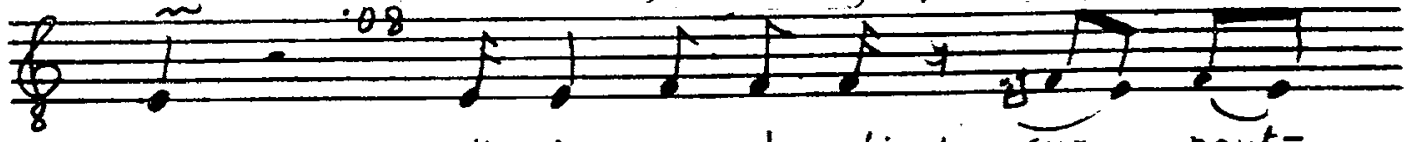

unan

Ke- jong gon-dang tirak su:... ngut:-

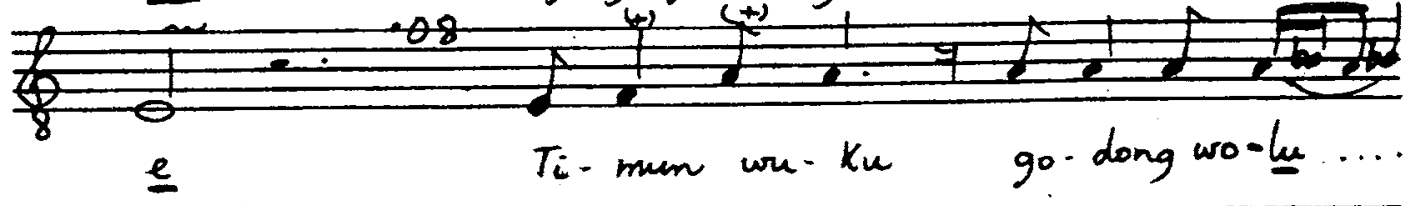

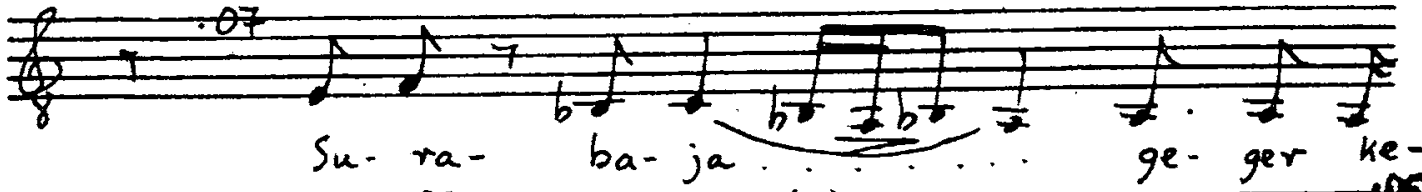

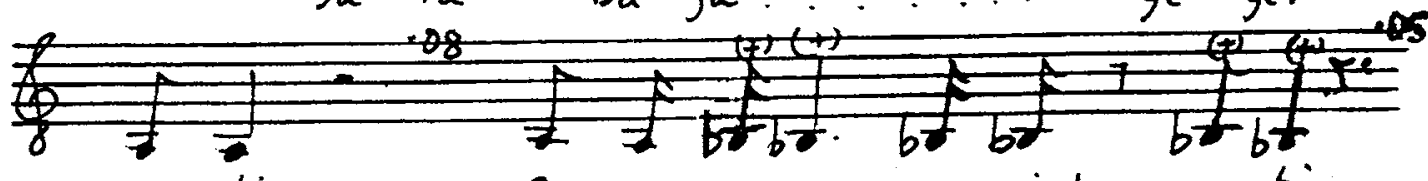
pa.
Ge-get-e wong ngo-jak
ma-tjan

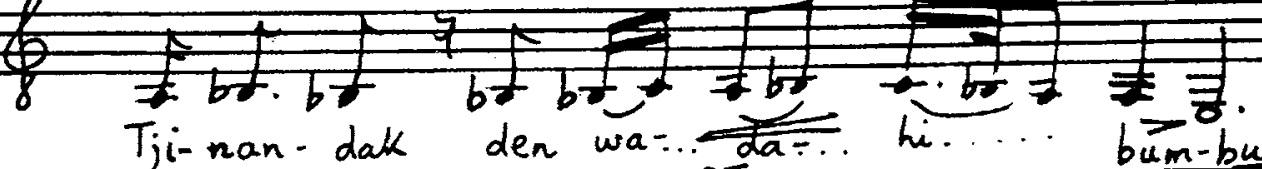
(f) $A$-lun-a-hun kar-ta-su-ra $\quad G a-d j a h$ me-ta tji- 
39. MASKUMMAMBANG

SINGER: HERSOEBEINO

T.I.: $0.29 \mathrm{~min}$.

O.P.: 2 tones lower

$(d=112)$
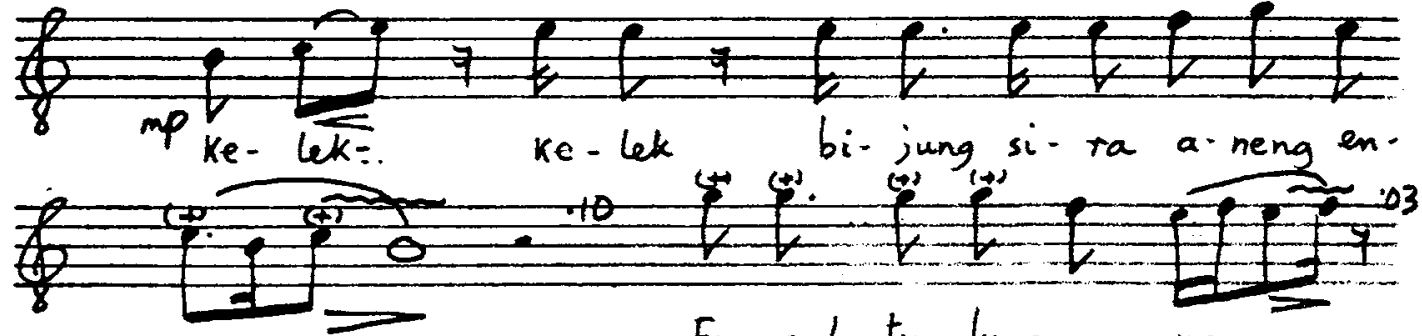

Eng-gal tu-lung-a- na...

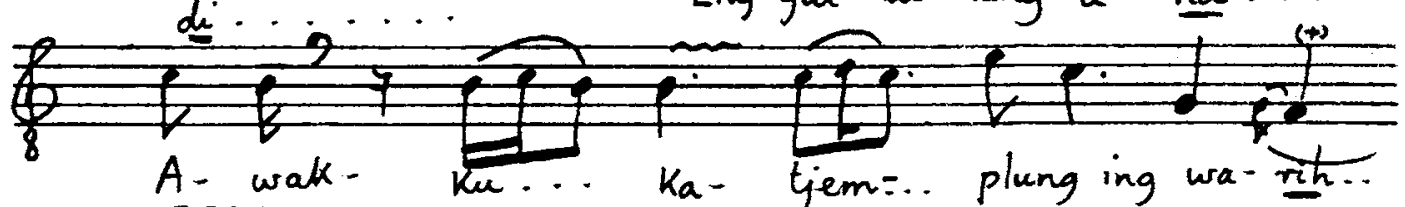

A- wakk - ku... $k_{a}$ - tjem-.. plung ing wa-rih..
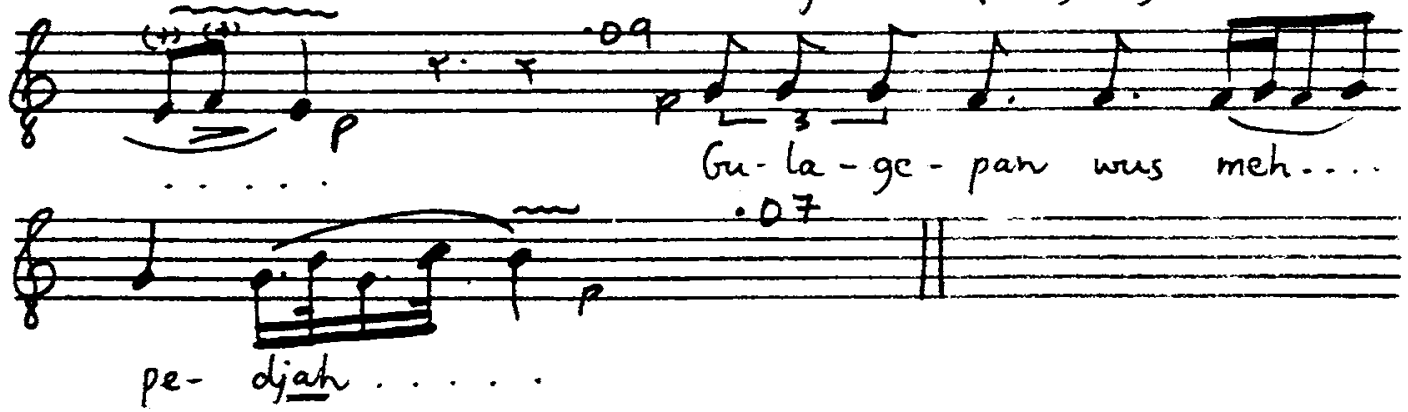
40. KINANTI GONDOMASTUTI

SINGER: HERSOEBENTO

T.L.: $0.90 \mathrm{~min}$.

O.P.: as below

\section{$(1=95)$}

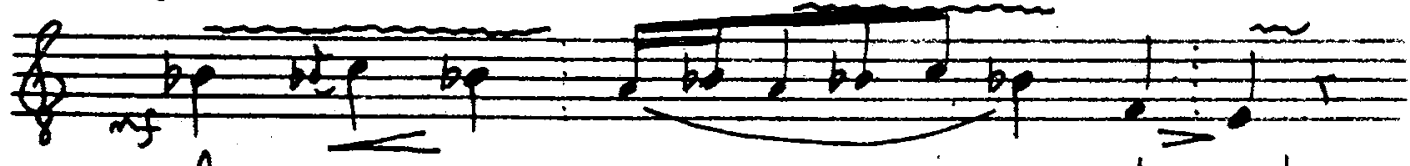

$A-\frac{1}{n_{0}-}$ man $m a=\ldots \ldots$ lum-pat

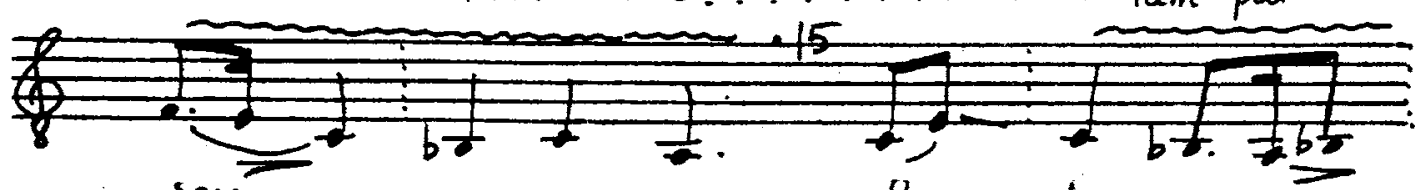

sam ... pun .... Prap ... teng wi-...

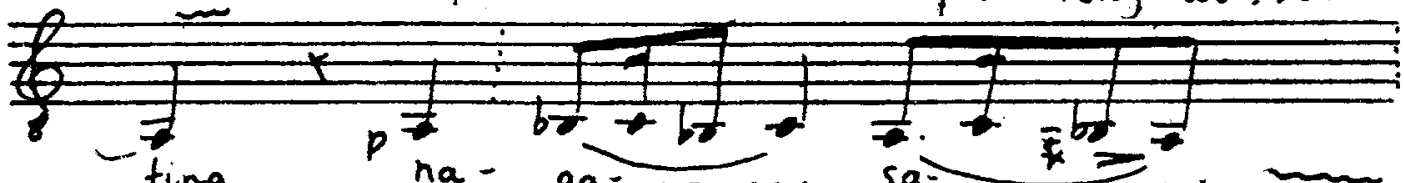

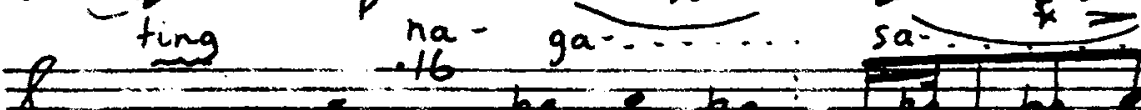

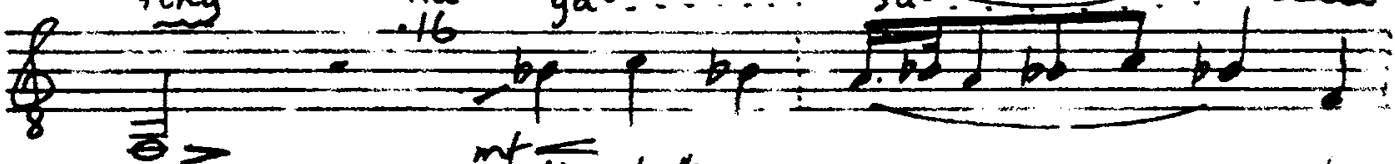

it mf $\overline{M_{u}}$ latma - ngan

7 idat

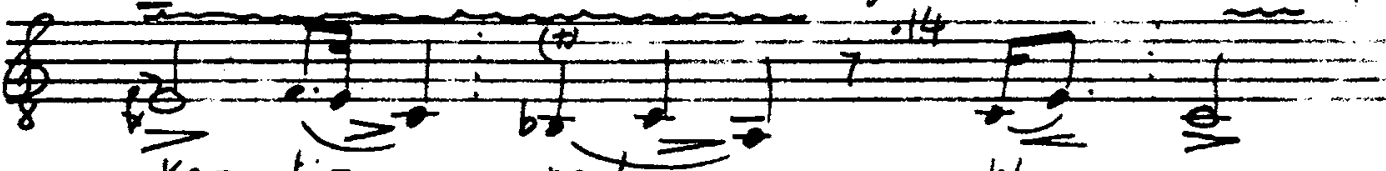
$\mathrm{Ka}-$
$t_{i}-$
ngat $=\ldots$
Wa-.
no-

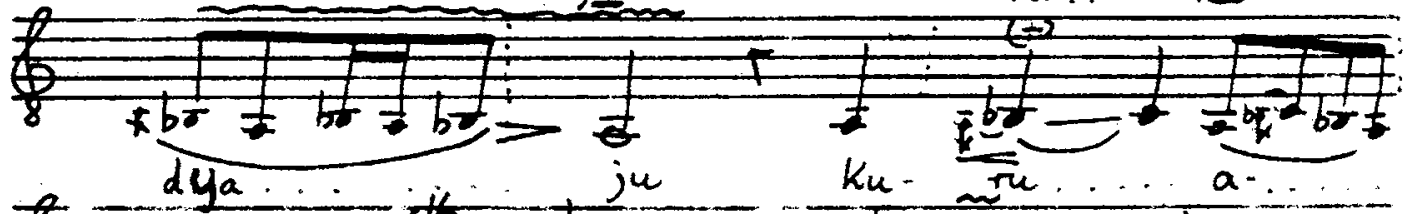

to lung ru sak a 
300

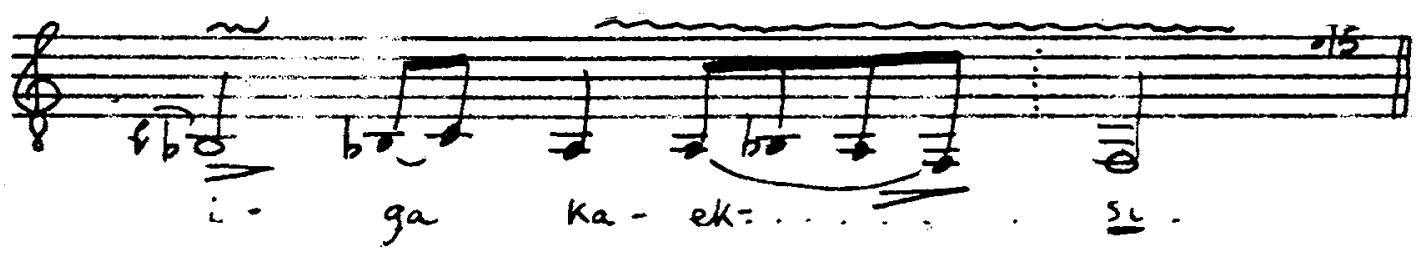


41. KINANTI PANGKUR

SINGER: HERSOEBENO

T.L.: $1.02 \mathrm{~min}$.

O.P.: $\frac{1}{2}$ tone higher

$(d=115)$

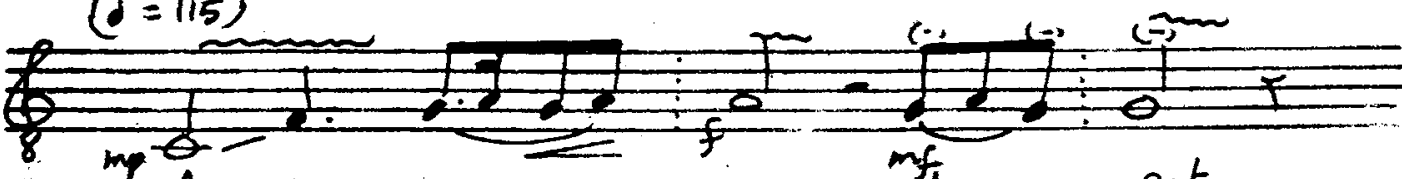

$m_{A}$ no. man ma. mf mot

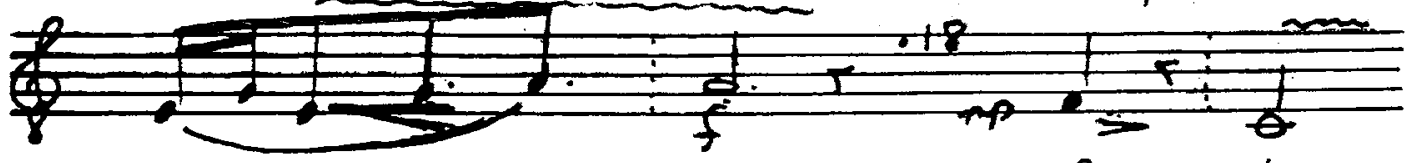

sam-

Sam

Ii Mu- lat ma-.....ngan- dap...
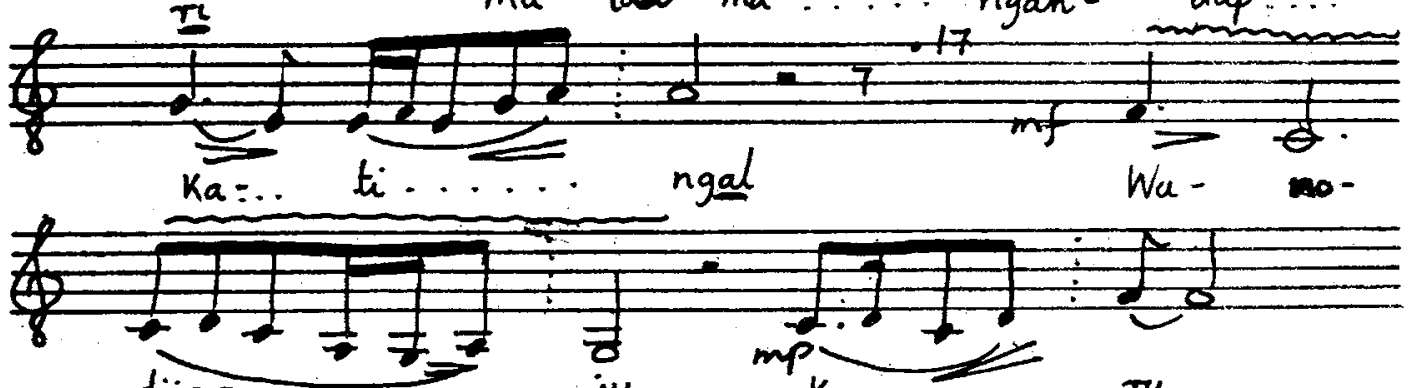

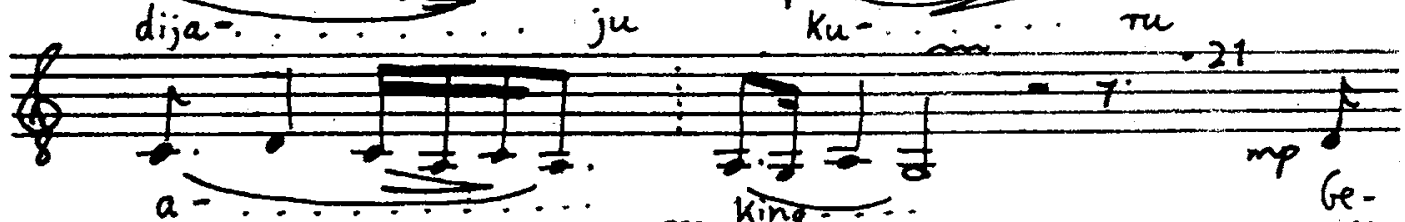

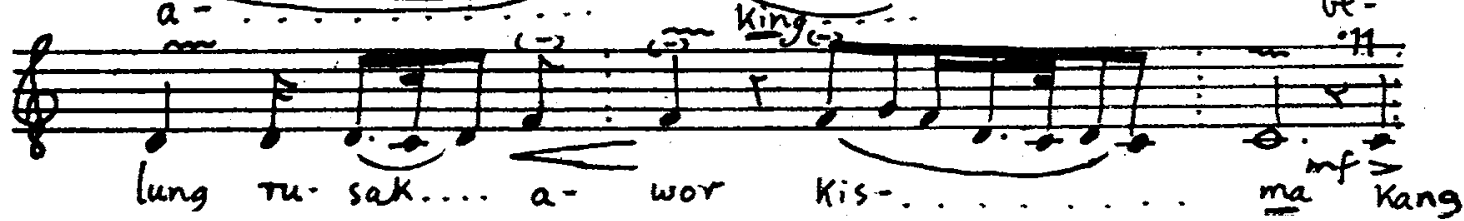




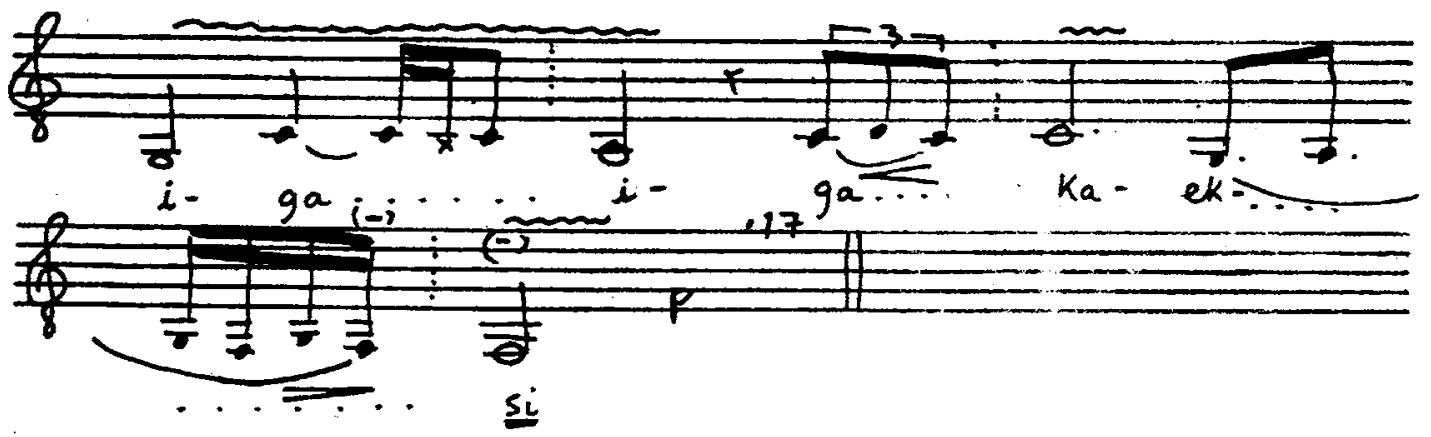


42. PANGKIUR PALARAN

SINGER: HERSOEBENO

T.L.: $1.06 \mathrm{~min}$.

O.P.: $\frac{1}{2}$ tone higher

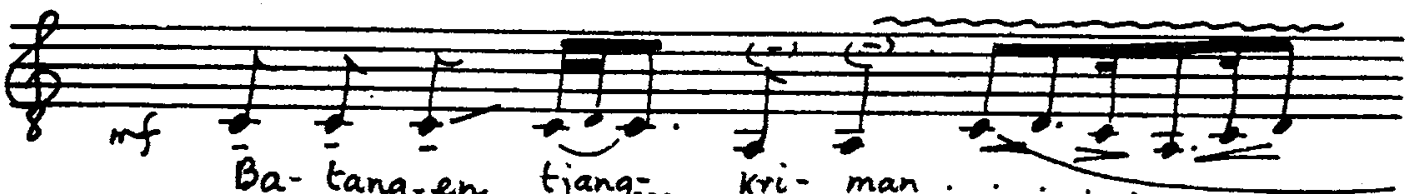

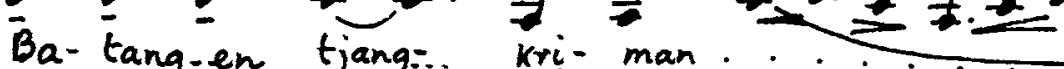
(1ng C $\mathrm{mf}^{2}=2$ Lu- lung a- na ge-dang A. na.... pi-lik nda-
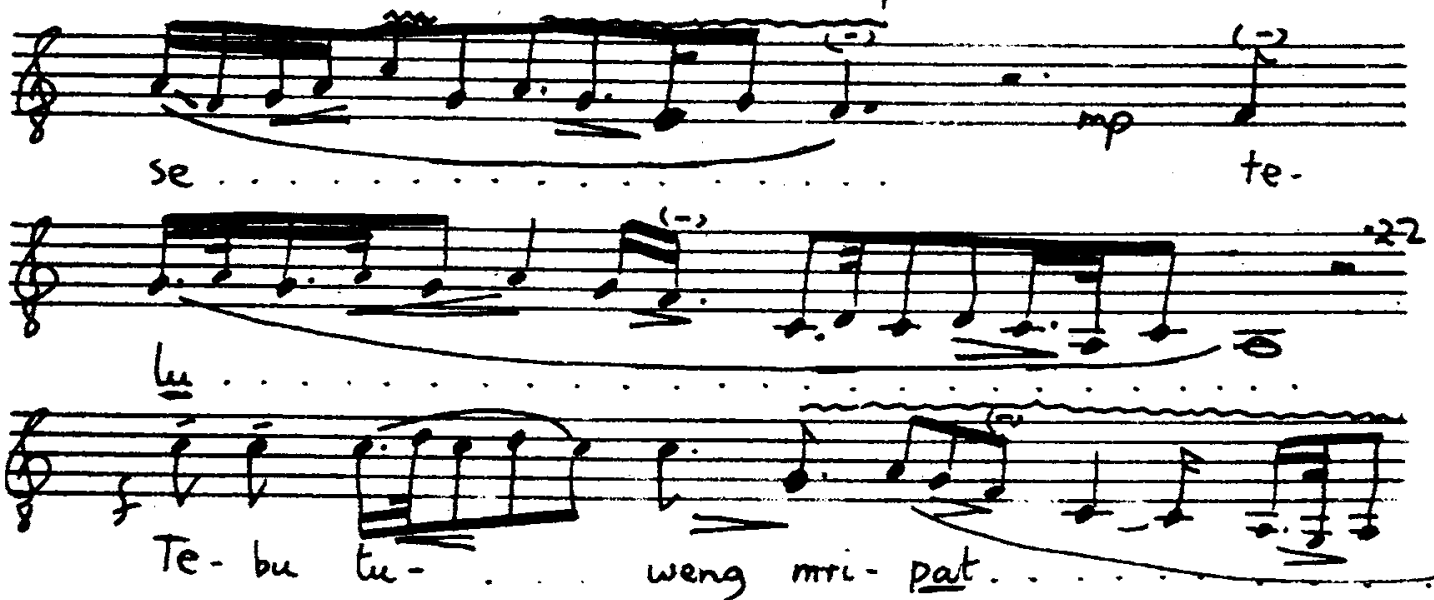


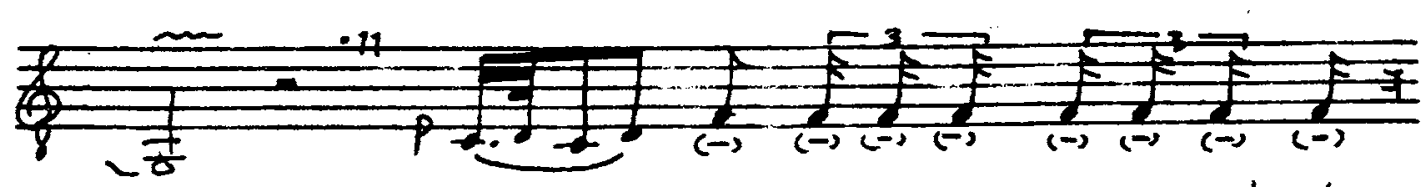
$k, a-. \quad$ da.lang en ma.ti da.tan
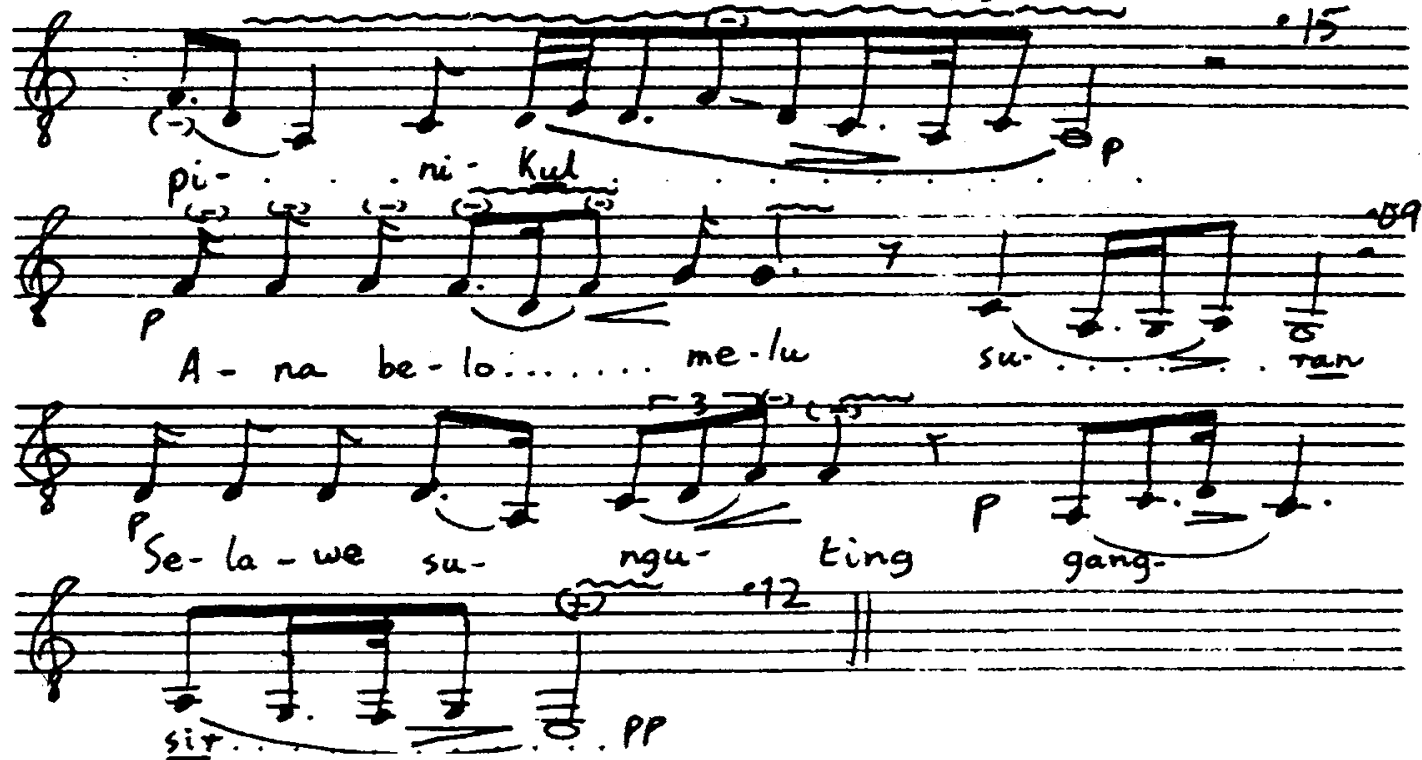
43. PANGKURR

Accompanied by GAMELAN from end of first line
SINGER: RUSMAN

HOME TOWN: SURAKARTA

SOURCE: LOKANANTA DISC

ALD-04I

T.L.: $2.87 \mathrm{~min}$.

O.P.: I tone higher

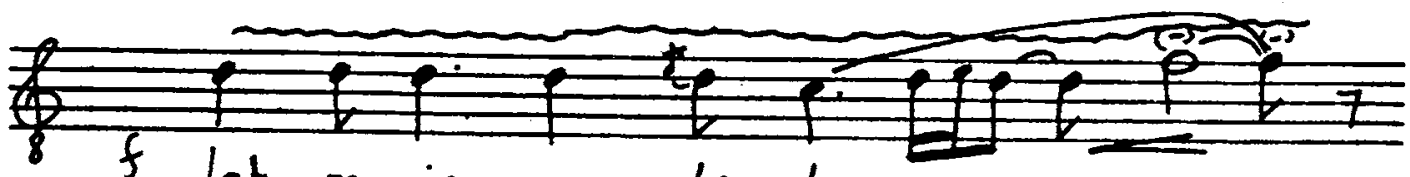
$f$ Lah pa-ja sun le- la.
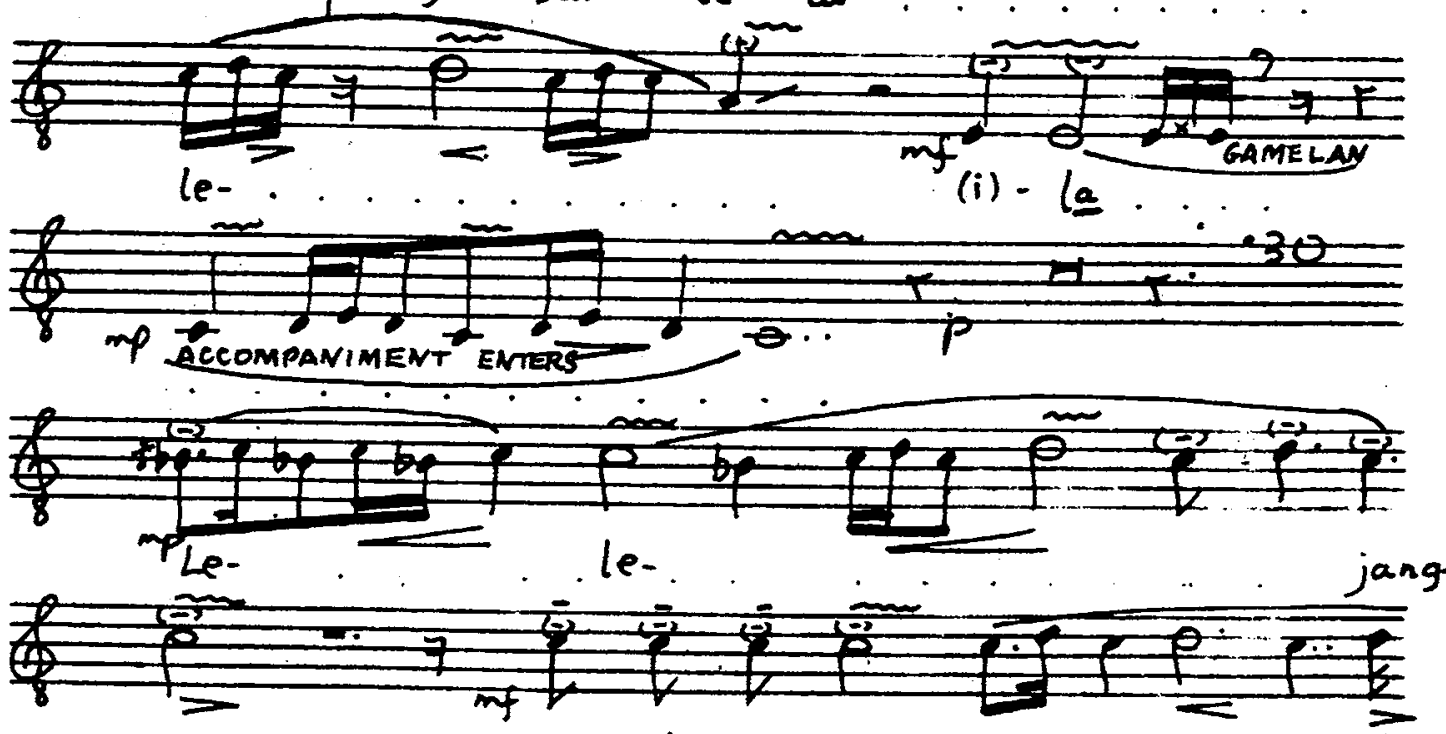

a

ngas-teng(e) sur mring
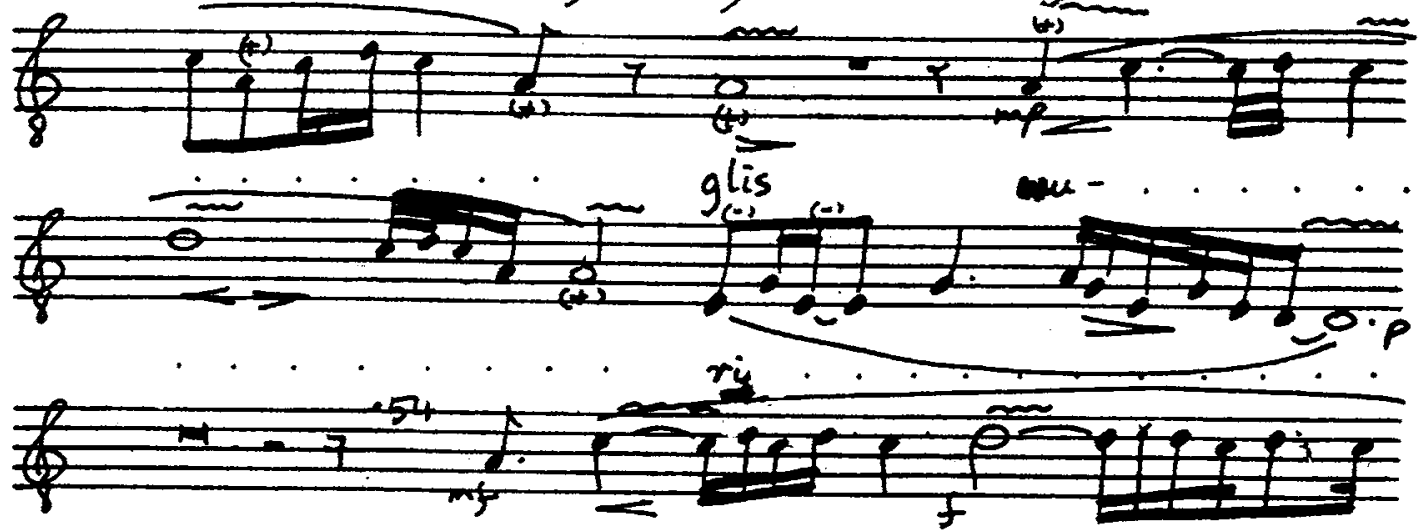

Li- na- 

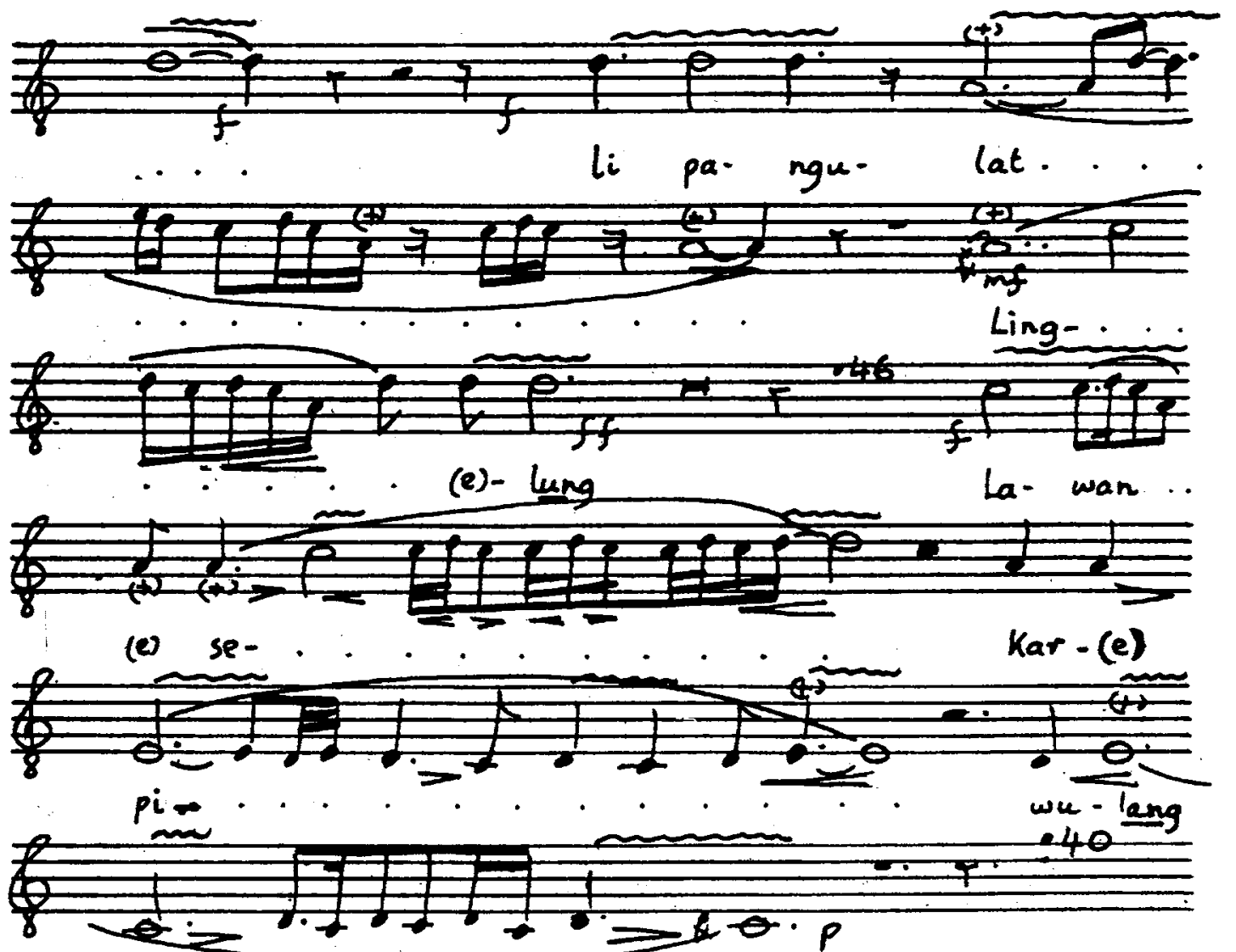

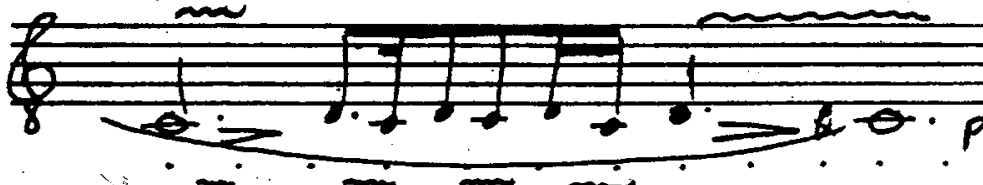

$\frac{1}{20}$ Lan-ta-tan-ing lu-lus

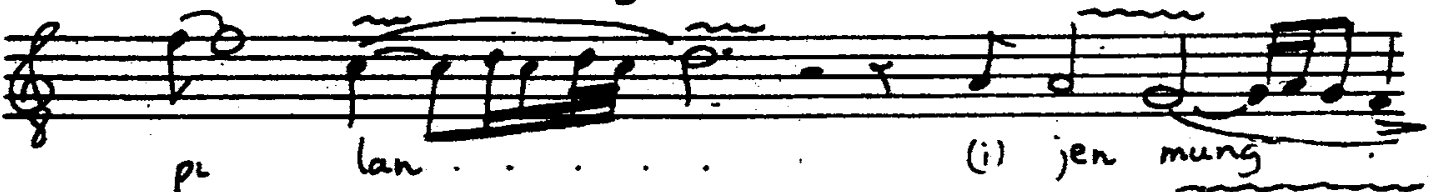

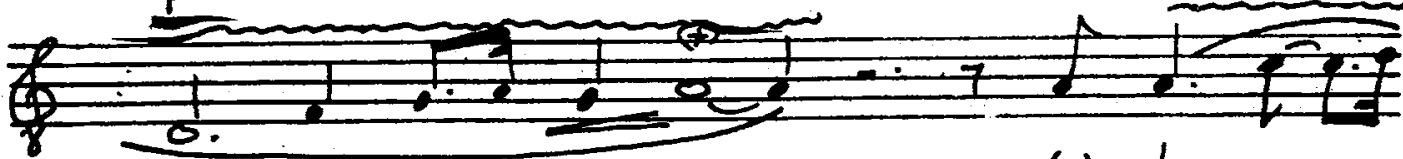
(e) lu(f) 
爭

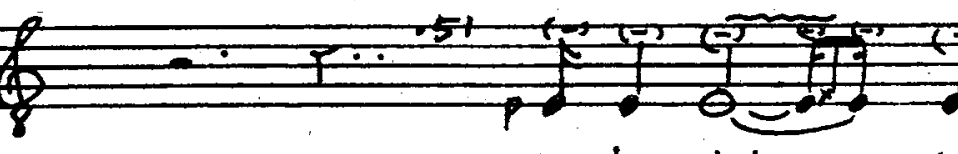

(e) Lan tek-

(e)
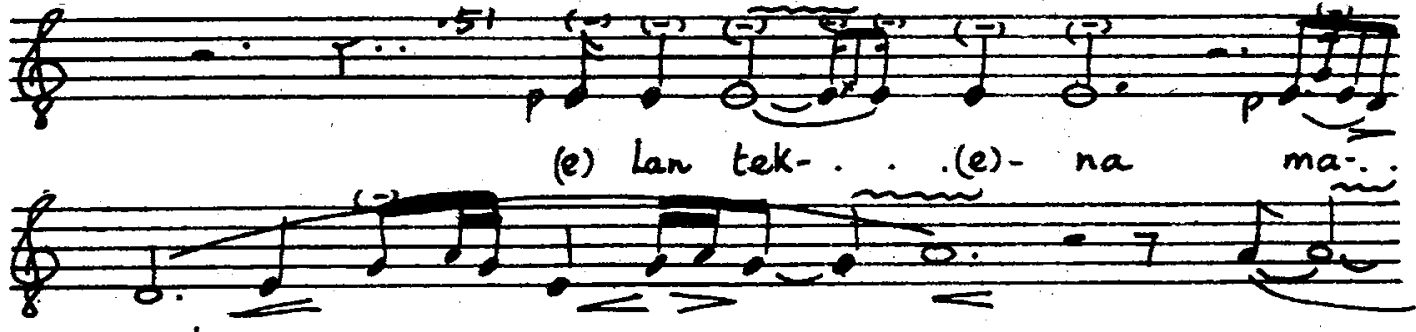
weh . . . . . . . . . . . .

nut-
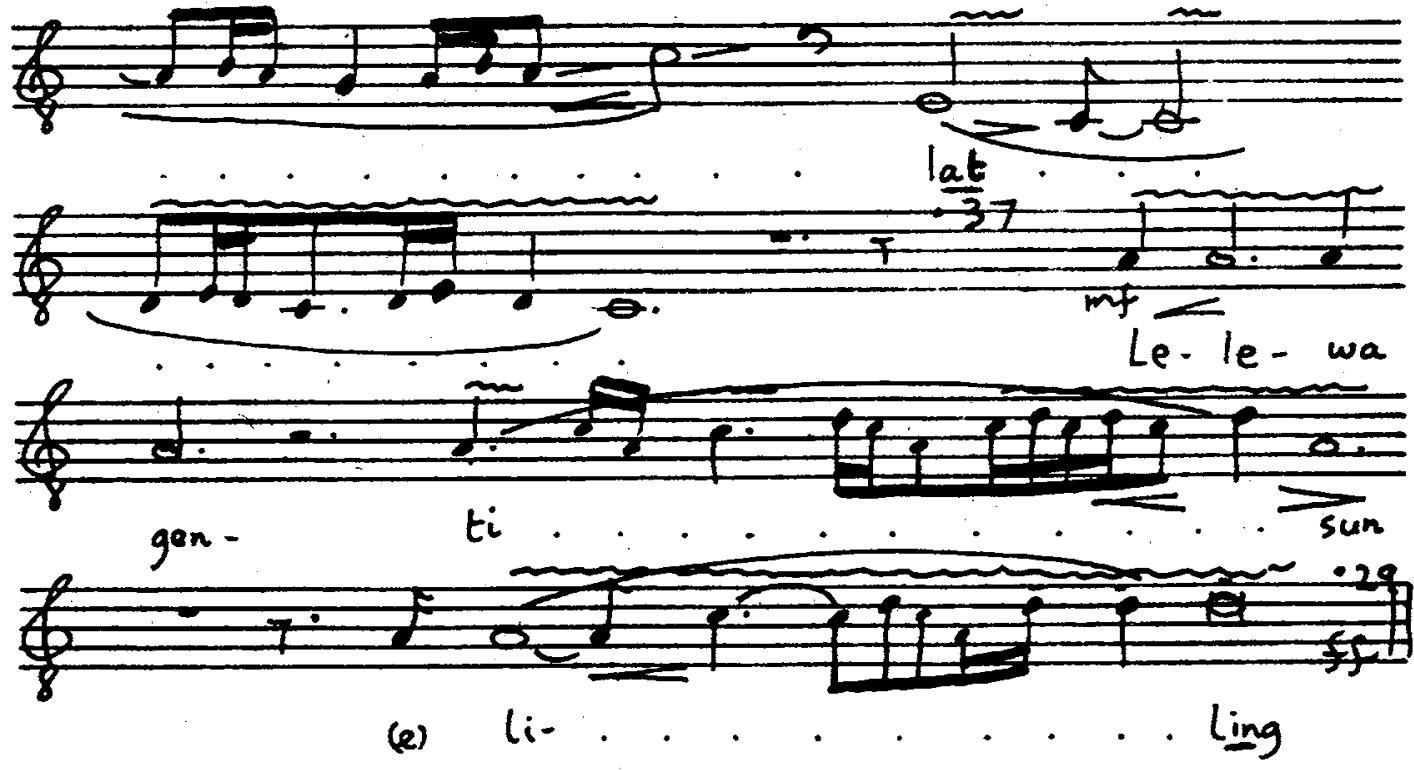
44. MIDJIL GRAMBJANGAN

(without GAMELAN accompaniment)
SINGER: RUSMAN

SOURCE: as in 43

T.L.: $1.44 \mathrm{~min}$.

O.P.: 1 tone higher

$d=116$
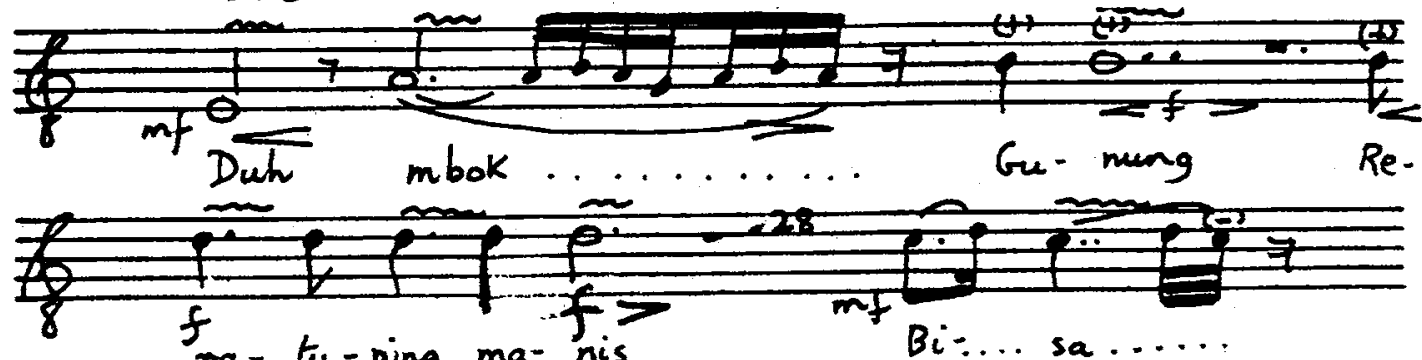

ra-tu-ning ma- nis

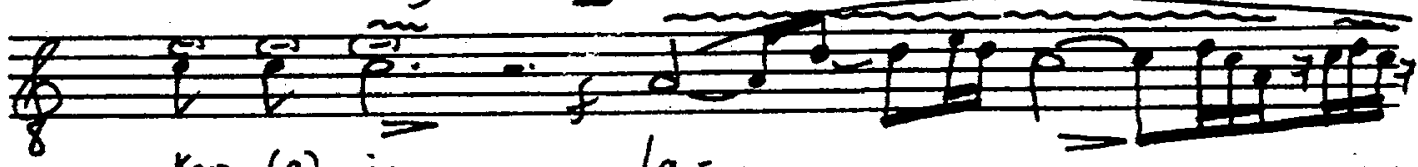

Kar- (e)-ja

la $\ldots . \ldots . .$.
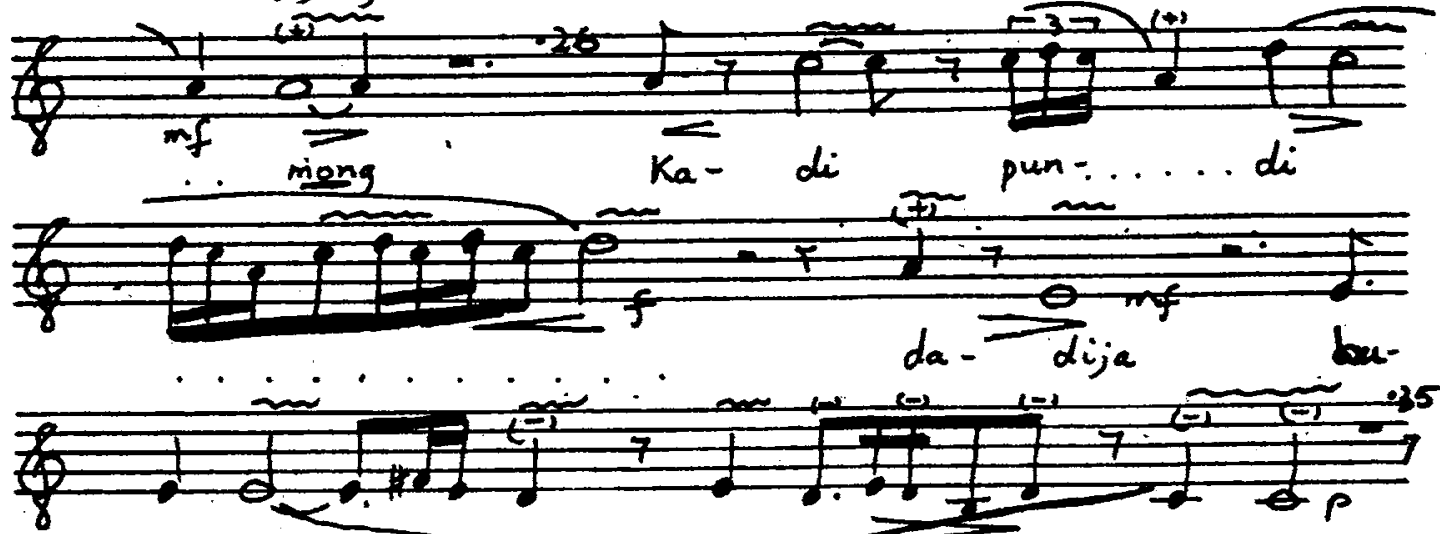

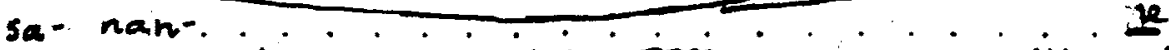
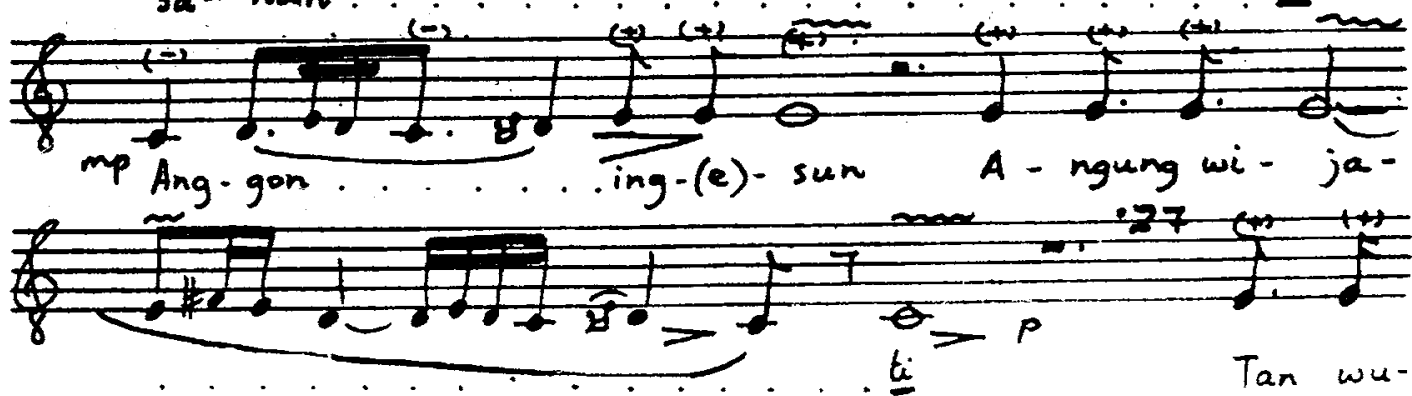

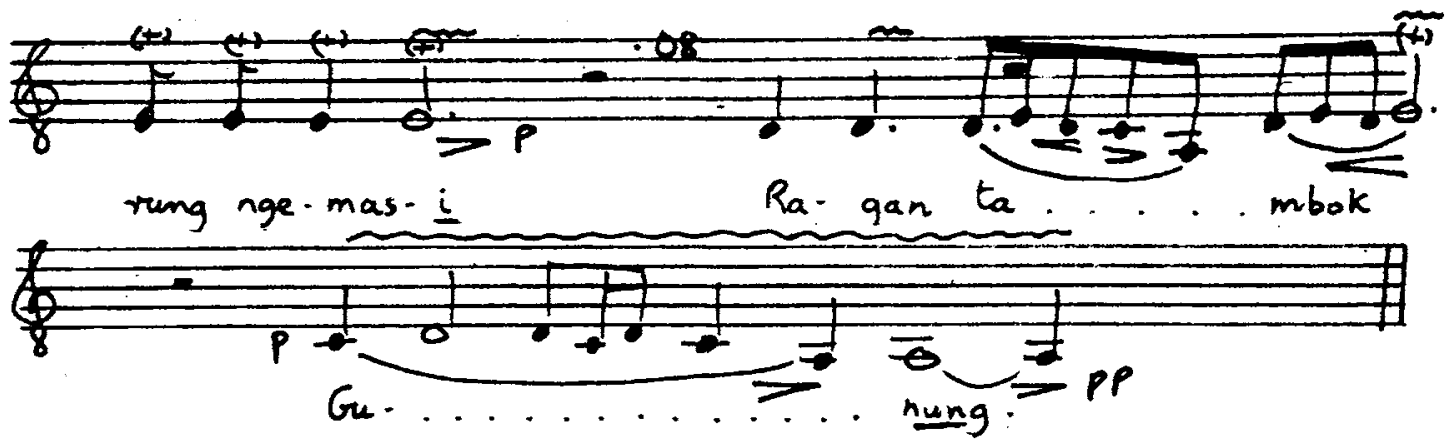
45. KINANTI

(with GAMETAN accompaniment)
SINGER: RUSMAN

SOURCE: as in 43

T.L.: $1.31 \mathrm{~min}$.

O.P.: 1 tone higher
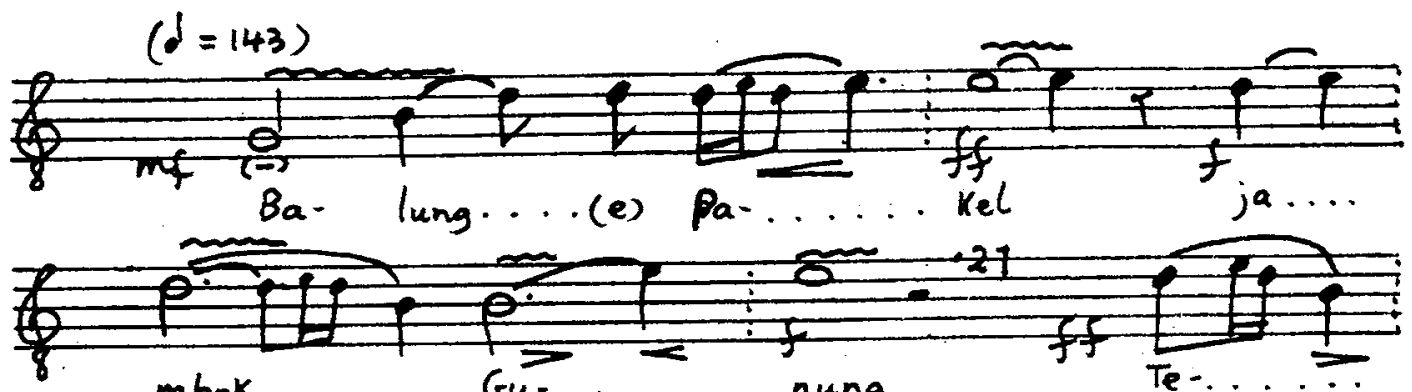

$$
\text { mbok.....Gu-......nung }
$$
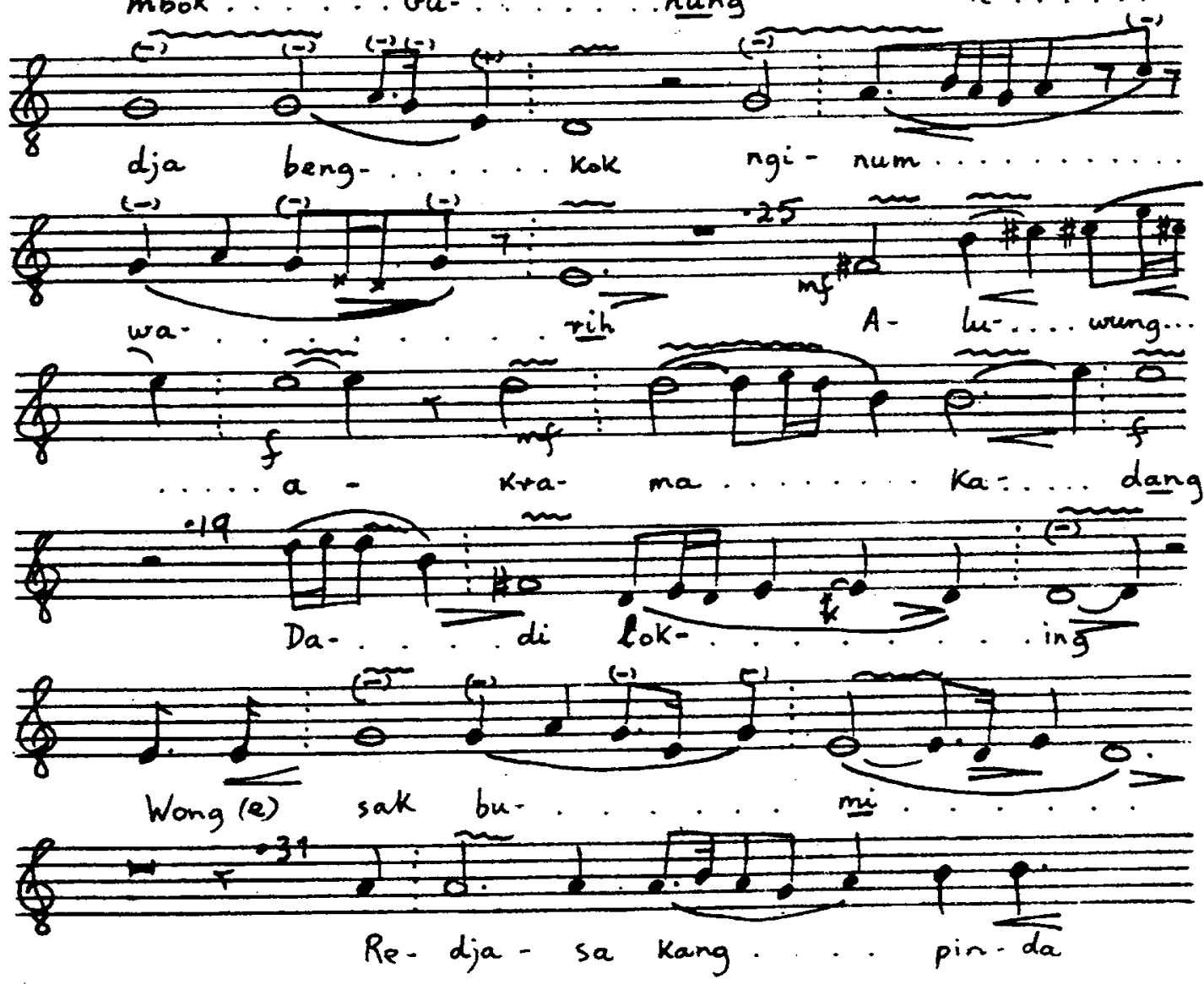


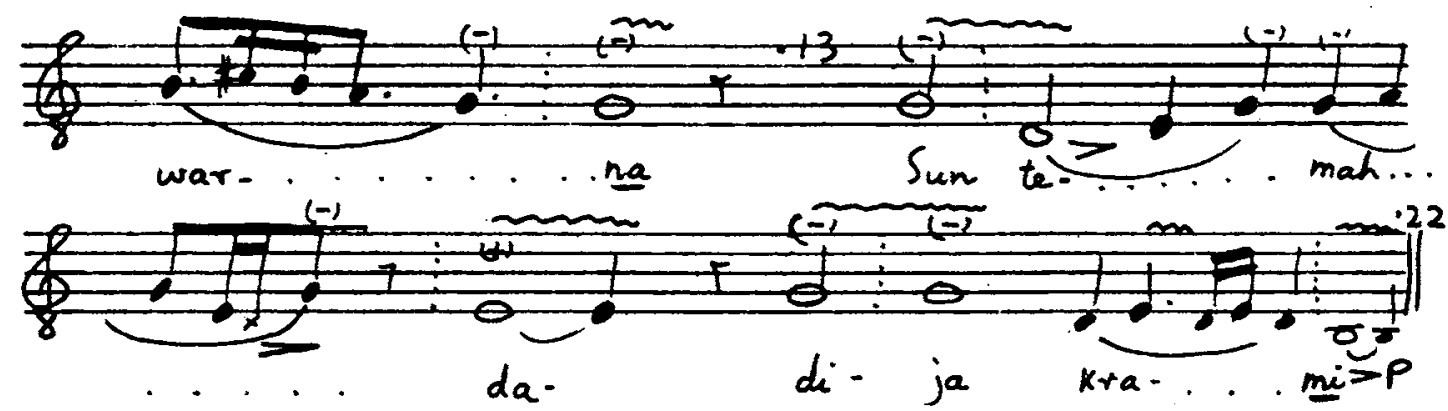


46. KINANTI

(with GAMETAN
accompaniment)
SINGER: RUSMAN

SOURCE: as in 43

T.L.: $1.27 \mathrm{~min}$.

O.P.: I tone higher

$(d=146)$.

(4)

$G_{i-}$ rang... ing $\ldots$ sun ... ja... mbok

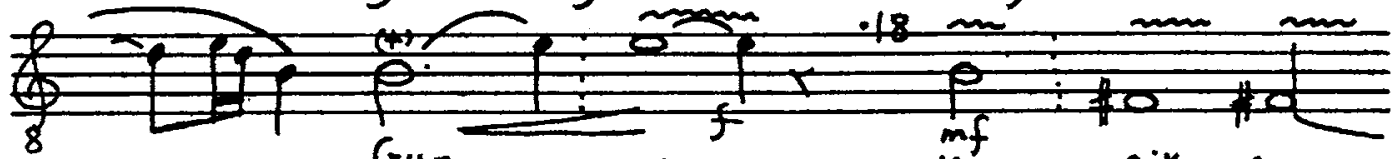
Gu-... nung ke $_{\text {n }}$ pik pong-

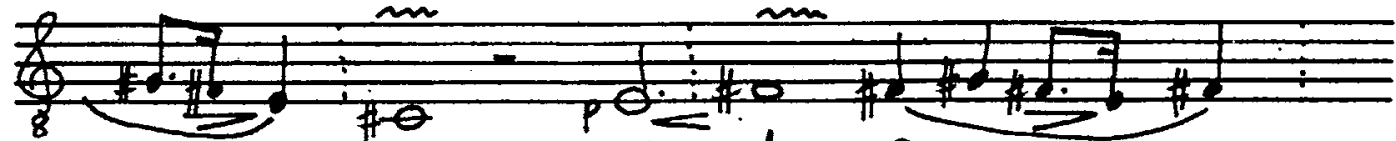
$8{ }_{\text {. }} \ldots \ldots$ gang $p$ pin- da we.........

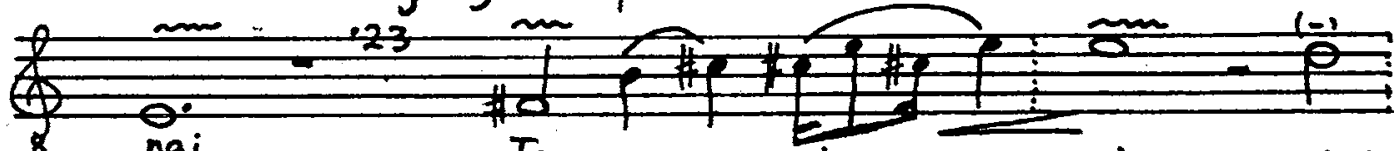
(Tan gu.... ming $\ldots \ldots$ sit teng..... pe ... djah Mung $\rightleftharpoons$ si-

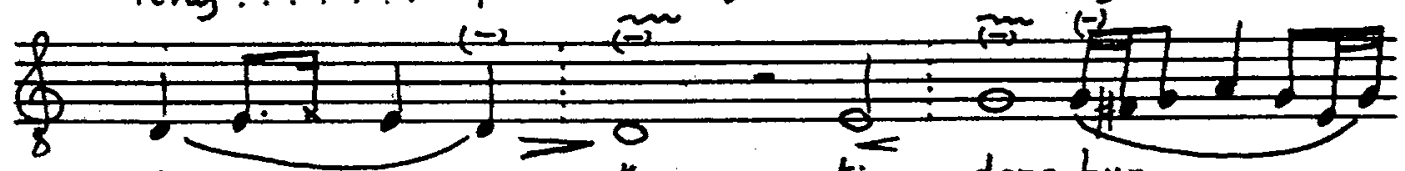
(1) di.........? Pek- si rengmang-....(e) कि sa $k u=\ldots$ nar ...... pa

Sun dang. 


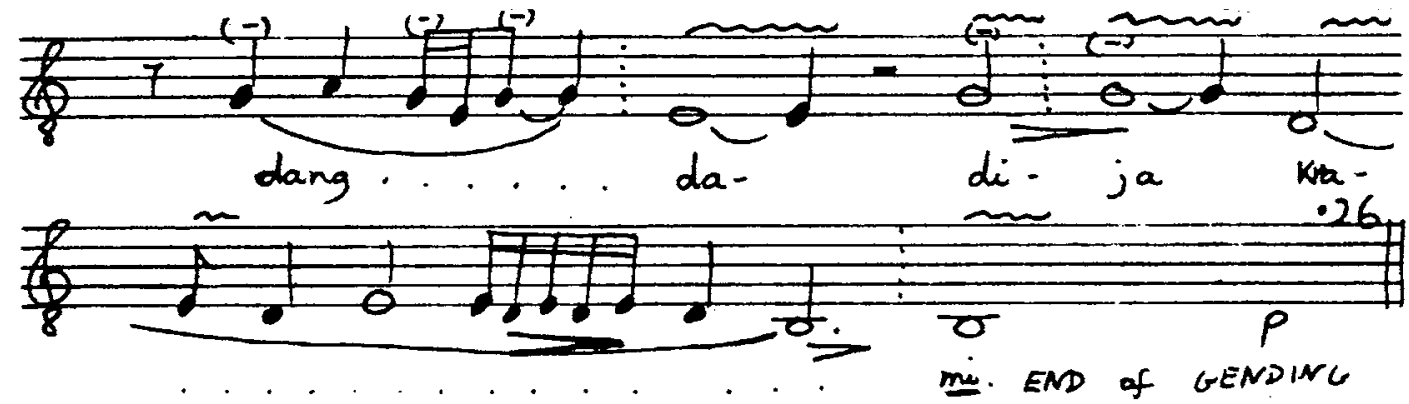


47. DANDANGGULA KASMARAN

SINGER: H. KARTOMI

HOME TOWN: BANDJAR

T.I.: $0.97 \mathrm{~min}$.

O.P.: 1 tone higher

$(d=106)$

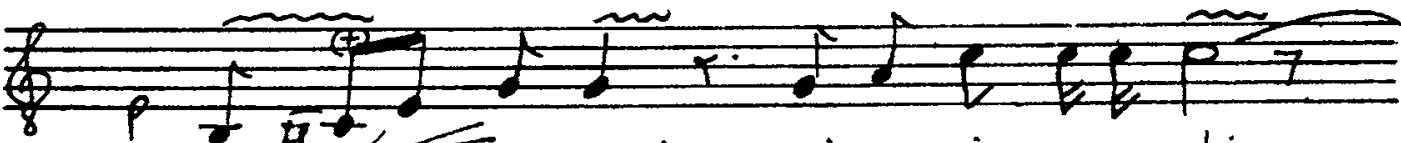

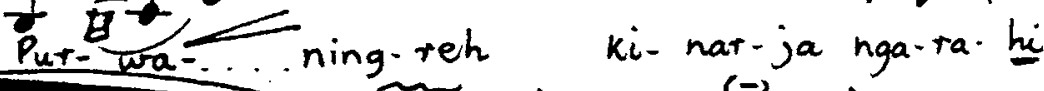

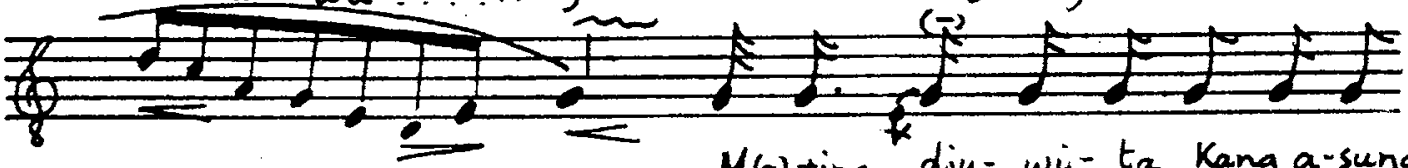
$\because$. . M(a)-ring dju-wi-ta Kang a-sung
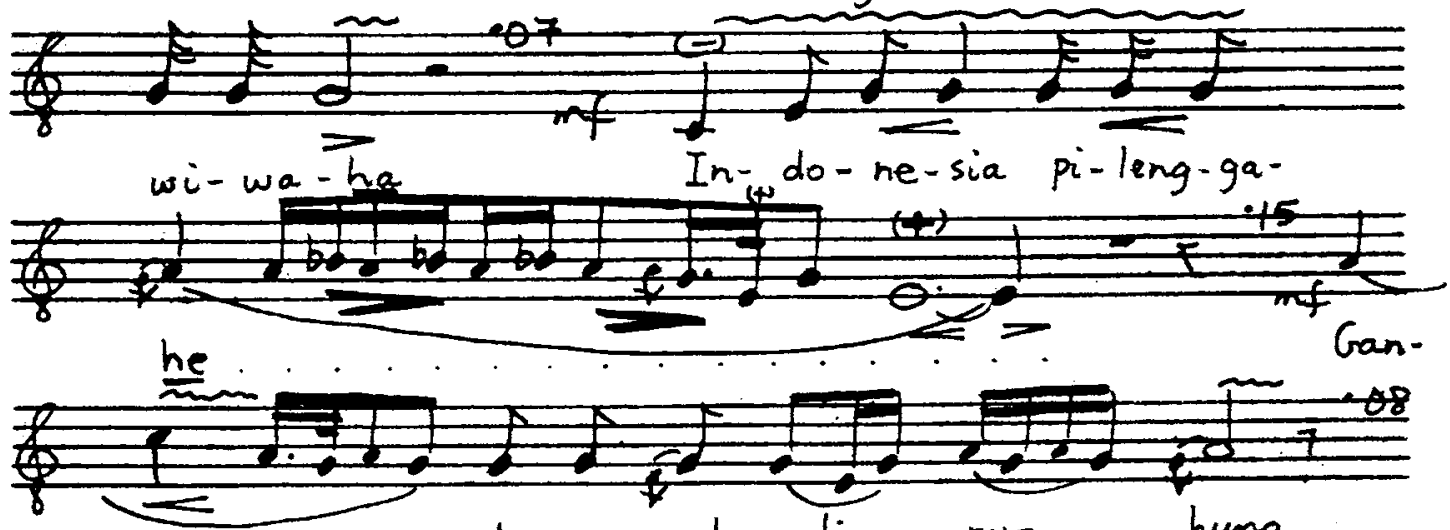
drung-gan-drungli=... nu-.... hung

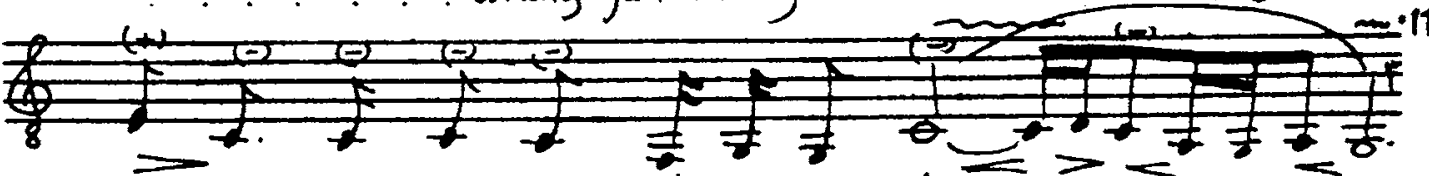

Re-reh $r i$ ich $\tan$ dju-wa-re-hi $>\neq$

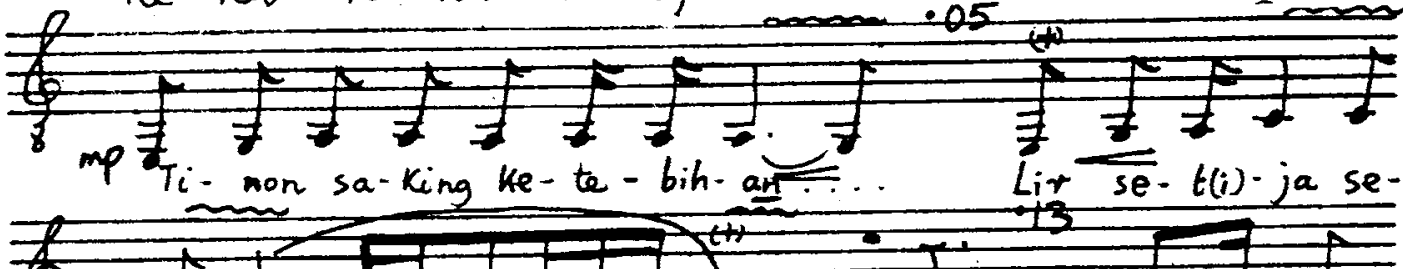

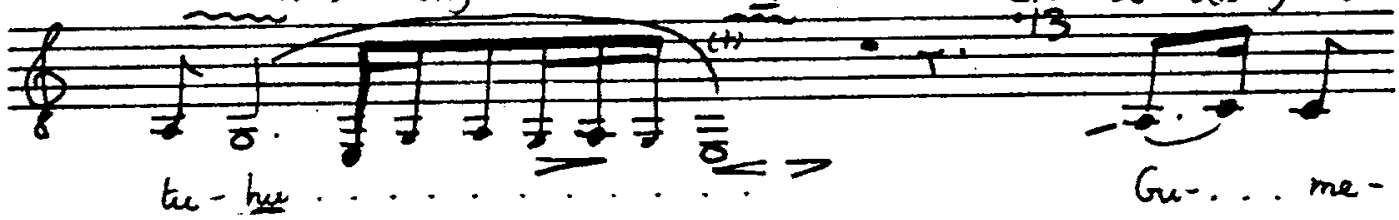




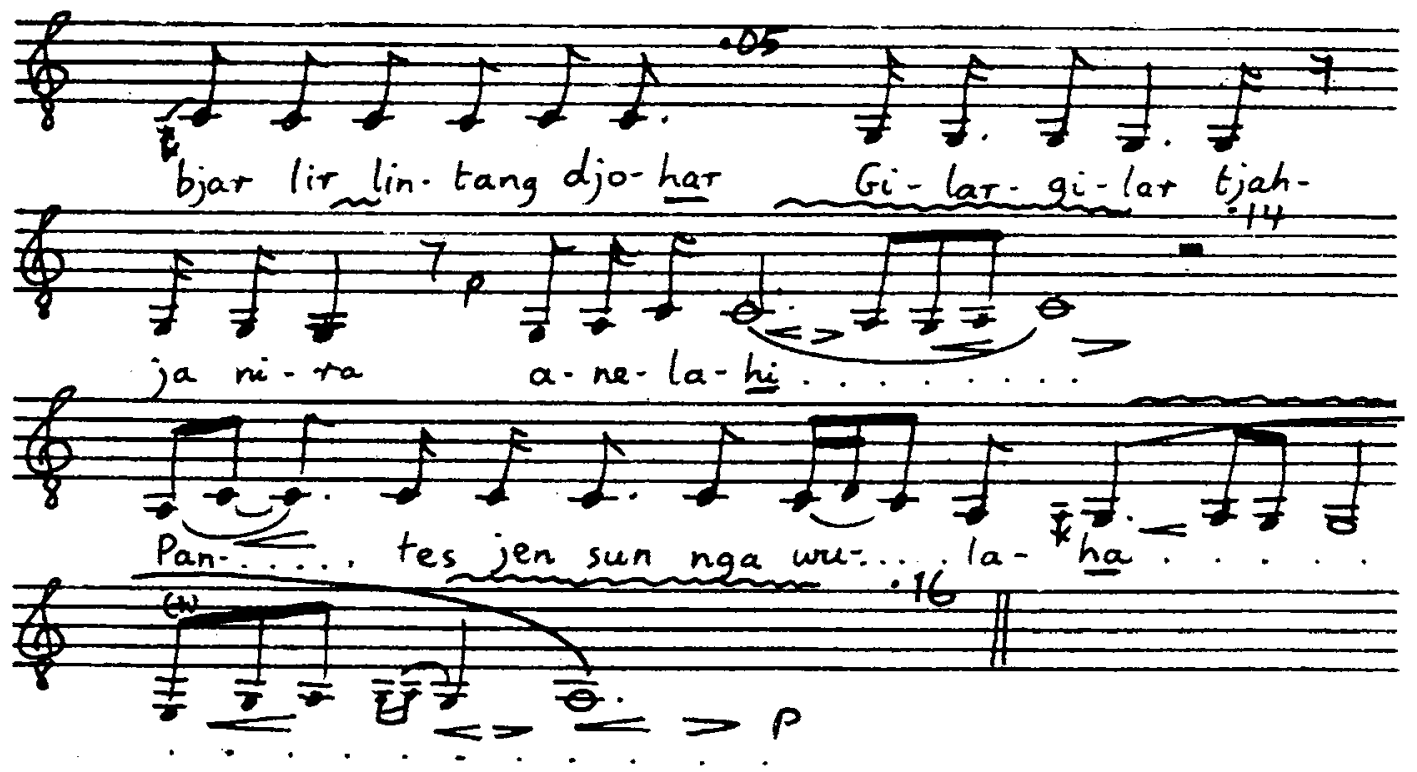


48. KINANTI

SINGER: H. KARTOMI

T.L.: $1.36 \mathrm{~min}$.

O.P.: as below

$(d=132)$

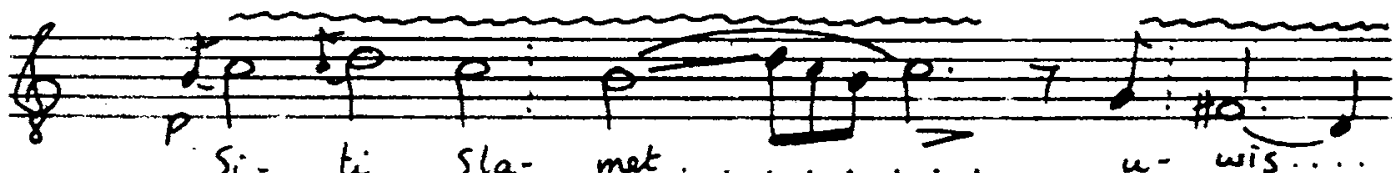

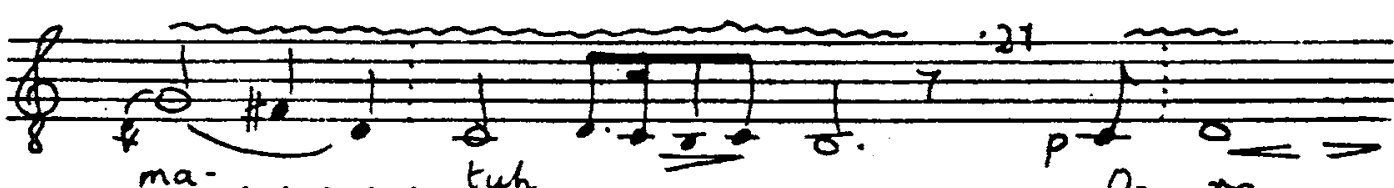
ma-...t.tuh... 0 ra

(6)

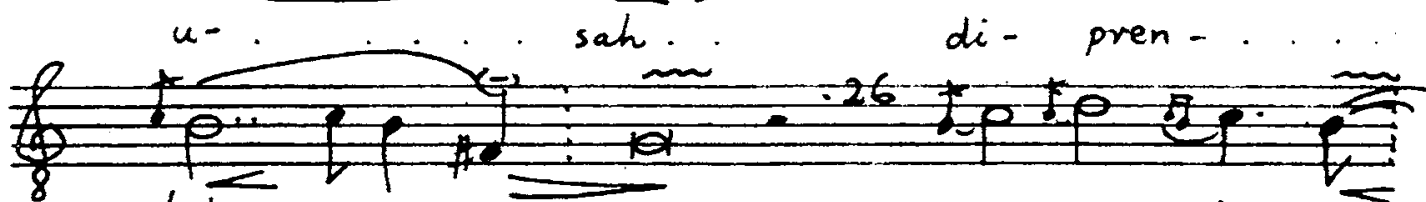
8 tah-... Jen wong tu- wa

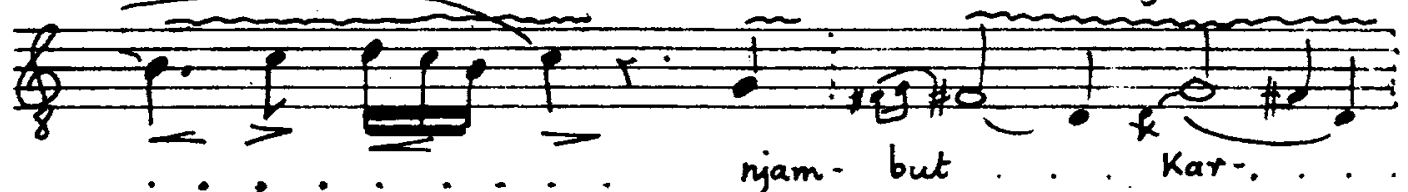

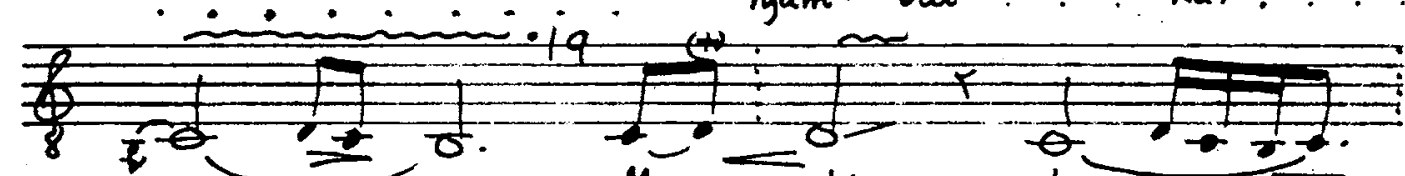
ja . M Mes.... ti ban

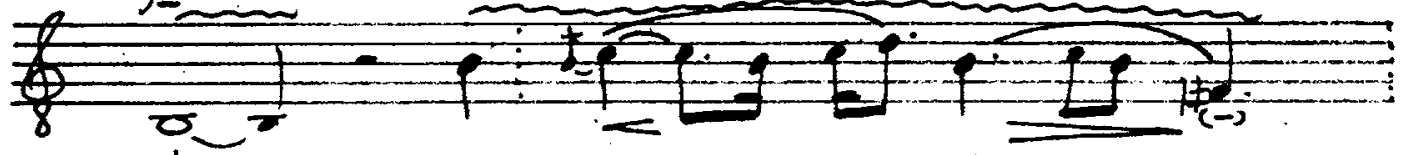
djur $a-$ ngre-..... wang-.....

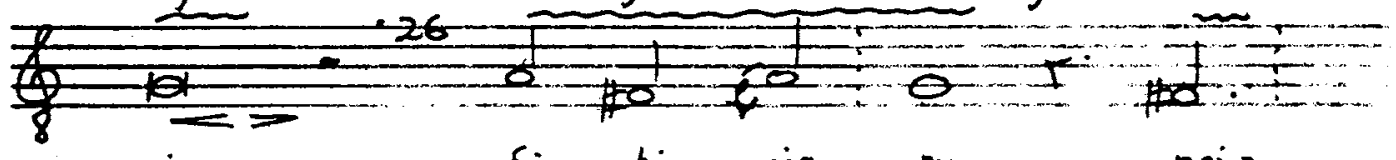
i Si- $\quad t^{i}$ nja- pu

ngi - 


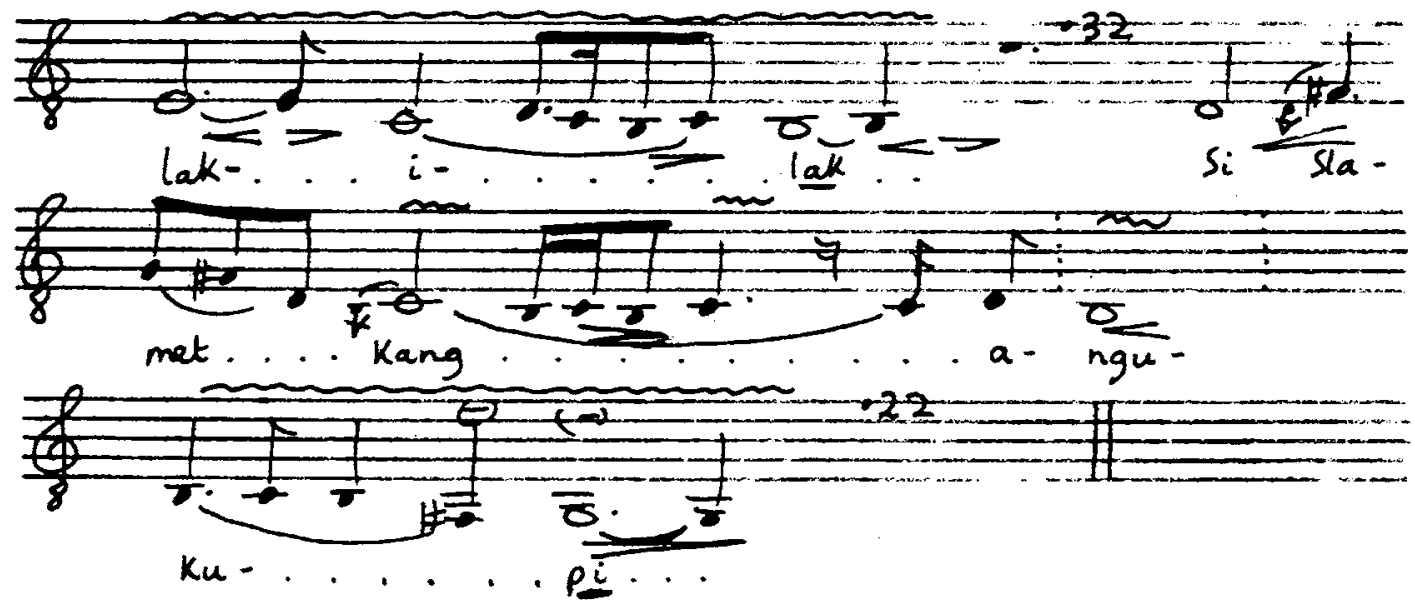


49. DURMA

SIITGER: H. KARTOMI

T.L.: $1.71 \mathrm{~min}$.

O.P.: as below

$(d=122)$

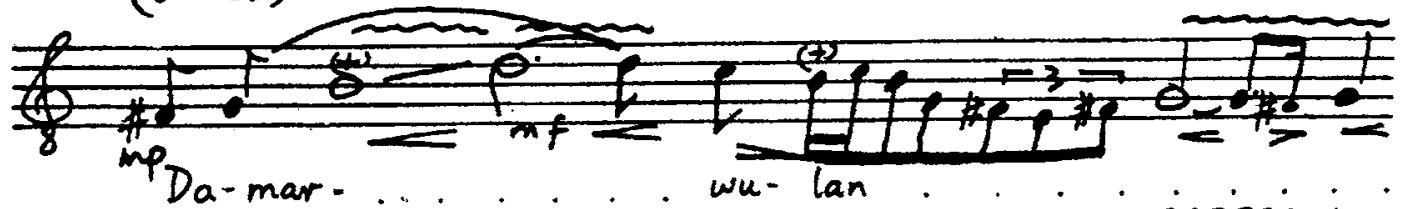

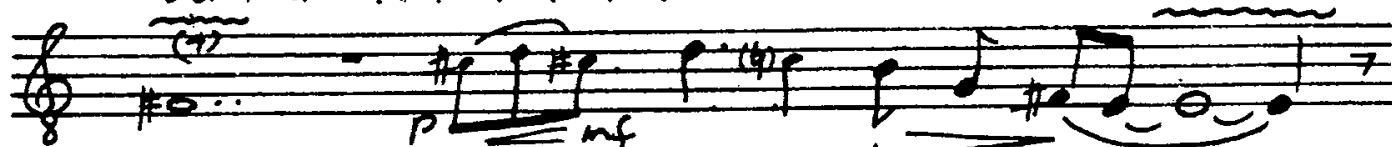

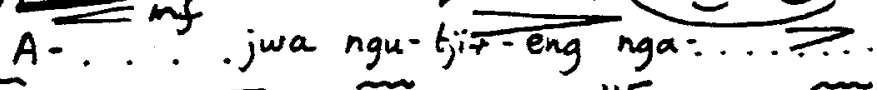

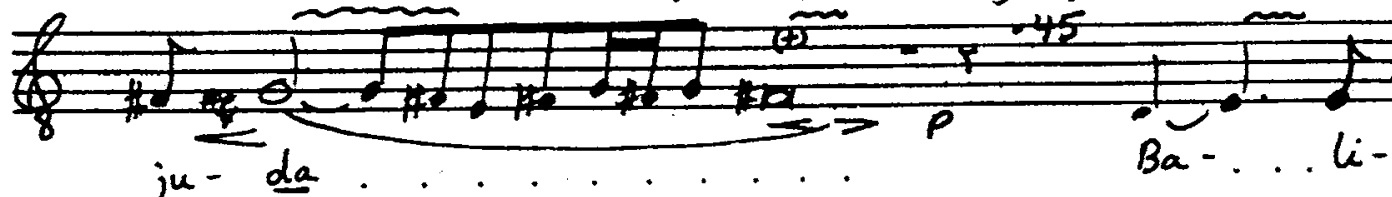
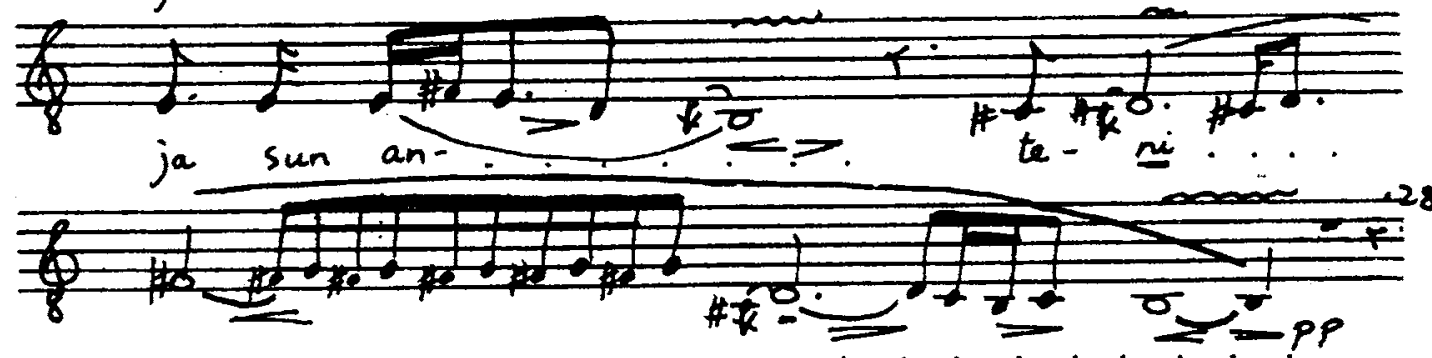

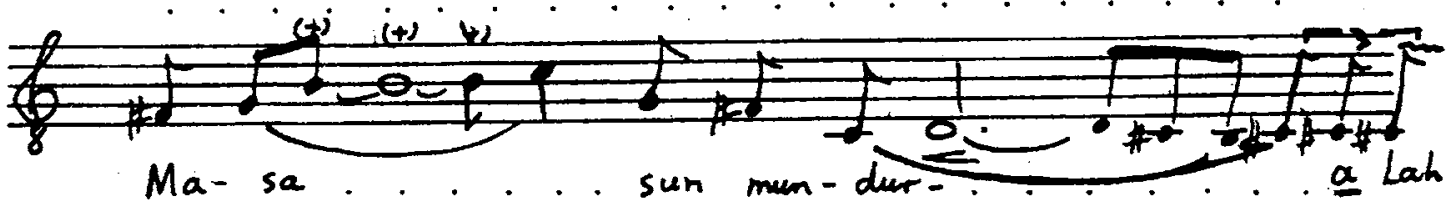

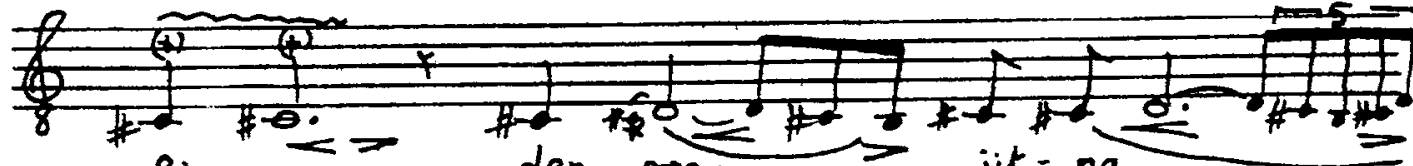
Bis - $\overline{m a}=$ den pra ijit jit-na $>$

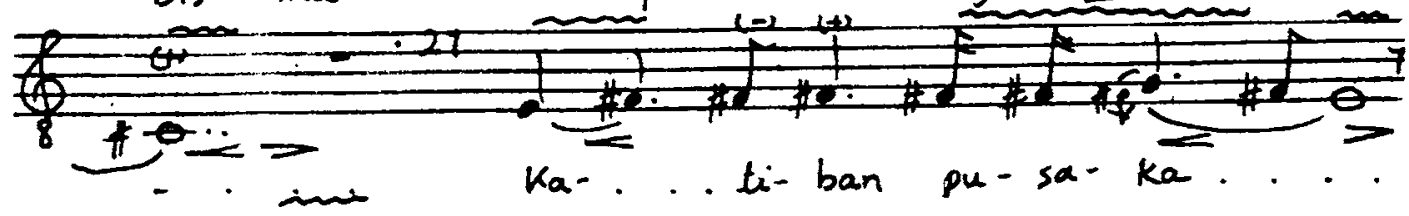



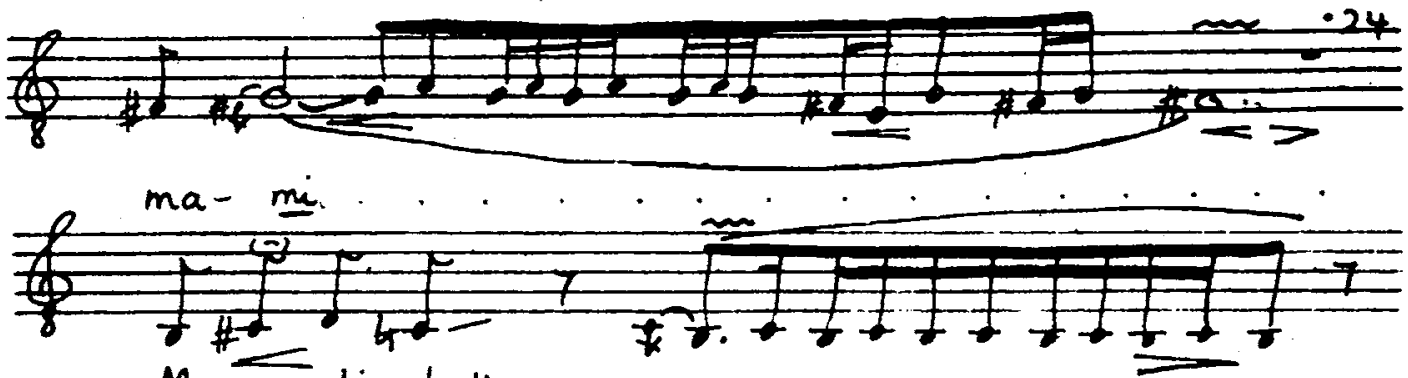
Ma- +a $t i$-bak.

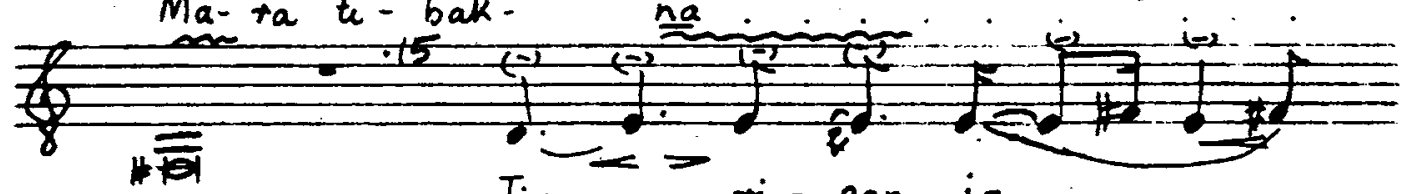

$T_{j u}$ $\dot{r}-\operatorname{gan}-i-$.

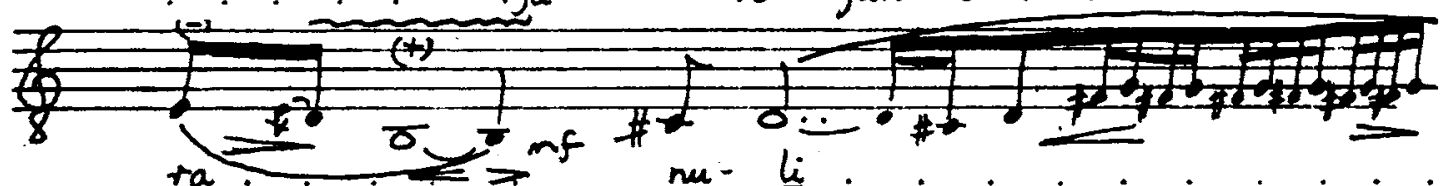
ra nu- $l_{i}$

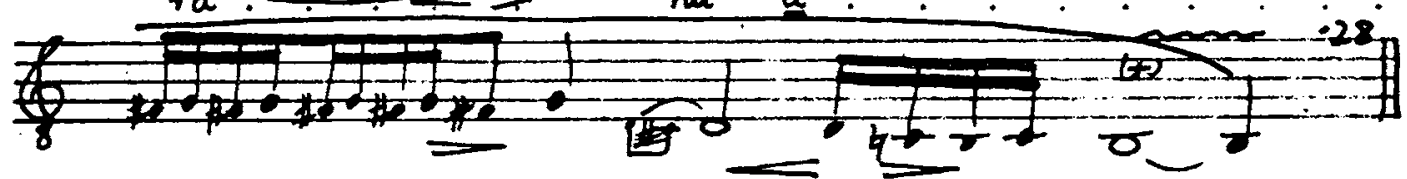


50. PUTJUNG

SINGER: H. KARTOMI

T.I.: $0.72 \mathrm{~min}$.

O.P.: 2 tones higher
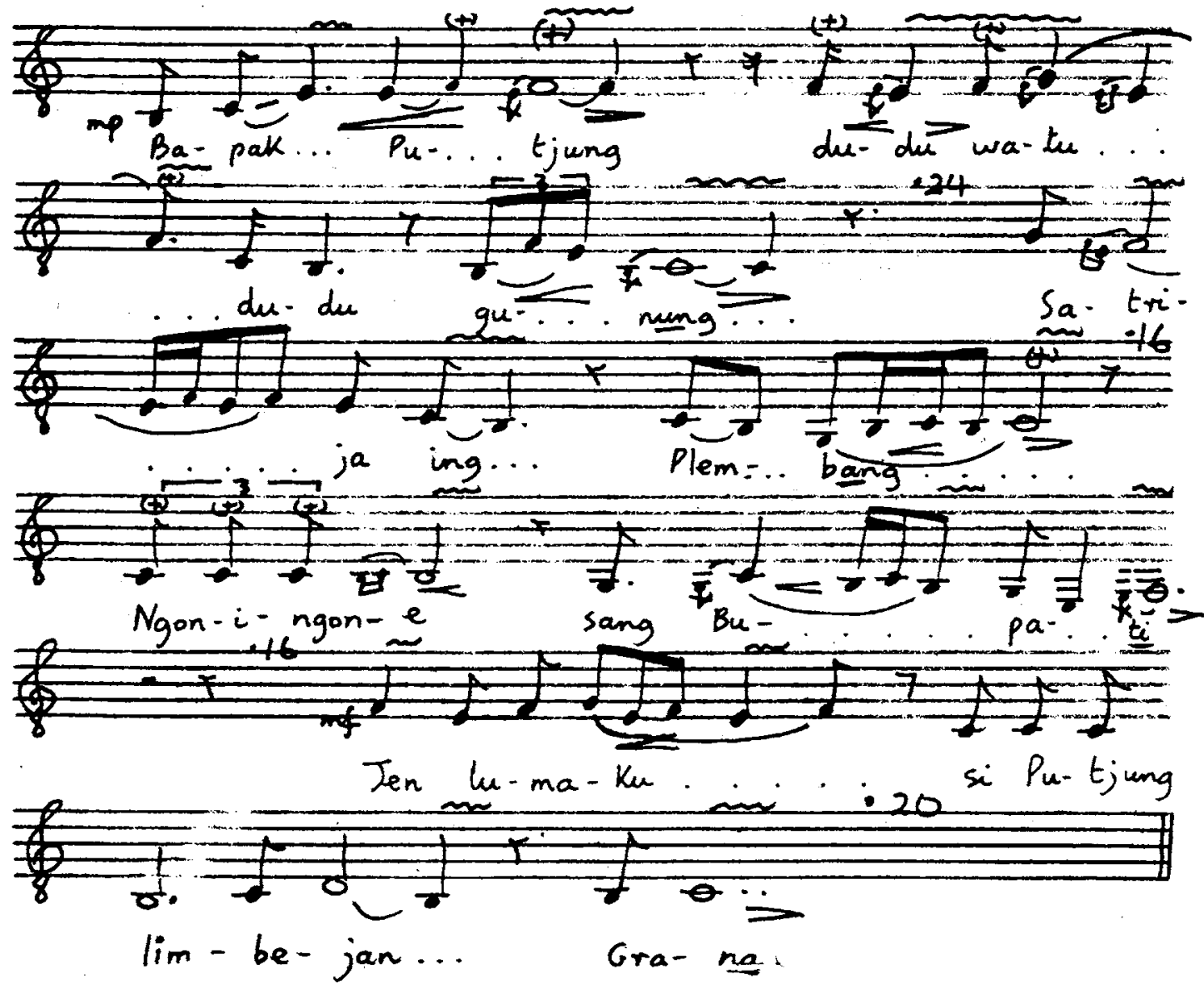
51. DURMA

SINGER: TRISNO

HOME TOWN: KIATEN

T.I.: $0.68 \mathrm{~min}$.

O.P.: 1 tone higher

$(1+144)$

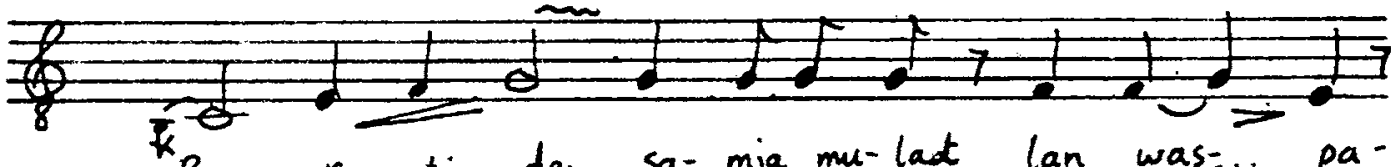

Pra... Kan-tja den sa-mja mu-lat lan was:.. pa-

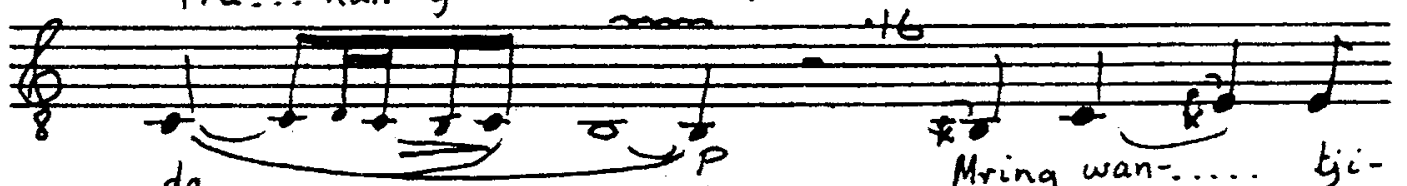
$\frac{f+1}{b}+1=0$ wan-.j. tji wi-ga- $\underline{\underline{k}} \quad J(-)$ wa Kong-si

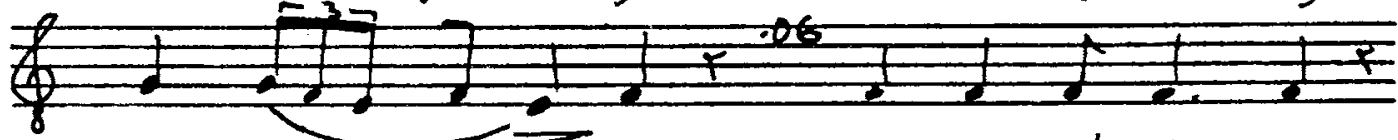

$\mathrm{Ka}-\mathrm{le} \ldots$ nan $\mathrm{Re}_{\mathrm{n}}-\mathrm{Ka}_{a} \mathrm{da}-\mathrm{ja}-\mathrm{ne}$

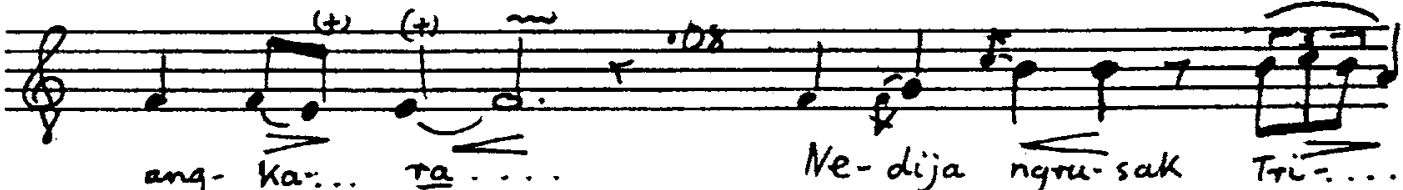

ang- ka-.. ra... Ne-dija ngru-sak Tri $\ldots$...
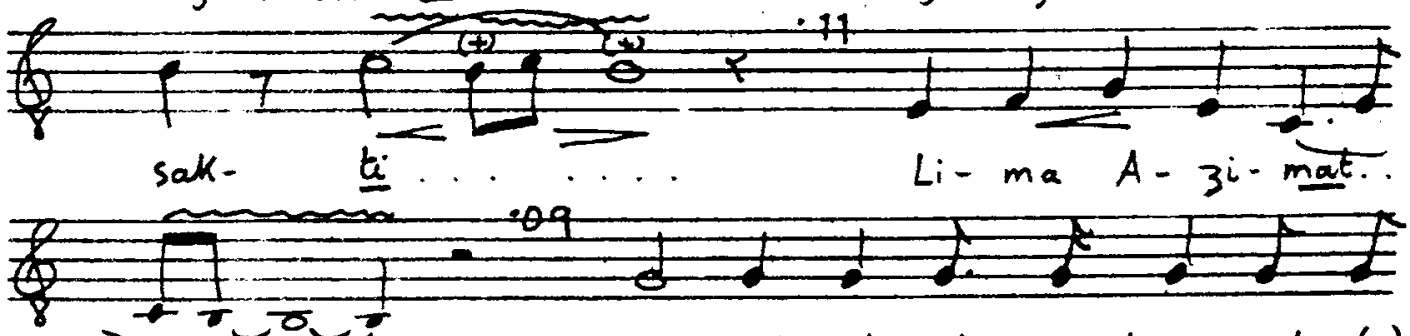

$+\frac{1}{\sigma}$

Kang da

$\underline{s i}$ 
52. MASKIIMAMBANG

SINGER: TRISNO

T.I.: $0.65 \mathrm{~min}$.

O.P.: 2 tones lower

$(d=104)$

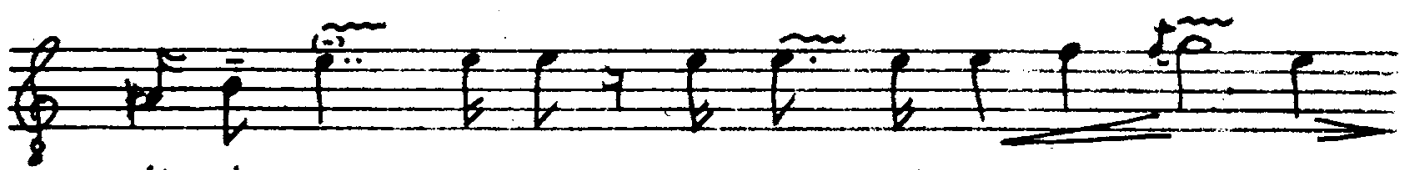
Ke-lek-....ke-lek bi-jung si- ra a-neng enHong-gal (o) tu-lung-a-
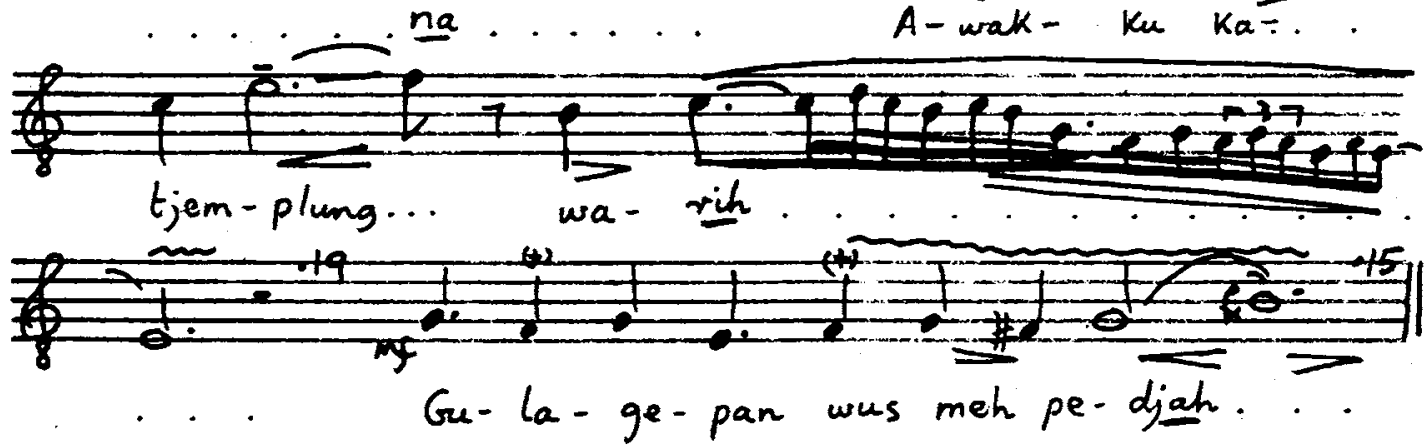
53. ASMARANDANA

SINGER: TRISNO

T.L.: $0.56 \mathrm{~min}$.

O.P.: $1 \frac{1}{2}$ tones higher

$(d=136)$

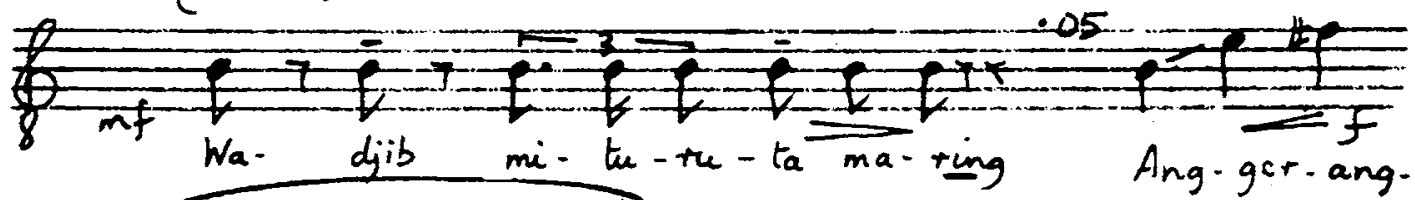

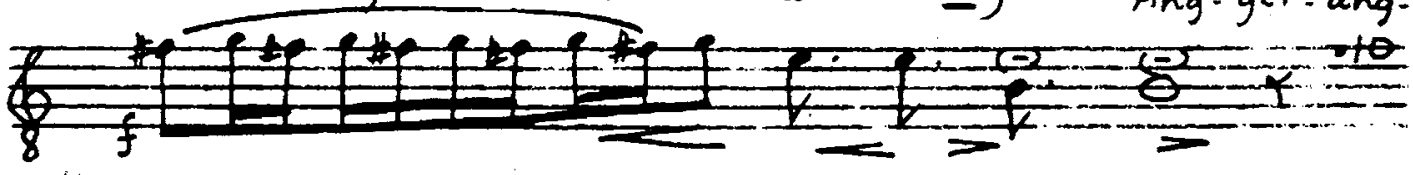
ger-. . . . . . ing a ga ma

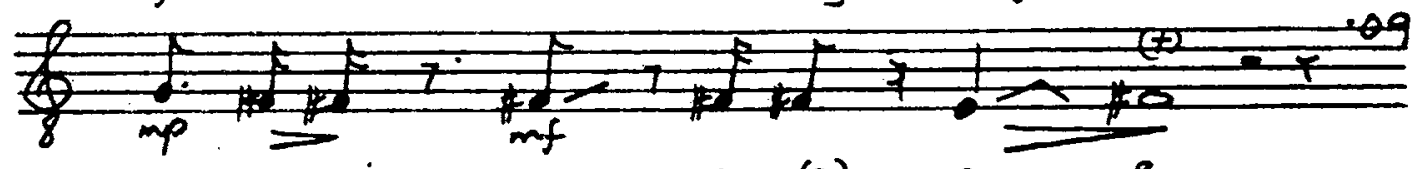
wong u-rip pate- ger-(e)- an- e e

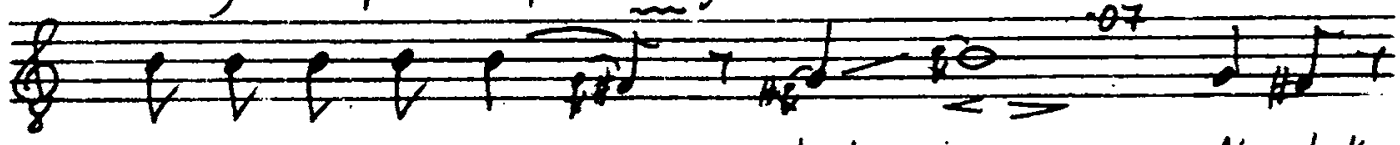
Te-te-pa-na sem-... bah-jang Nga-bek-

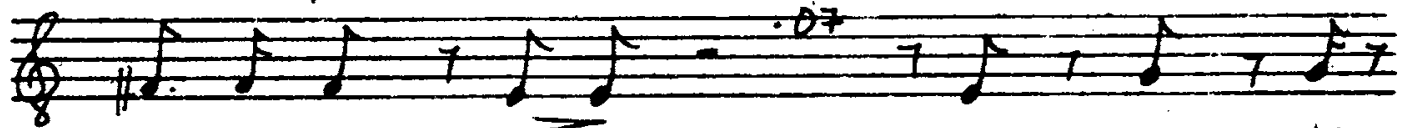
ti $m(-)+i n g \quad A+$ lah Ing wan- $t_{j i}$

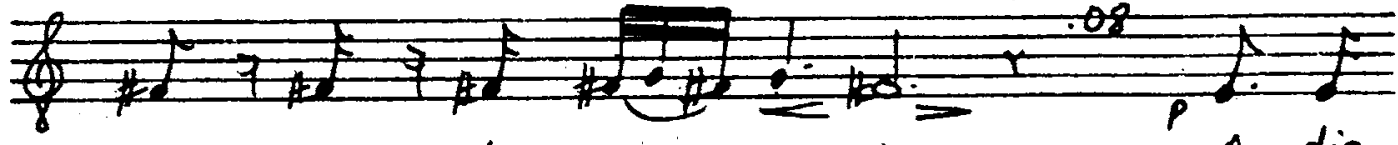
Kang wis $t i$ - nem-...t. $A$ idja

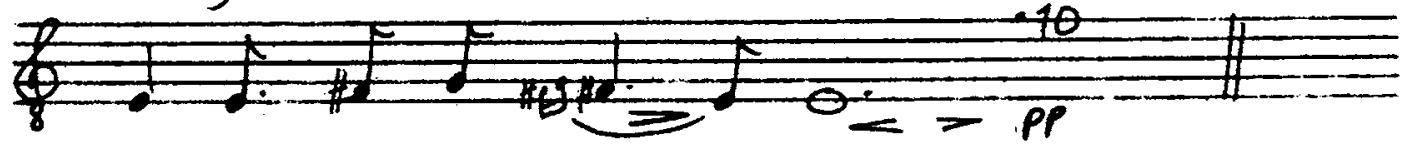
Kong-si Ka- li - wa-... tan. 
54. DANDANGGULA

SINGER: IMAM

HOME TOWN: SURAKARTA

T.L.: $0.96 \mathrm{~min}$.

O.P.: as below

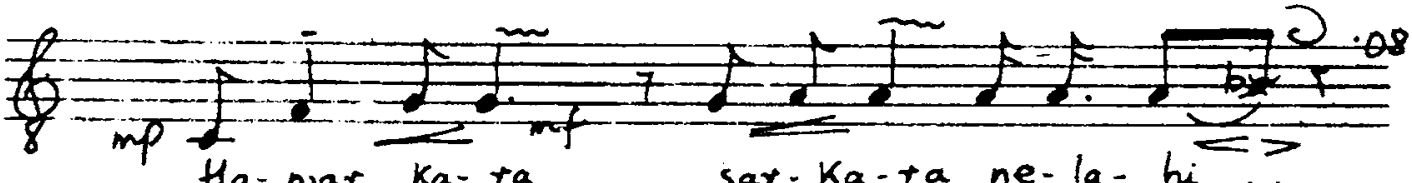
Ha-njar Ka-ra sar-Ka-ta ne-la- hi .

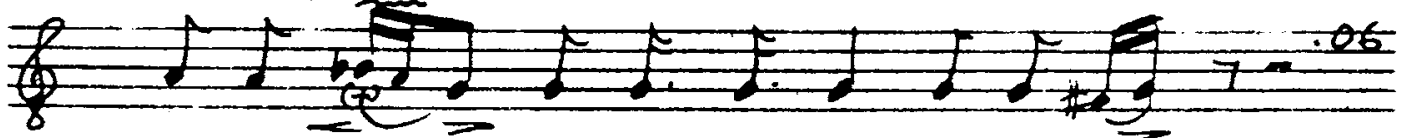

Ku-su-mah... jju Kang a-sung wi-wa-ha..

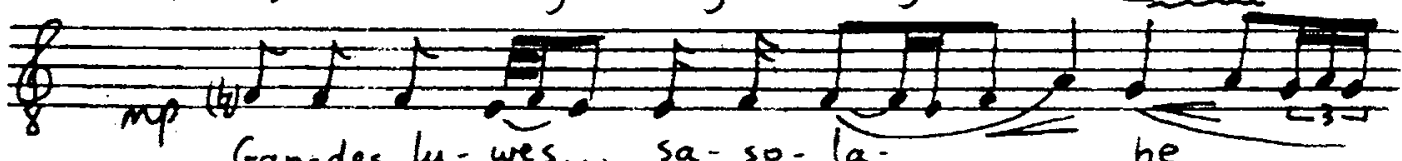
Gan-des lu-wes... sa-so-la . he....
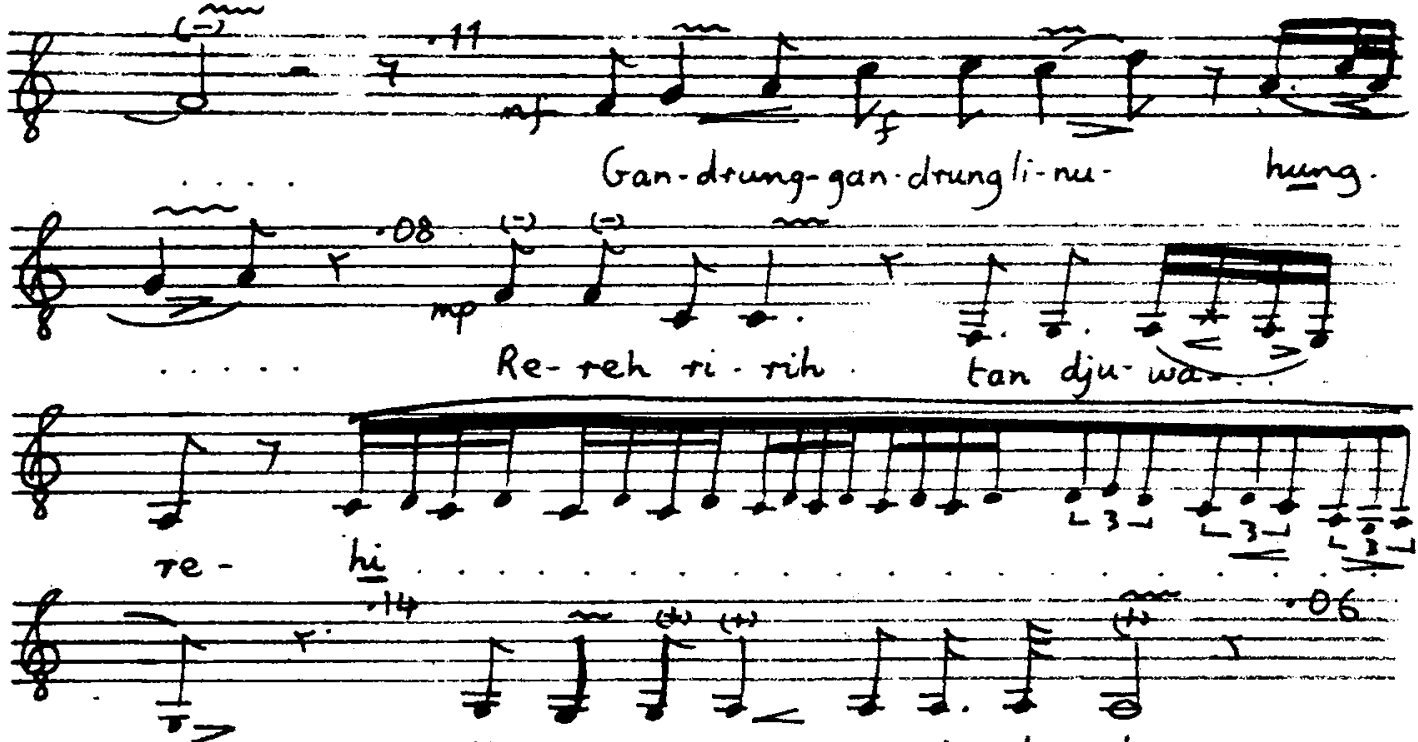

$T_{i}$ - non sa-king Ke-te-bi- han

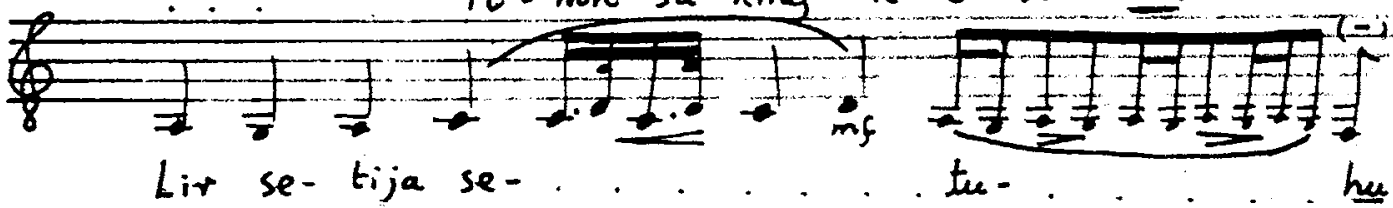




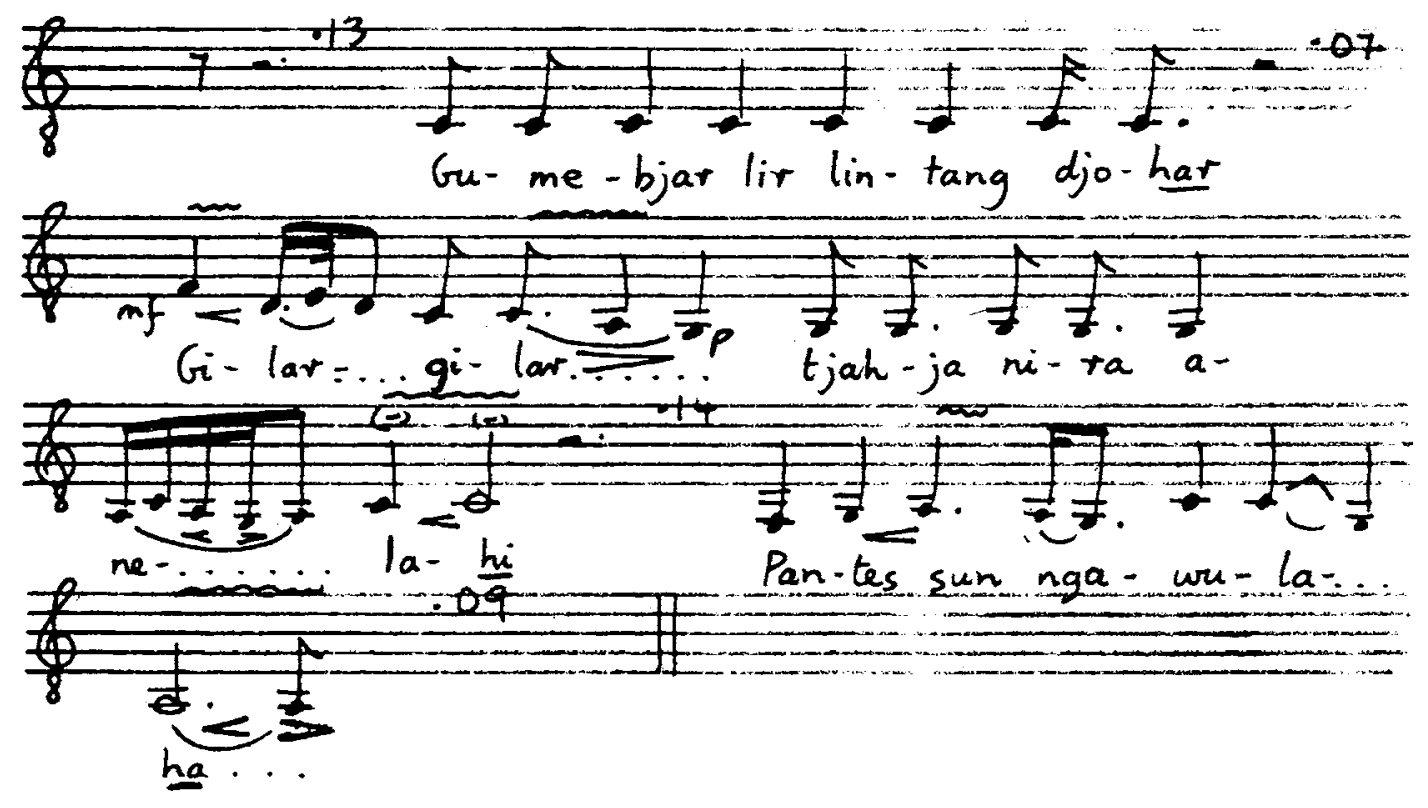


55. DANDANGGULA

SINGER: IMAM

T.L.: $0.60 \mathrm{~min}$.

O.P.: I tone higher

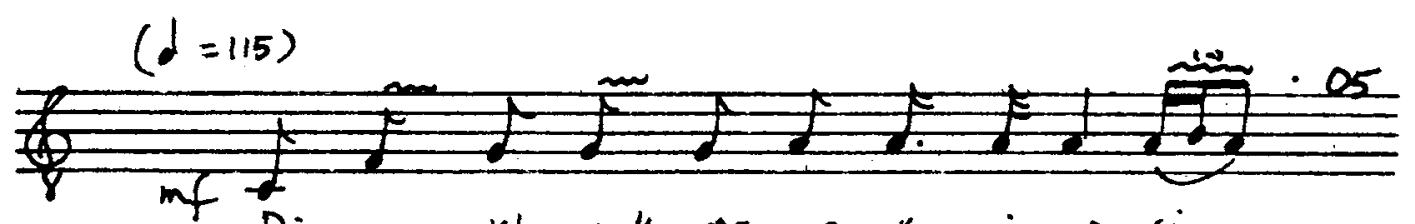

Dja-go klu-ruk ra-me ka-pi-ar-si.

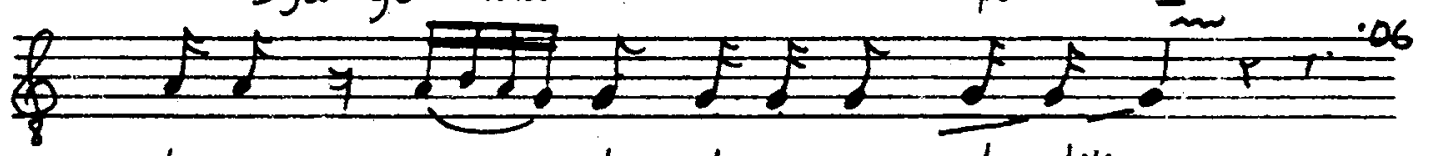

La-wa ka-... long lee re pan-de-lik - an

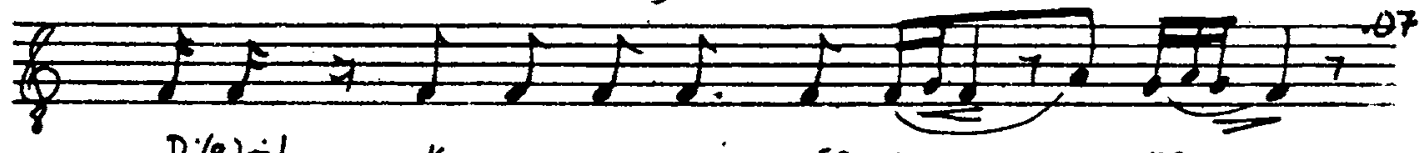

Dj(e)-ih Ka-wan-a-ning se-mu- ne

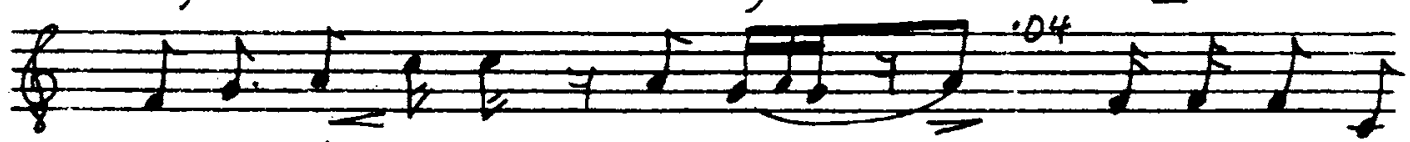

We-tan bang su-lak- i-pun Me-ra-tan-da.

(f) nijen wus ba-ngun en ${ }^{*}$ djing ${ }^{\circ}$ Bu-lan wus gum

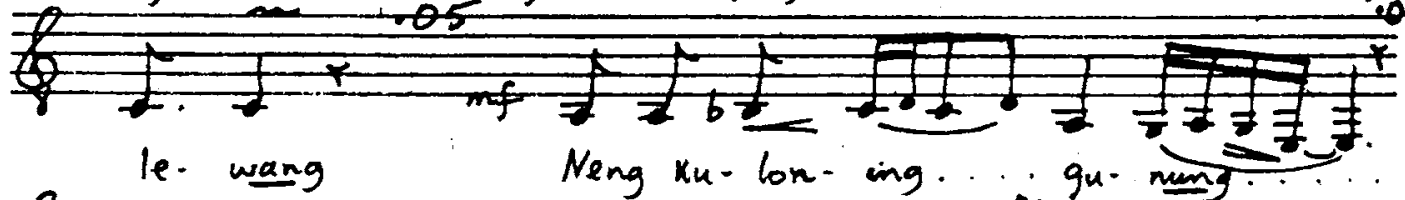

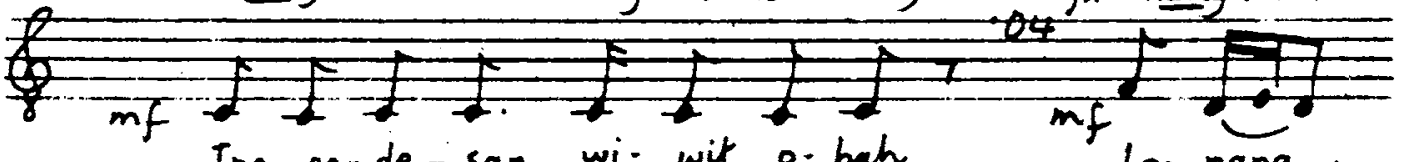

Ing pa-de-san wi- wit 0. bah ${ }_{\text {La- nang... }}$

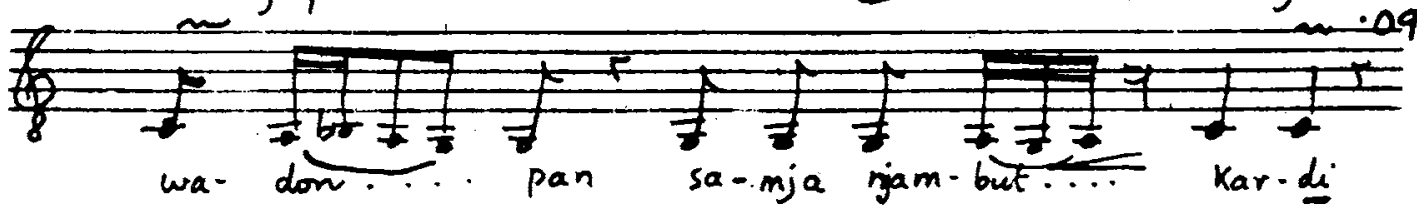




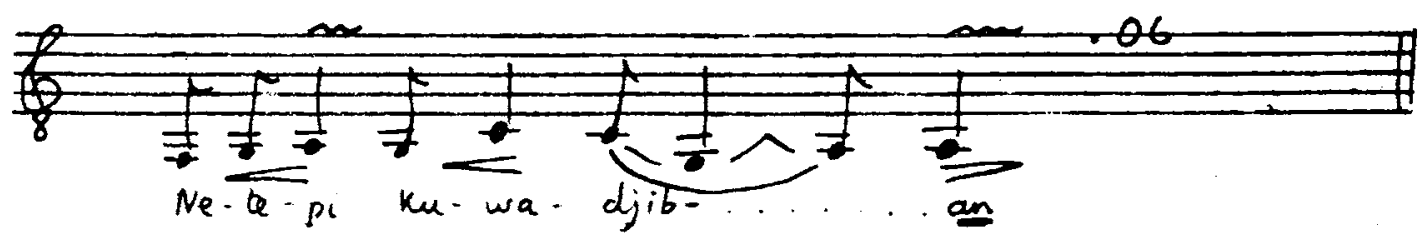


56. DURMA

SINGER: IMAM

T.L.: $0.49 \mathrm{~min}$.

O.P.: 1 tone higher
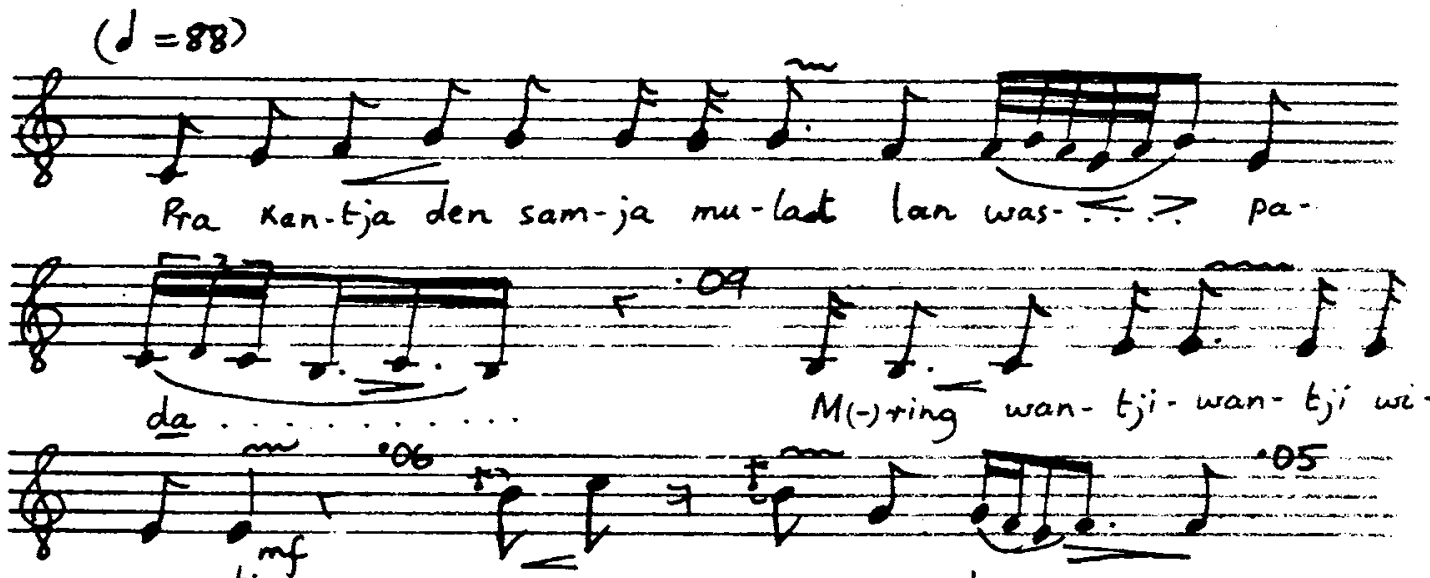
$g a-\underline{t i}$
Jwa kong- si
ka-le-... nan
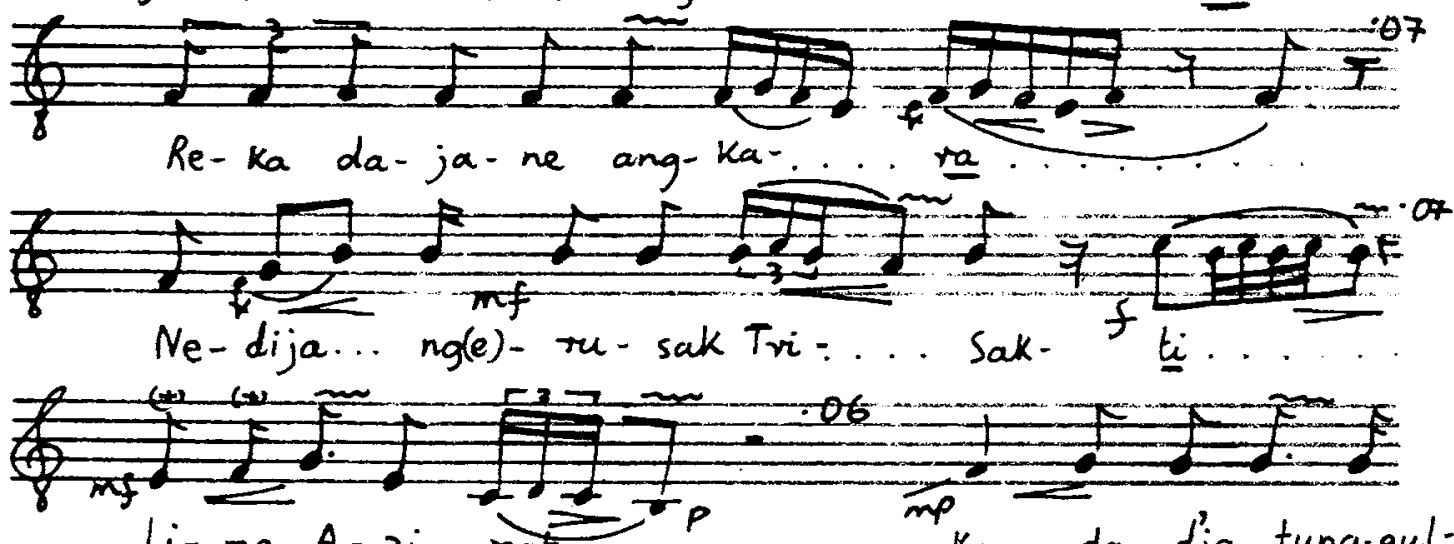

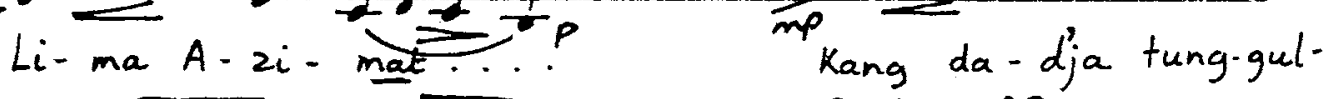

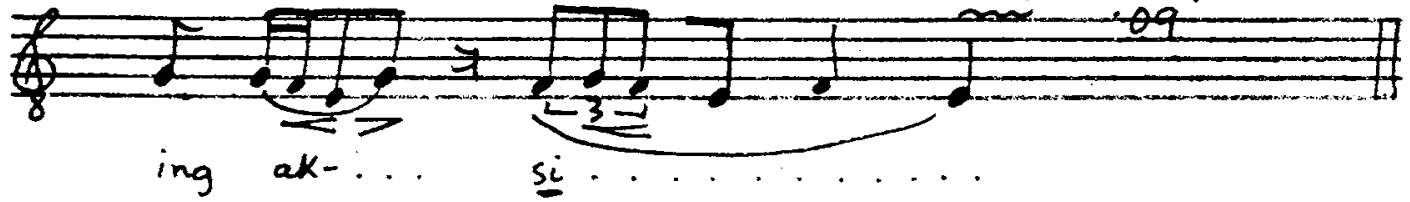


57. ASMARAINDANA

SINGER: IMAM

T.I.: $0.35 \mathrm{~min}$.

O.P.: $I \frac{1}{2}$ tones lower

$(d=103)$
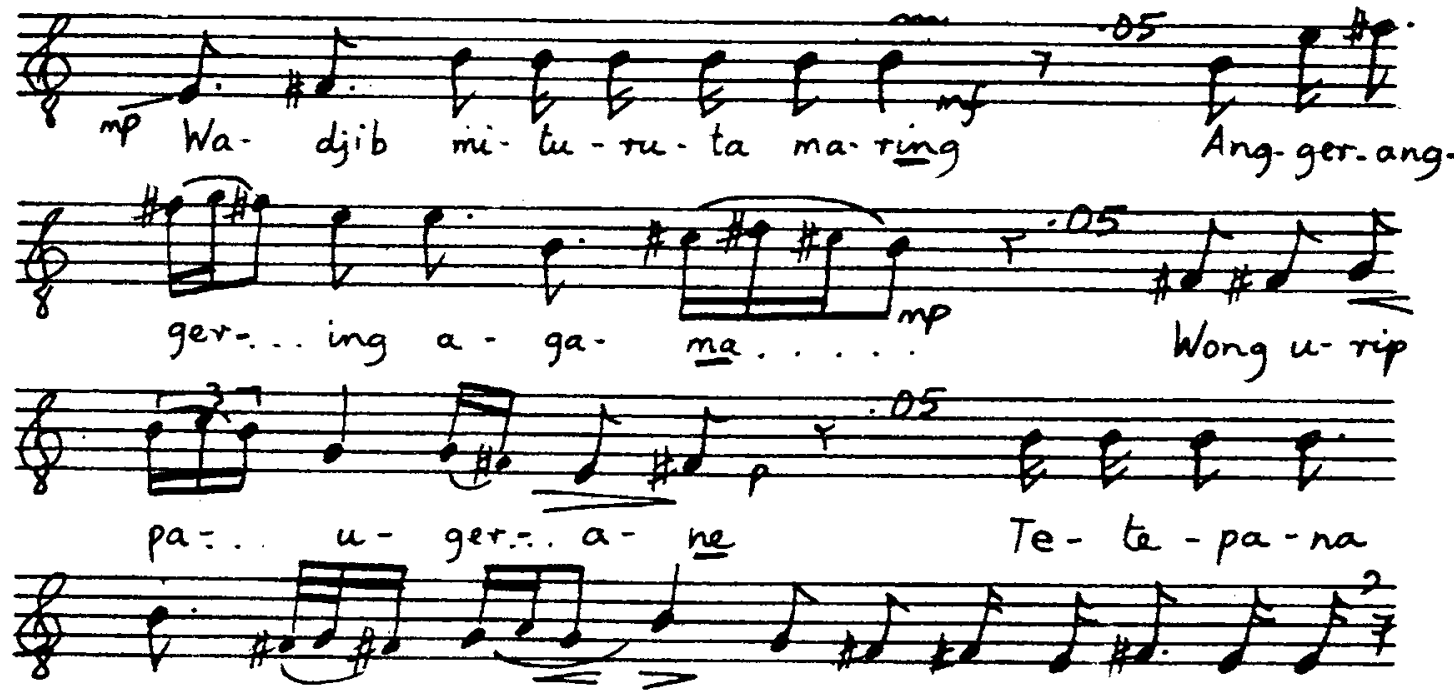

sem- bah-.. jang... nga-bek - ti mes ring Al- lach

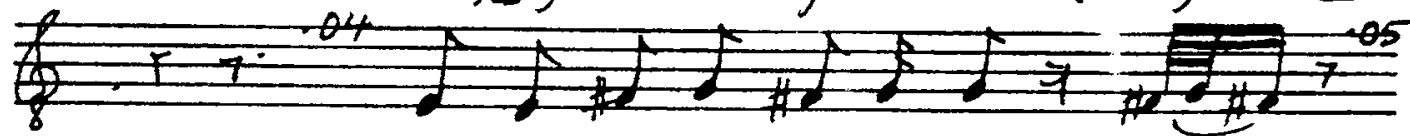

Ing wan- $t_{j i}$ Kang wis $t i \cdot n e m-$ ter...

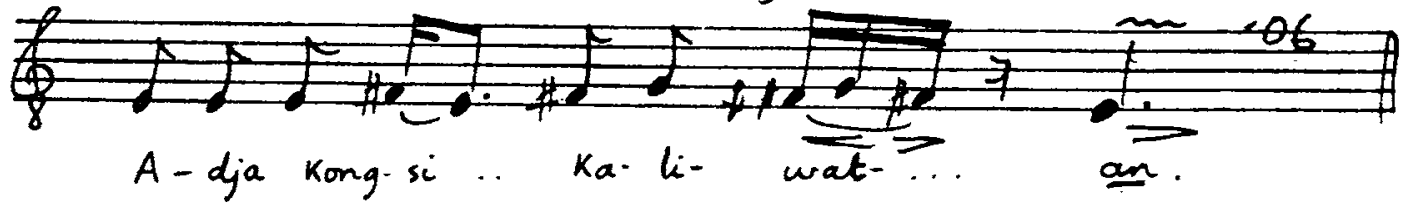


58. DANDANGGULA

SINGER: SUPARDI

HOME TOWN: MANGKUNEGARAN

T.I.: $0.73 \mathrm{~min}$.

O.P.: $I^{\frac{1}{2}}$ tones higher

$(d=115)$

\&mE

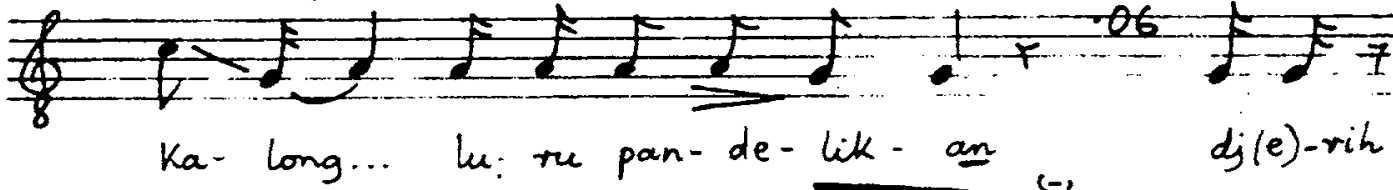

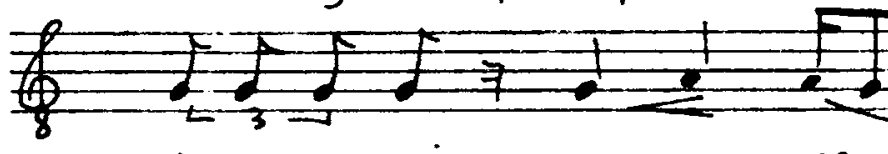
ka-wan-a-ning se- mu- ne

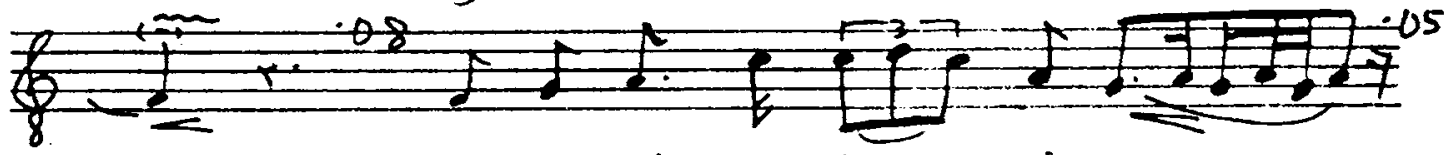
We-tan bang su-lak-... i- pun

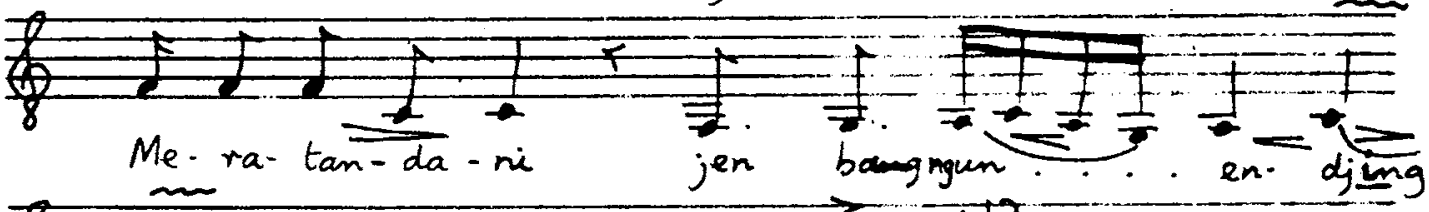

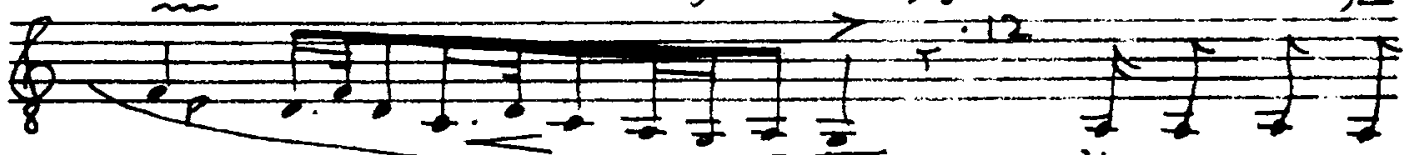
bu-lan wus gum.

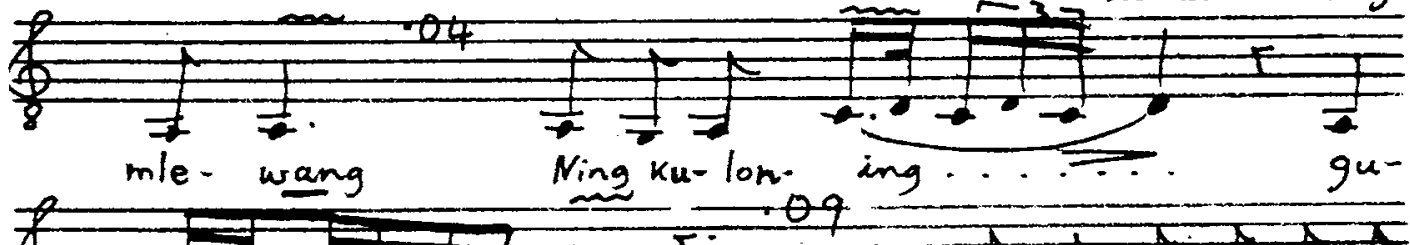
(f) 


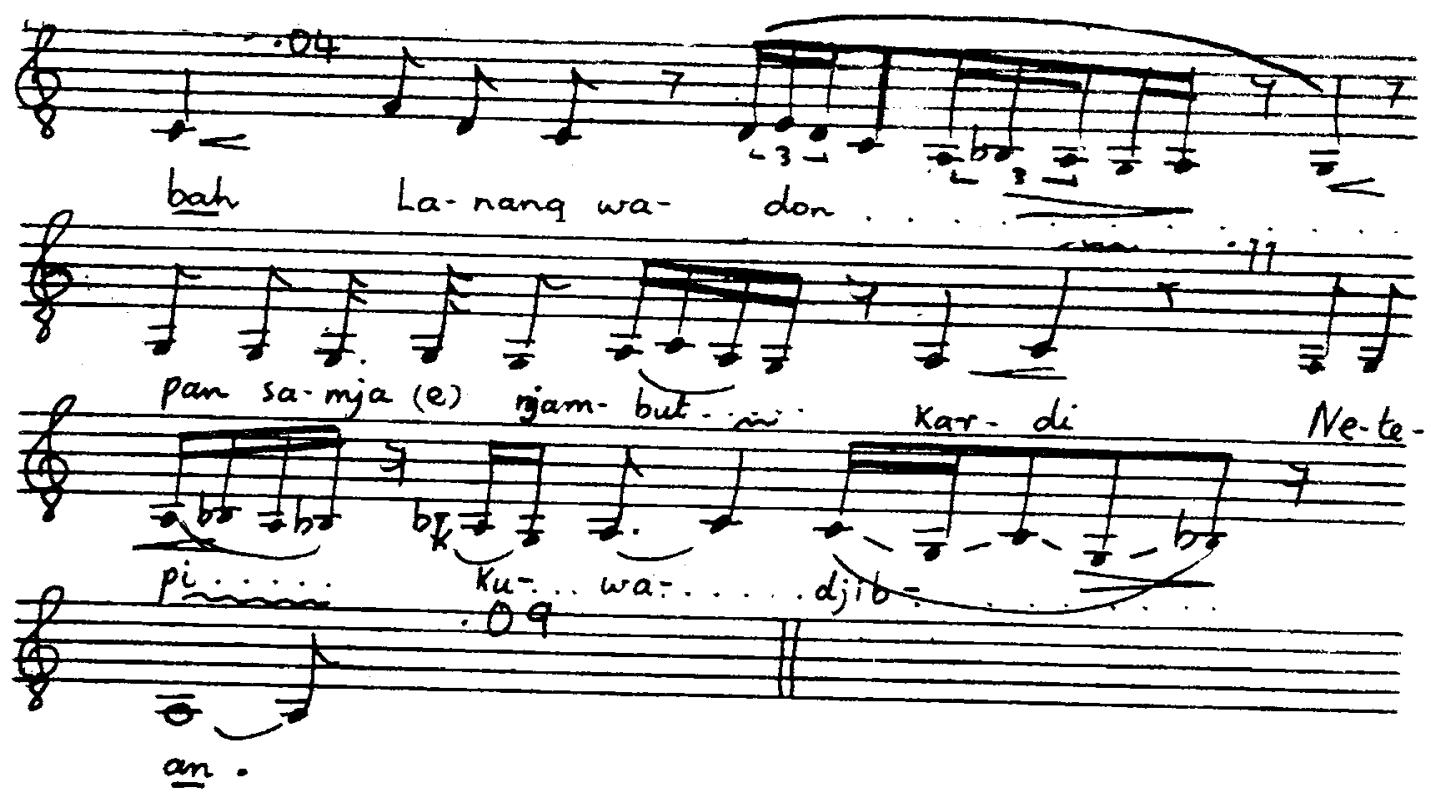


59. DURMA

SINGER: SUPARDI

T.I.: $0.45 \mathrm{~min}$.

O.P.: $\frac{1}{2}$ tone lower

$(d=104)$

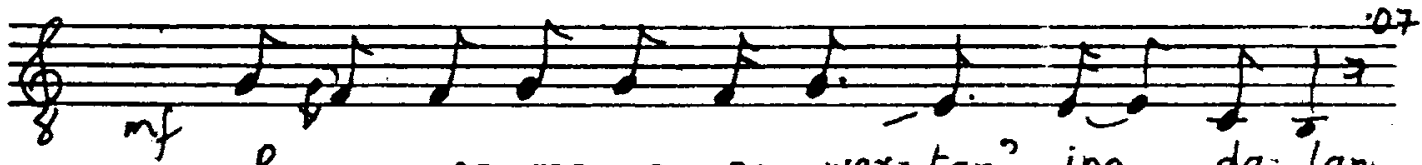
$\mathrm{Pa}$-man-pa-man a-pa war-tan' ing da-lan

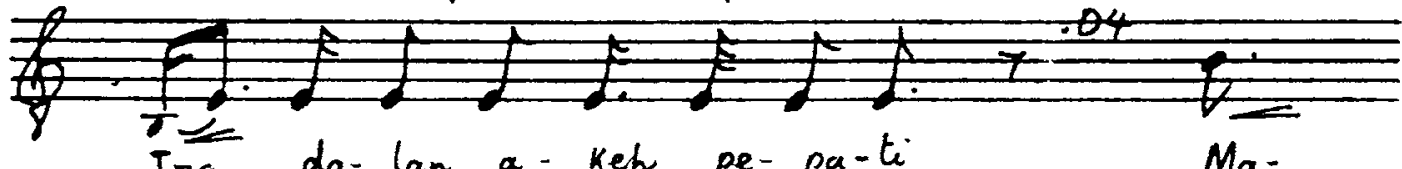

Ing... da-lan a-keh pe-pa-ti

$M a-$

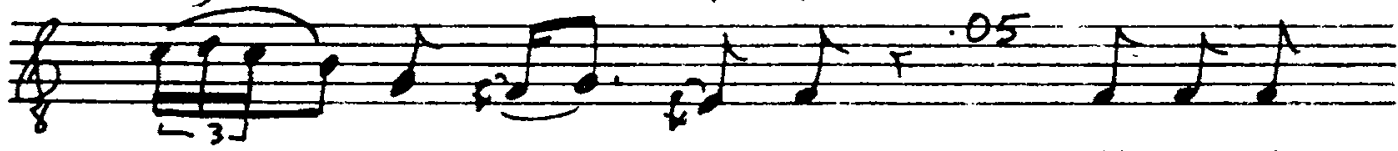

ti.....ke-na.. a a pa Ma-ti den

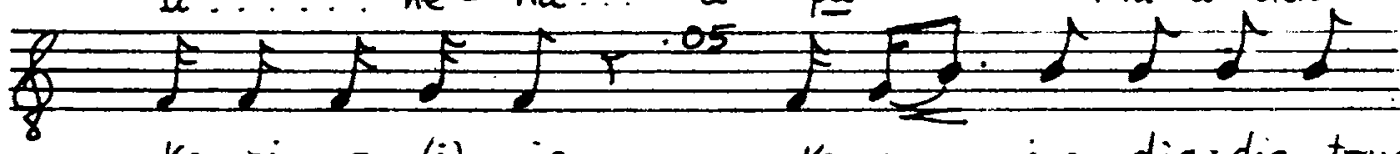

$$
k_{a}-n i-a-(i)-j a \quad k e-n a \ldots \text { ing dja-dja trus }
$$

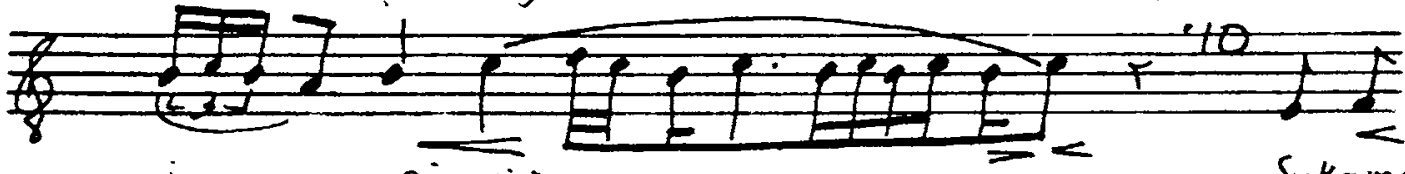

ing. ... $9 i-g i v$

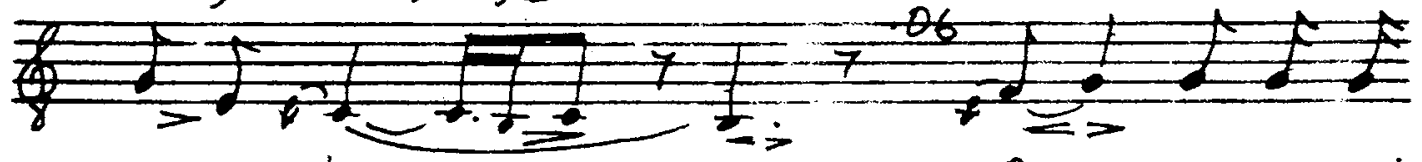

$$
\text { nja }=\text { lang }
$$$$
R a=
$$

ga ke - ri

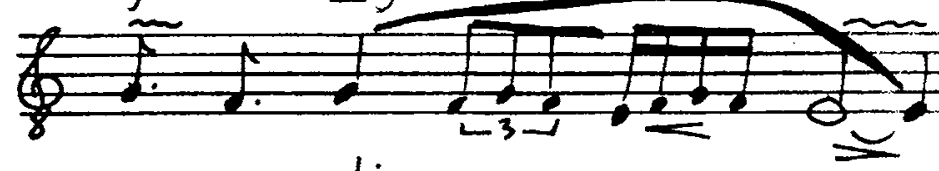

gu- mu- ling. 
60. SINOM

SINGER: SUPARDI

T.L.: $1.07 \mathrm{~min}$.

O.P.: as below

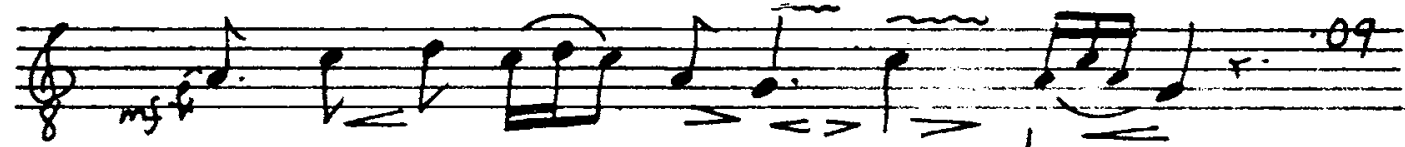

Ing mang-ke kang... ham-ba kan-da...
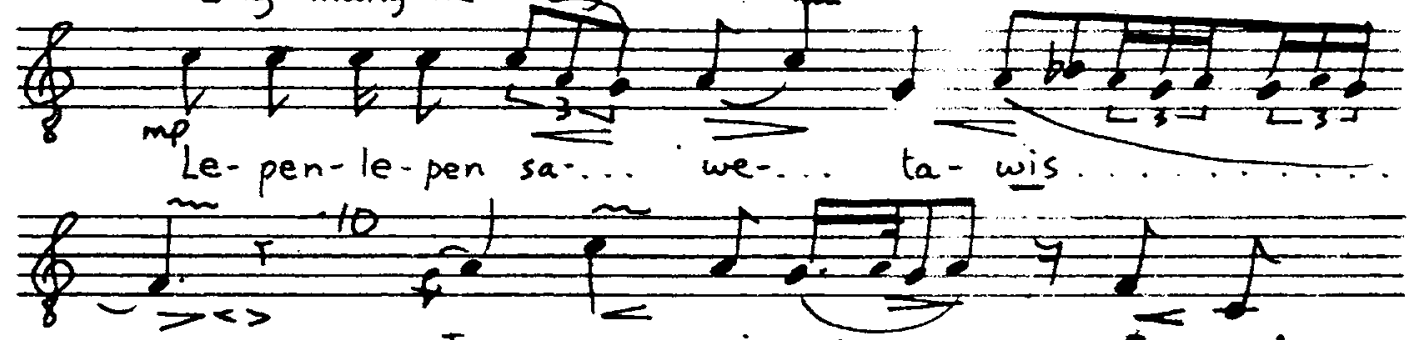

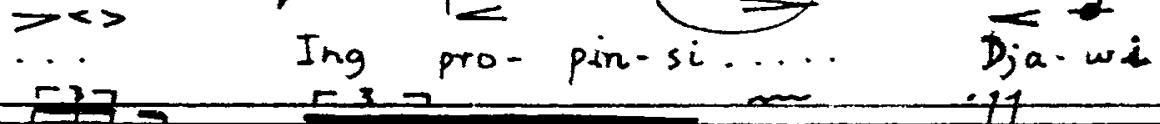

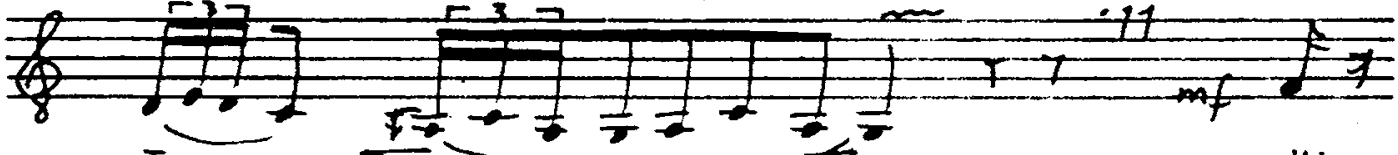

Te.... .2 ngah........

$K_{i}-$

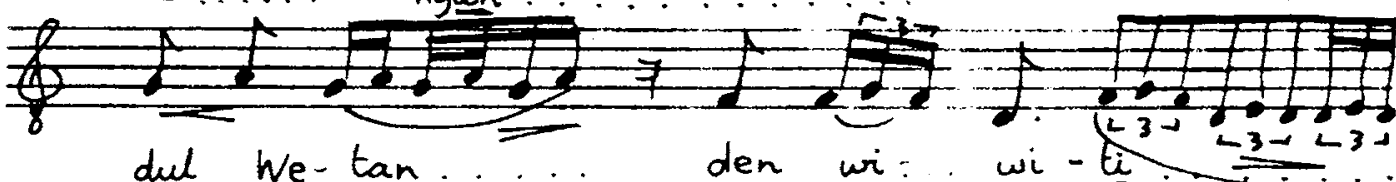
dul We-tan.... den wi . wi

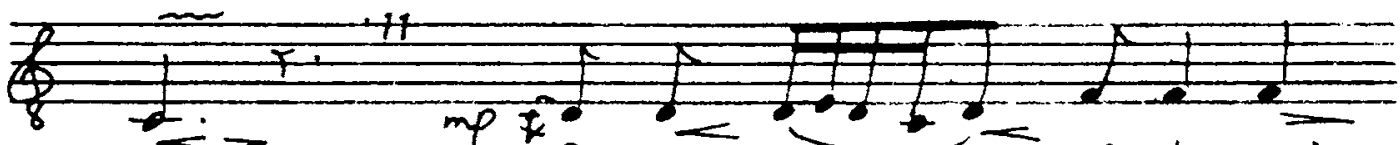
$\therefore$ Be-nga-wan.... So-lo mi.

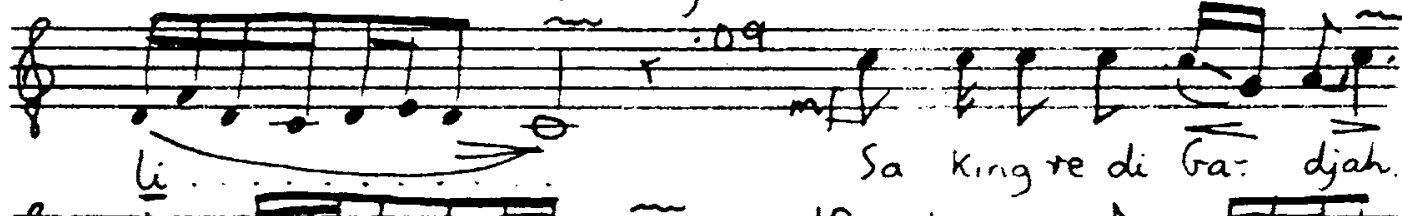

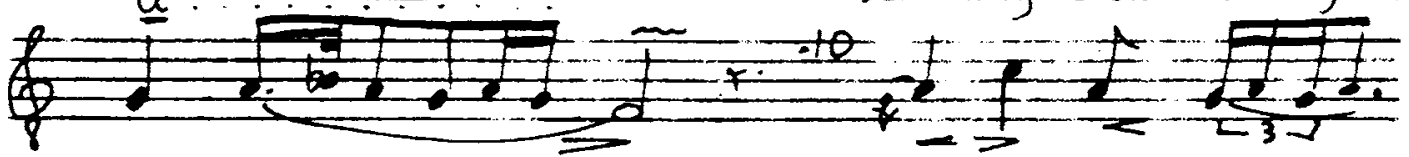
mung-Kur.. Wa kes - Wja ne- 

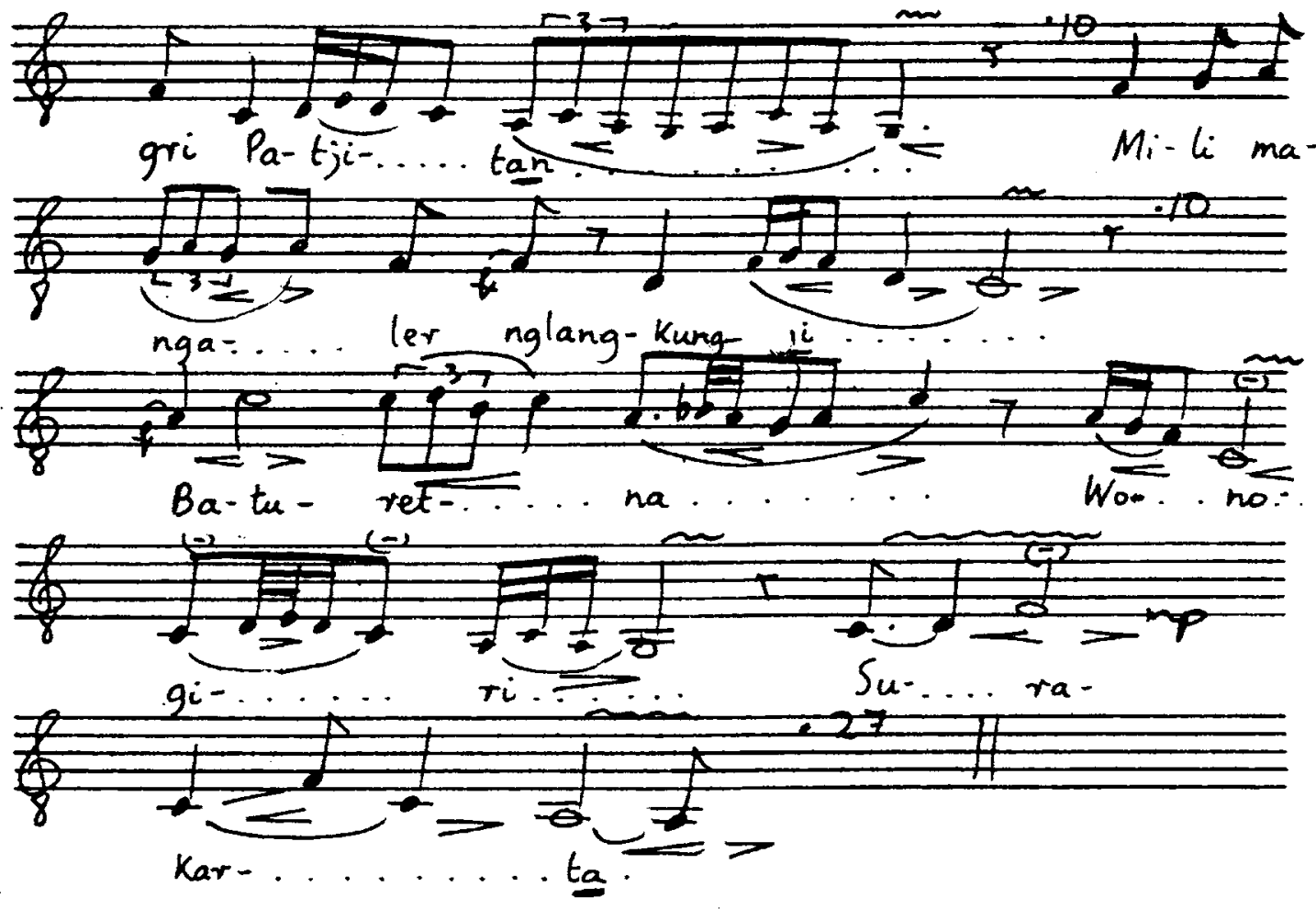
61. KINANTI SUBOKASTOWO

SINGER: SUPARDI

T.L.: $1.11 \mathrm{~min}$.

O.P.: $\frac{1}{2}$ tone lower
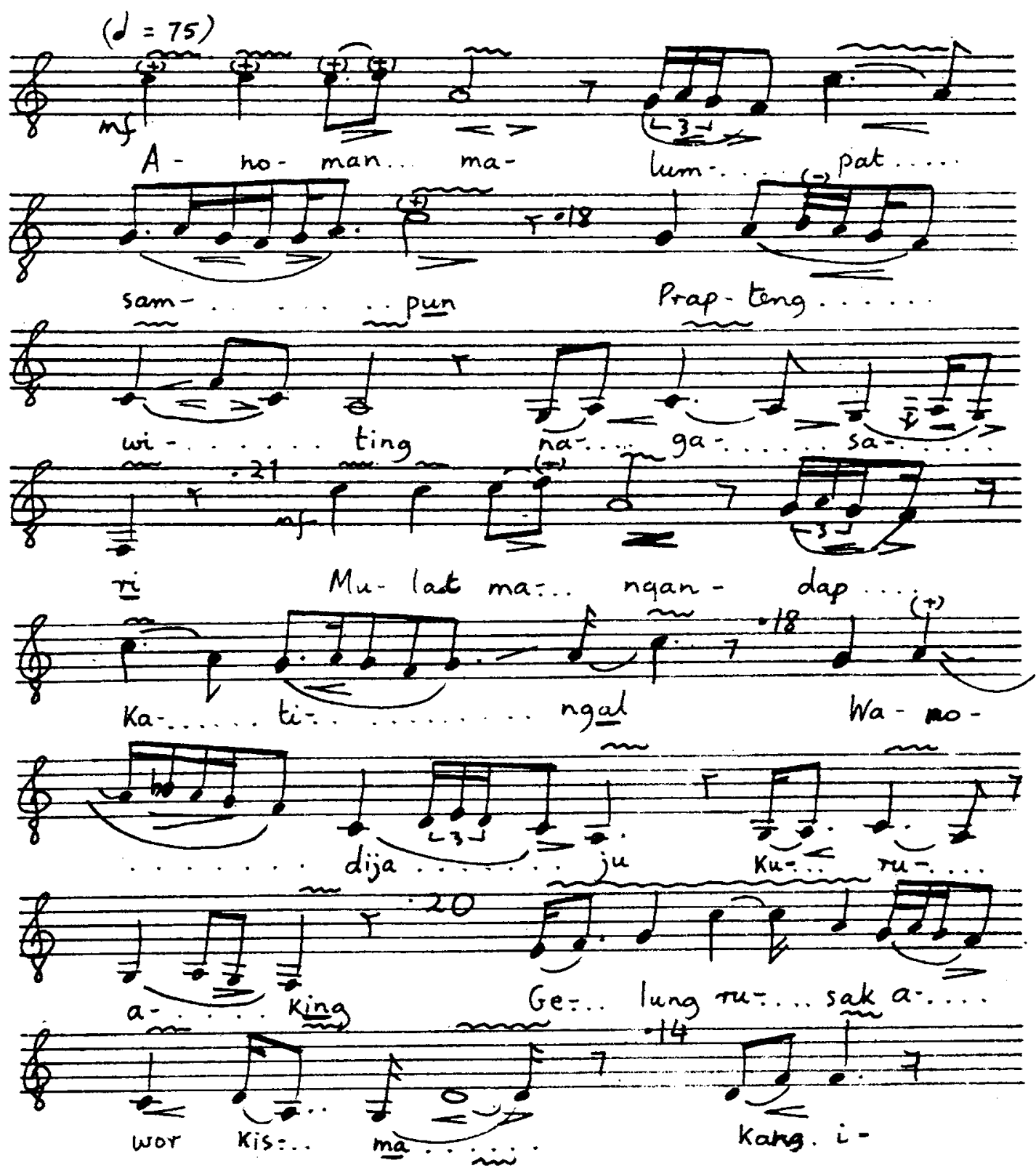


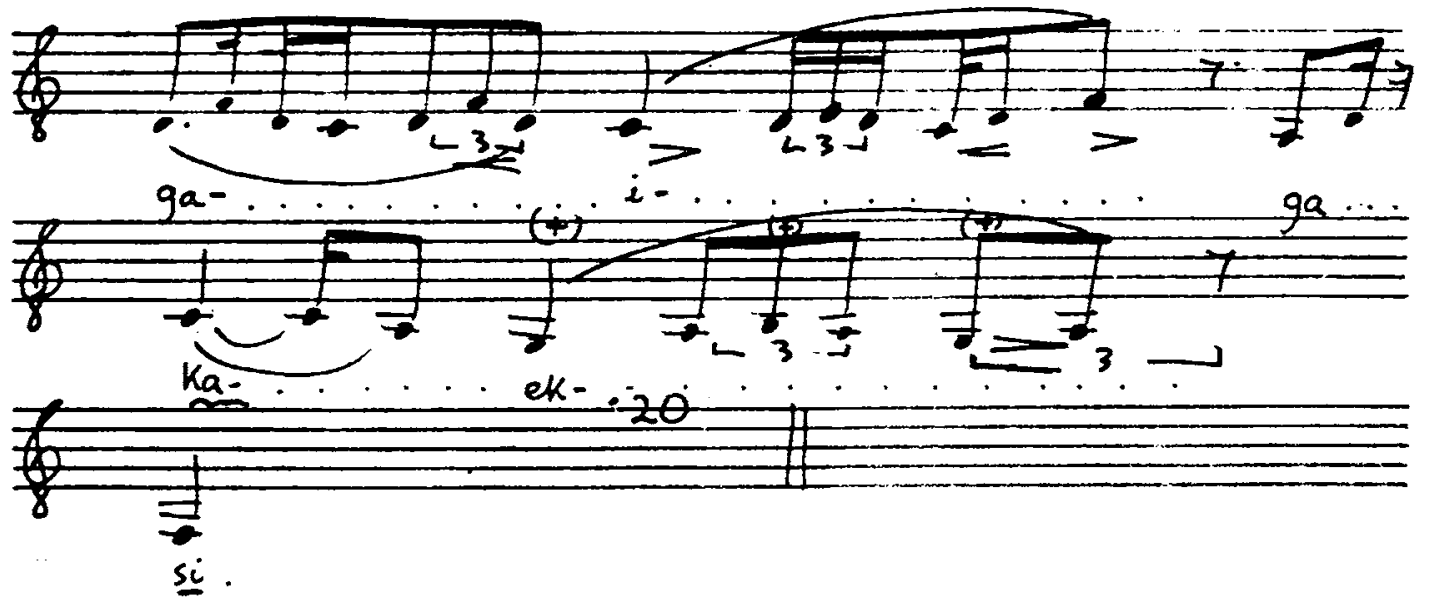


62. PANGKUR

SINGER: SUPARDI

T.I.: $0.42 \mathrm{~min}$.

O.P.: I tone lower

$(d=108)$

Ming-Kar-ming-Kur ing ang-
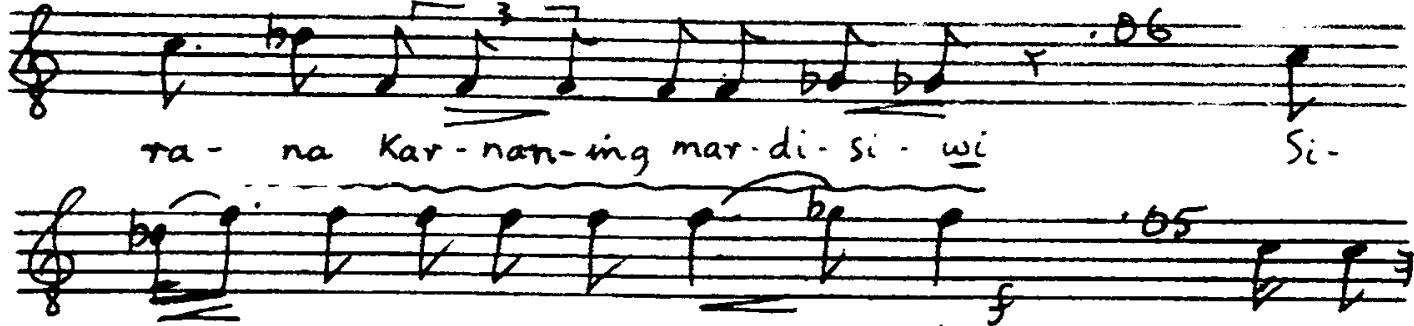

$\widehat{n a}=$, wung res-mi-ning $k i-. .$. dung Si-me.

ba

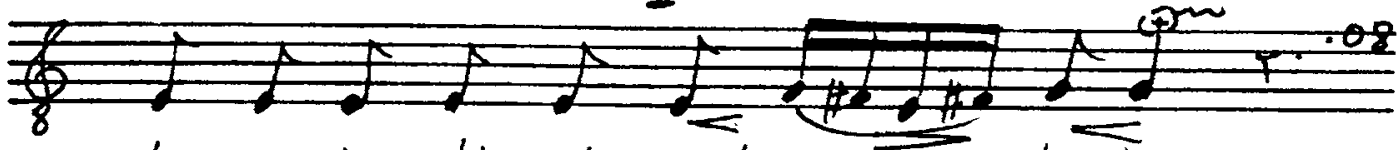

ta pa-kar-ti-ning ngel-mu. .... ku-hung

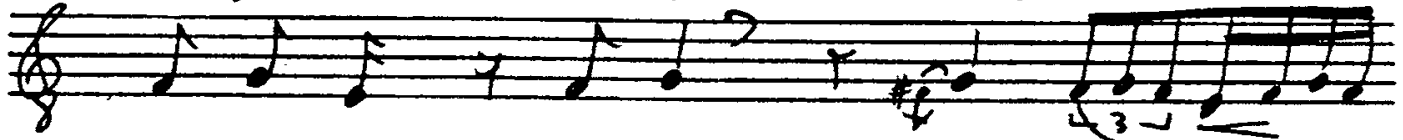

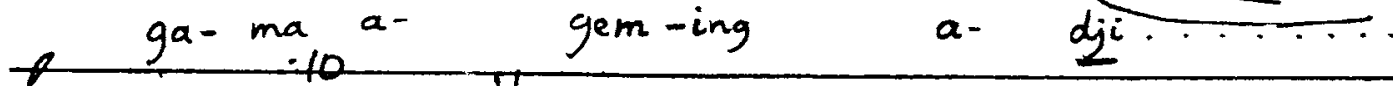

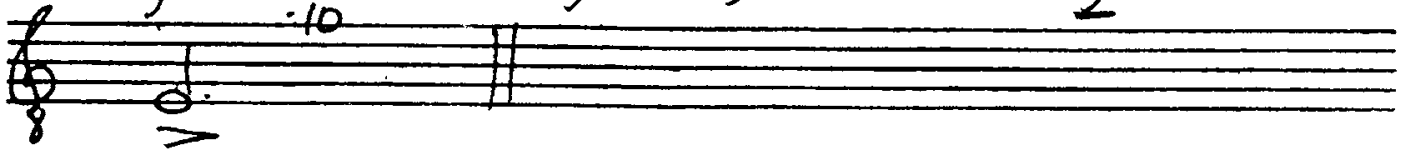




$$
(d=103)
$$
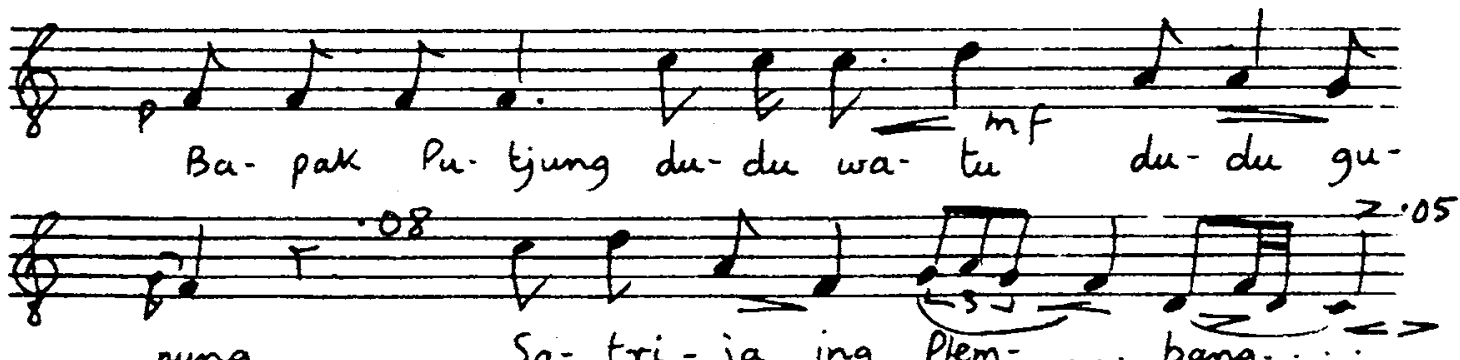

rung Sa-tri-ja ing Plem-.... bang

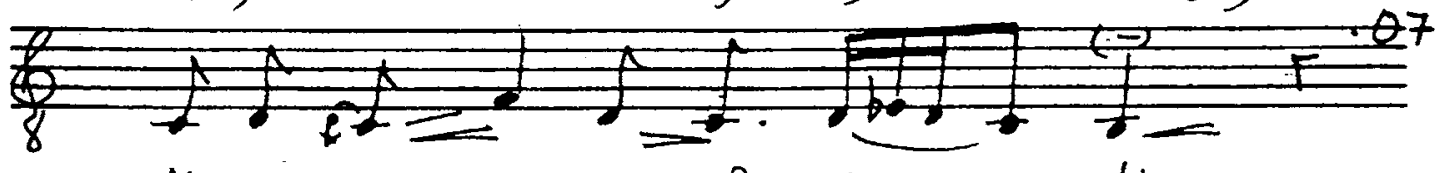

Ngon-i- ngon - e sana Bu-pa- ... th
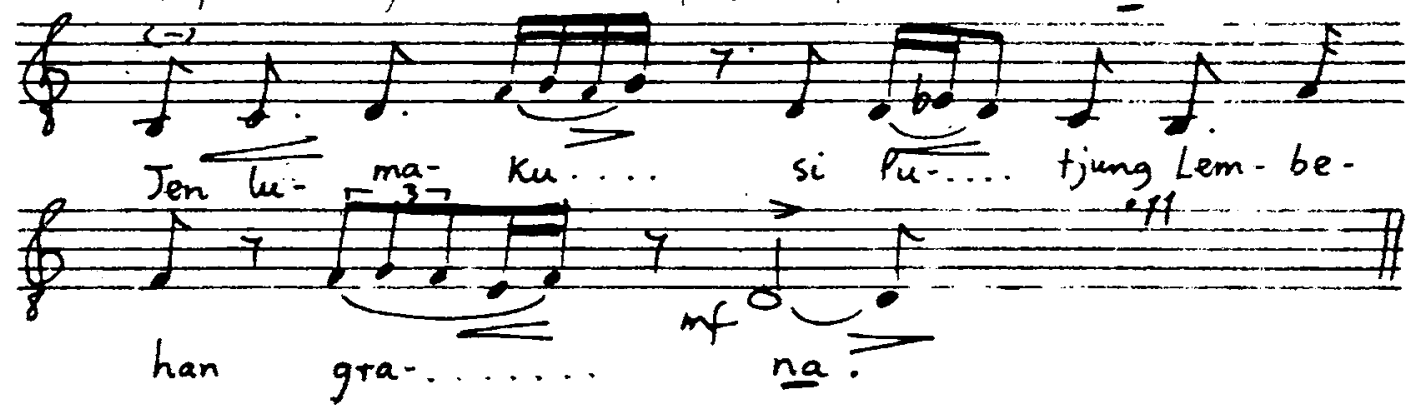
64. DANDANGGULA

SINGER: SUNARTO

HOME TOWN: KLATEN

T.L.: 1.13 min.

O.P.: $\frac{1}{2}$ tone lower

$(J=107)$

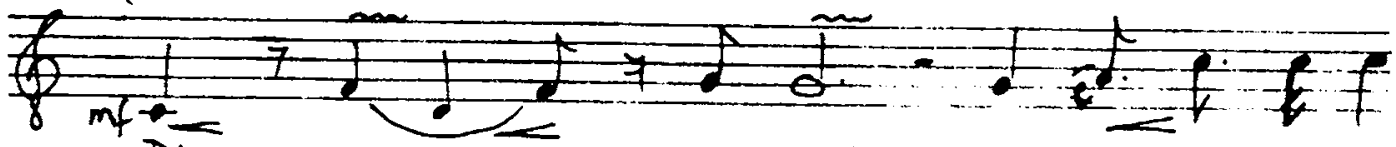
Dja- go... Kle-ruk ra-me ka-pi-ar.

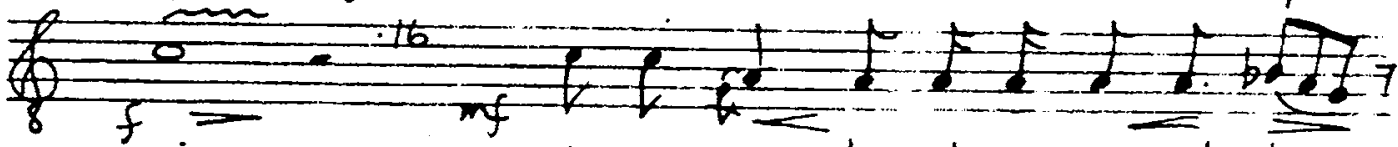
si La-wa Ka- long lu-re pan-de-lik-.. $\frac{1}{0}$

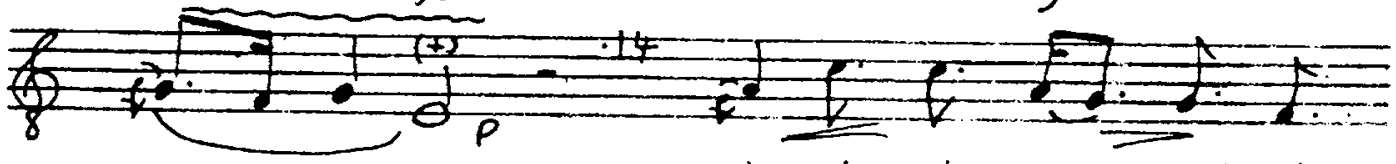
ne..... We tan bang su- lak - i-

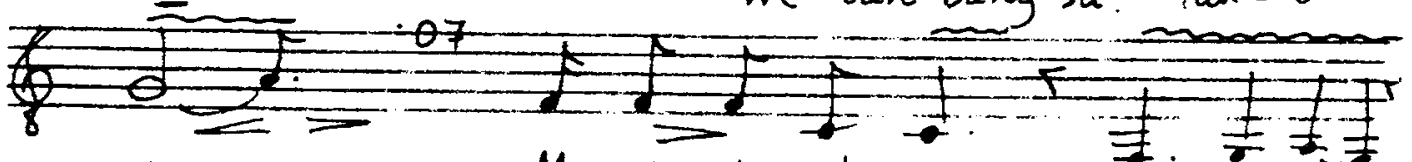
Pun Me-res-tan-da ni jen

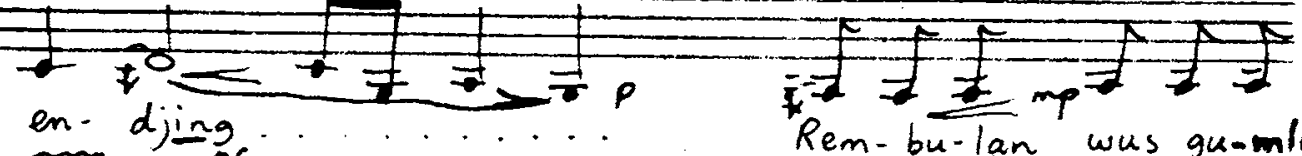

$$
\begin{aligned}
& \text { Rem-bu-lan wus gu-mle. }
\end{aligned}
$$

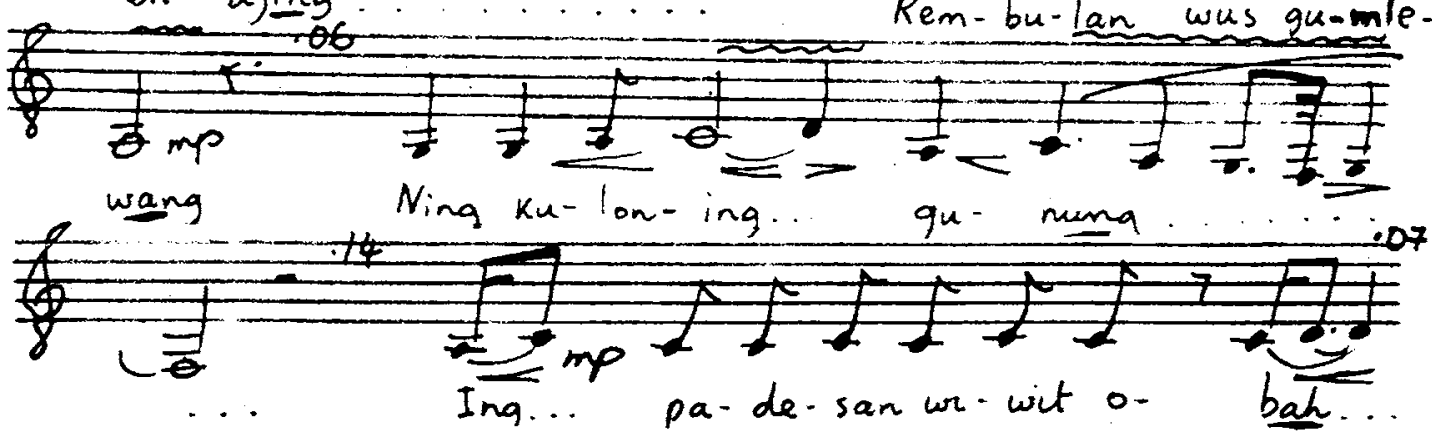




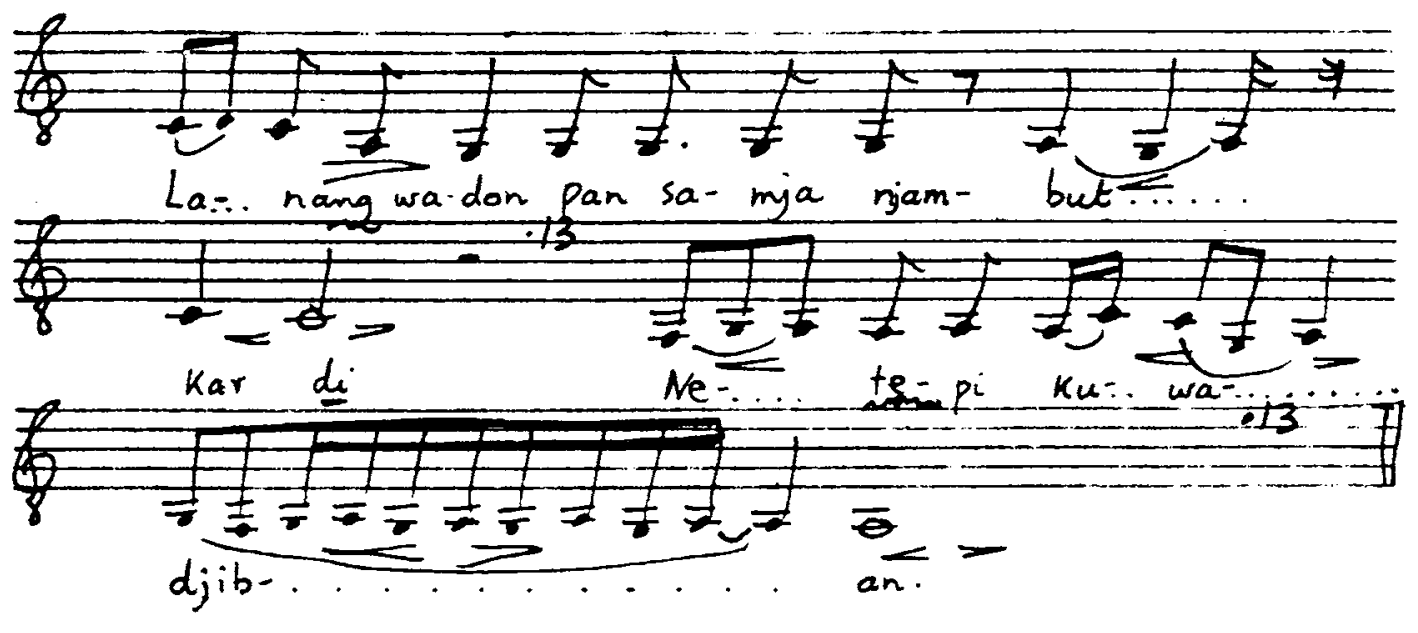


65. DURMA

SINGER: SUNARTO

T.L.: $0.59 \mathrm{~min}$.

O.P.: $\frac{1}{2}$ tone higher

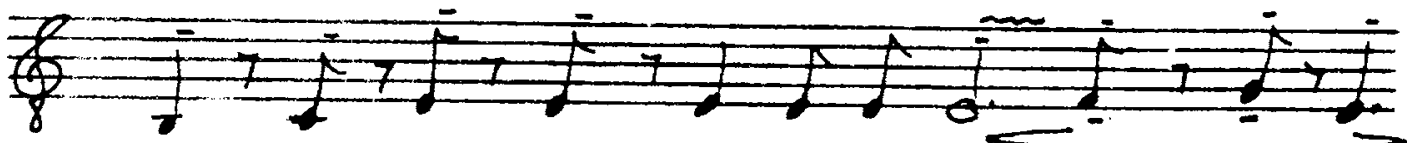
Pra Kan-tja den sa-mja mu-lat lan was- $\overrightarrow{p a-}$

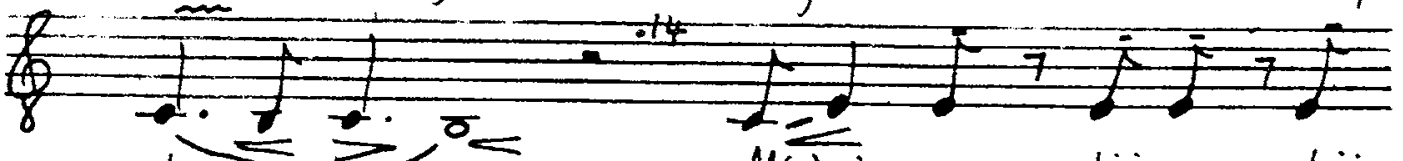
M(e)-ring wan- tji- wan- $t ; i$
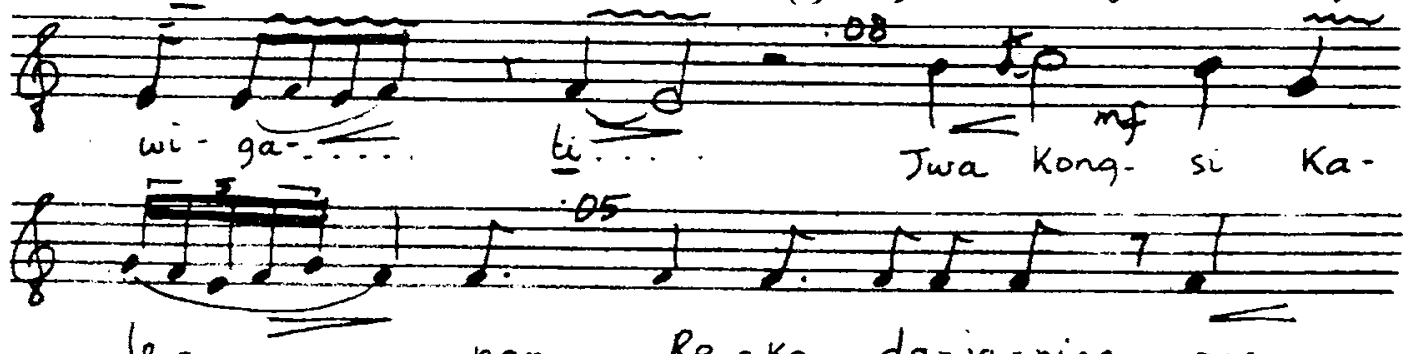

le...nan $R e-k a$ da-ja-ning ang-

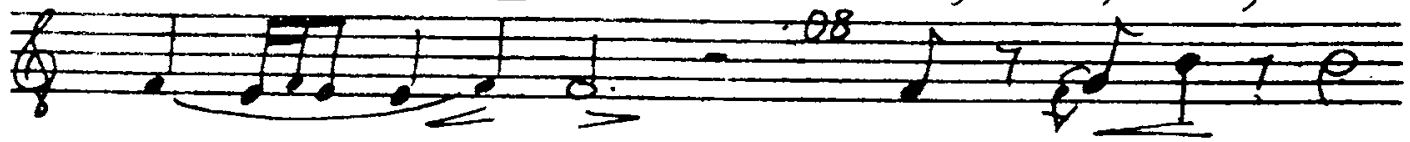

Ka-.... ta Ne- dija ngru-sak

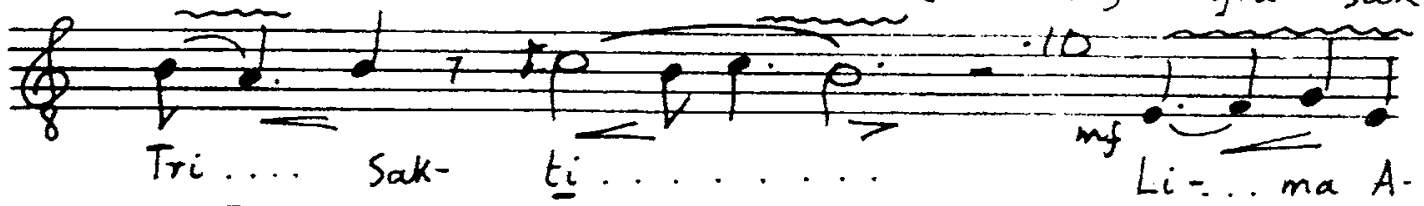

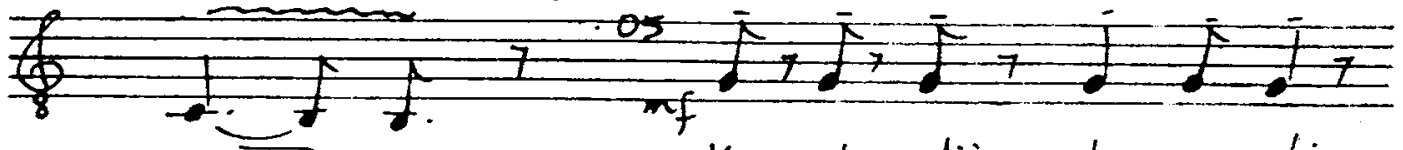

$z_{i}=$ mat Kang da-dija tung-gu-ling

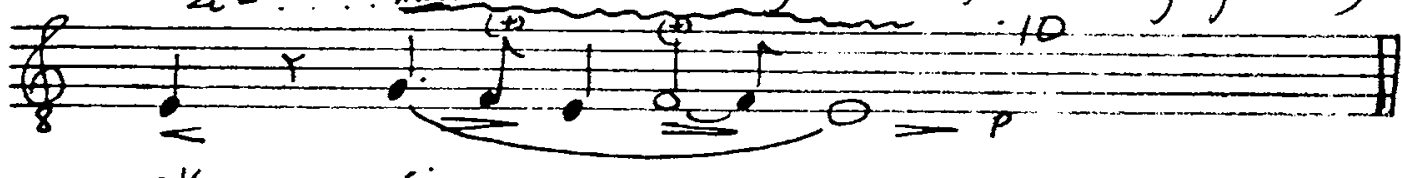

ak -

si 
66. ASMARANDANA

\author{
SINGER: SUNARTO \\ T.I.: $0.38 \mathrm{~min}$. \\ O.P.: 2 tones lower
}

$(d=104)$

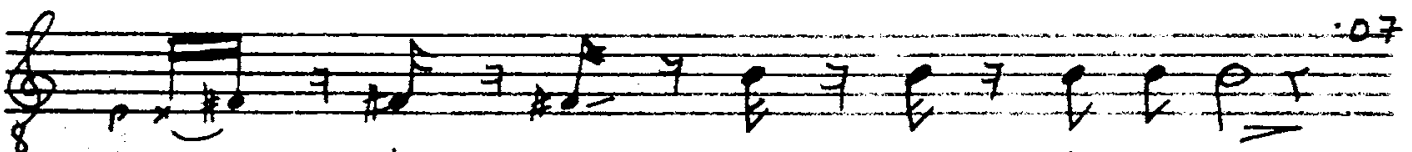
Wa:.. djib mi- tu- ru- ta ma.ring

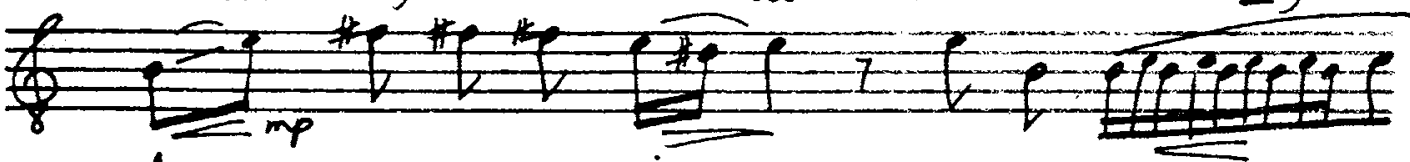
Ang $=$ ger-ang-ger-ing... $a-g a-m a \ldots \ldots$

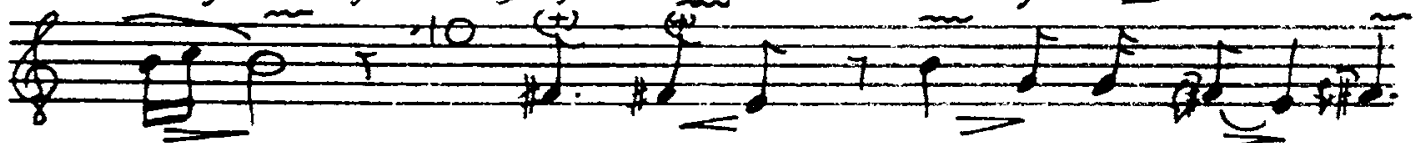

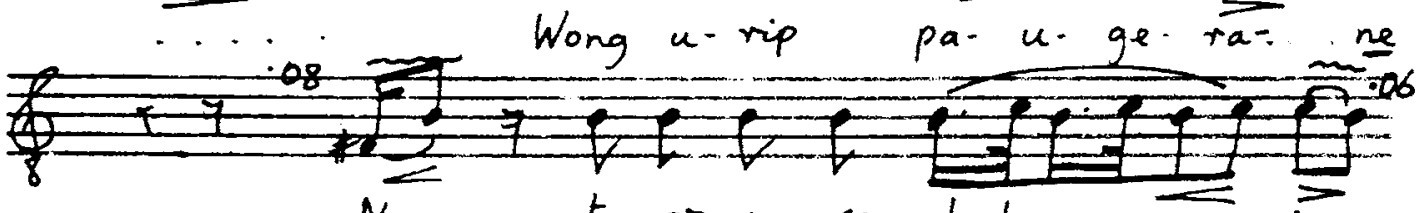
Ne-.. te - pa-na sem-bah.-.

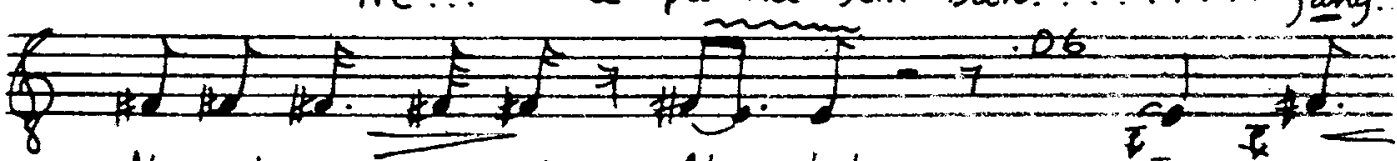
Nga-bek ti m(-) ring AL . lah 'Ing wan-

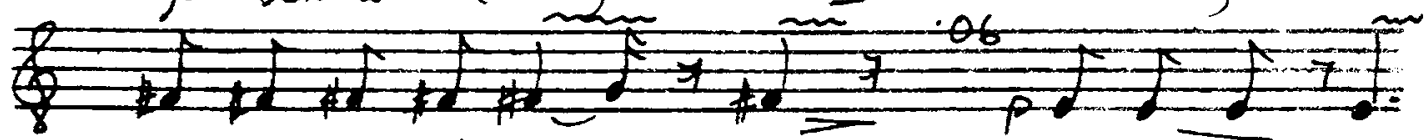
tji kang wis ti-nem:. tw A dia kong si

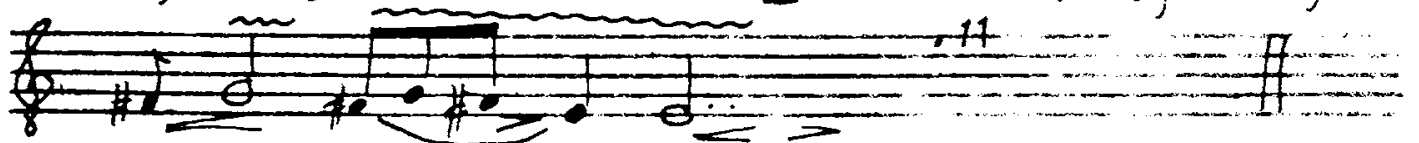
$\mathrm{Ka}-\mathrm{li}$ - wat $\ldots \ldots$ an 
67. PUTJUNG

SINGER: SUNARTO

T.I.: $0.38 \mathrm{~min}$.

O.P.: 2 tones lower

$(!=89)$.
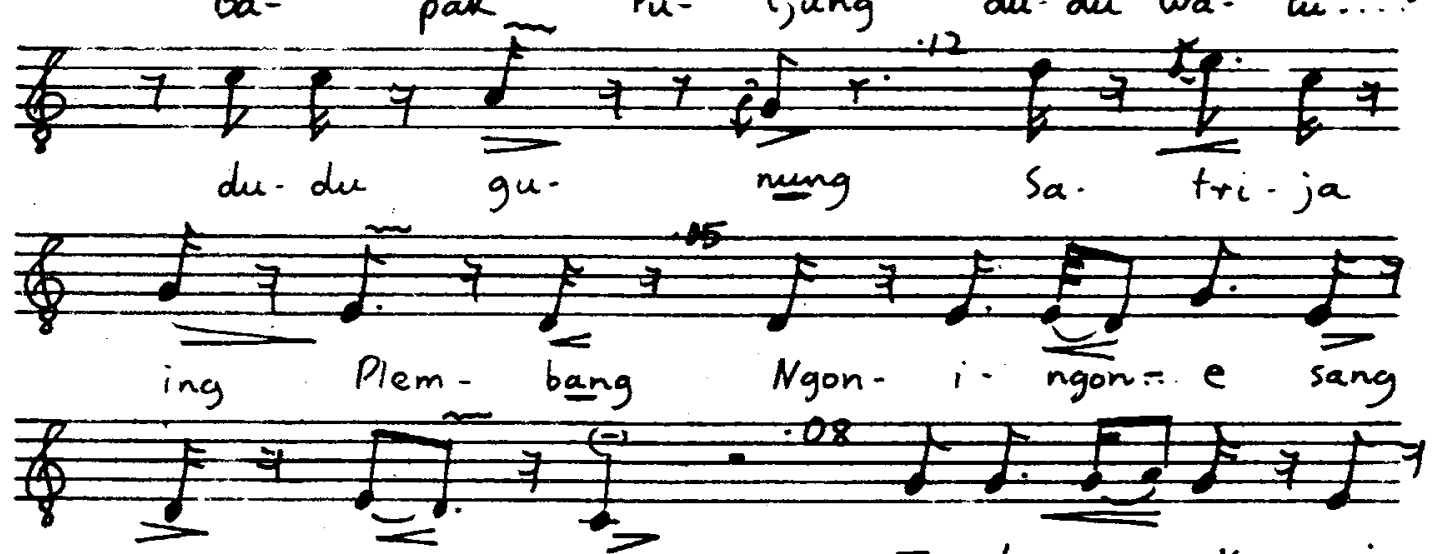

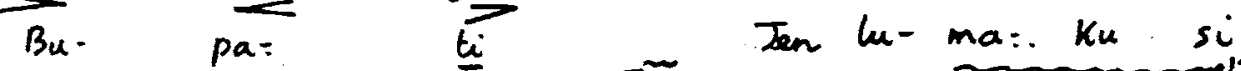

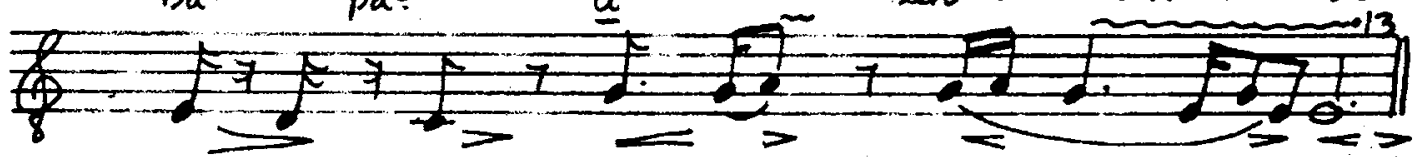

Pu- tjung lem- be- jan... gra.......na 
68. PANGKIUR

SINGER: SUNARTO

T.L.: $0.56 \mathrm{~min}$.

O.P.: 2 tones lower

$(d=112)$

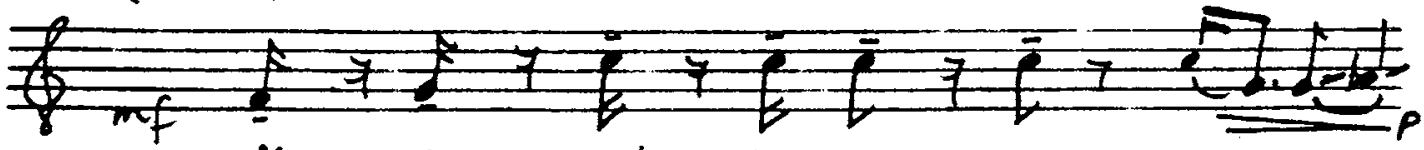

Ming-Kar - ming-Kur ing ang- Ka... ra ...

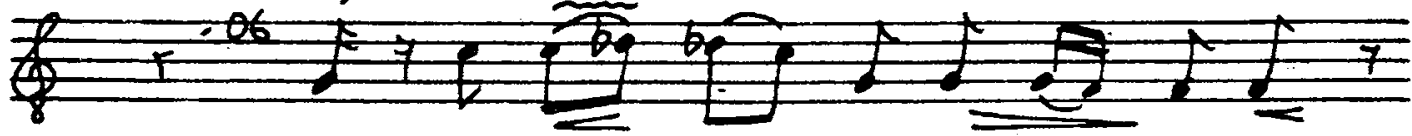

$A$ - ka.ra-.. na...ka-re-nark. ing mar.

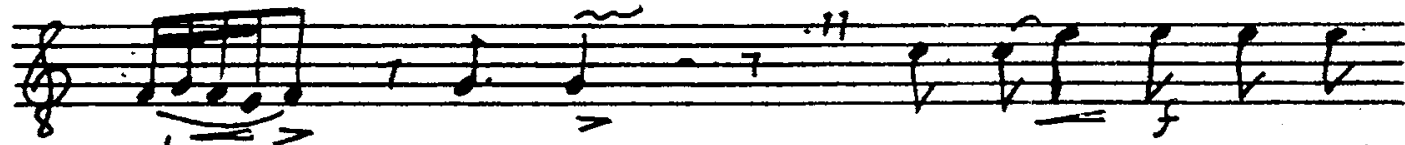
di $=$
si-na:
wung res-mi-

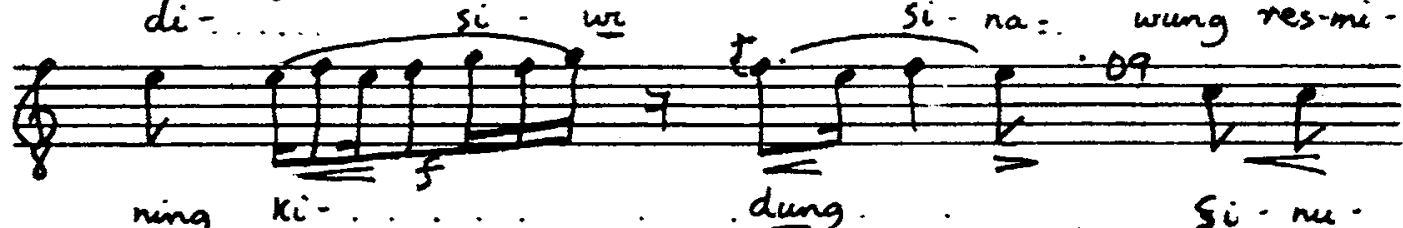

ning $x_{i} \ldots \ldots$. dung. ba... si- nu-Kar-ta $M(-)$ rih Ker-tar-..

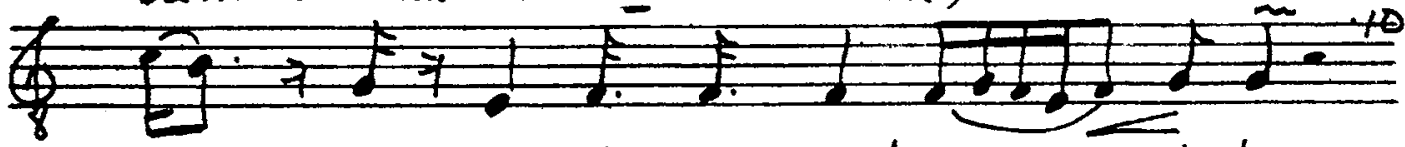

ta.. pa- kar-ti-ning ngel-mu....lu-kurg
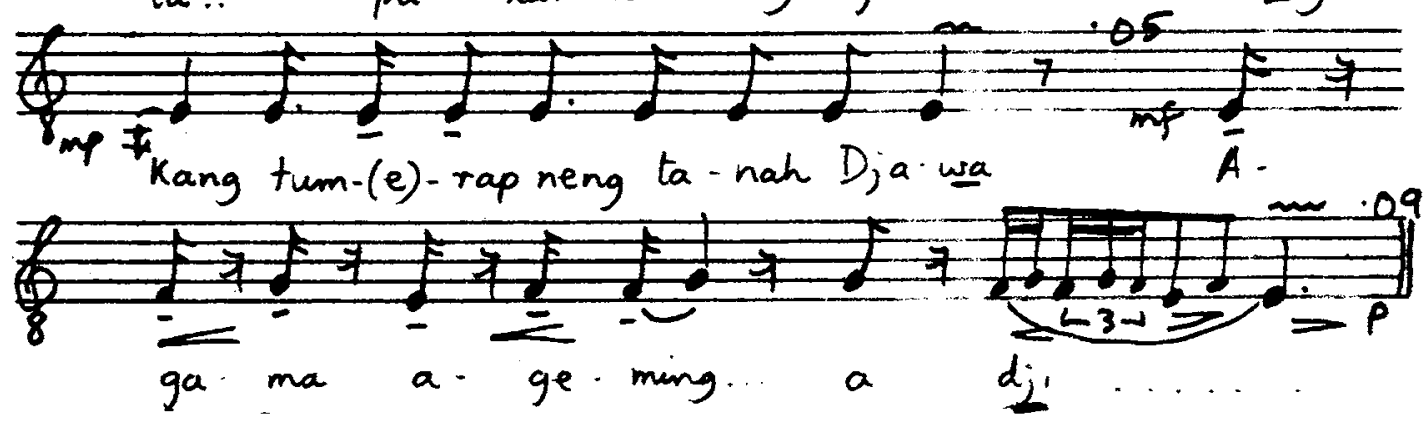
69. DANDANGGULA TLUTUR

SINGER: SUPARMAN

HOME TOWN: SEMARANG

T.I.: $2.07 \mathrm{~min}$.

O.P.: 2 tones higher
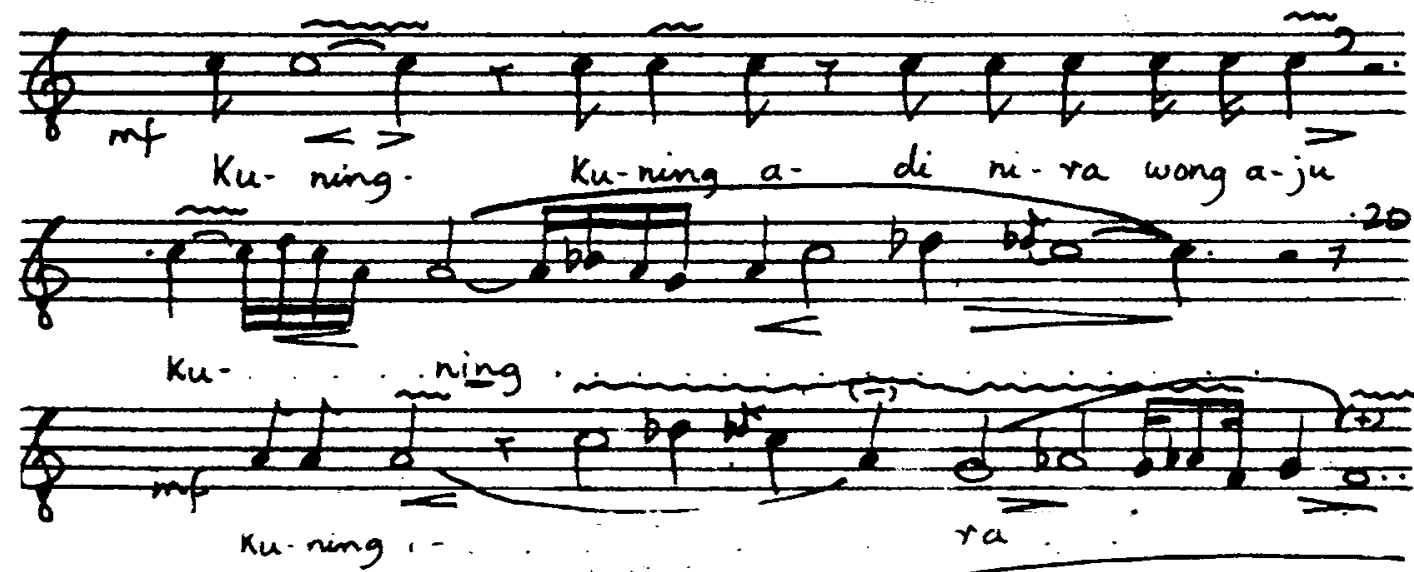

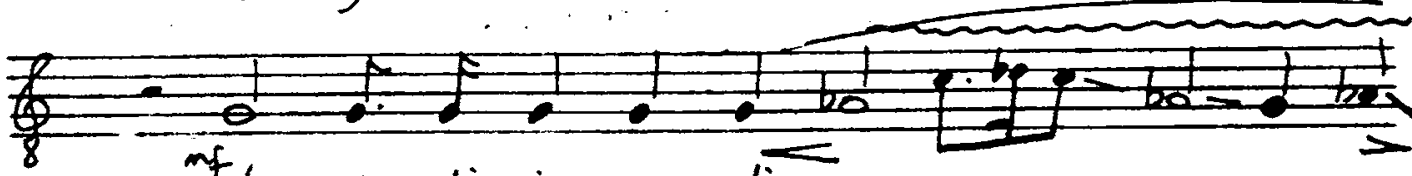
if tan ka-di ja pra-dja

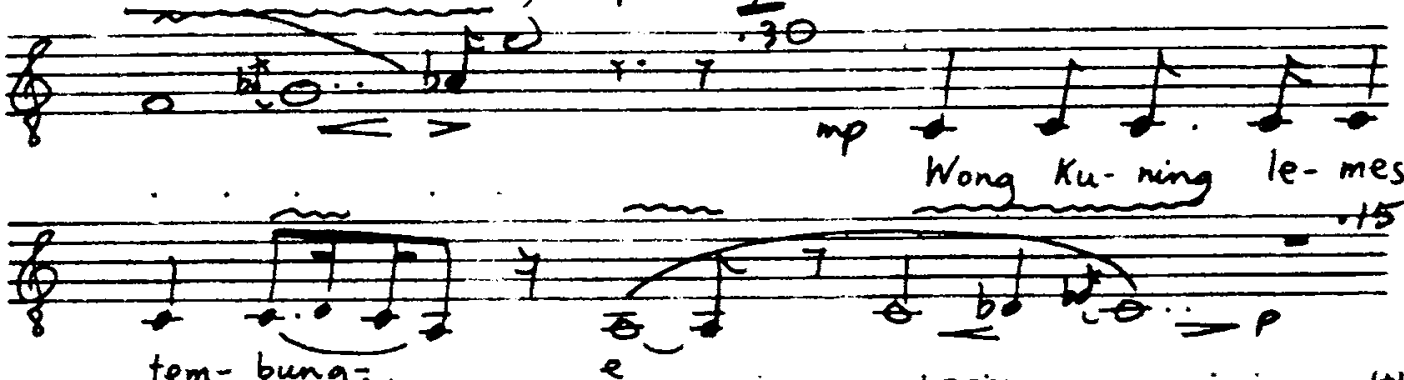

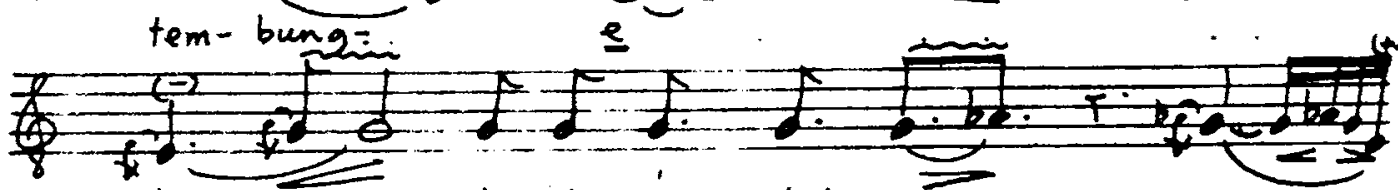

Le-. la-le-la duh wong...

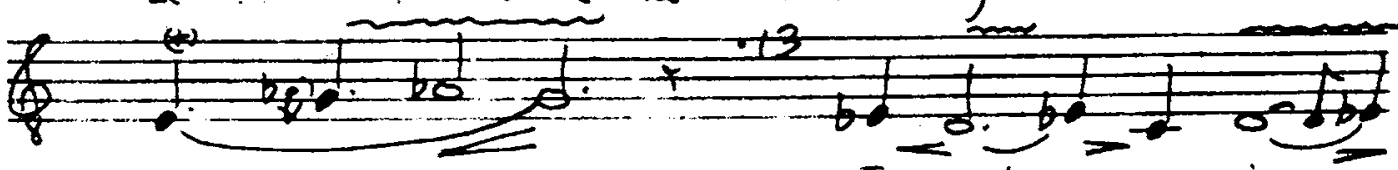

ju

Tan-sah re-ja. 


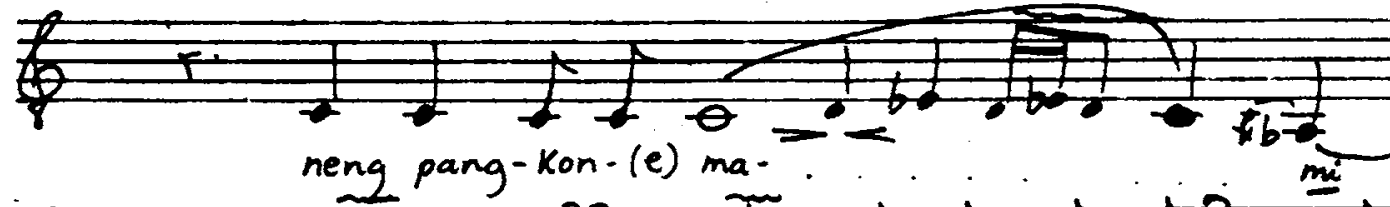

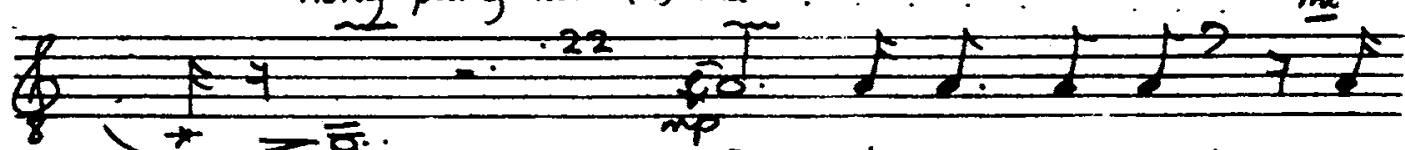

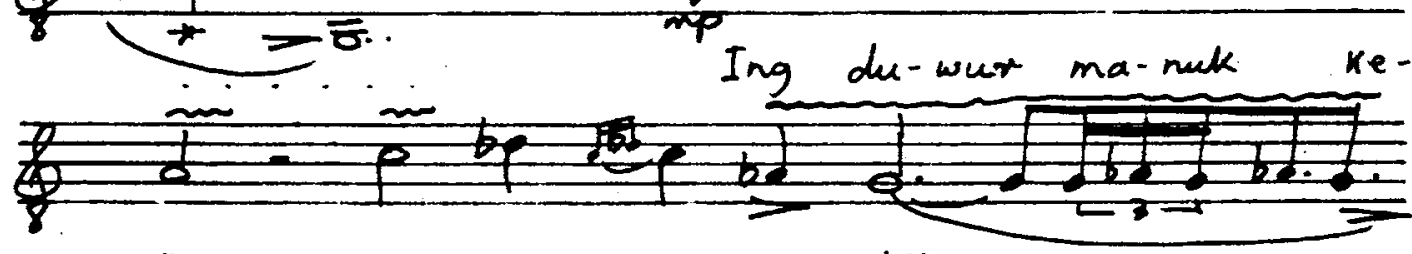

na-

wa

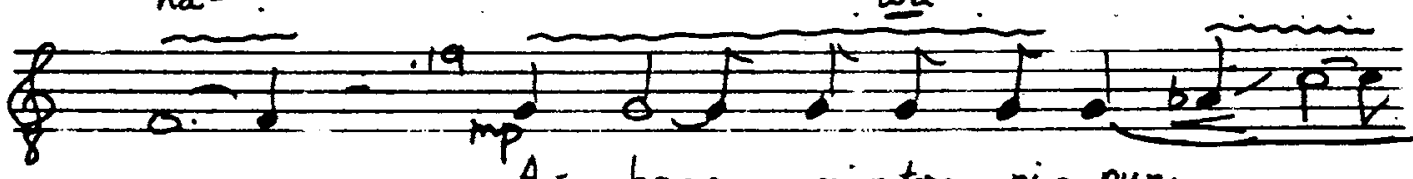
A - bang. mi-tra- ni-punm

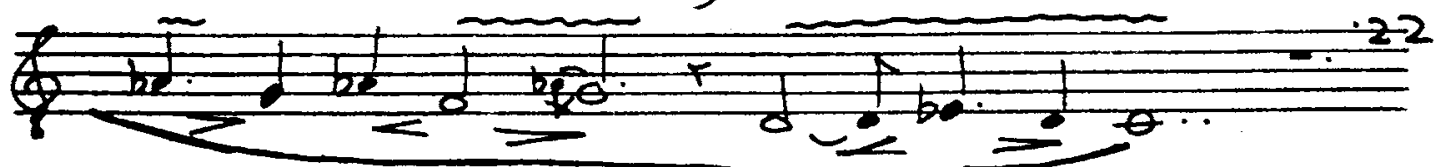

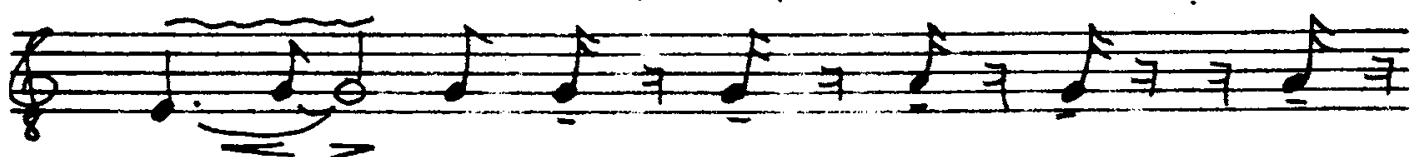
A.
dja
mu - tjuk
(e)

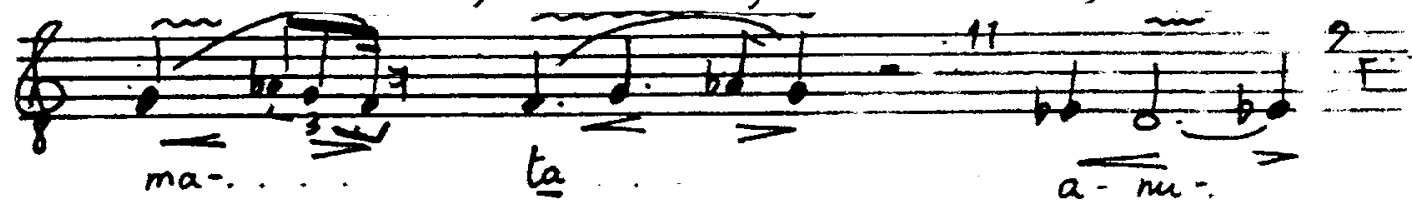

t.jk-a.
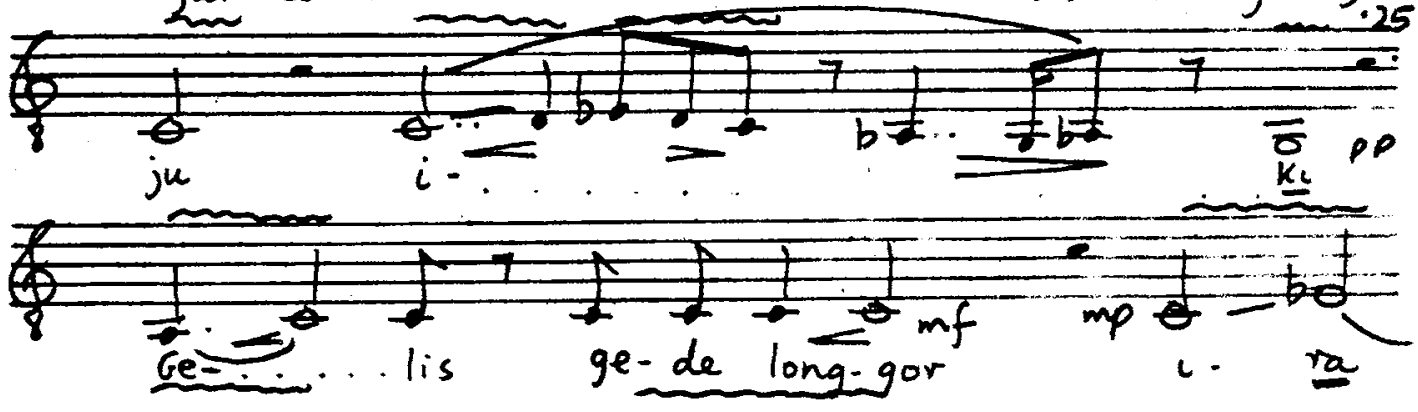


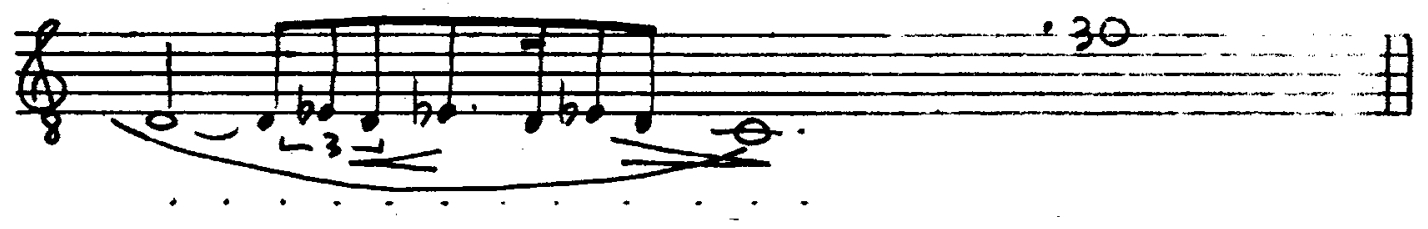


348

70. SINOM

SINGER: SUPARMAN

T.L.: $1.77 \mathrm{~min}$.

O.P.: as below
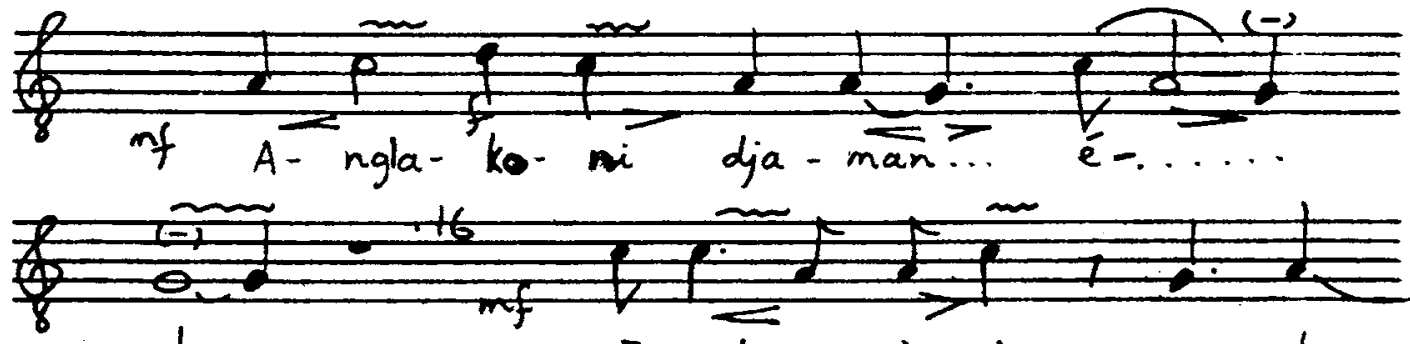

$$
\text { dan E-wut a-ja ing pam-bu- }
$$

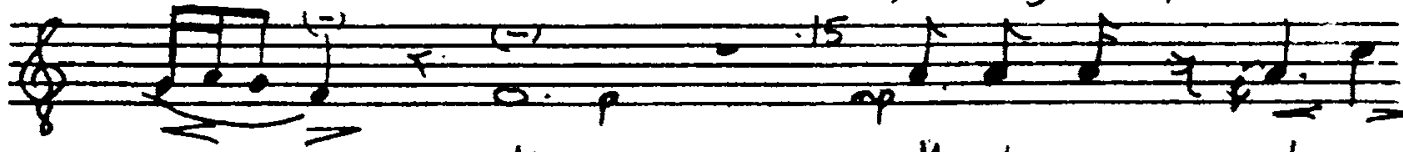

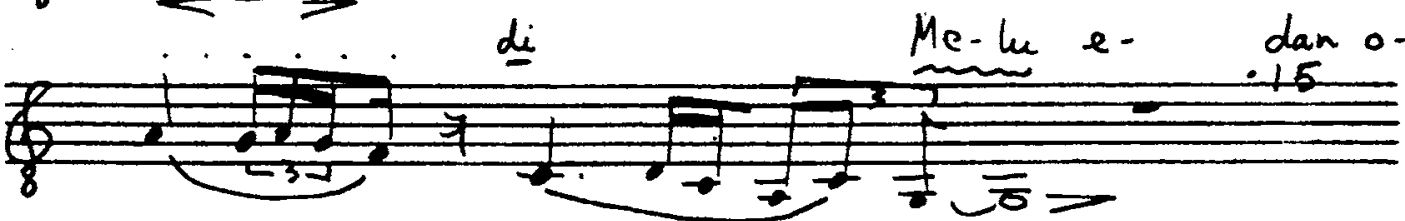

ta

ta-

han

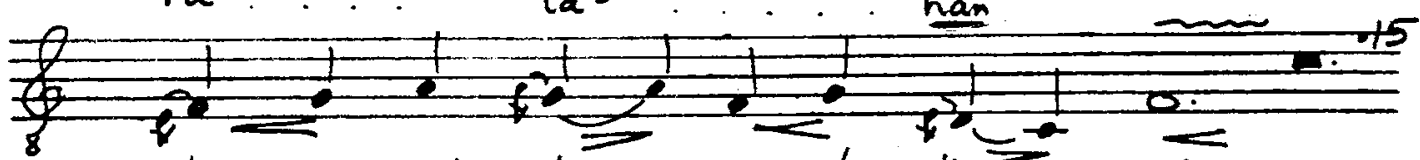

La- mun da-tan... ang.la- $k_{0}=\ldots$ ni

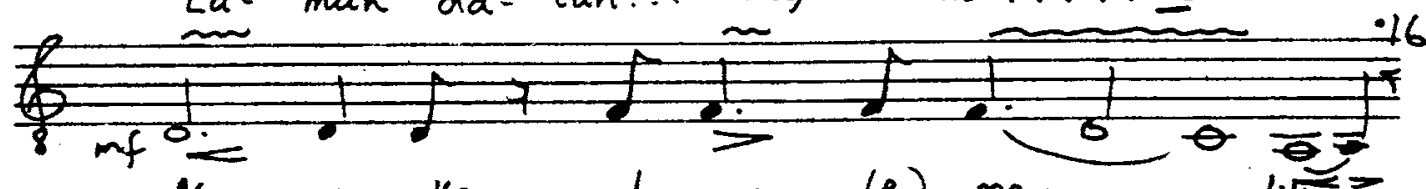

No- ra Ke- du-man (e) me-.

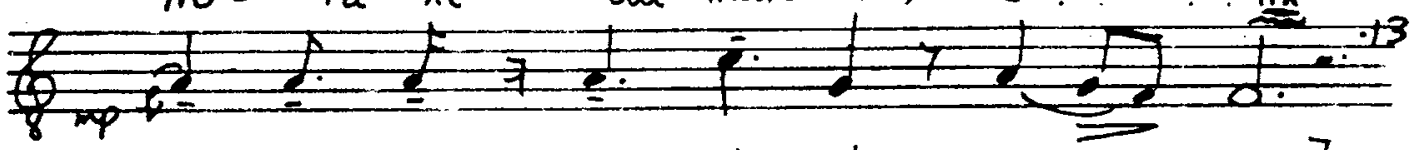

[Djan-dji-ne pa- $\frac{d a}{=3}$ lu gu-...ne ne

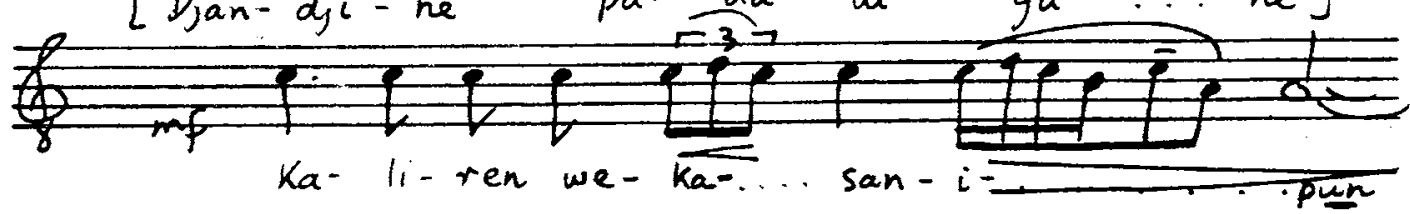




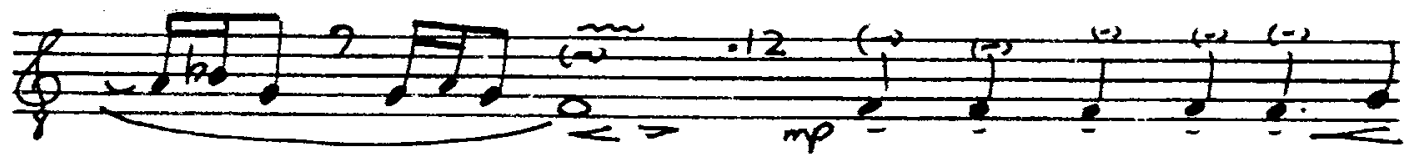

[ $P_{u}$ - dang-a-ne ba-jung

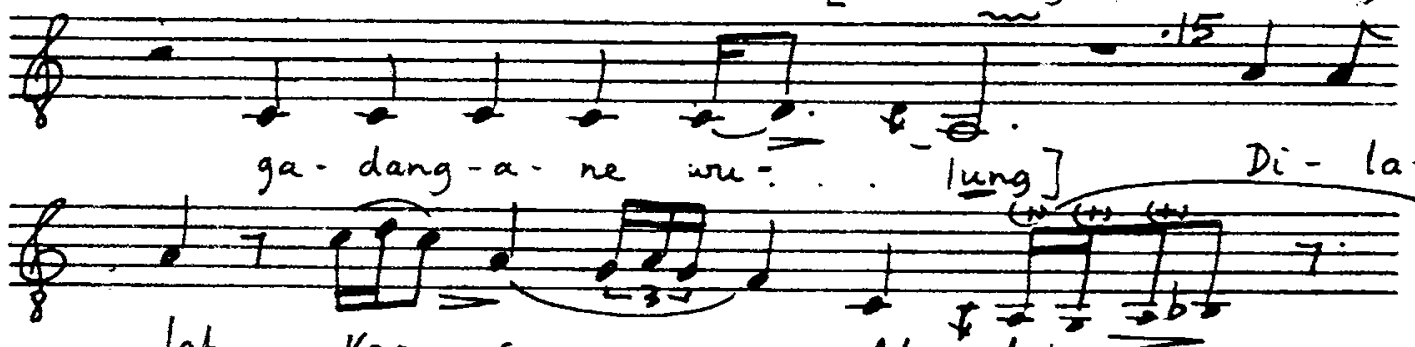
lah Ker... sa.......AC ${ }_{\text {lah }}$

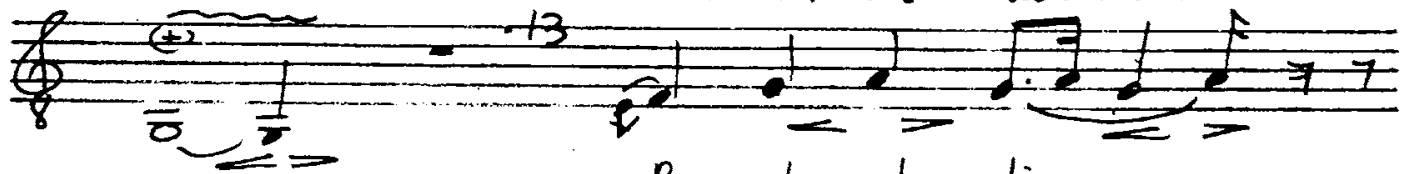

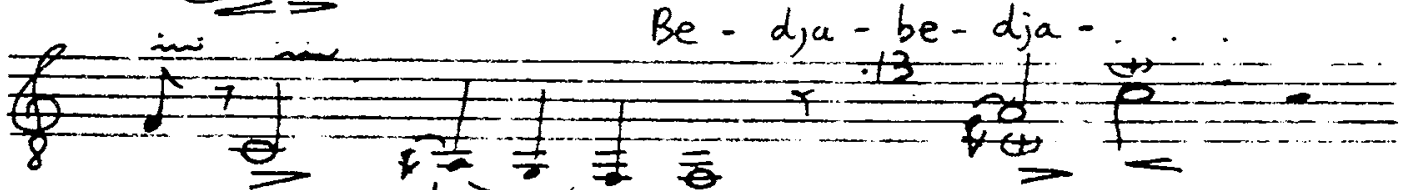

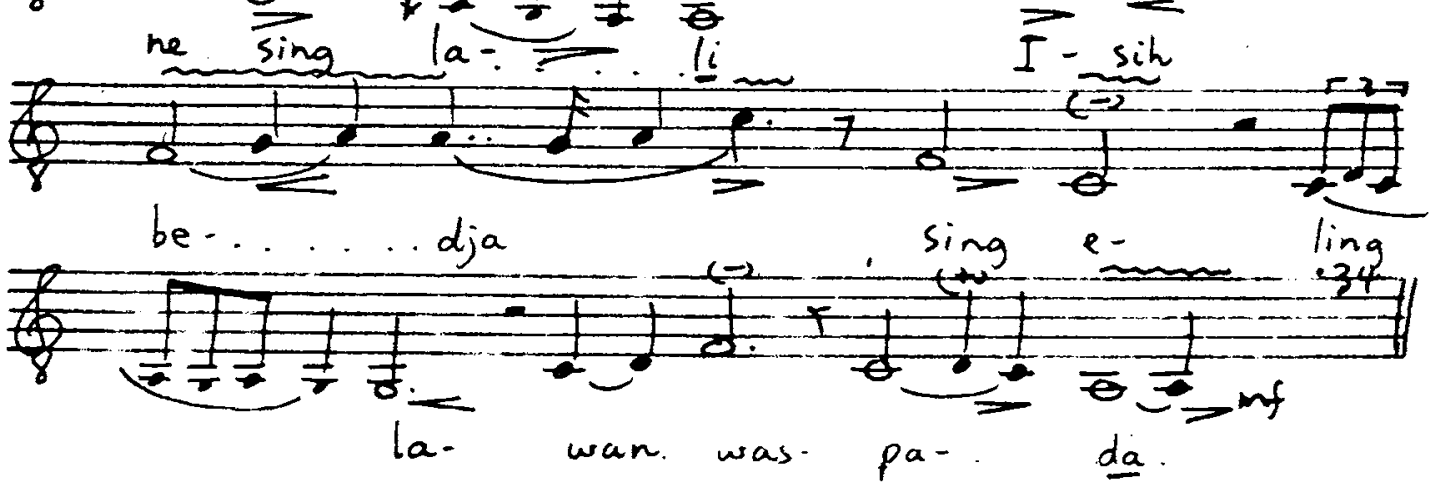


71. SINOM

SINGER: SUROSO DALADI.

HOME TOWN: NOT KNOWN

T.I.: $1.80 \mathrm{~min}$.

O.P.: I tone lower

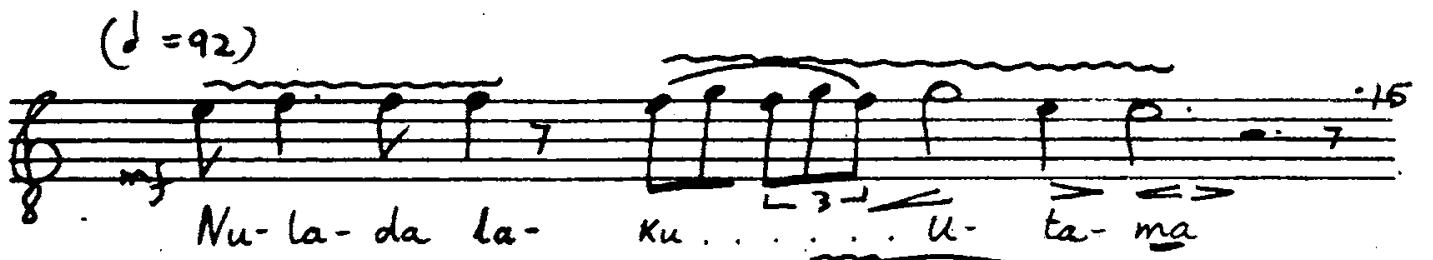

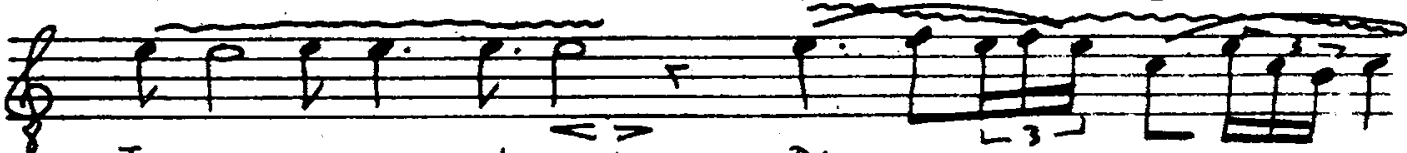
Tu-mrap-e wong ta-nah Dja-.

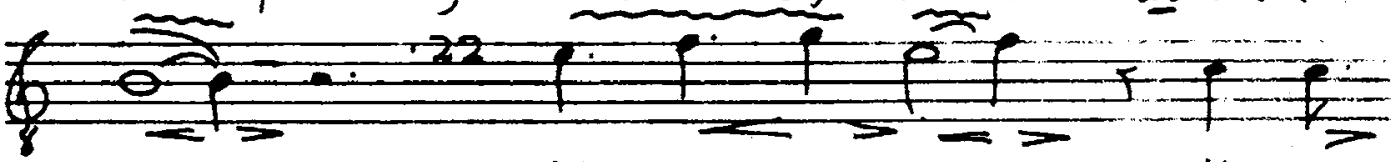

Wong a- gung ing... Ngek-si-

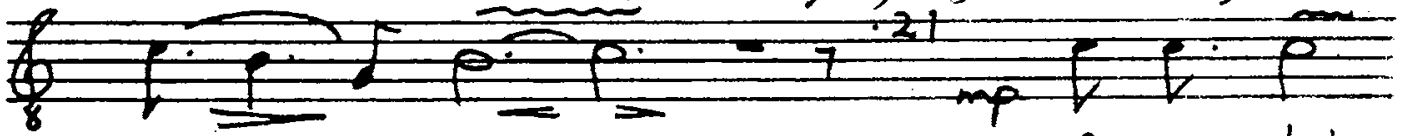
$\mathrm{Pa}$ - nem - bahan

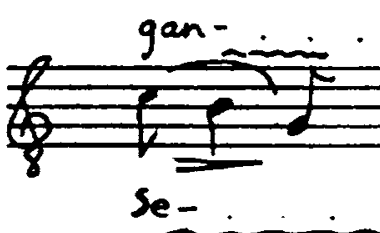

da. $\sim$

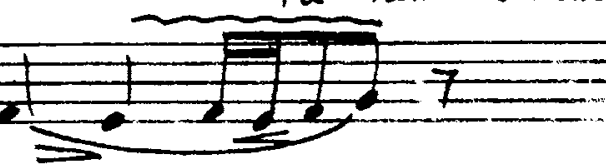

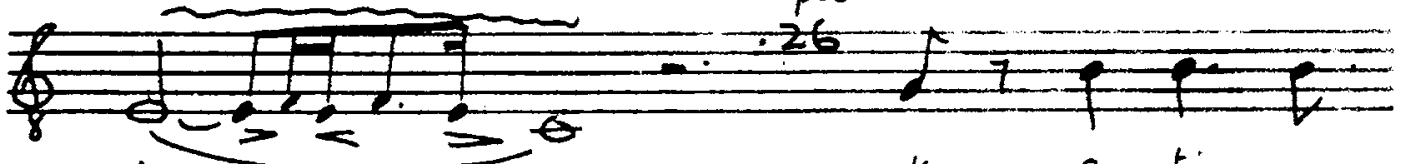
ti
mar - su- di
Su - da - ning $h_{\alpha}$-.
wa $\operatorname{lan}$

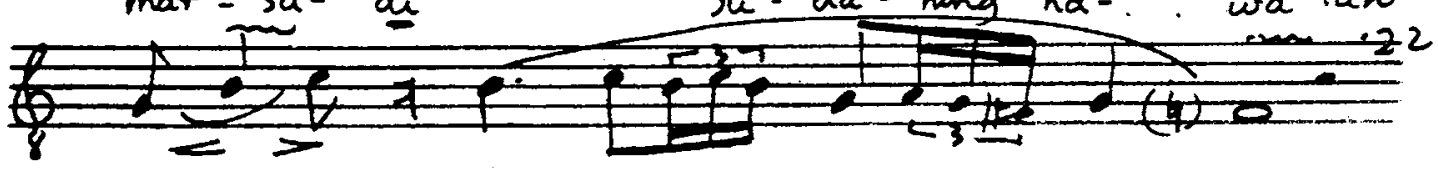

nap-. 


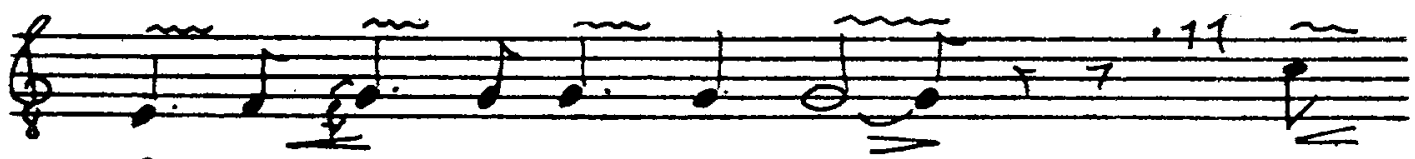
Pi. ne
ta
$\mathrm{Ta}$ -

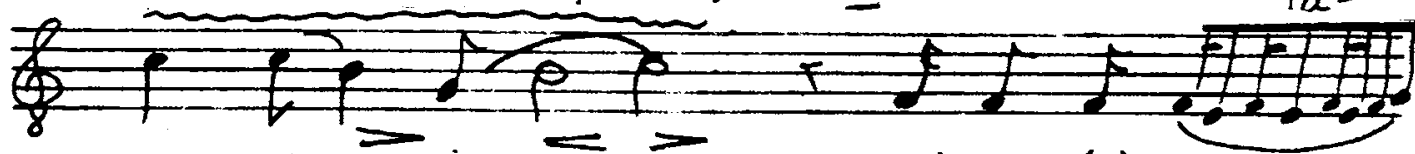

na $p_{i}=$ ing... $=$ si.ang (e) ra-...

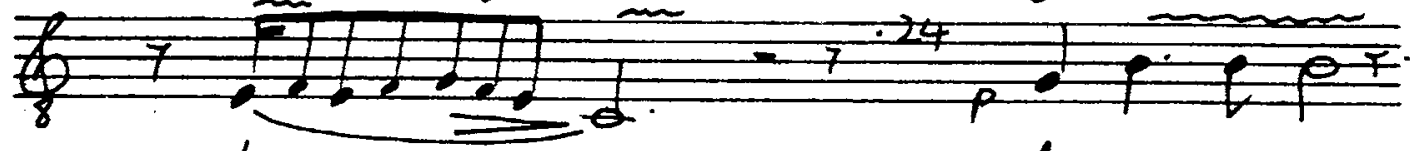

tri..... A-ma-ma-ngun
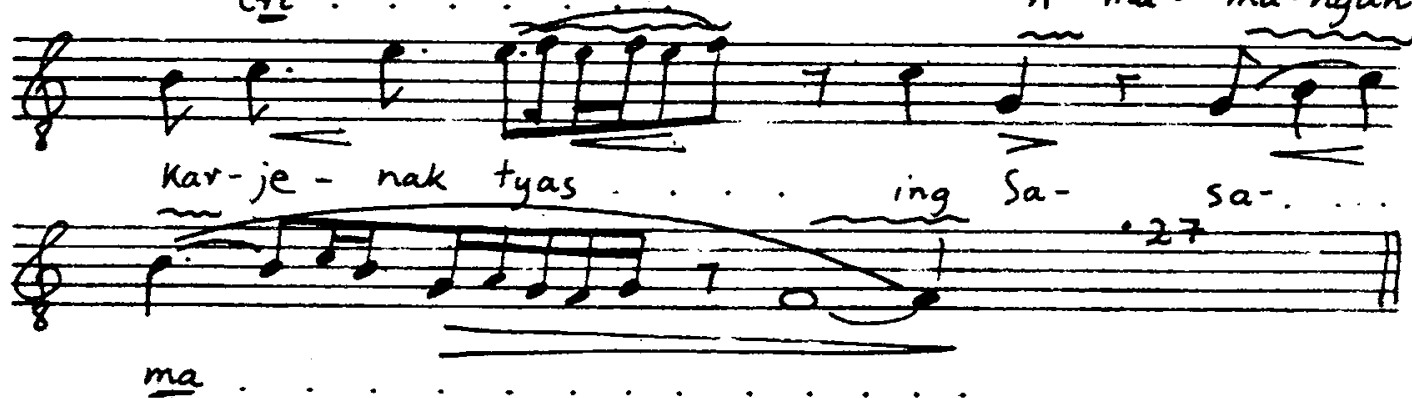
72. PANGKUR

SINGER: RETNA MARUTI HOME TOWN: NOT KNOWN

T.L.: $0.89 \mathrm{~min}$.

O.P.: $I \frac{1}{2}$ tones lower

$(d=120)$

$\frac{7}{8}$ (1)

Se-kar pang-Kur (e) Kang wi- nar-.....(e)-na

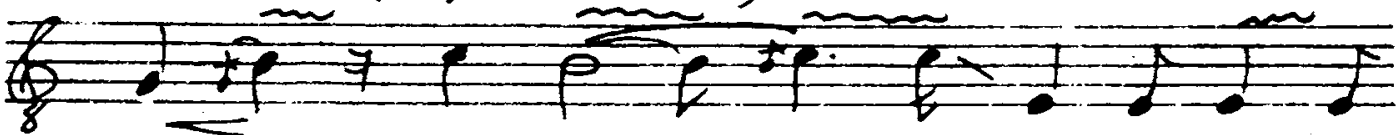

Le- la - bu. han....... (e) Kang kang-go wong

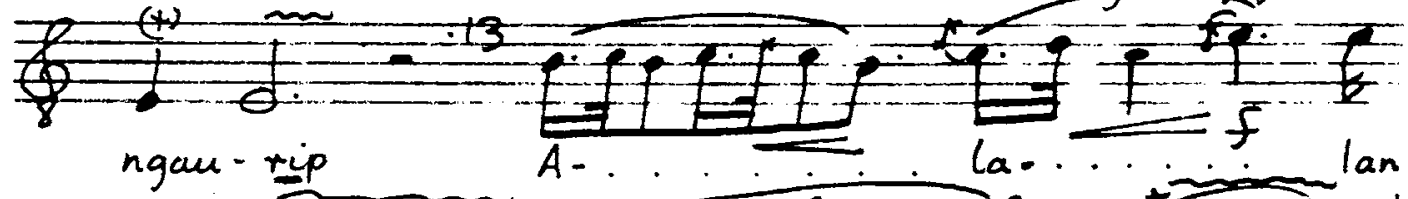

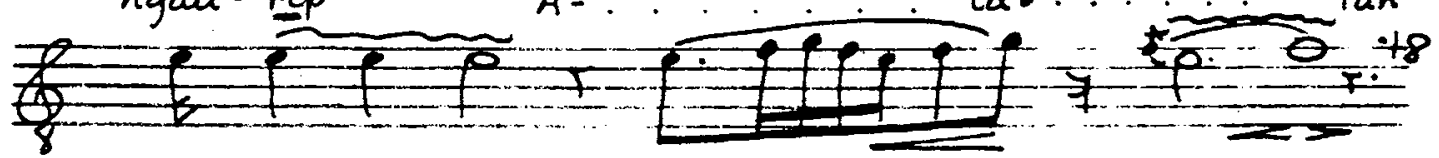

(e) be-tjik pu- ni-...... ku...

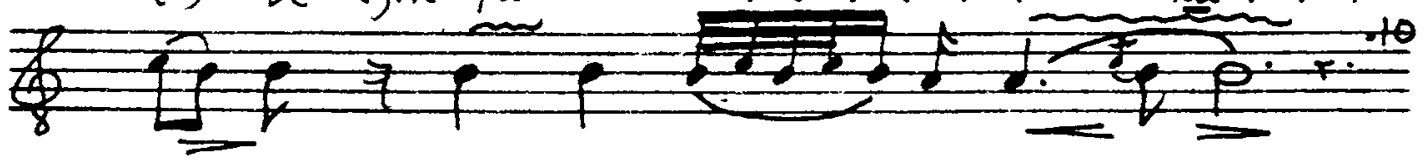
Pra-.jo- ga $\mathrm{Ka}$ - wruh $=\ldots a-n a$

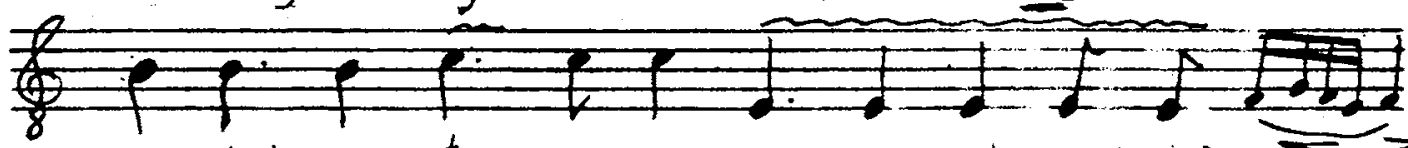
$A$ - dat wa-ton (e) pu- ni-ka di-pun (e) $k a-\ldots$ -

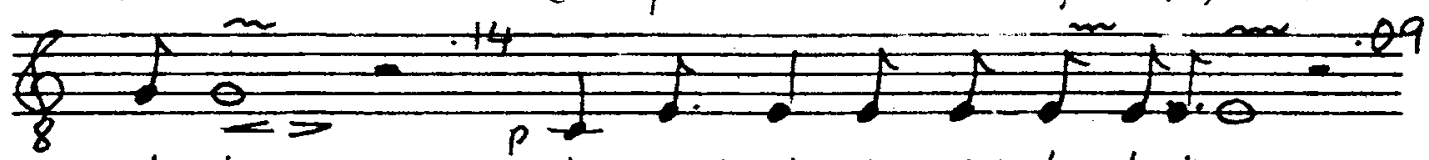
du-lu $\operatorname{Den} \ldots$ (e) ka-...es - ti si-ang (e) ra- 


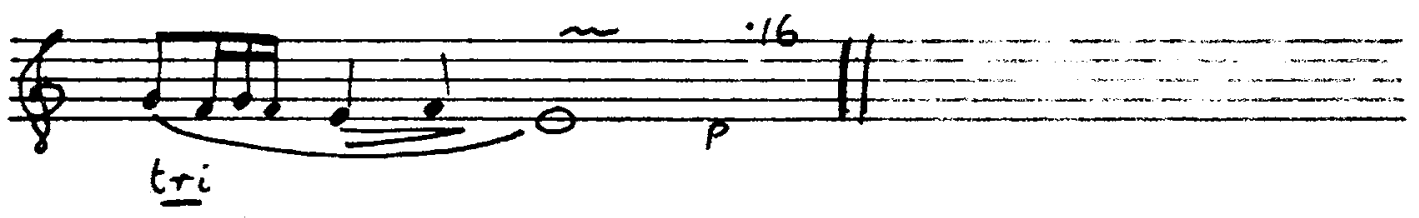


73. PUTJUNG

SINGER: PRAWOTO SAPUTRA HOME TOWN: NOT KNNOWN

T.L.: $1.06 \mathrm{~min}$.

O.P.: 2 tones higher
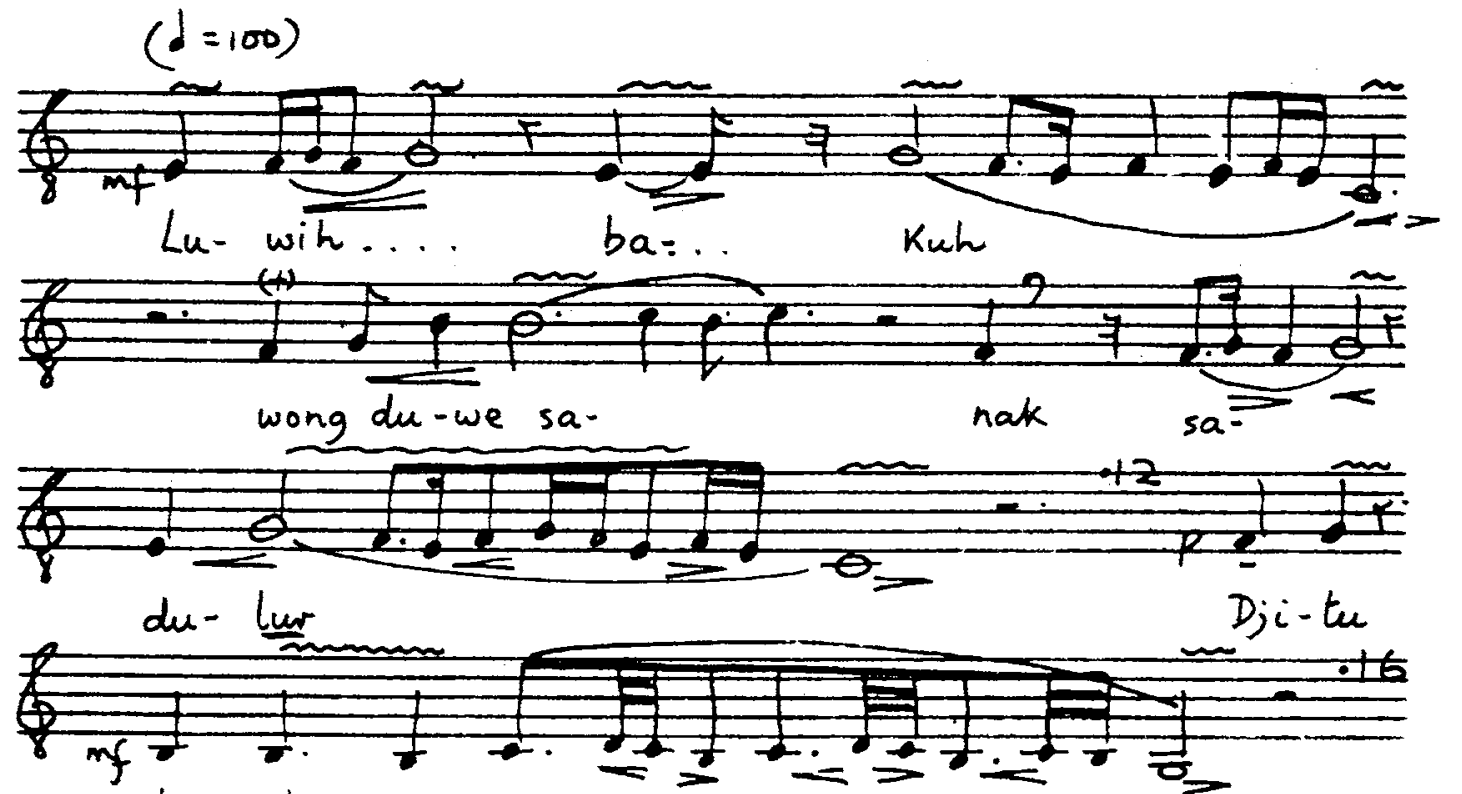
tan-ding i- ra

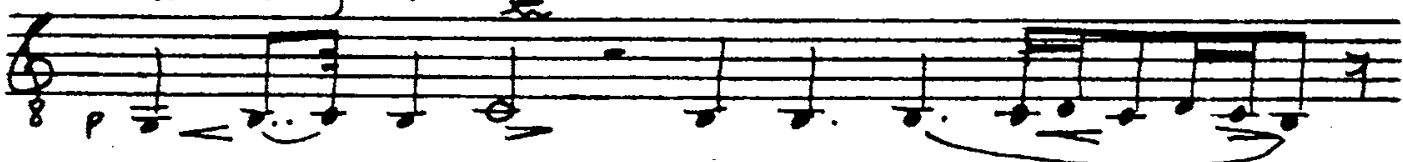

ten na... lang-sa

ba-rang pi- $>$

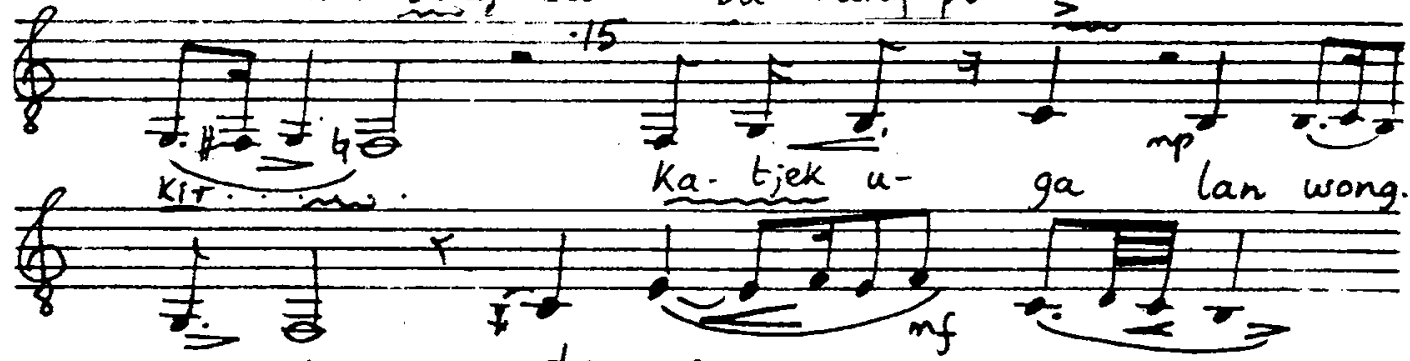

Kang $\tan$ du-we is i3i

$\sigma$

nak 
74. PUTJUNG

SINGER: P. SAPUTRA

T.L.: $0.76 \mathrm{~min}$.

O.P.: 2 tones higher

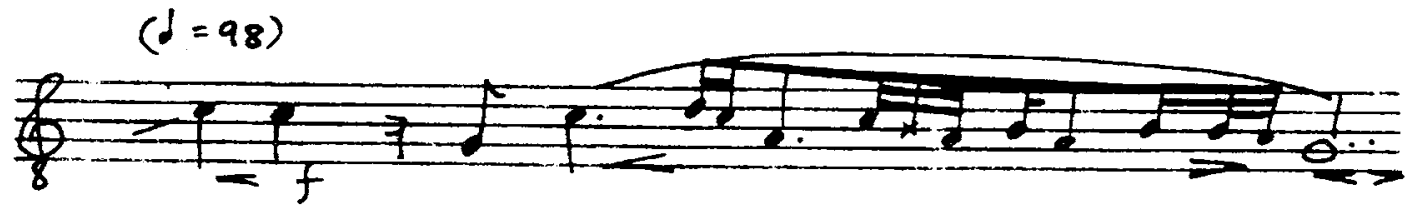

La-mun be-ner
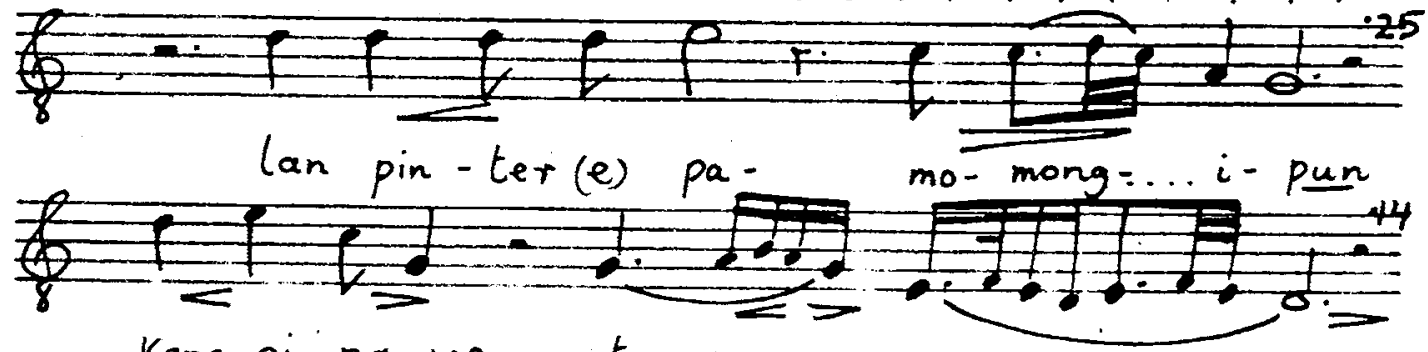

Kang gi-na-we tu-... wa

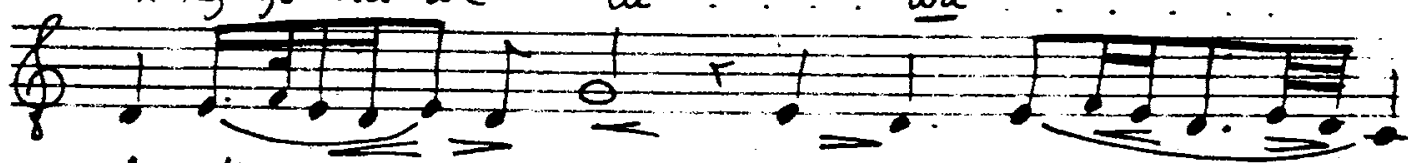

A. dja...ngang-go a- bot en-
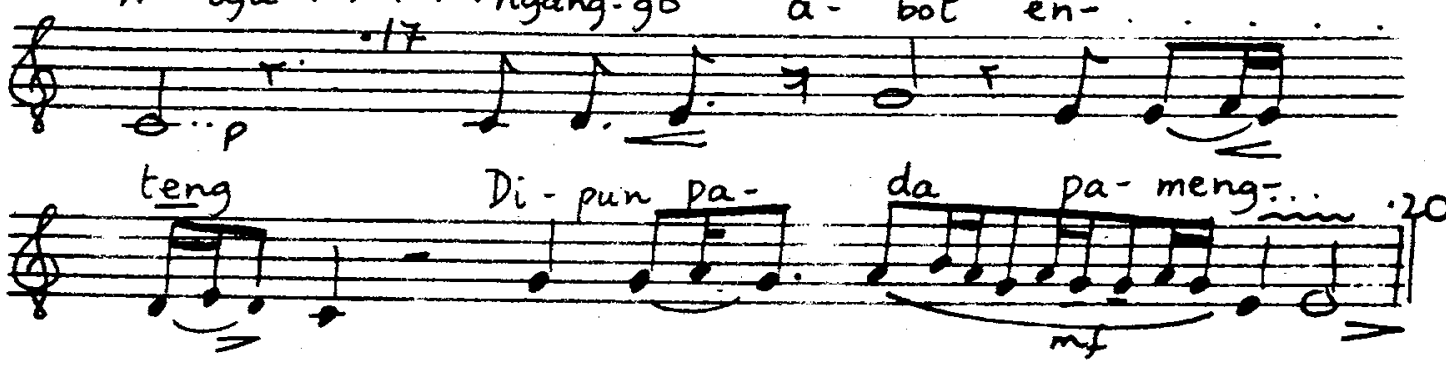

$k_{u}$. he mringsan $=t_{a} . . .$. na. 
75. PUTJUNG (Uran-uran Srepegan) SINGER: P. SAPUTRA T.L.: $0.91 \mathrm{~min}$.

O.P.: I tone lower

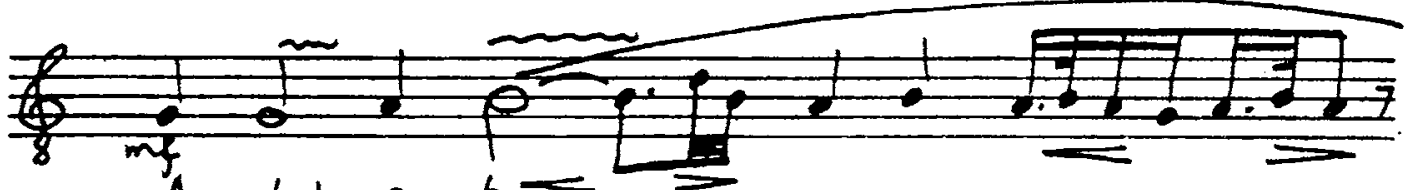
$A$ - bot en-teng.

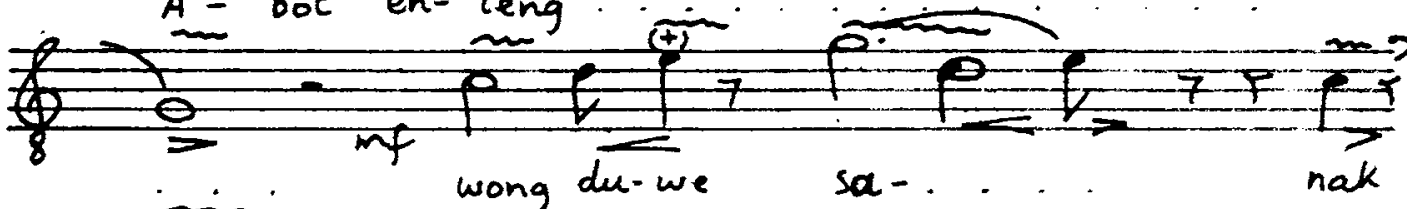

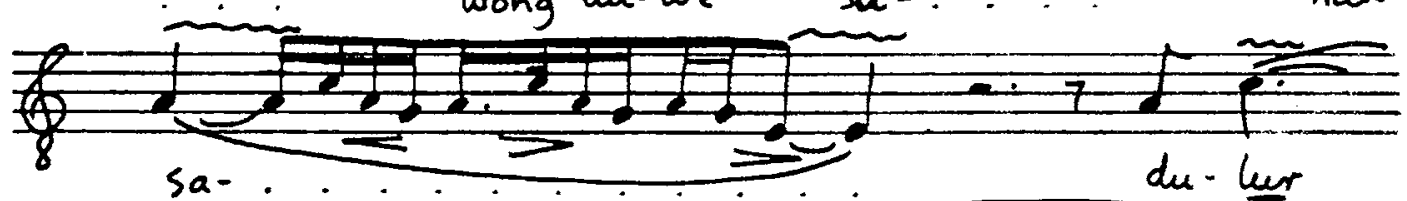

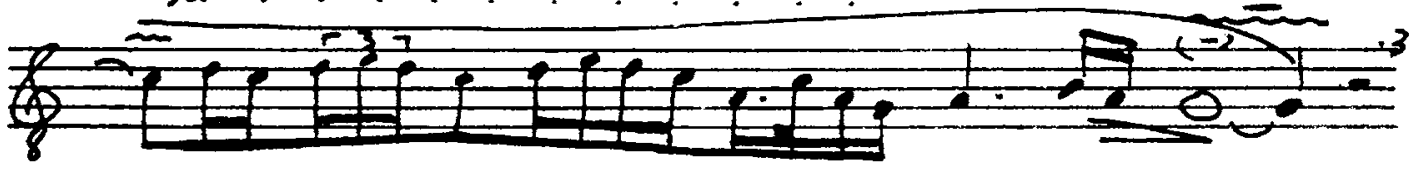

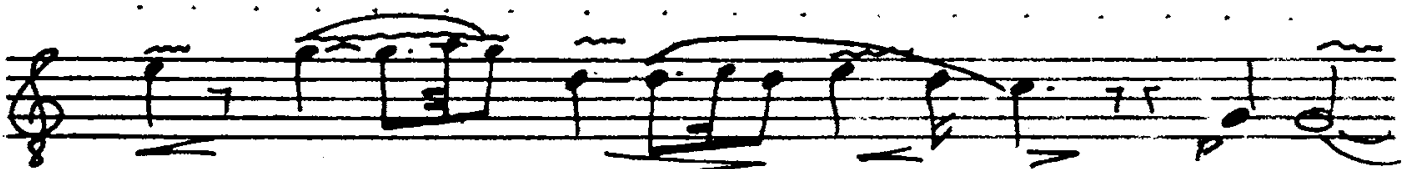
En- teng-... . e jen . . . pi-sah

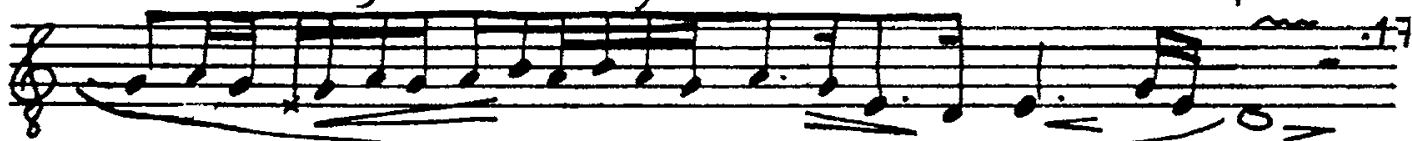

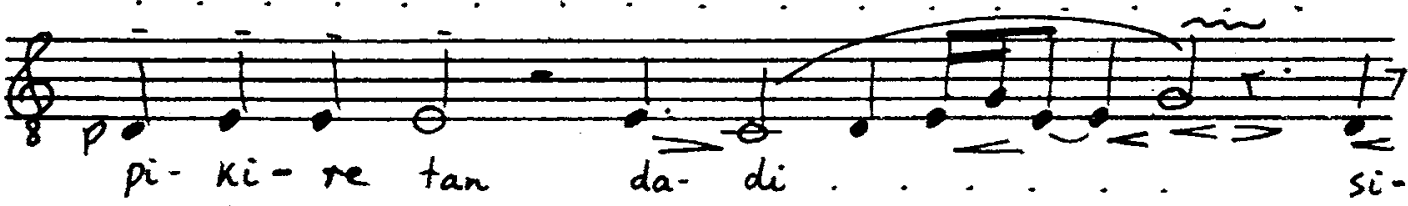

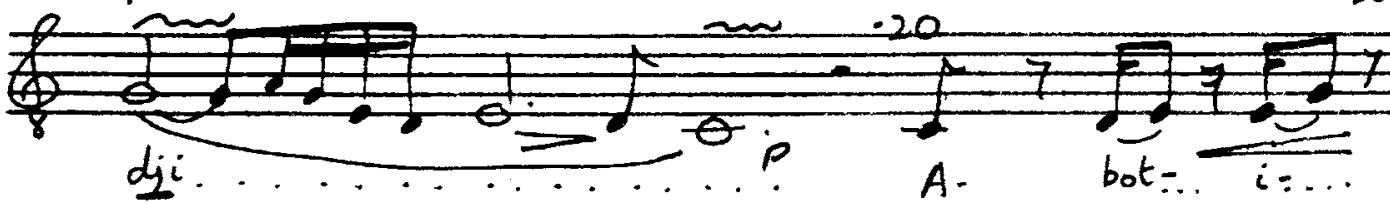




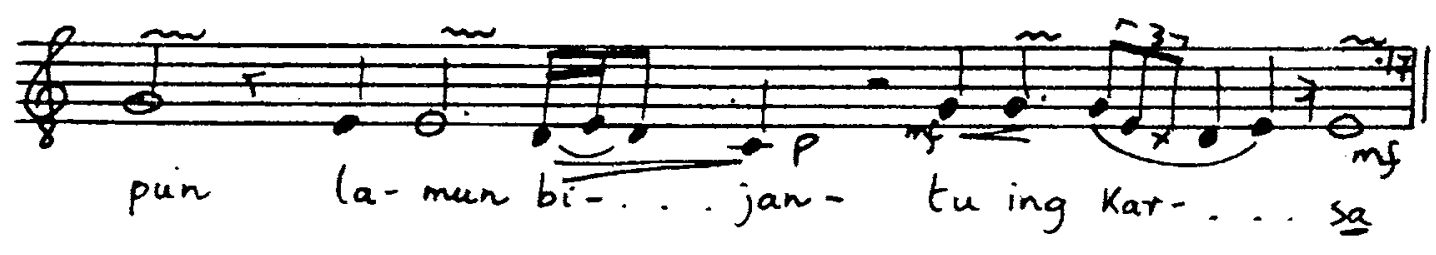


76. KINANTI

SINGER: P. SAPUTRA

T.I.: $0.90 \mathrm{~min}$.

O.P.: $\quad 1 \frac{1}{2}$ tones higher

$(d=144)$

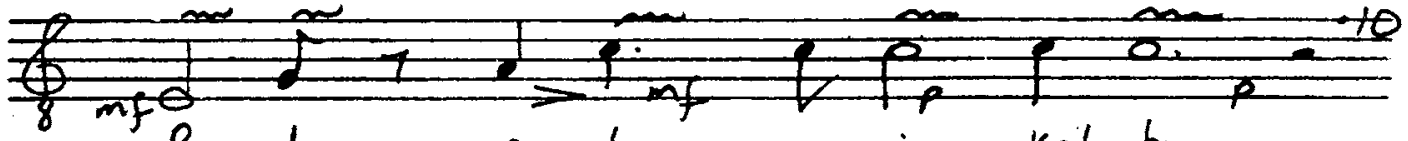

$P_{a}-$ da gu-la- ngen ing $\mathrm{kal}$ - bu

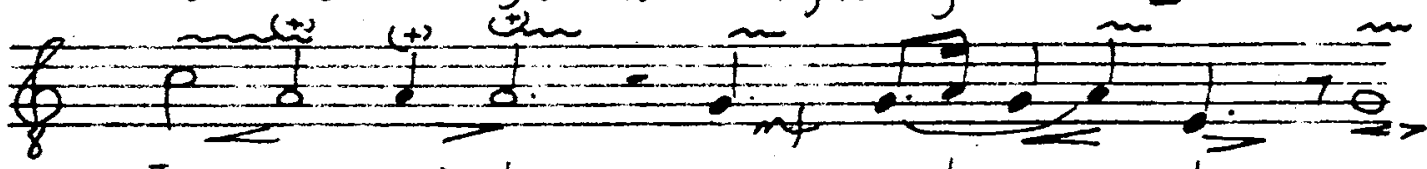

Ing sas. mi.ta. a- mrch tan- tap

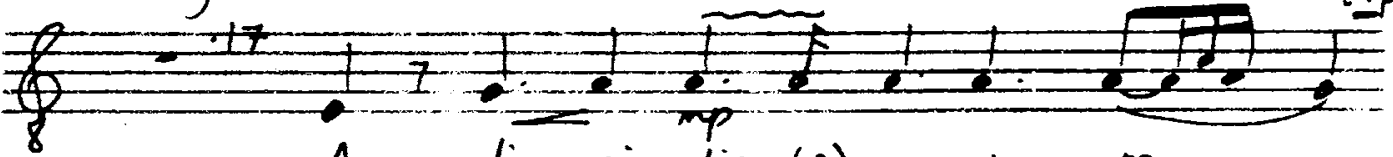
A- dja pi-djer (e) ma-ngan nen-.

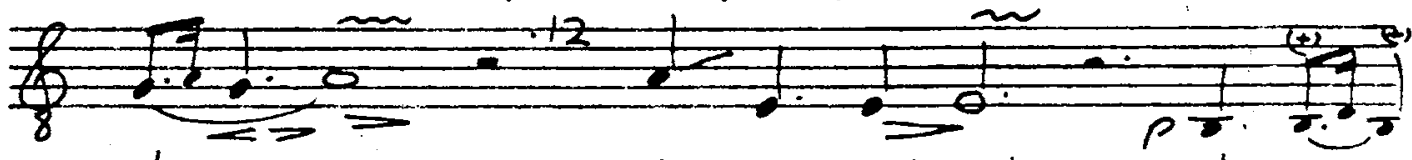
dra.... Ka-pra-wi-tain den Ka-.

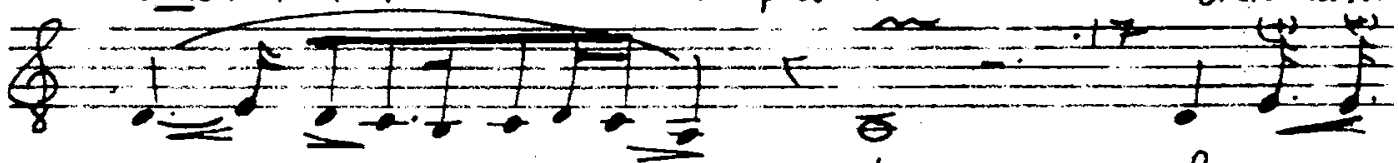
es-

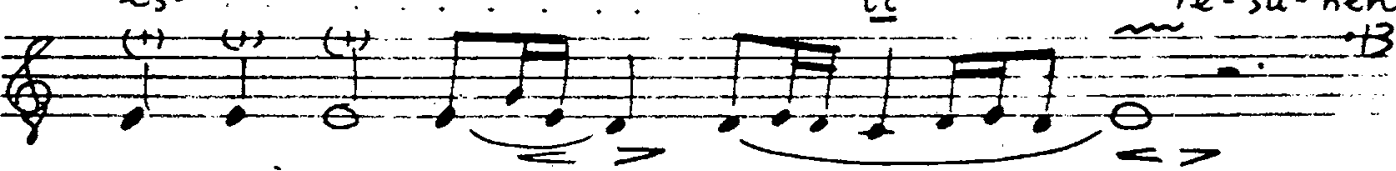

sa-ri-ra-ni-..ra.raram m

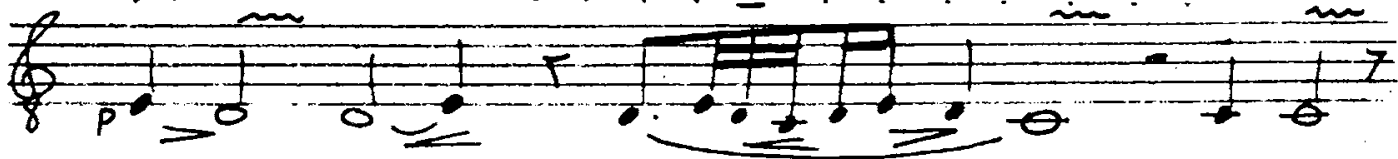

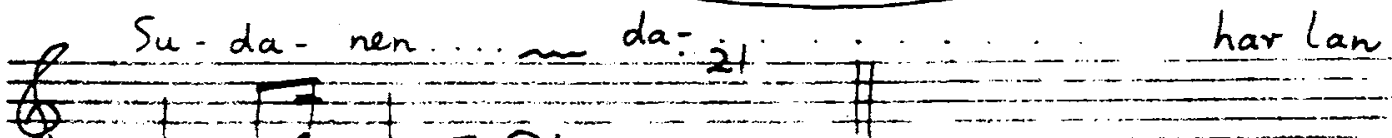
$\int_{0} \int_{0}+t_{0}=0$. gu- ling 
77. KINANTI

SINGER: P. SAPUTRA

T.I.: $0.95 \mathrm{~min}$.

O.P.: $1 \frac{1}{2}$ tones higher

$(d=126)$

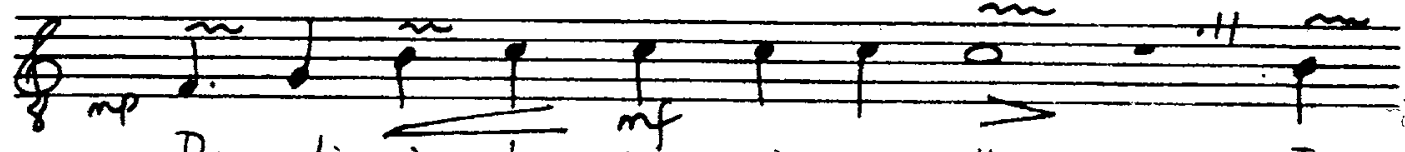

$D_{a}-d_{i}-\mathrm{ja} \mathrm{la}_{u}$ ni-re-ku Tje

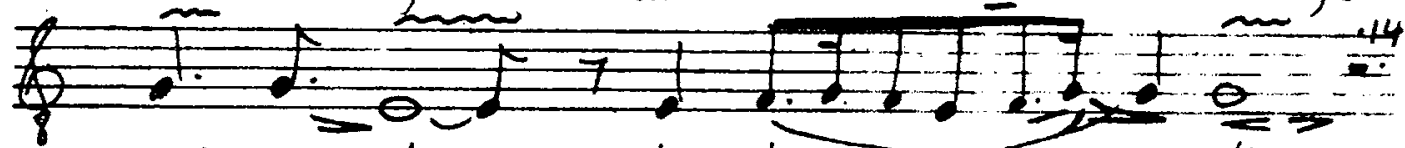
gah-en da- har lan gu-ling

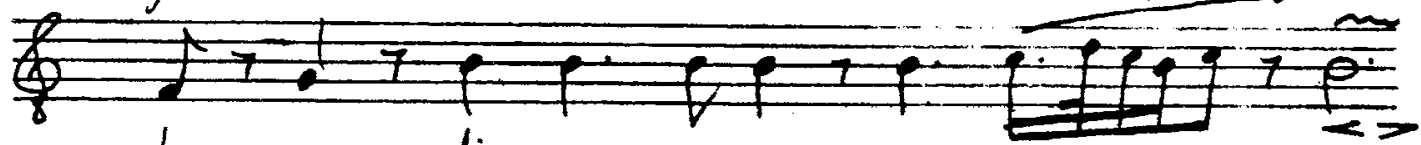
Lan a- dja a- su-Kan-su-Kan.

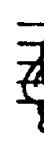

$2+14$

Z $m p$ $+2+1$ A- ngang-go-ho $\frac{1}{50}$ sa waA ngang-go-

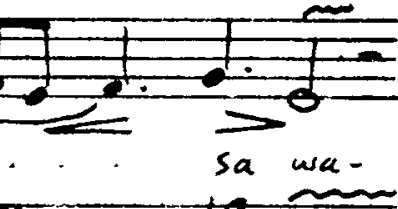
$I^{2}=19+1$ $=$ $+212$

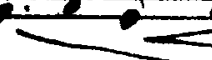

ta-

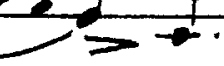

$1+\frac{1}{2}$

wis

A - la

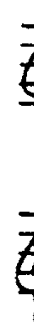

8

$\frac{1}{2}+\frac{1}{2}$

wa-tek-e wong
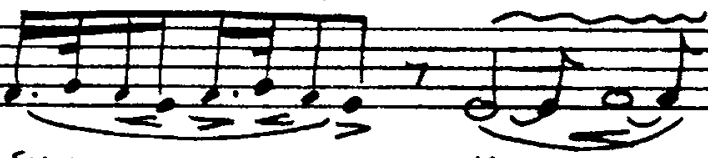

su- .

Ka

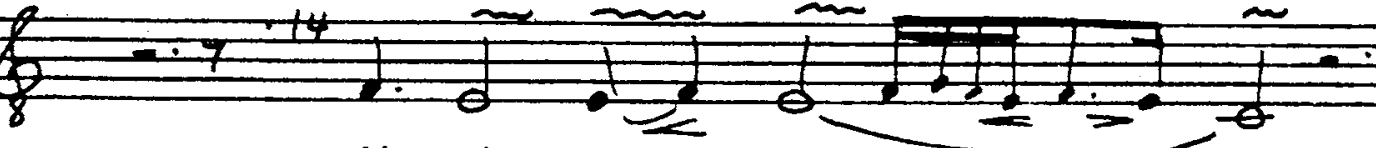

$N_{j u}$-da pra-.... jit-.

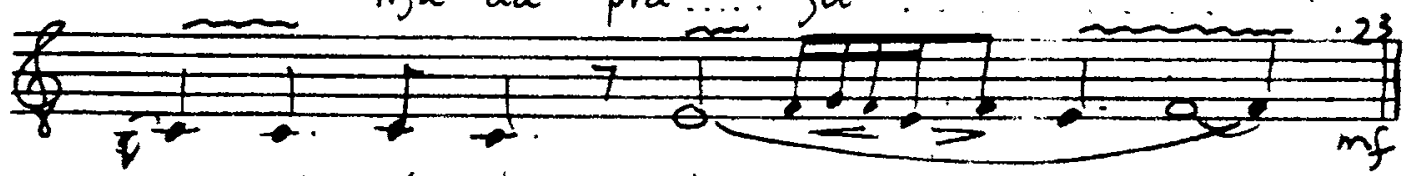

nan- ing

(e) $b a$ -

tin 
78. MIDJIL

SINGER: SUMARDJO

HOME TOWN: NOT KNNOWN

T.I.: $0.85 \mathrm{~min}$.

O.P.:

$(d=111)$
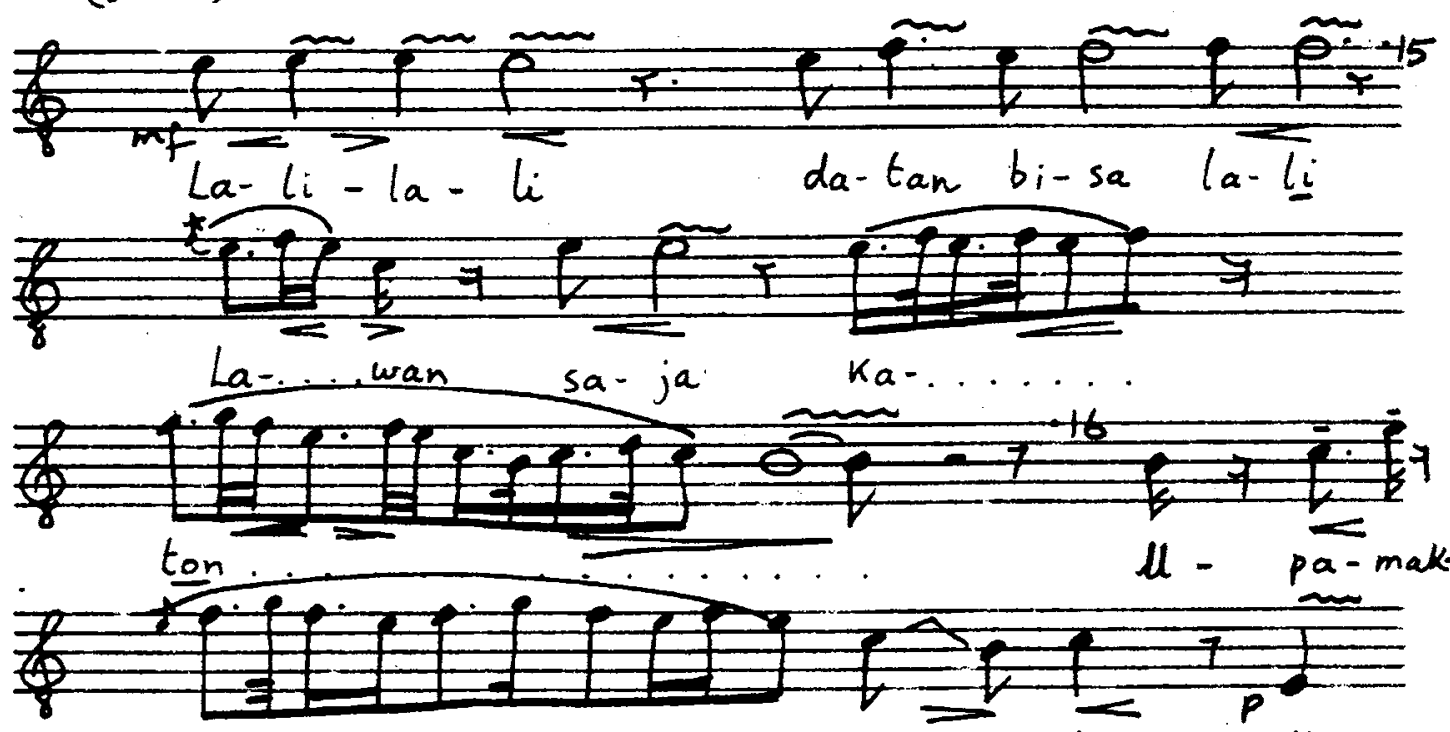

wi-wi-tan

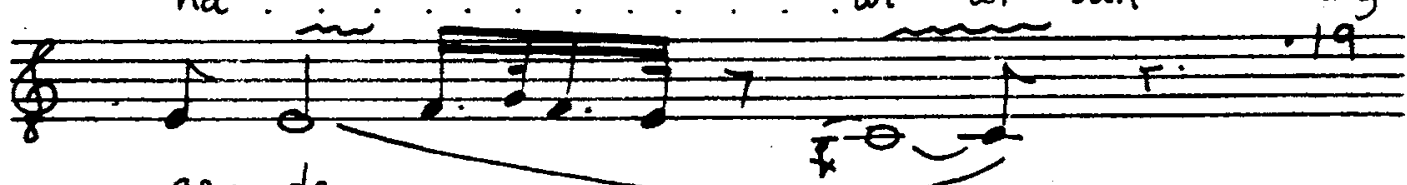

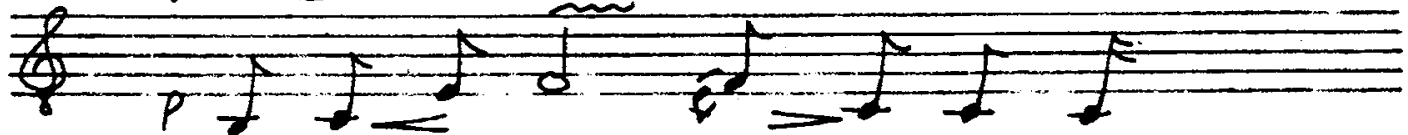

Ti-nu-tu-han da-tan bi-sa

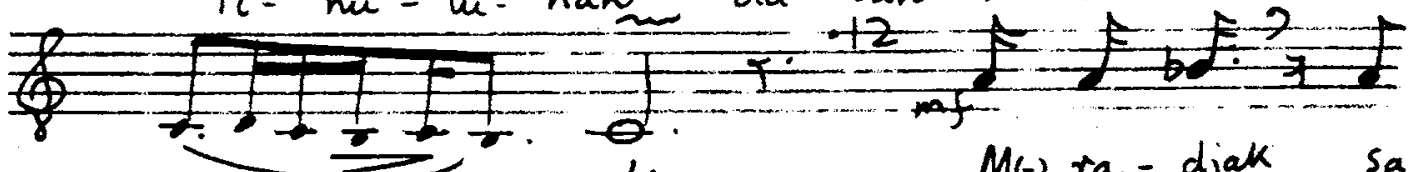

Fo 


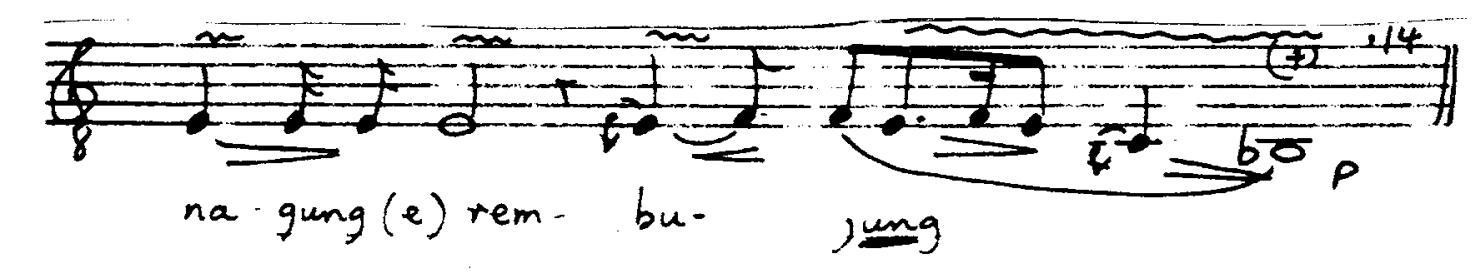


79. DANDANGGULA TURULARE

SINGER: A. HARDJONO

HOME TOWN: DJOGJAKARTA

T.L.: $0.69 \mathrm{~min}$.

O.P.: $\frac{1}{2}$ tone lower

$(J=94)$

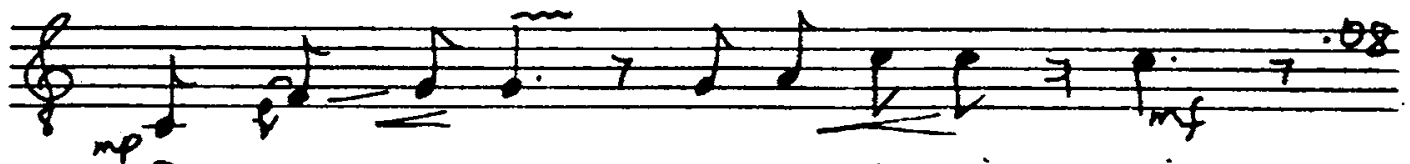

Dja-go Klu-ruk ra-me Ka-piar- nsi

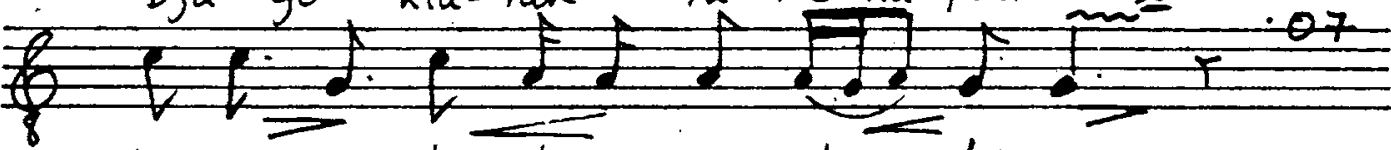

La-wa-ka-long lu-ru pan-de-.llik-an

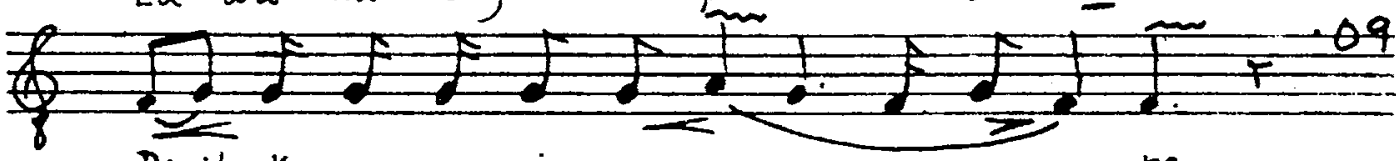

Djrih Ka-wan-an-ing se-mu-... in . . ne

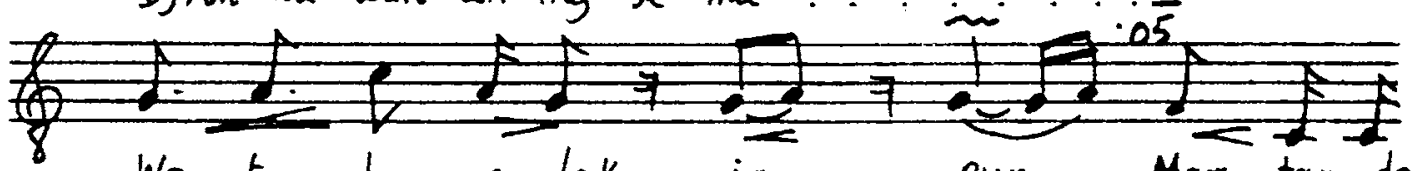
We-tan bang su-lak $i-\ldots$ pun... Mar-tan-da-

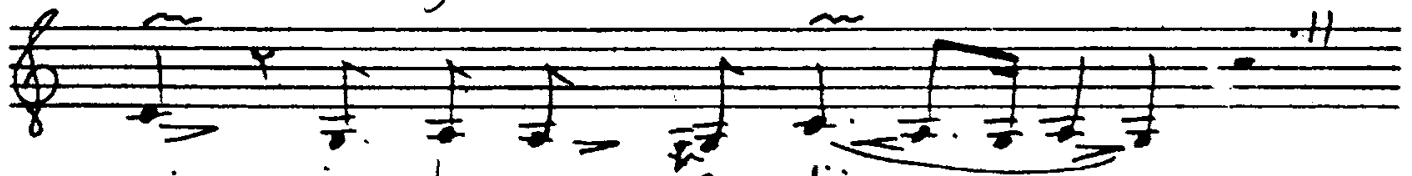

ni jen ba-ygun Fen-djing

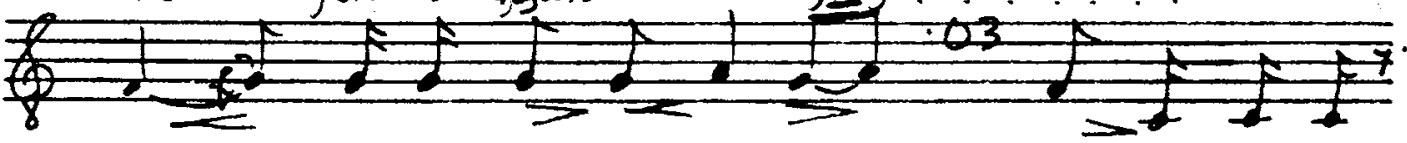

Rem-.. bu-lan wus gu-mle-wang, Neng ku-lon ing

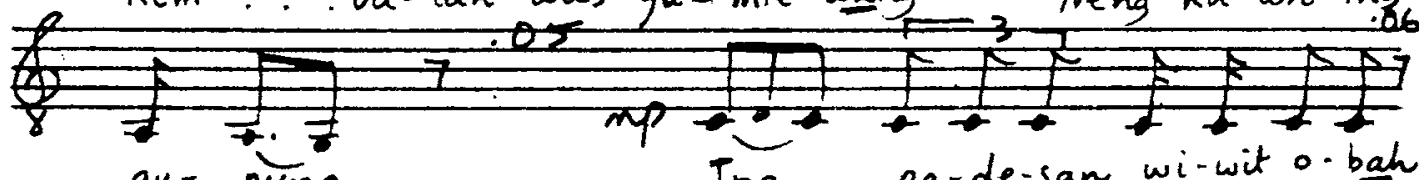

gu- numg... Ing ... pa-de-san wi-wit 0 -bah

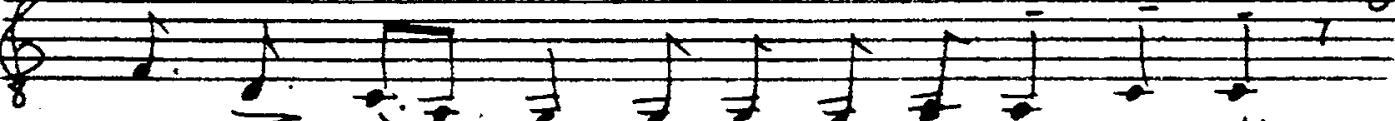
La- 
363

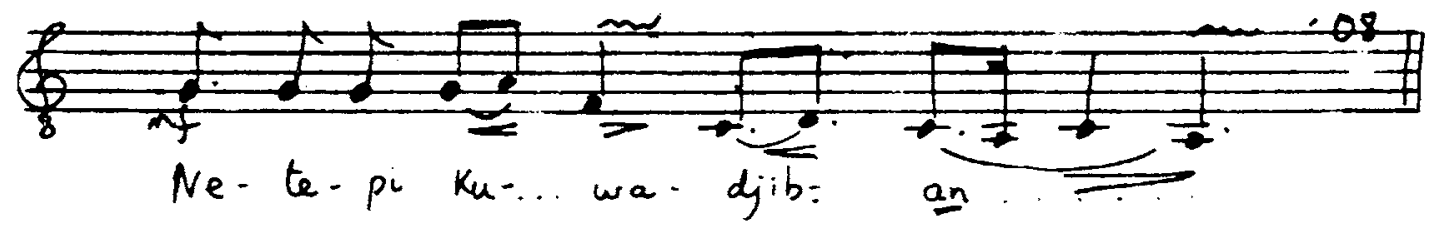


80. SINOM PARIKENJO

(Langendrijan)
SINGER: SRIKANDI

HOME TOWN: MANGKUJNEGARAN

T.L.: $1.15 \mathrm{~min}$.

O.P.: $\frac{1}{2}$ tone lower

$\left(\begin{array}{l}1 \\ (=84)\end{array}\right.$

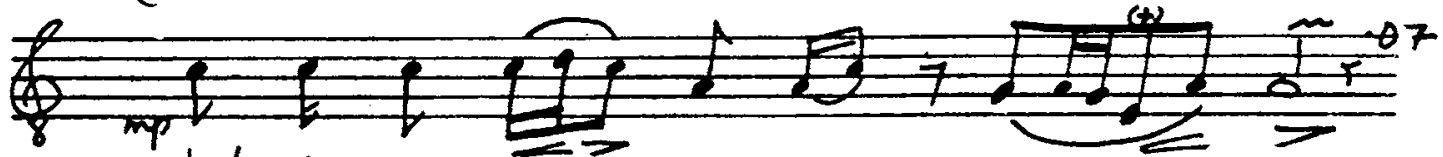

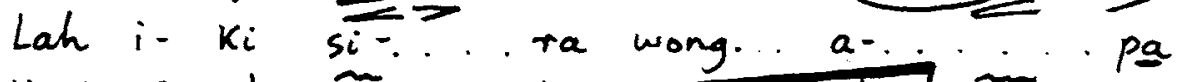

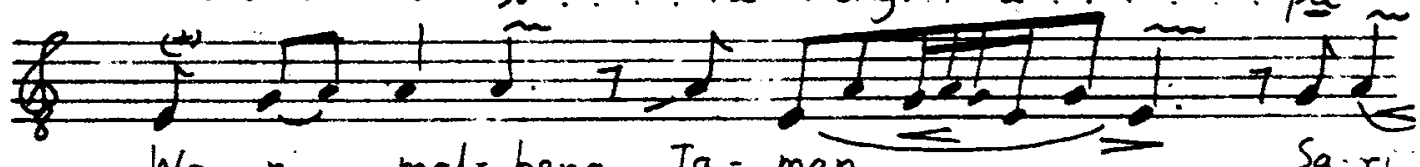

Wa- ni... mal-beng Ta-man... Sa.ri
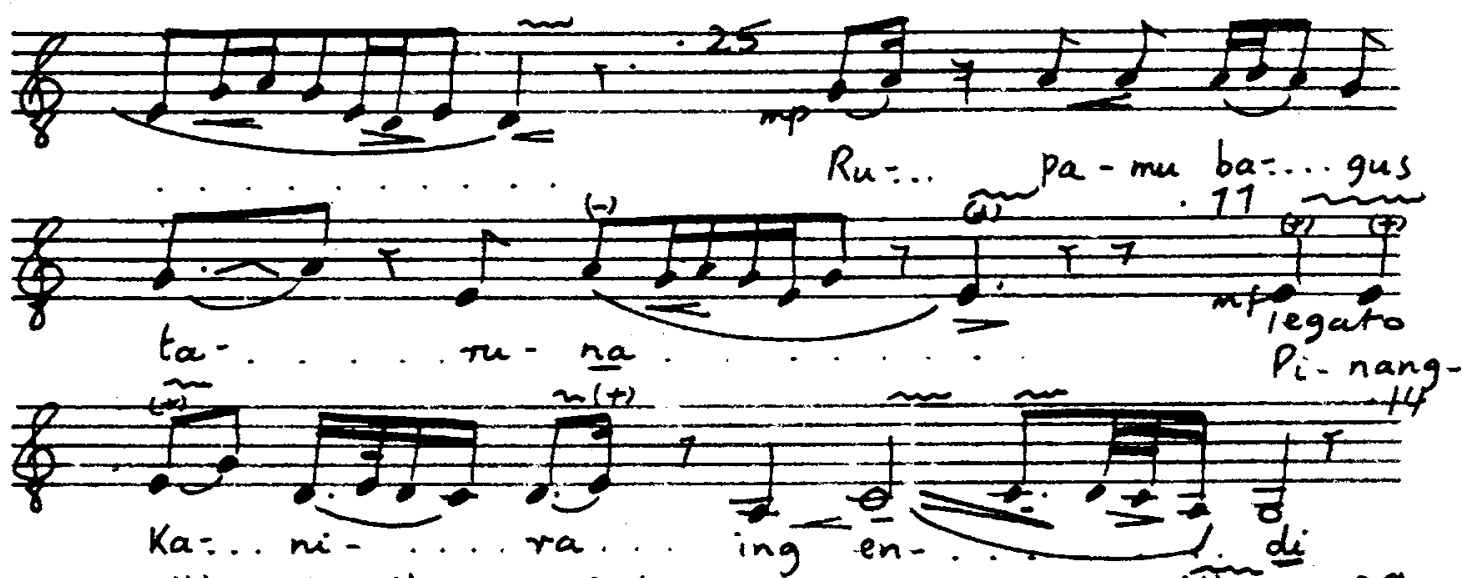

$\mathrm{Ka}_{\mathrm{a}} . . \mathrm{mi}-\ldots \mathrm{ra} . . \mathrm{ing}$ en ...

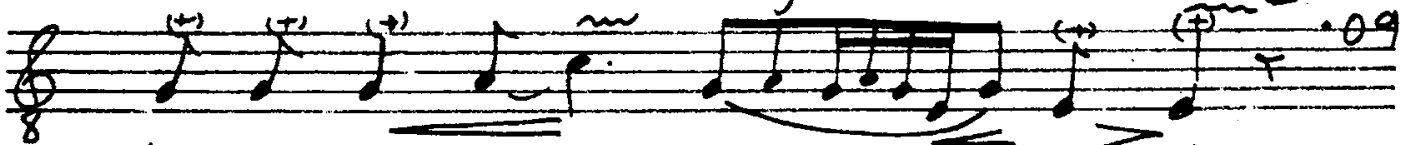

Lan sa- pa kang... we .... wang.

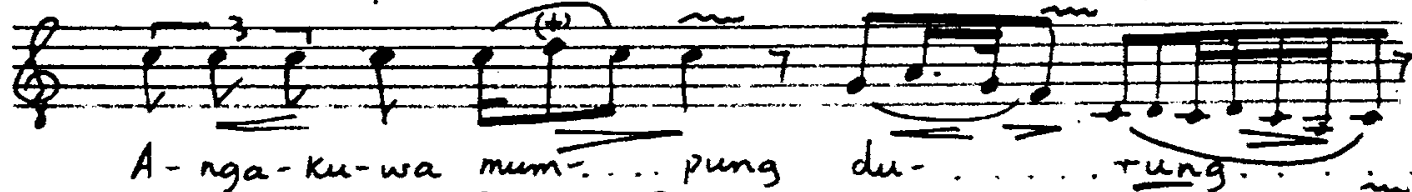
7 N 11 on

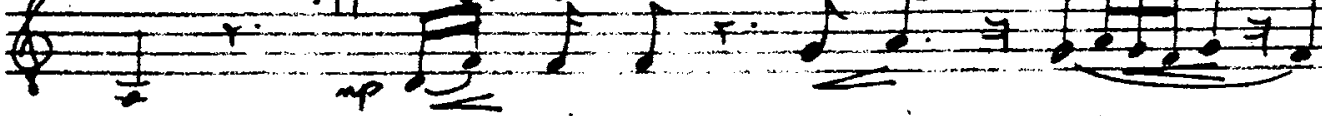
Pa... las.tra si-ja. si-...ja 


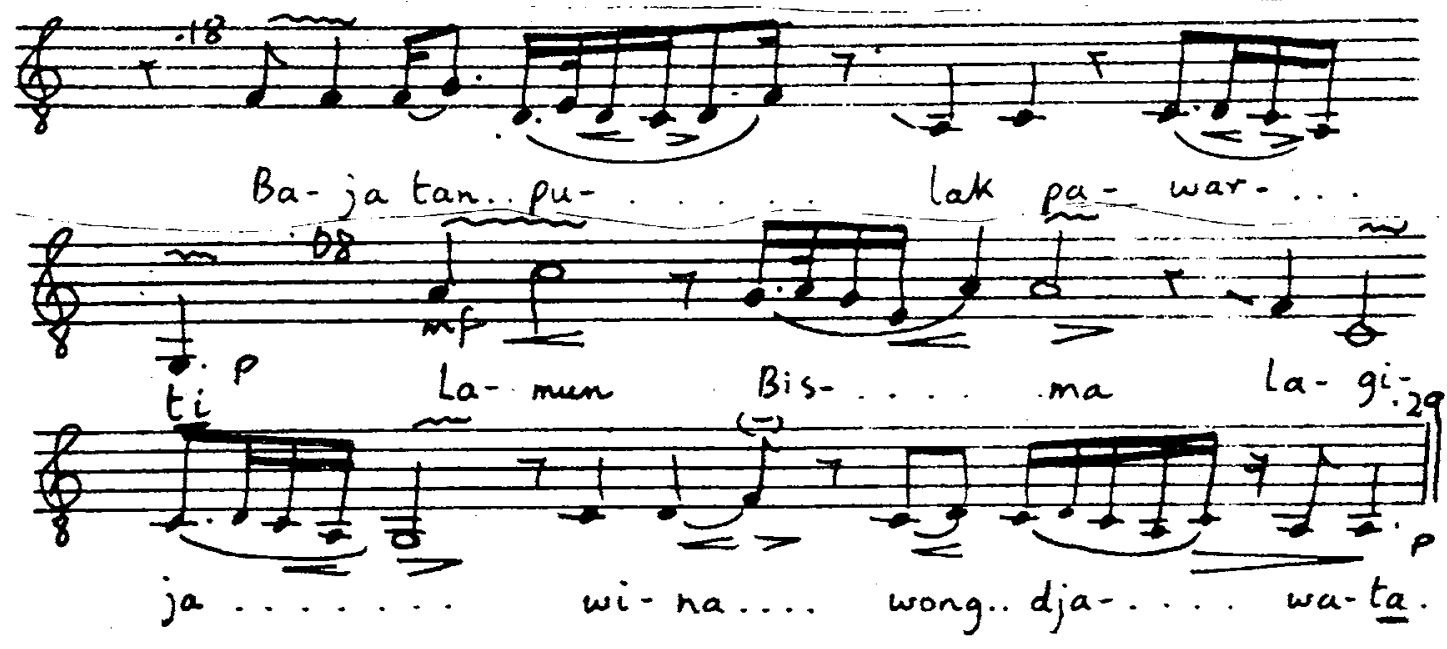


81. PANGKUR PALARAN

(Petilan Wajang Orang)
SINGER: SRIKANDI

T.L.: $1.29 \mathrm{~min}$.

O.P.: 1 tone lower

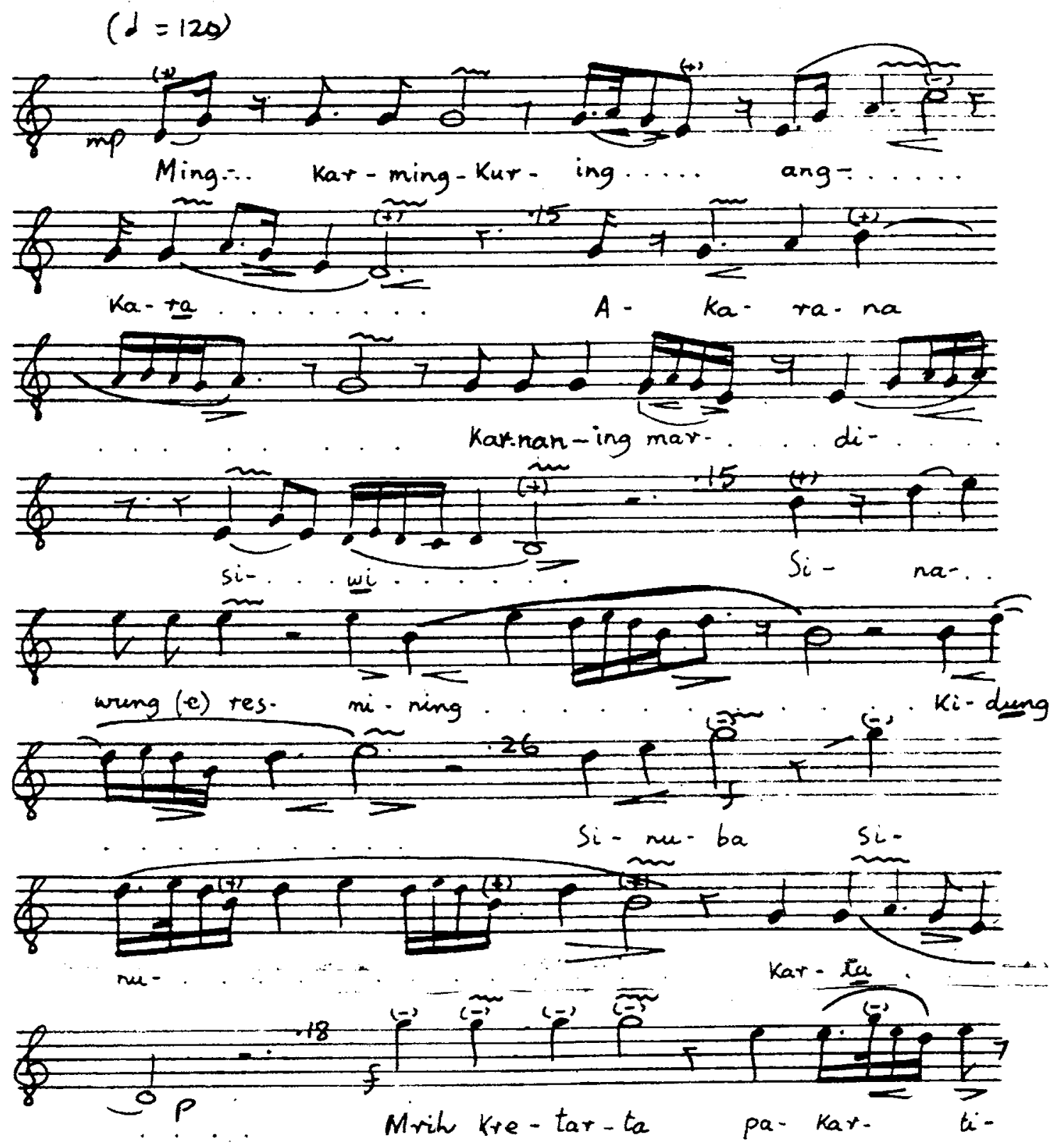



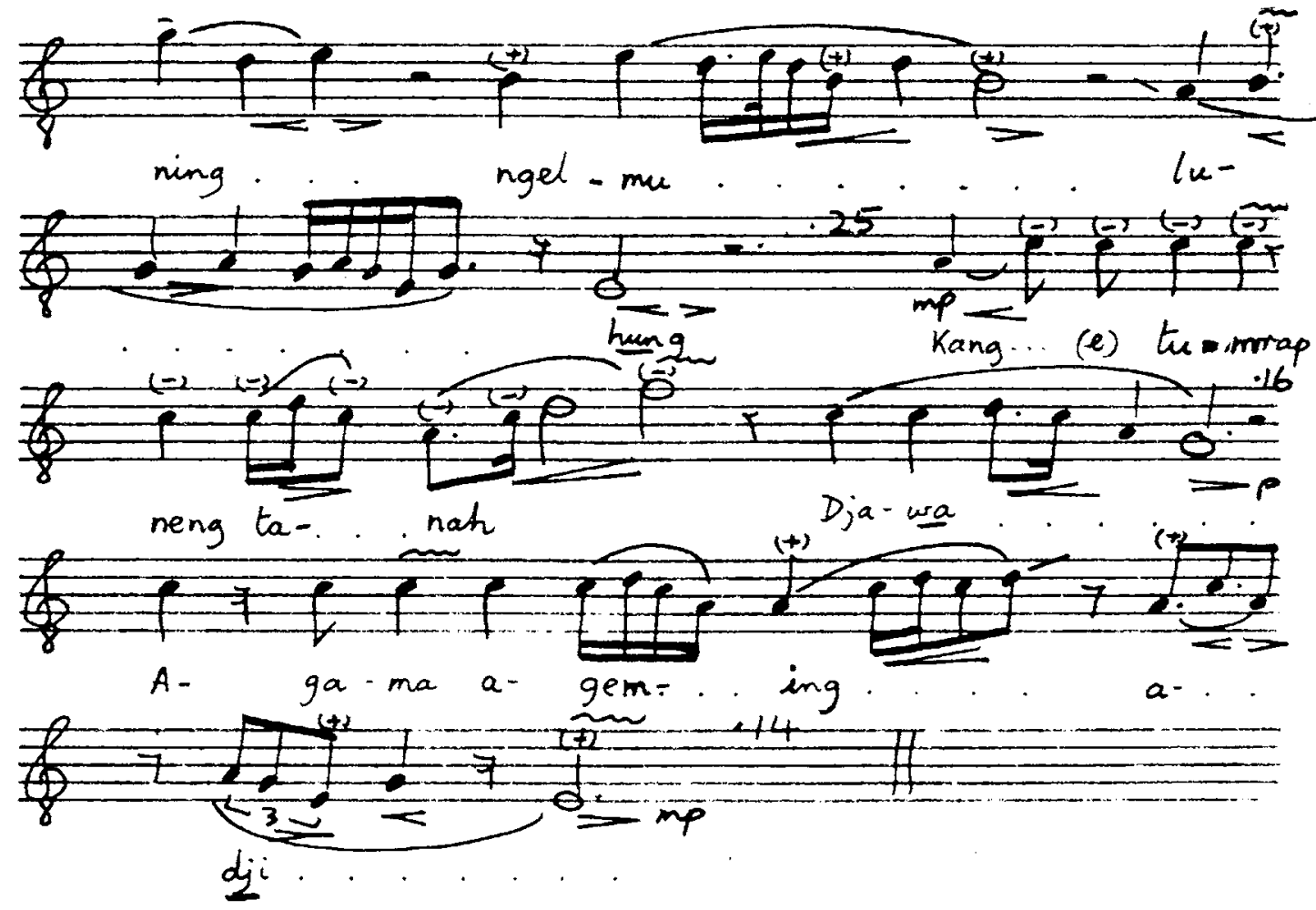
82. MIDJIL LUGU

SINGER: ARI

HOME TOWN: MANGKUNEGARAN

T.L.: $1.40 \mathrm{~min}$.

O.P.: $1 \frac{1}{2}$ tones higher

$$
(d=91)
$$

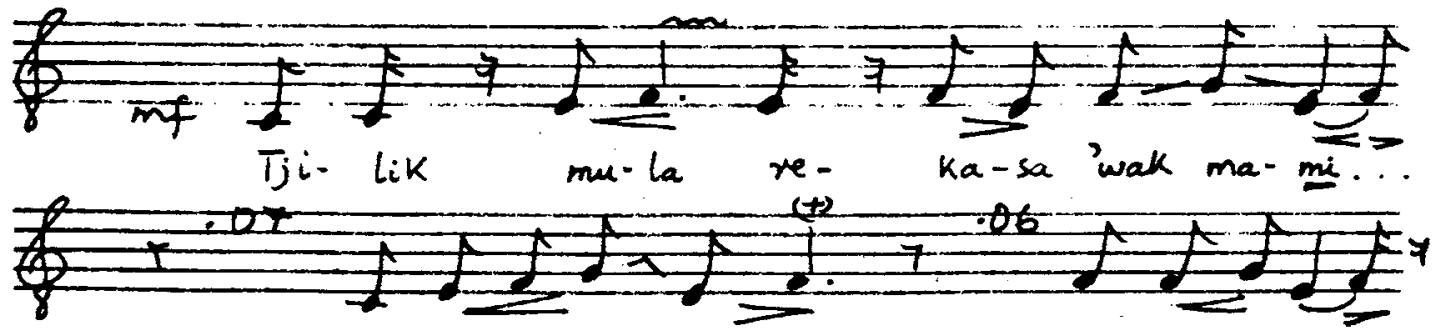

Nang-gung da-di la- Kon
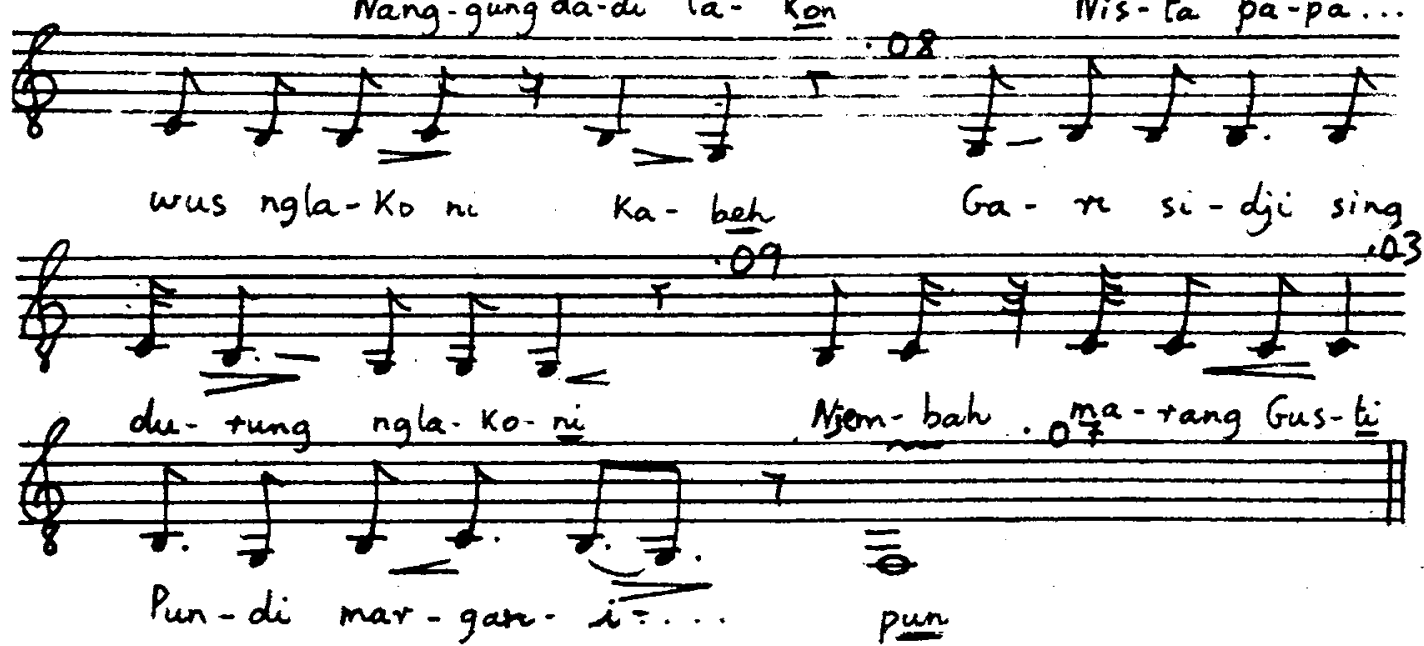
83. PUTJUNG(Pelog Patet Barang) From R. Tedjohadisumarto, Mbombong Manah, Vol. 3, Djakarta, 1958 (hereafter $M M)$. Transcribed from the number script.

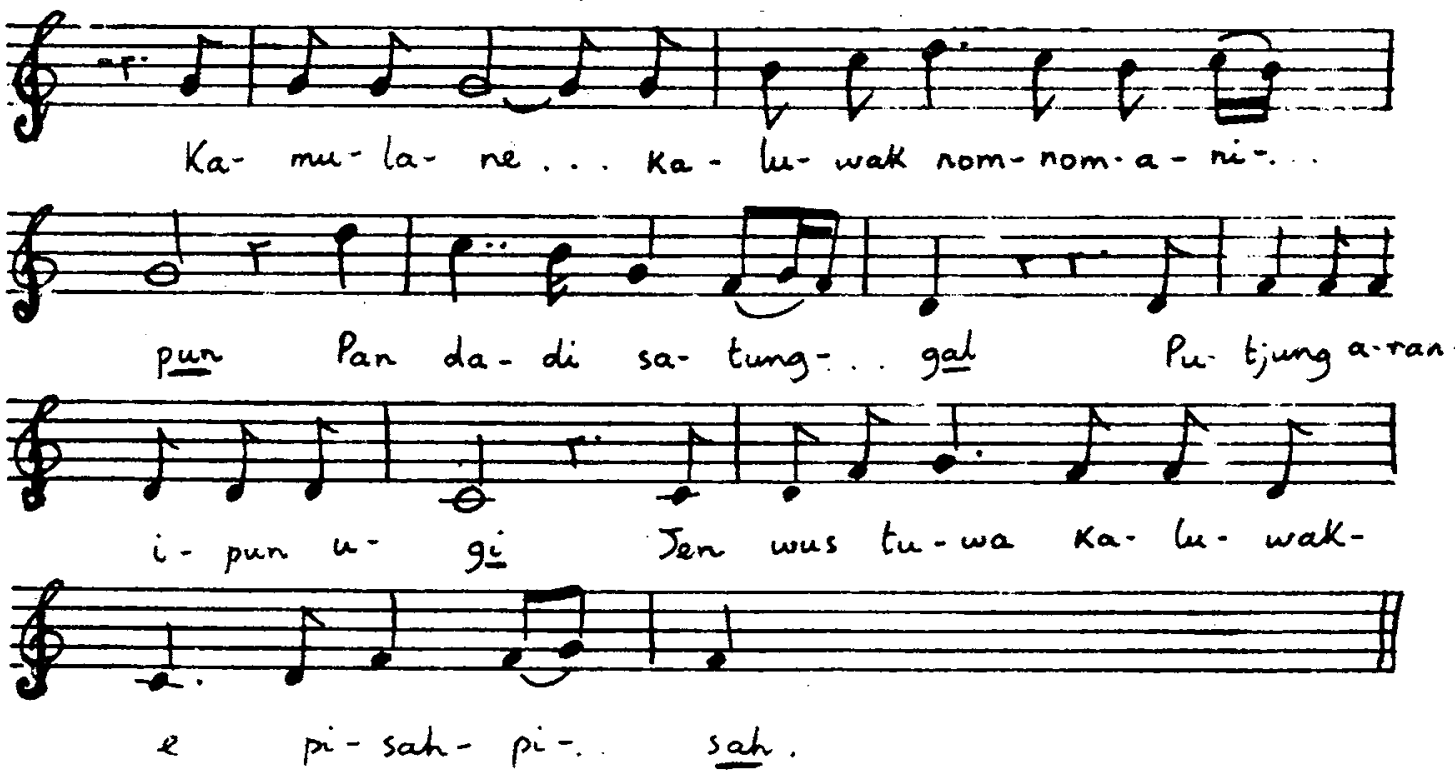


84. PANGKUR (Slendro Patet Sanga) From $M M$
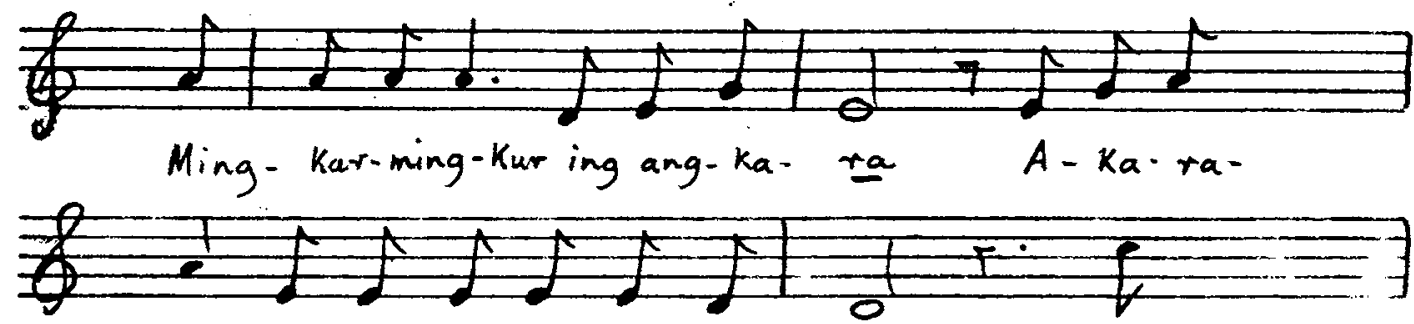

na ka-re-nan mardi. si- wi Si-

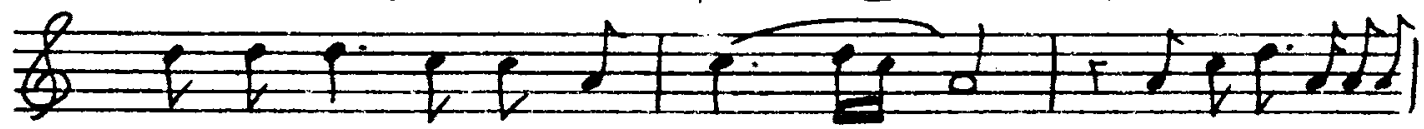

na-wung res-mi-ning $K_{i}$ - dung... . . Si-nu-ba-si-nu-kar.

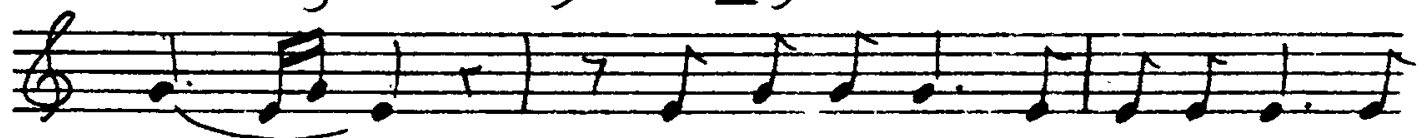

ta... Mrich kre-tar-ta pa-kar-ti-nung ngel-

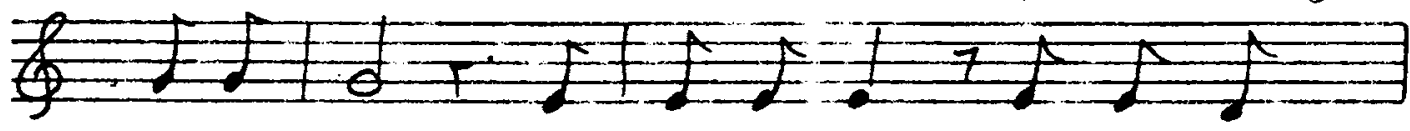

mu ke- hung Kang tu-mrap neng ta- nah Dja-

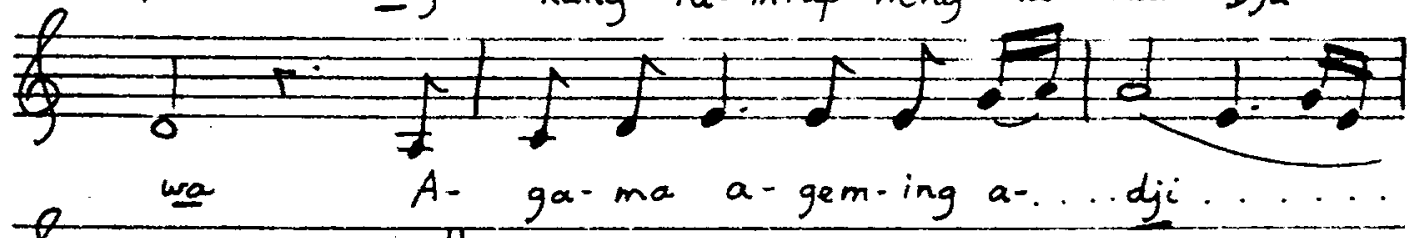

for 

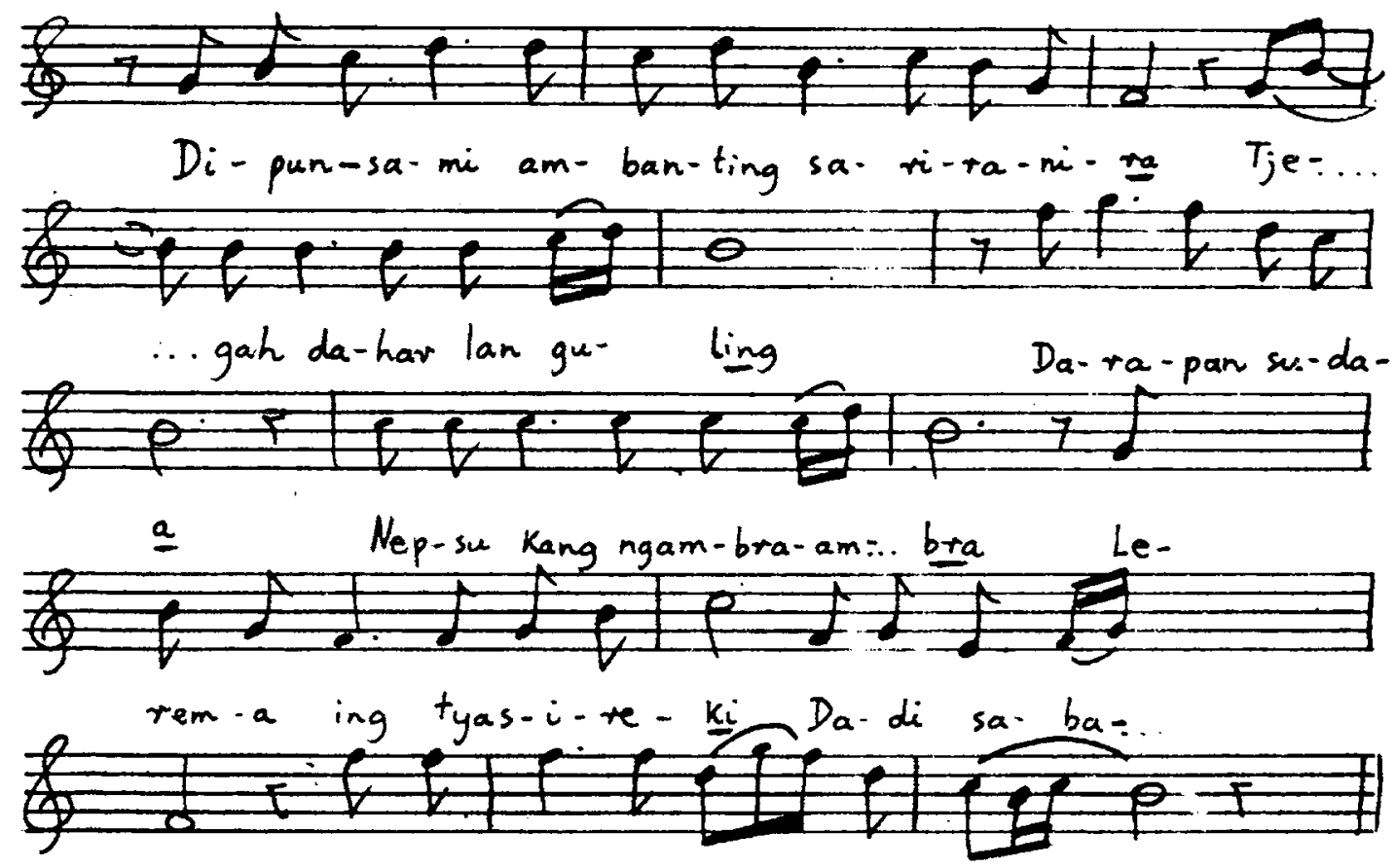

rang Kar-sa-ni-tales-...ta- ti .... 
86. MIDJIL (Slendro Patet Manjura) From MM

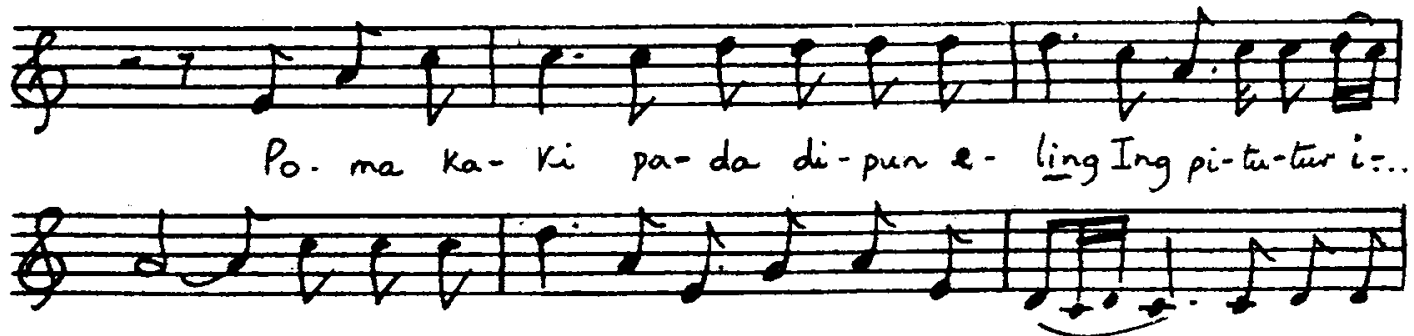

ngang Si-ra u-ga sa-tri-ja a-ran-ée.... Ku-du an-

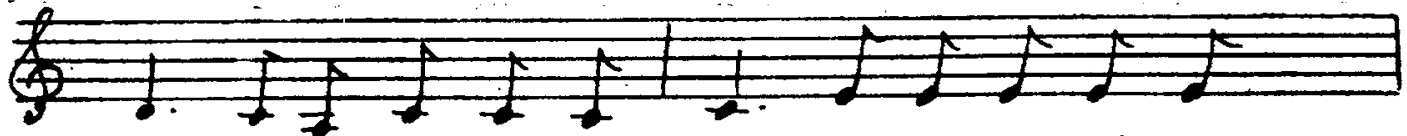

teng djat-mi-ka ing bu- di Ru-ruh sar-ta wa-

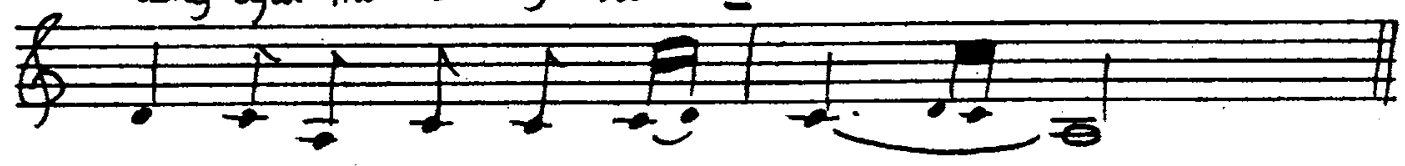

sis $S a-m u-b a-$ rang- $i=\ldots$ pun. 

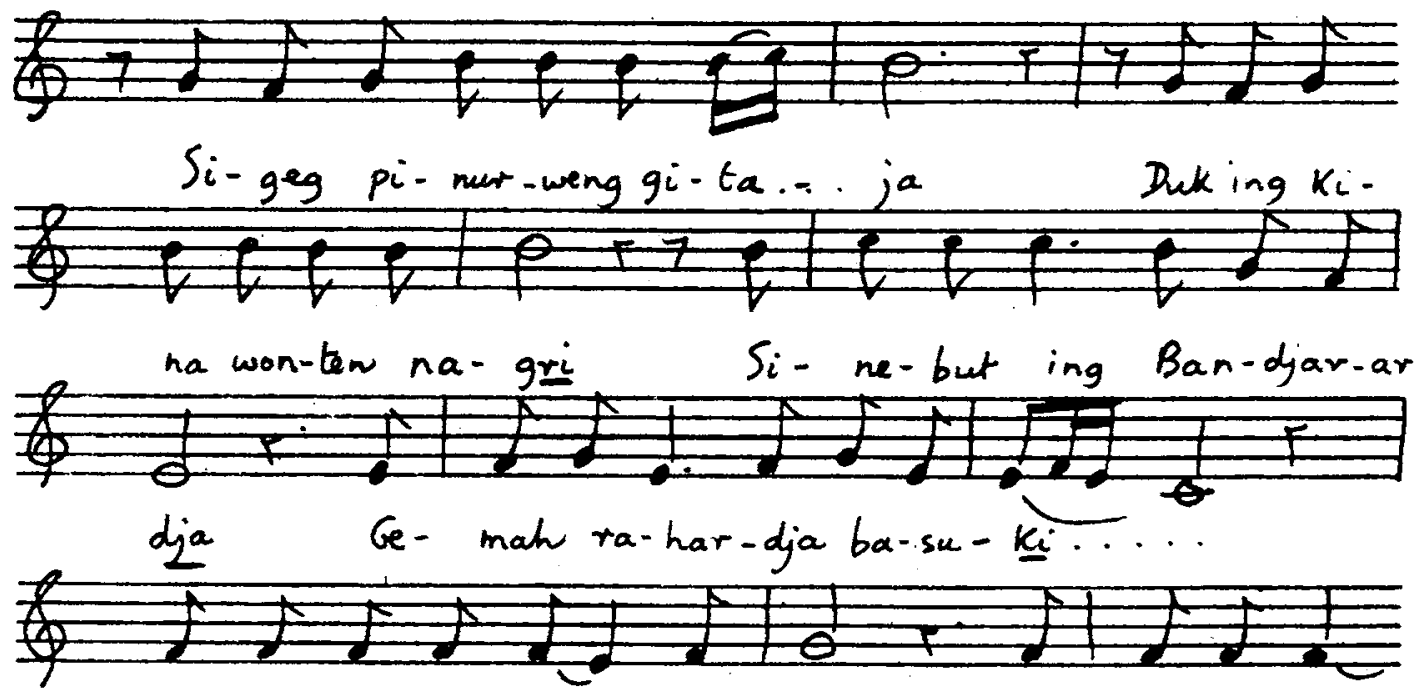

Ka-tjih-na pra wa.. dya lit Sa- mya kam-bah

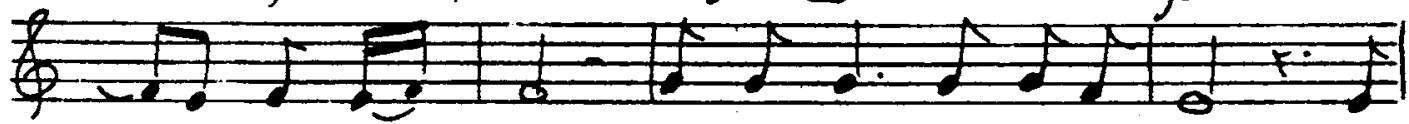
ing tyas a :... ju Tan ki-rang san-dang bo-ga $T_{e}-$

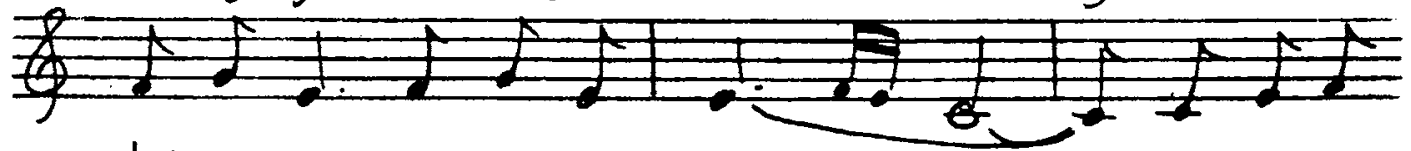

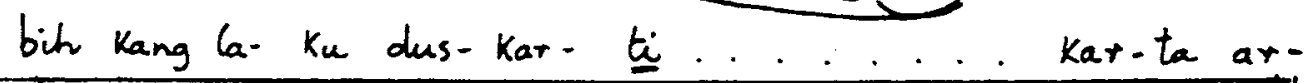

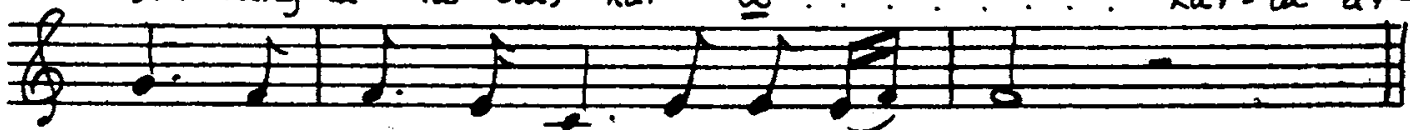
dja se-pi na-gri kang a-ma- da 
88. KINANPTI (Pelog Patet Barang) From $M M$

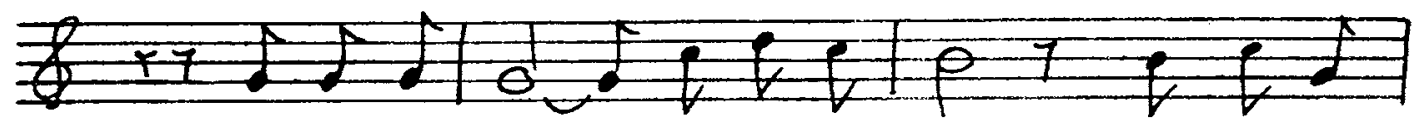
$\mathrm{Pa}$-da gu-lang- en ing kal-bu Ing sas.mi-

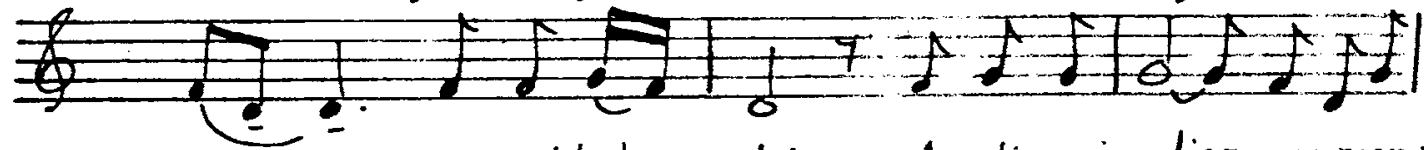
ta.... a-mich lan $=. t_{\dot{p} p} \quad A$ - dja pi-djer ma-ngannen-

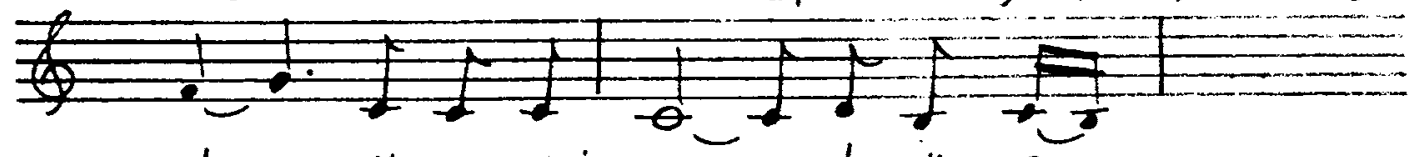
$d+a \ldots k a-p r a-w i-\tan \ldots$ den $k a-25-\ldots$

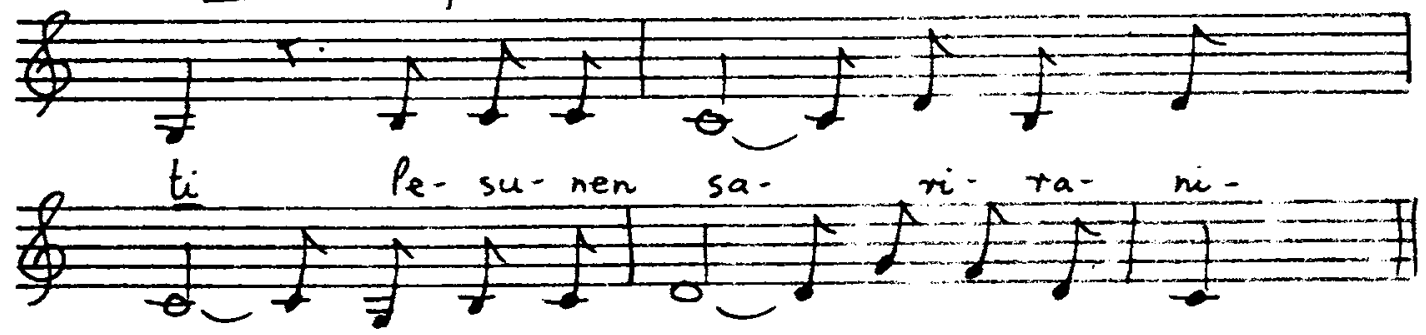

ra $S_{u}$-da-nen da- harlangu. ling. 
90. DANDANGGULA (Slendro Patet Sanga)

From $M$
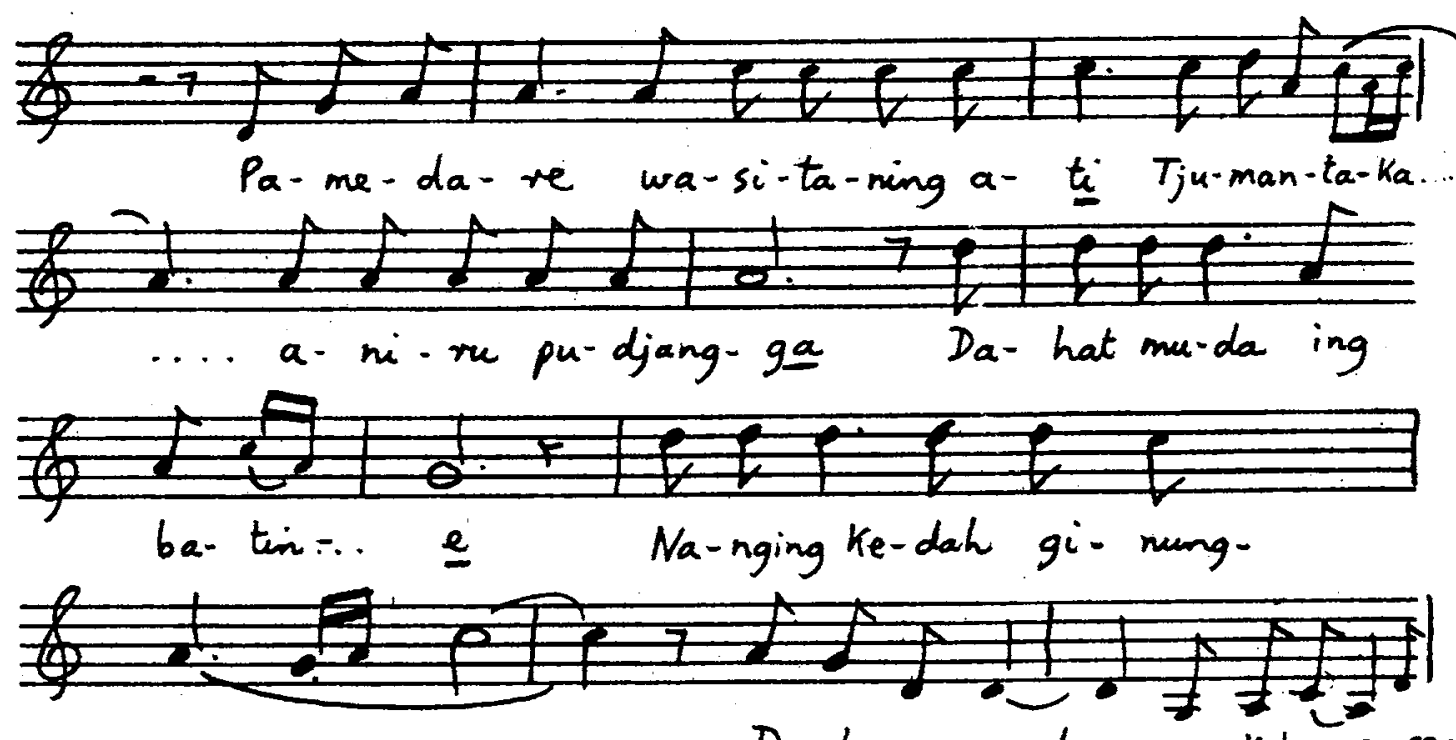

gung....... Da.tan we-ruh . jen keh nge sem-
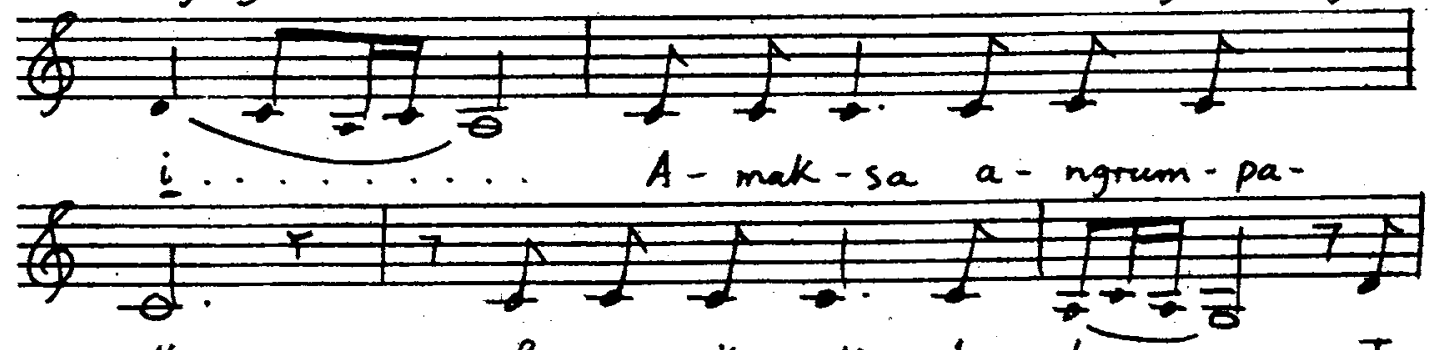

Ka Ba-sa Kang $K_{a}-\mathrm{lan}_{\mathrm{n}}-\mathrm{tur}_{\mathrm{r}} \ldots . . \mathrm{T}_{k}-$

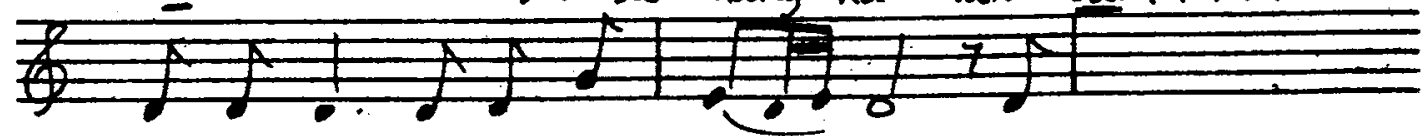

tur kang $K_{a}-t_{u}-l_{a}-t_{u}-l_{a} \ldots T_{i}$.

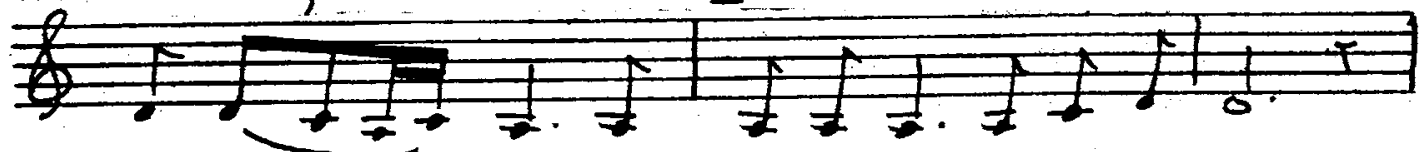

na.la-.... ten $r i$ - nu-ruh ka-la-wanti-rih 


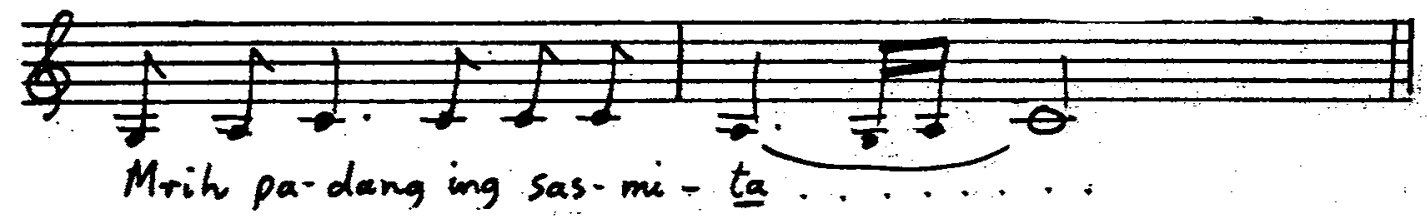


91. ASmarandana (Pelog Patet Nem)

Tji-na-ri-ta lang-kung pe-kik Na-bi Ju-sup na-ma-ni-

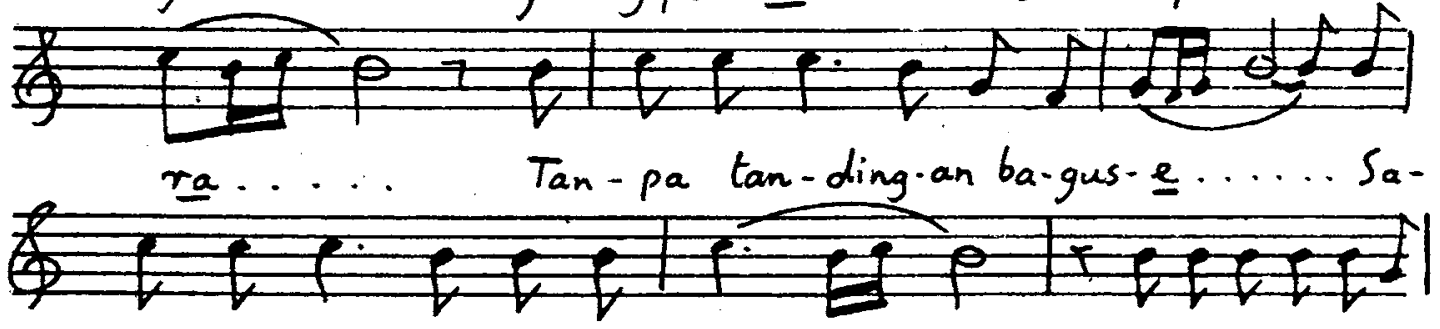
in - deng-ing Kang bu-wa- na...... Tanwon-ten kangku-fji.

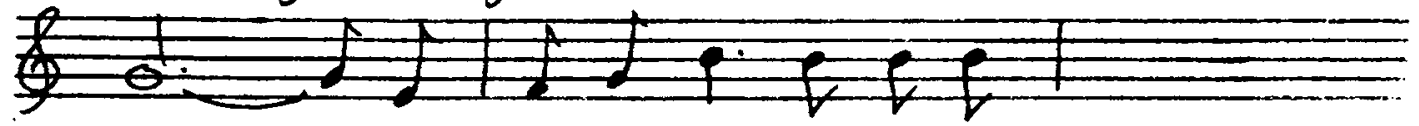

wa...p pa-sa-li-ra-ni-pun a-

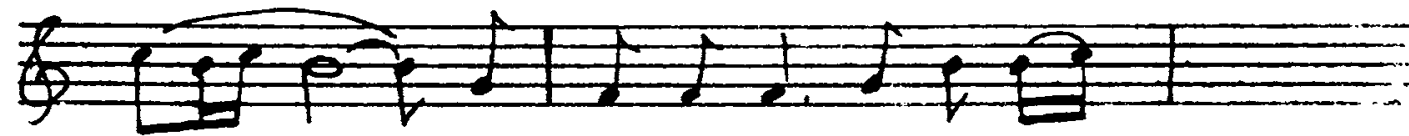

lus...... Mi - wrah ing pa-Kar-ti-ni...

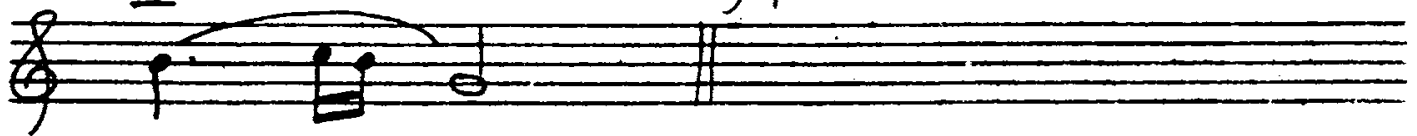

ra. 
92. PUTJUNG (Slendro Patet Manjura) From MM

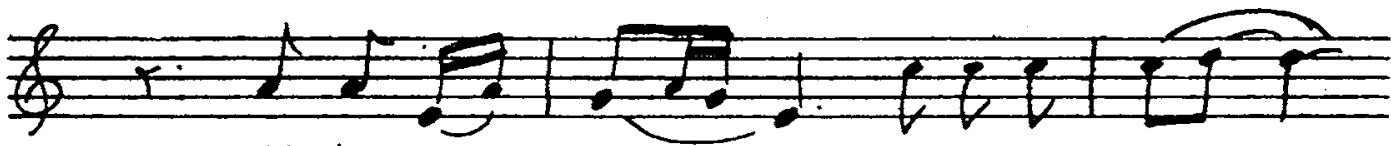
Ngel-mu $i=\ldots k u \ldots k$ Ka-la-Kon-......

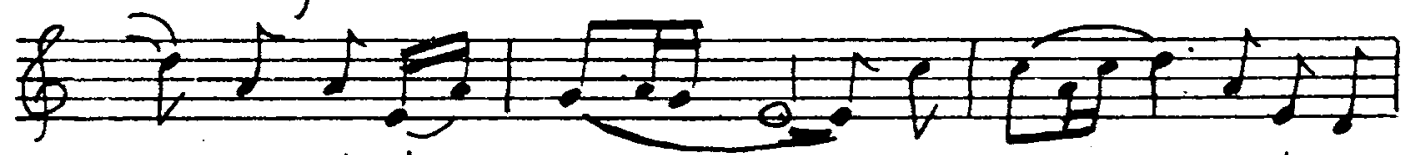

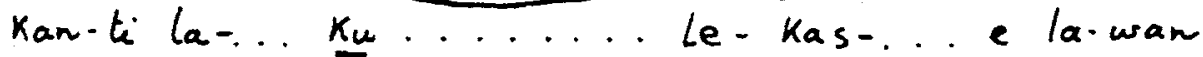

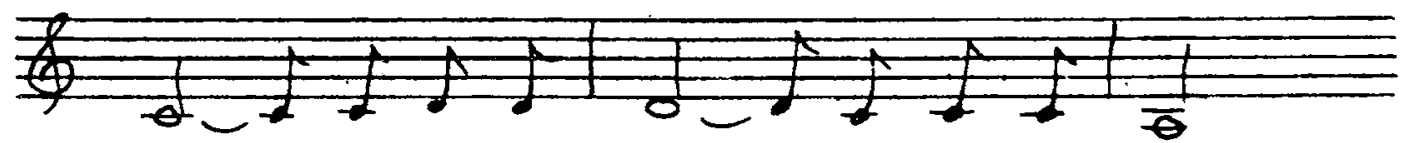

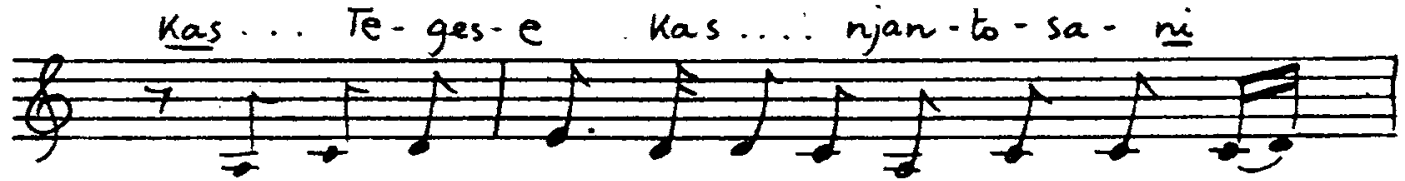
Se-dya bu- dya pa-nge-kes-e dur ang-Ka-.. ra. 
93. PUtJung (Pelog Patet Barang)

From $M M$

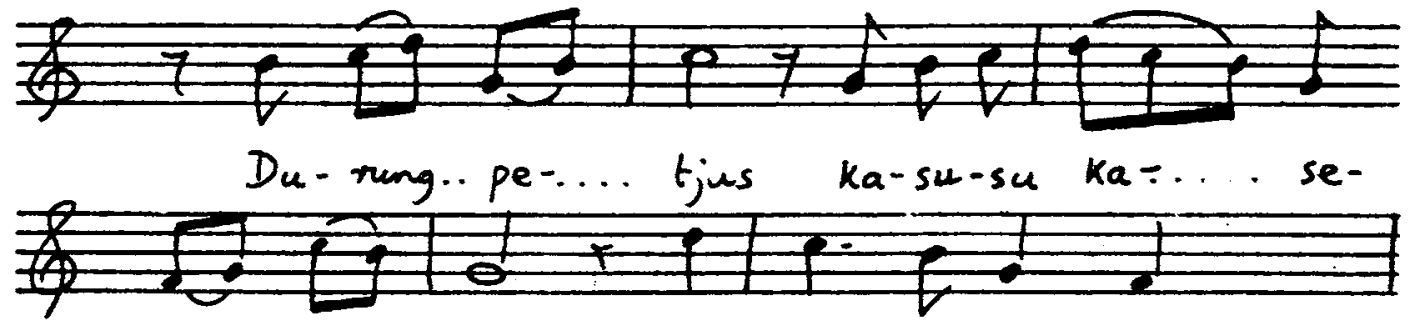

$$
\text { lak... be -... sus A- mak-na-ni ra- }
$$
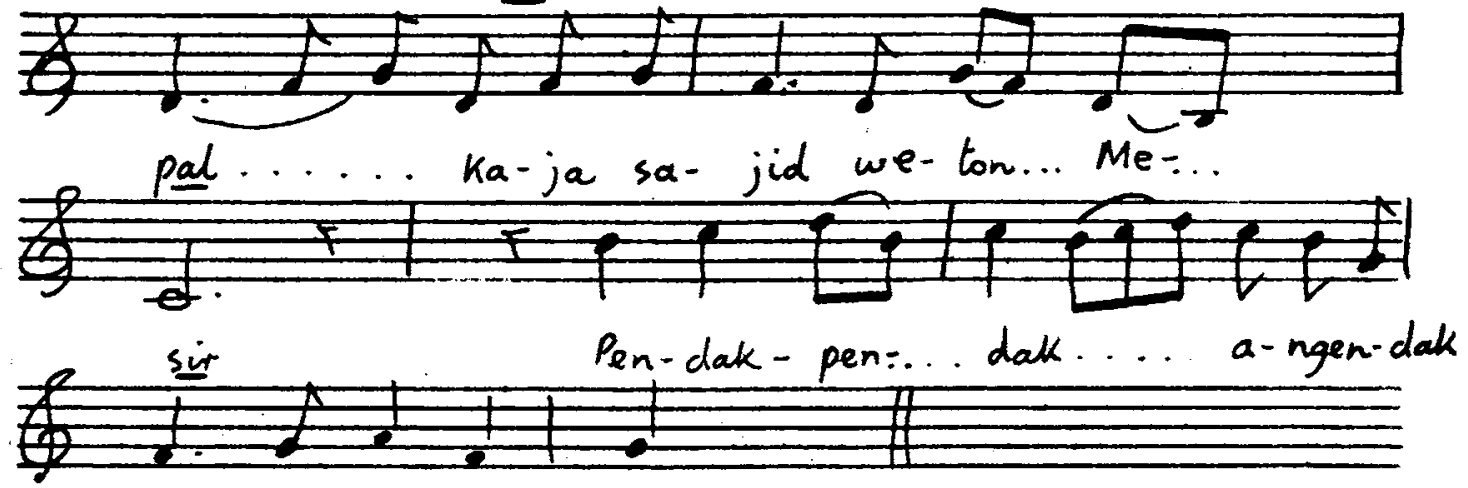

gu-na-ning djan-ma. 
94. PANGKUR PALARAN (Slendro Patet Sanga) From MM

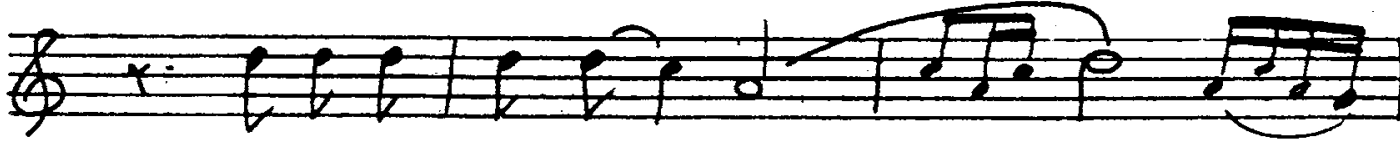

Dji-ne-djer neng $W_{e}=\ldots$ da $\ldots . . . .$. ta...-

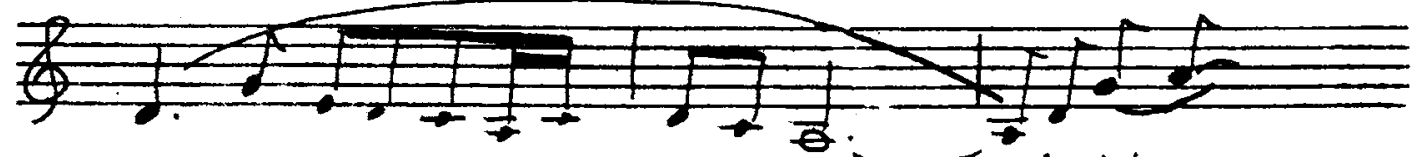

$\underline{m a}$

Mrih tan...

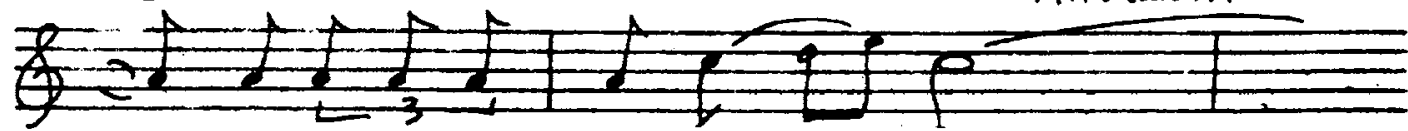

Rem-ba Kem-beng-an-ing pam-

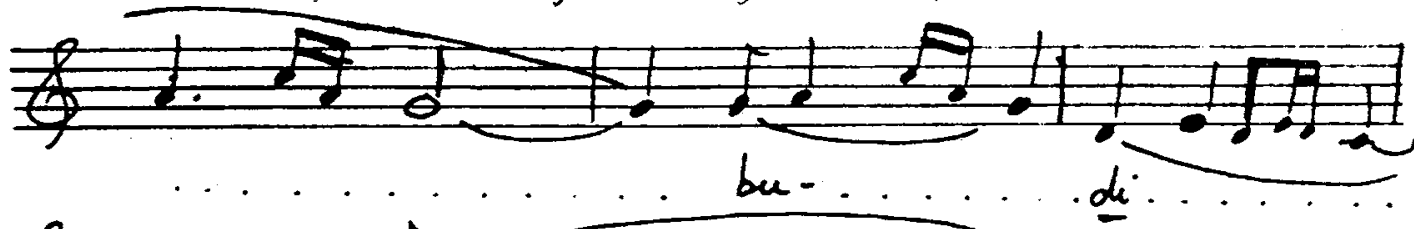

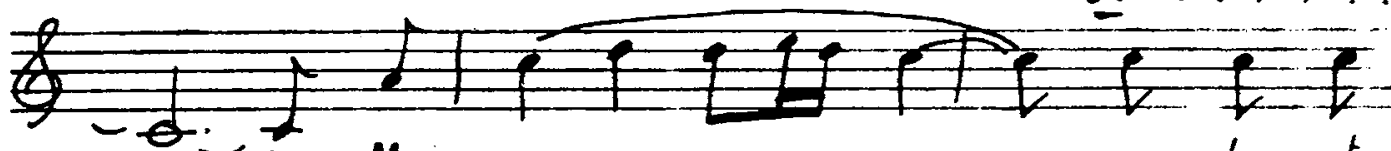

$=$ Mang- $\mathrm{Ka}_{a} \ldots \ldots$........ dyan th-

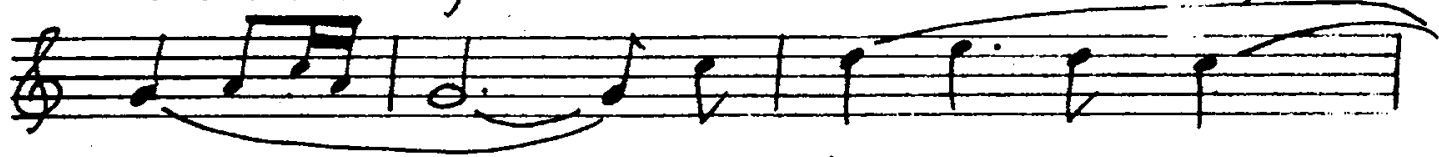

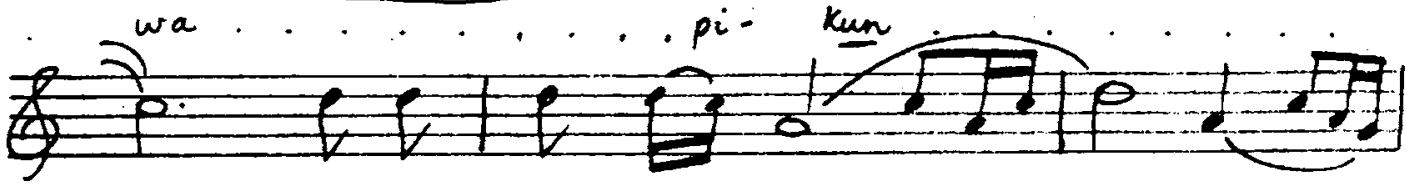

. Jen tan mi-ka=...ni.

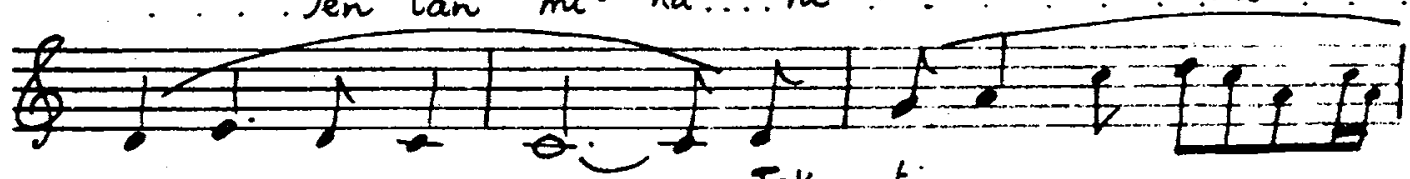
sa..... Jek-ti. 


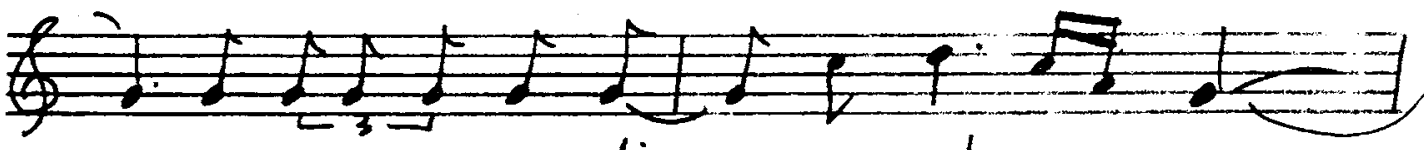

$$
\text { se-pi a-se-pa lir.... se-pah }
$$

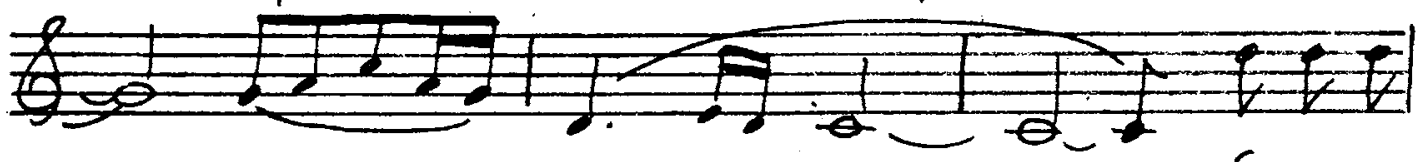

Sa-mang-sa.
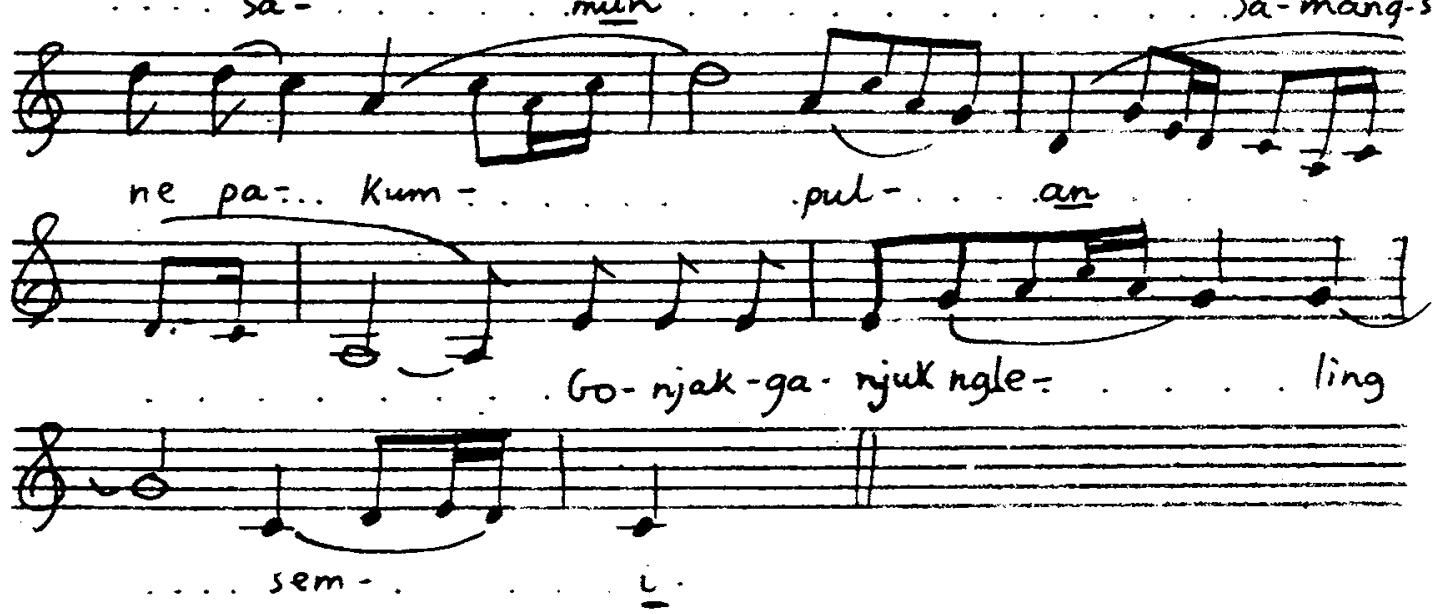
95. DURMA PALARAN (Pelog Patet Nem)

From $M$

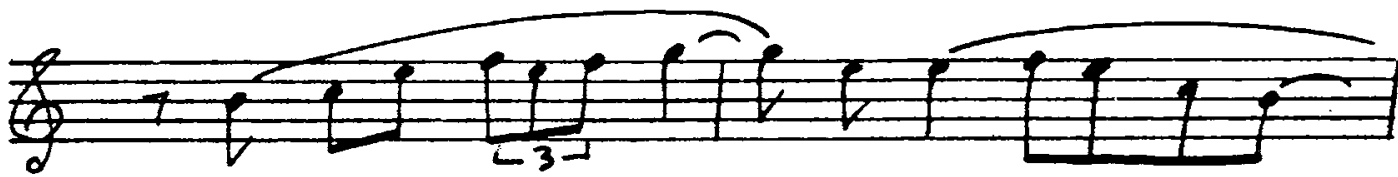

Da-mar-. . . wellan.

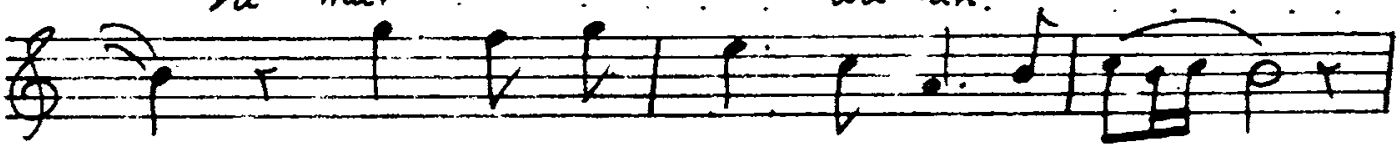

$a-j$ wa ngu-tji-reng nga-ju.da...

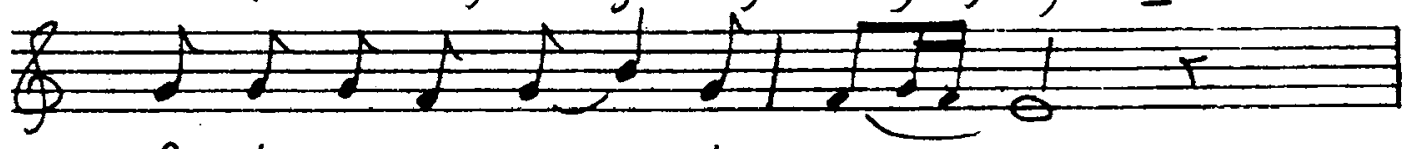

$B a-l i$ a sun an... te. ni....

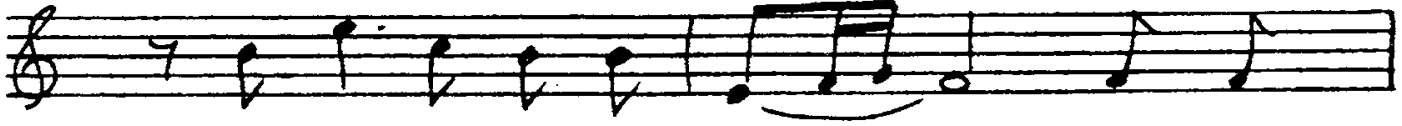

Sun mang-sa man-dur-a. Lah Bis-

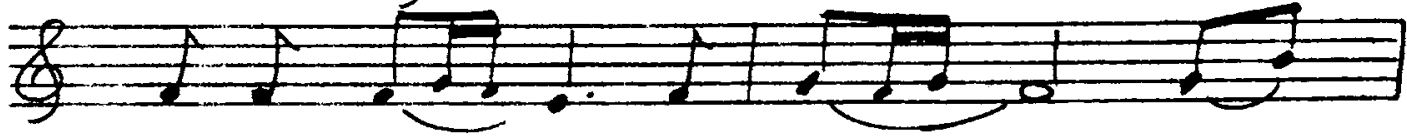

ma den pra-. jit na $\quad k a=\ldots$

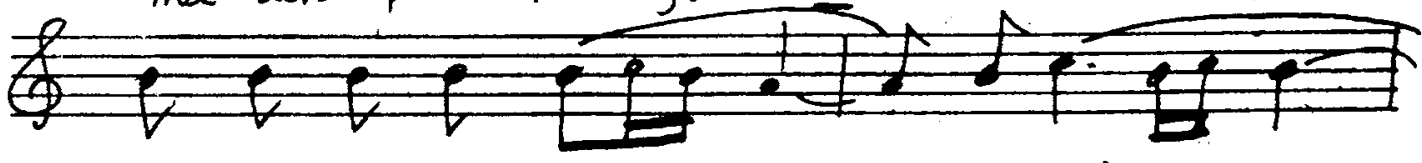

ti - ban pu-sa-ka..... ma-mi...

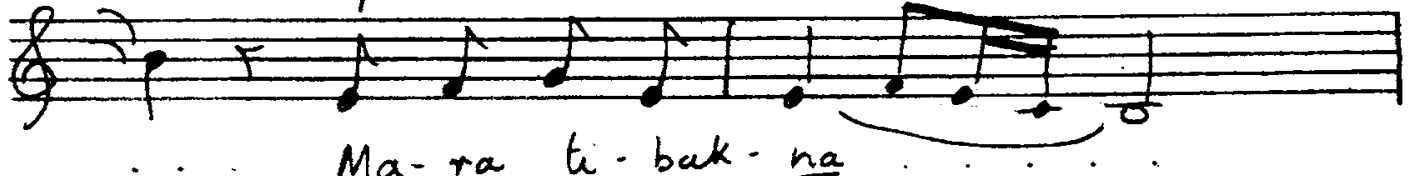

$M a$ - ra ti-bak - na ....

$\frac{2}{4}+1+2+1+2$

Tju-ri-ga-mi-ra...nu- $\underline{h}$ 


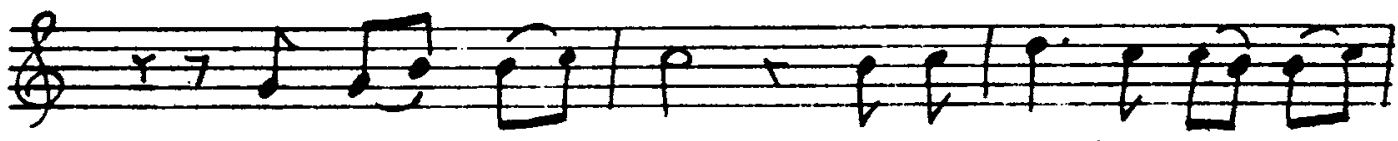
Man-djing...wa:... na ta-ni e-tang pring:.ga:..

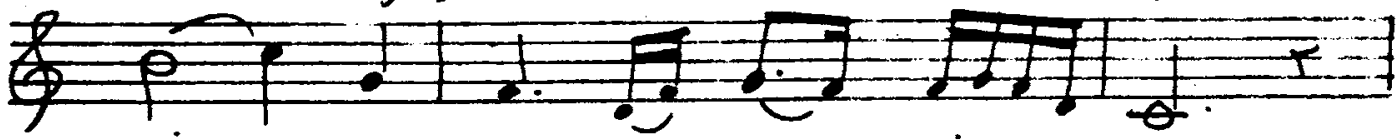
ming.... Mar - ga dju... rang... si-... grong
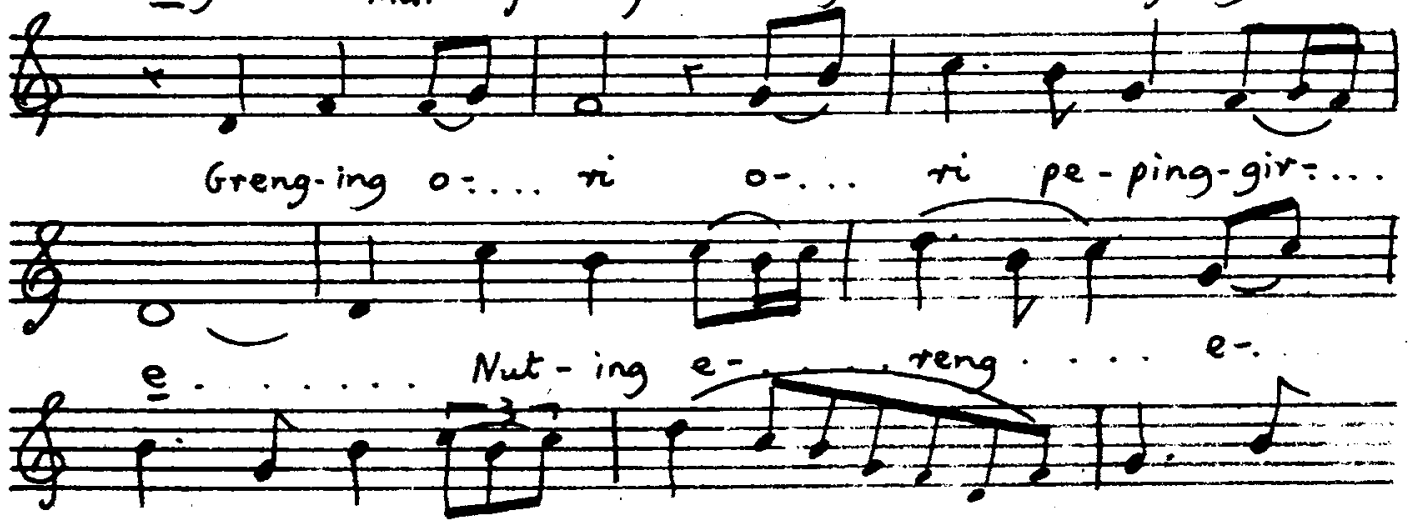
reng dju-rangtre:.. bis........Pe-pe-

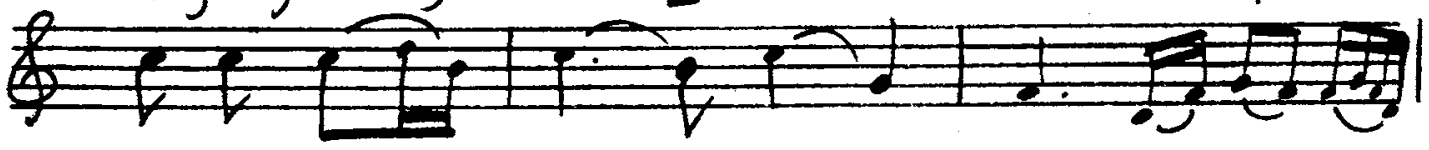
reng-e mi-.... ring... pa-... rang tju-.ri.. pa... $\frac{7}{6}$ 
97. SINOM PALARAN (Slendro Patet Sanga) From MM

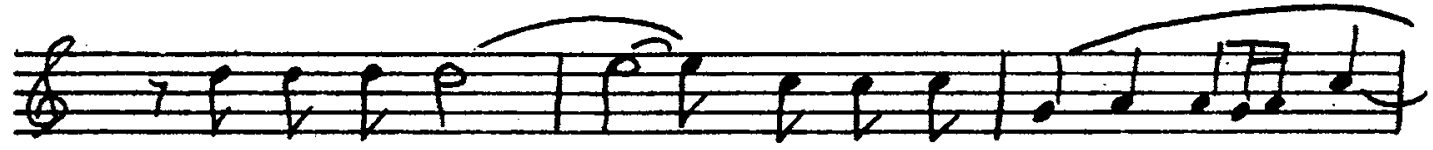

EL Ku-lup $\mathrm{Da}_{a}$

$$
\mathrm{Ka}=\mathrm{la}-\ldots \text { wan gar-wan-ta }
$$

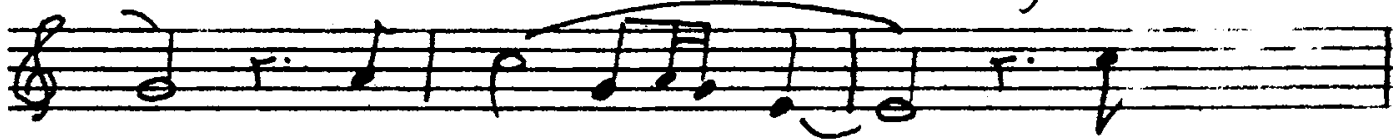

$$
k_{\alpha}-k_{i} \ldots \ldots \ldots \quad N_{i}
$$

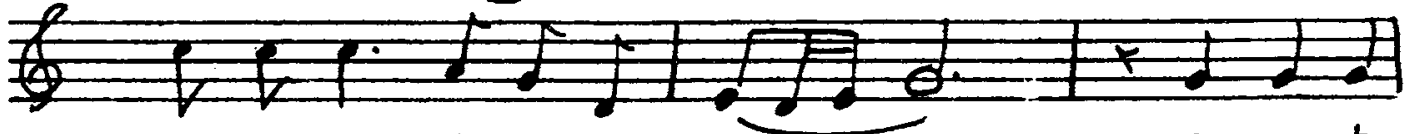

$$
\text { Ken Ra-ra An-djas-ma- A . Pa ta }
$$

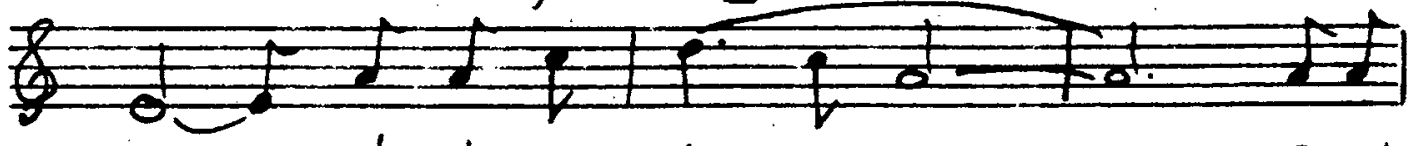

$p a-. . d a$ ba-su- $k_{i} \ldots \ldots$ Jen da-

1)

sar si-ta...jek- ti.......... Pu-traine sa-du-luer

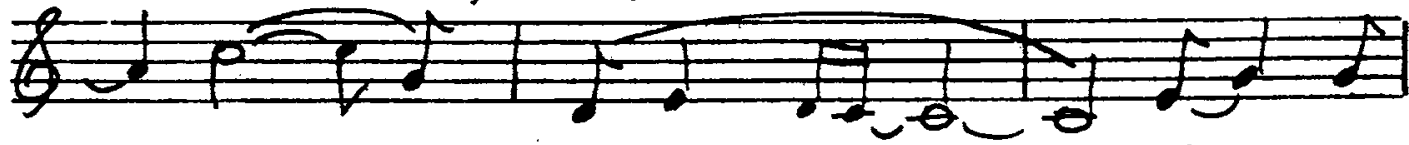

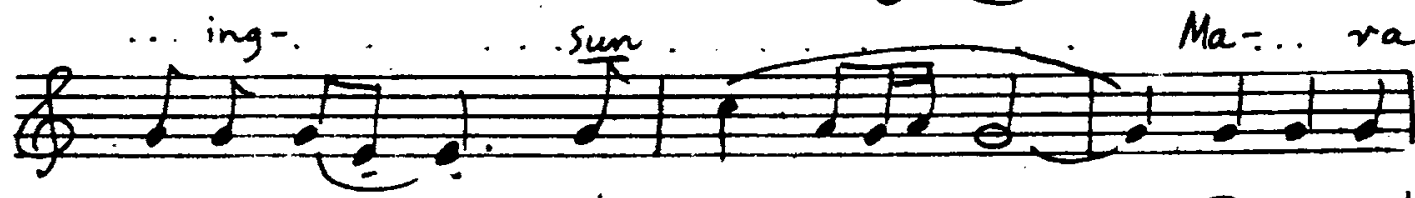

$$
a-g e m e-\ldots t_{u}-a \ldots \text { Tan } u-\operatorname{sah}
$$




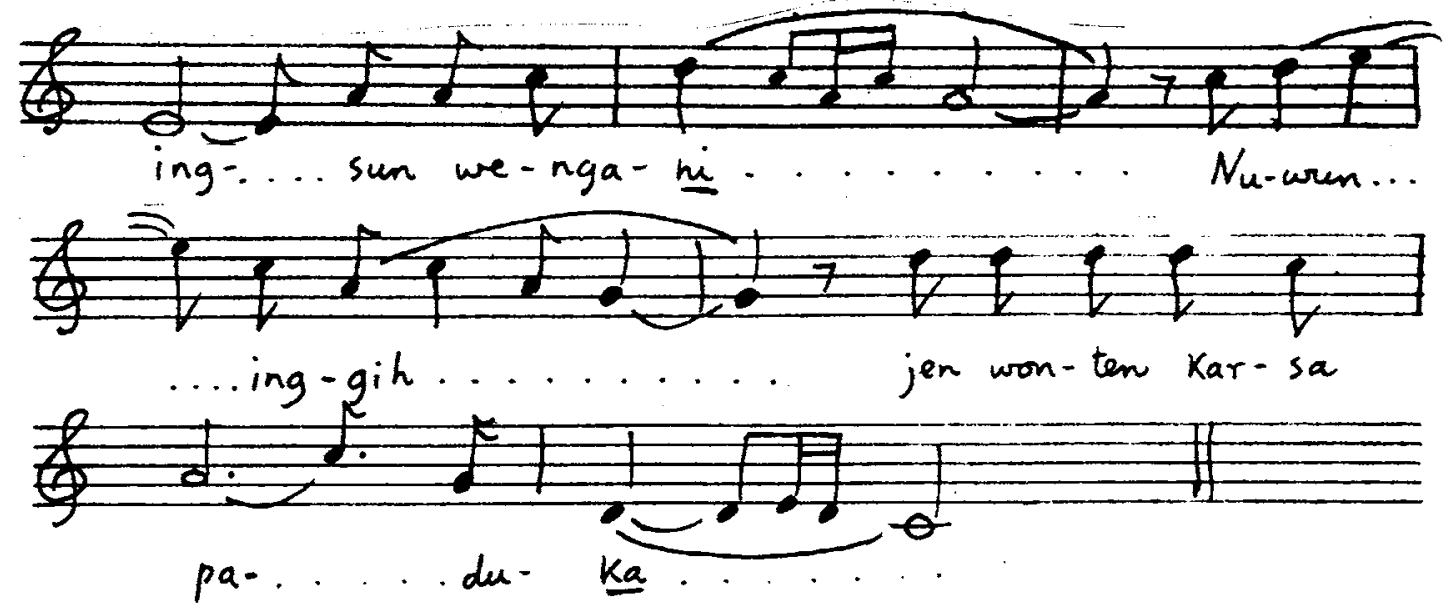


98. DANDANGGULA TLUTUR (Slendro Patet Manjura) From MM

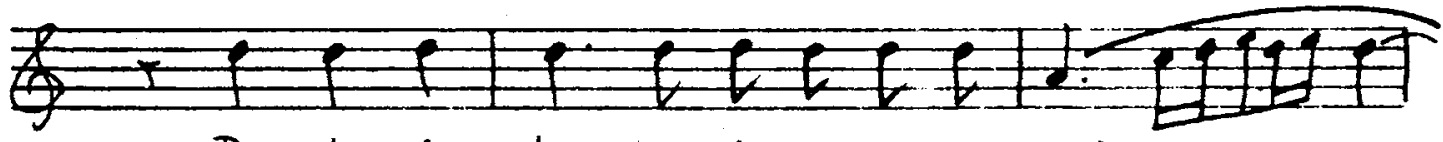
De- dep $t i$ - dem pra-ba-wa ning ra- tri

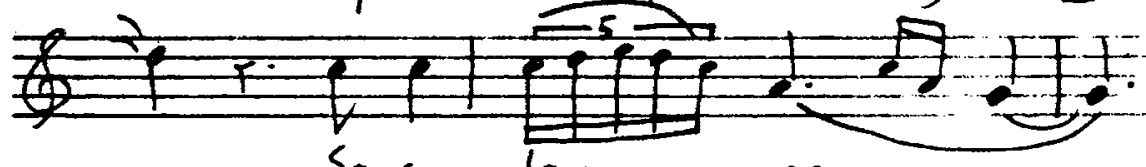

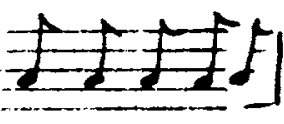

wus man-Ljerka.

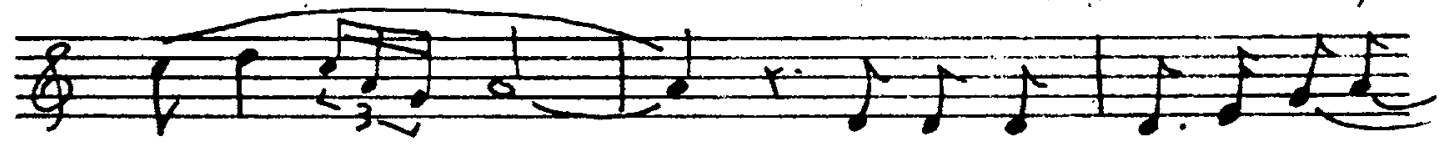

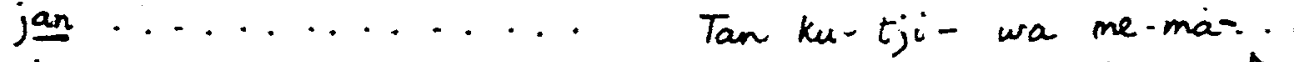

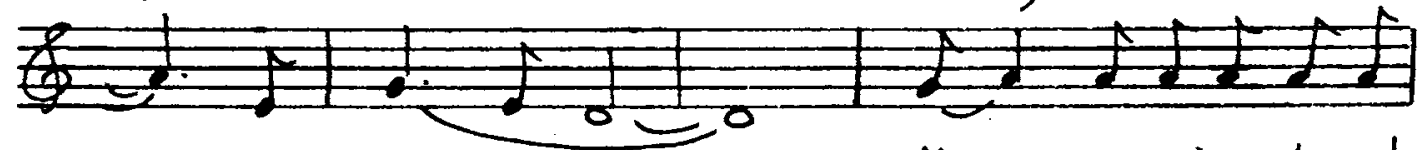

Mong ...gepsri-na-teng da-
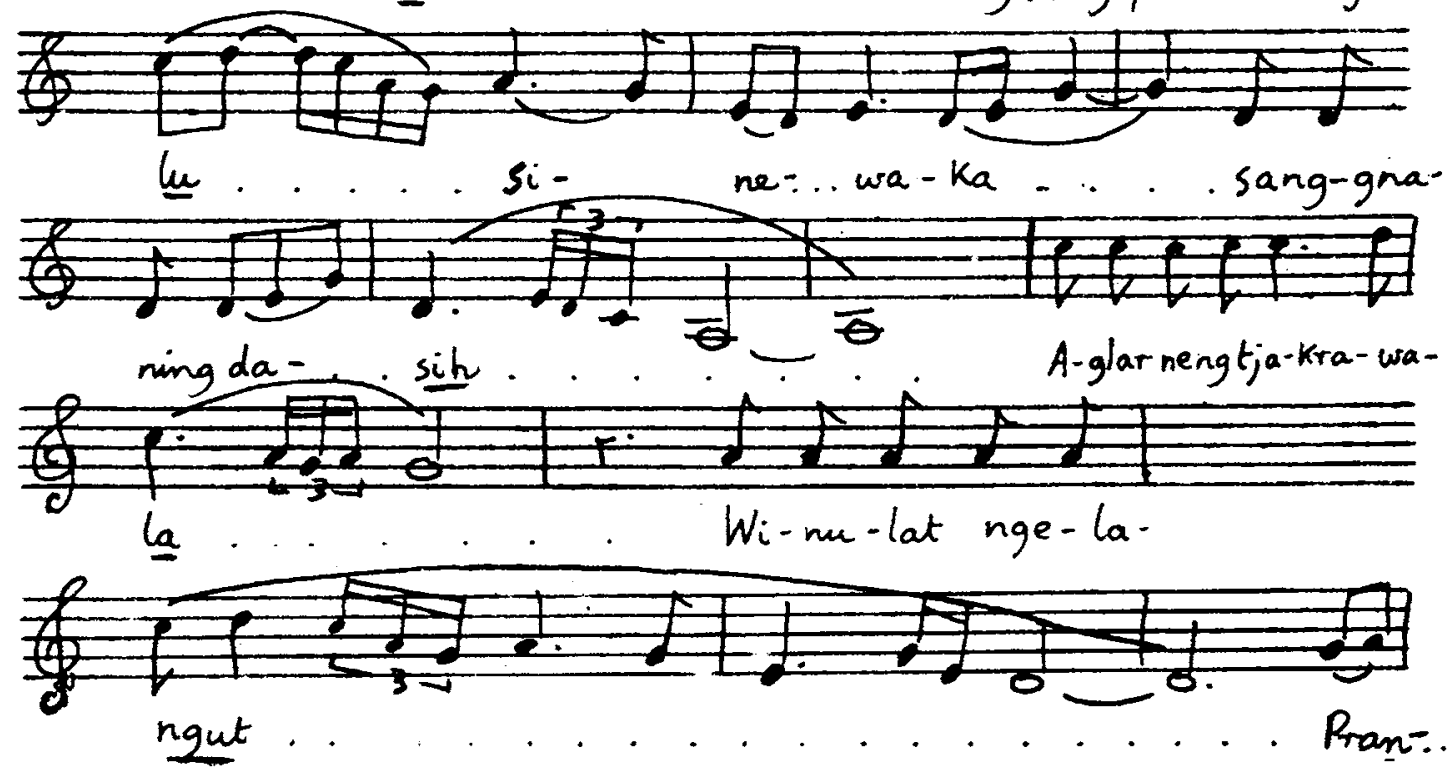


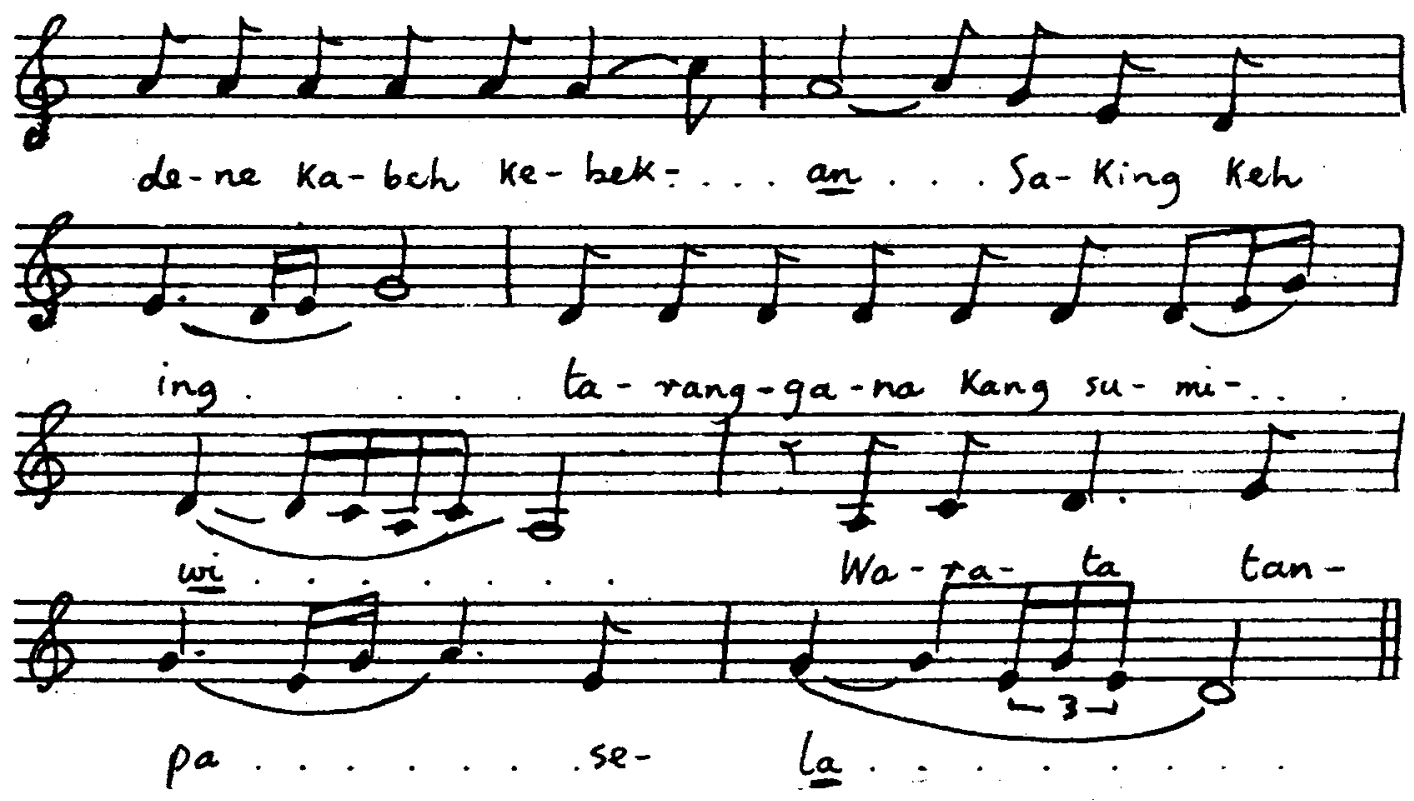


99. DANDANGGULA PALARAN (Slendro Patet Sanga)

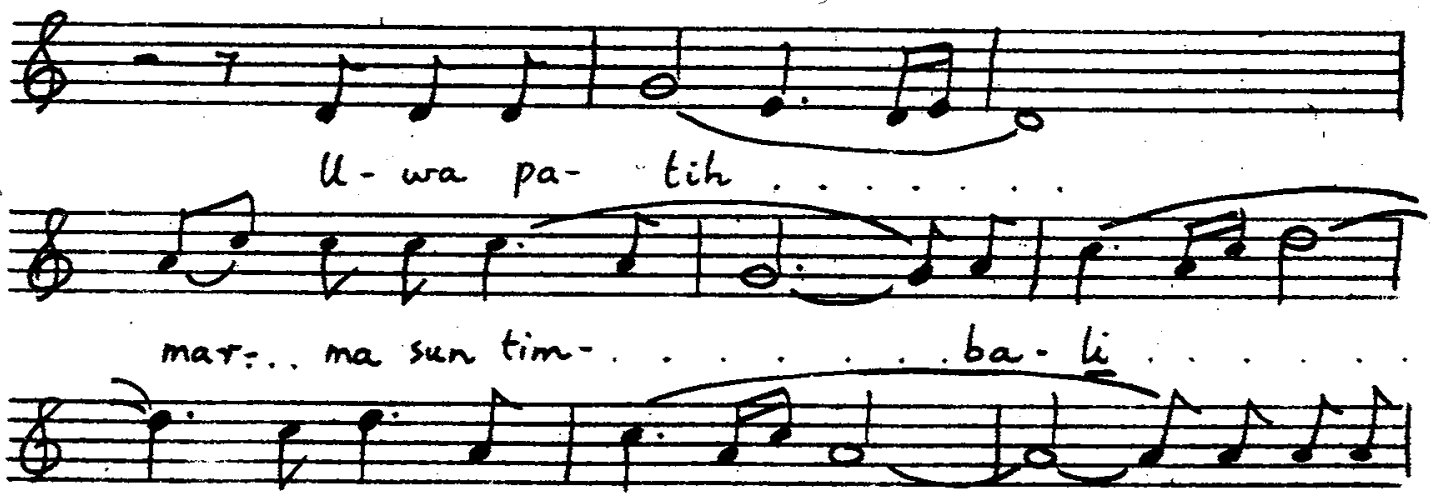

Ing-sun pa- ring.......... we-ruh ma.
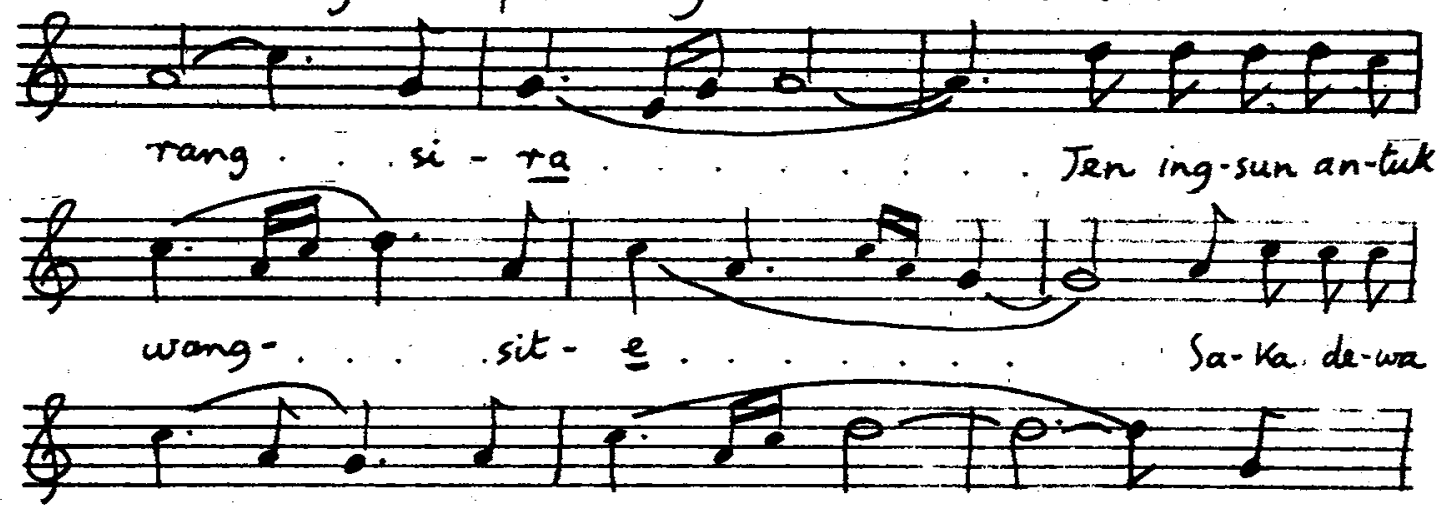

$l_{-}$..... nu - hung........ . Sa-

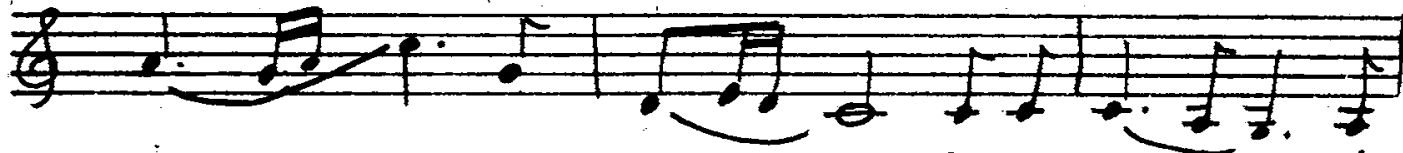

ba-... na-ne... pa-prang-an ..i-

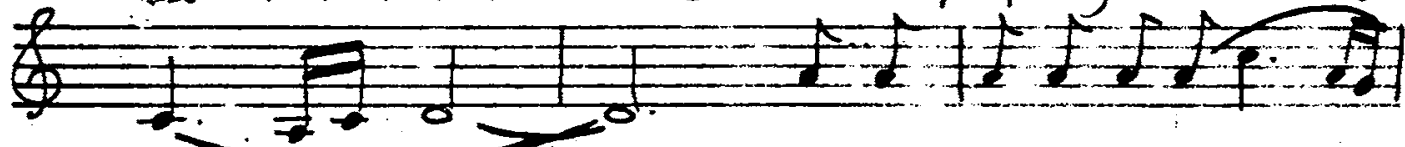

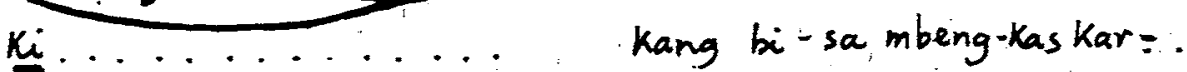



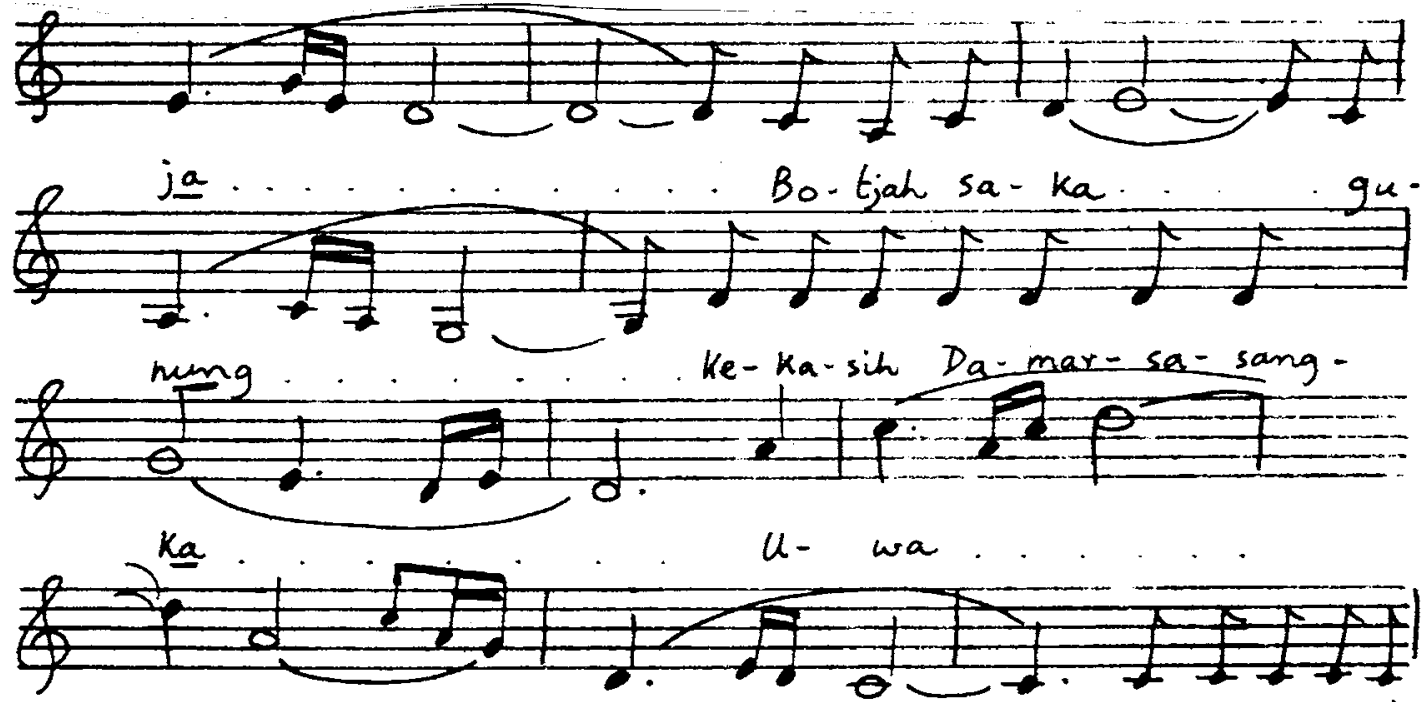
ma-ra u-pa-ja-
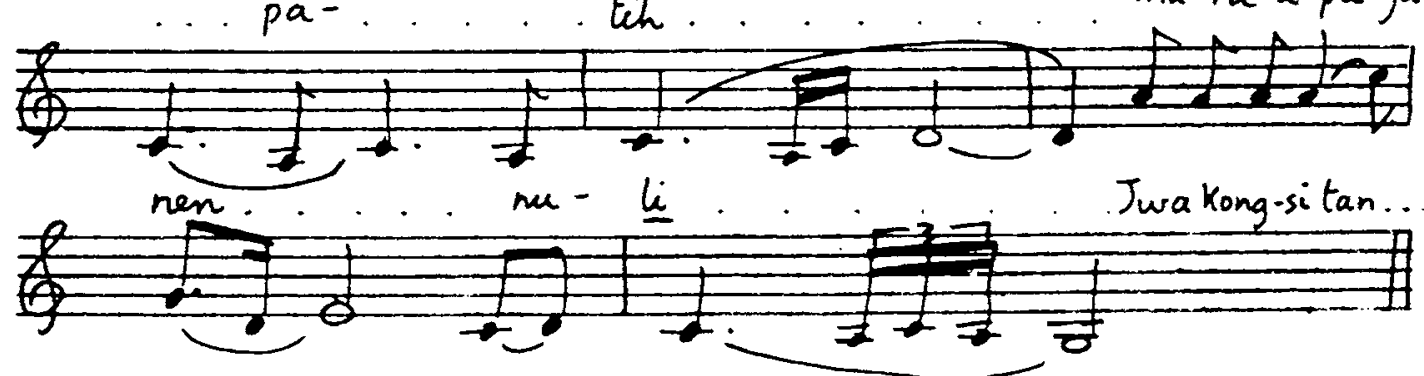

$\mathrm{Ke}$-. . pang-.. gia 

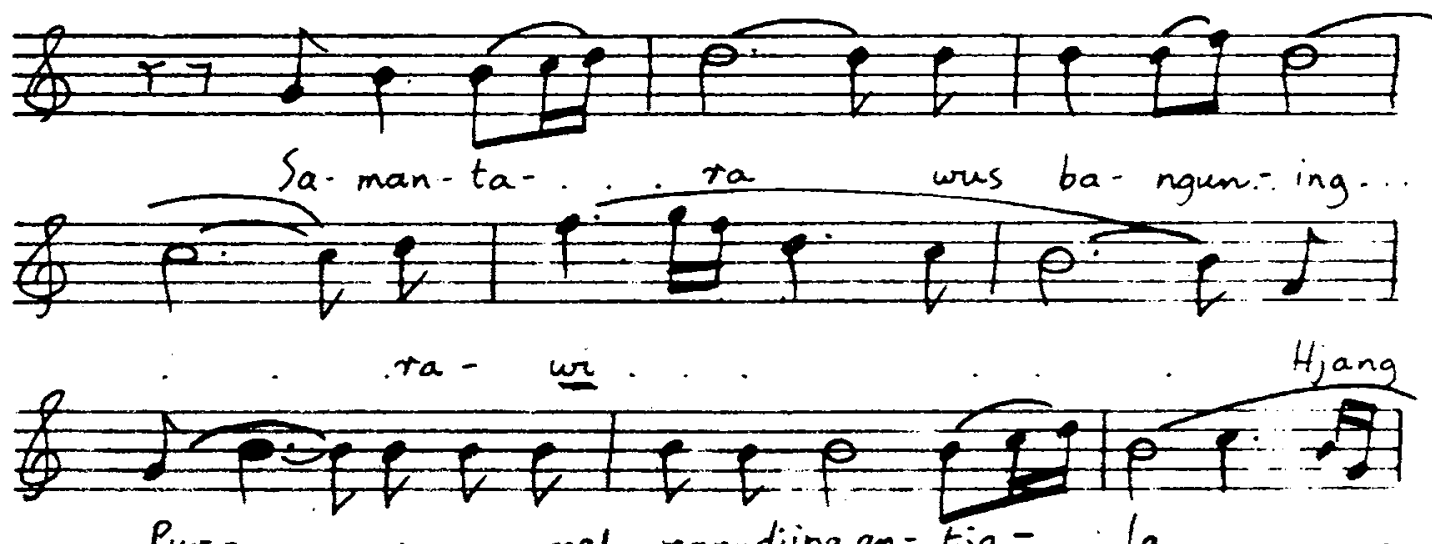
Pur.. . na-ma meh man-djing an-tja-. la
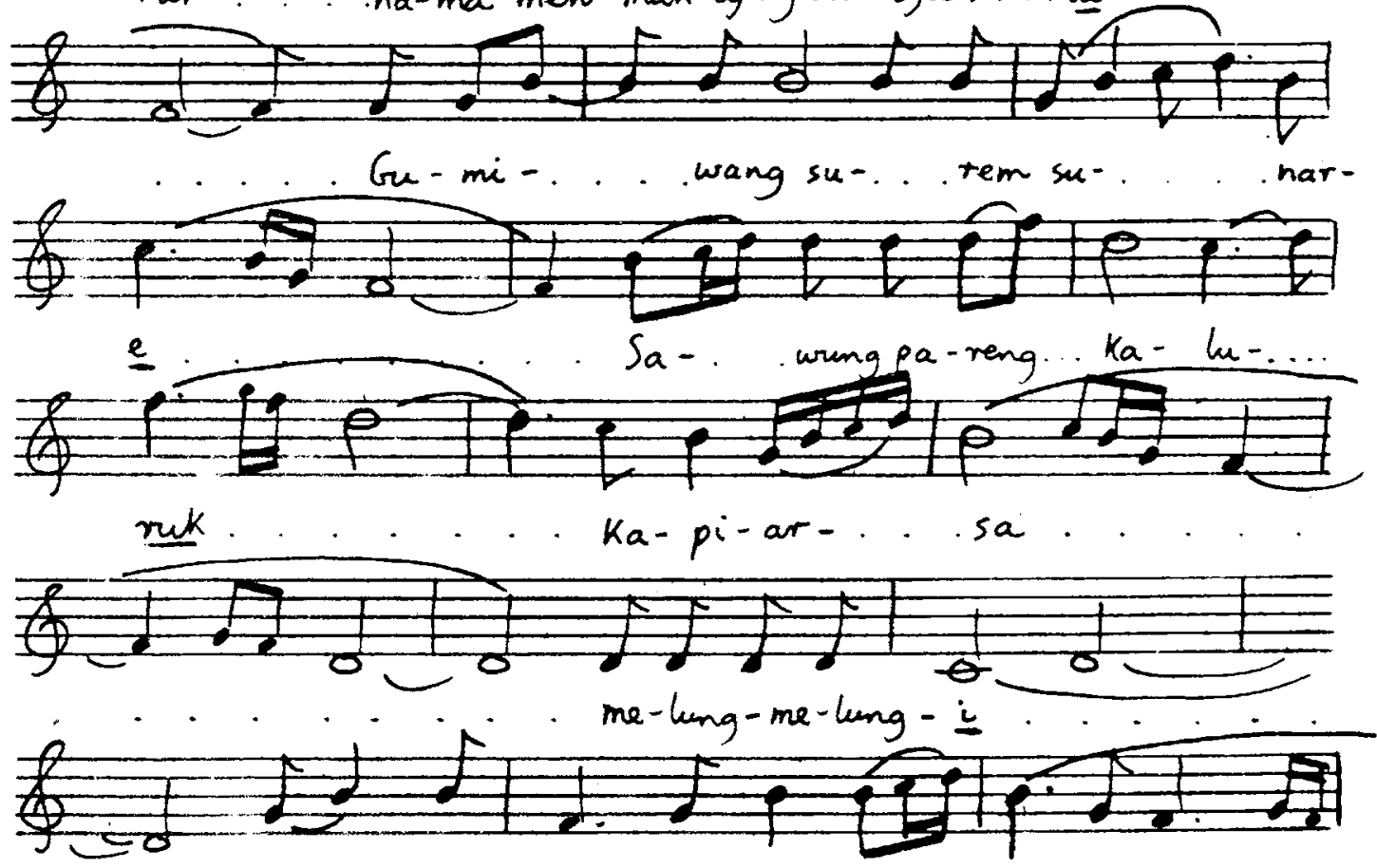

Mring...kang. Ka- su-wen nen-... dra. 


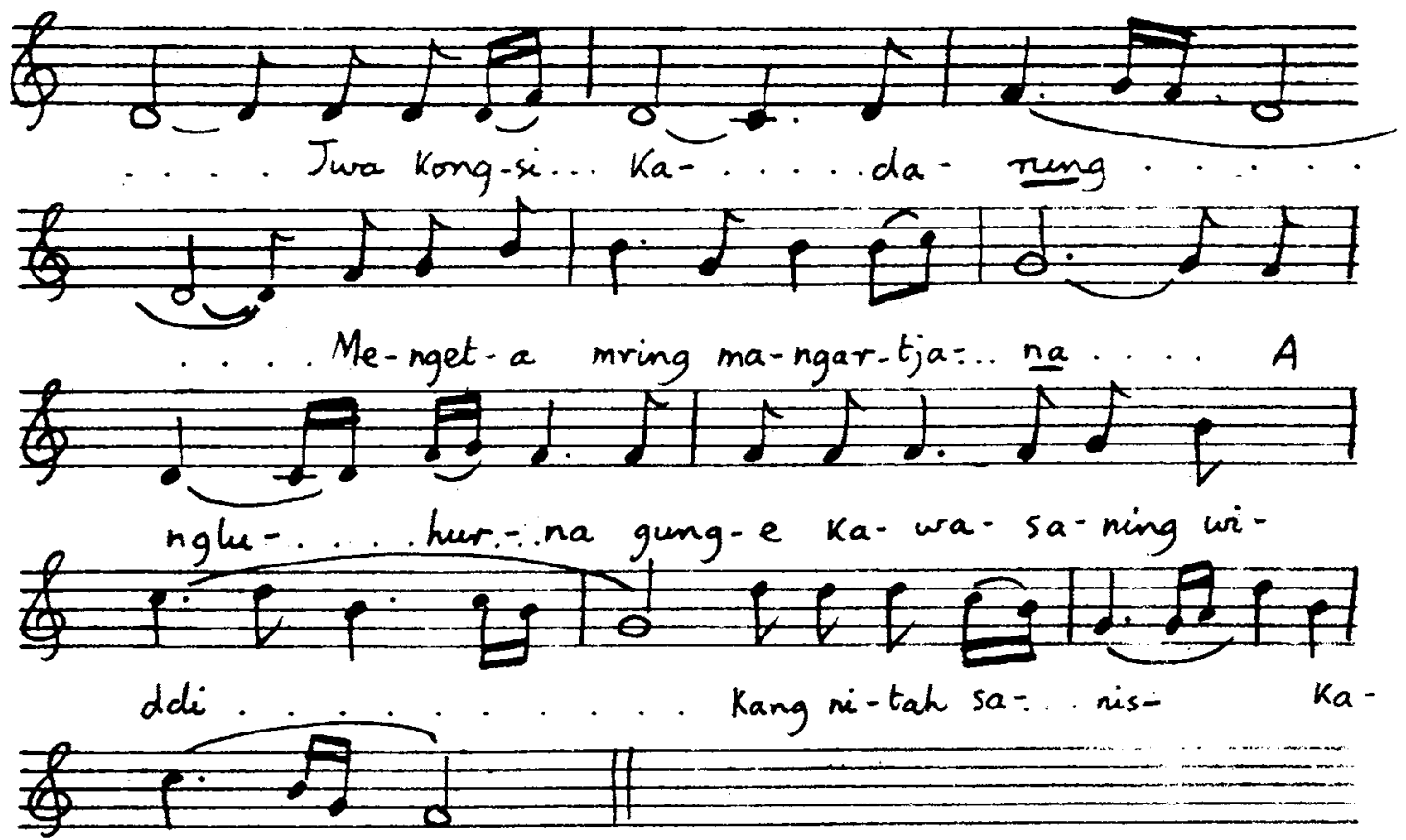

ra. 
102. PUTJUNG LARAS MADYA (Tjangkriman) From S.T.D.
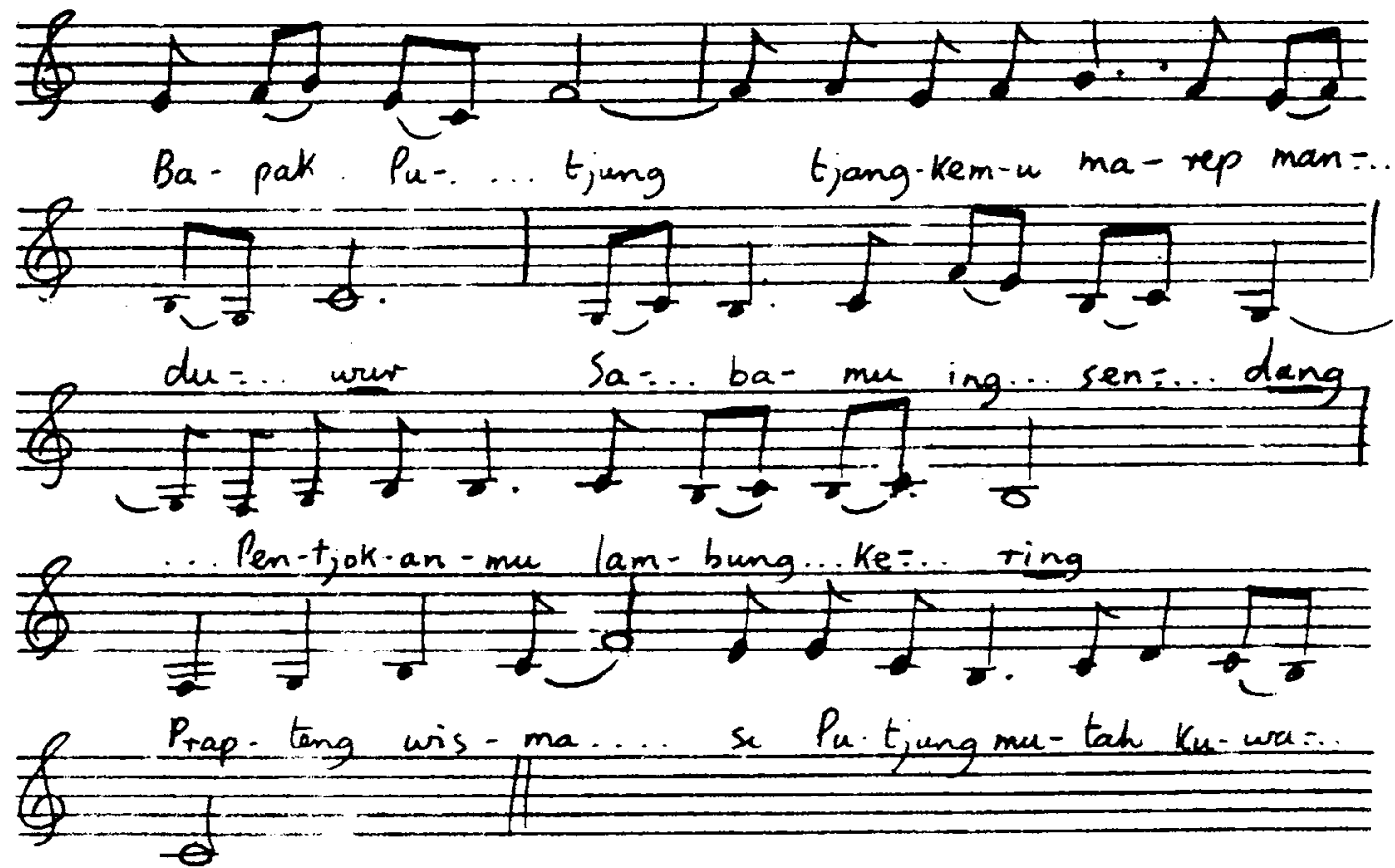

) 

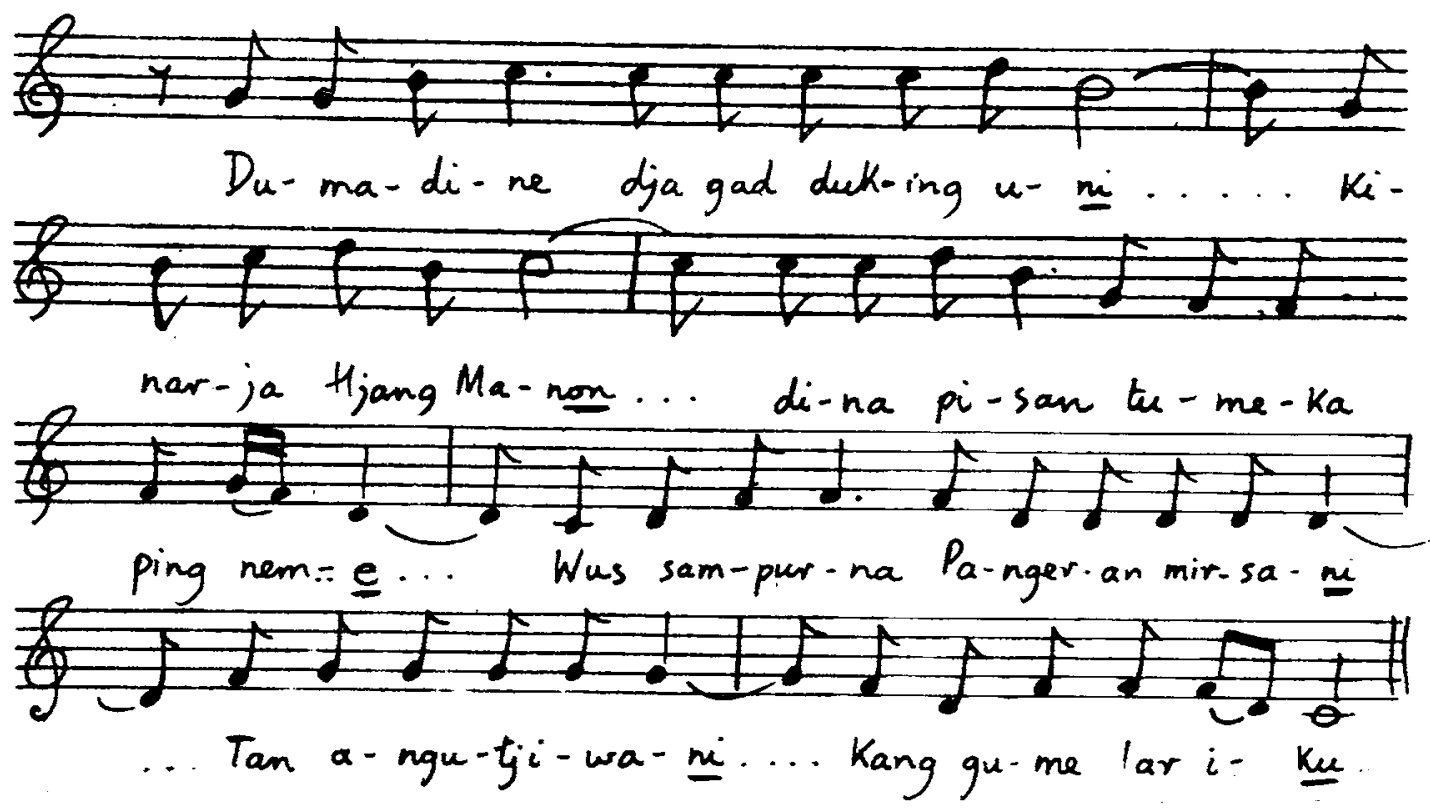


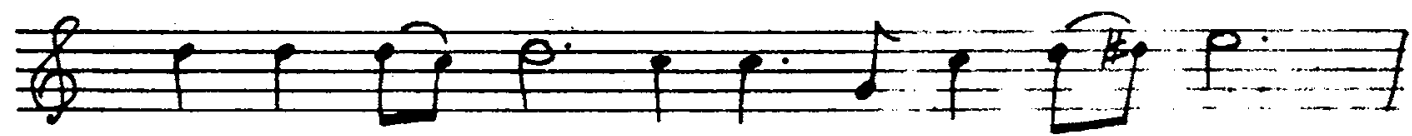

$T_{j i}$ - lik mu $=.$. la re-ka- sa wak ma mi

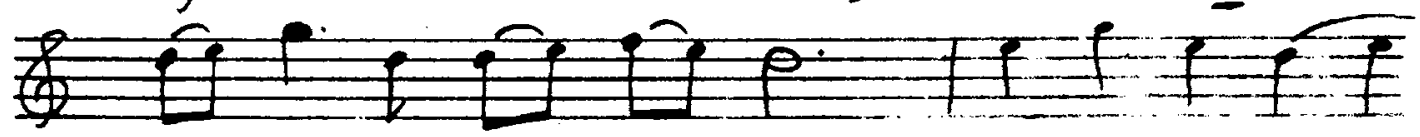

Mang.-gung da-di... la-.. Kon Nis-ta pa-pa.

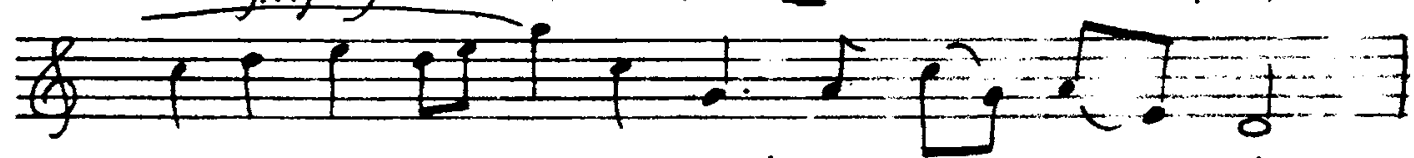
wus ngla-kon $i=\ldots k a=$ beh
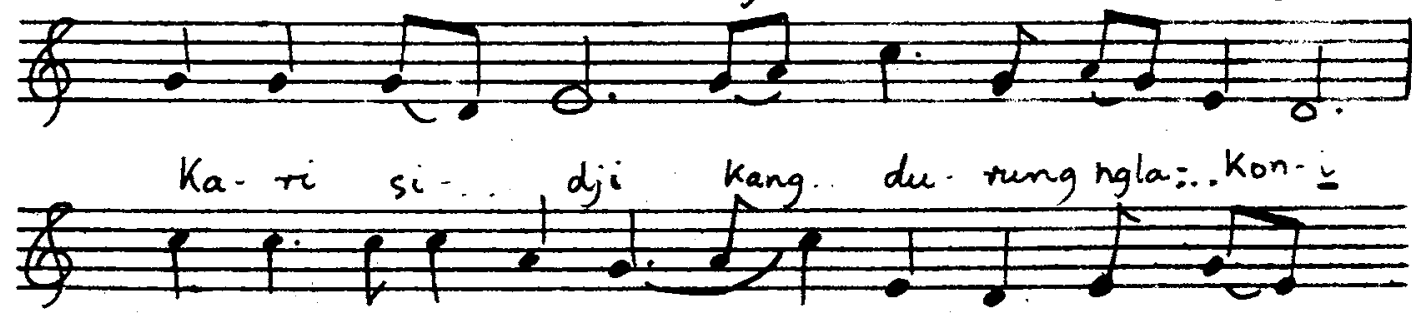

Nga-bek-ti mringfus-ti ... Pun-di mar-ga-.

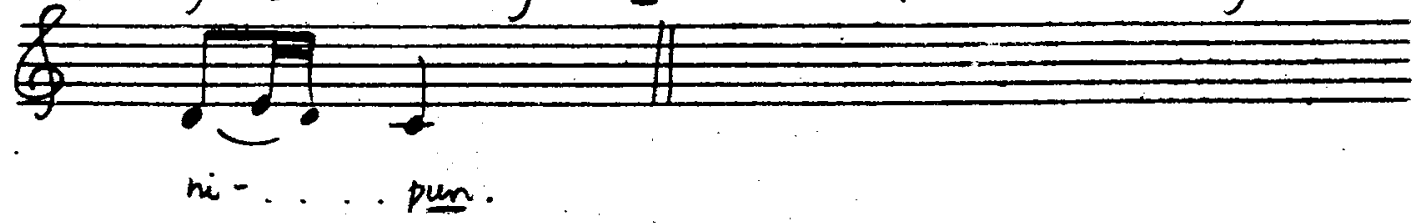




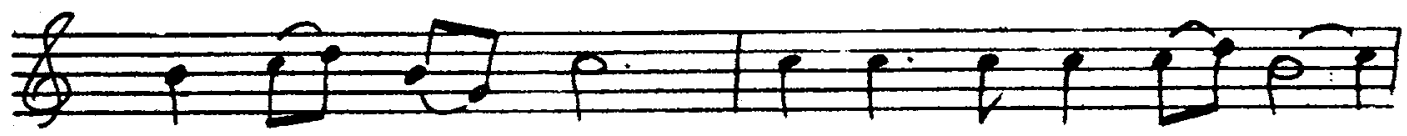

I-rim:- $i=\ldots$ rim lin-tanglan-djar ngi-rim.
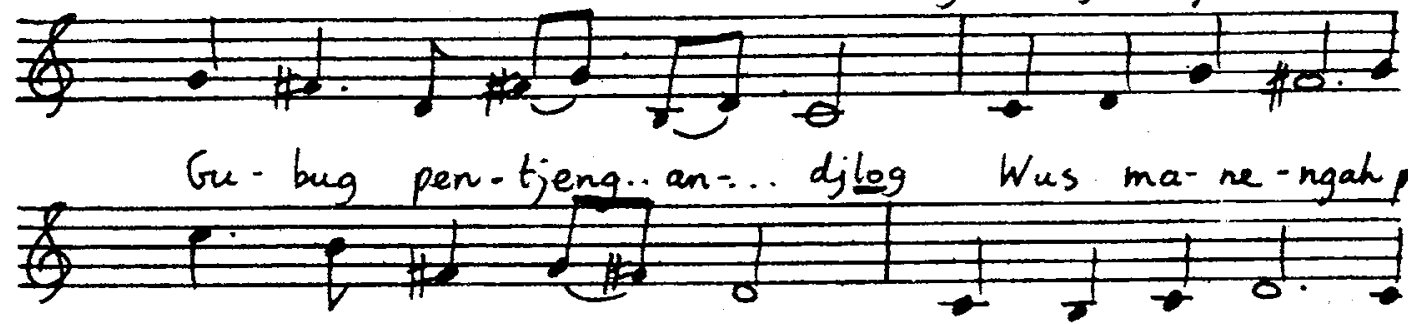

u. ne sang ra-. den $D_{j a}-K_{a}$ be-lek ma-
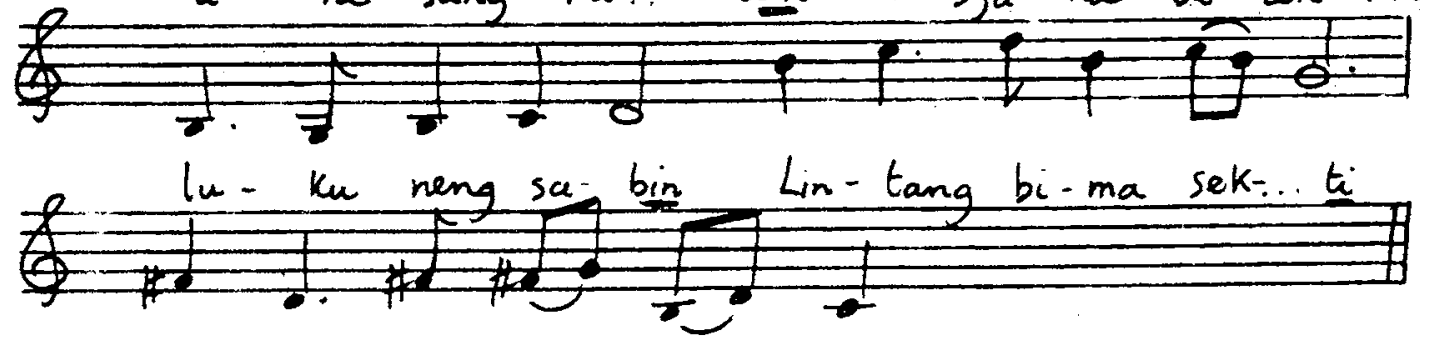

$N_{\text {. }}$ - tich $k_{u}$ - da... da-.. wouk. 

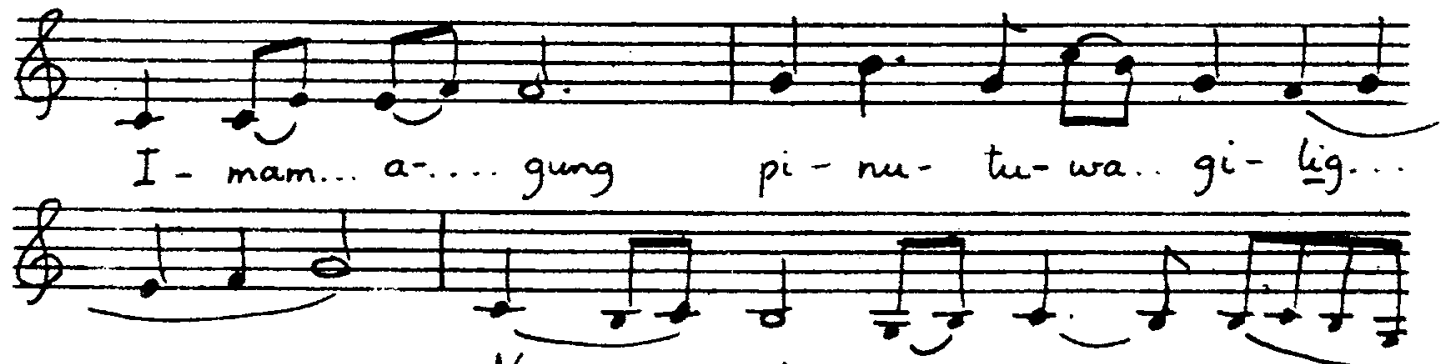

$$
\text { Ngo-......djok - o......d,ok-... }
$$

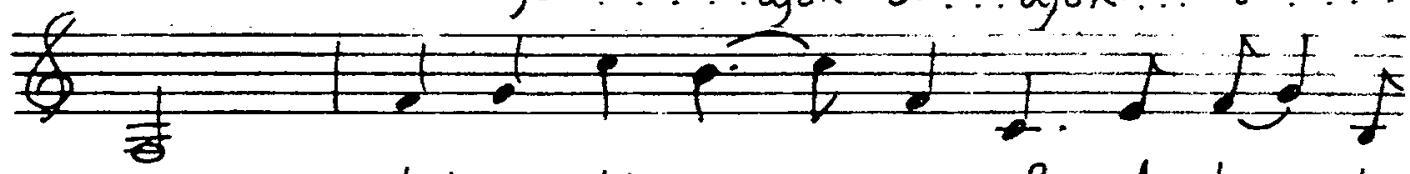

wong Lah mi-lih-a.... mring Bar A-bas. ba.
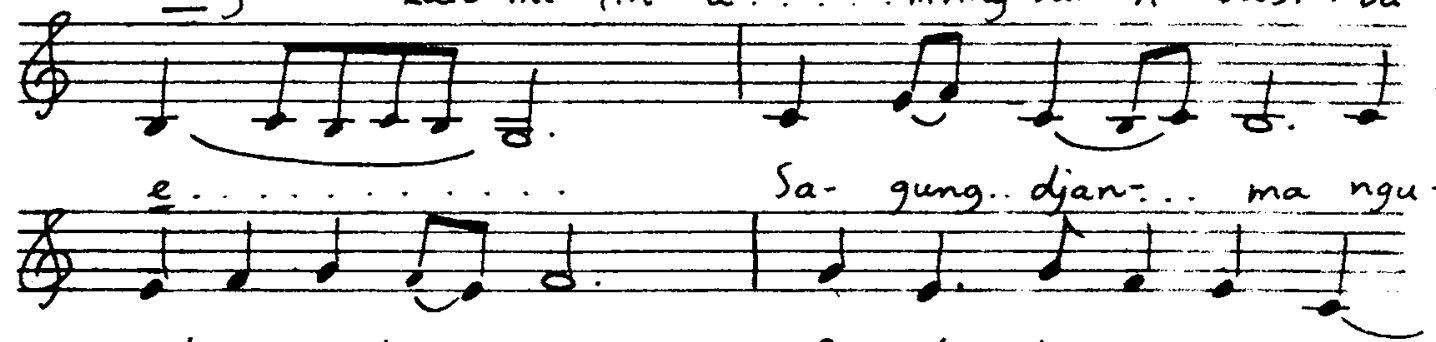

wrih-u-wuth sa-.. mi Bar A-bas ngong pi- lih
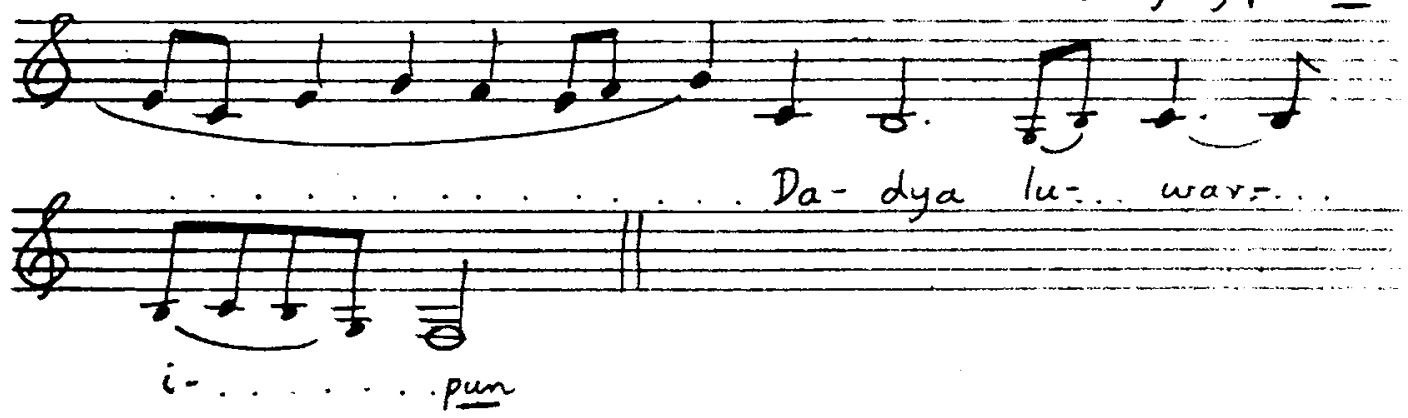


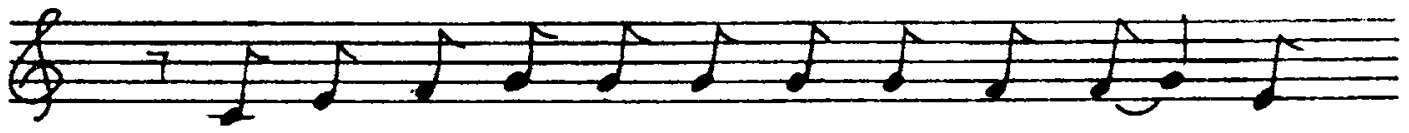

Gja u-mang-sah dja-ka $D_{a}$ - wud mringpa-... prang-
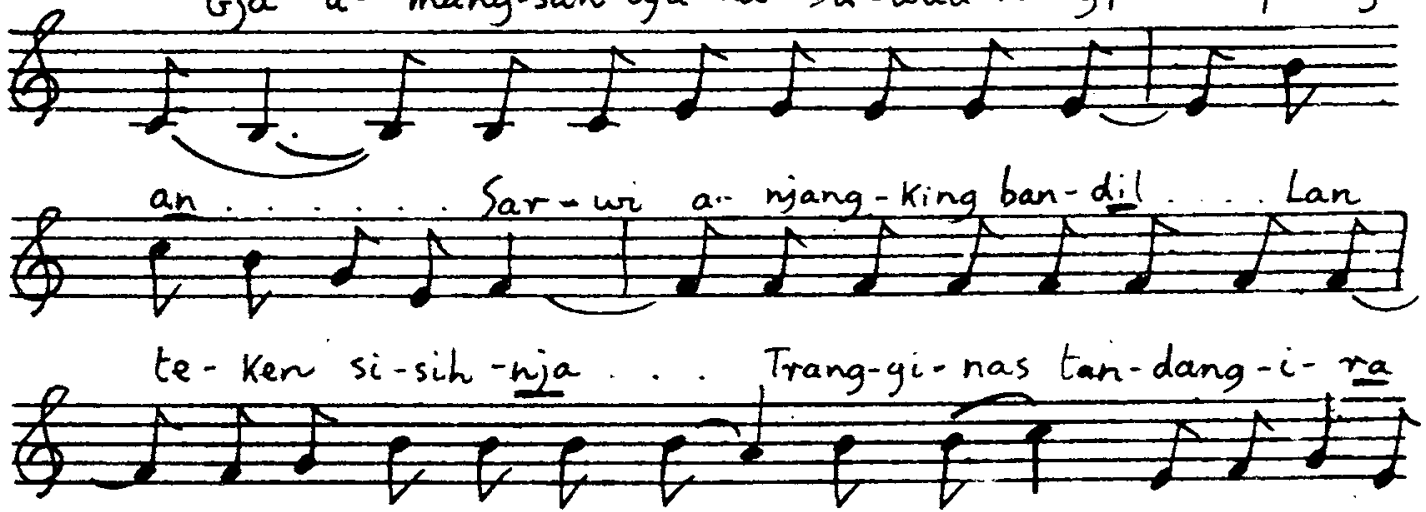

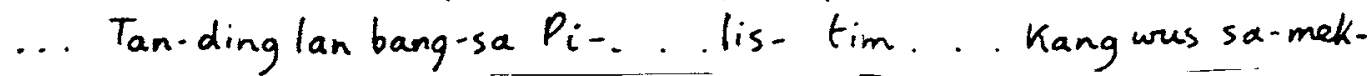

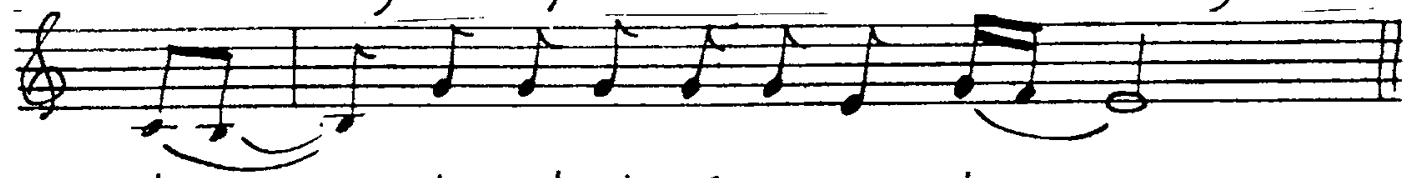

ta.... Kang da-dya Se-na-pa-ti. 

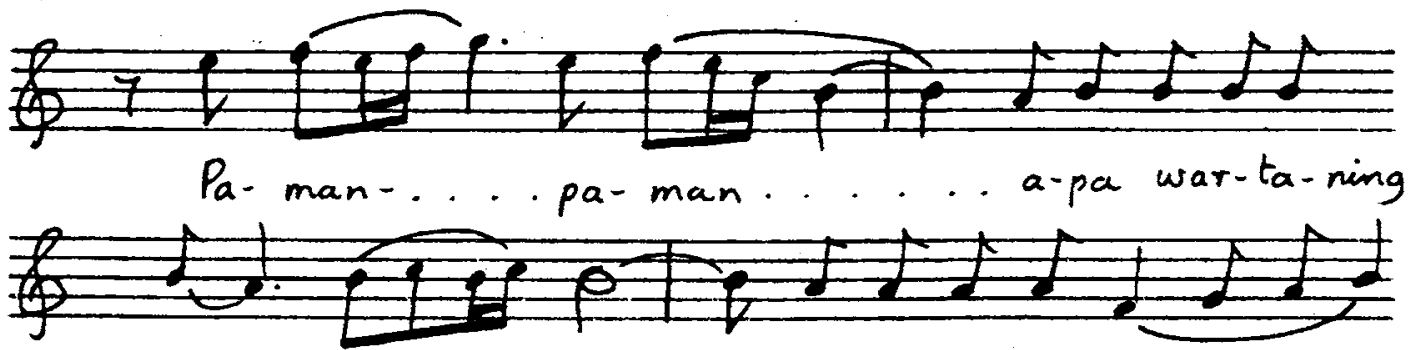
nde = ..da-... Lan ... Nde-da-lan Keh wong

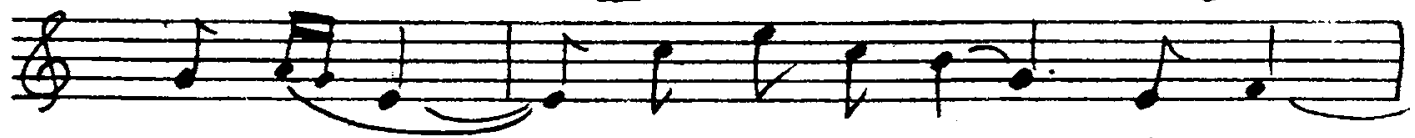

$$
\text { ma-ti...Ma-ti ke-na... a-pa.. }
$$

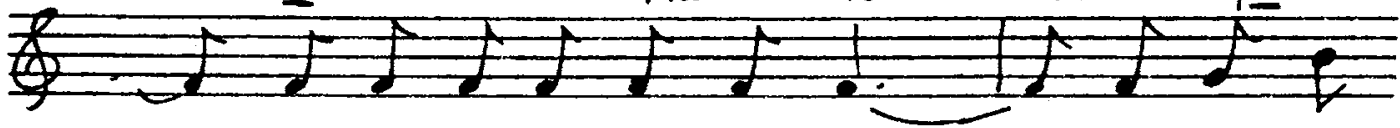

..? Ma-ti den ka-ni-a-ja... Ing dja-dja
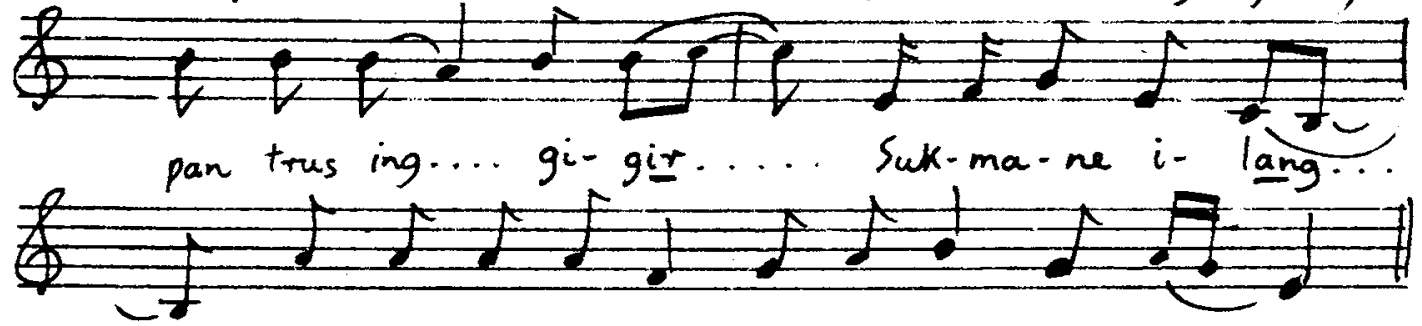

...Ra-ga ka-ri gu-.... mlin-ting... 


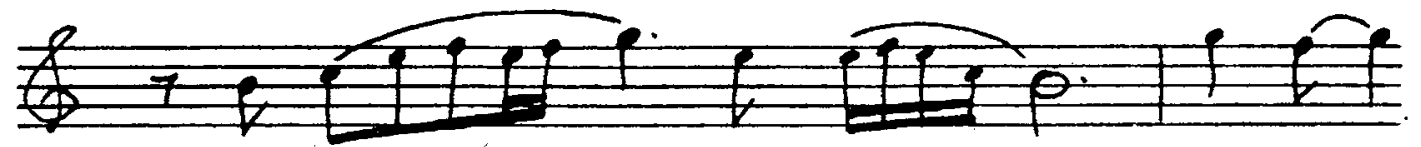

Tin-dak........... r. ra...... Lut wrus
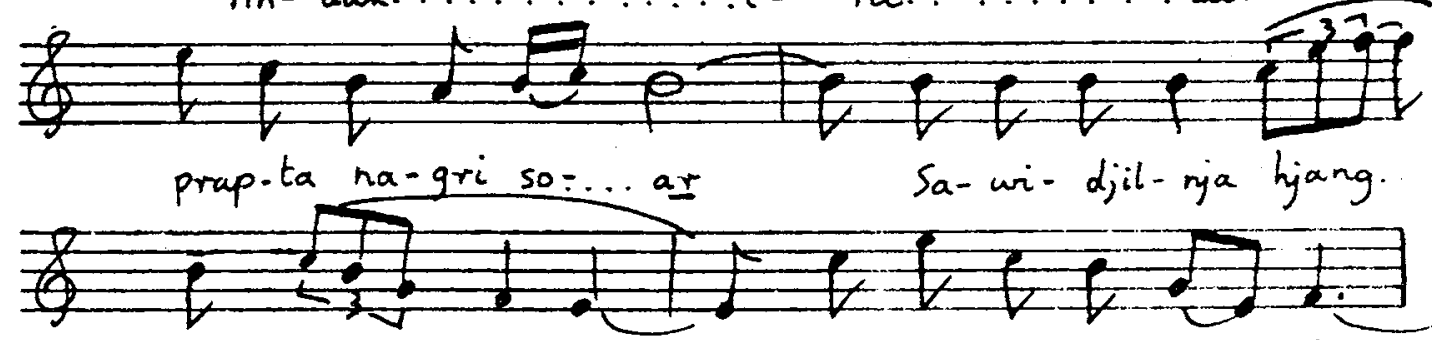

ra-wi...... Nu-lja Gus-ti Al-.. lah

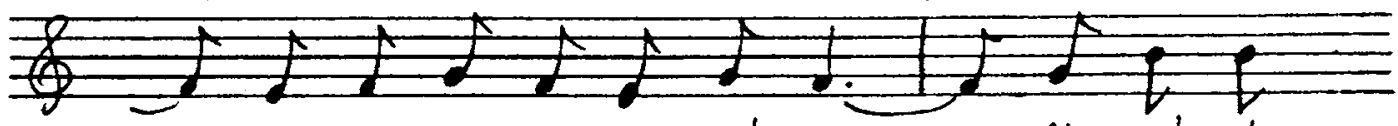

... An-dja-wah-ken wa-li- rang....Mjang la-tu

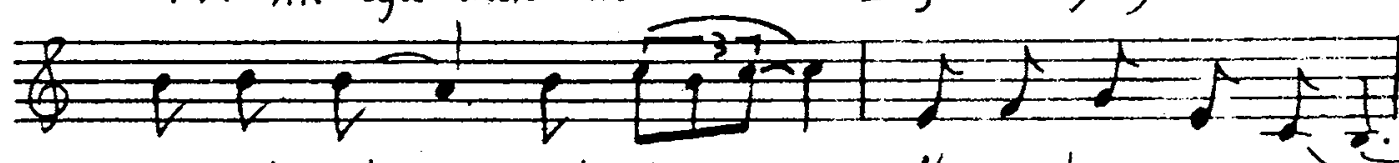

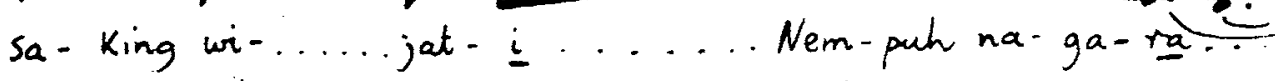

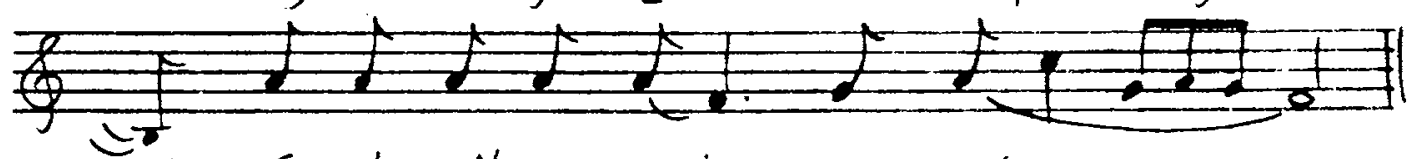
$\ldots$ Sa-dum Nga-mo-rah.. sa. mi......... 


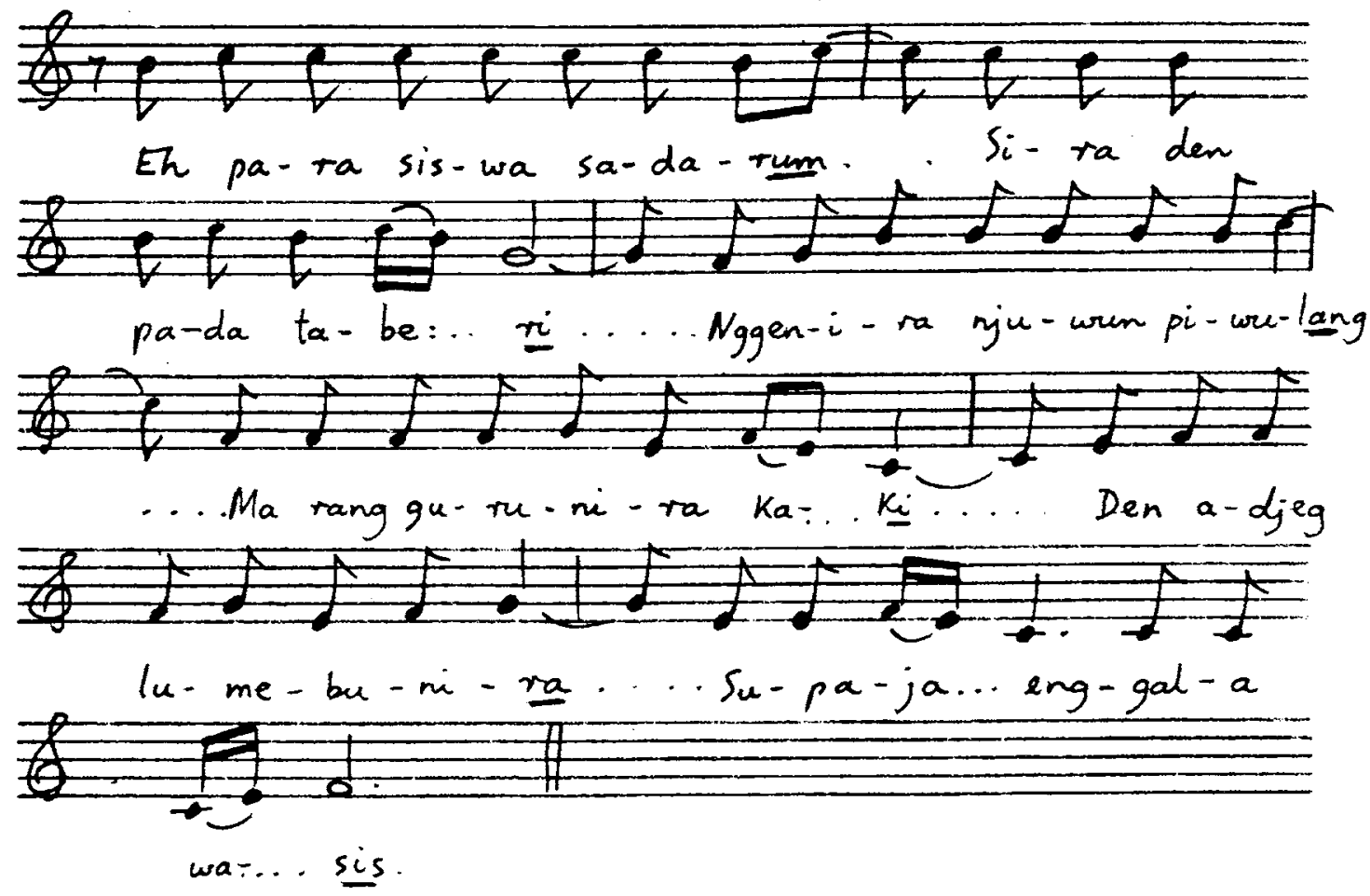


111. KINANTI (SUBOKASTAWA) PANEMBRAMA From S.T.D.

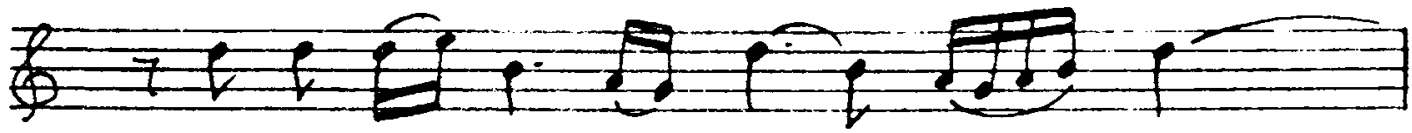

Kan-ti su-...ka ing...tyas....u-..... Iun

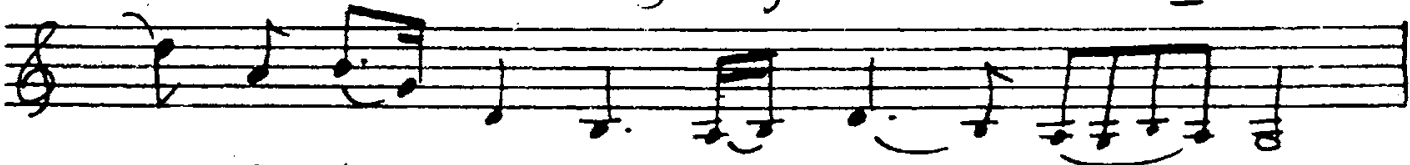
Am-ba... pa-ra kan =.tia...s sa-... mi

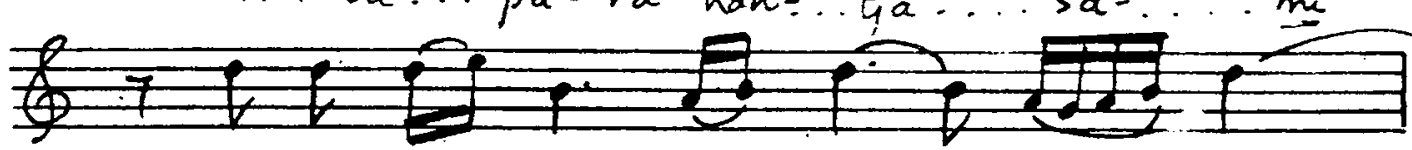

Nga-tur-a ... ken pa-...nem-... bra-... ma

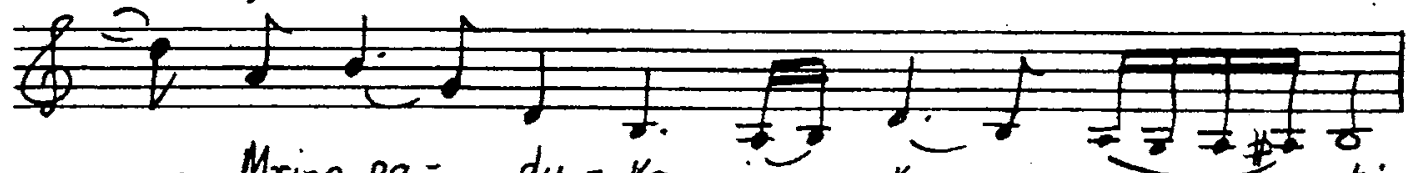
Mring $p a=\ldots d u-k_{a}$ ing . kang... prap ...ti

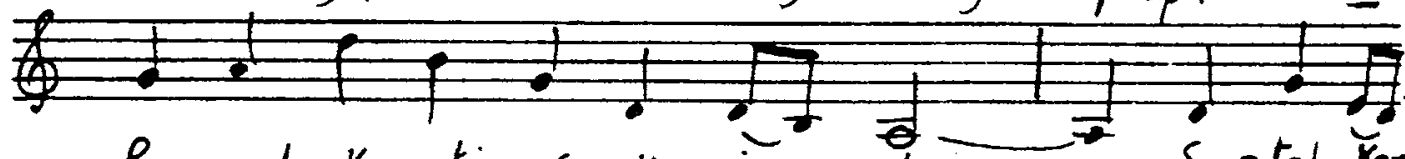
Ra- wuh Kan- $i$ su-ka ing... tyas... So-tah Kar-

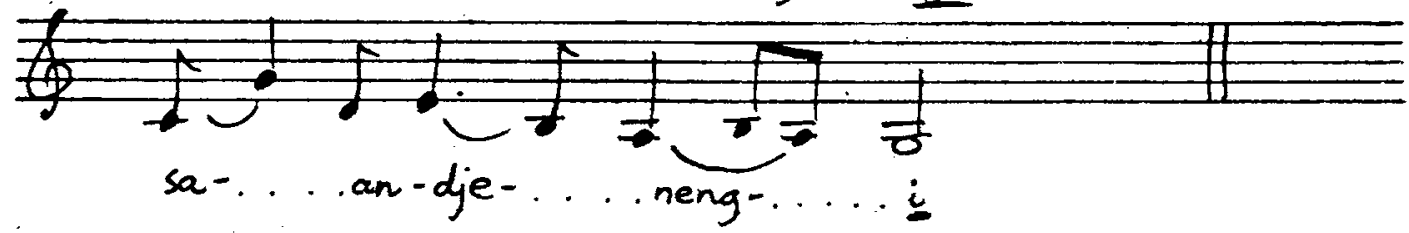


404

112. KINANTI SANDUNG

From S.T.D.
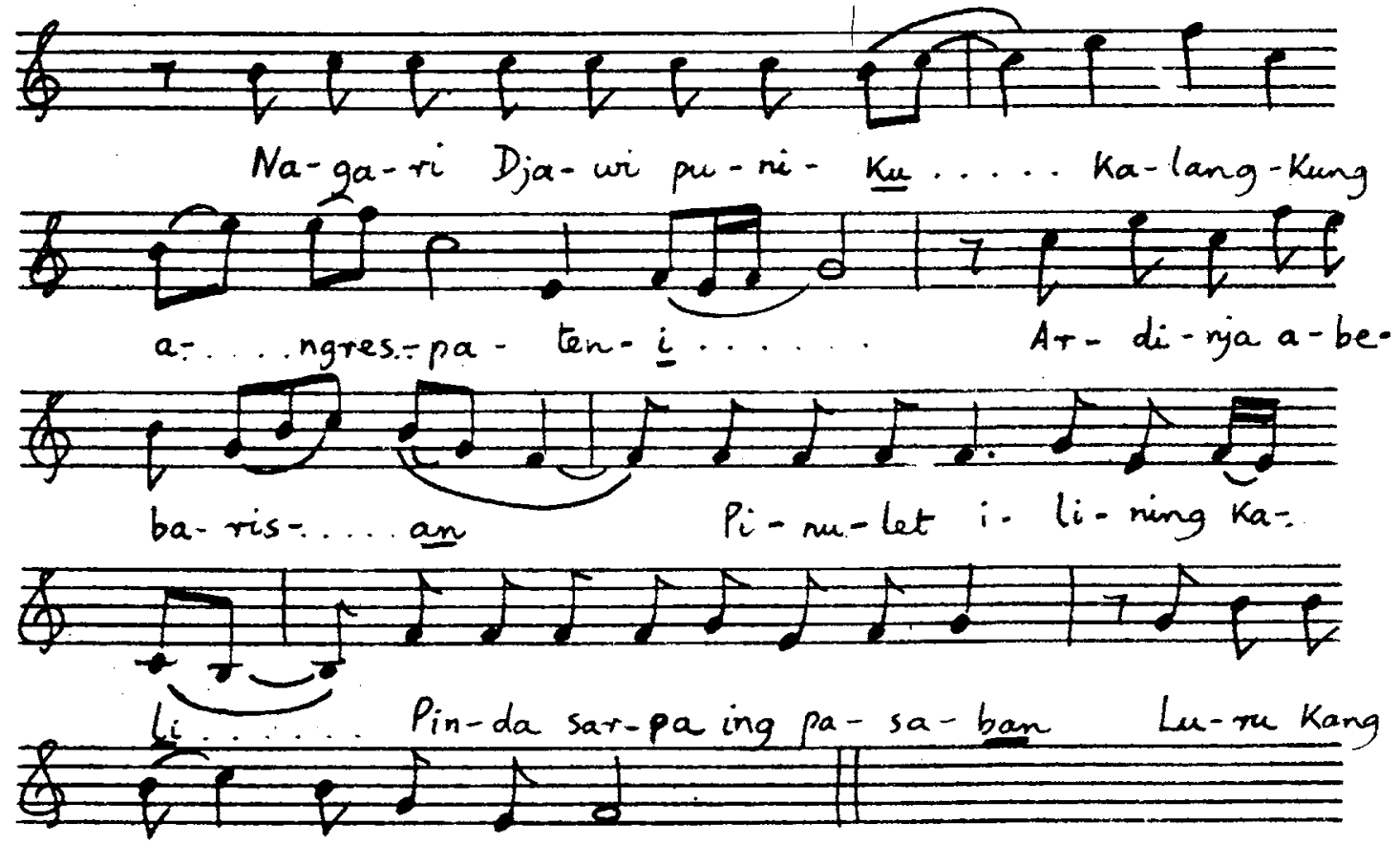

ki....nar-ja buk-ti. 


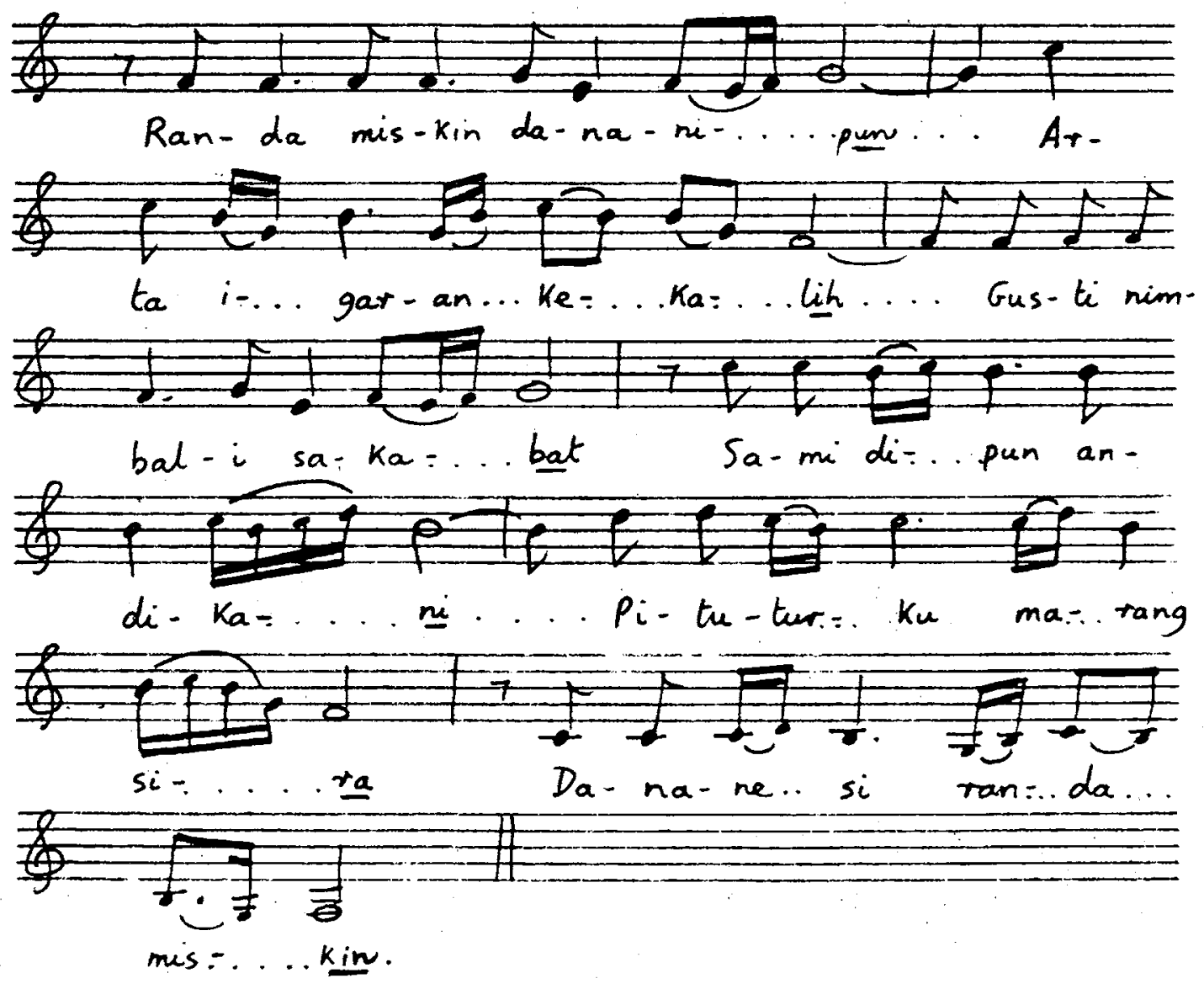




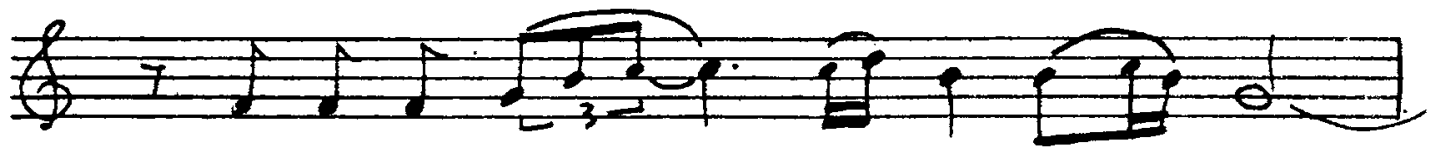
Tu-mun-tur an-...... tar- ing $a-\ldots$. tur

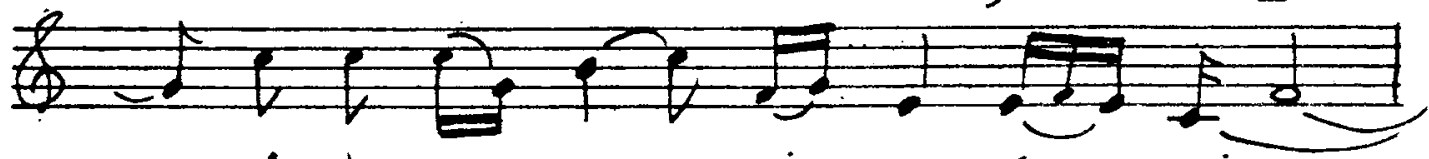
Am-ba pa... ra... sis... wa sa

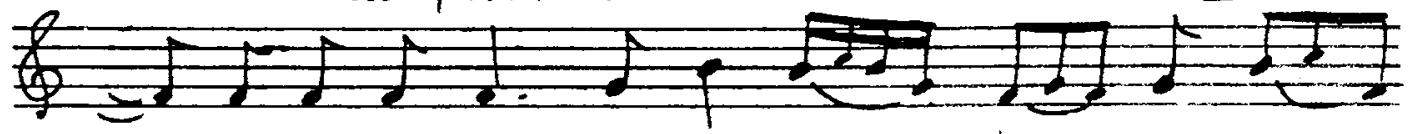

...Kang sa-mja sa-e-Ka-pra-..dja.. Sa-gung.
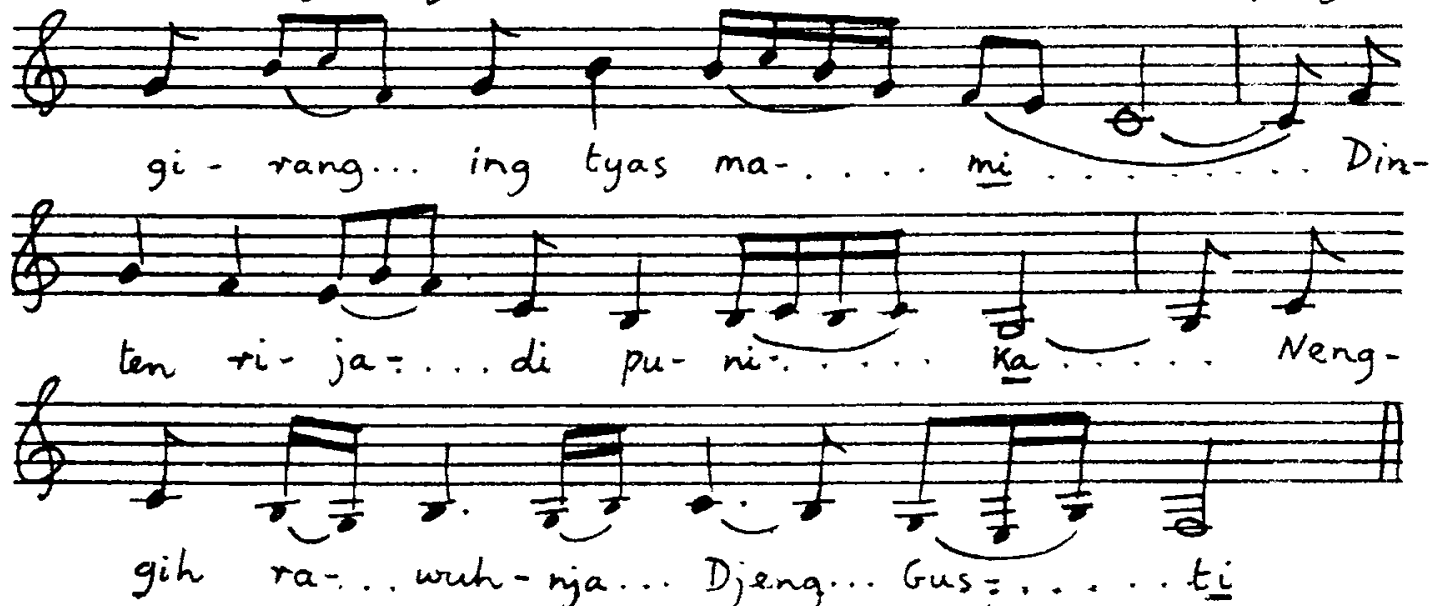


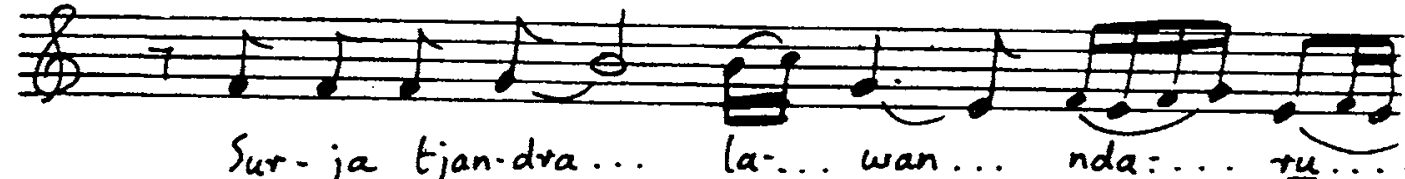
舟
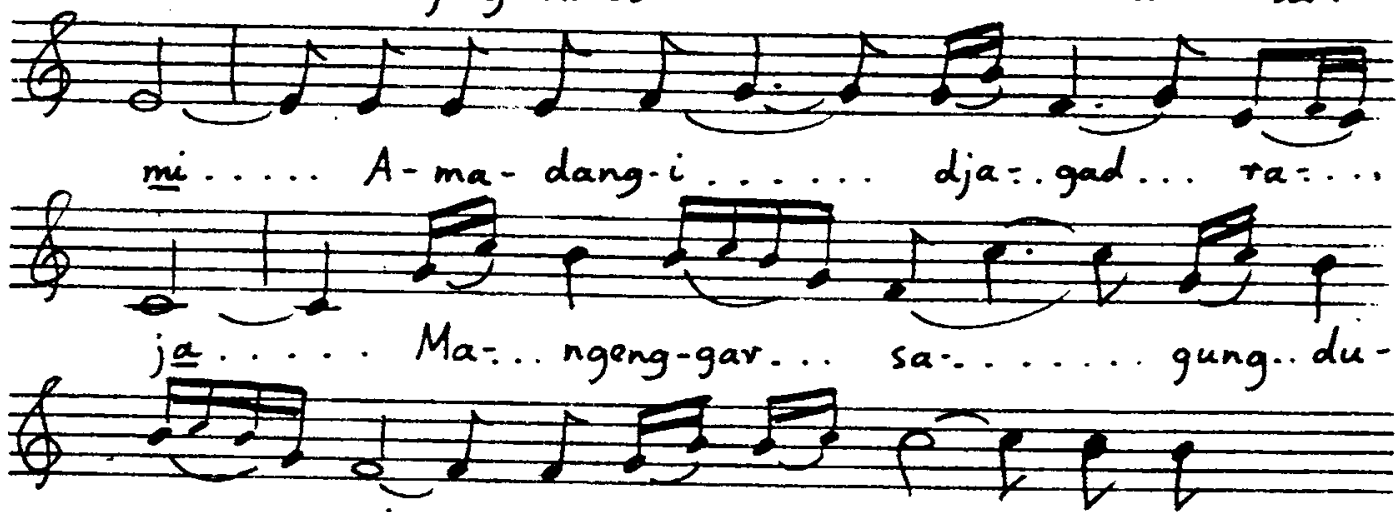
ma.... di ... Nja.ta.. wim:.. buh... weh mar-
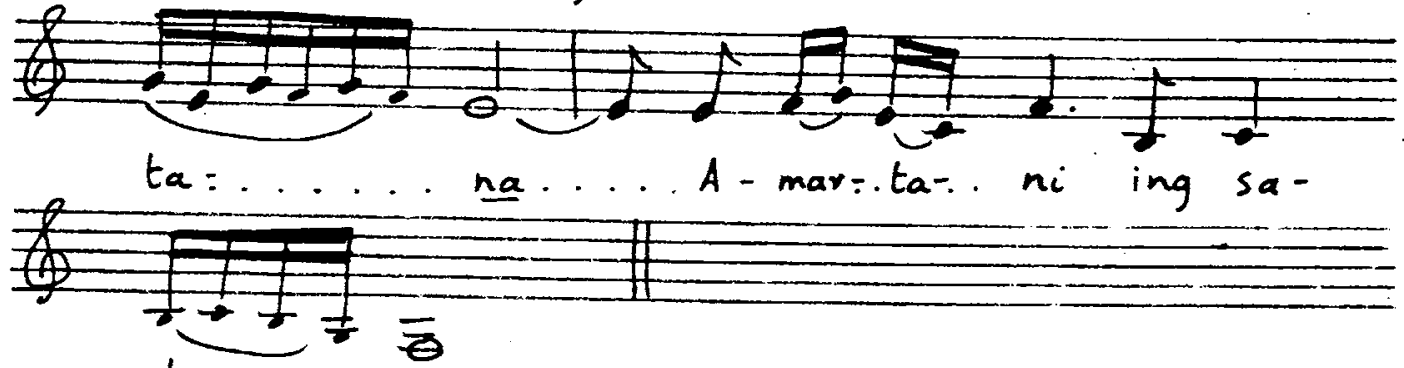
bu $=\ldots . . . m_{i}$. 


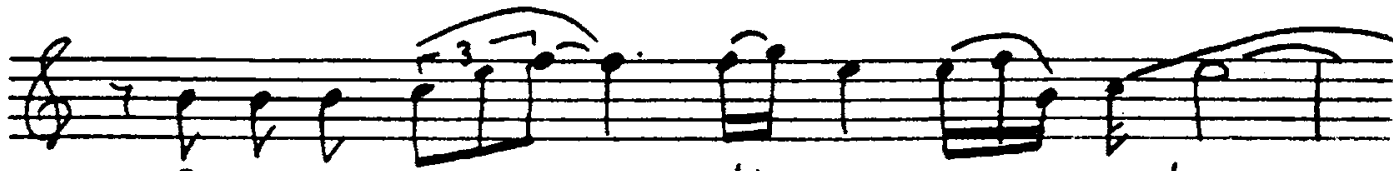

Po-ma si. ta.... di = pun e-.. mut...

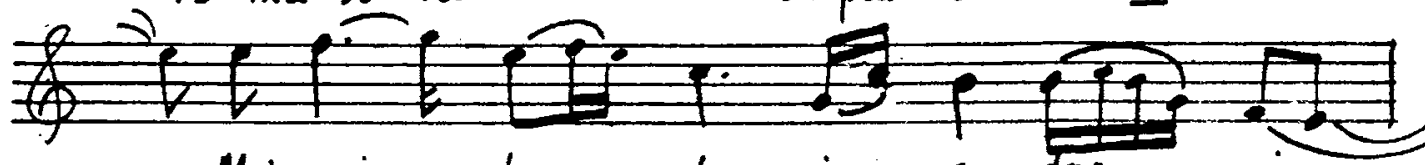

.. Mring pi ... tu.... tur ing.. su-dar:... mi...

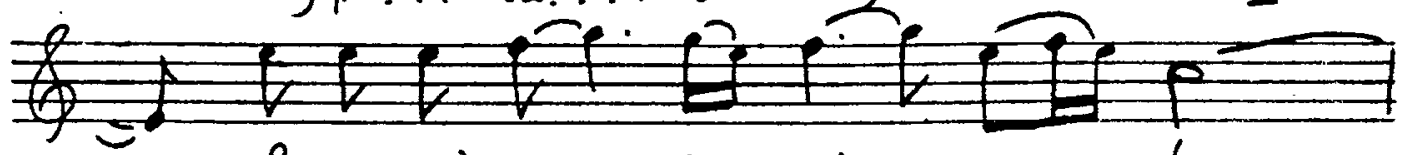

... Ba-pa pi-nang=.. Ka =..ning... wre.... lang
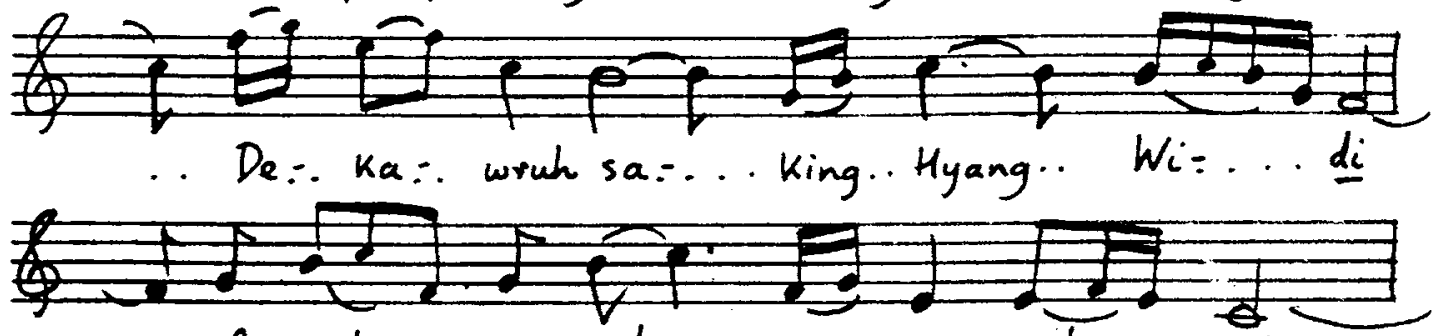

$\ldots$ Re-reh... ru-ruh... pa . nga-rah... nja.

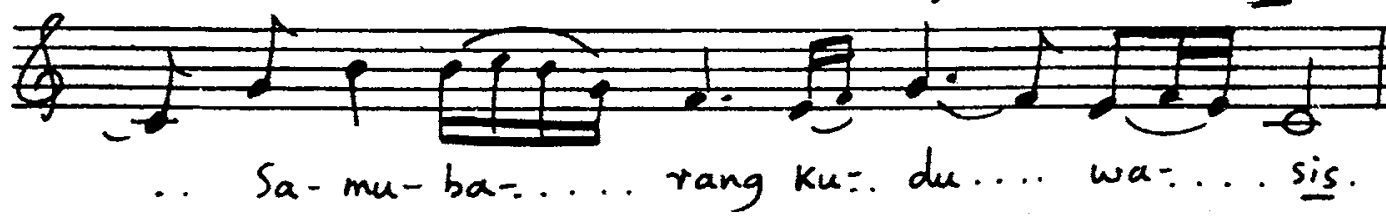




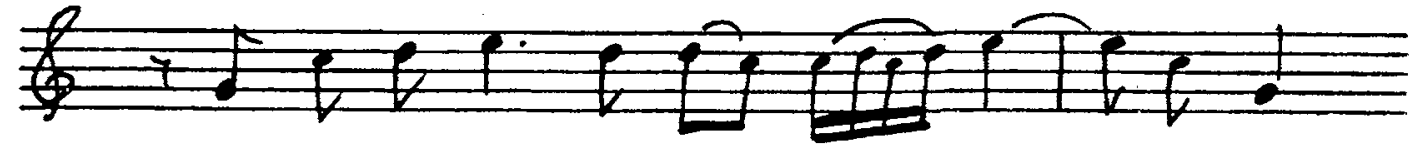

$\mathrm{Na-ik}$ gu-mung tu-run.. gu-...nung... Me-rje-

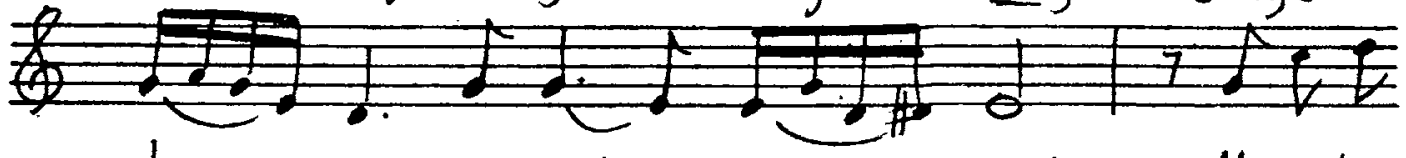

be-...rang pa-rit ...pa-.....rit Ma-suk pa.

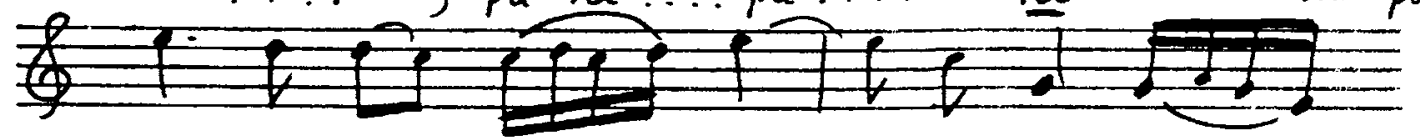

dang $k l u-a r . . . p a-\ldots$ dang... Se-ha-ri.

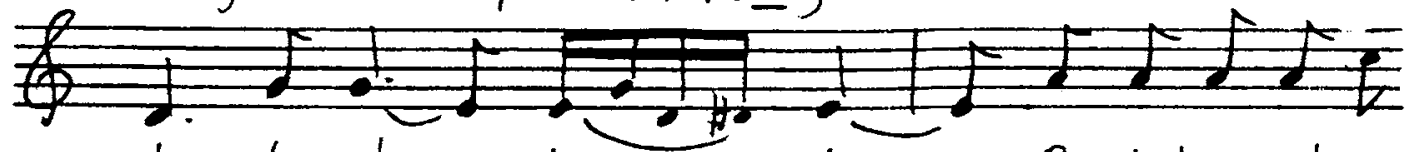
be- lum ber-..hen-.............Pa-jah-nja bu-Kan

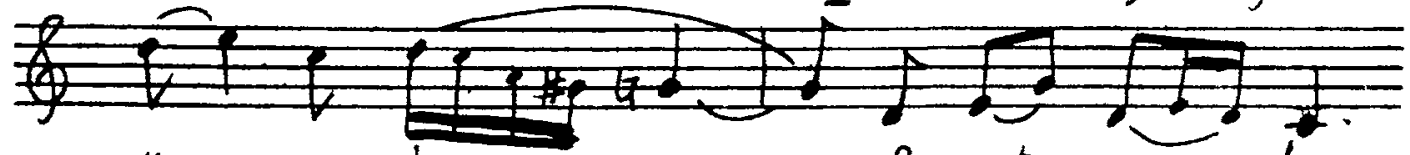

Ke... pa- lang......... Pe-rut... se $\ldots$... la-

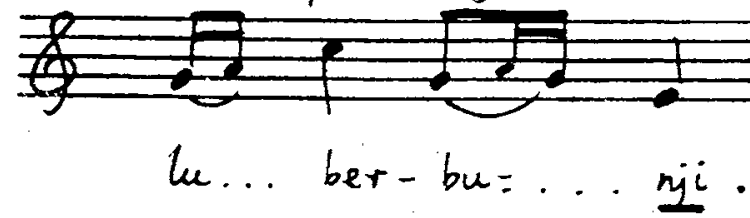



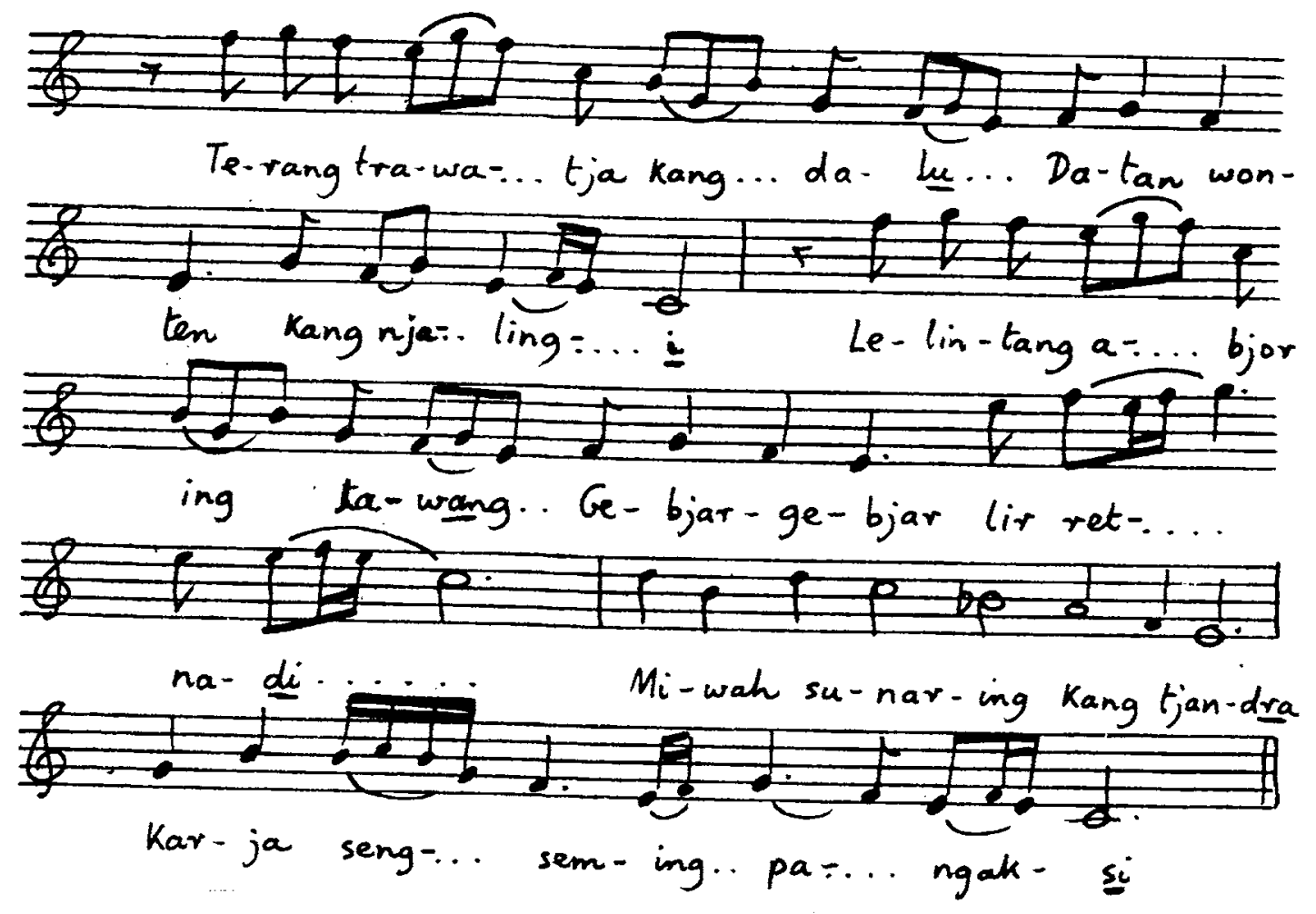


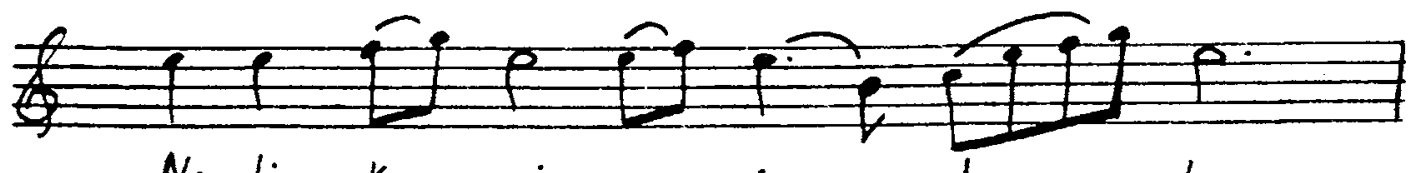
$N_{a}-l_{i}-k_{a}=$ ni-ra... ing... da $\ldots$.... k

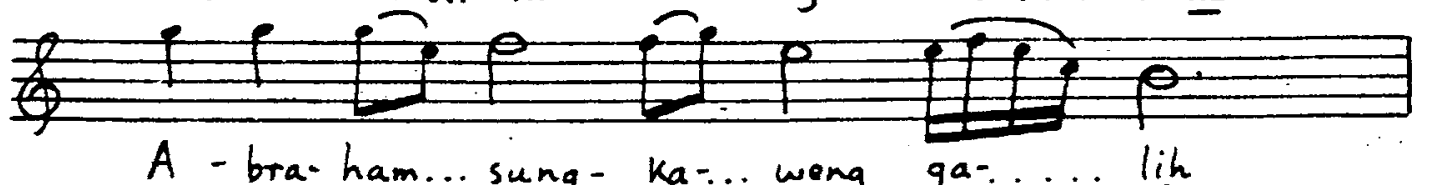

$$
\text { A - bra-ham... sung-ka-.. weng ga-... lih }
$$

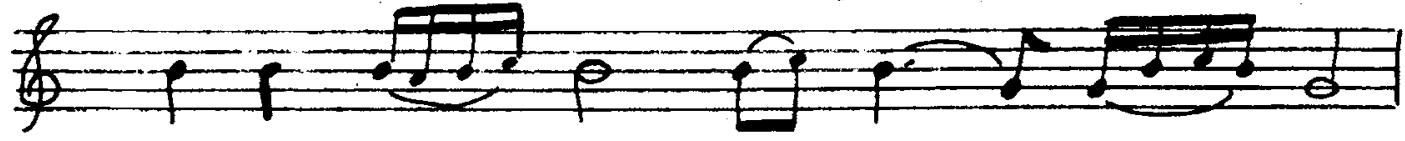

Ngra-os- $a-$. ken ge- sang-.. i-... ta

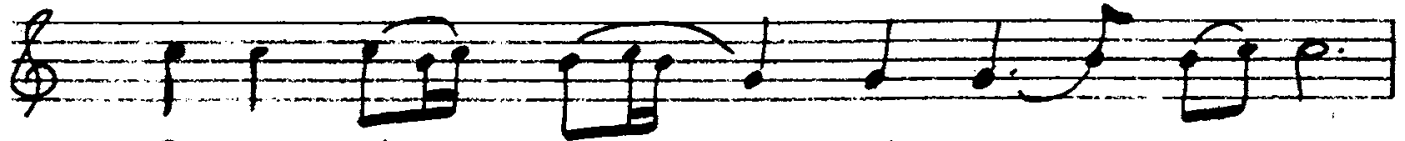

De.ne da-... tan.... du-we... si.. wi

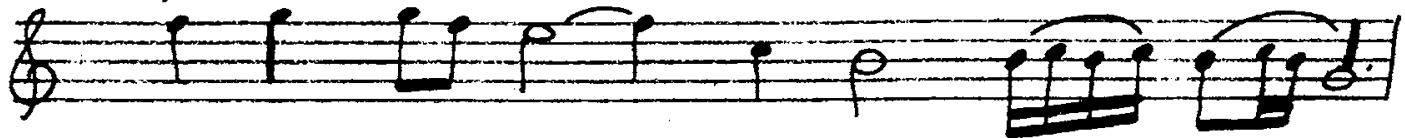

Sa. pa ba:.ja ben-djing-i ... ra....

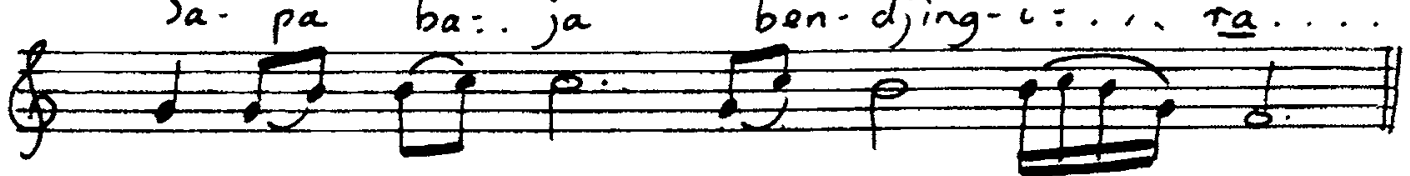

Meng-ku =.. wa :. tis an-..gu-.. man... ti. 


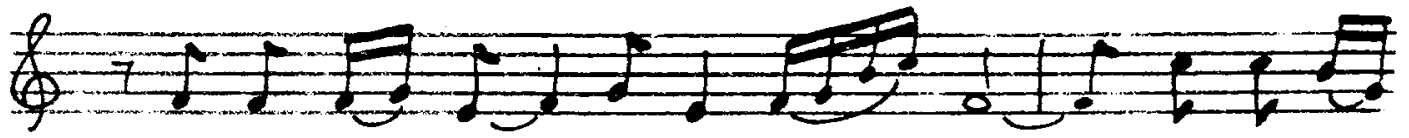
$k_{a}-b_{u}-K_{a}$. bi $=$ na-bat $K_{i}-\ldots$ dung. . Pa-nem-bra:.

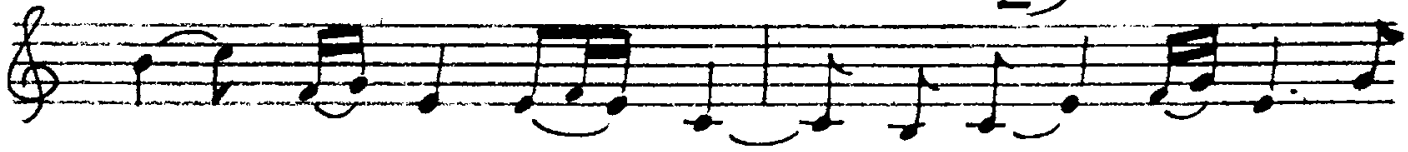
ma $=$ ning.. pramu... rid

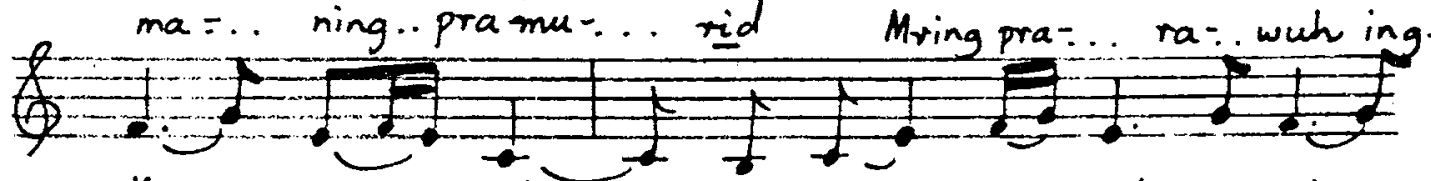
Kang.. sa-... mja... Har-sa... sgr. dju an-dje..
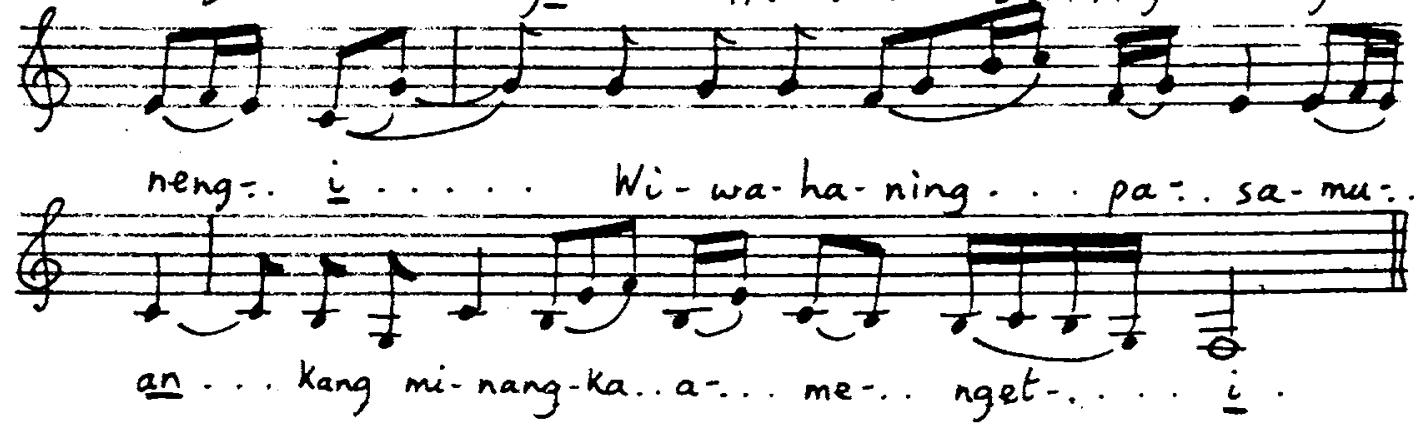


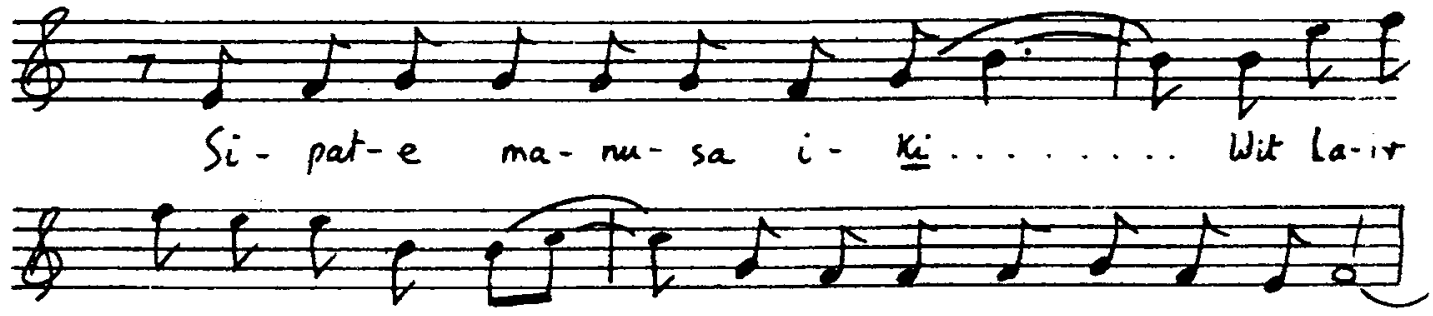

King gu-wa gat-ba..... Pa-nas pe-rih Kang Ka-dar-be

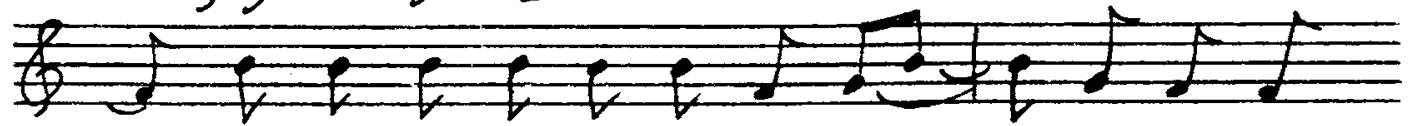

...A- wit dja-gad sa-i-si-nja... Wus ke-neng

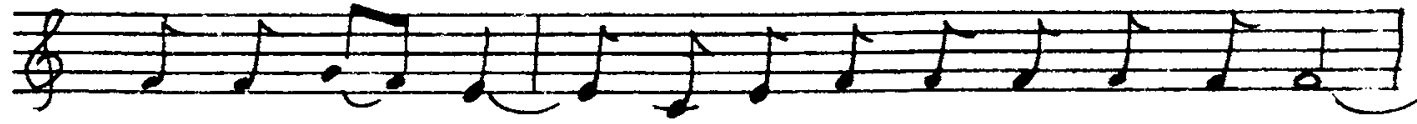

$i$ - pat-i-.. pat... Tu-ma-ma mring pa-ra ma-Kleck

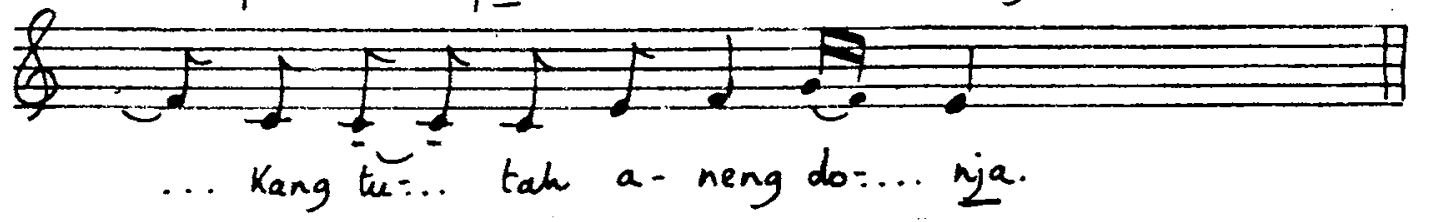




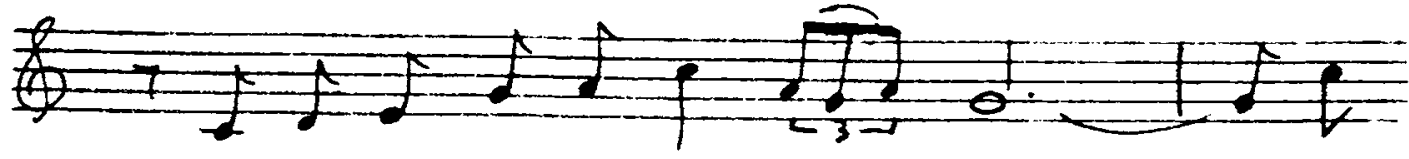

Duk ing ku-na a-na djan ... mi ....... Tje-

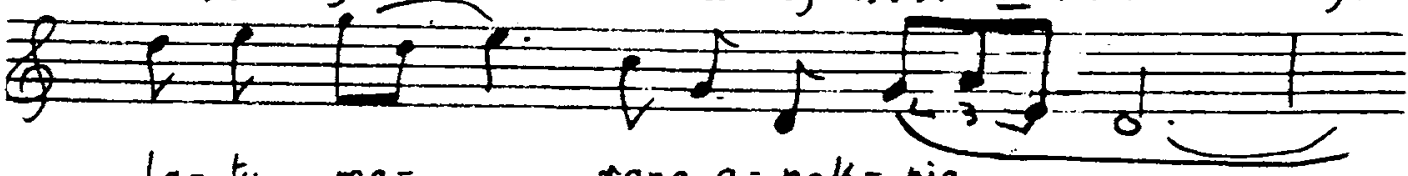

la-te ma-...... tang a-nak- nja.

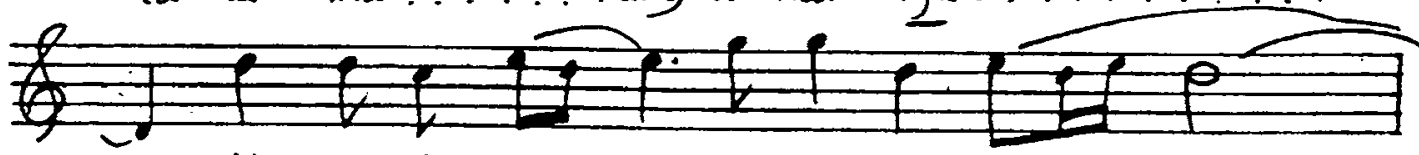
Ma-ra ti- ngal... a-na ang-ger.

... Pa-ri ing-Kang..... Ku-ning sa- mja..

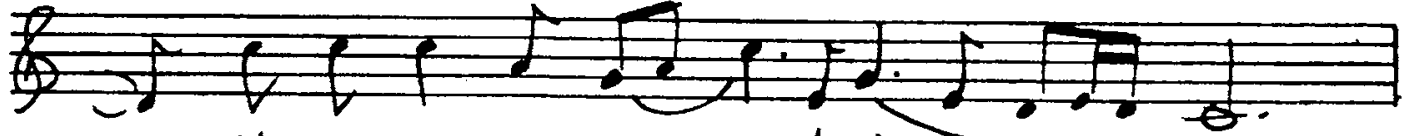

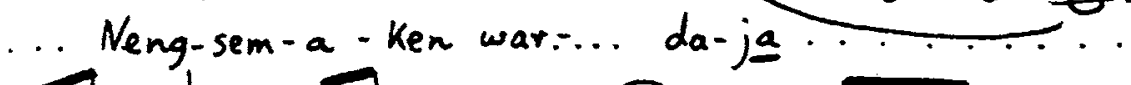

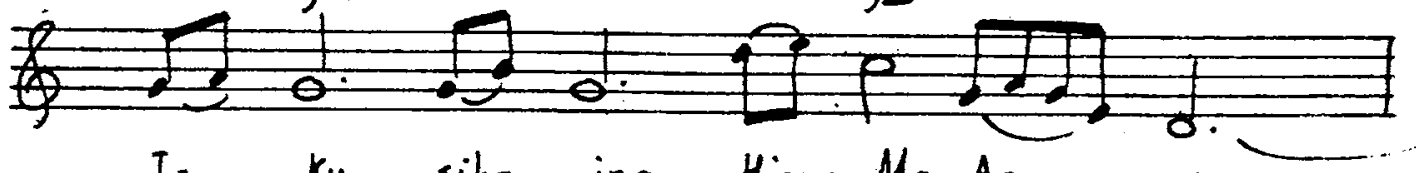

I.... Ku sih.... ing Hjang.. Ma $A . .$. gung....

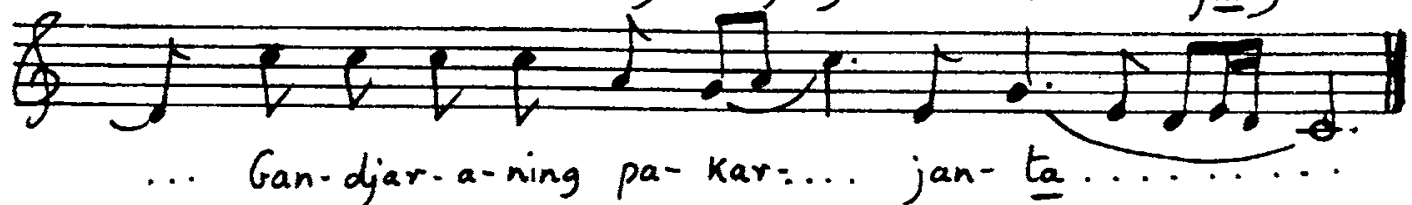



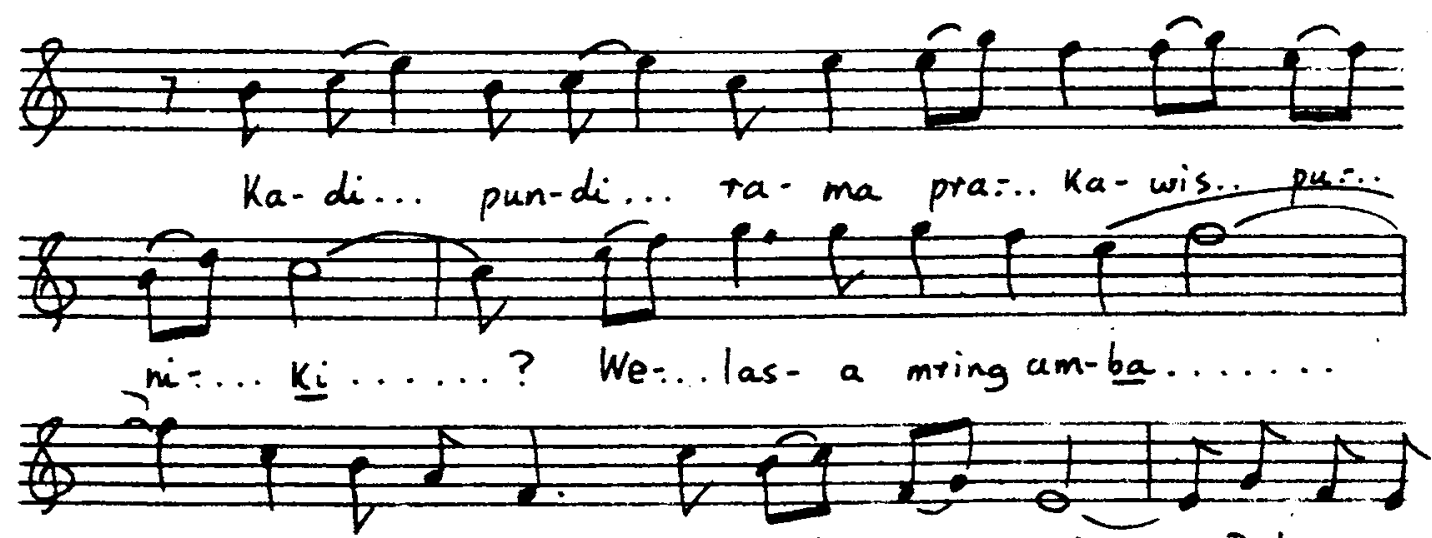

... Pa- ting-a-bar- Kah mring. má $\therefore$ mi ... Duh ra-ma

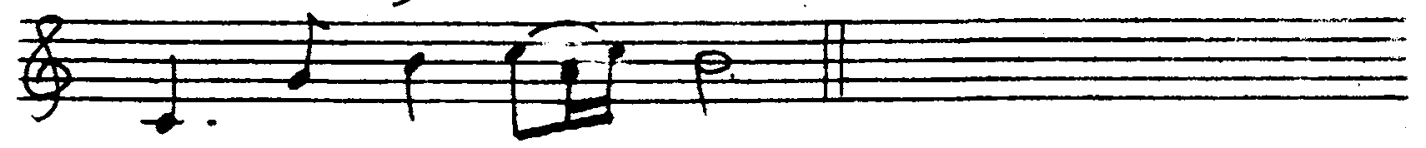

tyang se- puh ku-.... la 

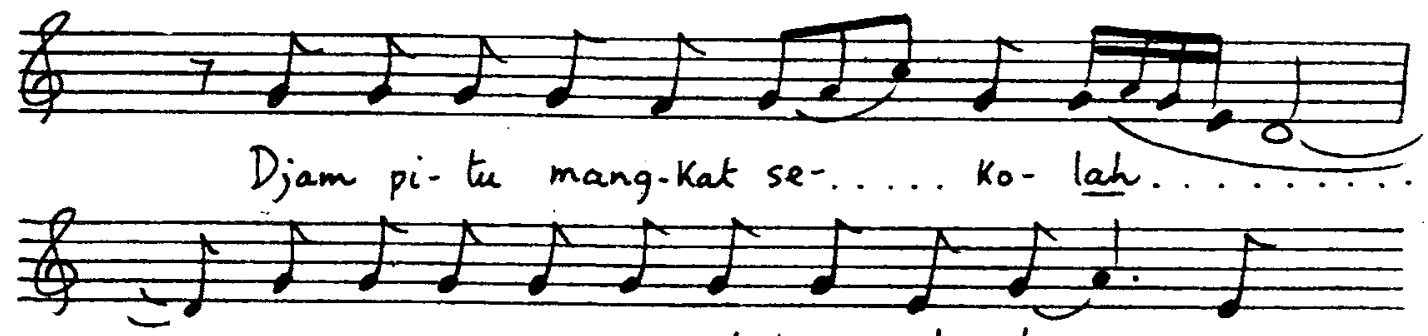

... Ka-ja nge-ne wa-djib-e da-di... mu-
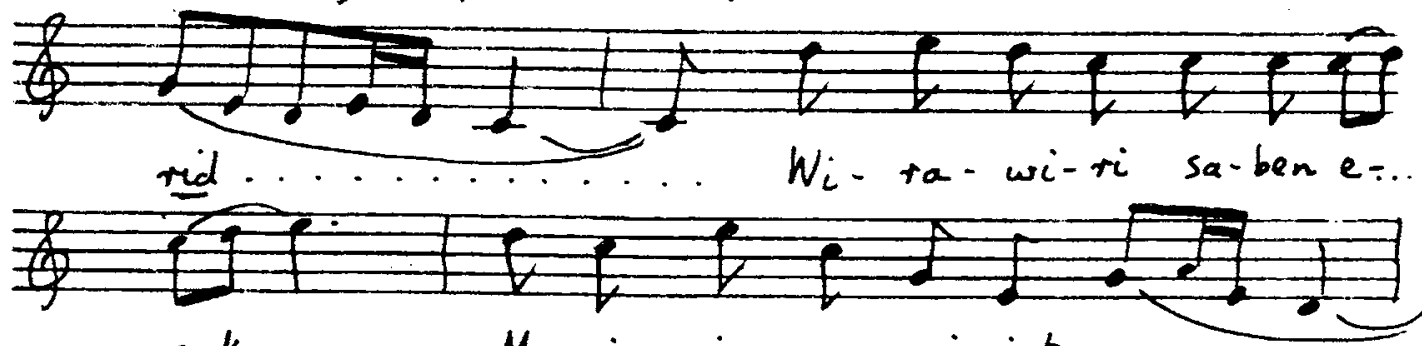
suk ... Me-njang ing pa-wi-jat- an......

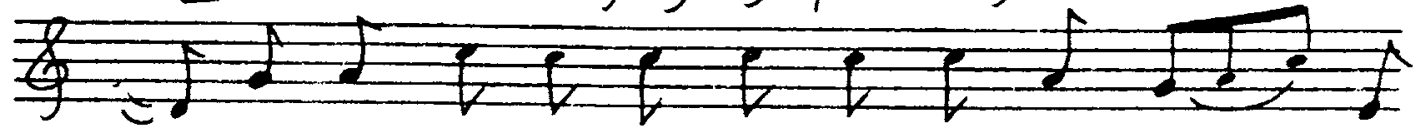

.. No-ra $u$-wis-u-wis la-mun du-rung... Kur-

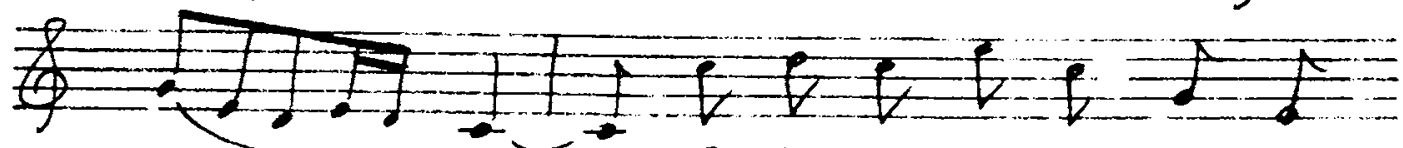
sus........ Pra-tan-da-ning ka-pin-ter-

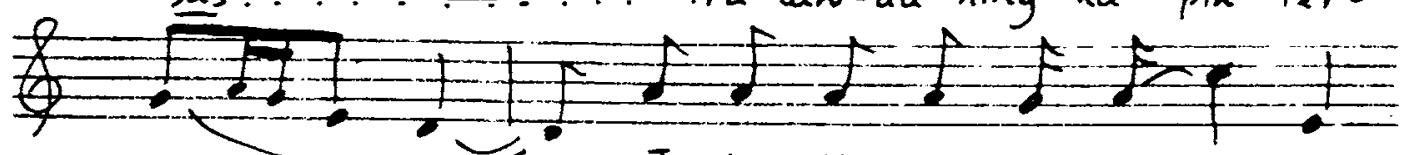
an........ I-ke Kang si-ra $u-\ldots$ pa-

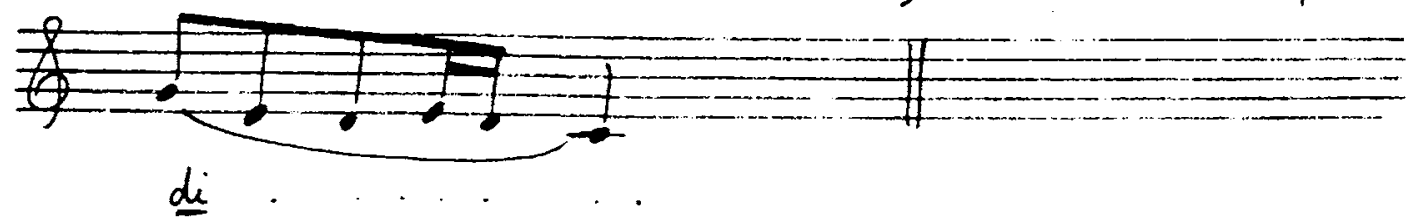




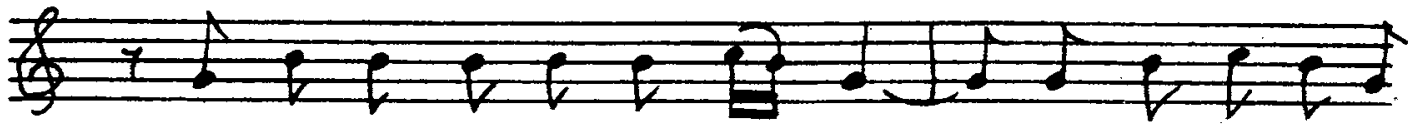

Lah pa-da mang-sa pa-dar. a..... Eh Ab-sa-lom de-

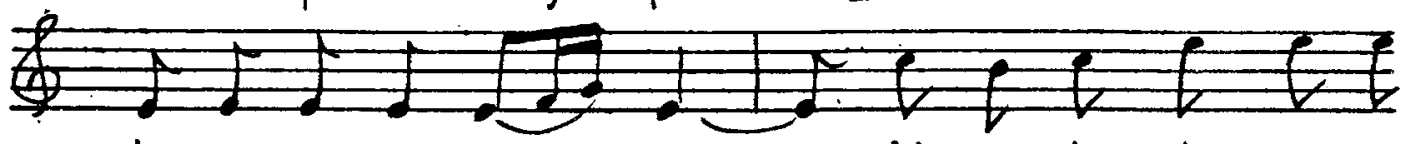
leng-en ga-man ma-... mi.... Ma- ra tim-bang-a-na

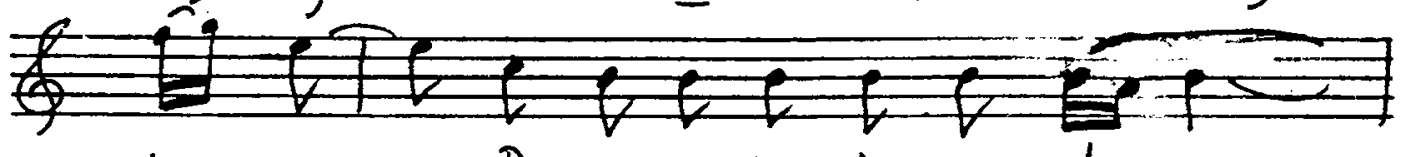
ing... - sun.... De- ne a. Kar-ja gen-dra.....

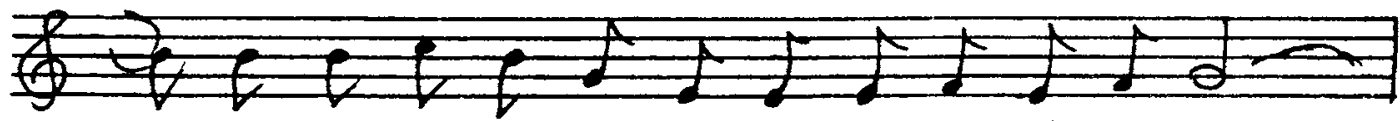
D- ra dja-mak am-bek-e si mu-da pung-gung..

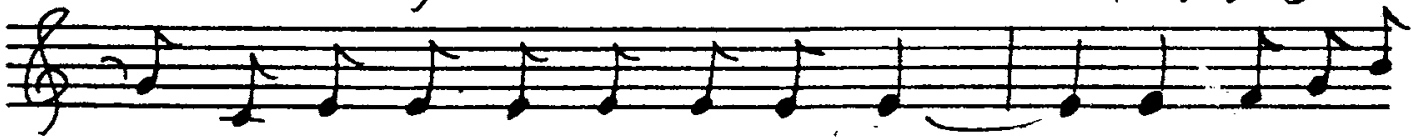

... Lah sa-i. ki ra-sak. $e-$ na..... Tum-bak pa.mung

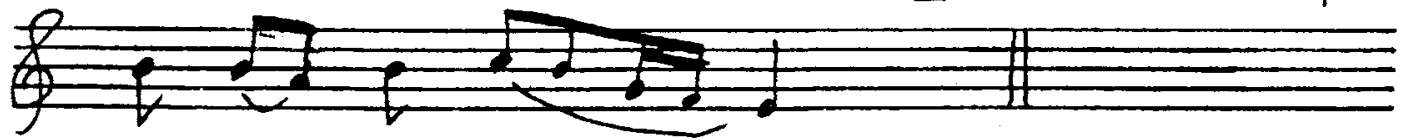

Kas- ing... pa- $\underline{\underline{k}} \ldots \ldots$. 


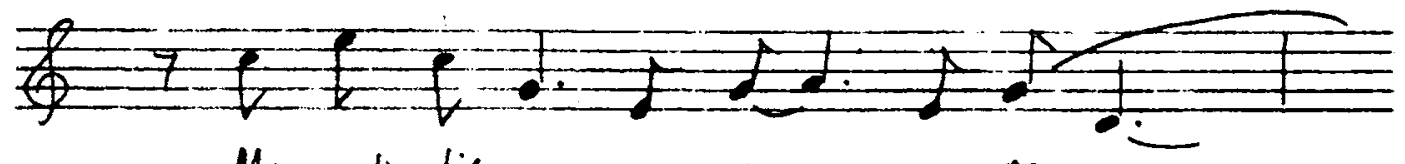
Me-nak-djing-ga u- ra-.. u- ta

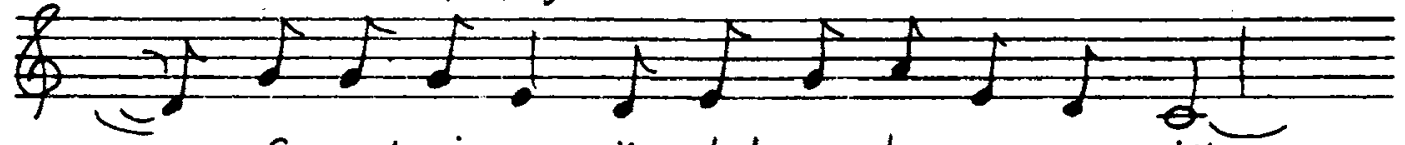
.. Ga-gak i-reng kun-tul u-les-e pu-tih.

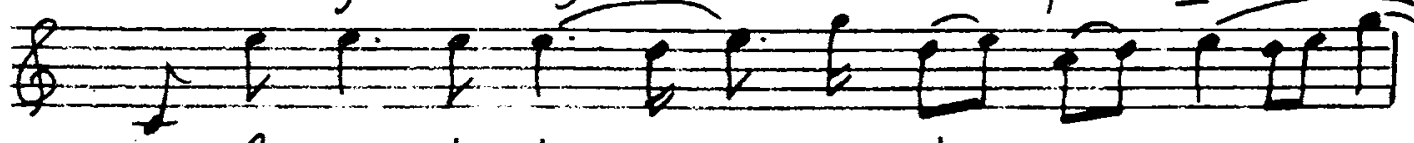
$\ldots$ Ba-ngo tu lak..... en - das ...i... pun...... यद djo mang-sa $i$-teng-e se- ta- un..... Ba-le -ngur

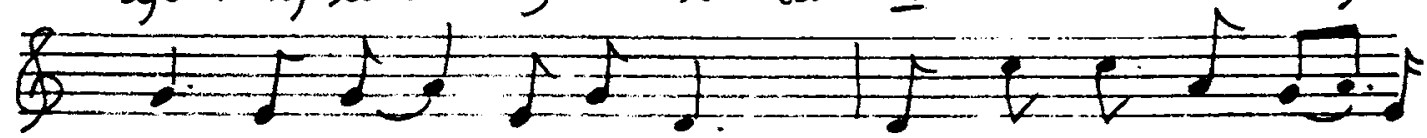
$p u-\operatorname{tra}-n e .$. ba-njak ........ En-dog be-bek. neLat tes:.. me-... ri . 


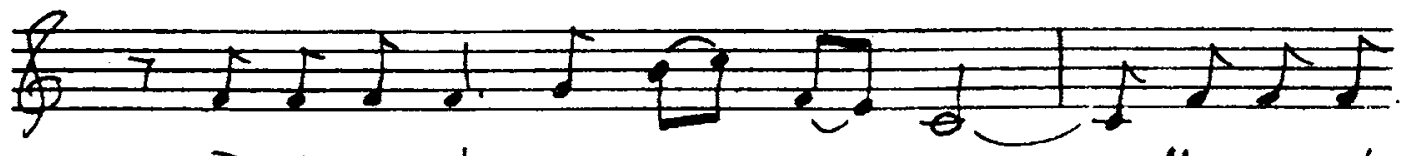
De-du-ga la- wan pra-.. jo-.. ga......Mjung wa-ta-

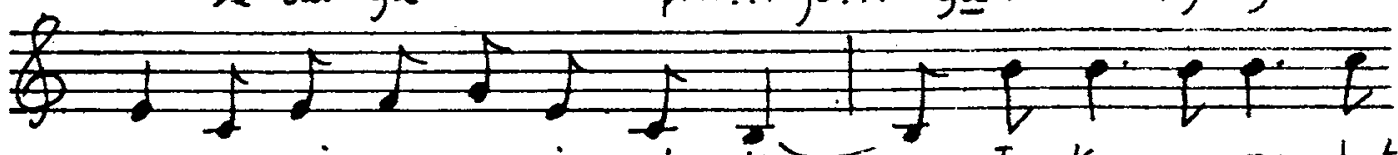
ra re-ri-nga a-jura la- $\underline{i} \ldots$.... I- Ku pa-ra-bot

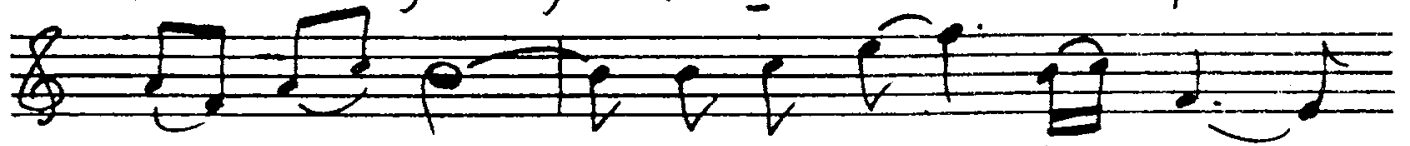
sa... tu... hu.... Tan ke-na... ti-.. ning-..

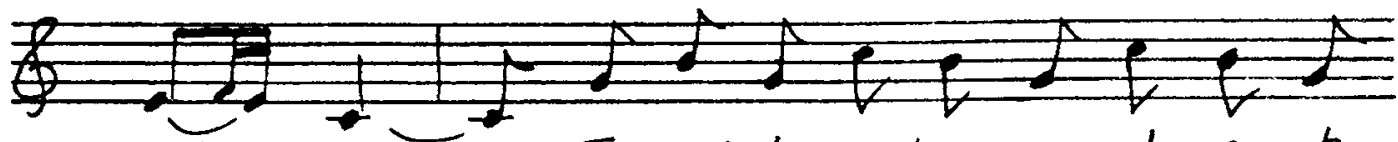
gal... a ...... Ta-ngi lung-guh a- nga-deg sar-ta

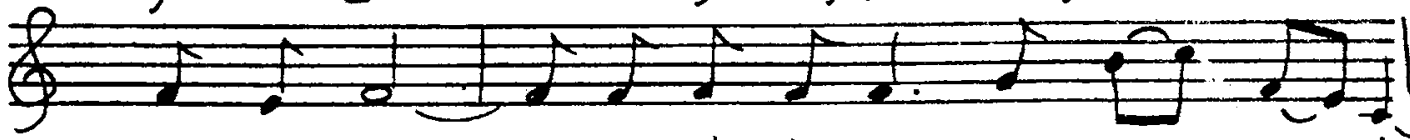
lu-ma-ku.... Tje-la-tu me-neng-a-... nen-. dra

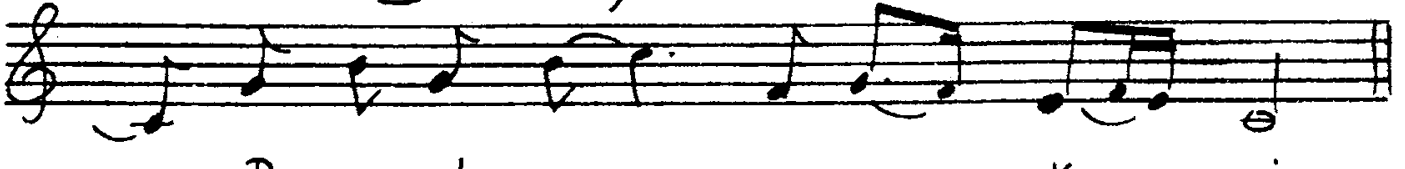

$D_{u}-g a-d u-g a \ldots$ no- $+a \ldots K_{a}-. . \quad r i$ 


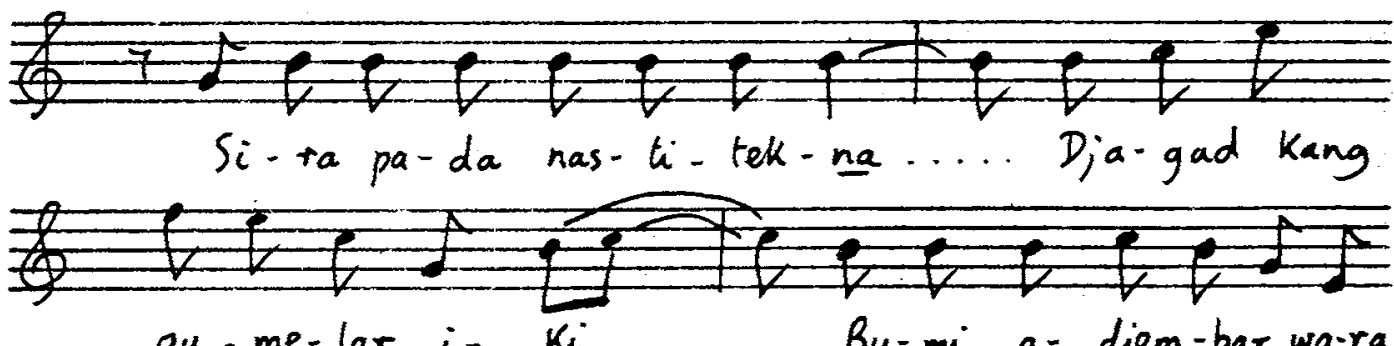
gu.me-lar $i-K_{i} \ldots . .$. Bu-mi a-djem-bar wa-ra-
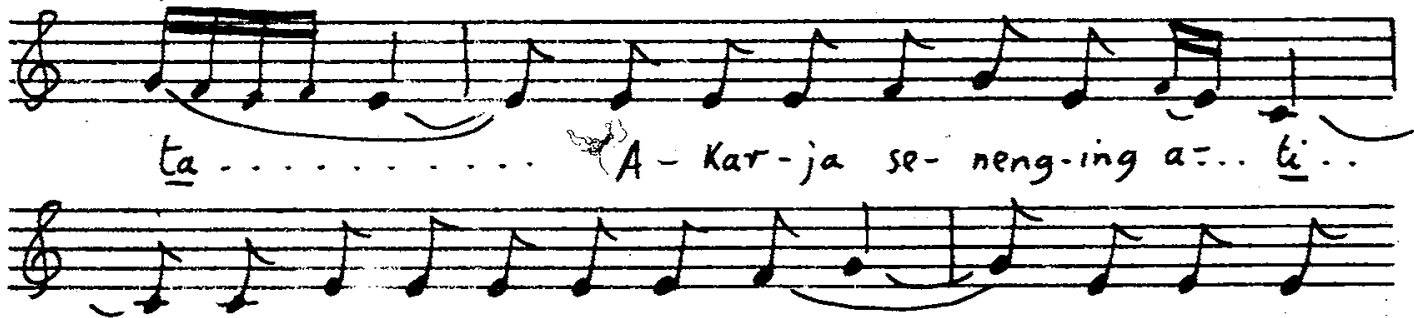

... Ti- nu-kul-an Sar-wa-sti....... Ngre-sep-a-

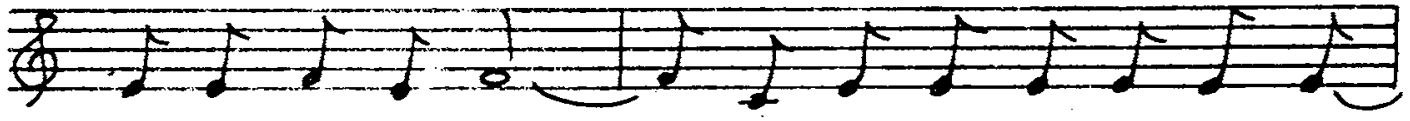

Ken ing pan-du- Le ..... Sa-man-ten Ka-wa-sa- ja

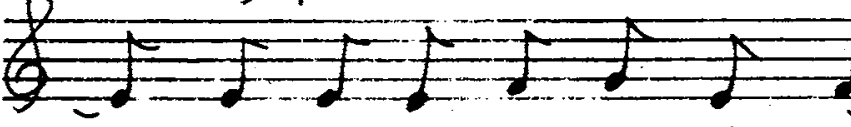
... Kang Mur-beng la-ngit lan bu:.. mi..... Ing-Kang wa.

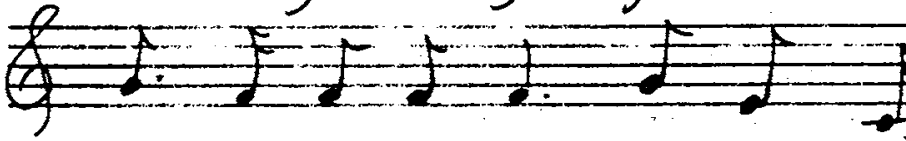
djib pi-me-dji ing pa-ra djan... mi 

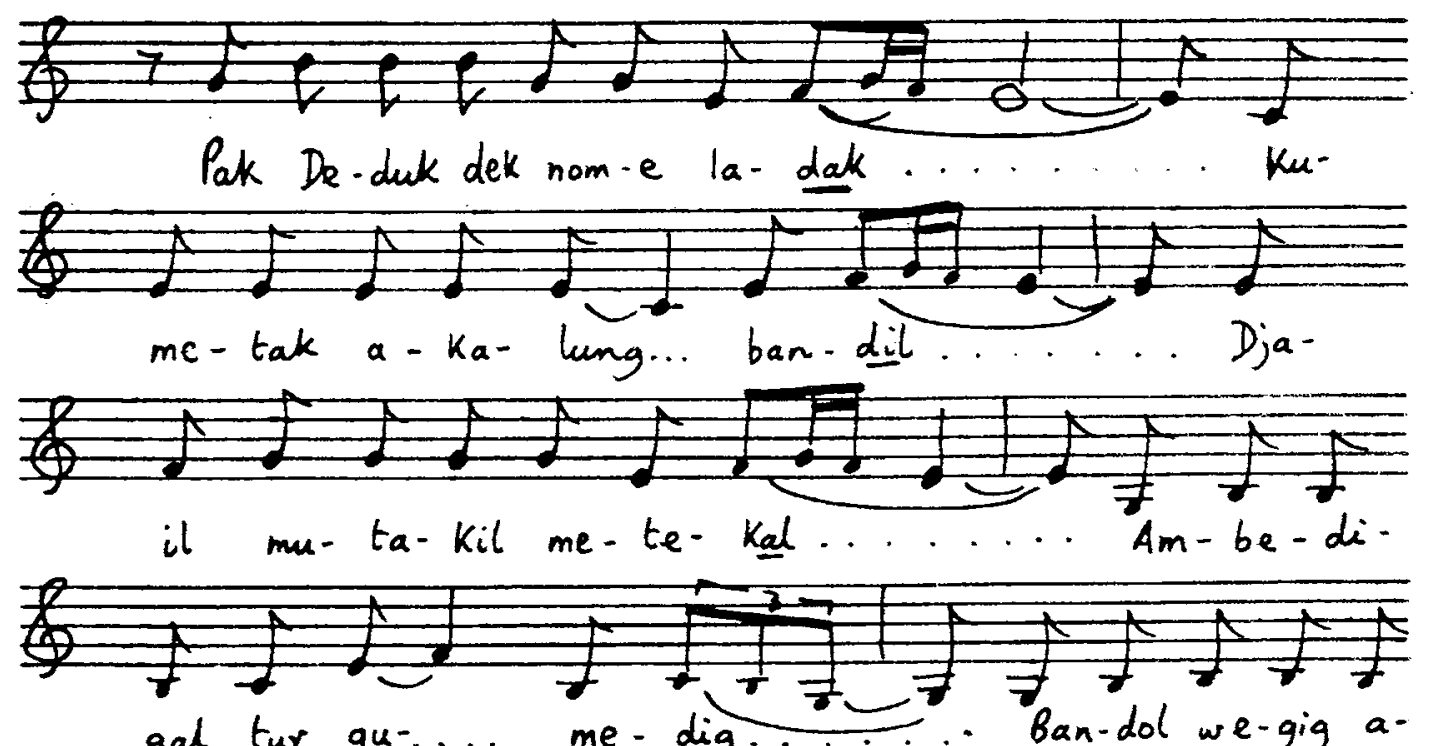
gal tur gu-... me - dig..... Ban-dol we-gig a-

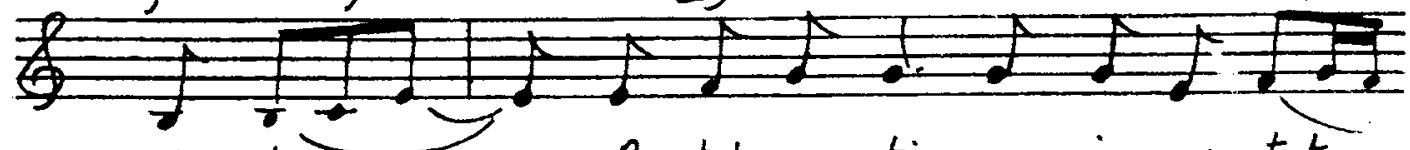

dju-lig...... Po-tet pe-ting-an ing pe-tut.

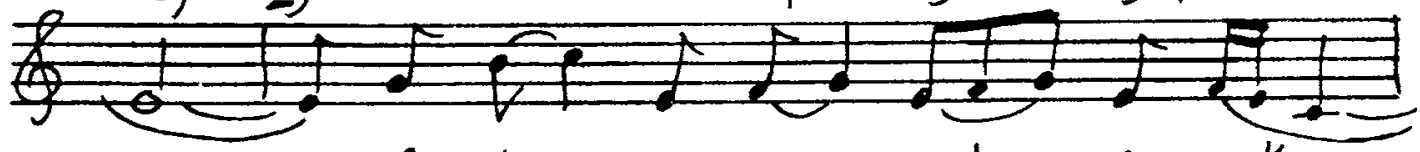

Po- to... pa-ngru-..sak... sa- nak...

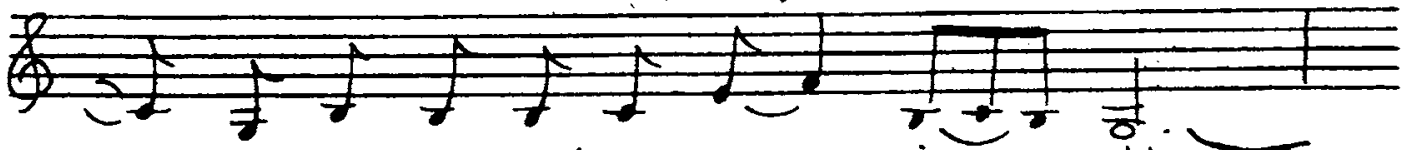

Si. nung ka-mul-jan - ing... i-... blis P ... Nging we-kas-... an ... Pak la-dak mri-pat.. 
423

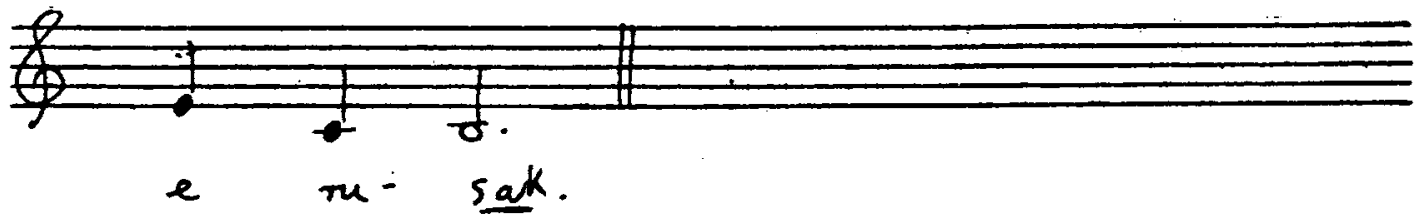




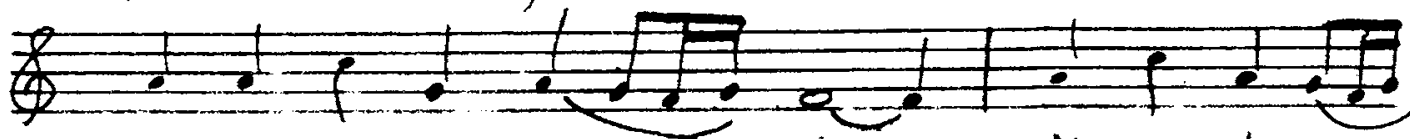

E- nuh a-ma-reng-... Nem a- tus war.

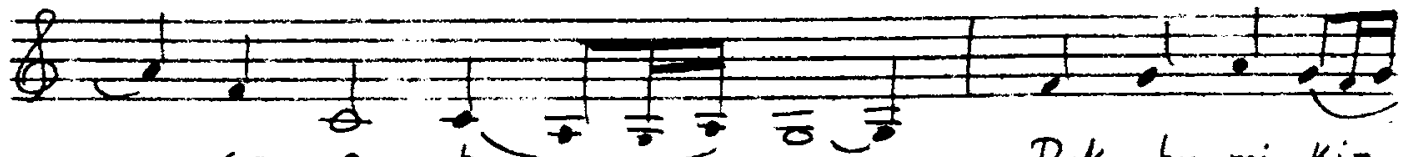
... sa $e$ - tang-... hia.. Duk bu-mi $k_{i}-$.

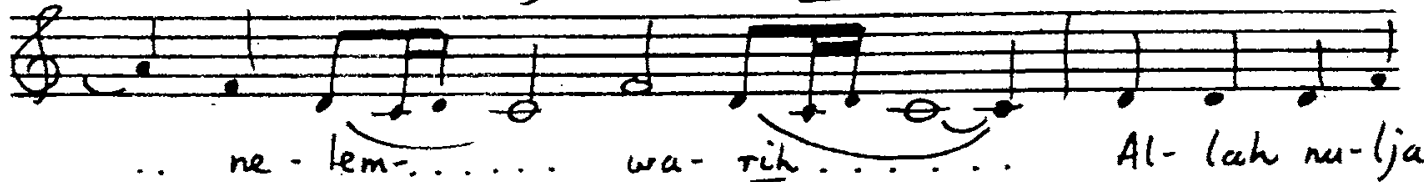

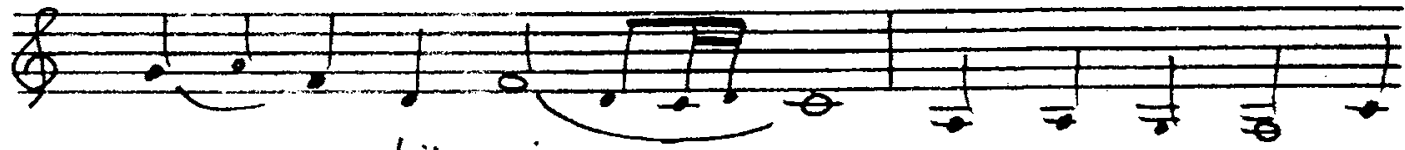
ngan $\ldots$ tjing-i....... $k_{0}-r_{i}$ ning ba- $i$

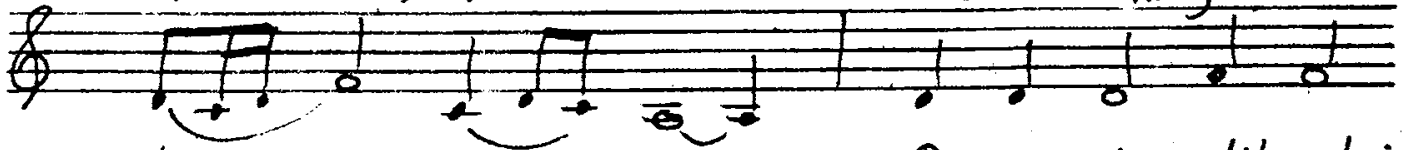
ta .... ni -... pun $D_{a}$-sar ing djla-dri

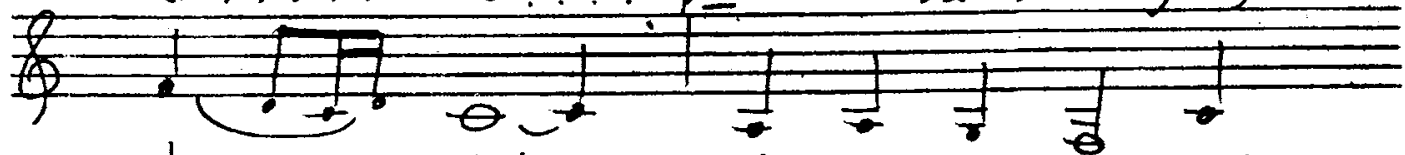
beng... Kah... $A$ - me-nga $\boldsymbol{K}_{0}-r^{-}$

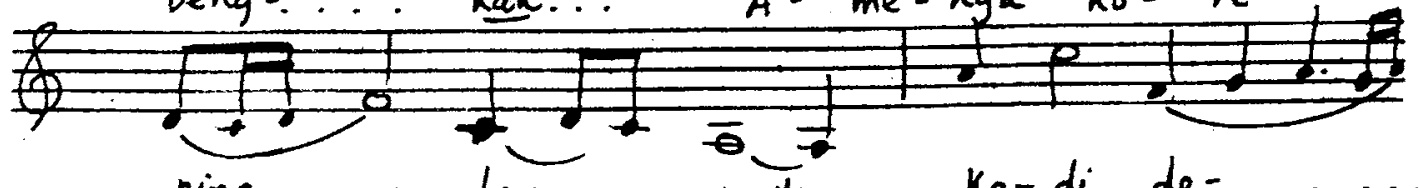
ning..... la l.... ngit..

Ka- di de-. 

Wus lu-mrah.e ing dja-man sa-i. ke... Bottiah ge-

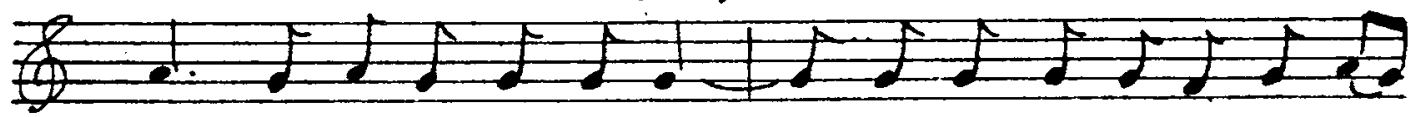
de fji-lik wa-djib sa-mja.... Ngu-di un-dak-ing Ka-wruh-.

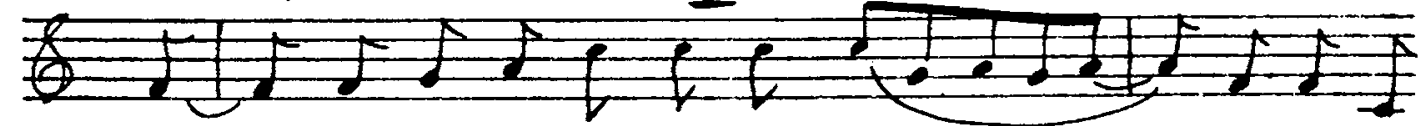
l... Sta-na Ha-ten si-na- $\underline{n} \ldots \ldots$.... Sa-gung ka-

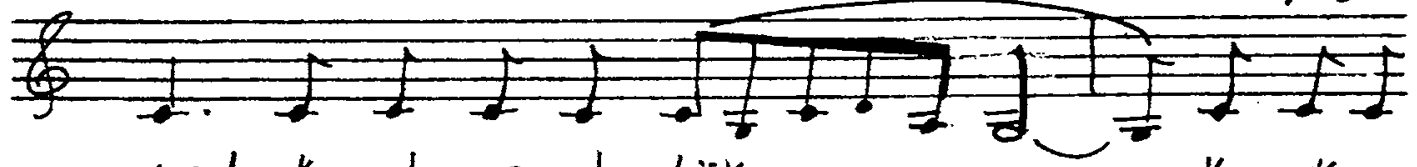
wruh kang be-ner be-t,ik ............. Kang ka-mot

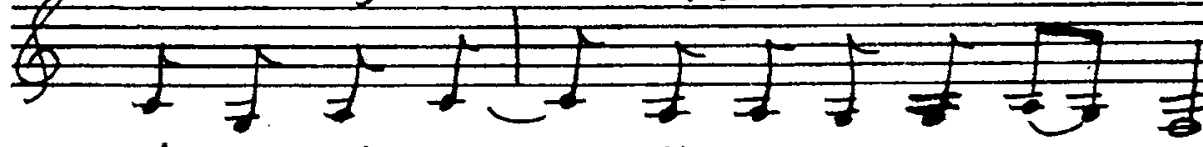
djor-ning la-jang .... Mi-wah sa-king gu... ru ..... ... Den ma-dep man-tep ing dri-ja ..... Go-ra go da a-lang-an a-dja pi-ni-kir.... Te-mak kait

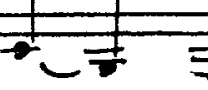
but se- dya $=.$. $\frac{1}{2}$

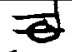
ria 

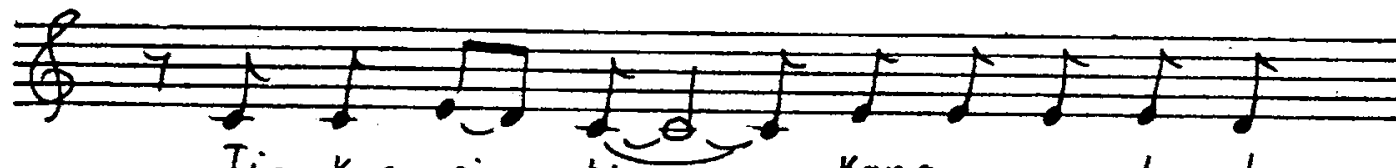

Ti- Kus $p i=$. ti....... Kang a-na-ta ba-

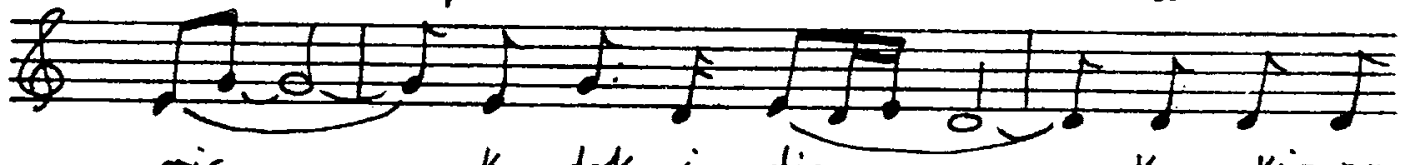
ris........ko-dok i-djo....... Kang $k_{i}$-nar-

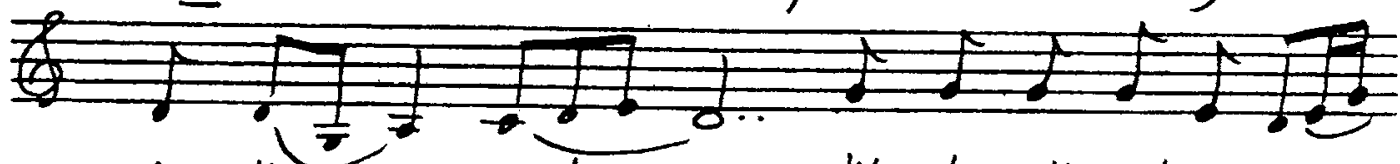
ja $k_{0} \ldots \ldots$ pral ........ Wa-lang Ke-rek sa-re.... $\operatorname{san}- \pm \ldots \ldots$ Ju-ju $K_{\alpha}-p_{i}-\tan -i-p$ unn ....

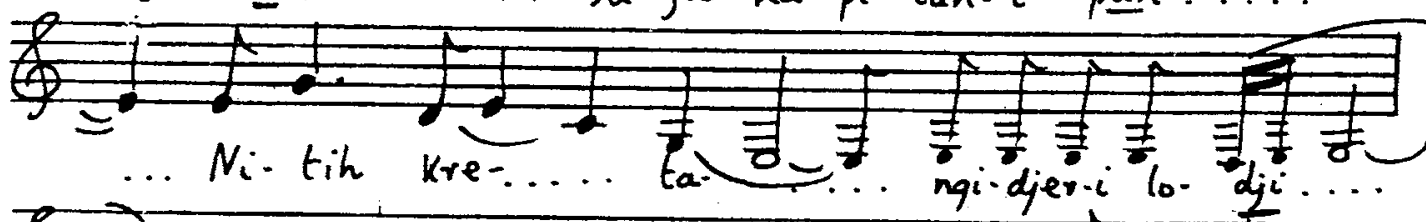

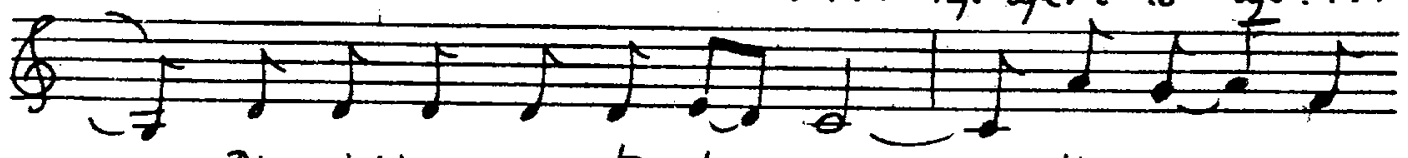
Djang-krik u-pa te-te-. gar..... ke-mang:. ga

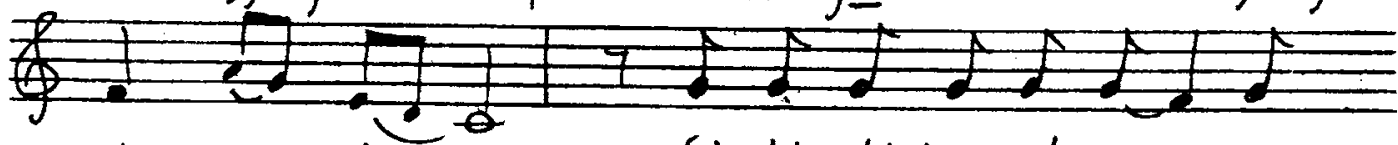

Kang nun $=. t_{\text {un }} \ldots . . . \quad$ Si tje-tjak pa-da $a=$. su-

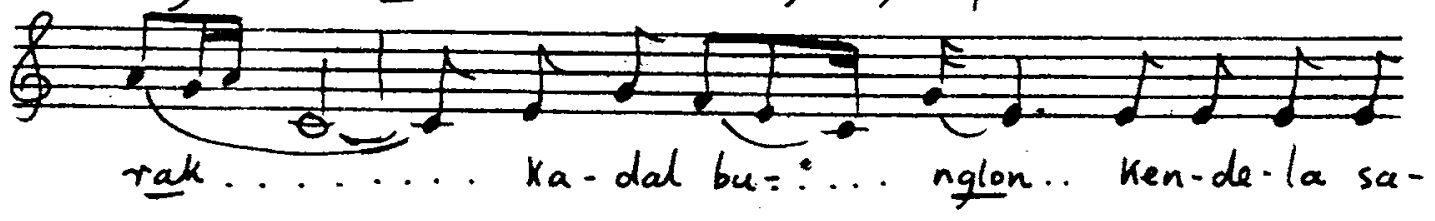




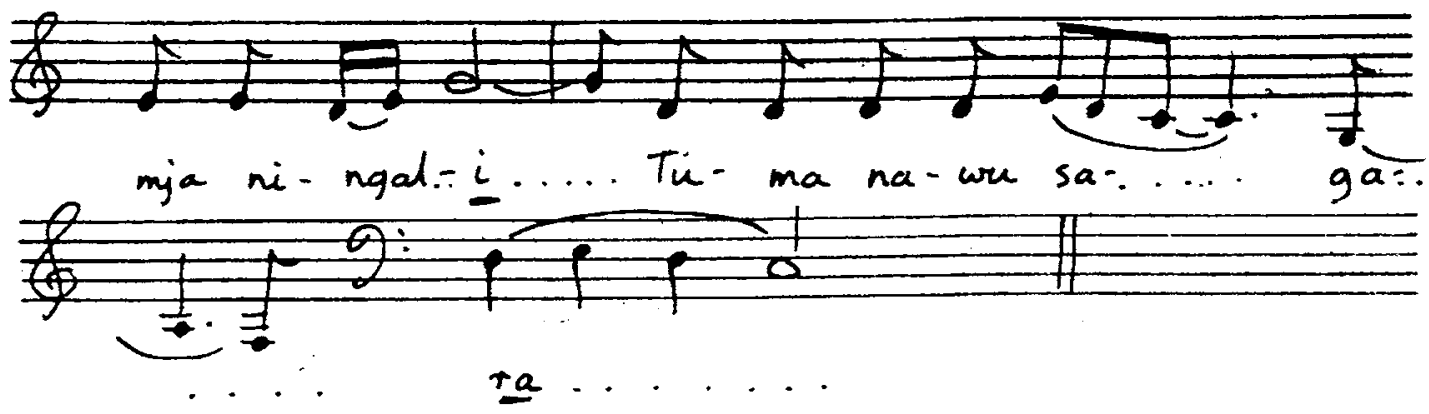



Be.dug ti-ga da-tan ar-sa qu-ling..... Pa.

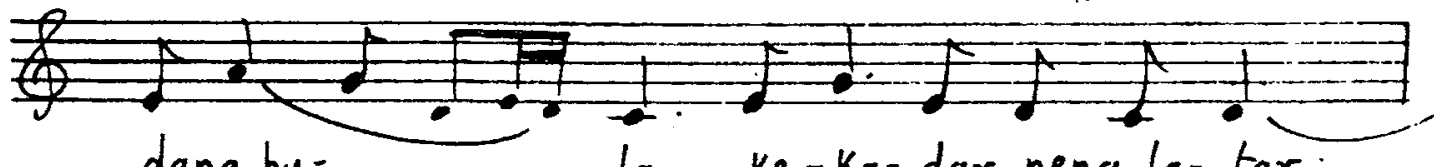
dang bu-...... lan ke-ka-dar neng la-tar:.

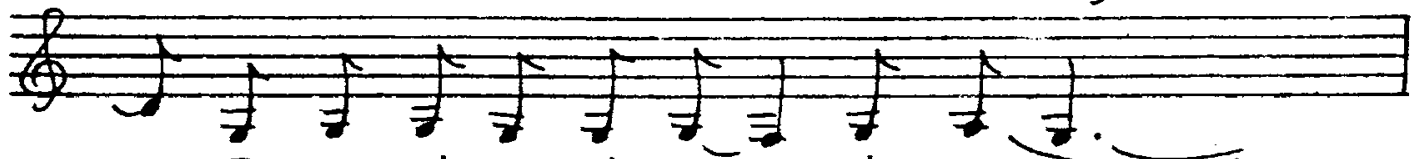
... Te-nguk-k-nguk ling-gih... de- we .....

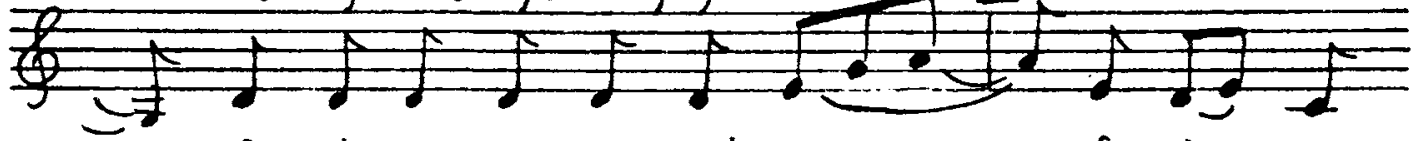
Bun tu-mu-run king du-wur....... Sa-ja... ngge.

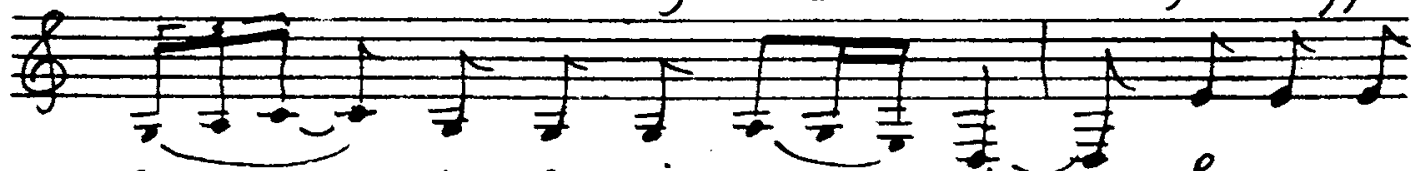
ges.... ra-sa-ning $a-\ldots \ldots$ Ru-ma-sa jen wus $10 . \ldots$ la $\ldots .$. Ba - bo .... ra $-9 a-\ldots$ ning

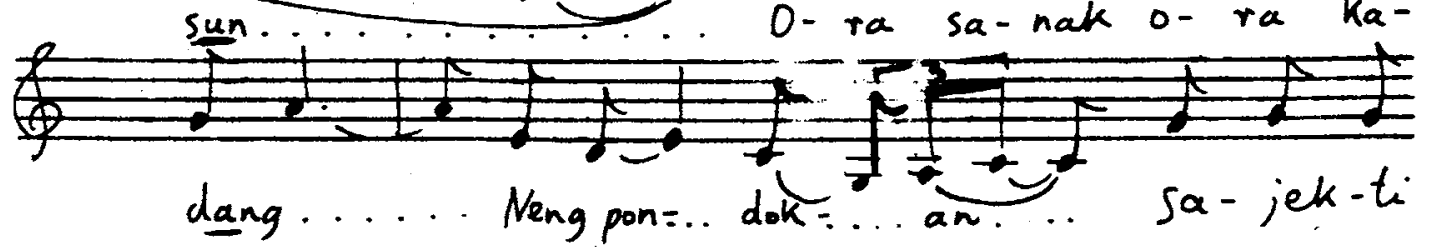




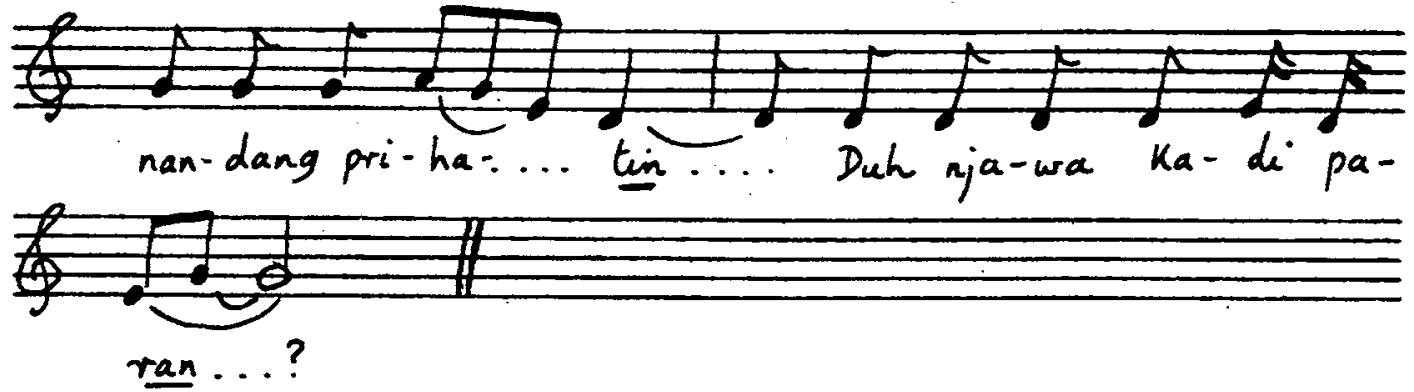



Mar-ma min.ta....... pra-tan-da kang

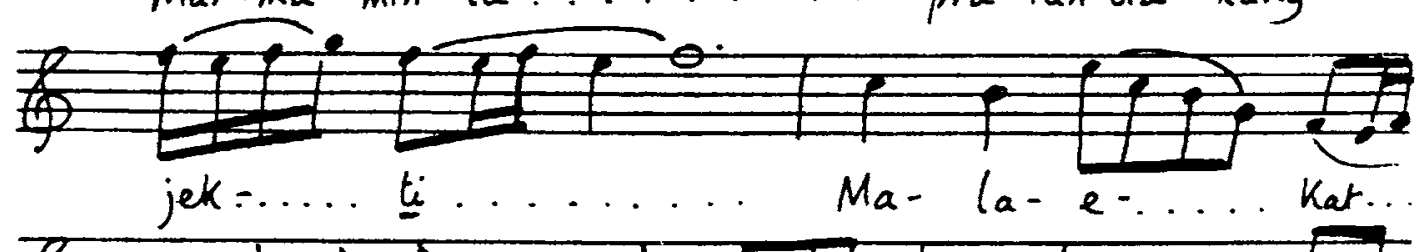

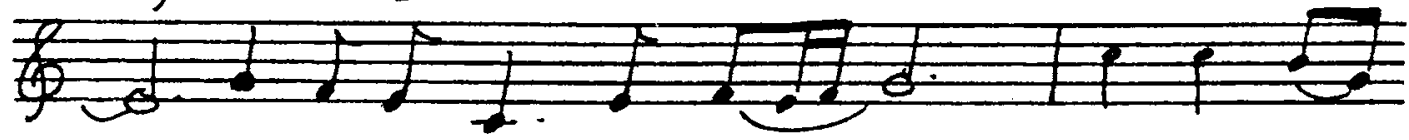

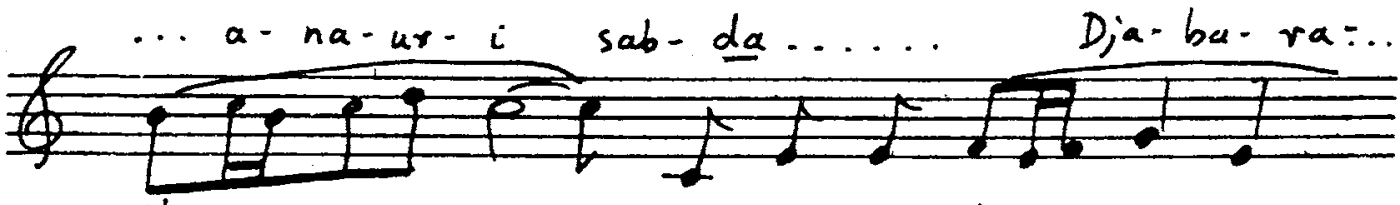
il........... ing-sun $k_{i}-j e$.
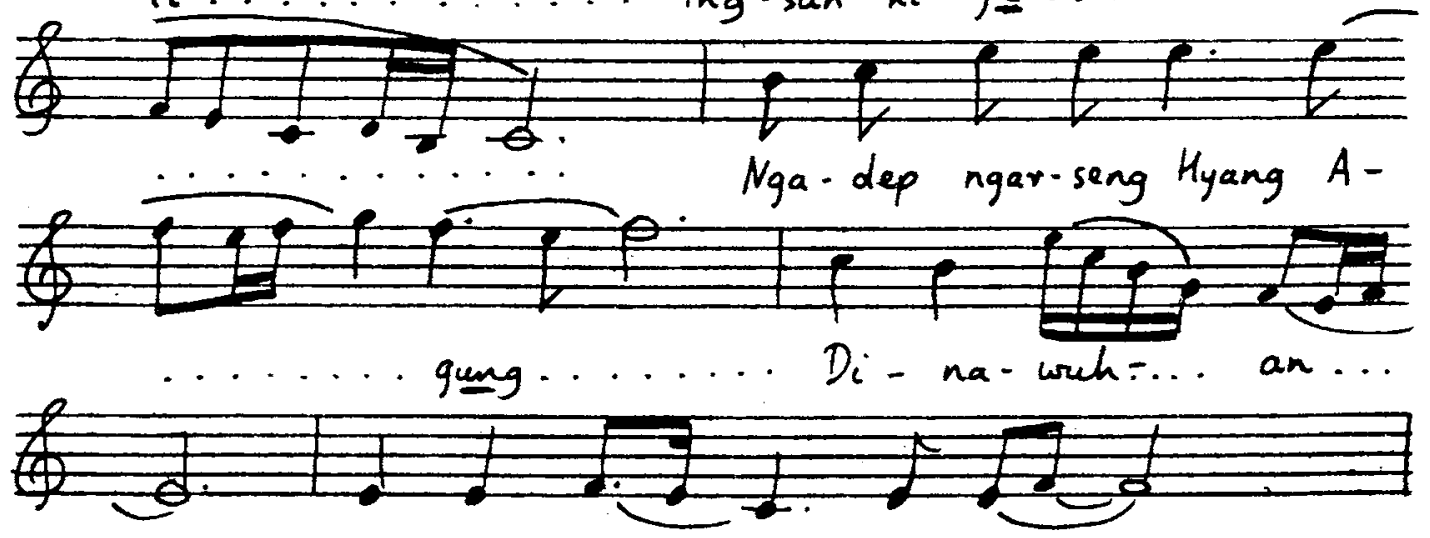

$$
\text { mang-sit si ....... re- } \underline{k i}_{\text {. }} \text {. }
$$

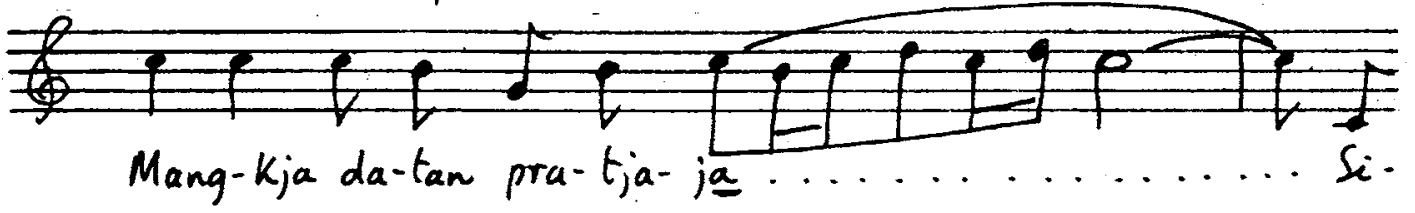



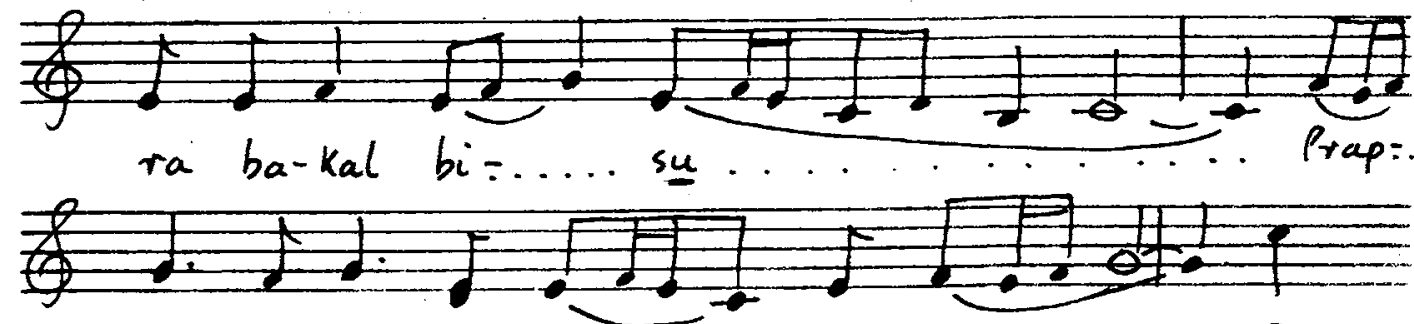

teng ka la-kwaning..... mang.sa....... Ing

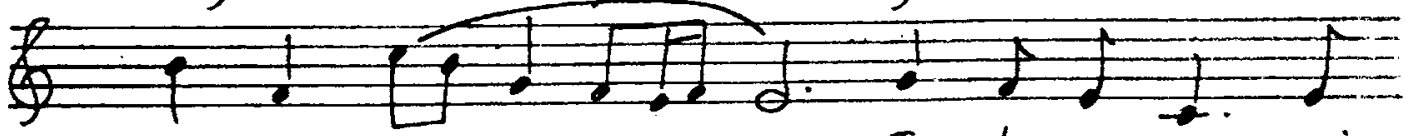

sa- reh-e........ Tu- tur ing-sun mring

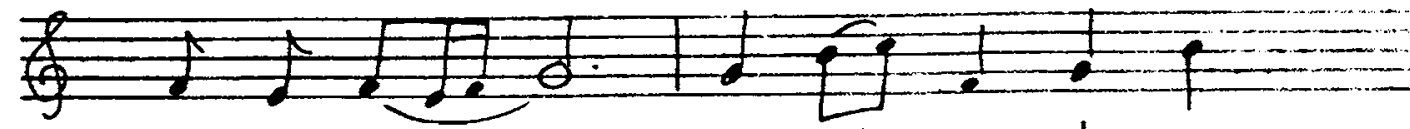

si - re-ki..... Wit si-..ra tan pra-

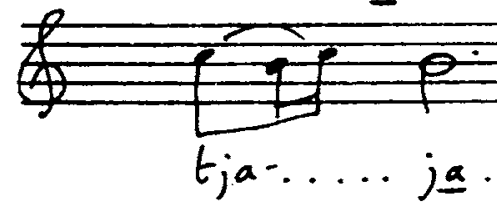


136. LADRANG PANGKUR. (Pelog Patet Barang)

Text of Sinden line in the Kinanti

Djugag and Kinanti metres.

From S. Probohardjono, Gending Djowi, Vol. 2, Surakarta, 1963.

Transcribed from the number script.

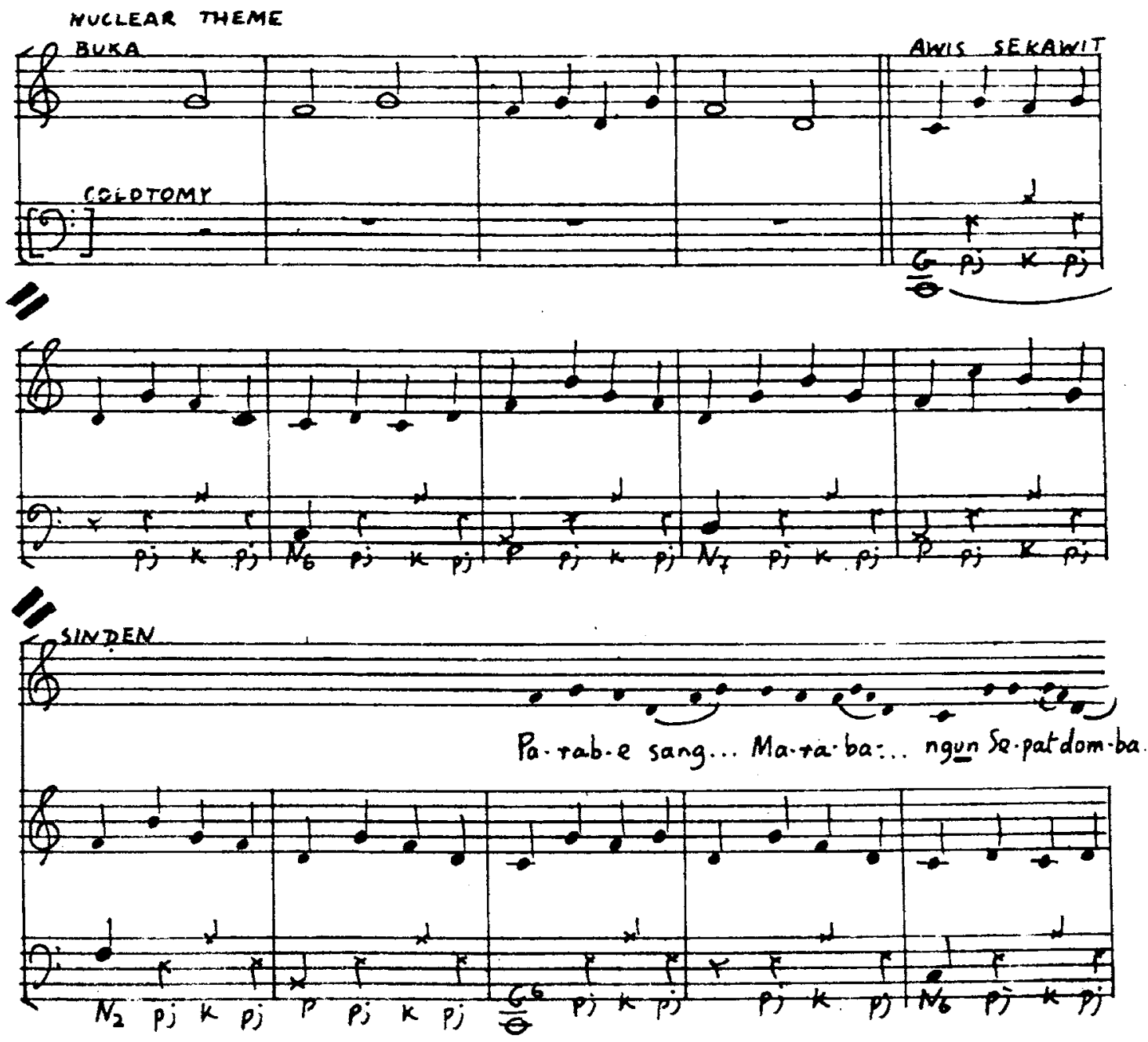

The barred lines above are the nuclear theme which is played by the balungan instruments of the gamelan. The unbarred line is a 'free'-rhythmic indication of the Sinden's part (see of text). $K=$ Ketuk, $P j=$ Kempjang, $P=K e m p u r$, $N=$ Kenong, $G=$ Gong. 

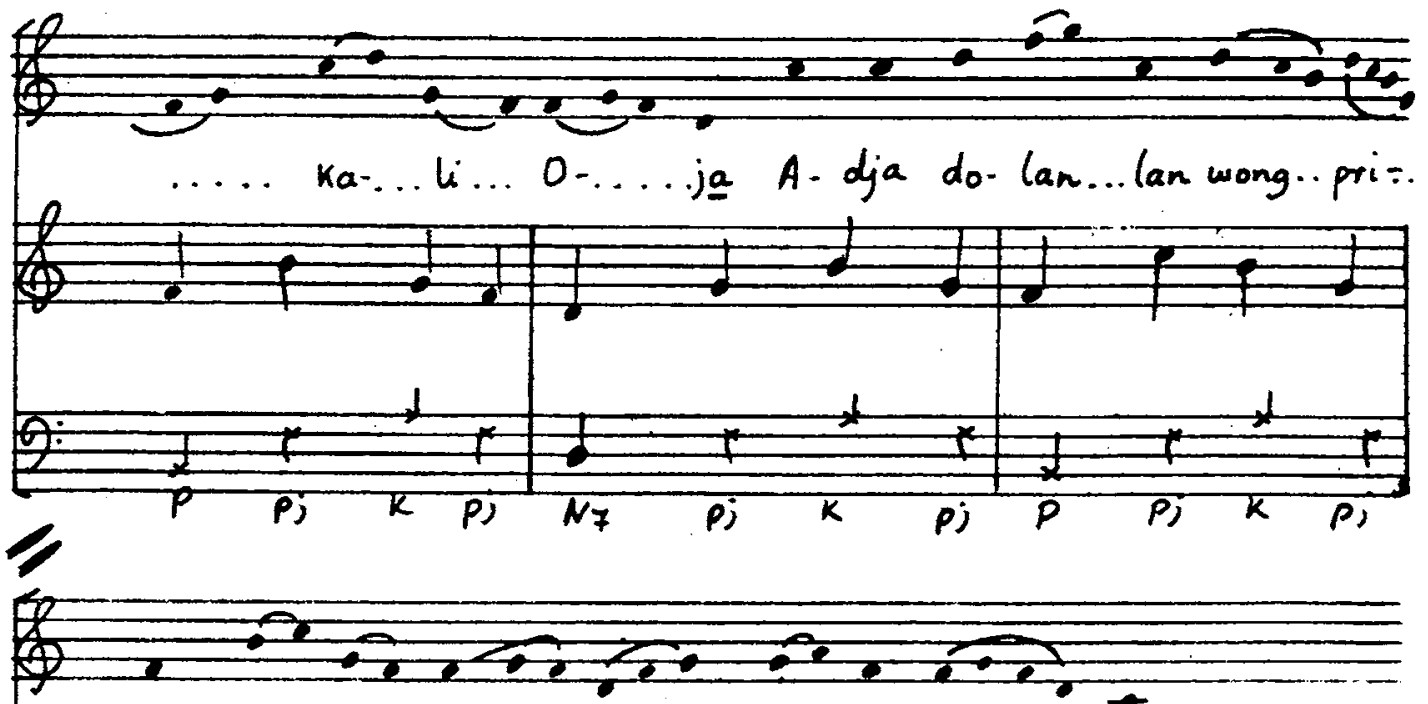

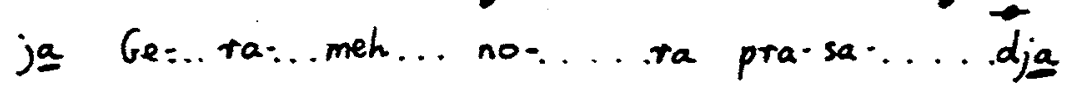
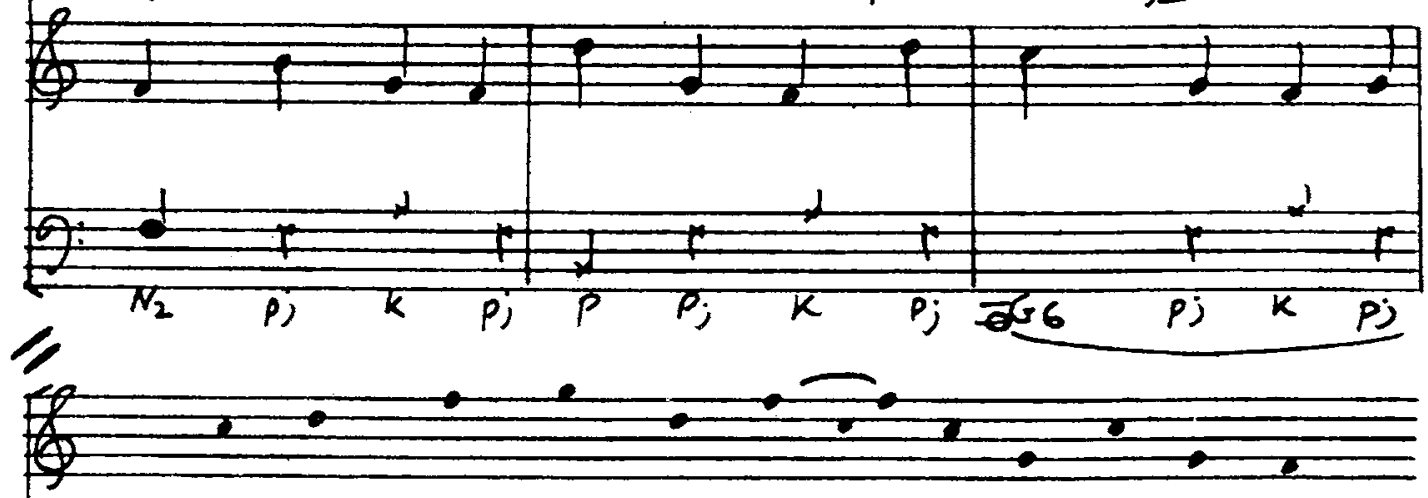

Bu-bar rjam-but ga-we... me-lu me-njang va-

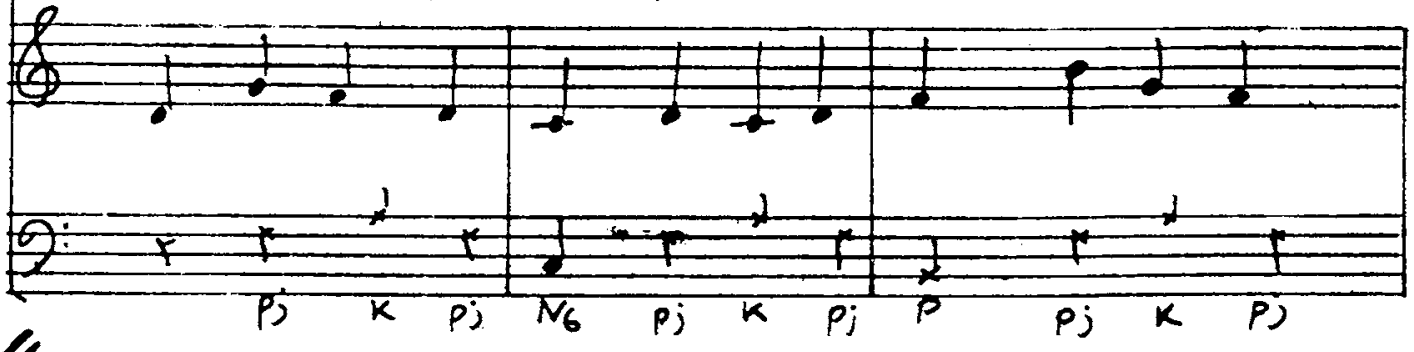




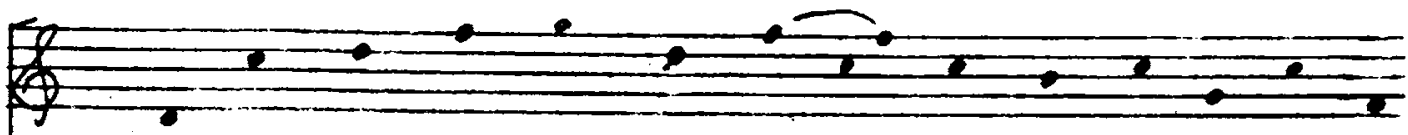

tan non-ton ra-me ra-me.. le-dek-e dja-til-an
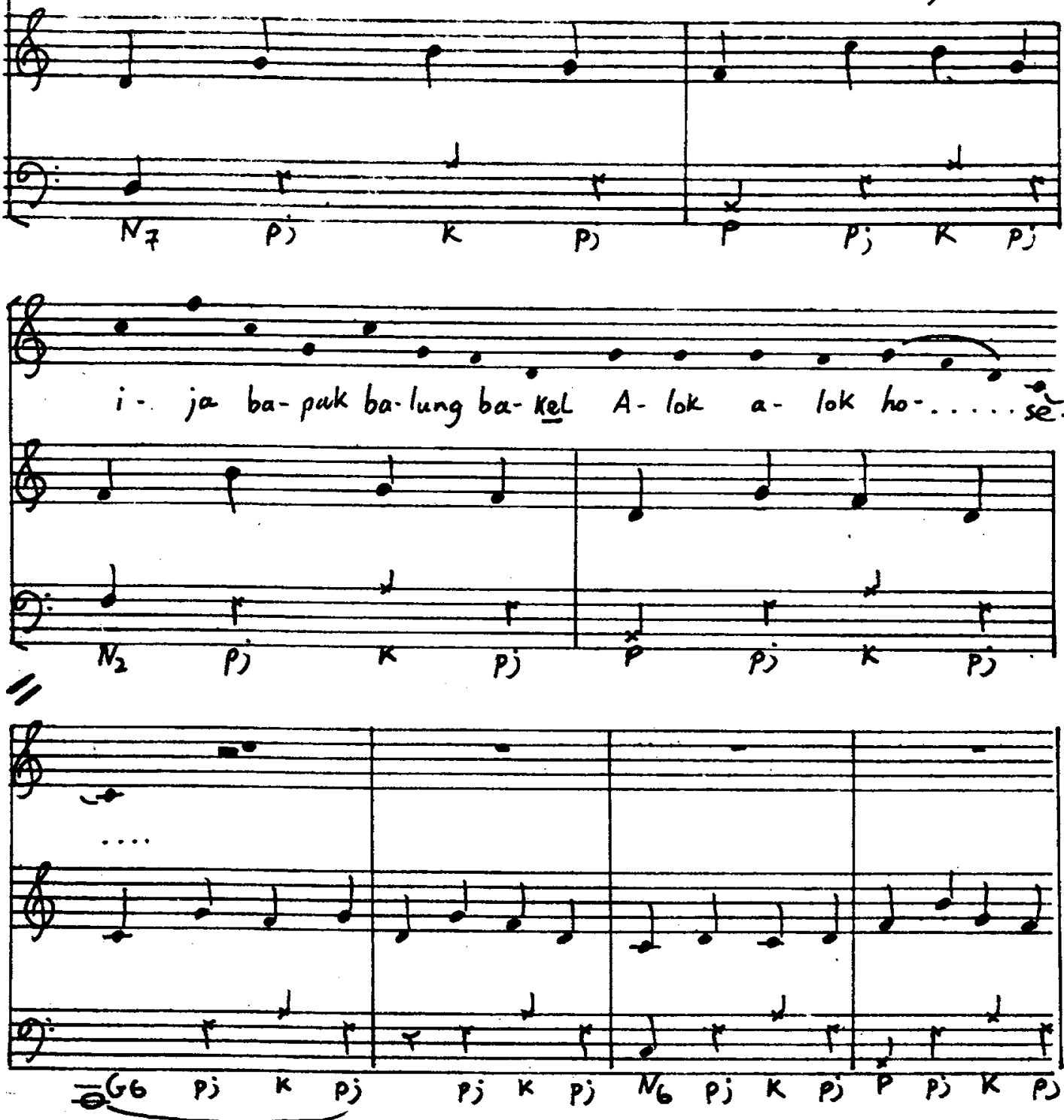

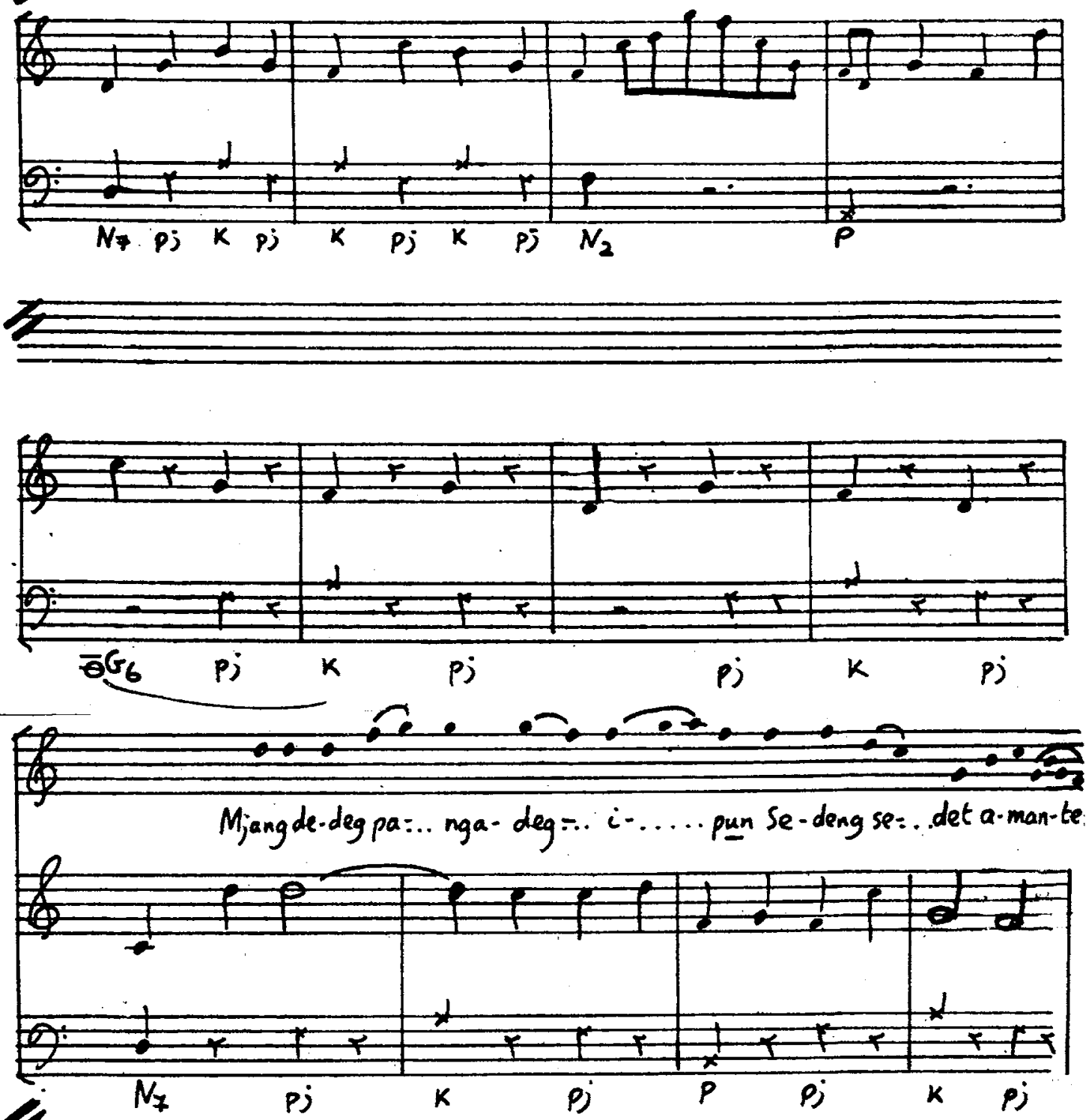


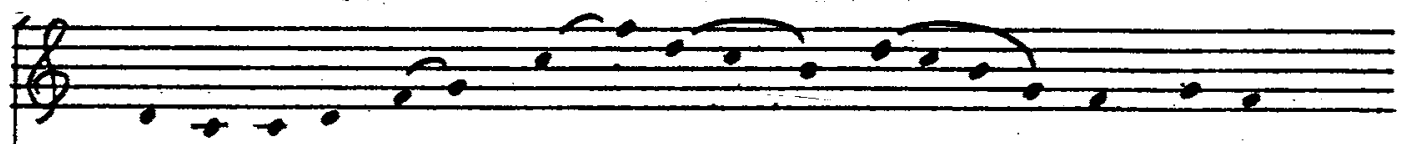

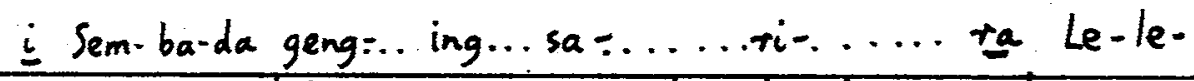
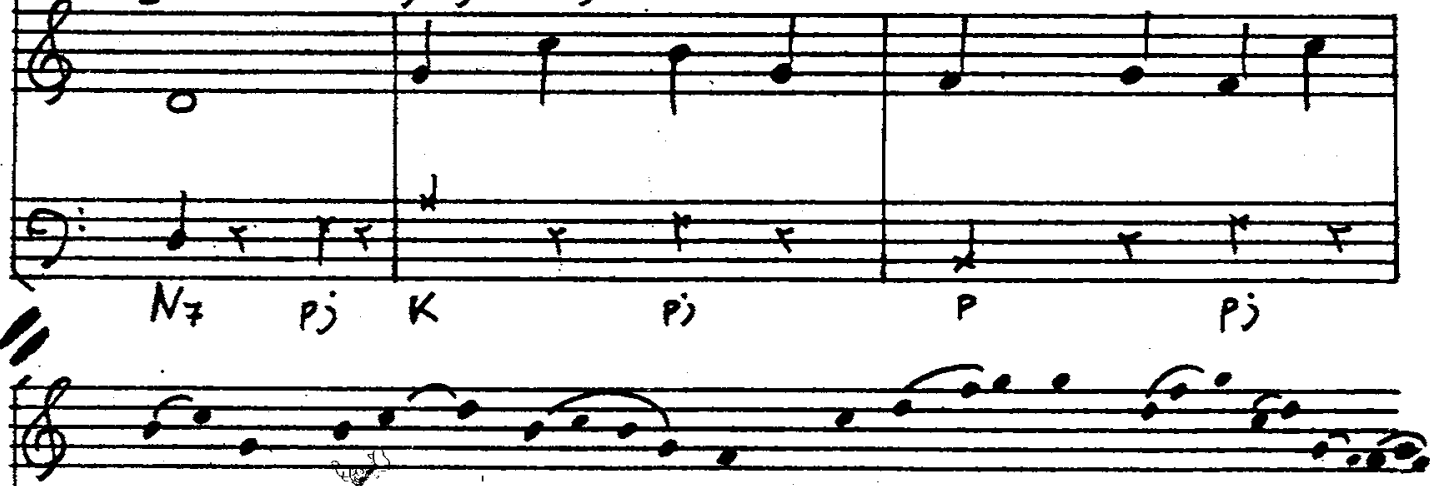

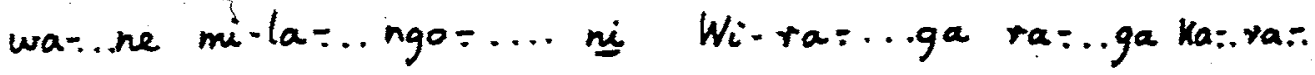
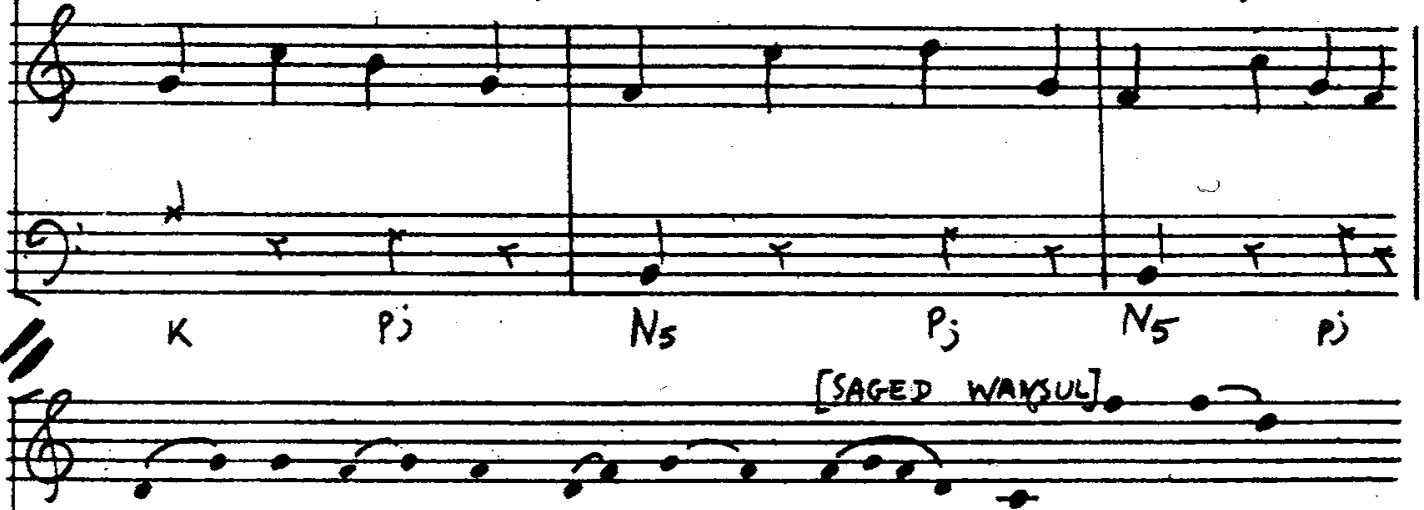
na... Weng dyah.. hyang hyang..ing... bu...... mi Hyang-ing...
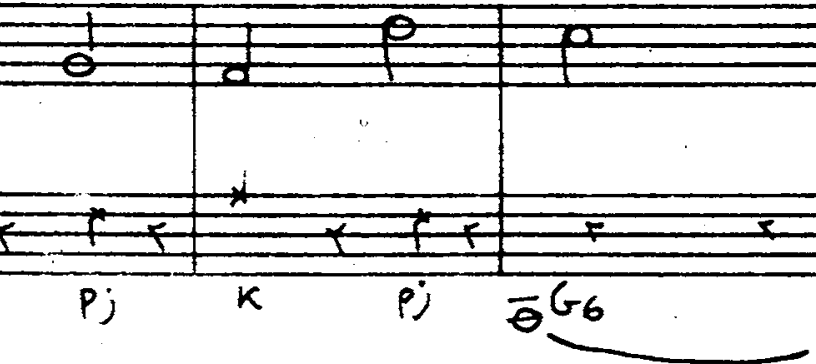


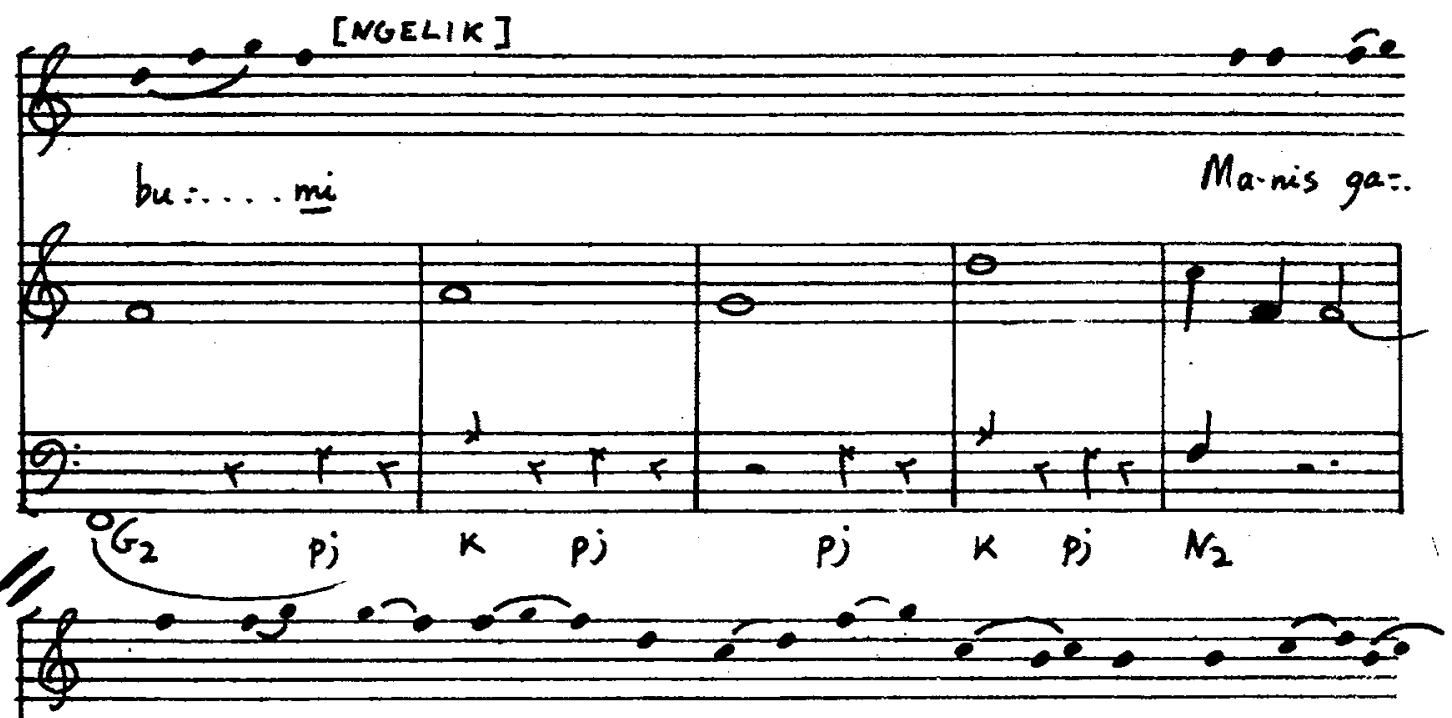

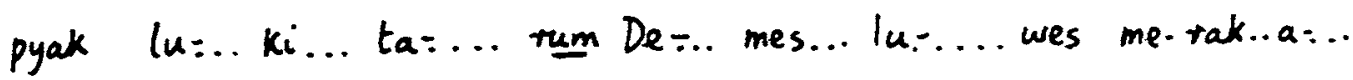
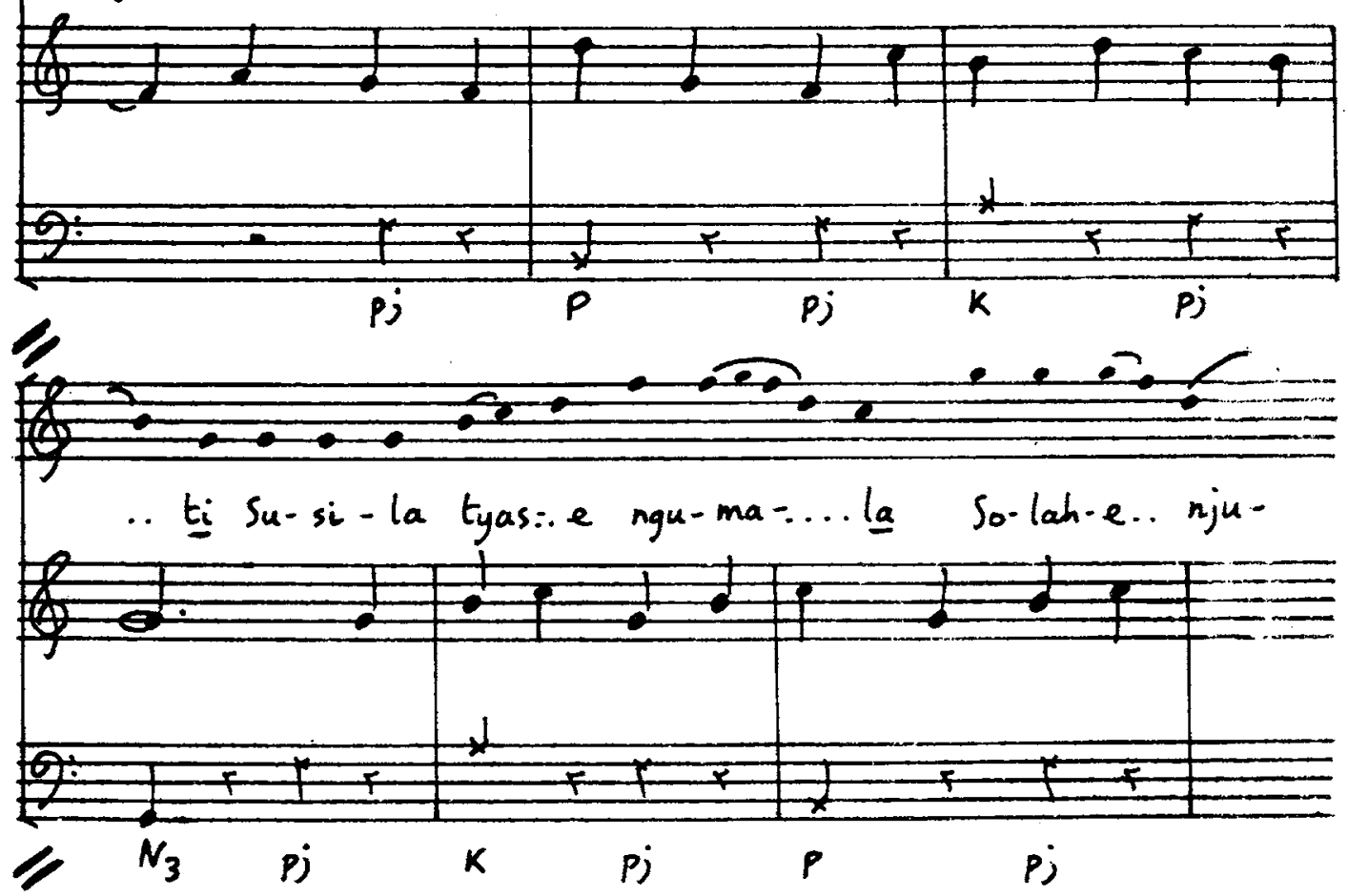

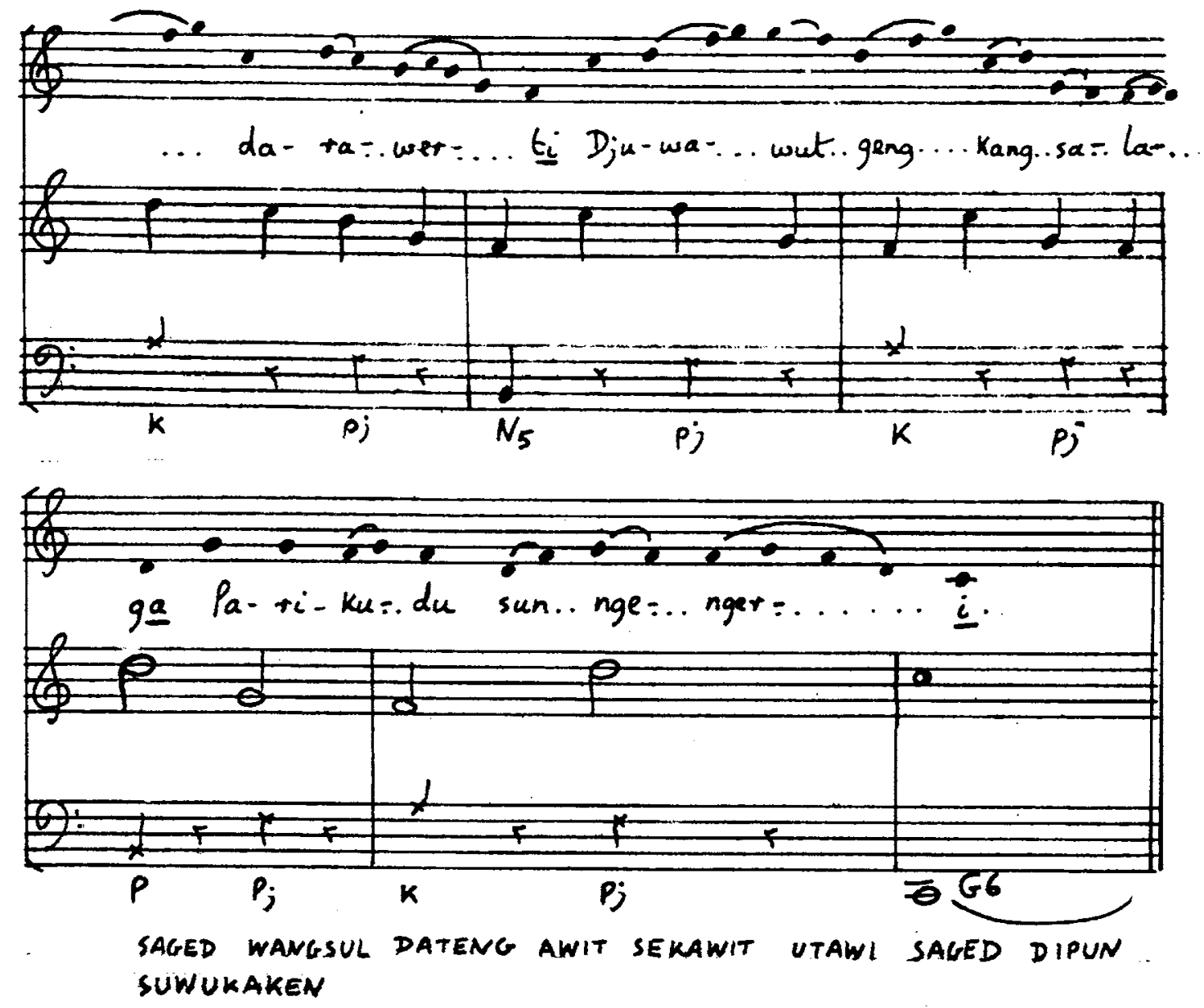
137. KETAWANG MIDJIL SULASTRI (Pelog Patet Barang)

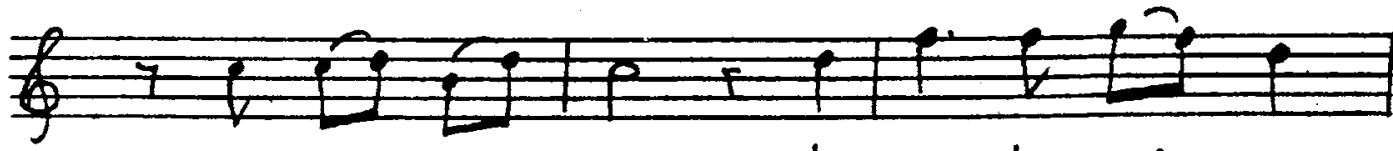
Man-djing..wa-... na. tan e-tang pring:. ga-

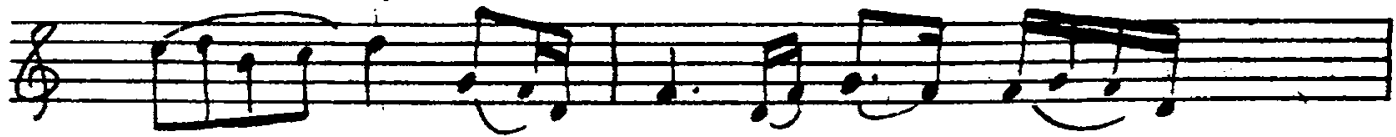
ning..... Mar =. ga dje $=$. rang.. si $-\ldots .$.

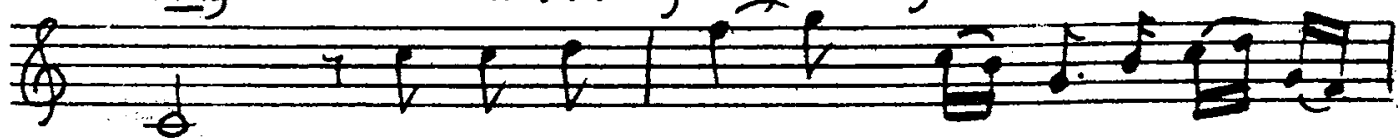

grong Grenging o- ri... 0 ... ri pe-ping-gir:.
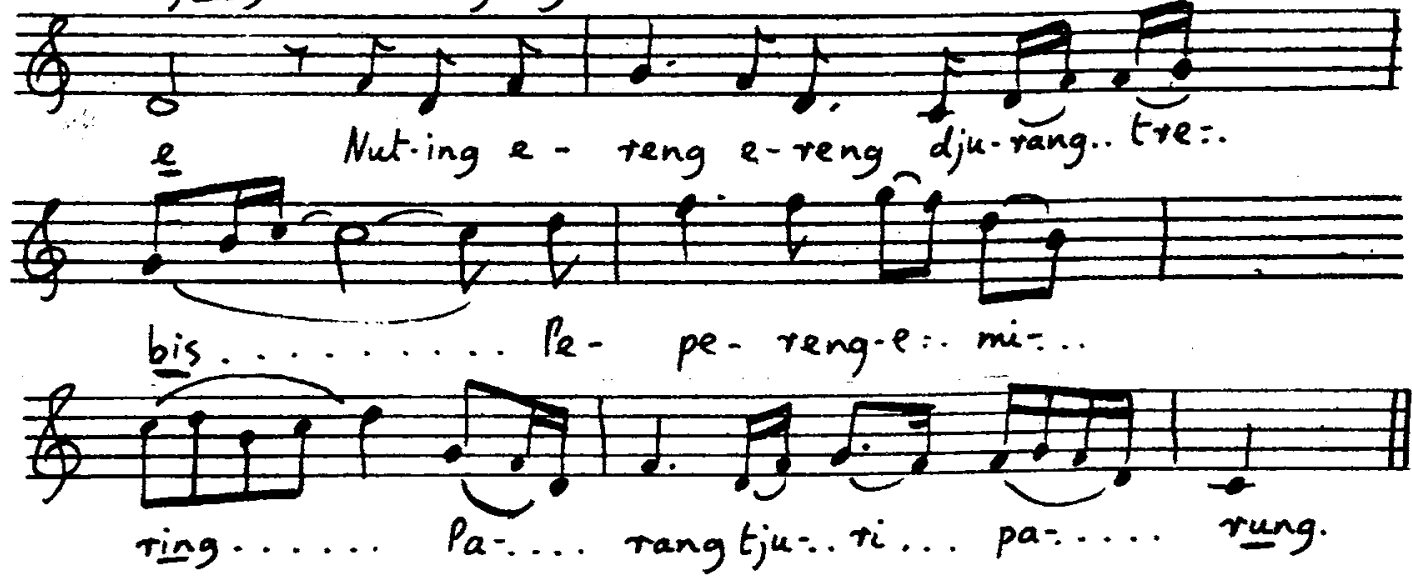
138. GERONG GEIVDING PANGKUR In the Kinanti metre
From Ki Prawiradihardja, Serat Mardi Laras, VoI. I, Surakarta, 1961. (Hereafter $S . M . L$. Transcribed from the number script.)

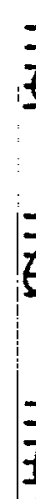

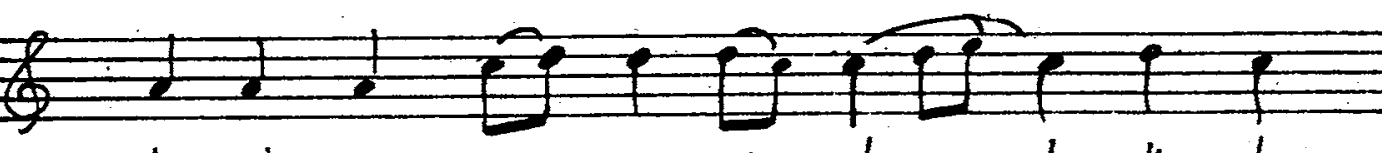
ka-pjar sa swa-. ra-ning.. da-... le $k a-$ long

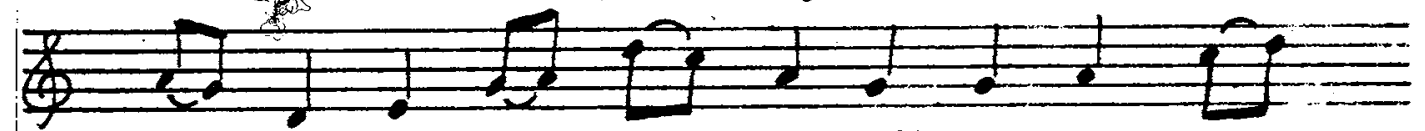

Ke=. Ka-lang-an.. a-.. myih Me-mang-san sa:.
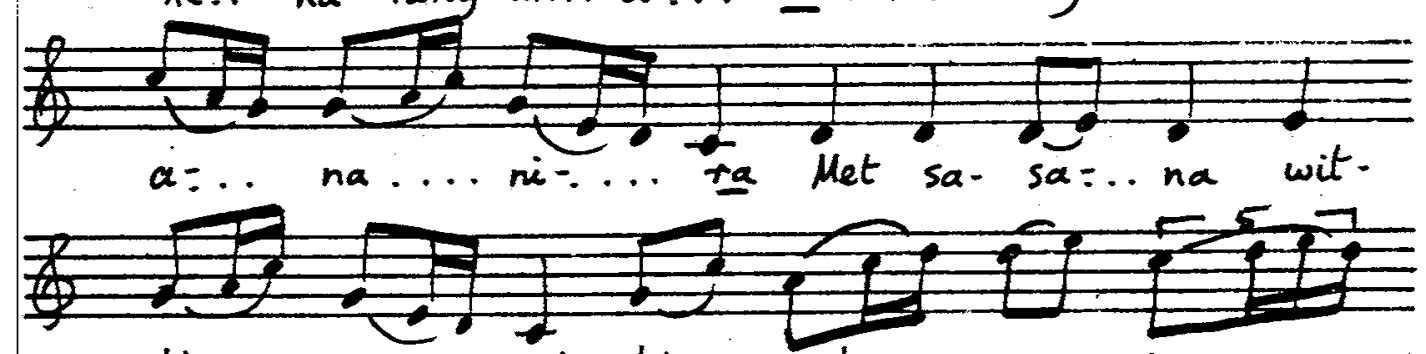
ting... wh-... ni We ... neh... nang.. ka $=\ldots$

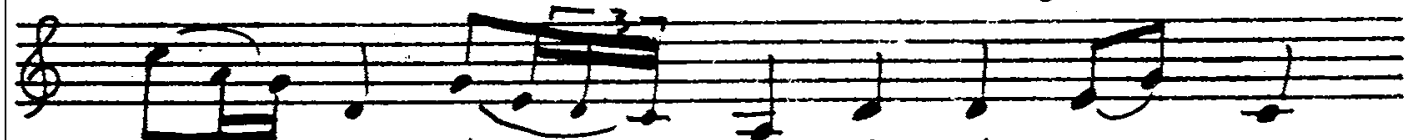
djam ... bu ben ..... da $\operatorname{Ran-du~ka-..~ran-~}$

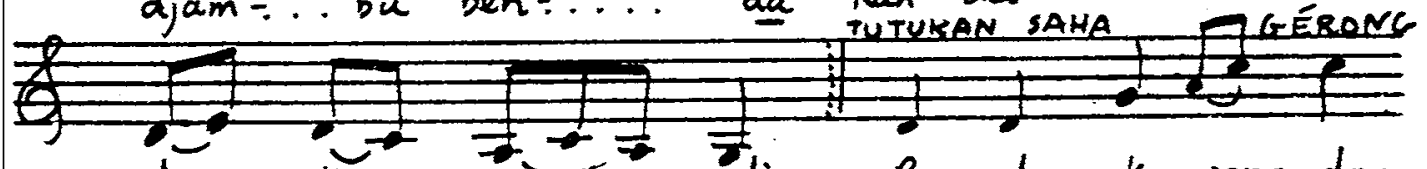
dang:- $k_{e}=\ldots$ ran..- ding: Ran-du ka-ran-. dang-

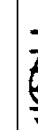
IEN BADE NGELIK 
139. KOOR SEKAR PUTJUNG NIRBAJAN

From Stencil Actief, Ballet Prambanan, no date. Transcribed from the number script.
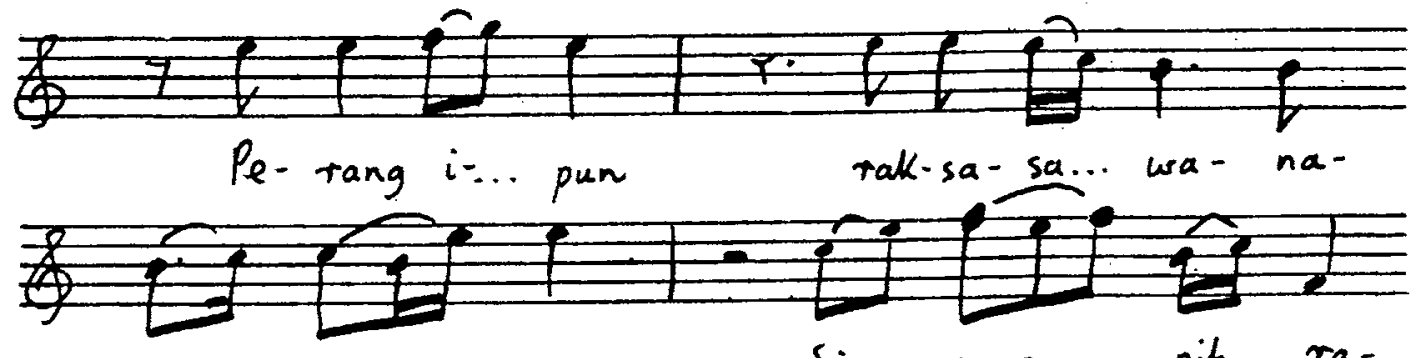
ra... sam... pun si-.. na $\ldots$ su pih... ra-
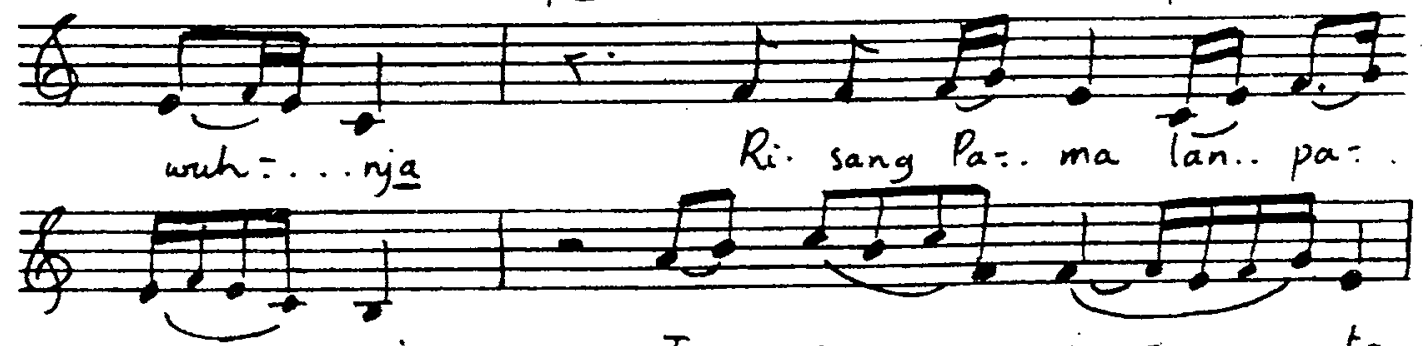
$n g i . .$. ring $\operatorname{Tan} \ldots$ sa $\ldots . . . \operatorname{ran} \ldots \ldots t a$

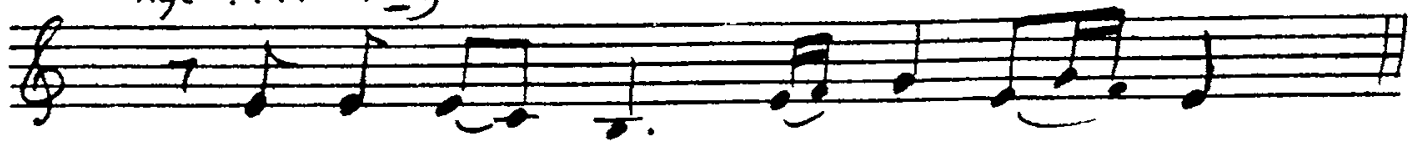
A. no-man.. mun- djuk. ma-ngax... sa. 
443

140. PANGKUR WANTAH (Slendro Patet Sanga)

From S.M.L.

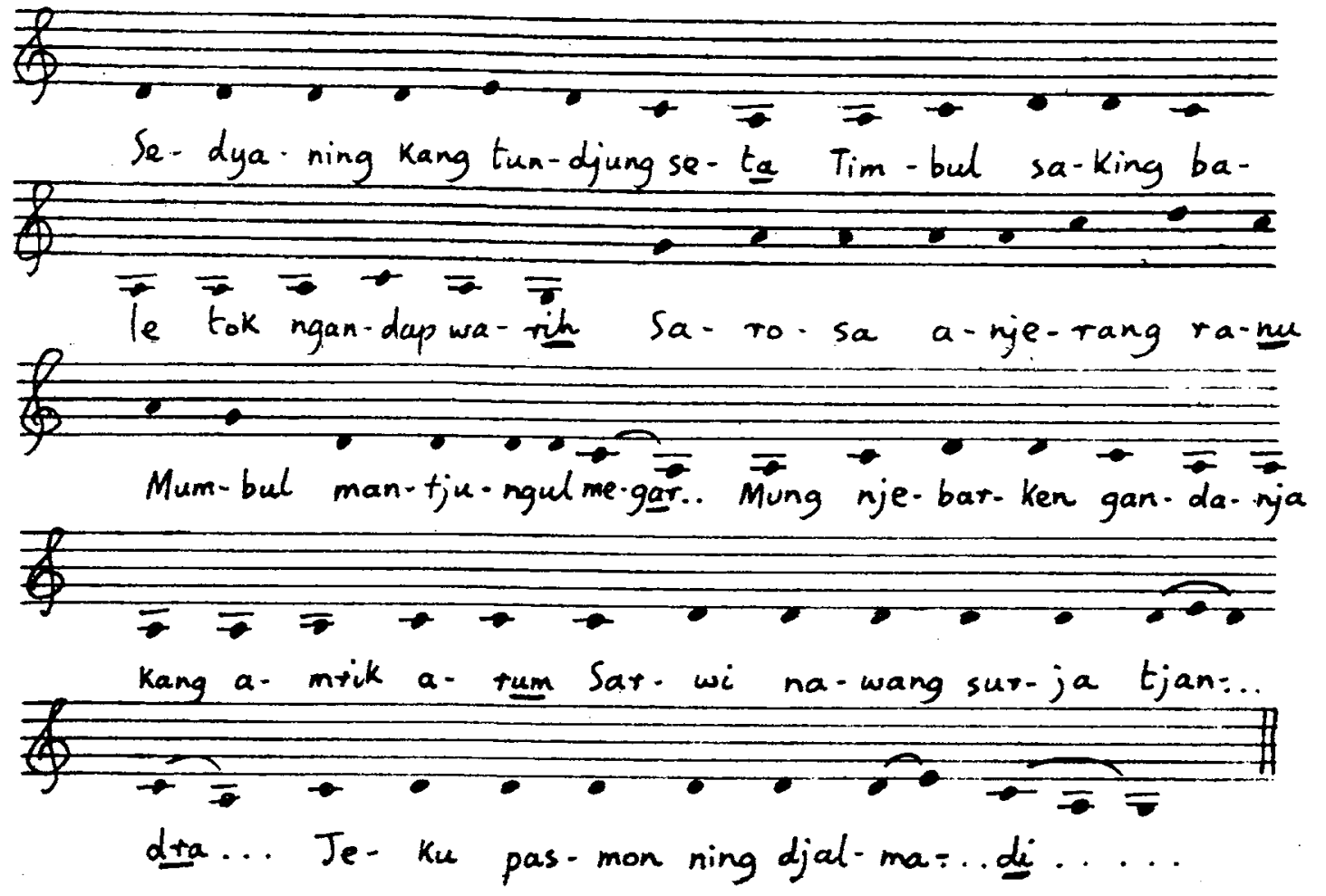


141. PANGKUR IAGU PARI PURNA From S.M.L.

(Slendro Patet Sanga)

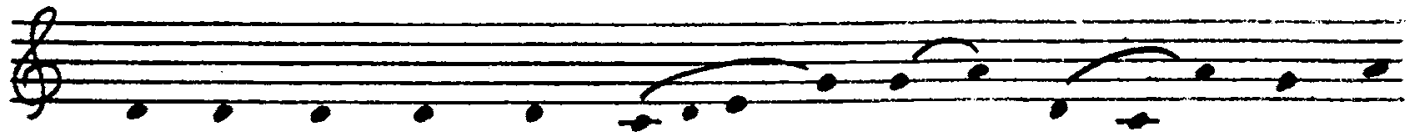

Jwa $k_{a}-d_{i} d_{j a}-\operatorname{man} s a-. . .$. mang.: $k_{j a} . .$. Prating-

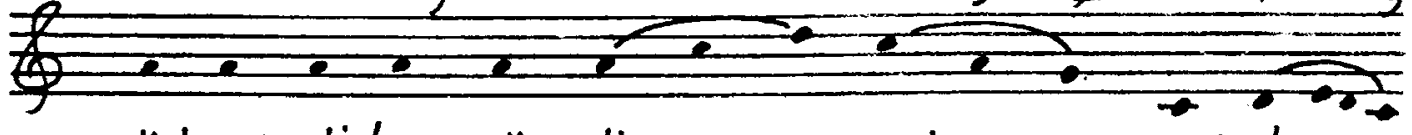
Kah-e djal-ma $\mathrm{Ka}-\mathrm{lim}-. .$. put.... buk- $\underline{\text { E..... }}$

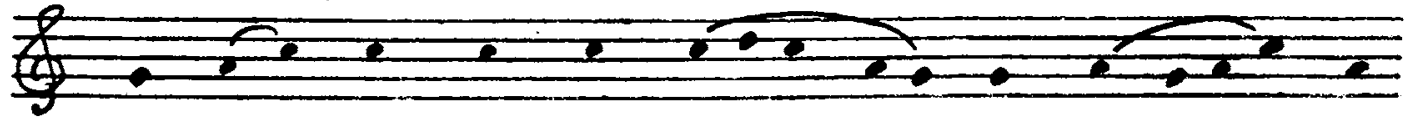

Lu-mrah.. mun-djang.nun-djang.... nu-bruk.... Da舟 tan nge-tangwi..... sa-..ja... li-jan mar-ga si - ne - rang..a - nglit de ... lang-gung.... Su-

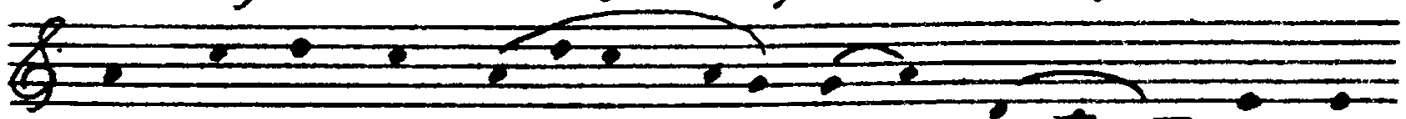
pe $k a-l a-m u n ~ m a-\ldots . . n u-$ swa.... $T_{i}-n i-$

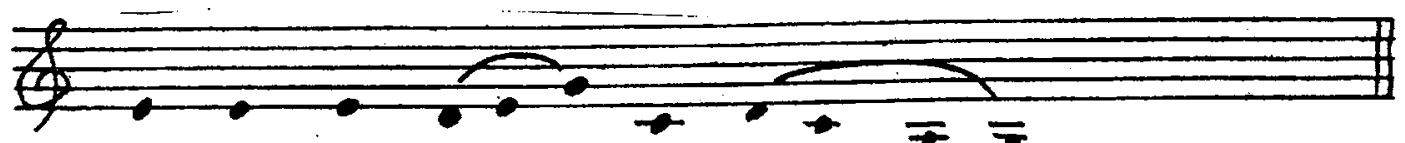
tah mang-ka pa-... lu-pi...... 
Tan-pa kan-ti klen-tung-klen-. tung Tu- rut ta- ti-

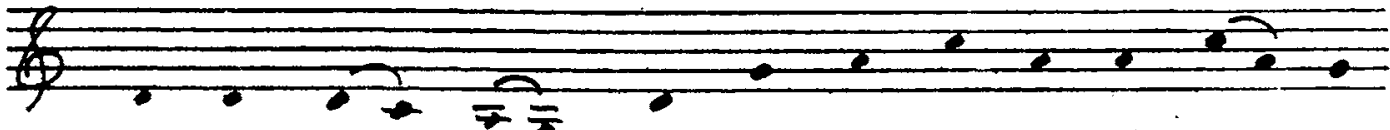

rak-ing sa... bin.. Sa- ben pa-ri pi-ja-tan.- nan

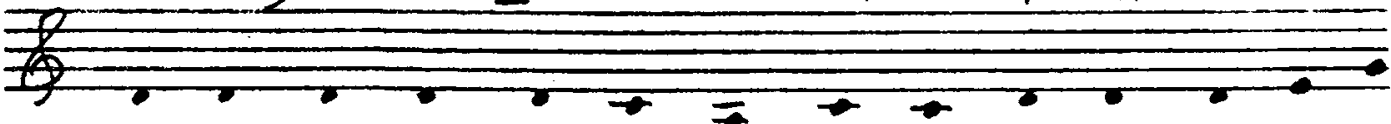
Pi-na-rik-sa ring $k_{i} t_{a}$ - ni $T_{i}$ - non sung seng-sem-ing

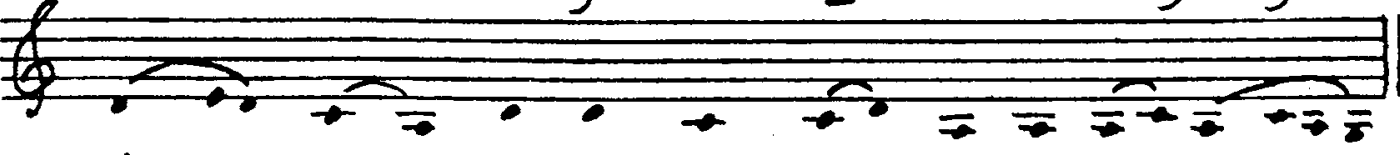

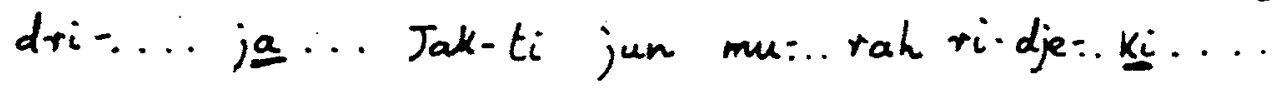


446

143. KINANTI LAGU KASATRIJAN

(Slendro Patet Sanga)
From S.M.L.

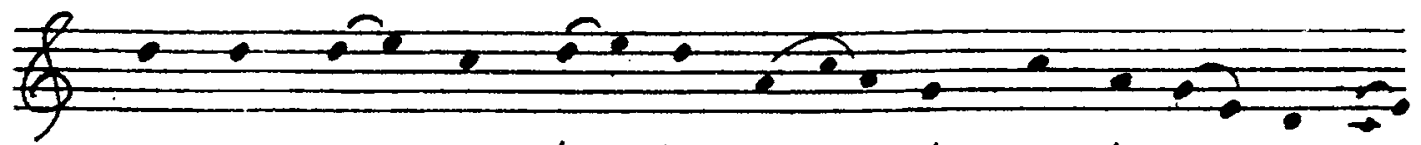

Ron-don nan...a-le-.dung-le-.. dung Se-dengtan-.dur-an..

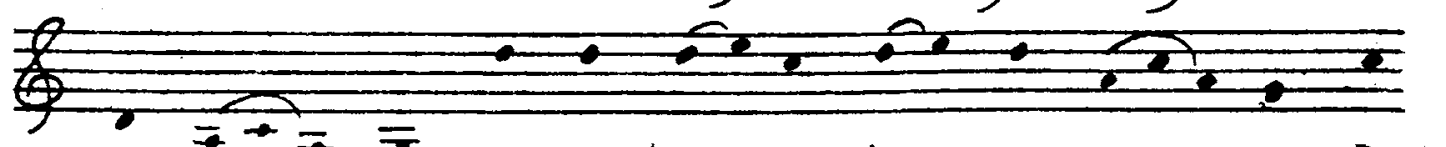

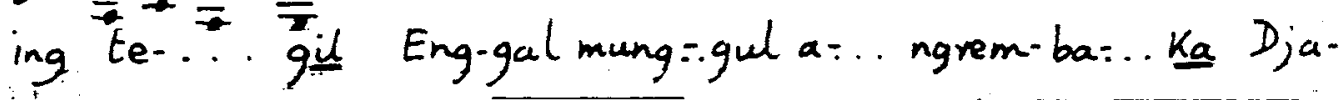
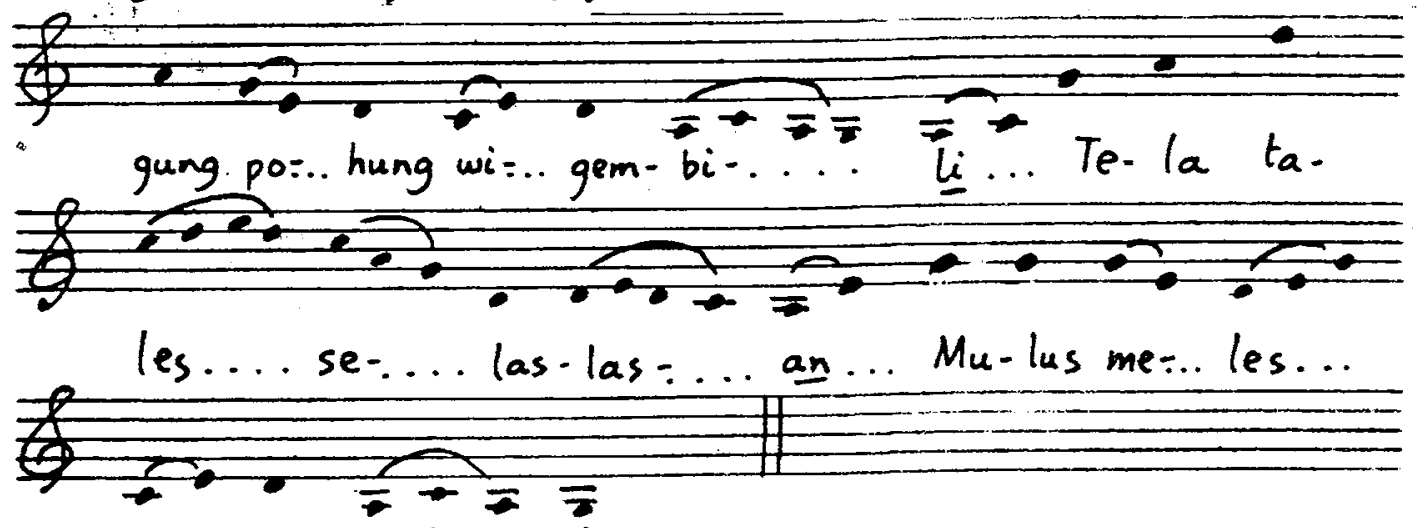

$a$... nge moh..... 
447

144. PUTJUNG WANTAH

(Slendro Patet Sanga)
From S.M.L.

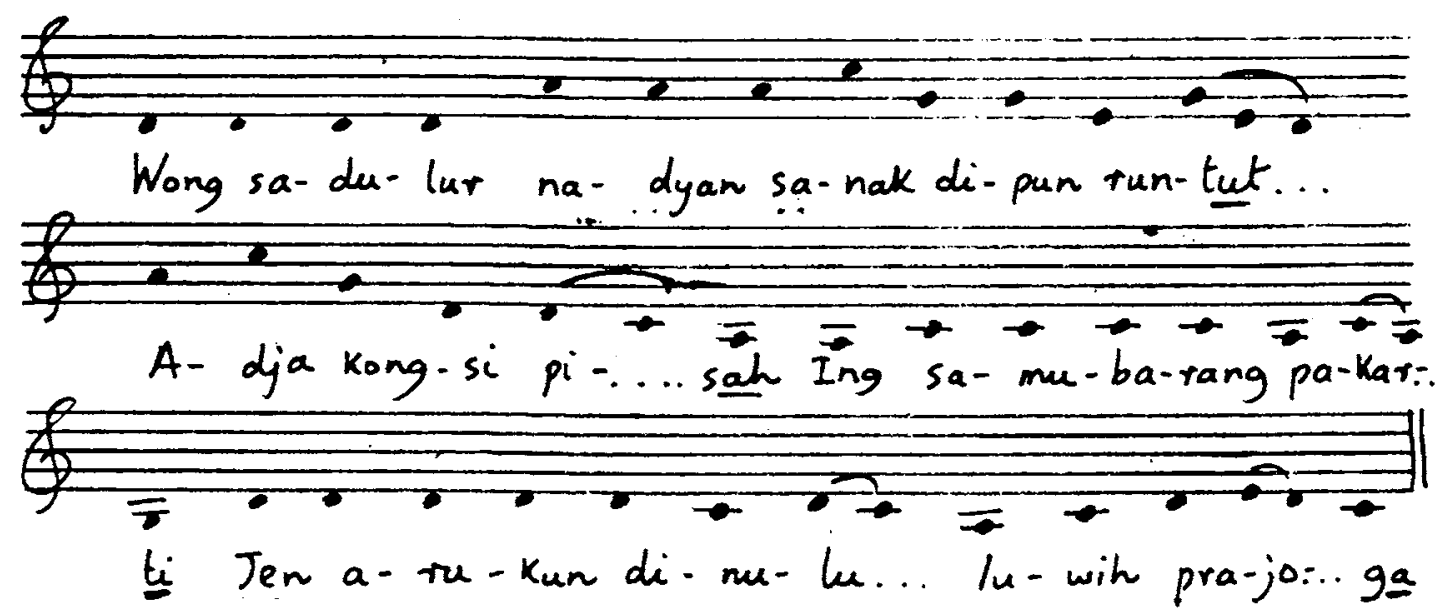


145. PUTJUNG LAGU LARAS MADYA (Slendro Patet Manjura)
From S.M.L.

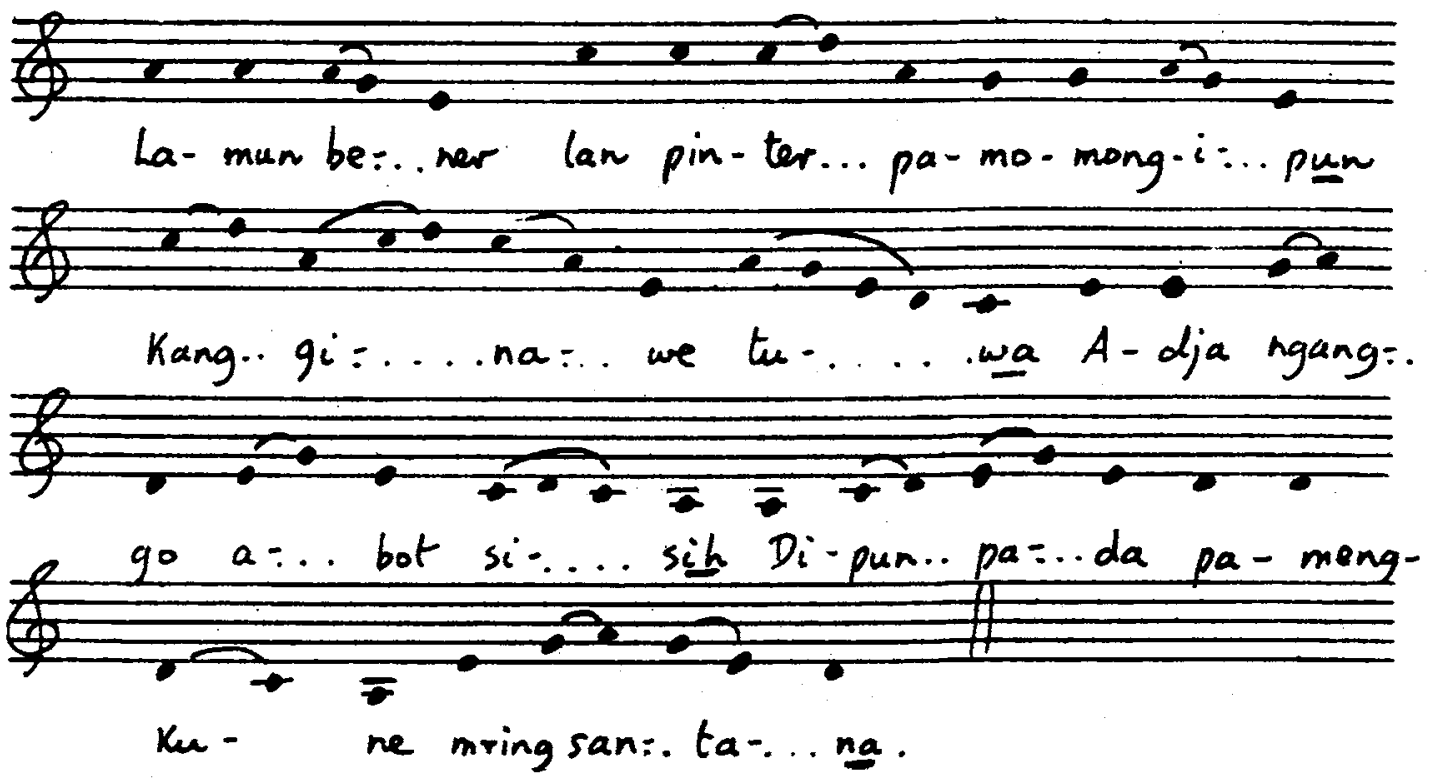


146. SINOM (Pelog Patet Barang) from 'Gending Ketawang Sinom Pariajata'.
SINGER: RUBINEM (Sinden)

T.I.: 2.82 mins.

O.P.: as below

Accompanied by gamelan, including rebab and suling solo instruments.

Recorded by Radio Republik Indonesia, in Studio

Djogjakarta.

$(d=122)$
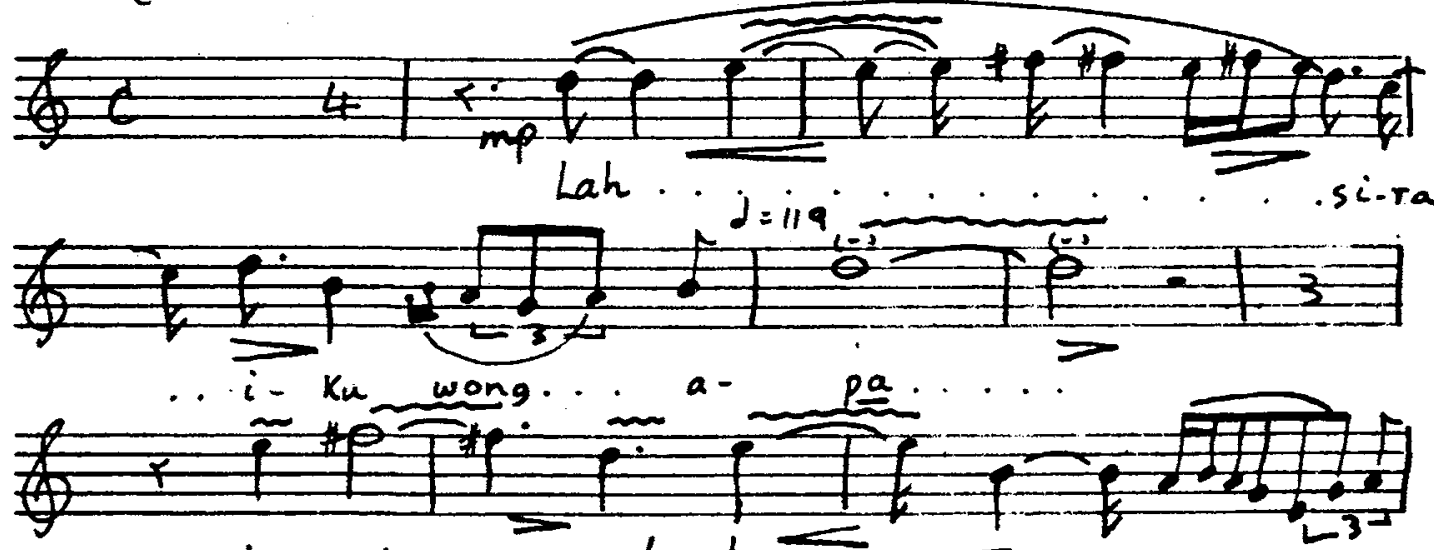

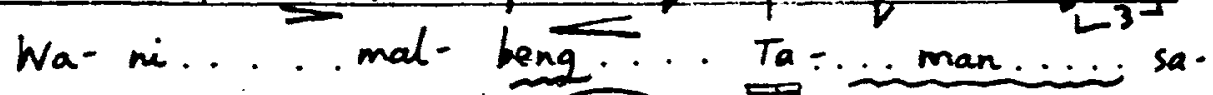

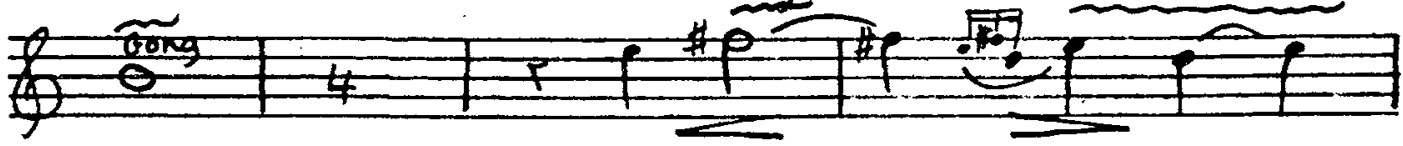

i $R u-p a-\ldots$ mu $b a-\ldots$

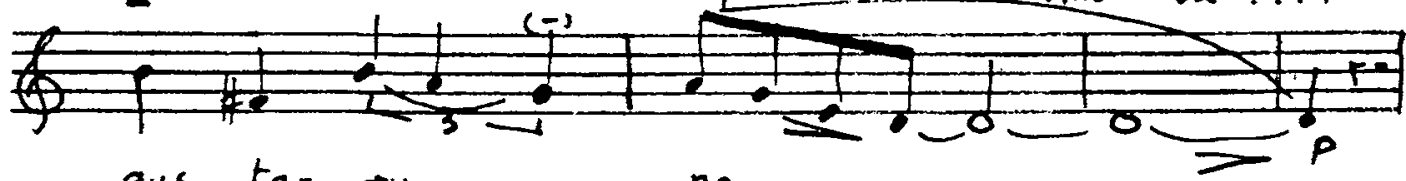

gus ta- ru-.......na
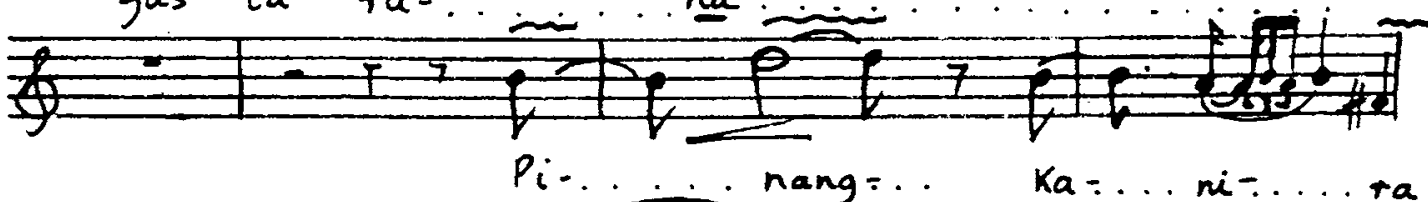

$\mathrm{Ka}=\ldots \mathrm{ni}-\ldots+\mathrm{ra}$

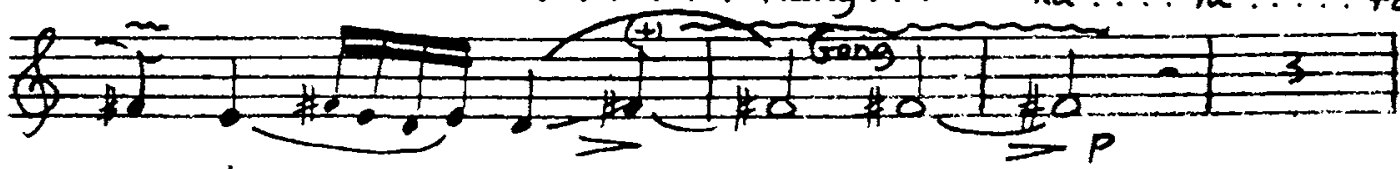

... ing

di.

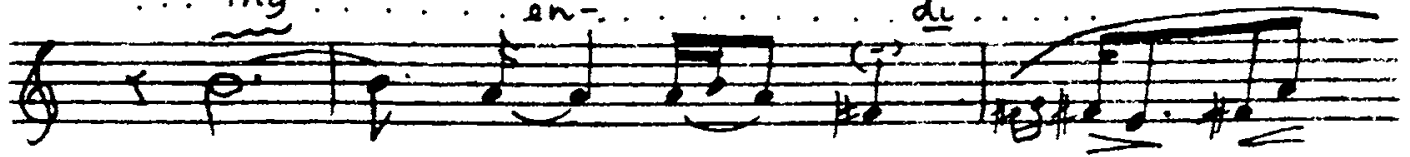

Lan... sa... pa... Kang we-. 


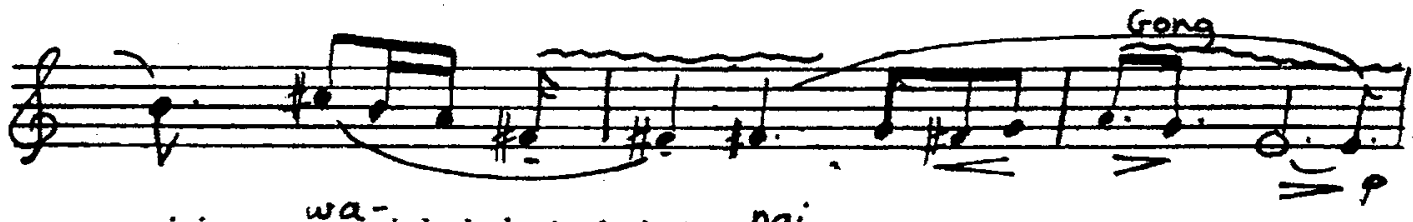

wa-.

ngi

专-

$A-\operatorname{gga-....~ku-wa...~mum-~}$

Z1

pung du..... tung......... $\mathrm{Pa}_{\mathrm{a}}$ las....tta... si-

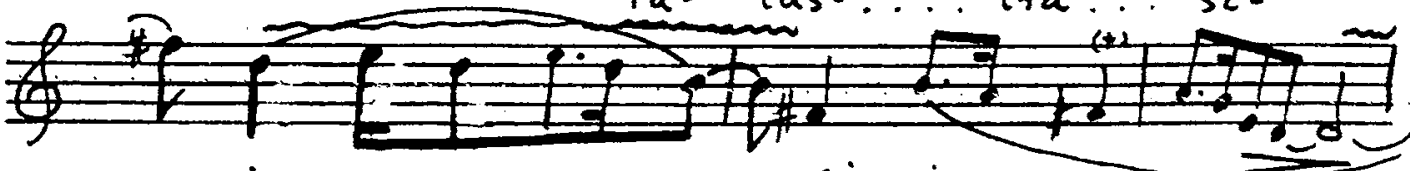

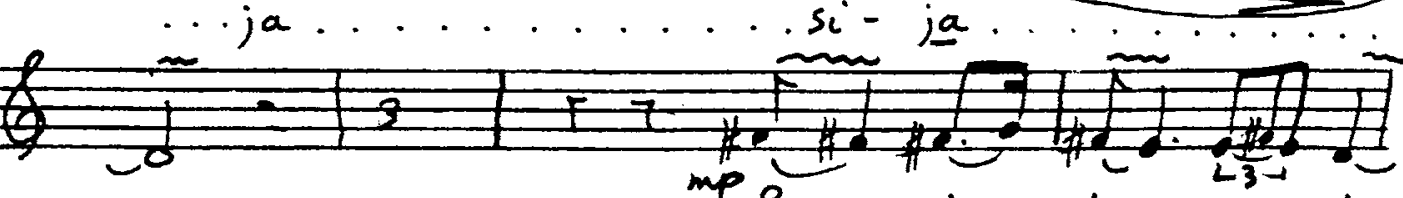

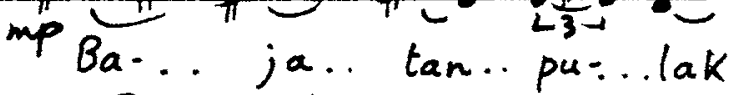

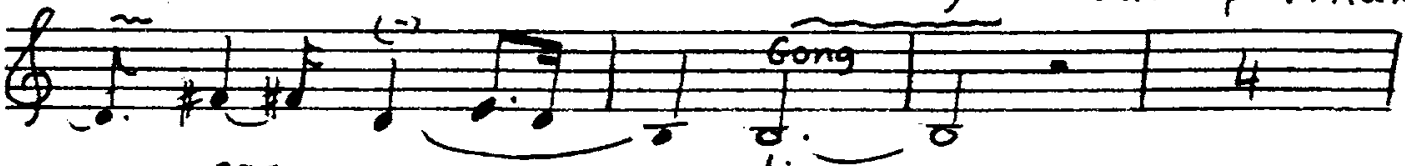

$\cdots$ pa-in war..

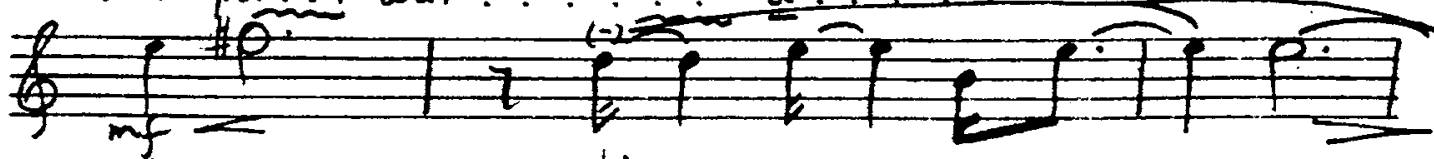

$2^{\text {La-mun }}$

la- gija

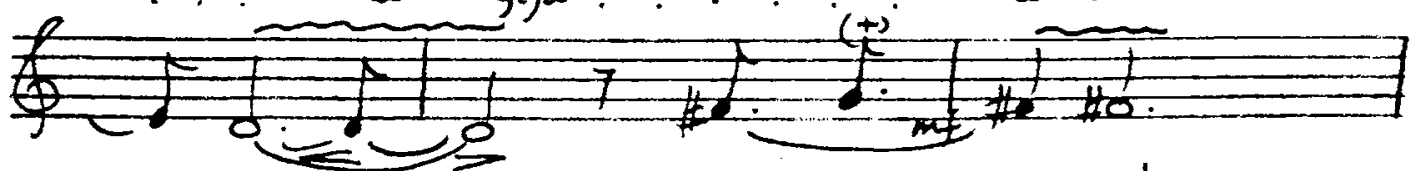

na....

wong...... dja - 
451

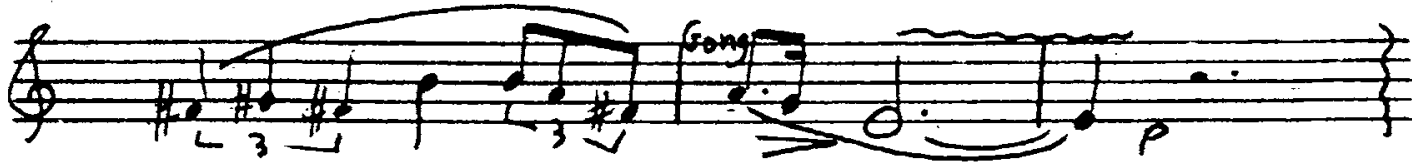
$w a-. . . . . . . .6$. 
147. KINANTI as Gerongan in Ketowang Djajakusuma Slendro patet manjura

SINGER: IRAWAN

HOME TOWN : SURAKARTA

T.I.: $0.72 \mathrm{~min}$.

O.P.: $\frac{1}{2}$ tone lower

$[K=$ Ketuk, $N=$ Kenong, $P=$ Kempul, $G=$ Gong $]$

$d=68$

GERONGÄN
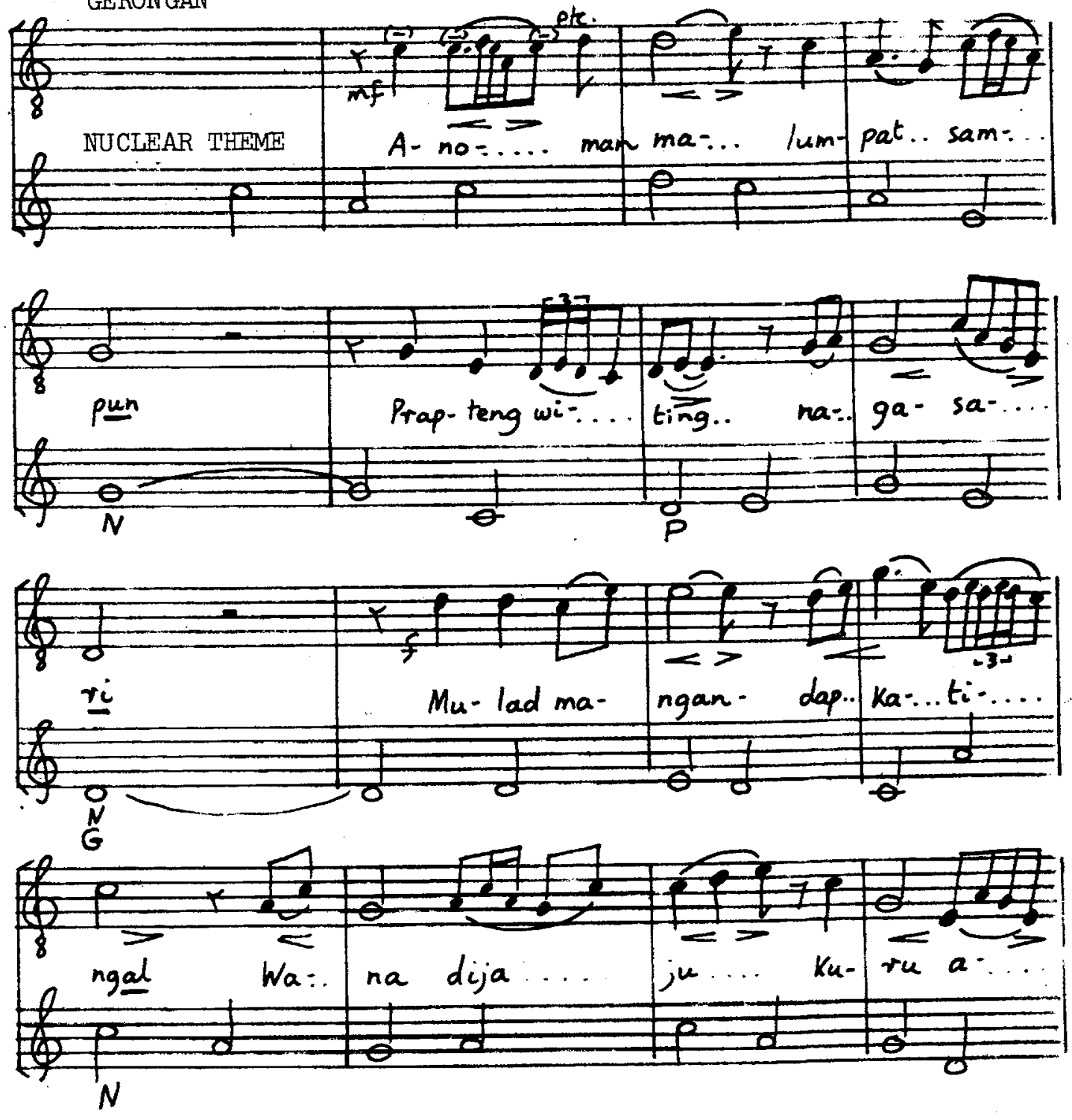


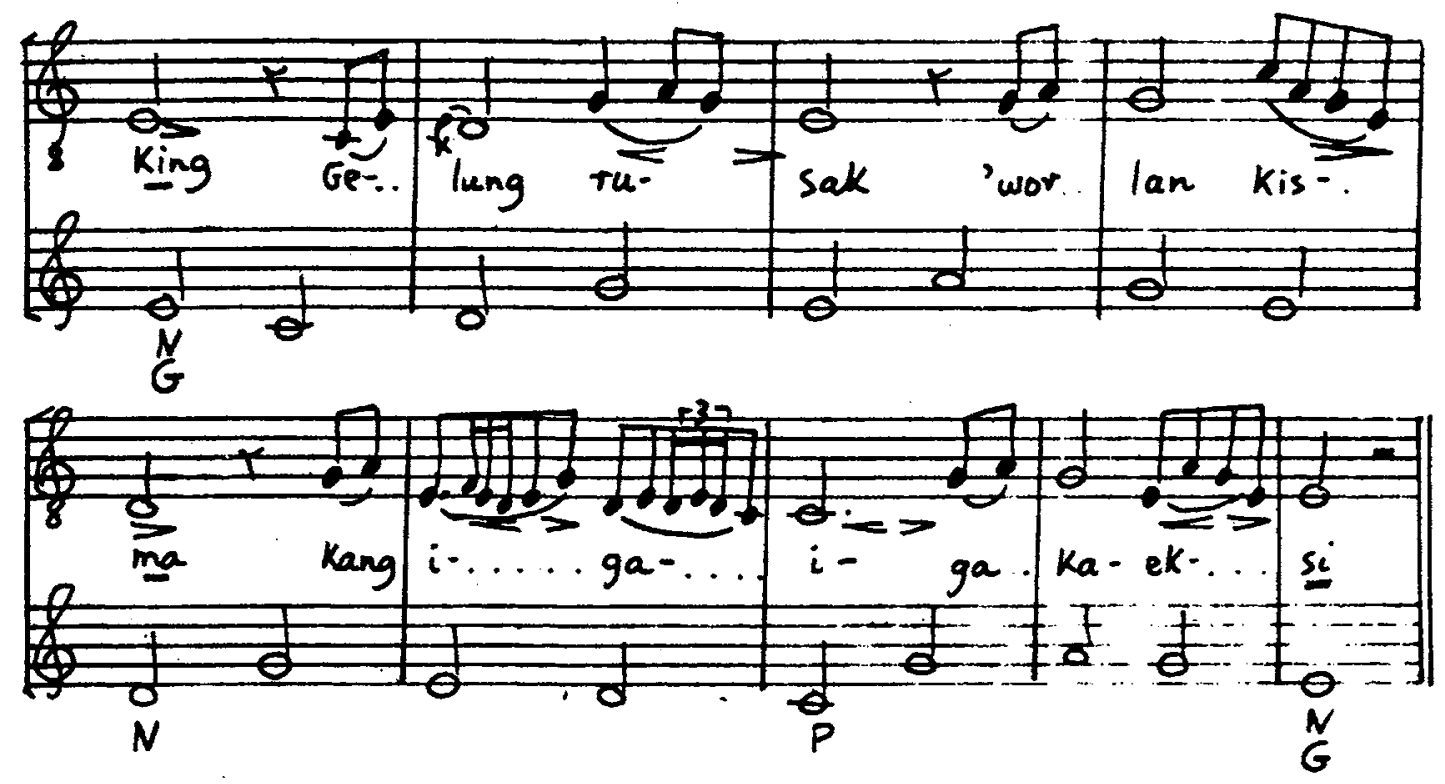


Appendix II (cont'd)

THE SUNDOWN TRANSCRIPTIONS 


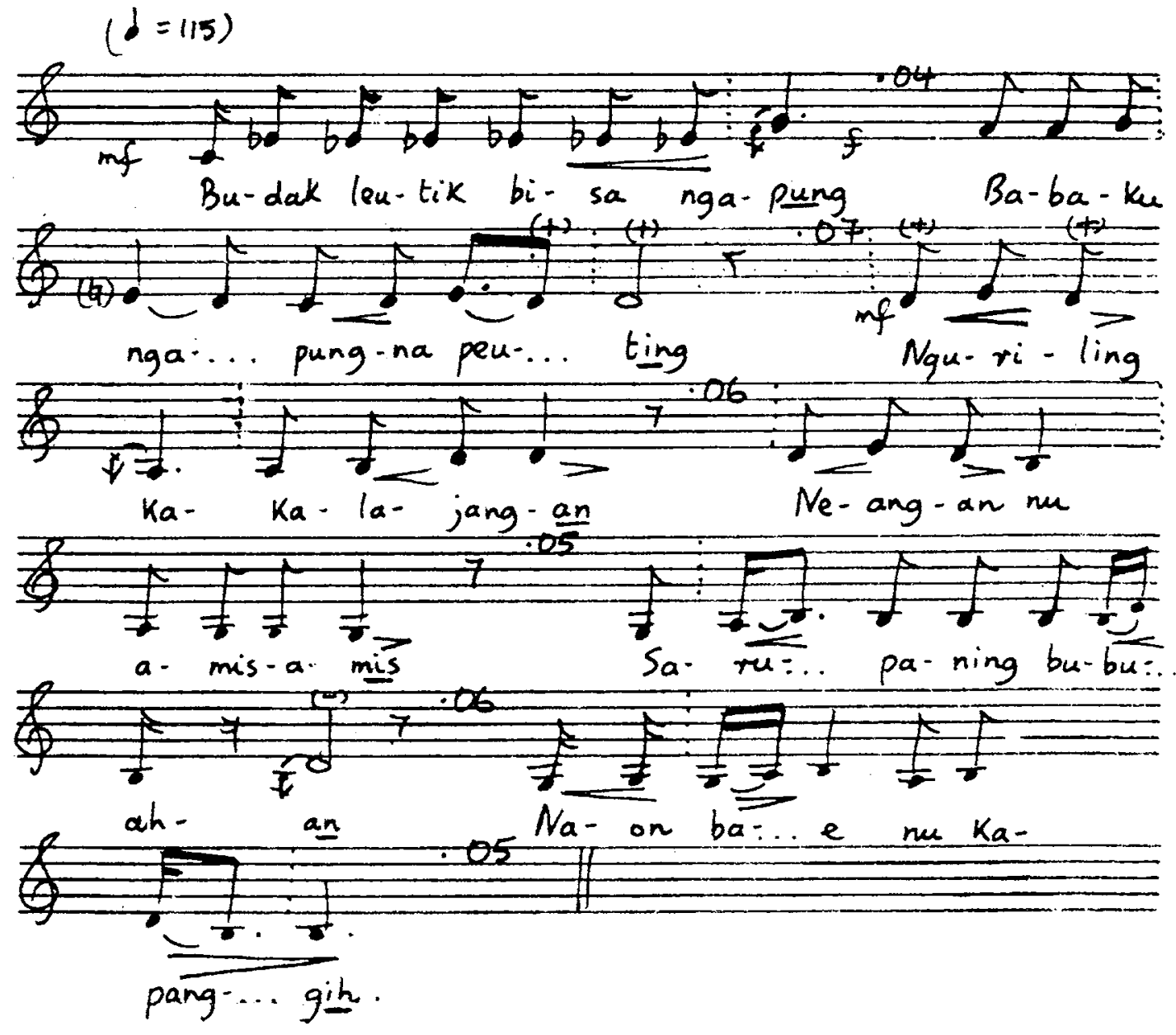


3. ASMARANDANA

SINGER: K. TOBING

T.L.: $0.30 \mathrm{~min}$.

O.P.: $\frac{1}{2}$ tone higher

\section{$(d .=132)$}
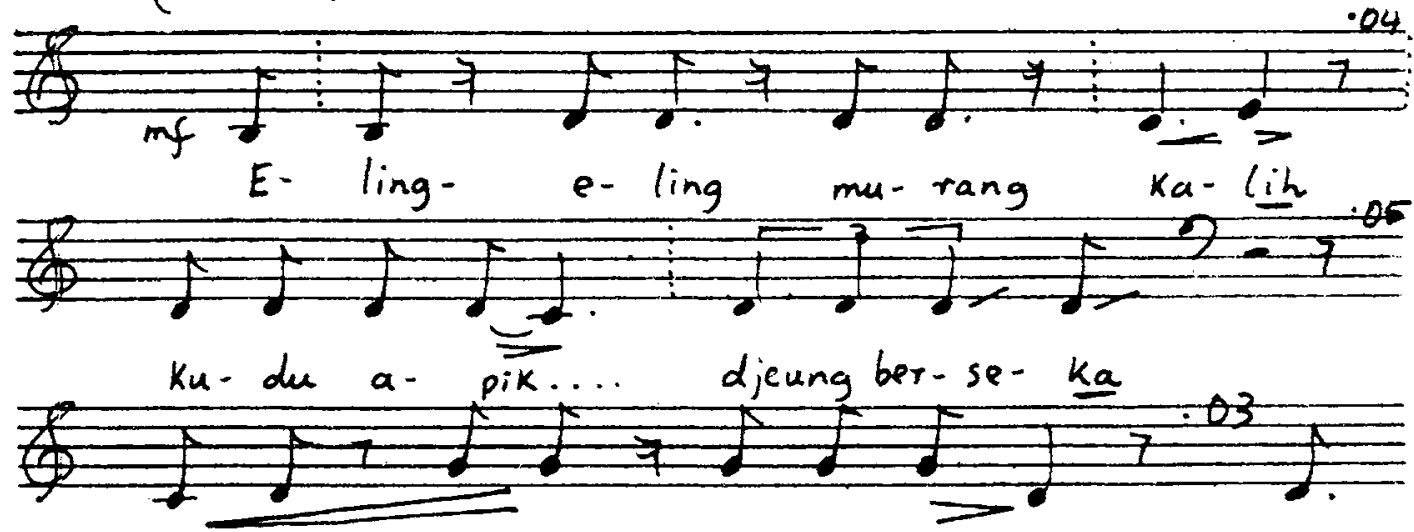

U- lah

o. doh

$K a-p a-n g a n g-g e$

Mun

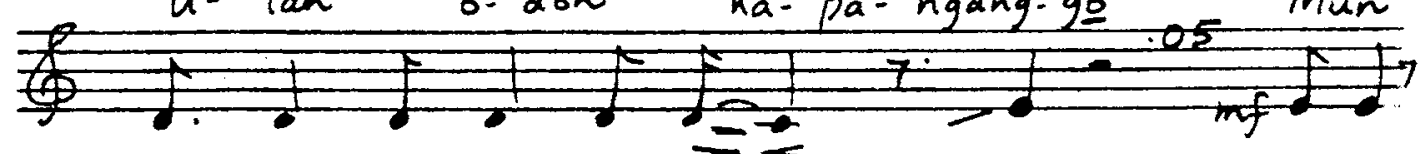

ko. for gen-ivat seu-seuh..

an So-eh
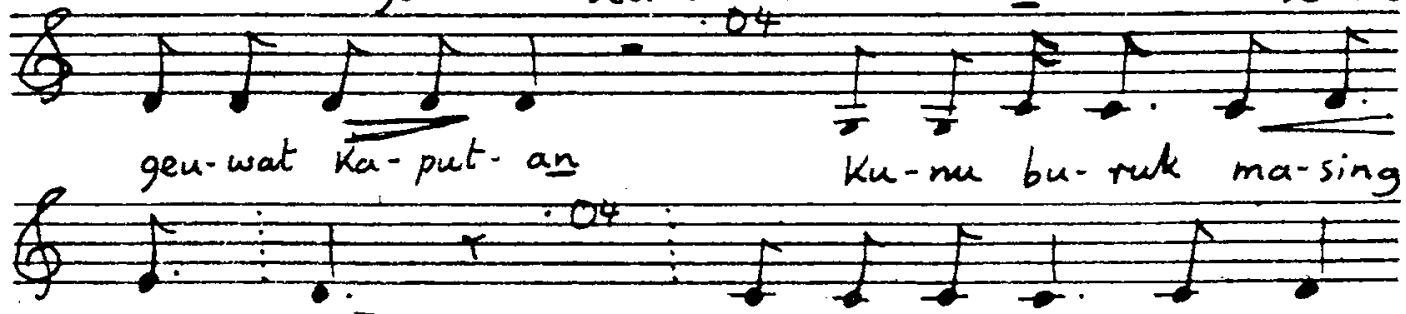

$\frac{b_{u}-\frac{1}{2} \cdot 05}{7} \cdot \frac{k u-m u a-n j a r \text { ma-sing }}{7}$

le. bar 
4. MIDJIL

SINGER: K. TOBING

T.L.: $0.63 \mathrm{~min}$.

O.P.: $2^{\frac{1}{2}}$ tones lower

\section{$(d=71)$}

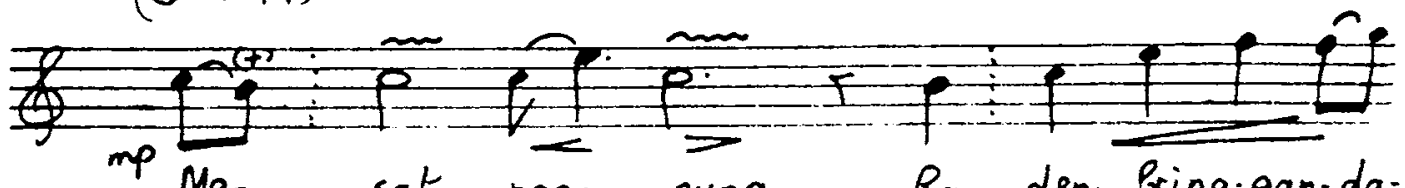

Me-... sat nga-... pung $R_{a}$ - den Pring.gan.da:
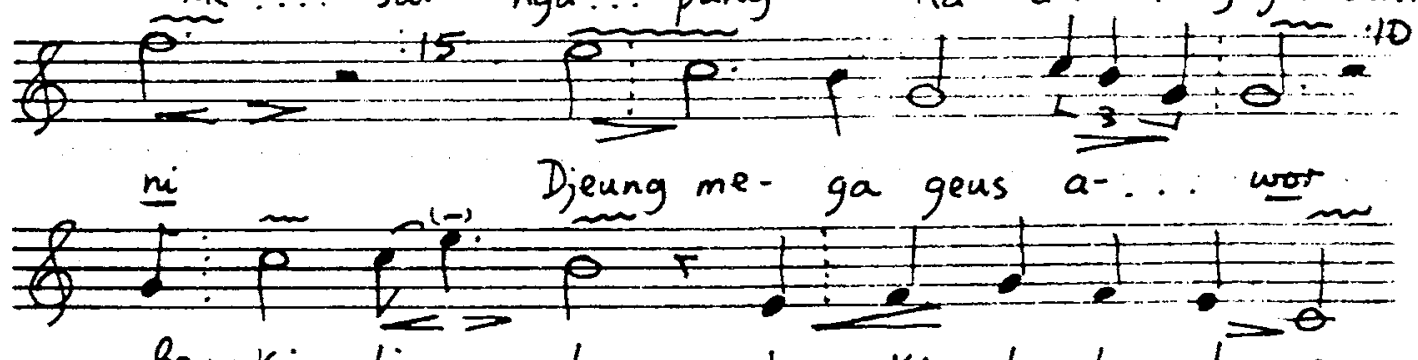

Beu-ki $\overrightarrow{l i-. . .}$ la beu-kinlu-hur ba-e

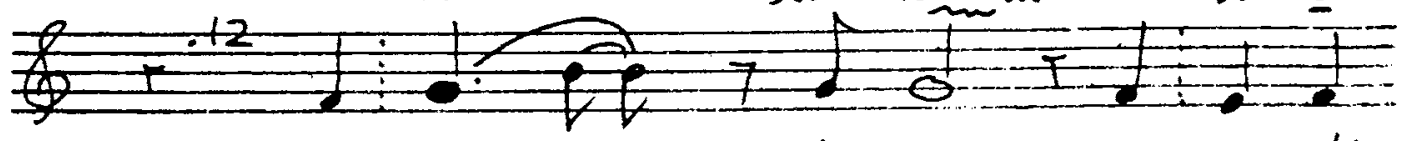

La-rak... li. rik ni-nga-li

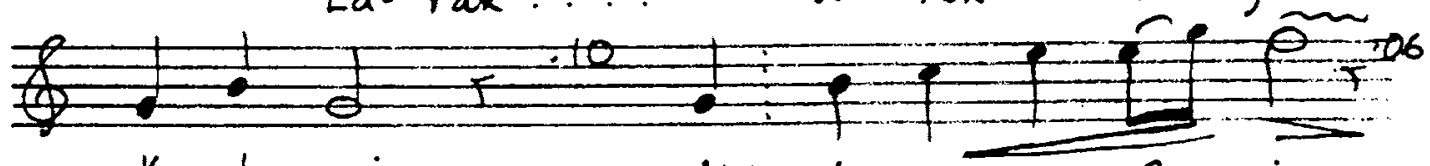

Ka. bu $=$ mi Ngi $\quad$ la - ri Kang Ra:.. i

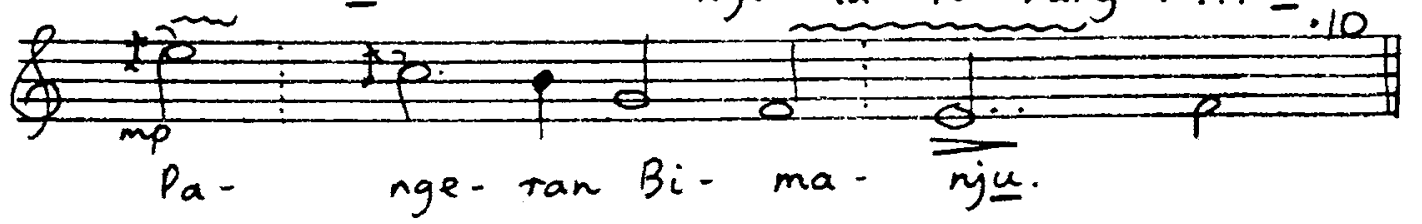


5. DANGDANGGULA

SINGER: K. TOBING

T.I.: $0.63 \mathrm{~min}$.

O.P.: $2^{\frac{1}{2}}$ tones lower

$(d=126)$

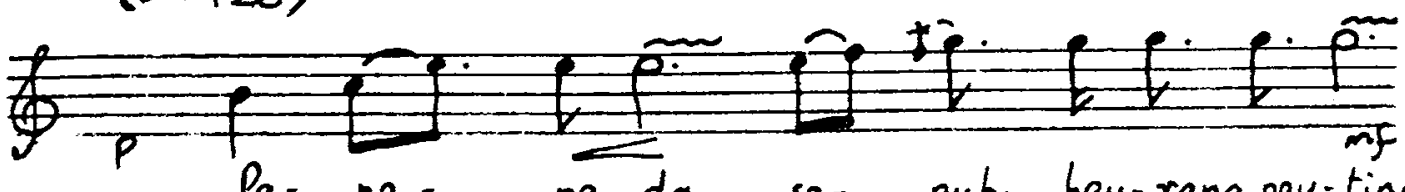
$\mathrm{Pa}$ - ne $\ldots$ ne-da se -.. puh beu-rang peu-ting

f) La:. in ha...jang... di-ki-rim-an tu-ang fo

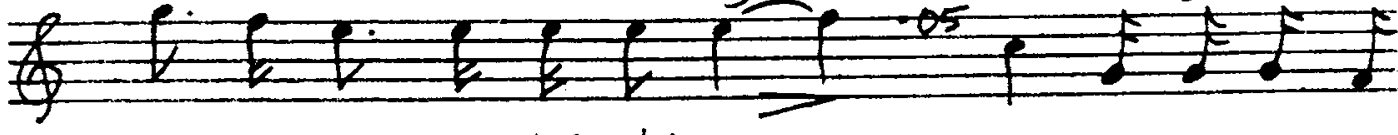

Ngan hajjang u-lah bi-ngung.. $\quad D_{i}-k_{i}$ - tim -an nee

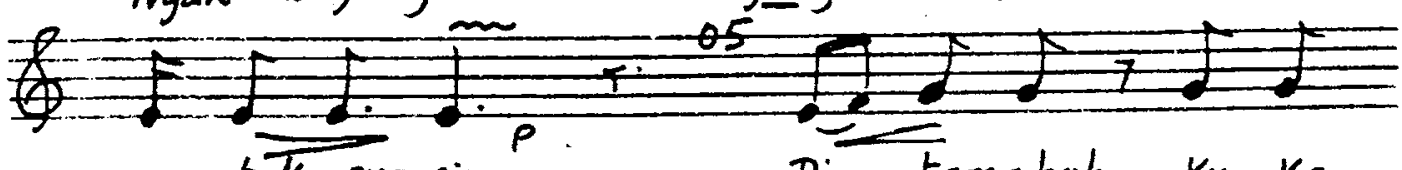

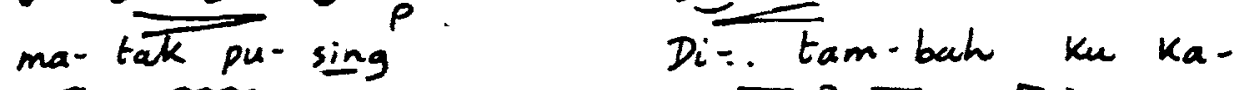
(1) me... lang

Nu ma-tak mang-pa-ung?.

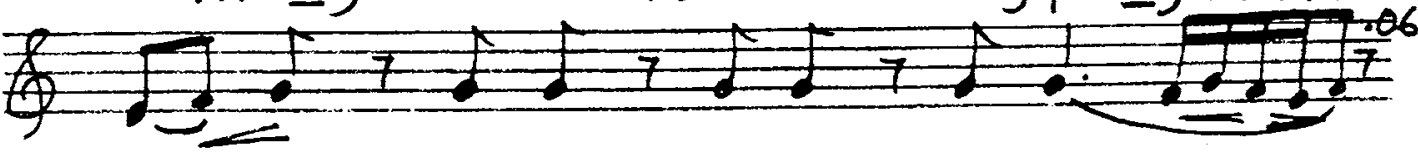
Ma-.. nah se-puh ma-sing se-nang.

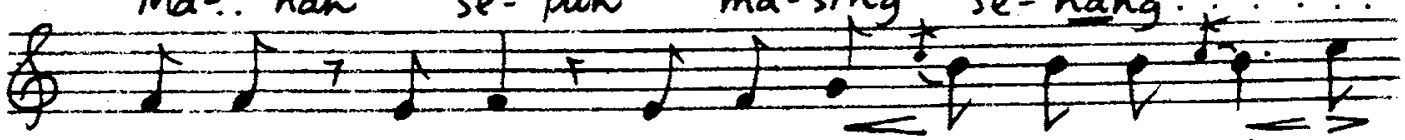
$T_{i}$ - is pi-kir se-nang nga-he-nang-nga-he-ning for Su-ka ma-nak bu-nga-.. ngang. 
$(d=126)$

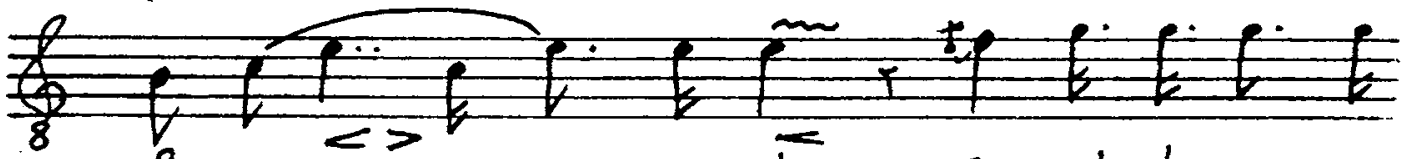

$\mathrm{Pa}_{\text {- ne- }}<>$ ne-da se-puh beu-tang peu-

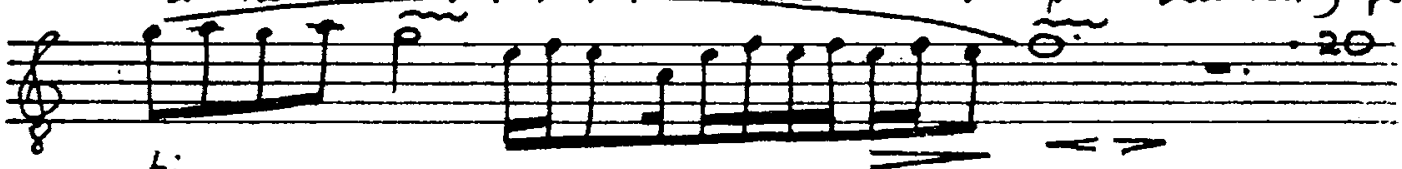
ting

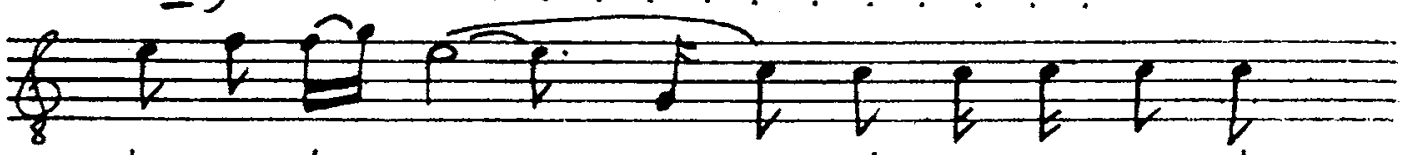
La- in ha-..jang di-ki-rim an tu-

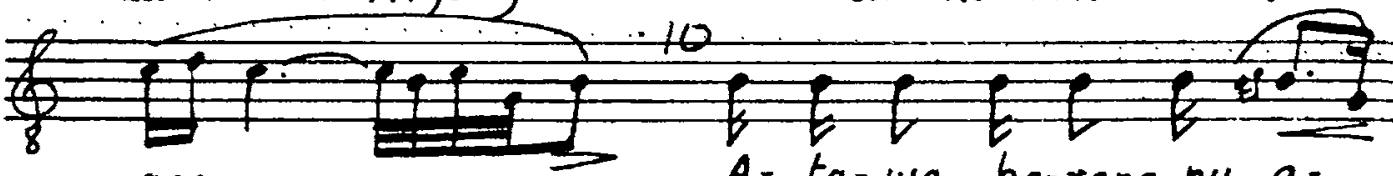
ang ba-rang nu $a$ : Ngan ....ha. jang...u. alah bi ngung... Di-ki-tim... an nu

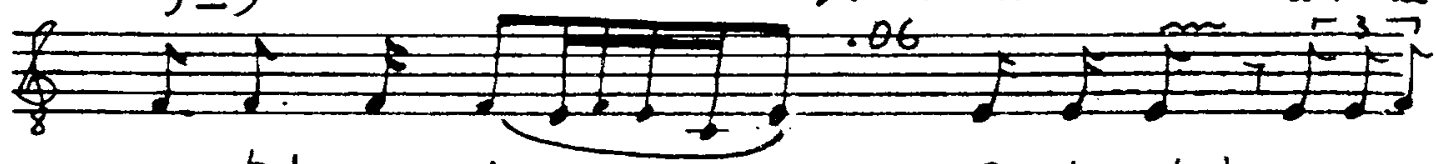
ma-tak pu-sing..DDi-tam-bah kuka-me

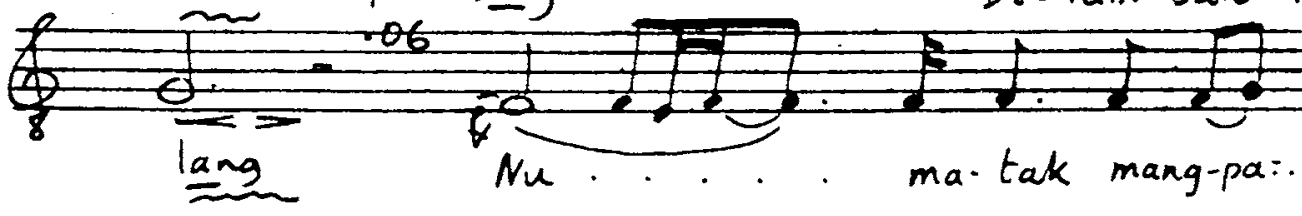



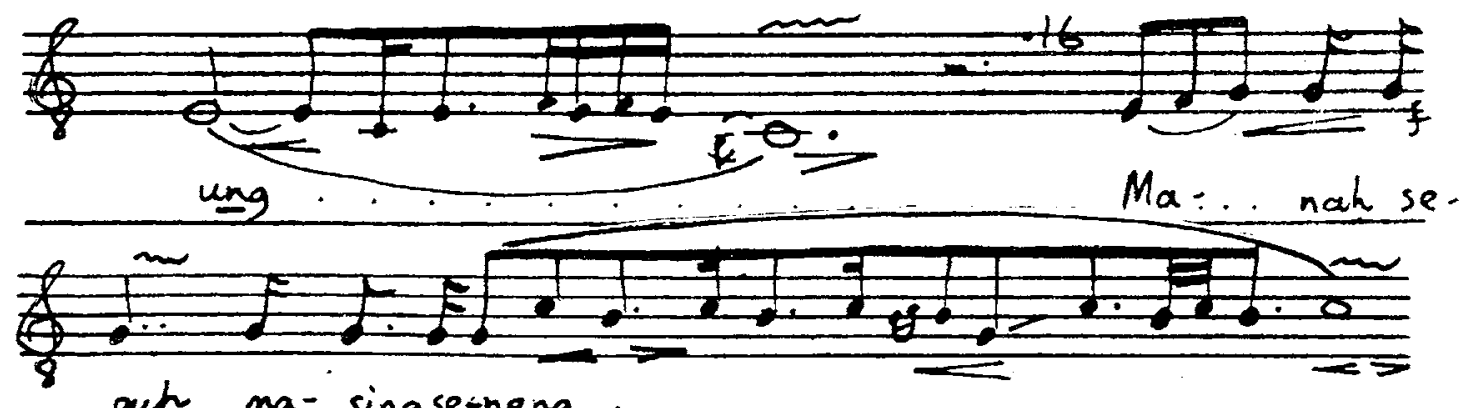
put ma- singse-nang

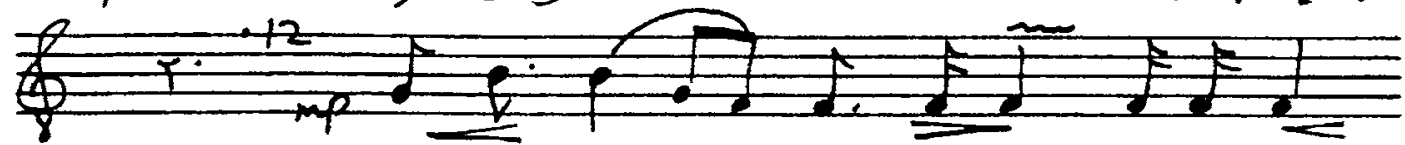
$T_{i}$ - is $p_{i}=\ldots$. Kir se-nang nga-he-nang-
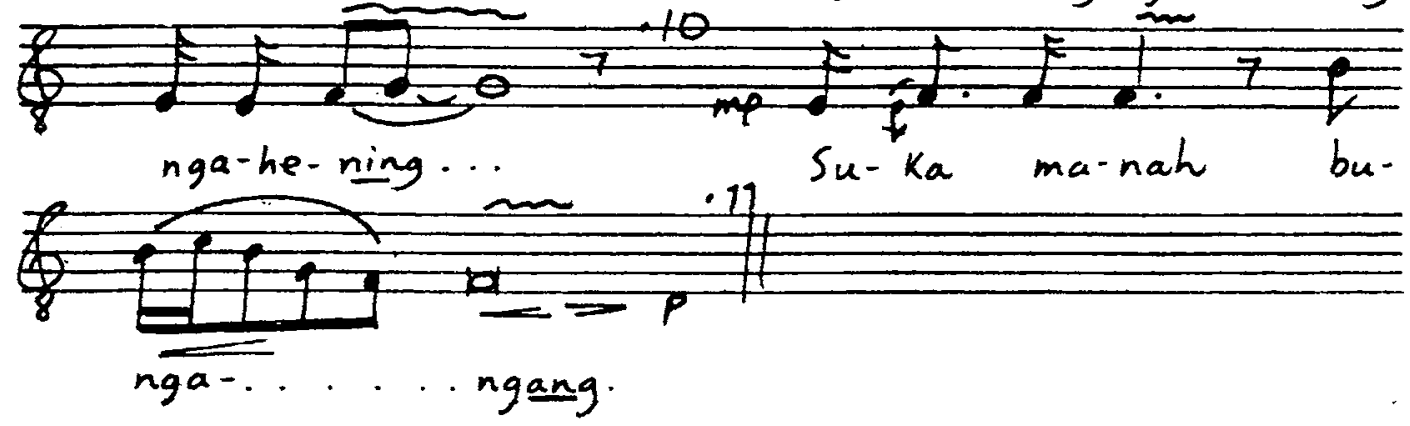
7. SINOM

SINGER: H. KARTOMI

T.L.: $0.62 \mathrm{~min}$.

O.P.: $\quad 2^{\frac{1}{2}}$ tones lower

$(d=96)$

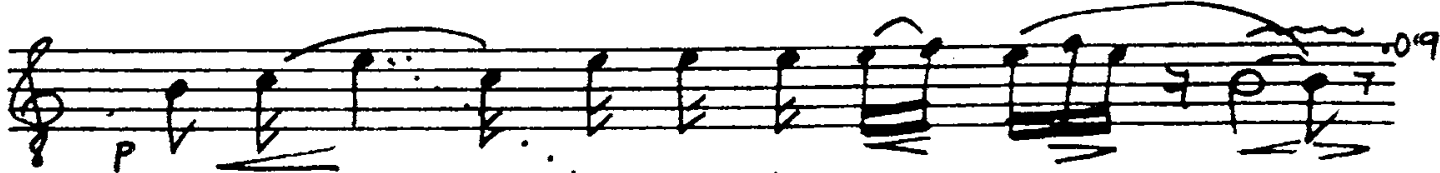

War-na... . war.na lauk em-.. pang

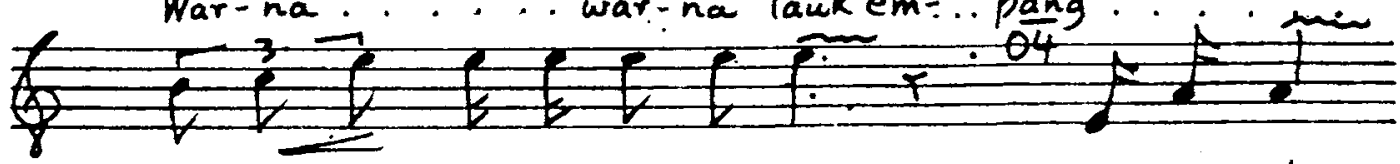

Seu-eur nu sa-mi djeungping-ping $P a-q u$-lung

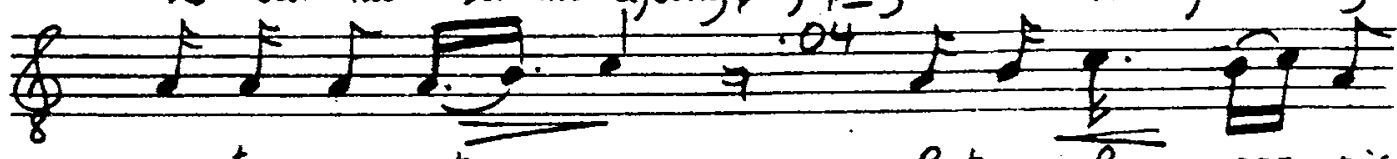

pa-tum-pang-tum :.. pang Rat-na $\overline{R_{a n g}}-g a-$ nis

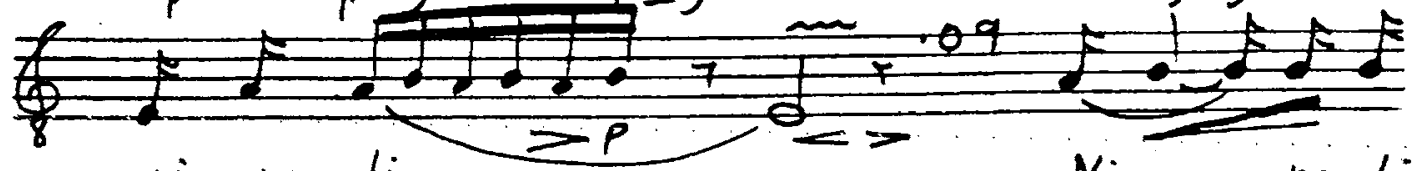

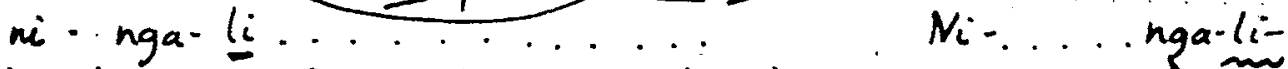

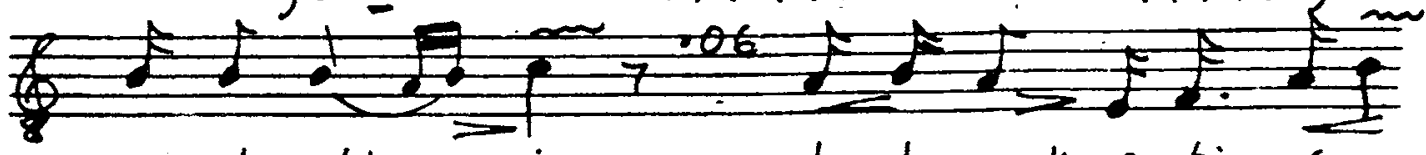

keun lauk tja.... $\quad$ La-la-wak pa-ting su-ru-

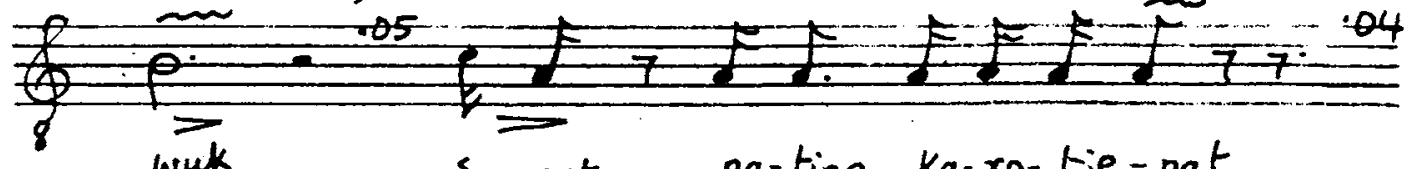

se-pat pa-ting ka-ro-tje-pat

Dju-lung-dju-lung nga-dja. ling $\ldots . .$. djing

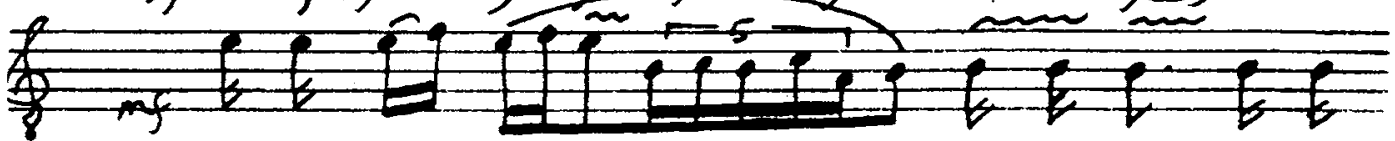

Si-si bai. long...... ba-ling.bing si-si

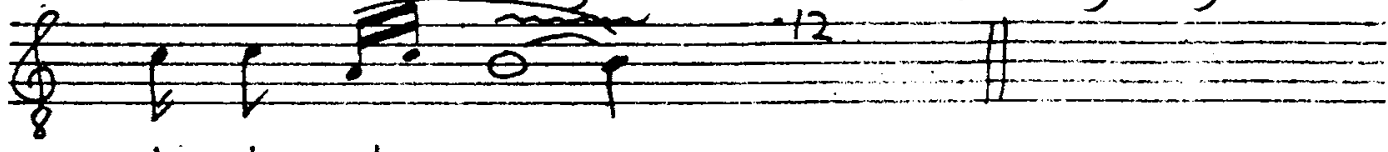

ba-lung-bang..... 


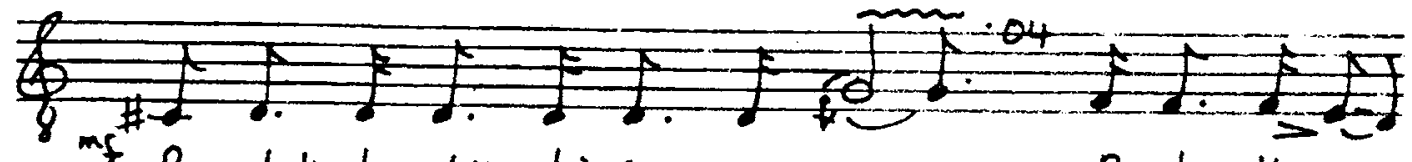

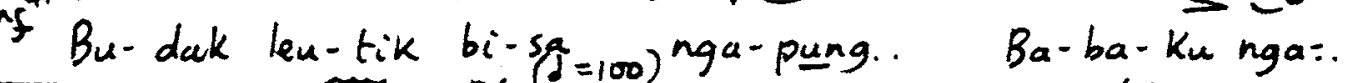
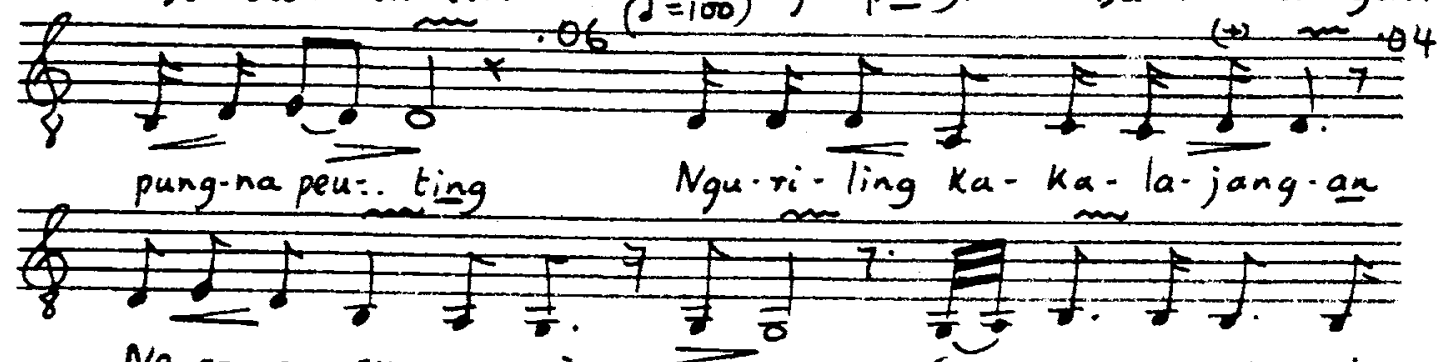

Ne-anguan me a-mis- $a_{\text {- mis }}$ Sa-- tu-pa-ning bu-

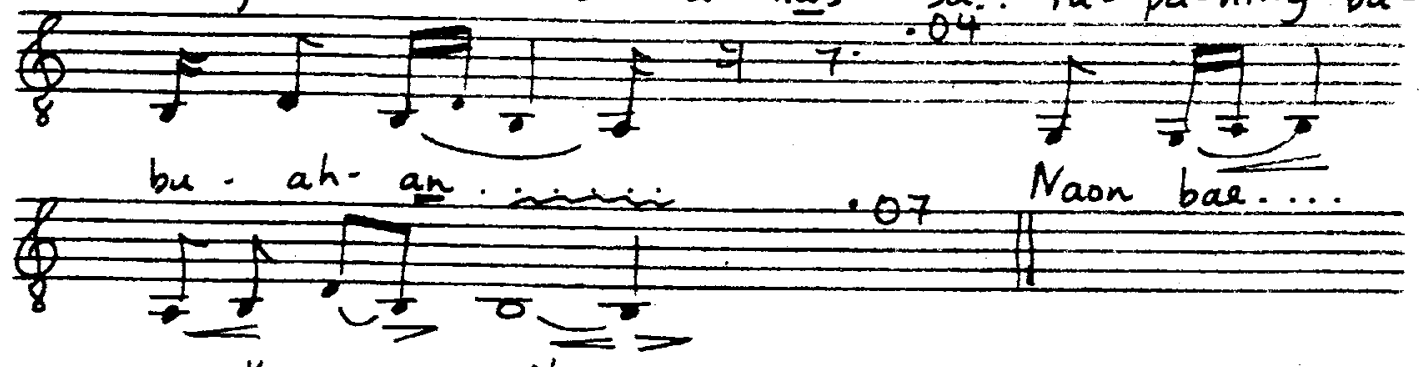

mu ka-pang.. gih... 
9. KINANTI

SINGER: H. KARTOMI

T.L.: $0.85 \mathrm{~min}$.

O.P.: as below

$(d=92)$

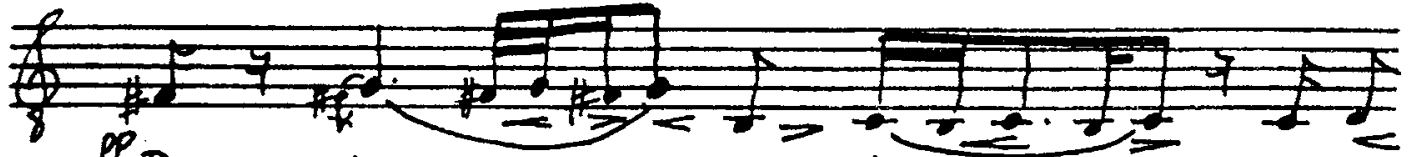
F

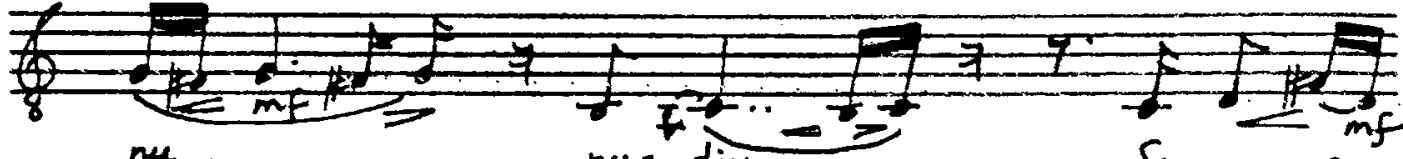
nu...... $n{ }^{-} d_{j u} \ldots$ Se.nang ga:.

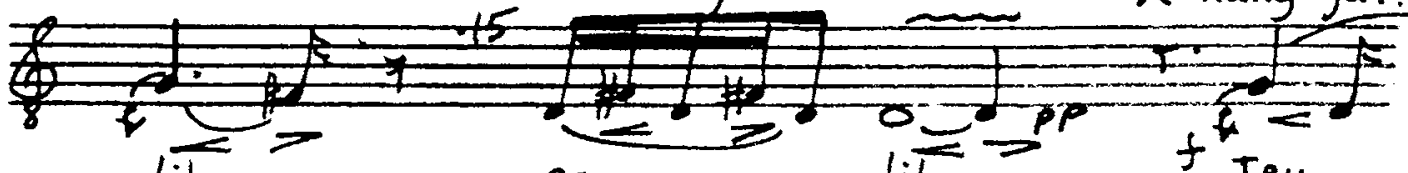
lin.....

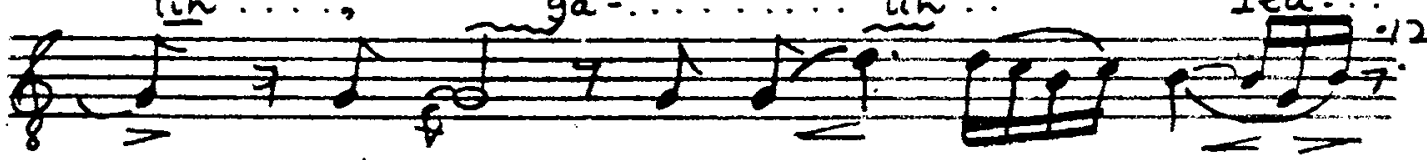
… $N_{\text {gin }}=$ tun ........ keun.. se-... rat sa-.

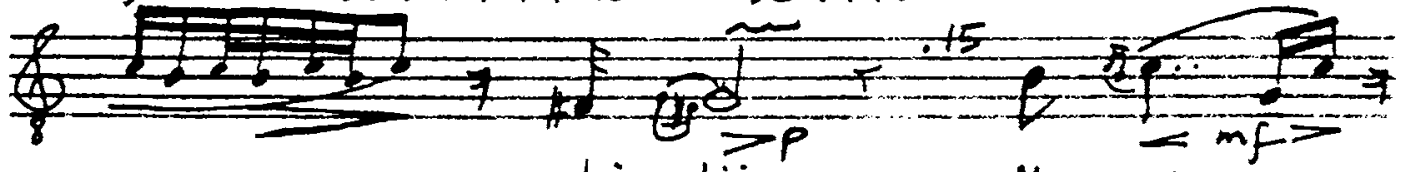

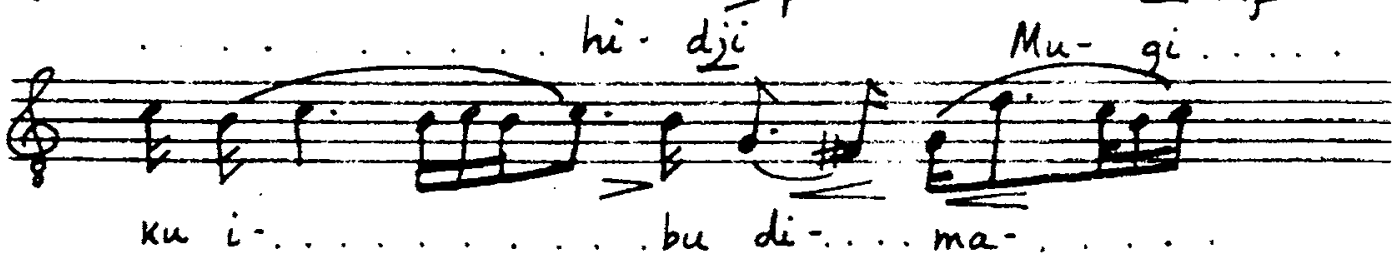




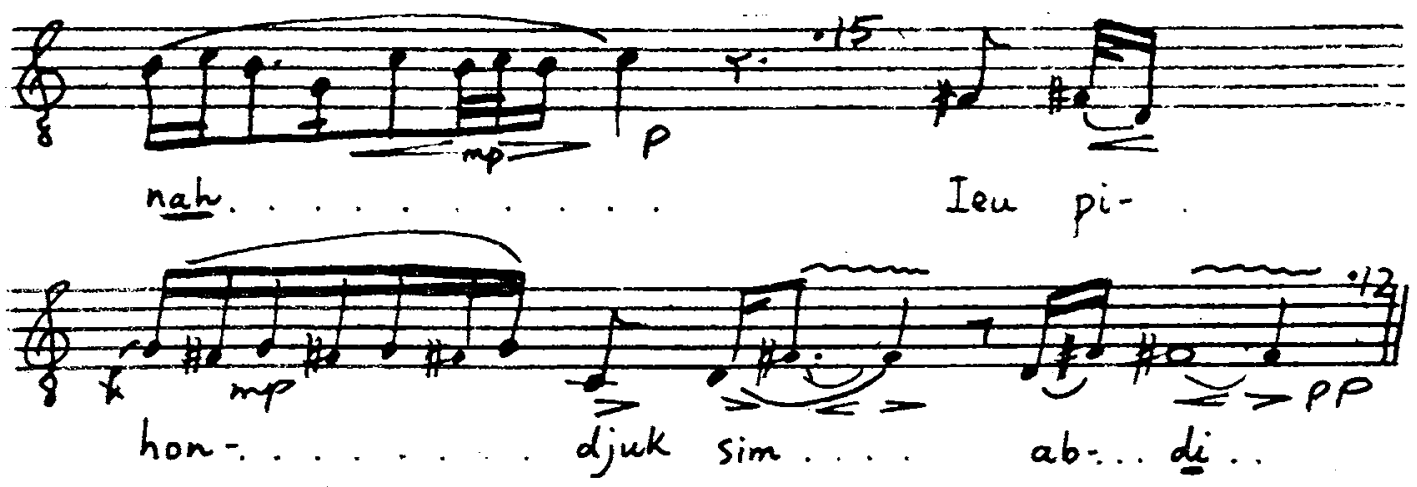


10. KINANTI

SINGER: H. KARTOMI

T.I.: $0.41 \mathrm{~min}$.

O.P.: $\frac{1}{2}$ tone lower

$(J=120)$
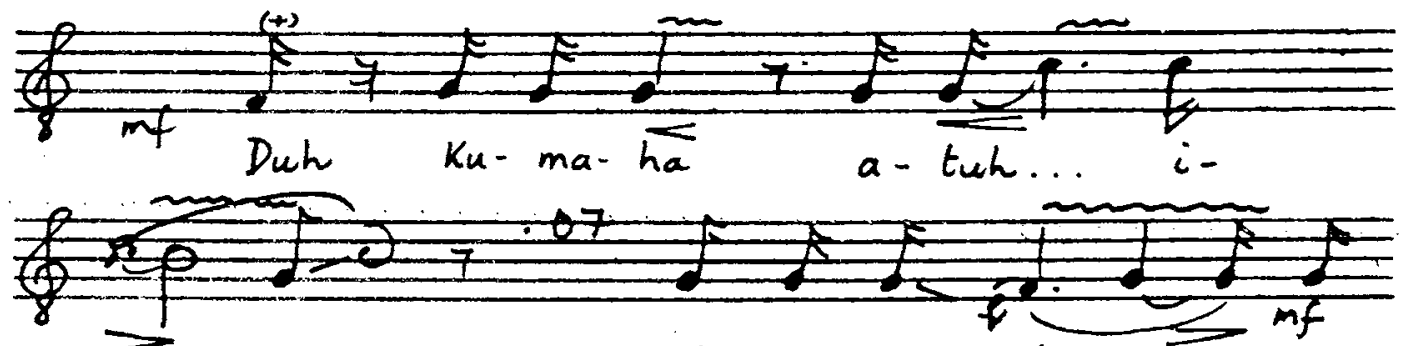

bu.

A- nu nu-dju.

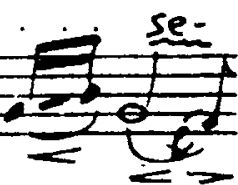

nang ga-lih Teu $a b$ - di nu sang-sa-. Ta...

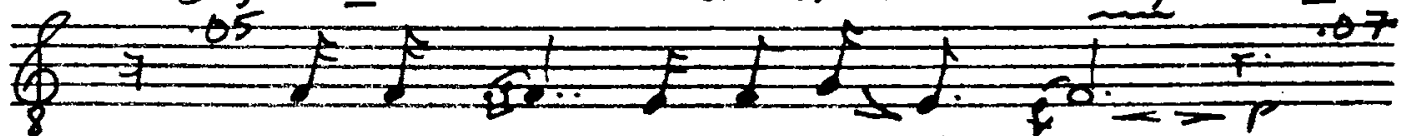

Ngin-tun-keun se-tat sa-hi- dji

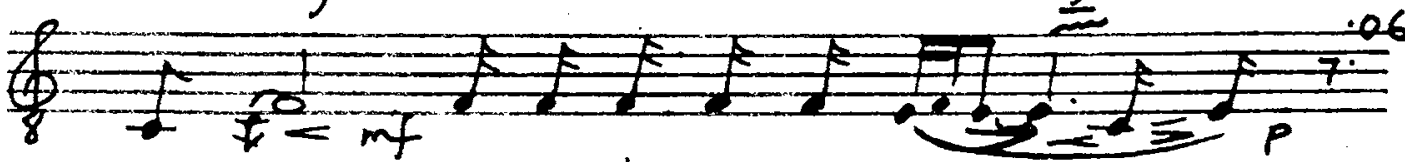

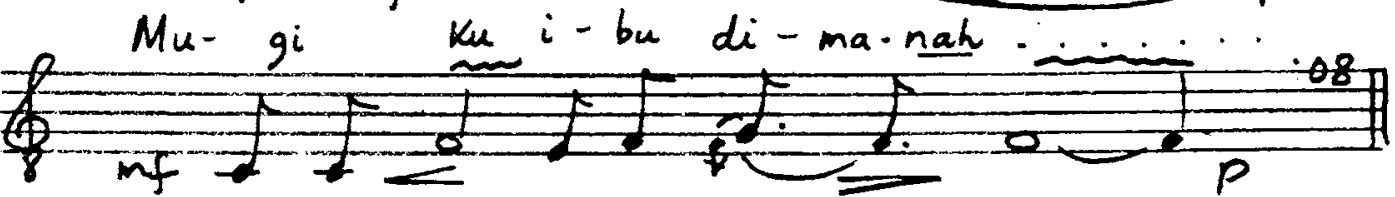

Teu pi-hon-djuk sim ab-.....di. 
11. PANGKUR

SINGER: H. KARTOMI T.L.: $0.45 \mathrm{~min}$.

O.P.: $\frac{1}{2}$ tone lower

$(d=118$

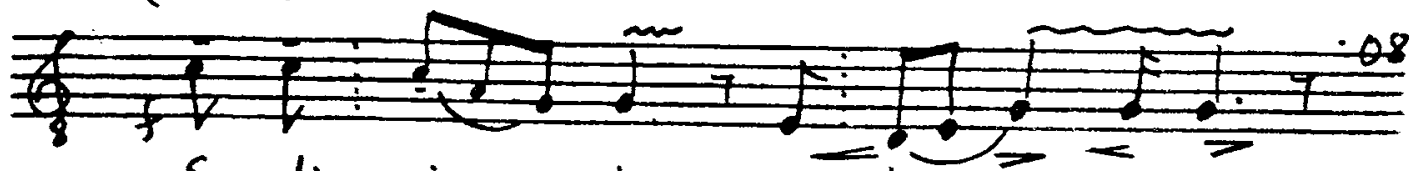

Se-dja nja:...ba nga-la-.. la-na

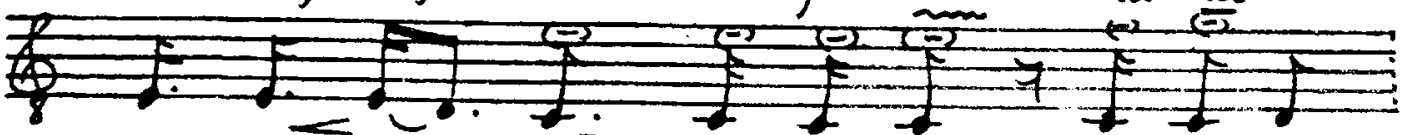

$N_{g i}-\operatorname{tung}_{g} \cdot l_{\text {lem-; }}$ but nga-dja-djah mi-lang-an

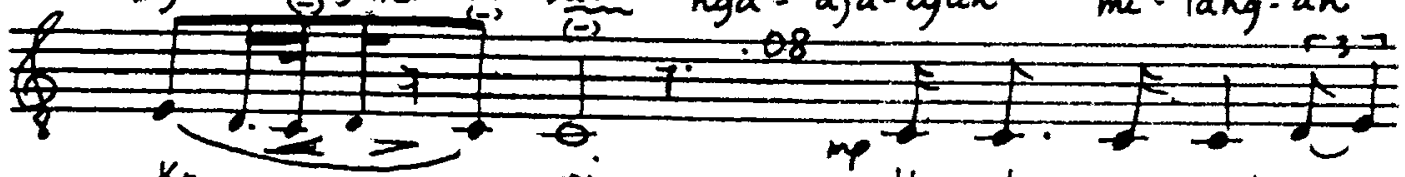

$k_{0}-\ldots+$ mon Hen-ten pu-guh nu..

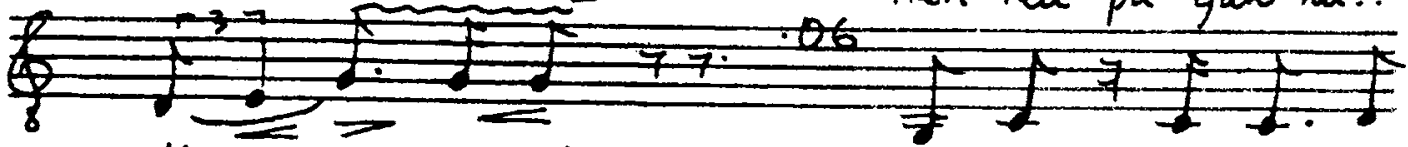
di:...djug-djug Ba-lik pa-man sa-

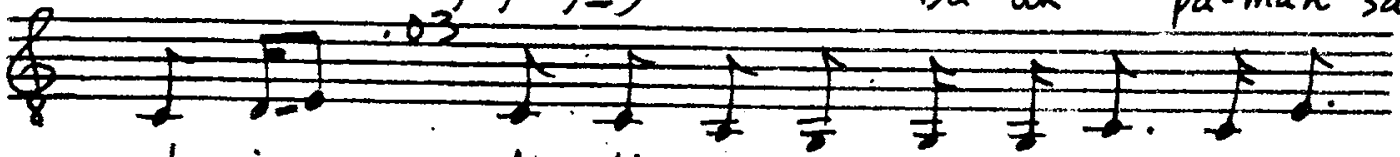
$d a-j a . . \quad$ uNu $t i-m a-n a \quad t_{i}-l u-$ an se-mu

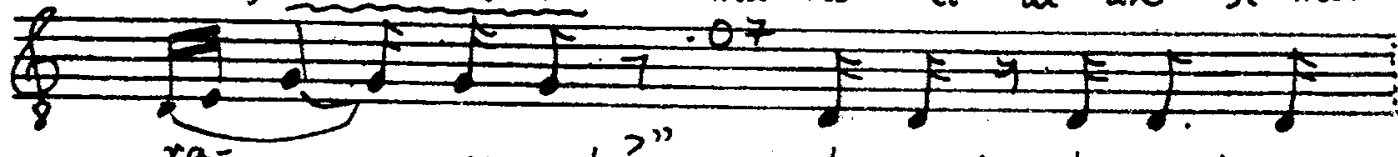

Fija-suh?" Lu-rah be-gal nga-

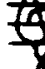

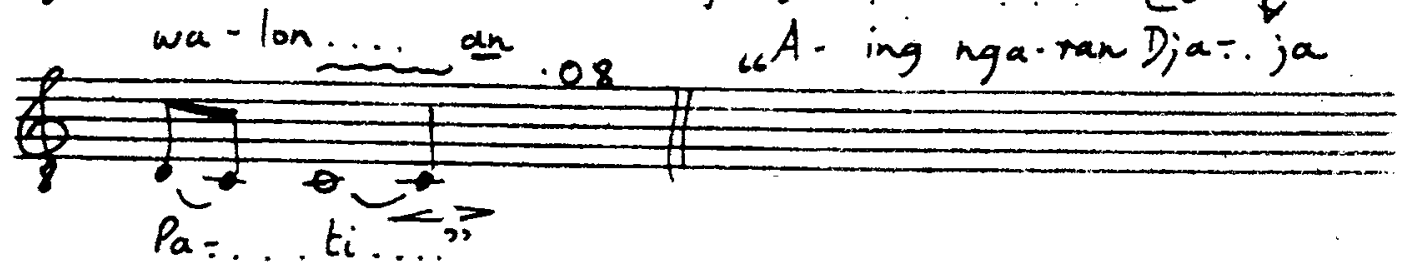


12. DURMA

SINGER: H. KARTOMI

T.L.: $0.49 \mathrm{~min}$.

O.P.: as below

$(=107)$

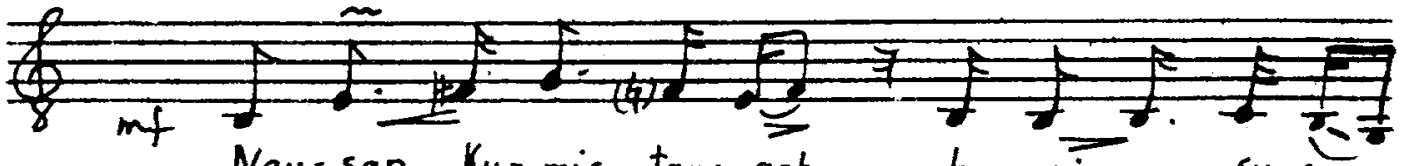
Ngu-sap $K_{u}$-mis tang-gah.. ba- ri-na su-sum-.

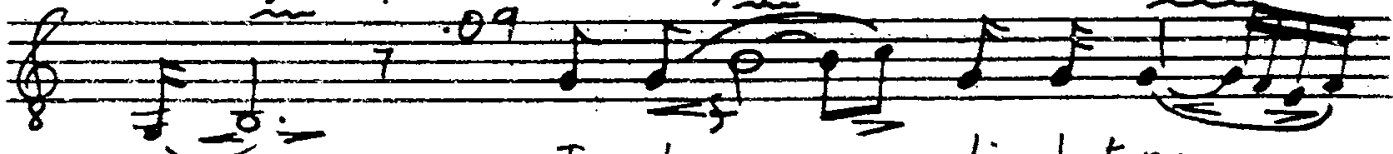
-

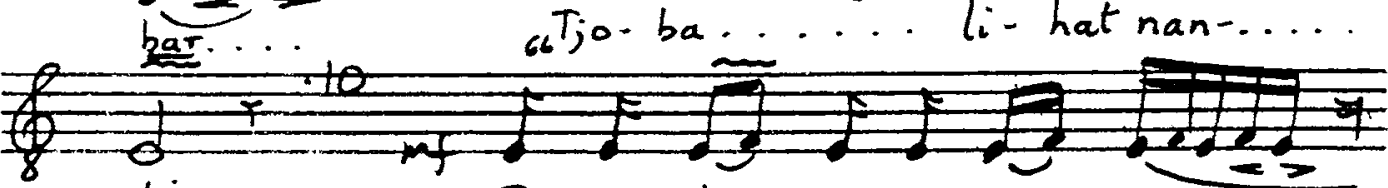

ti $\quad D_{i}$ - da-lam. pe-pe-rang

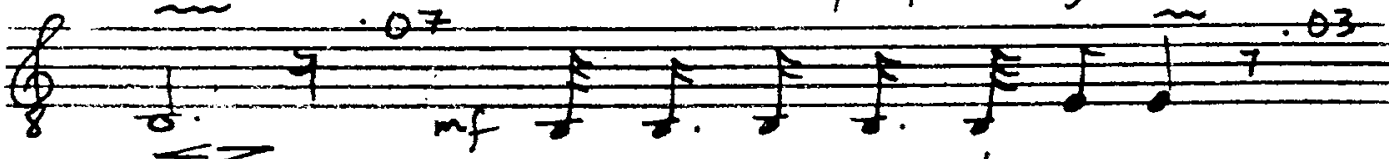
$\therefore$ Gu-a pu-nja bi-a-sa

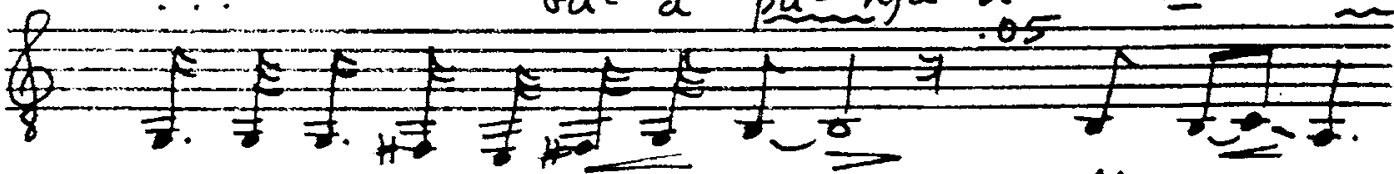

Dan guia pu- nja be-ra-ni... Me-nang-..Kap

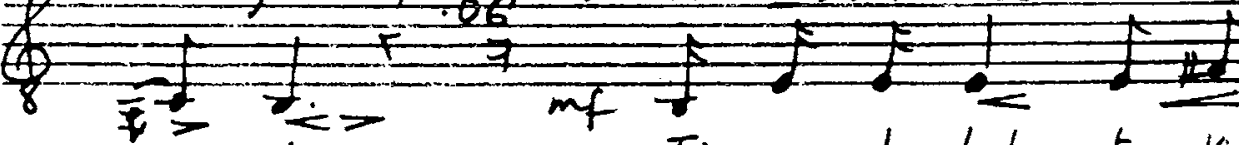

ra- dja Ti-a-da-lah ta-kut

$8=-1+2+2$

ma....... t. ti ${ }^{\prime \prime}$ 


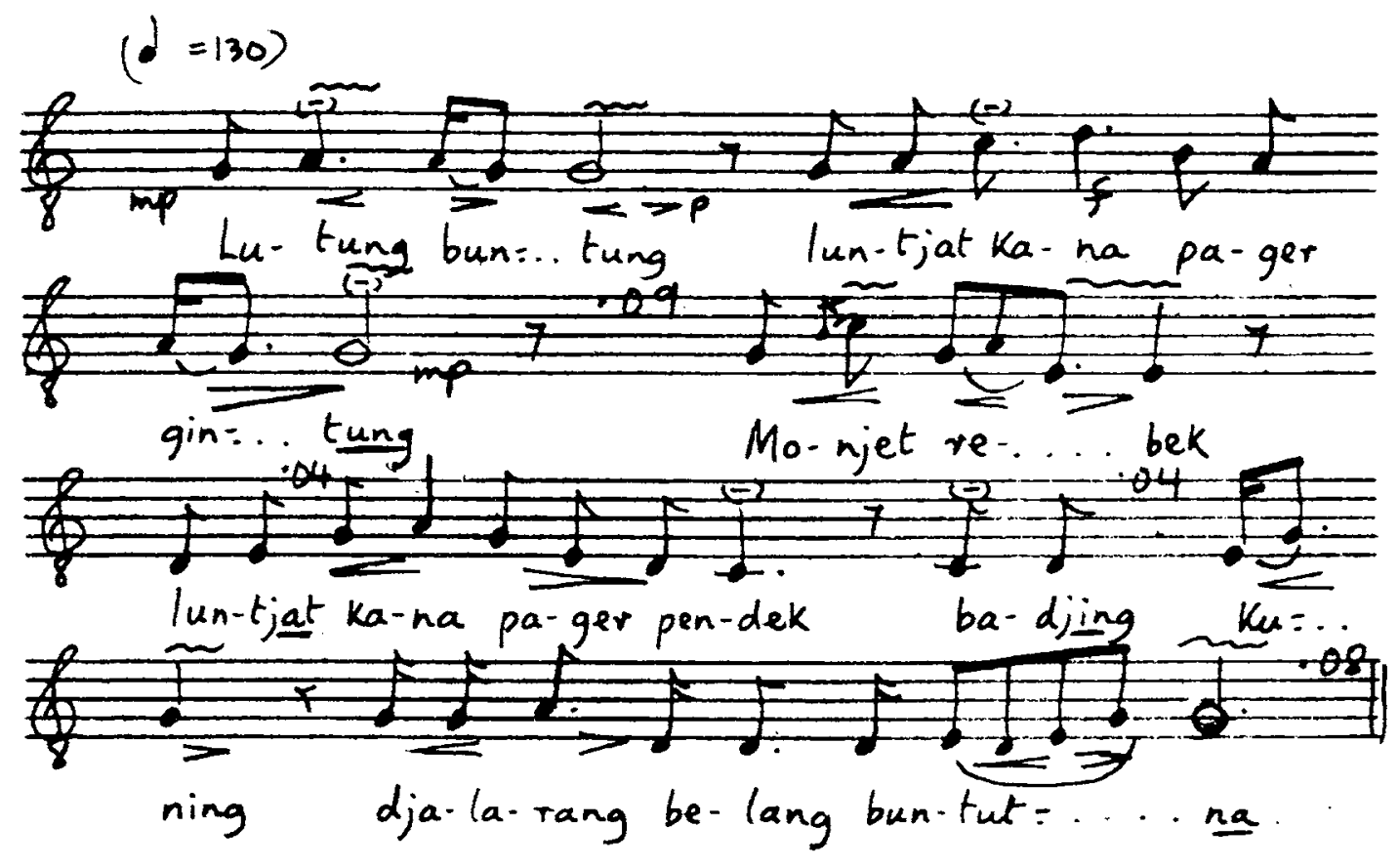


14. ASMARANDANA

SINGER: H. KARTOMI

T.L.: $0.34 \mathrm{~min}$.

O.P.: 1 tone higher

$(d=125)$

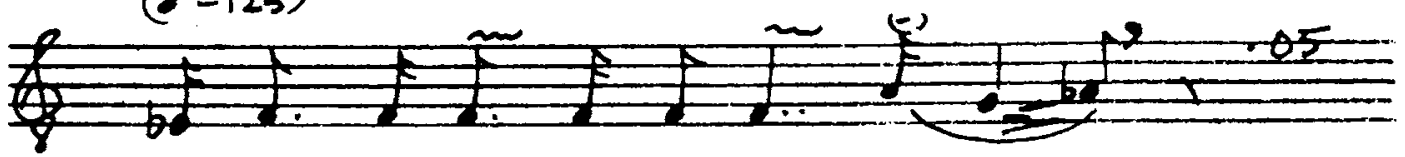

$E-$ ling-e-ling mu-rang $k_{a}-l i h . .206$

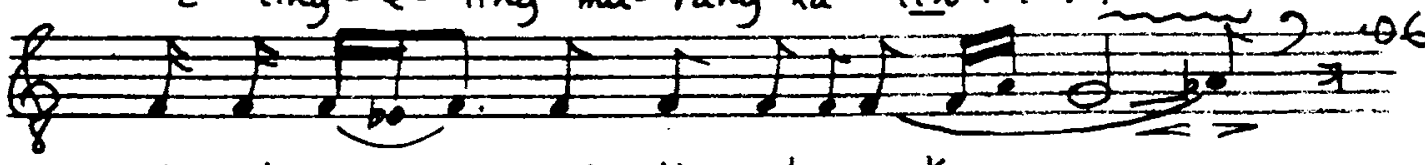
$k_{u}-$ du $a-\ldots$ ipik djeung ber-se-ka......

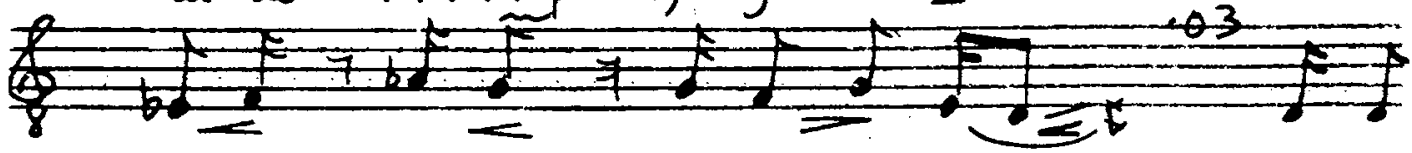
U.lah o-doh Ka-pa-ngang-go... Mun Ko-

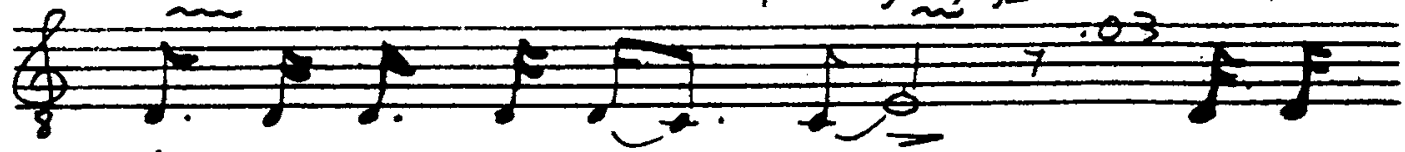
tor geu-wat seu-seuh... an ... So - eh (2) $+2$ ma-sing bu-twh ...... ku-nu a-njar ma-

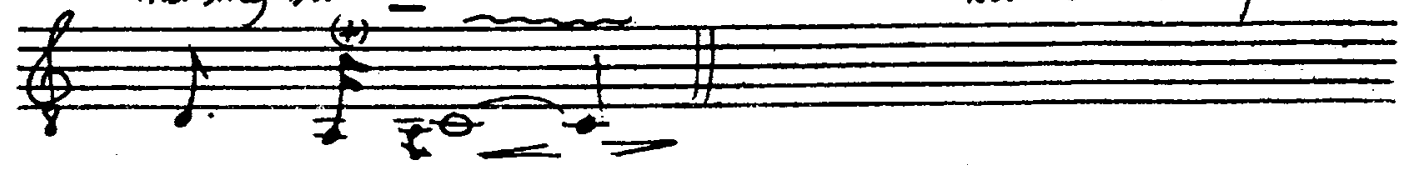
sing le bar.... 
15. MASKUMAMBANG

SINGER: H. KARTOMI

T.L.: $0.30 \mathrm{~min}$.

O.P.: $I^{\frac{1}{2}}(t)$ tones lower

$(d=88)$

7

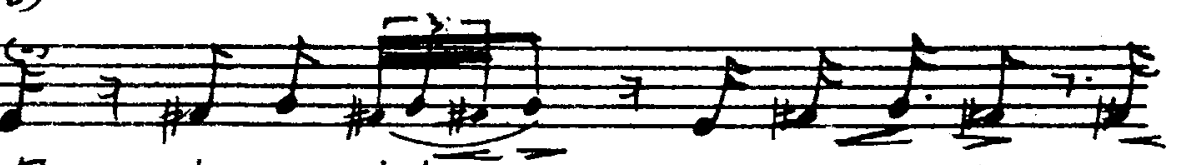

mp Eh ba-tu-dak... ku-du mi-kir ti
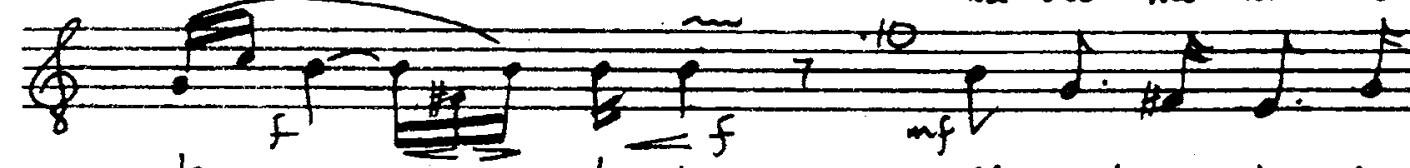

leu....... leu-tik
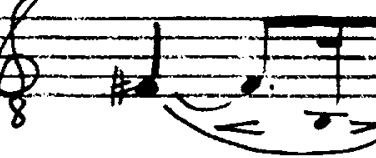

an
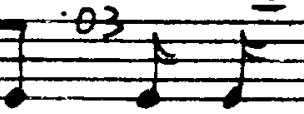

Ma-neh Ka-hu- tang-
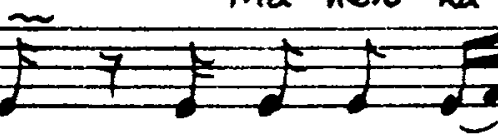

$k_{u} k_{0}-10 t$

ti ba-rang la-.

$\exists$

Ku

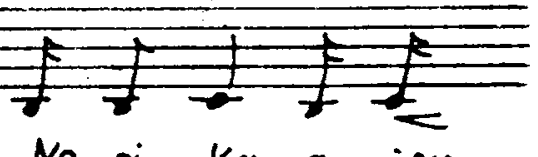

hir.:

Ne-pi Ka-a-jeu-

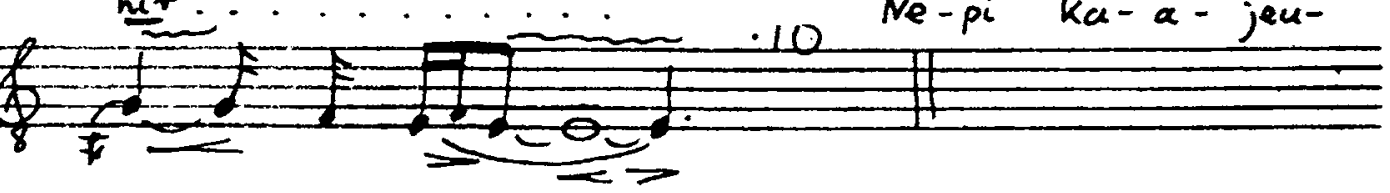

na... pi-san.... 
16. MIDJIL

SINGER: H. KARTOMI

T.L.: $0.59 \mathrm{~min}$.

O.P.: $I \frac{1}{2}$ tones lower

$(d=140)$
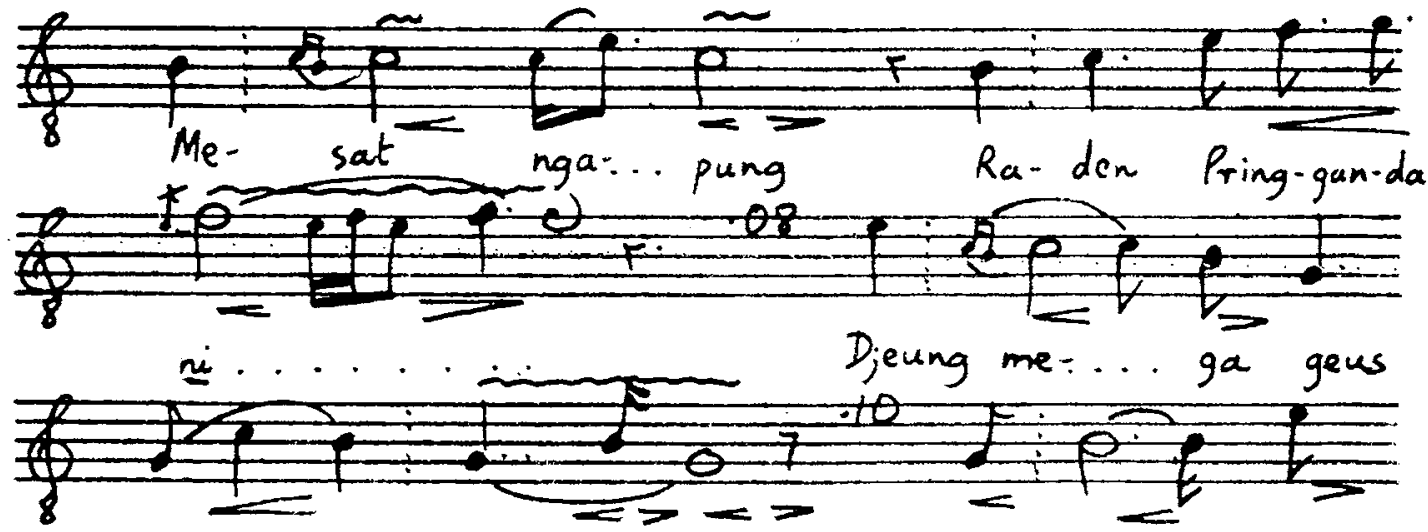
$a$ -
wor.
Beu- Ki...
li-

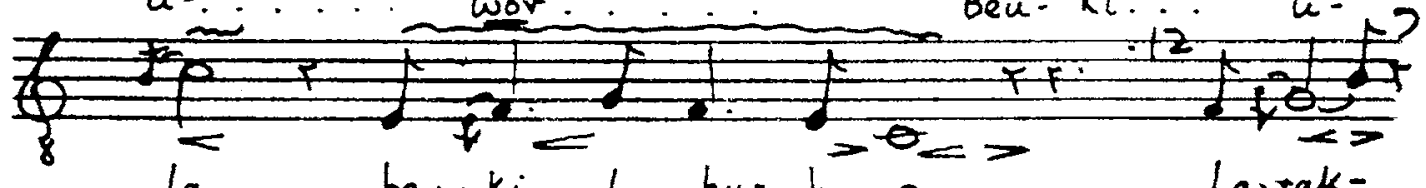

la beu-ki lu-hur ba-e La-rak-.
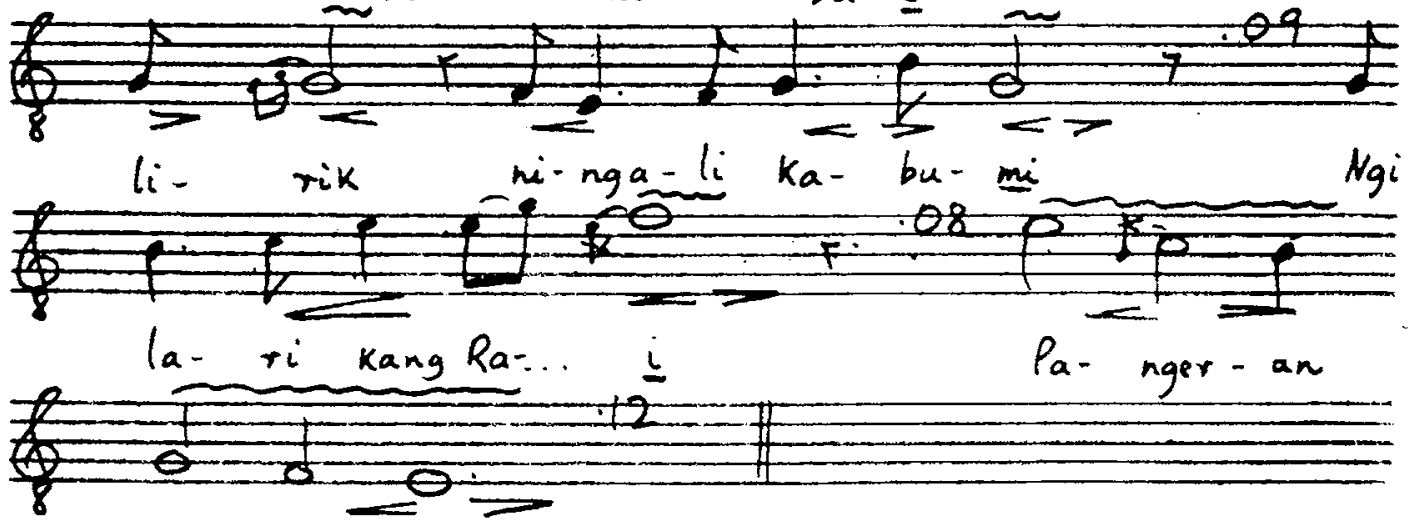

Bi. ma- nju. 


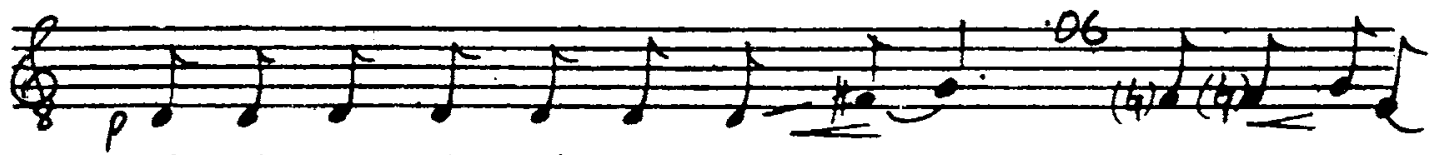

Bu-dak leu-tik bi-sa nga-pung.. Ba-ba-kunga-
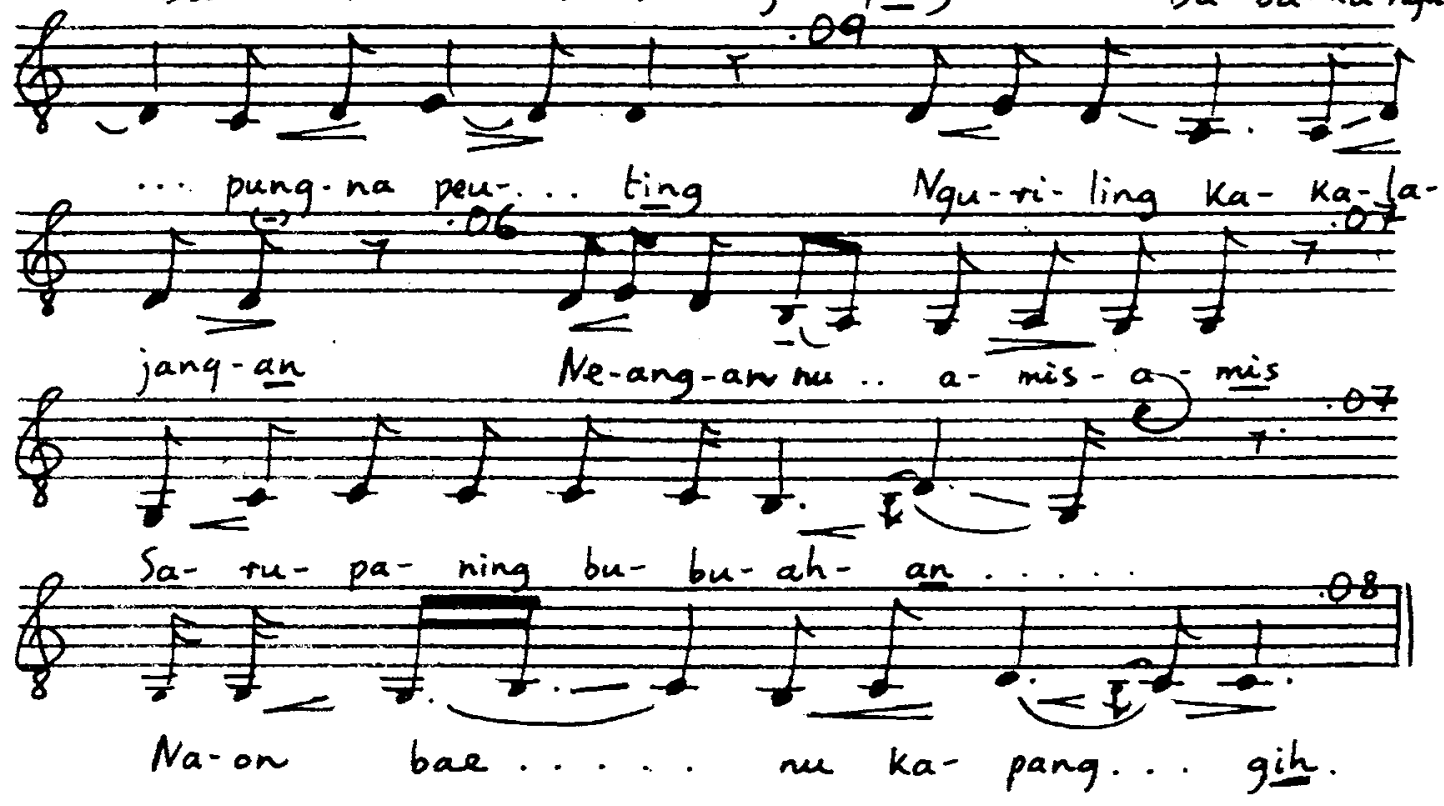
18. KINANTI
SINGER： SUDRADJAT

HOME TOWN: SINDANG KEMPENG T.I.: $0.81 \mathrm{~min}$.

O.P.: 2 tones higher

$Q=135)$

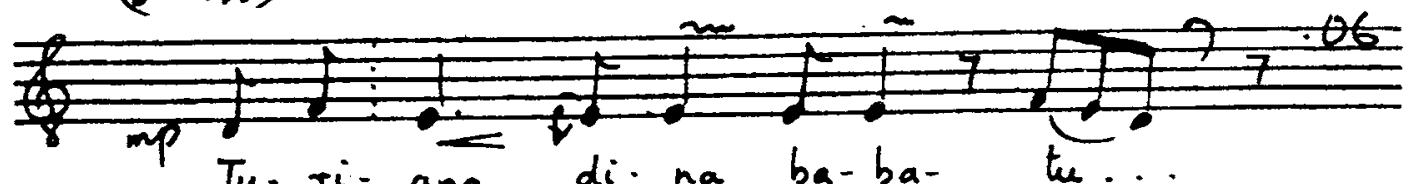

Tu. ri- ang di. na ba-ba- k...
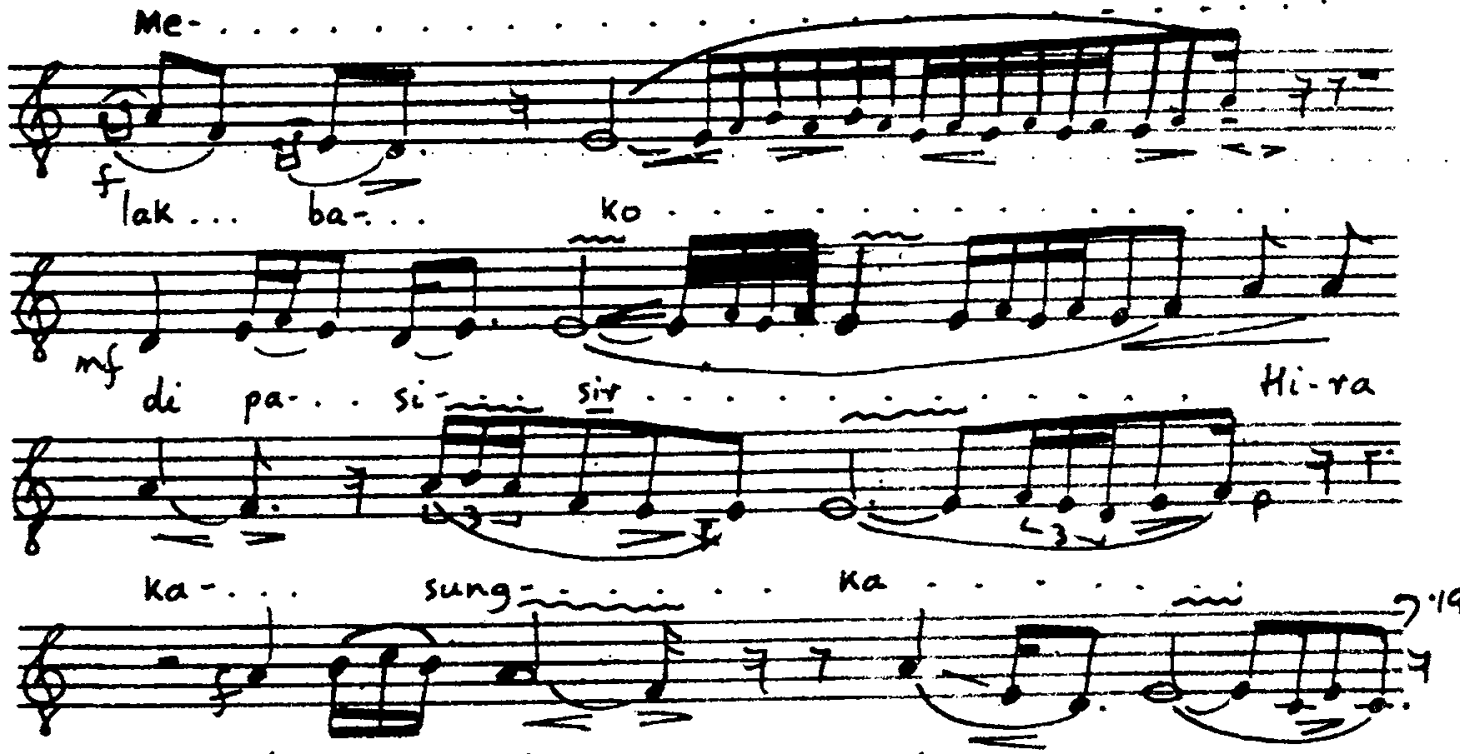

di $\mathrm{Ka}$ -

dja-

ga

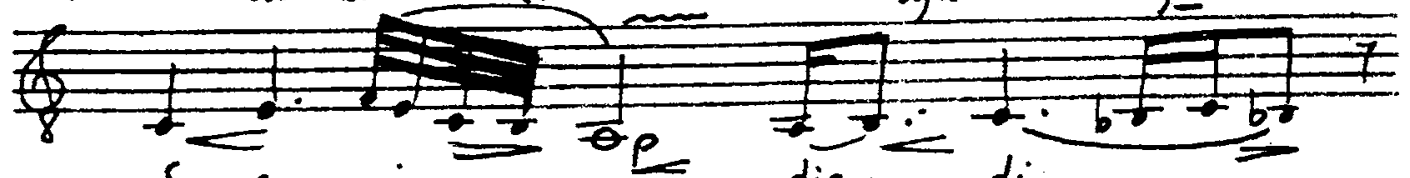

Sa-sa-wi. dja $=\ldots$ di.

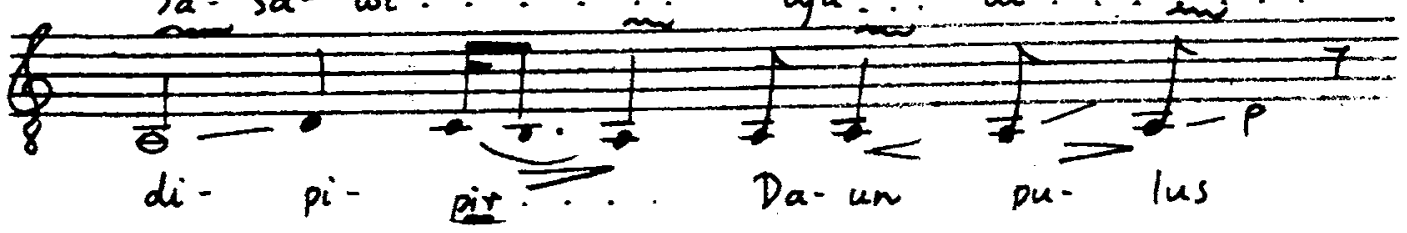




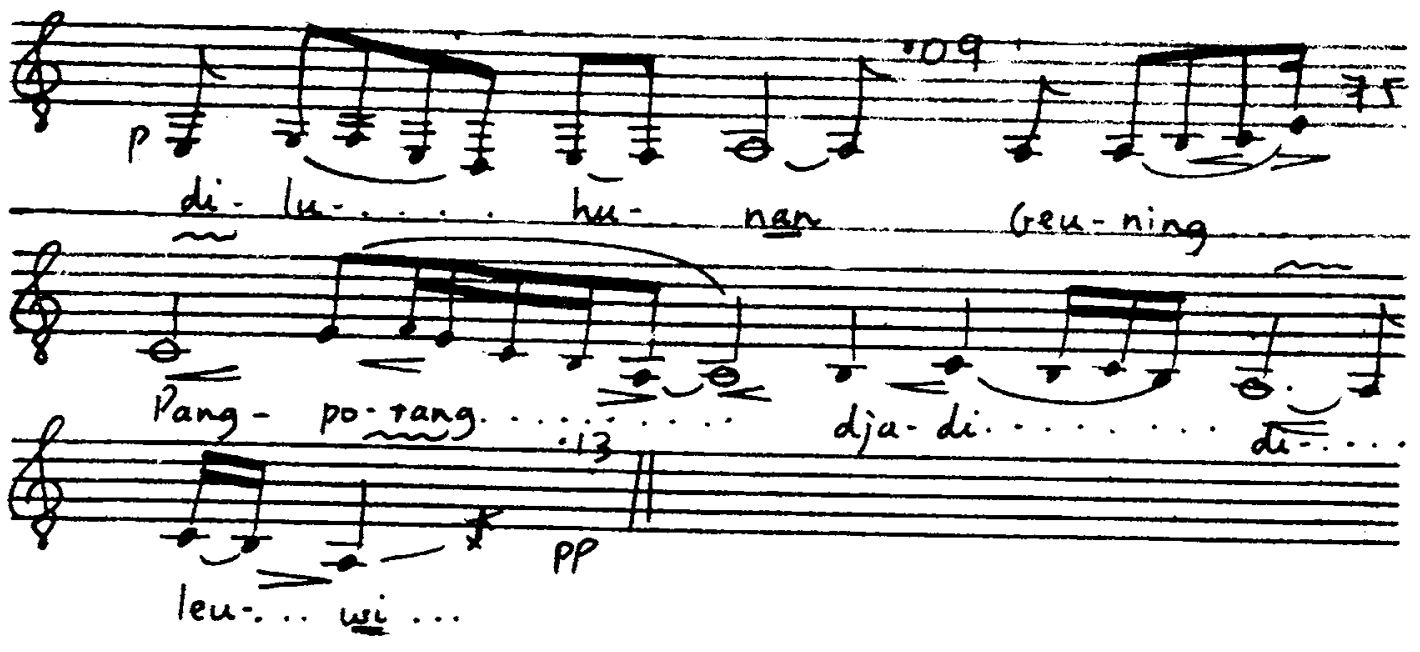


19. ASMARANDANA

SINGER: SUDRADJAT

T.I.: $0.64 \mathrm{~min}$.

O.P.: $2^{\frac{1}{2}}$ tones higher

$(d=135)$

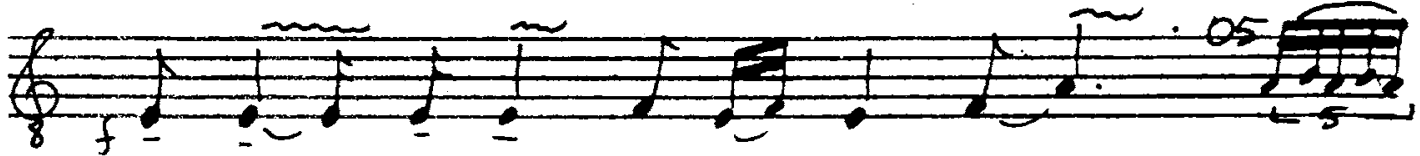

Bo- sen... ngu-ping si- ang.. weng- $i \ldots . \quad \mathrm{Ka}-.$.

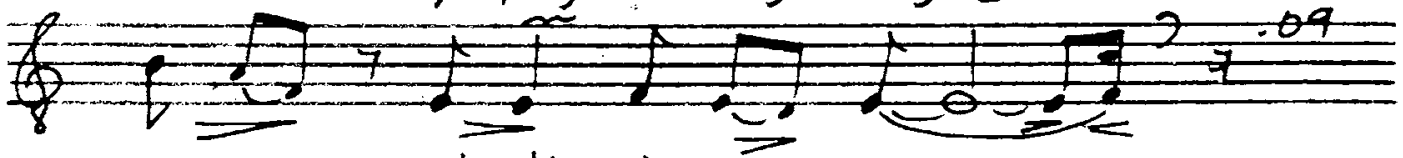

$$
\text { ma-na.. } a b-\alpha i \text { nja ne=. ang. }
$$

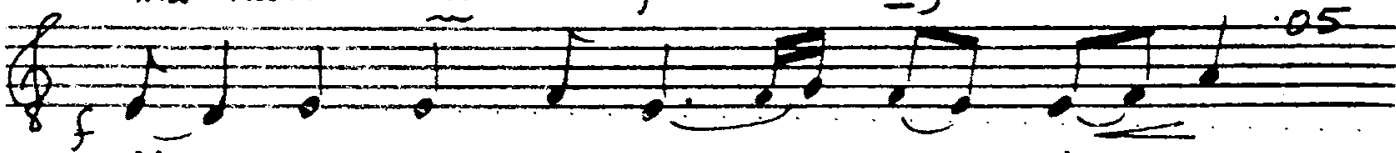
Mun.. sum-ping $k_{u} a_{n} \ldots \ldots$ djeun... ba....e

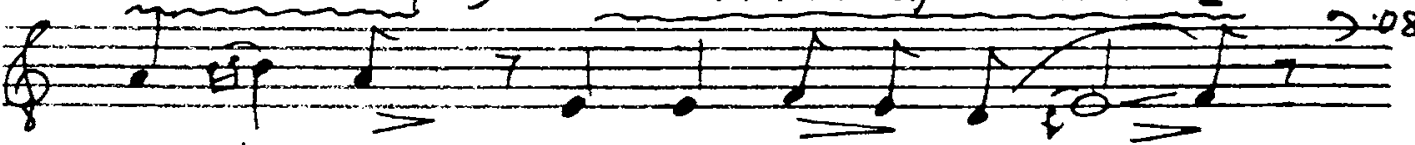

U. lat sok ngang-go a-le-man...

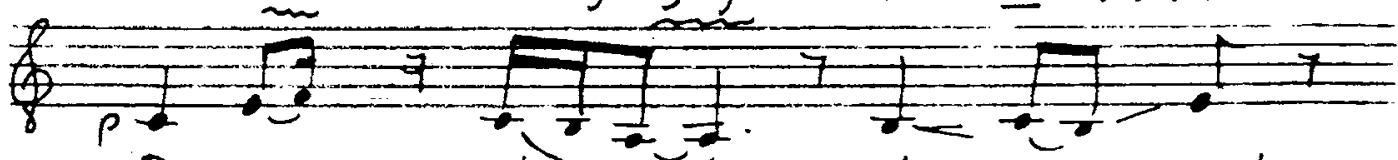

Da mo:. al..... de - se... mah-

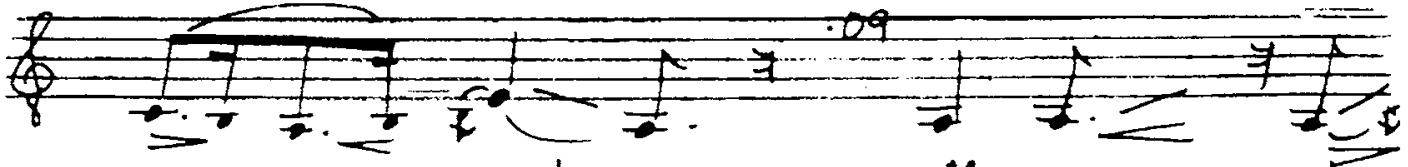

se-.... mat.. Ma-na-a sib.

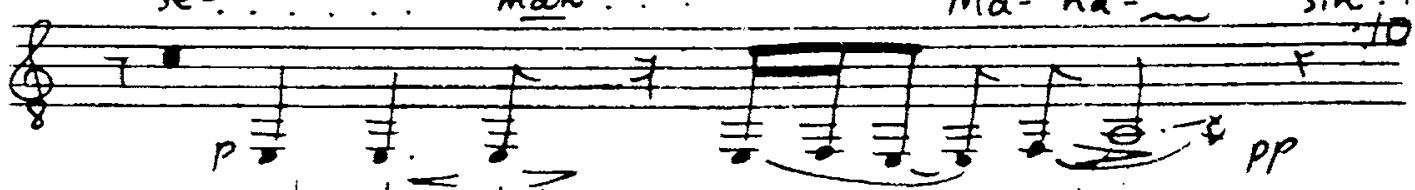

$a b \cdot d=$ teh 2 anq..

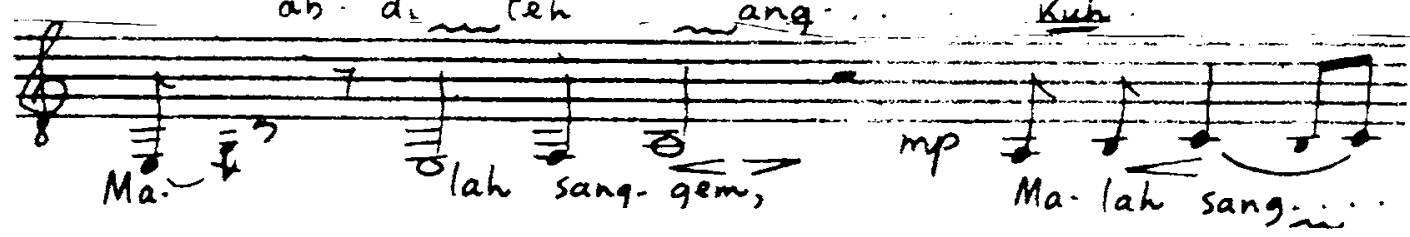




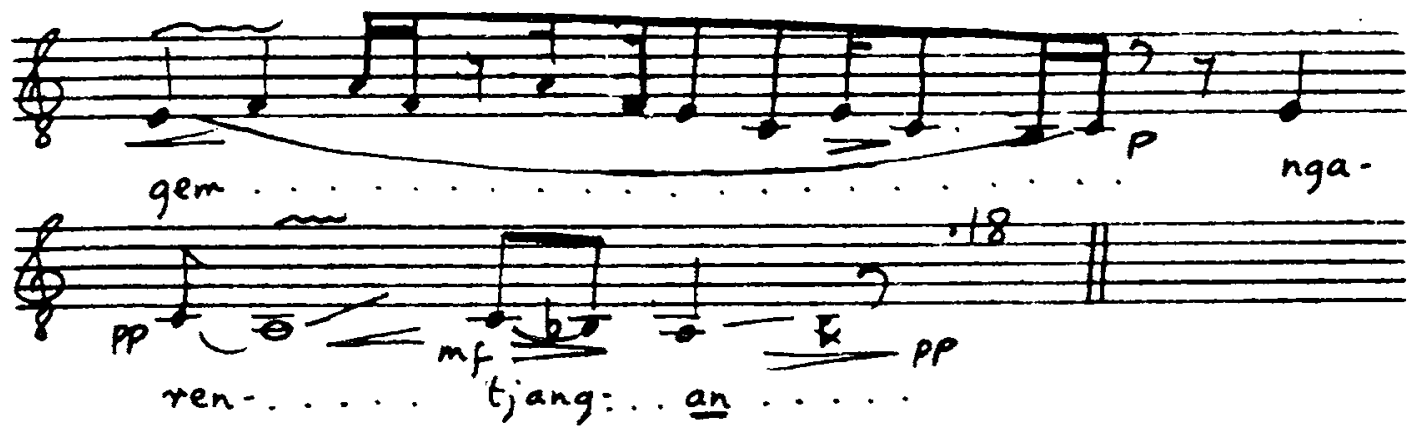


20. KINANTI DJEMPLANG TITI

SINGER: SUDRADJAT

T.I. (verse 1): $0.58 \mathrm{~min}$. (verse 2): $0.56 \mathrm{~min}$.

O.P.: $\quad 2 \frac{1}{2}$ tones higher

$(d=135)$

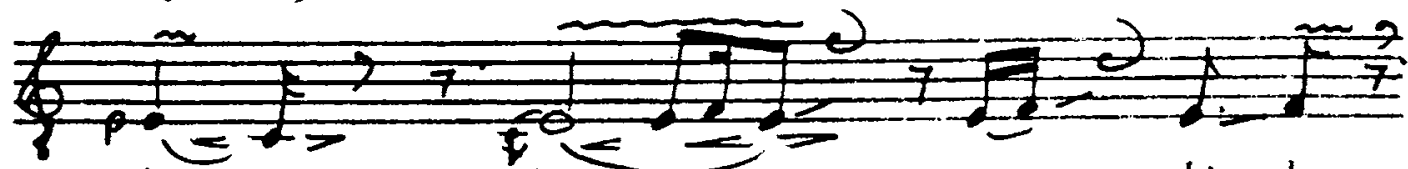

$k_{u-\ldots} \ldots k_{u-\ldots} \quad p_{-}-. \quad t_{i}-l_{u}$

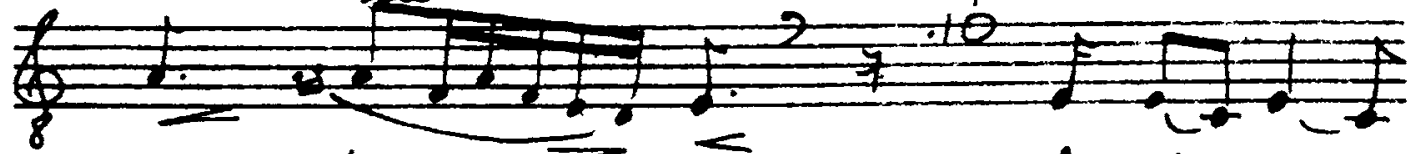

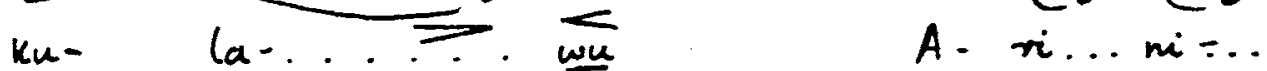

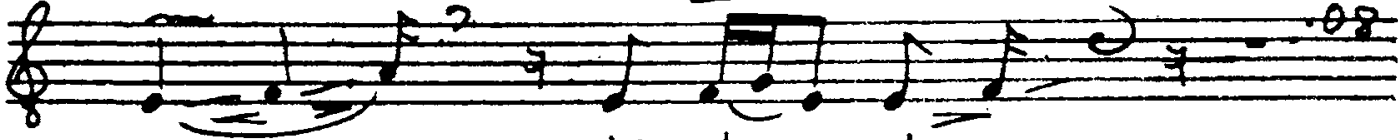
hi-deung... deu-i

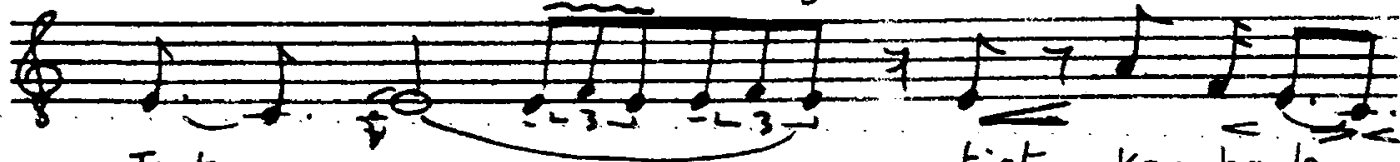

Tjat... man ........ tjat $\mathrm{ka}_{a}$ - ba-le...

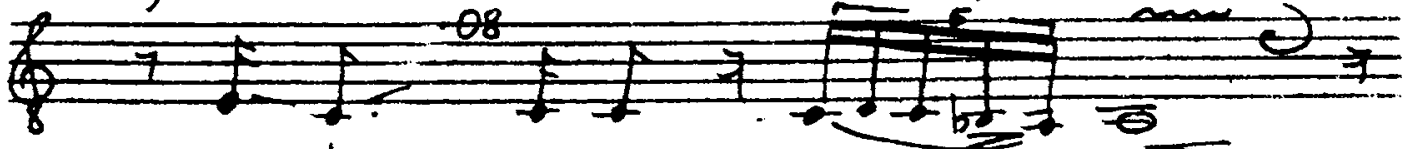

pu- lang Nga-it ma-... jang

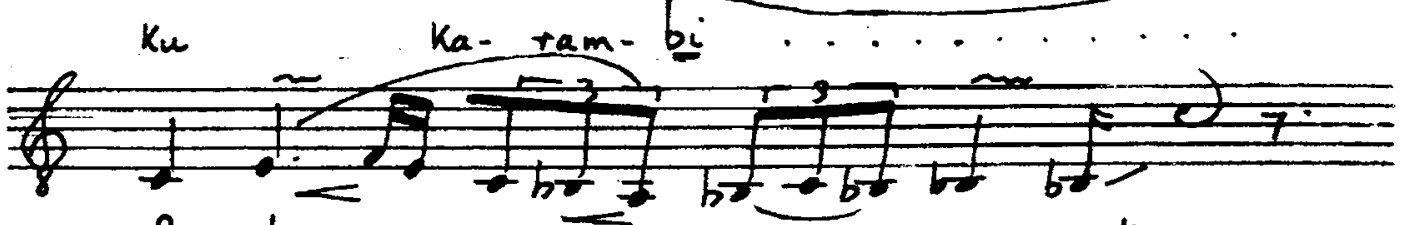

$\mathrm{Ba}$ - do..... ang... ma-nuk

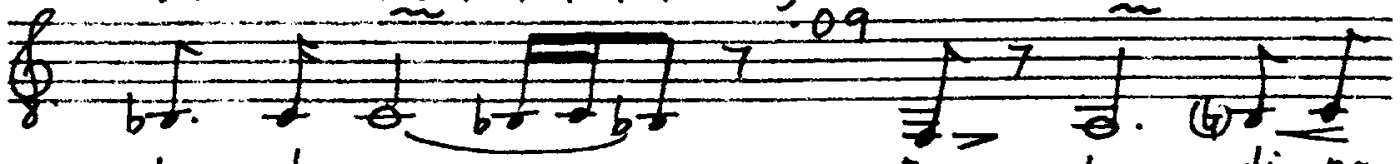

ba- do-ang.... Eun- teng di-na

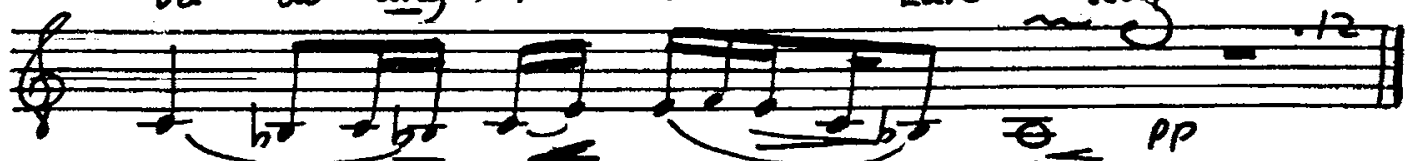

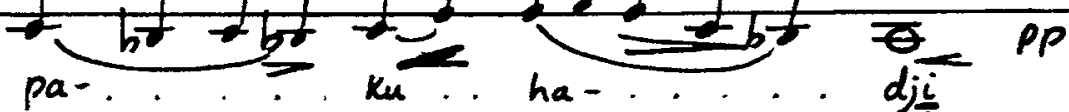




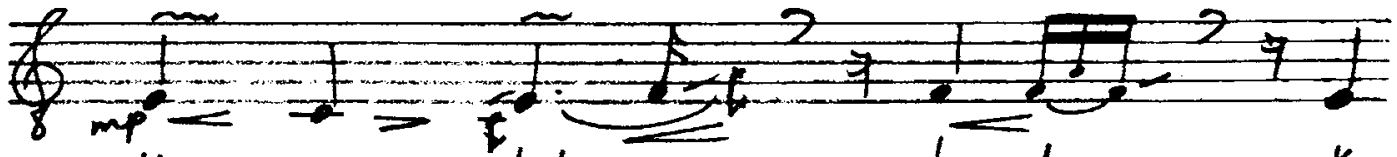
U. (e) lah.... ben-du... ku

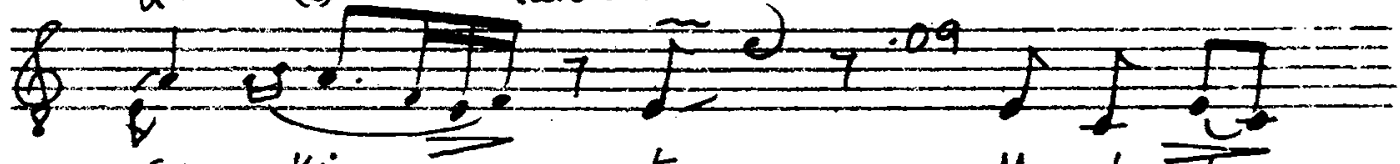

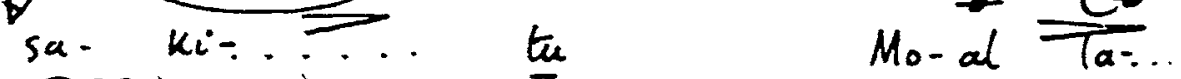

$7+129+27^{09}$ mi... wang-sul... den-i

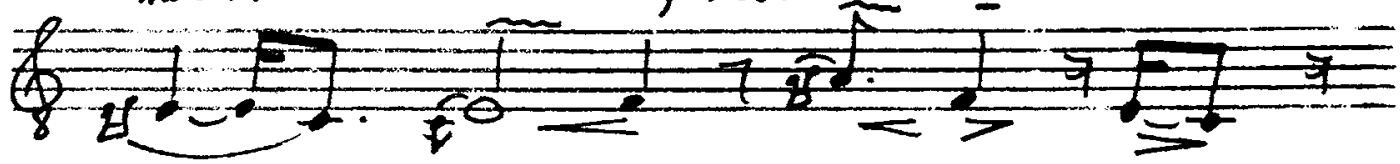
So...... te- ang sa- hes teu..

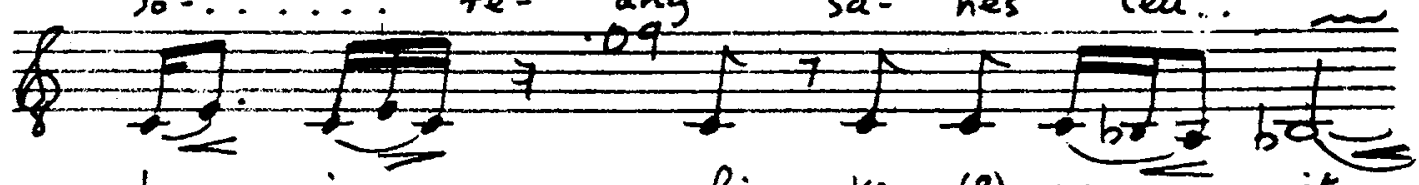

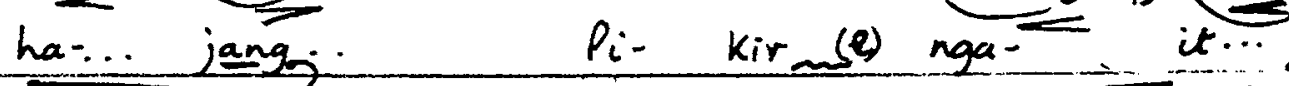

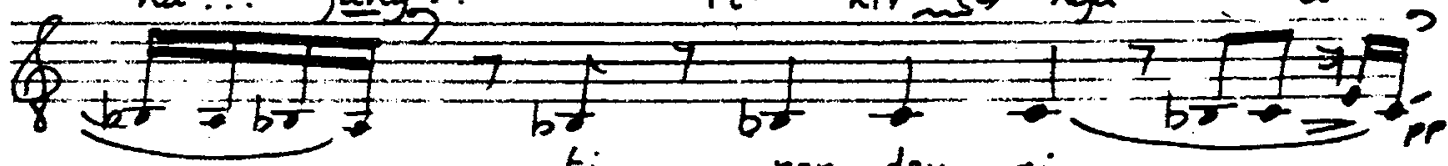
$8=1=08$ Da-go-an . an ab-

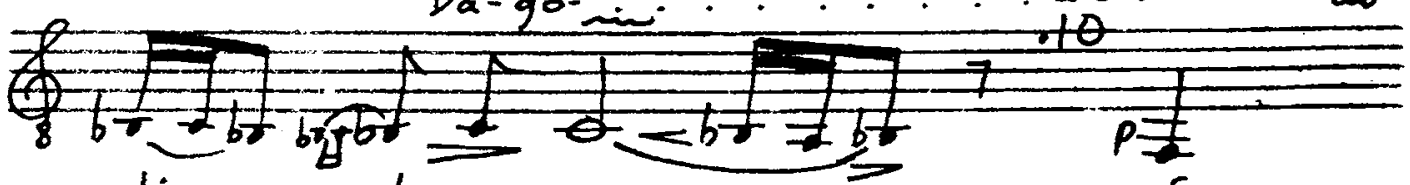
di vin da-go- an ...? Sa-

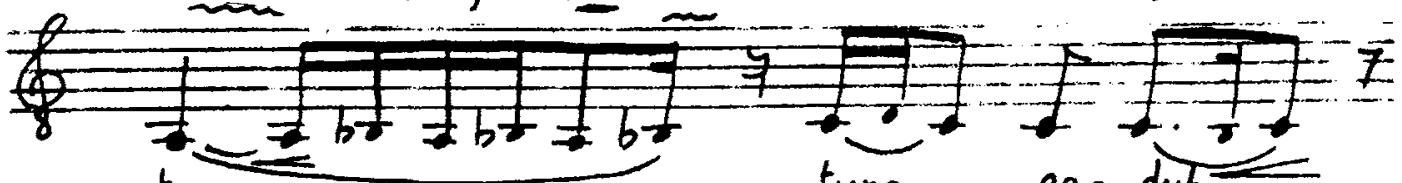
tung- tung 11 aa-duh $s_{a} .{ }_{l_{a} .} \mathrm{k}_{i}=$ 
$(d=132)$

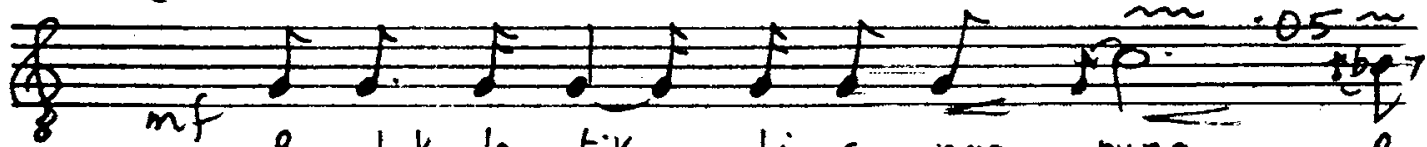
Bu-dak leu-tik... bi-sa nga- pung $\mathrm{Ba}$
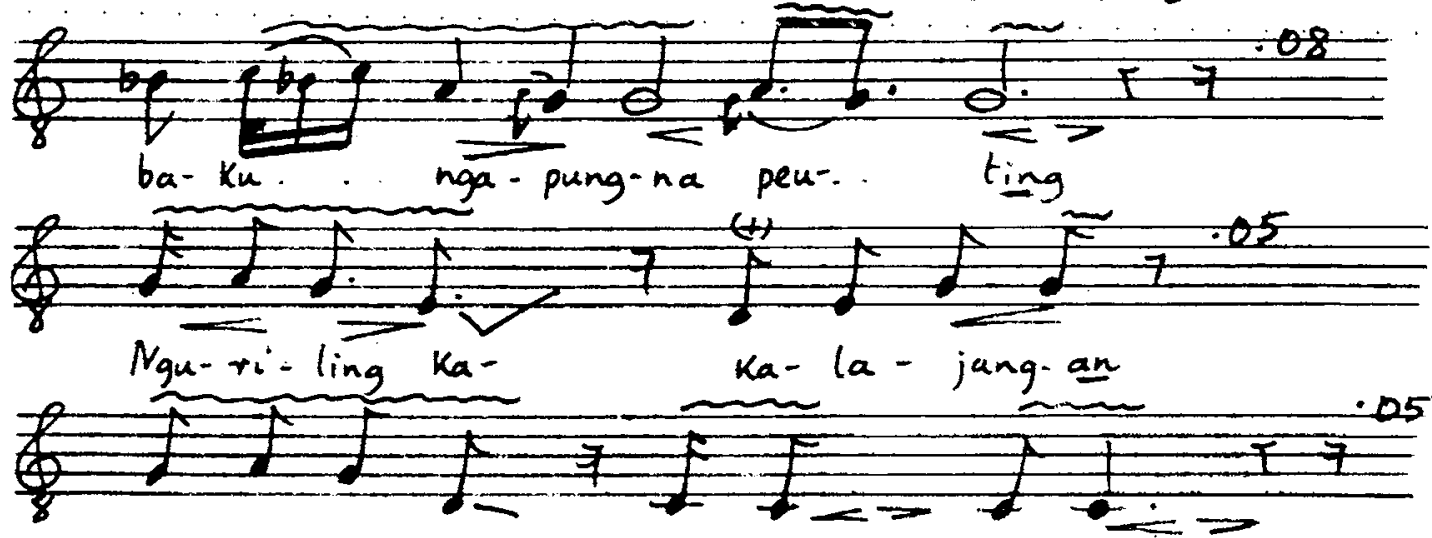

Ne ang-an nee a- mis. a-mis

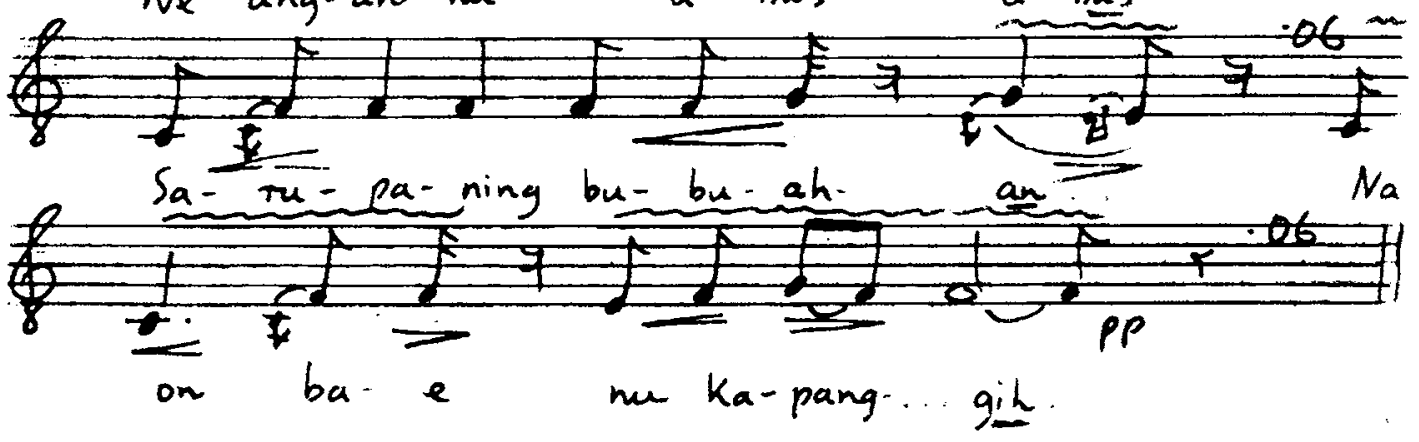


$(d=132)$

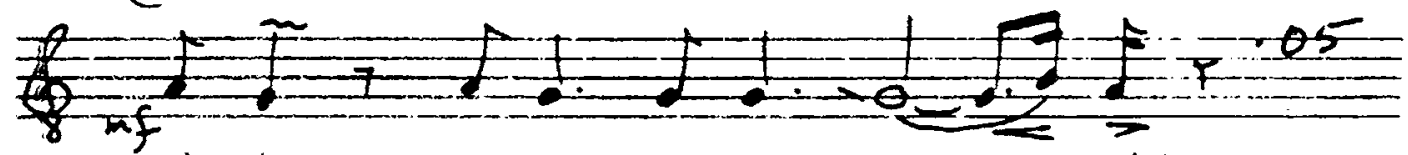
E-ling- e-ling mee-rang-ka-ji... lih

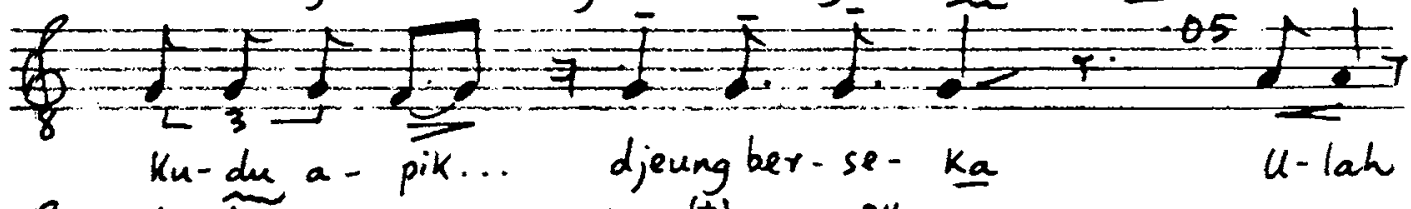

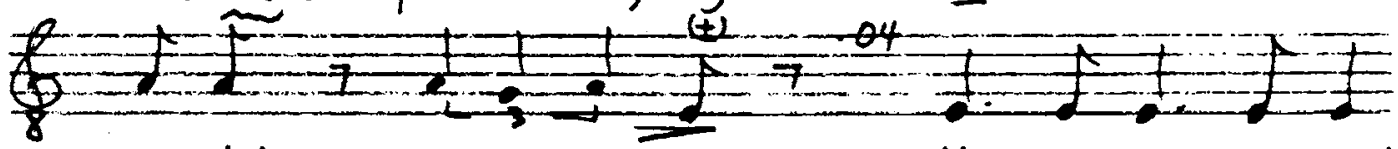
D.doh ka-pa-ngang-go Mun ko-tor geu-wat

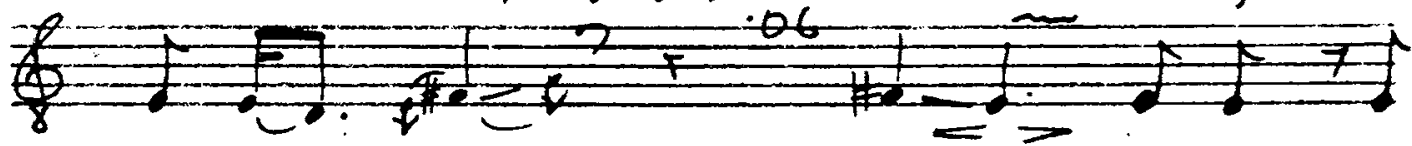
seu-sech.. an ... So- eh gen-wat $\mathrm{Ka}$ -

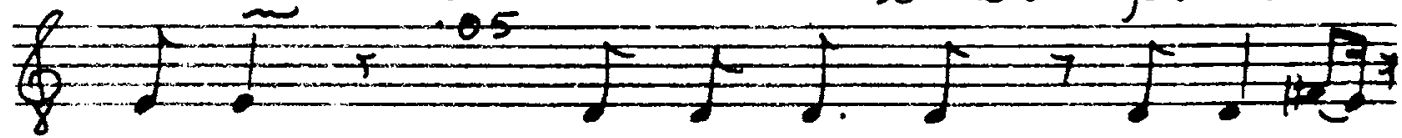
put-an $\quad k u-$ mu bu- ruk ma-sing bu=.

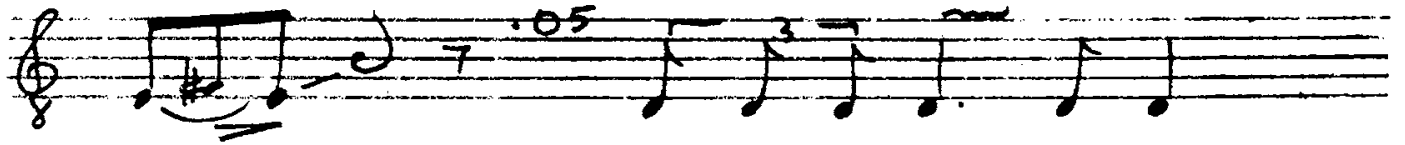

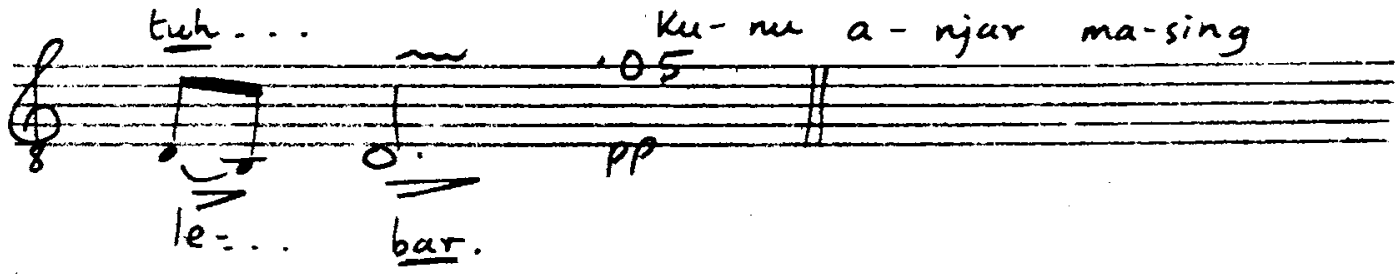


484.

23. DURMA

SINGER: SUDRADJAT

T.I.: $0.39 \mathrm{~min}$.

O.P.: 1 tone higher

$(d=107)$

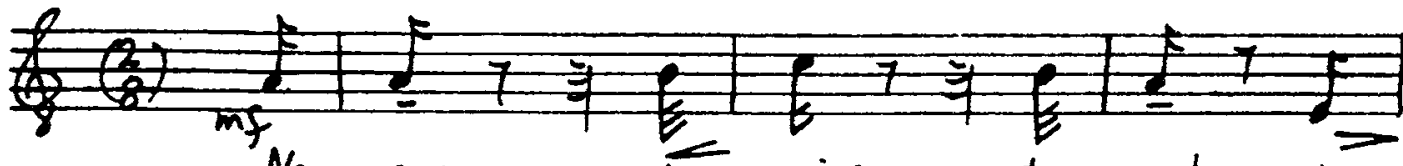
${ }^{\mathrm{Ngu}}-\operatorname{sap} \mathrm{ku}-\mathrm{mis}$ tang-gah ba-

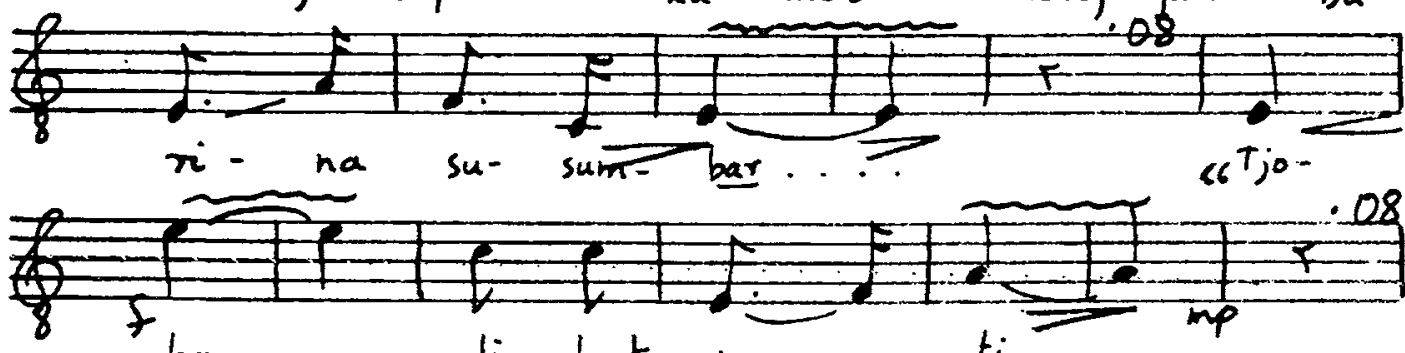
ba.... li. hat nan-... ti...

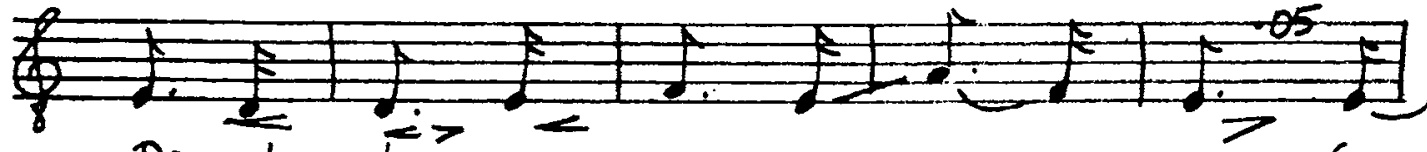
$D_{i}-$ da $_{\text {lam }}$ pe- pe-... . rang- ioi an Gu-

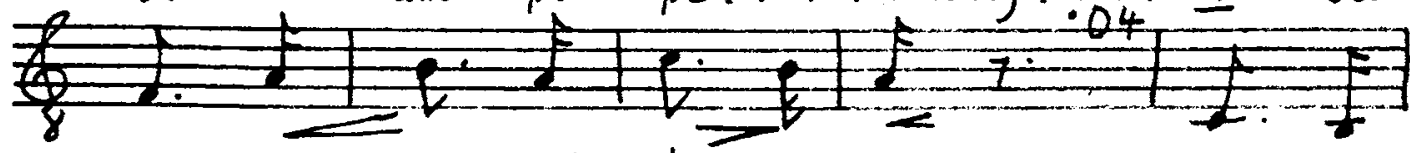

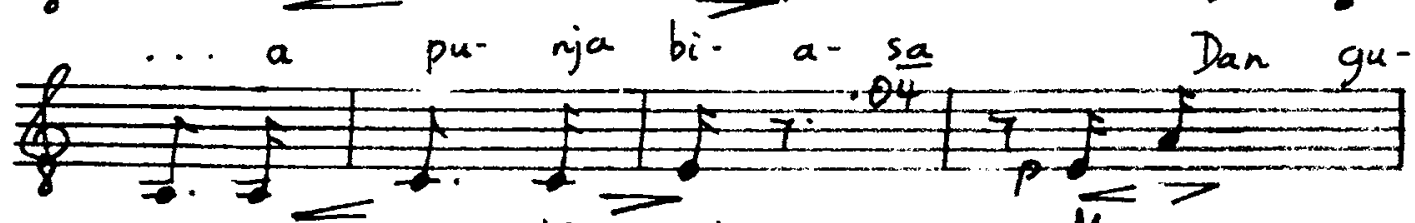
a $p u=$ nja $b^{2}+a-n i$ Me-nang.

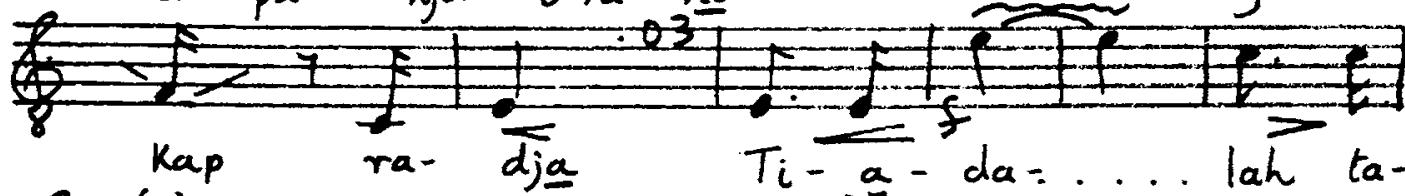

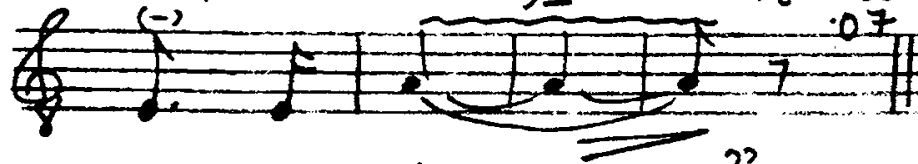

kut ma- ti.....? 
24. MASKUMMAMBANG

SINGER: SUDRADJAT

T.L.: $0.25 \mathrm{~min}$.

O.P.: $I^{\frac{1}{2}}$ tones lower

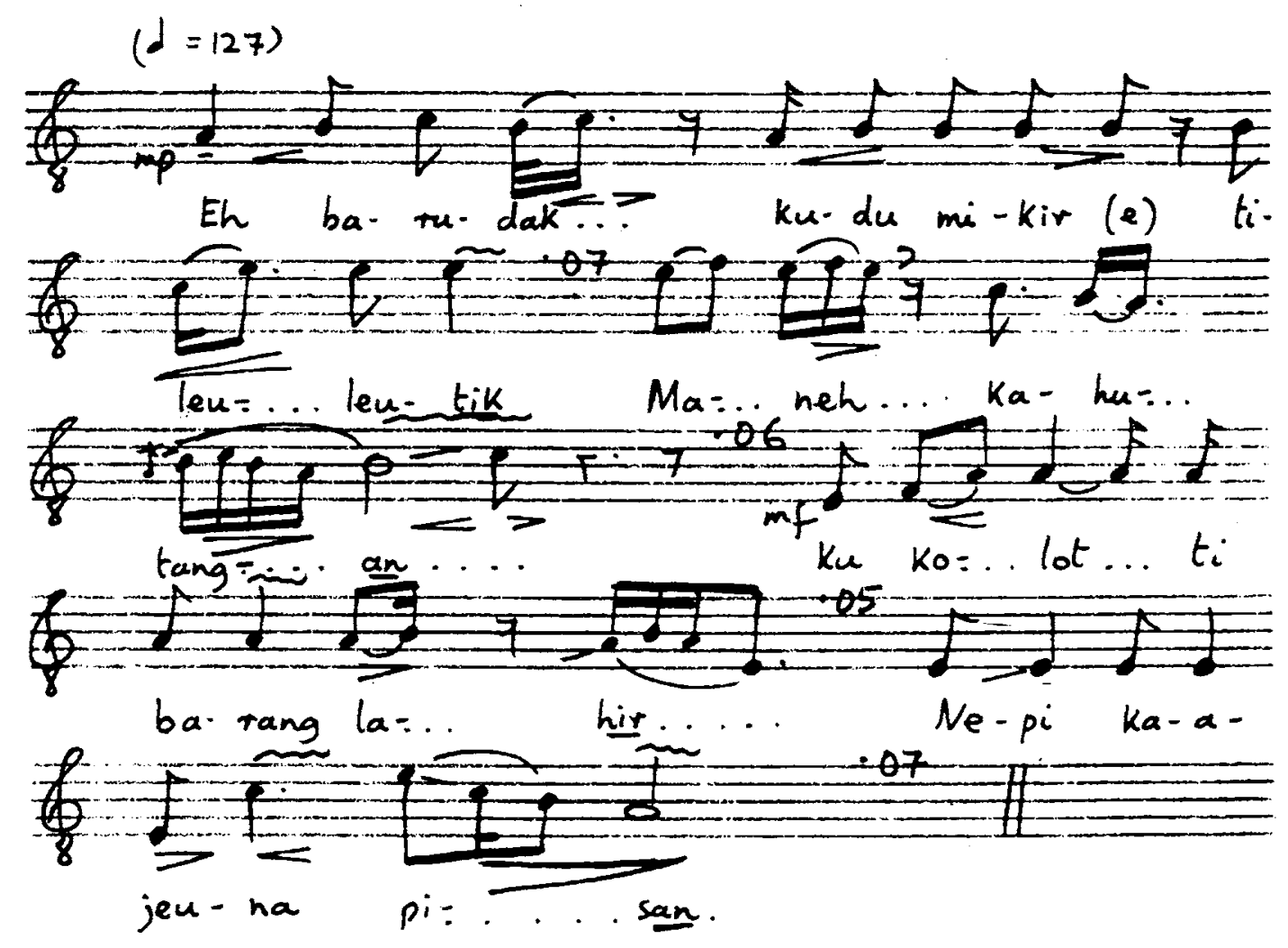


$(d=126)$

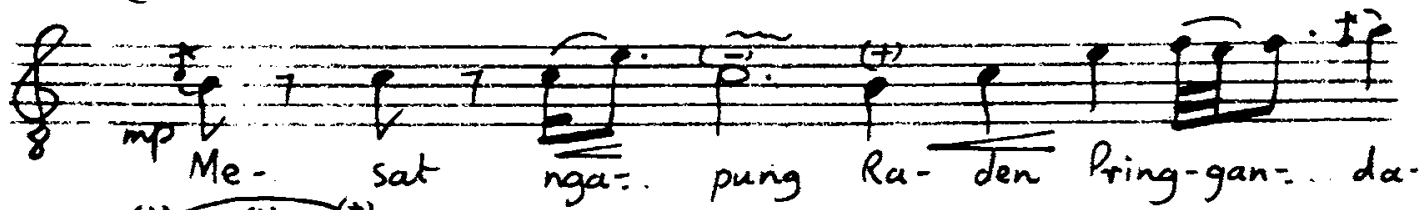

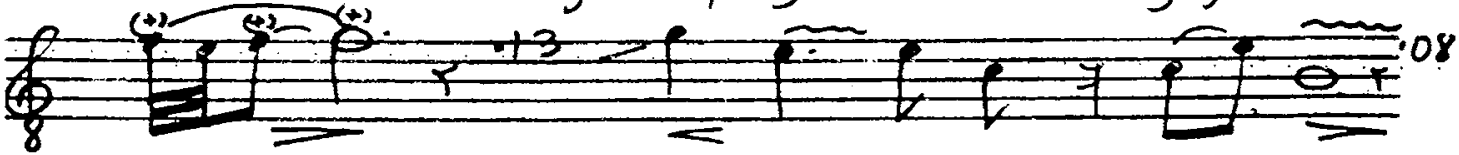

ni.....

Dieung me-ga geus a-... wor

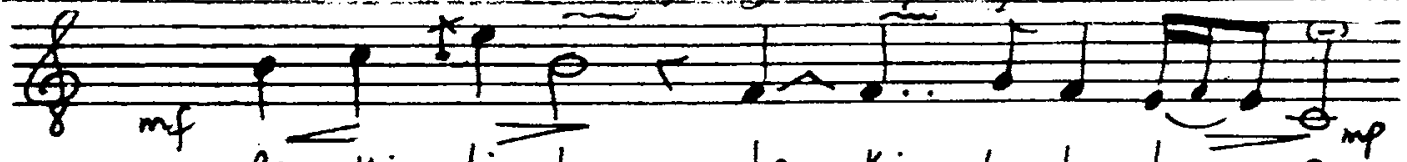
Beu-ki $\quad l i=1 a$

ben-ki h-hur ba:

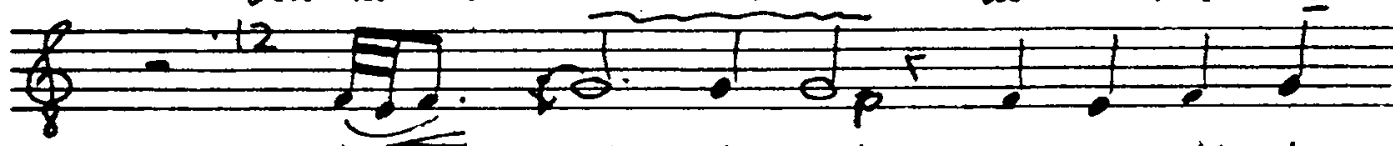

La... rak-li-rik ni-nga.li $\mathrm{Ka-}$
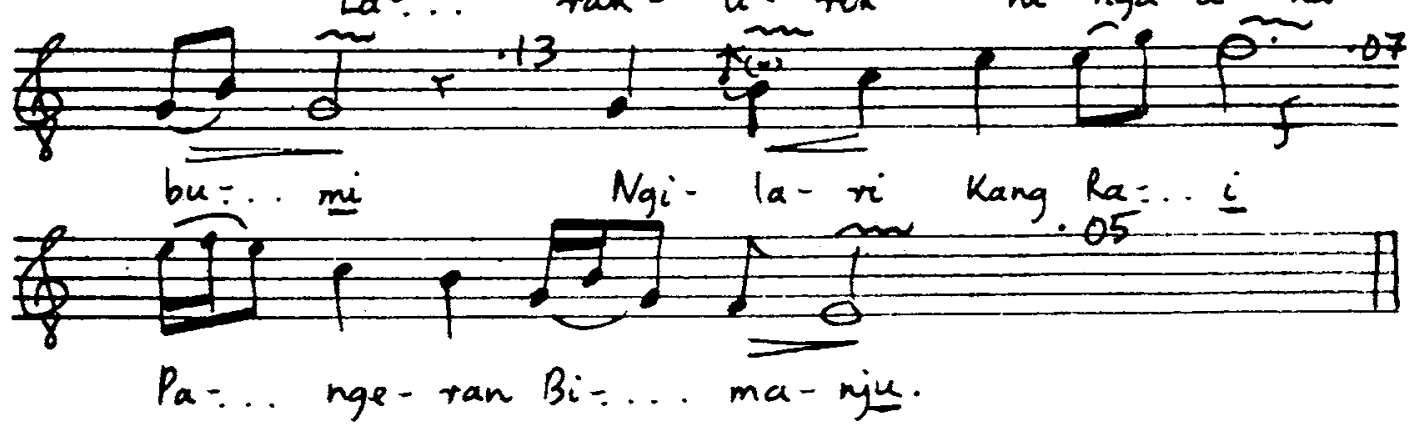
26. PANGKUR

SINGER: A. HAMID

HOME TOWN: TASIKMALAJA

T.L.: $0.47 \mathrm{~min}$

O.P.: $2^{\frac{1}{2}}$ tones lower

$(d=125)$

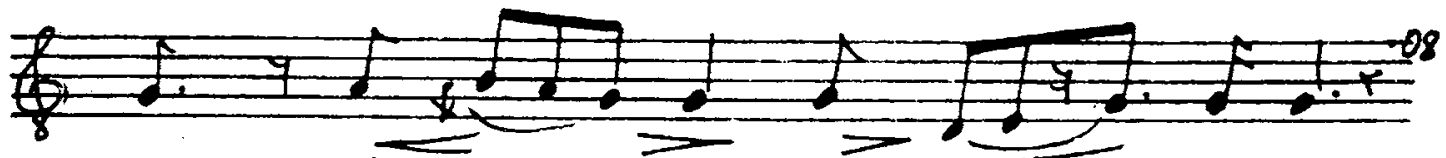

Se- dja nja-.. ba nga-la-... la - na

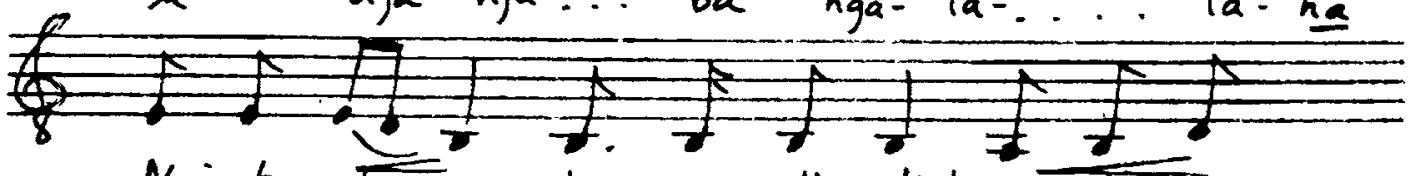

Ngi-tung tem:.. bur nga-dja-djah mi-lang-an

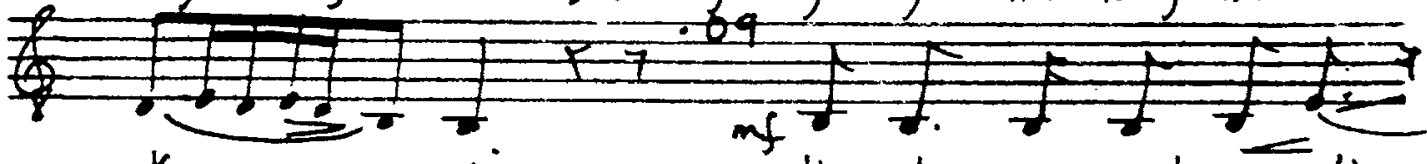

$K_{0}=\ldots$ t... Hen-ten pu-guh nue di$\ldots$ djug-djug $_{i}$

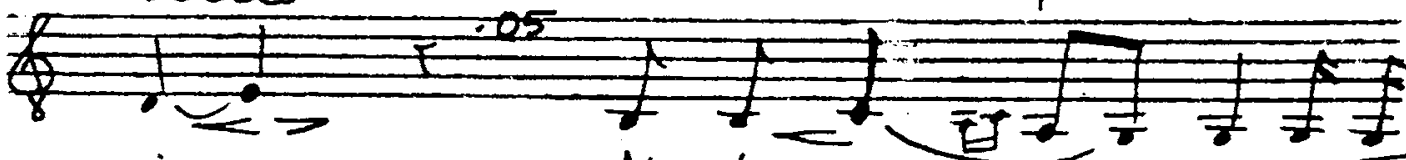

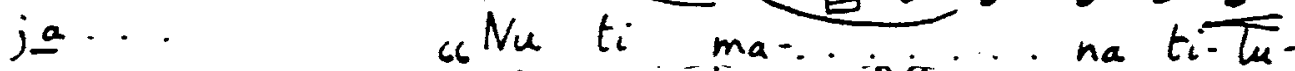

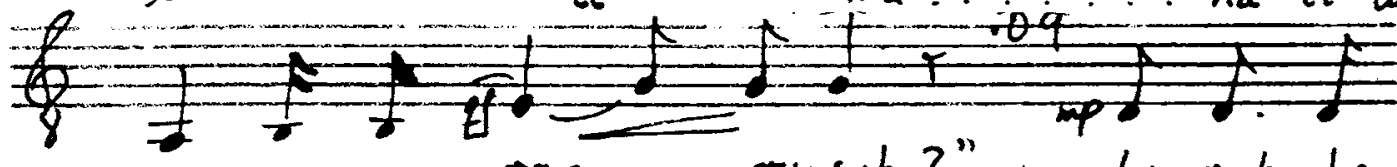

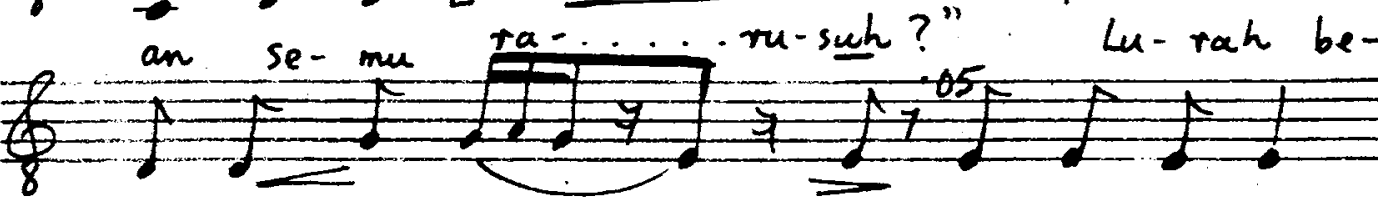

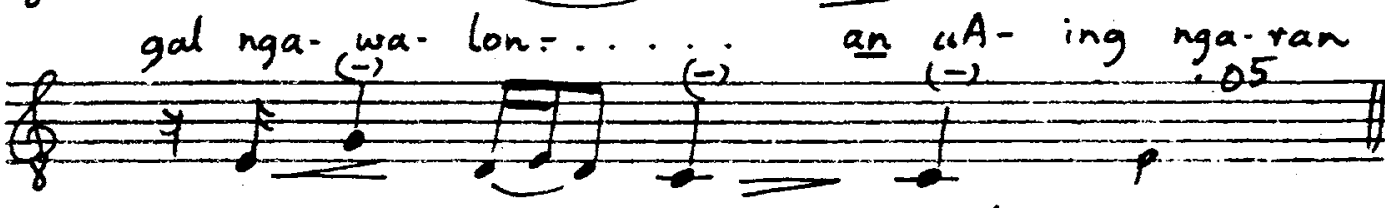
Dja-ja Pa-....... $\underline{t i}$ " 
$(J=132)$
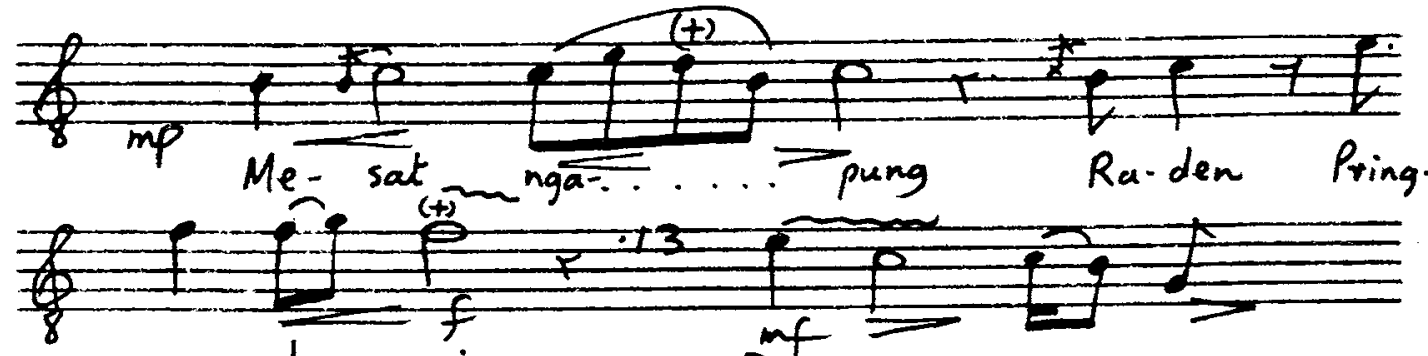

$$
\text { gan-da... ni Djeung me- ga... geus }
$$
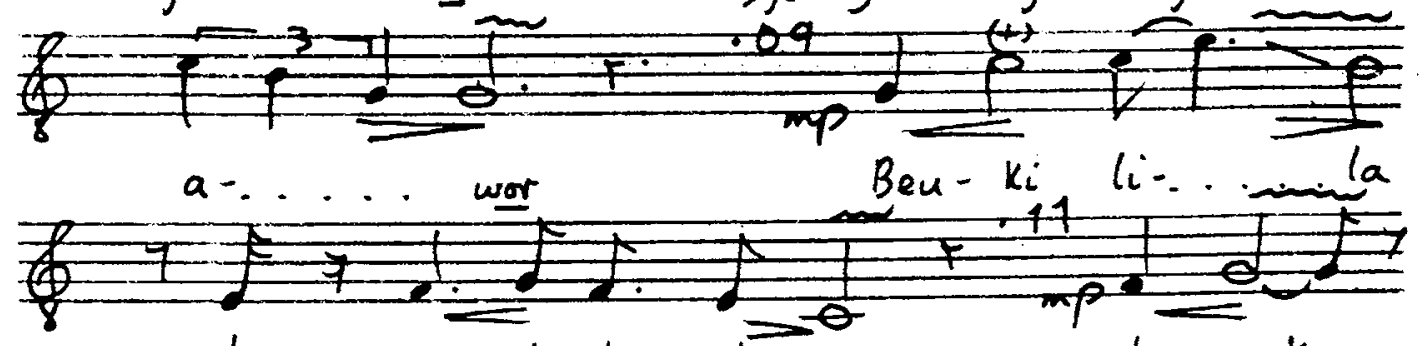
beu. $k_{i}$ lu-hur $\overrightarrow{b_{a}-} \mathrm{e}$ La-rak-

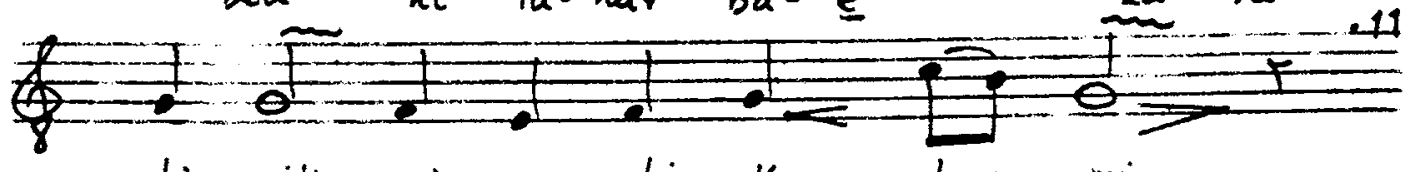

li- rik ni-nga-li $\mathrm{ka}$ - bu $=. . \mathrm{mi}$
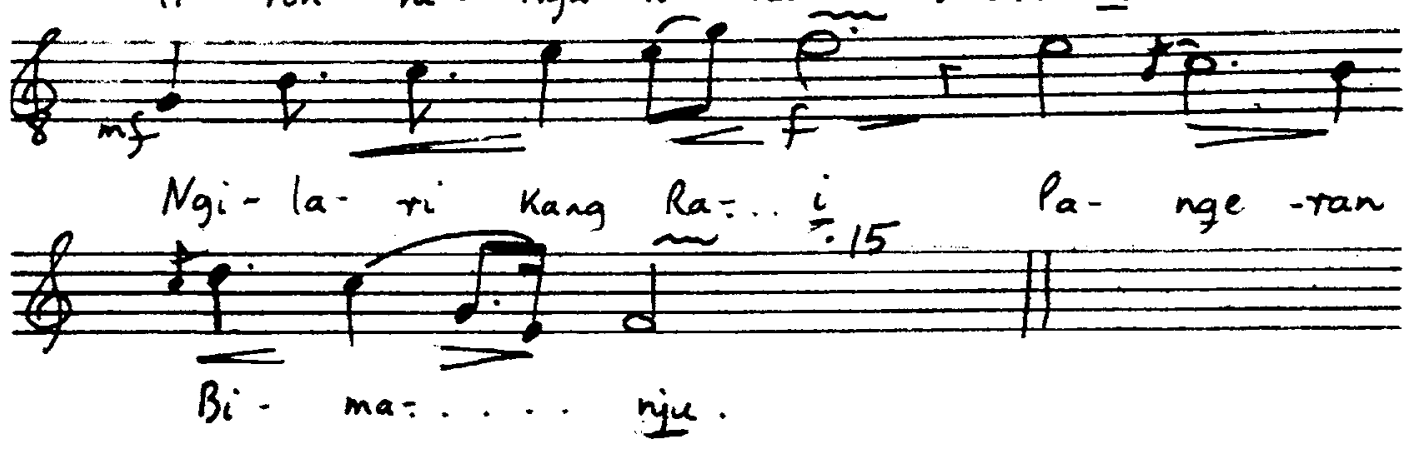
28. DANGDANGGULA

SINGER: A. HAMID

T.I.: $0.82 \mathrm{~min}$.

O.P.: I tone lower

$(d=125)$

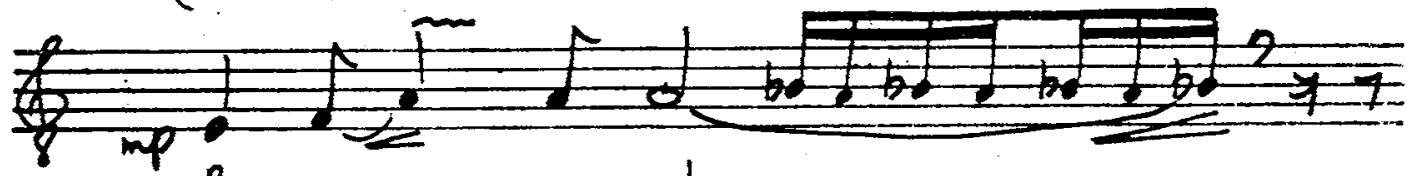

$\mathrm{Pa}_{\mathrm{a}}$ ne-... ne- da...

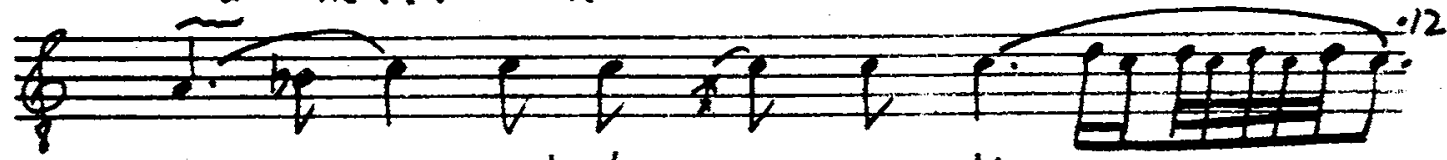

Se-...... puh beu- tang peu-ting,

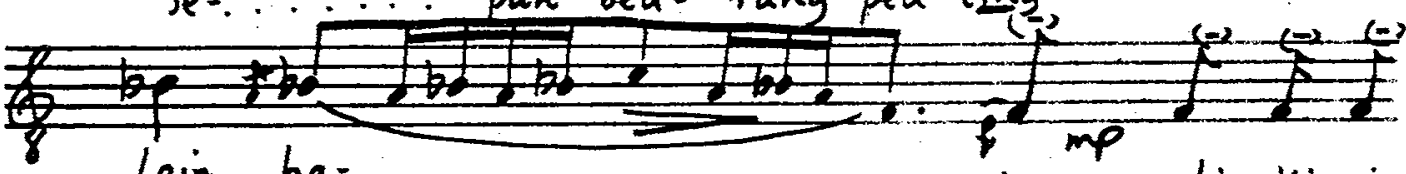

Lain har.

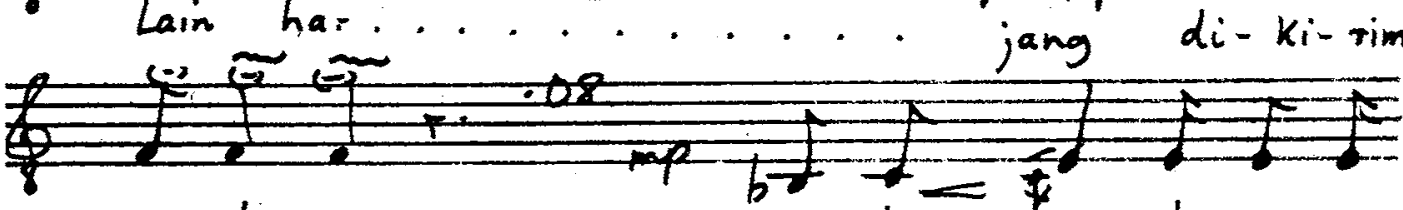

an turang $\quad A-t_{a}=$ wa ba-tang ne

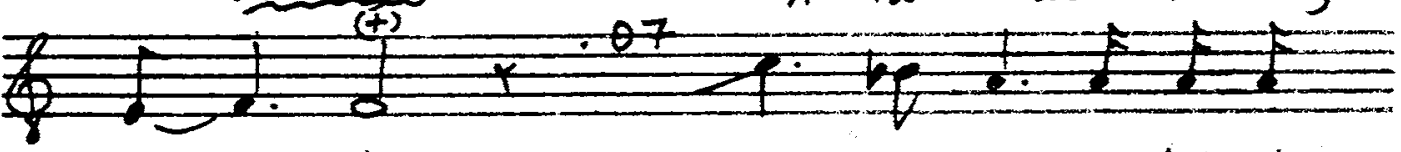

a-... heng Ngan ha-jang u-lah bi-

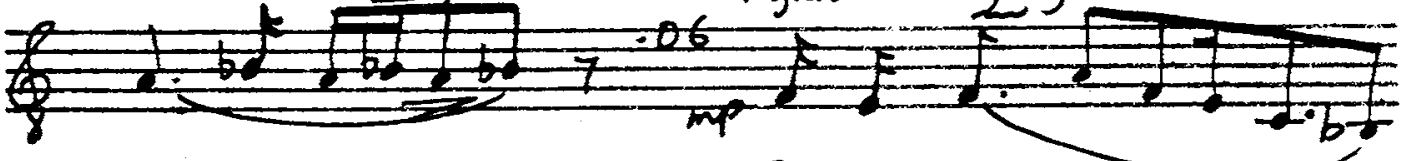

ngung... . . $D_{i} \cdot k_{i}$ - tim-..

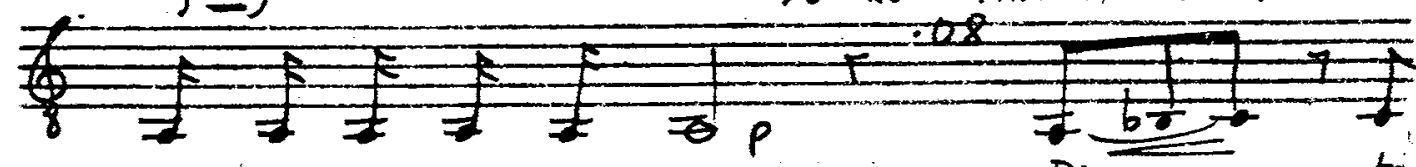

an nu ma-tak pu-sigg $D_{i}-\ldots$. tan-

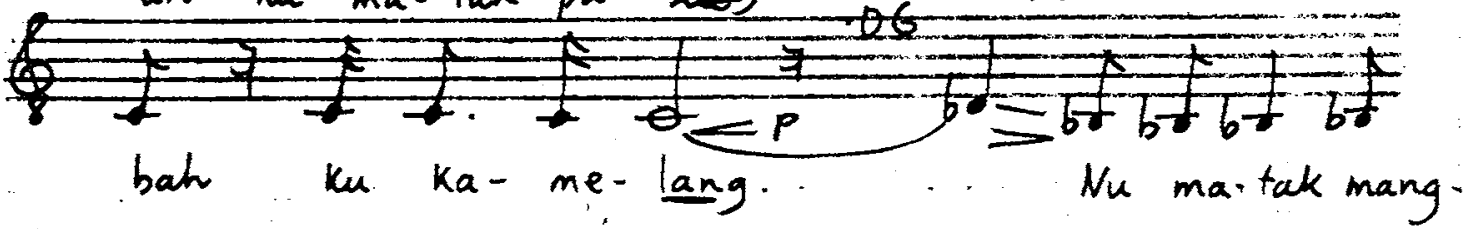




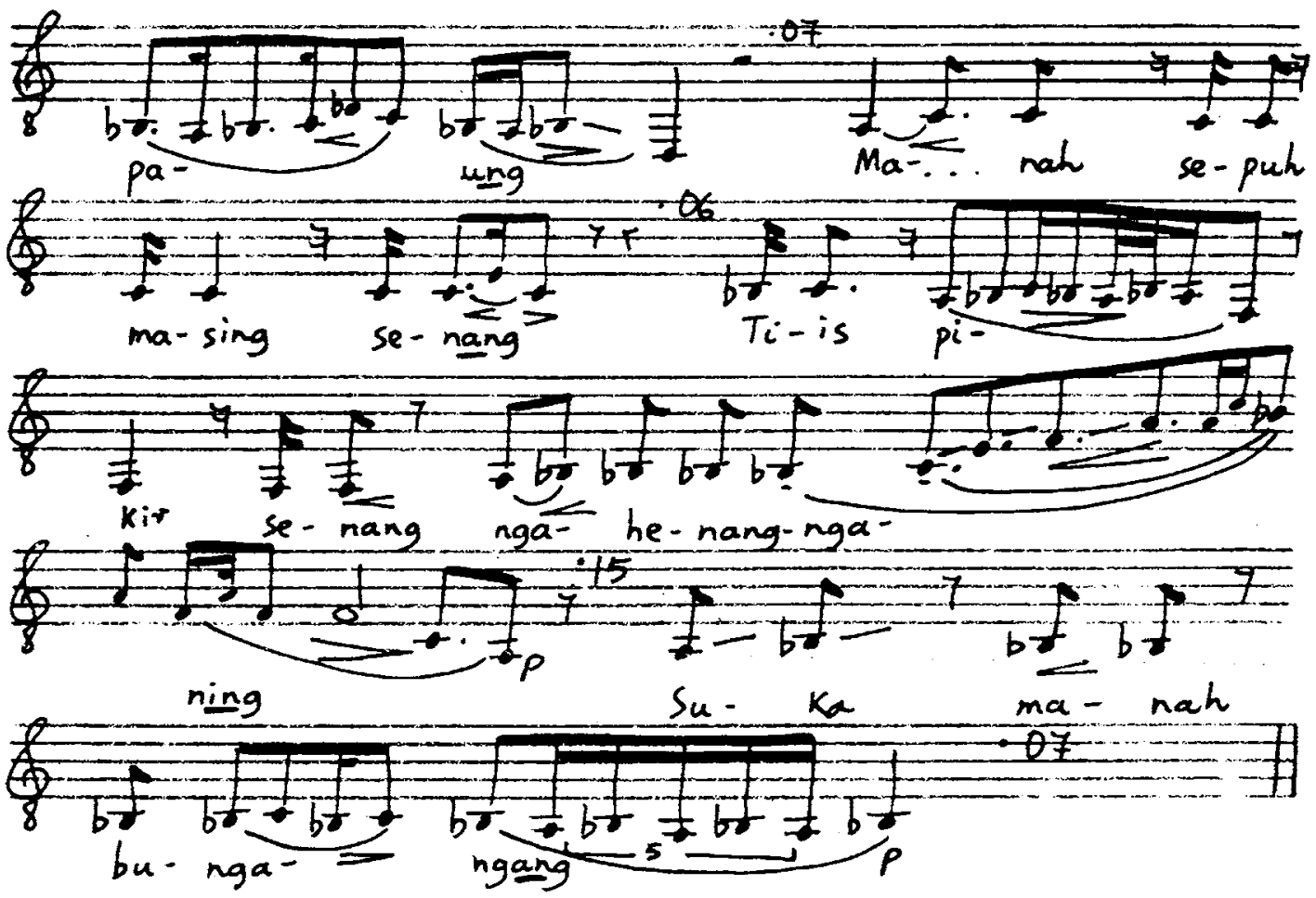


$(d=116)$

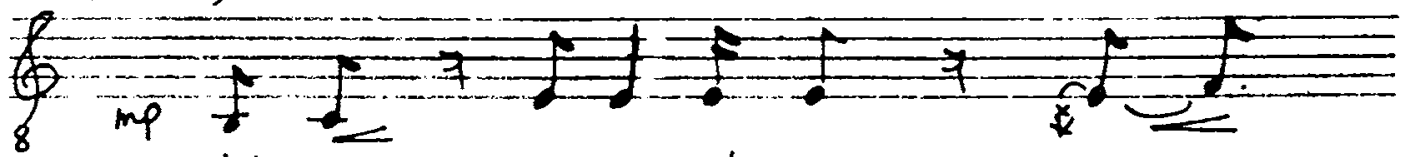
War-na- war-na la-wk em-

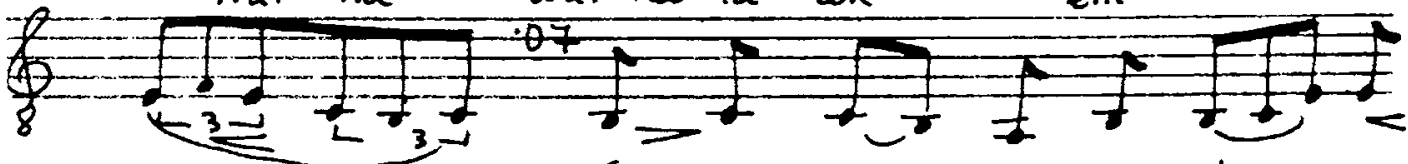
pang Seu-eur nu.. sa-mi djeung.ping-

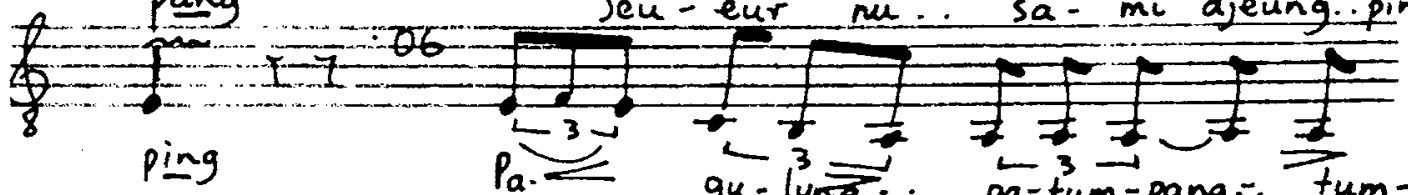

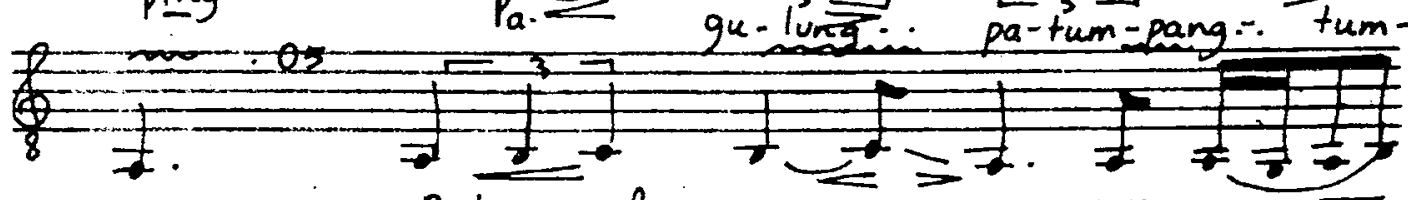
pang Rat-na Ranq-ga- nis ni-nga-

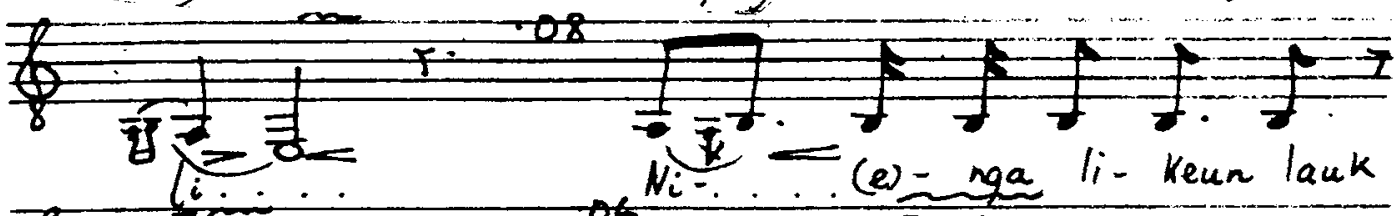

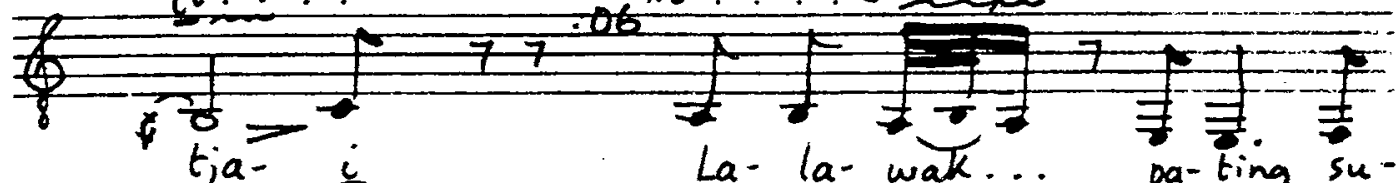

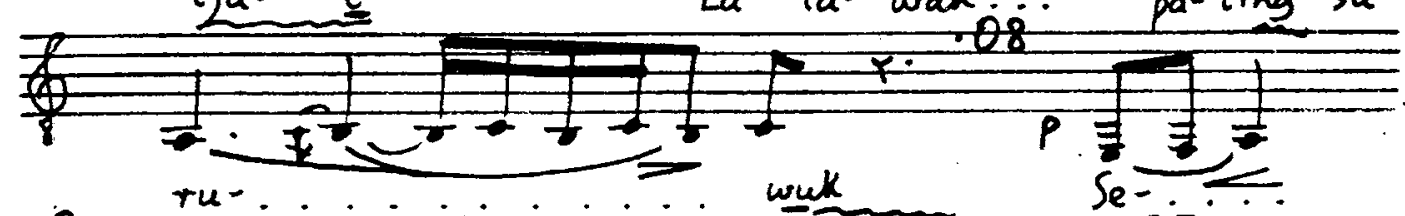

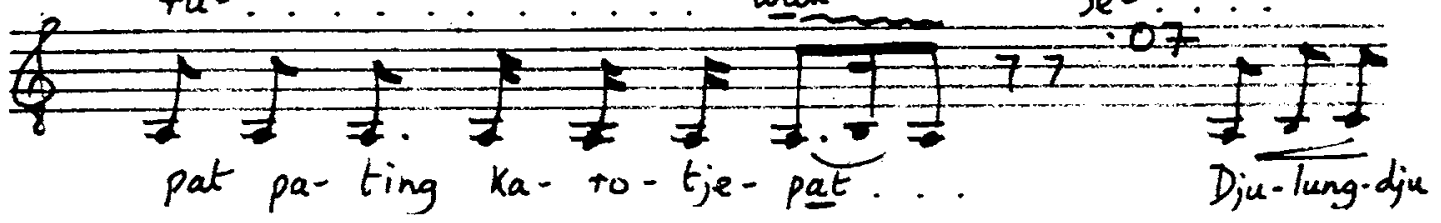


492.

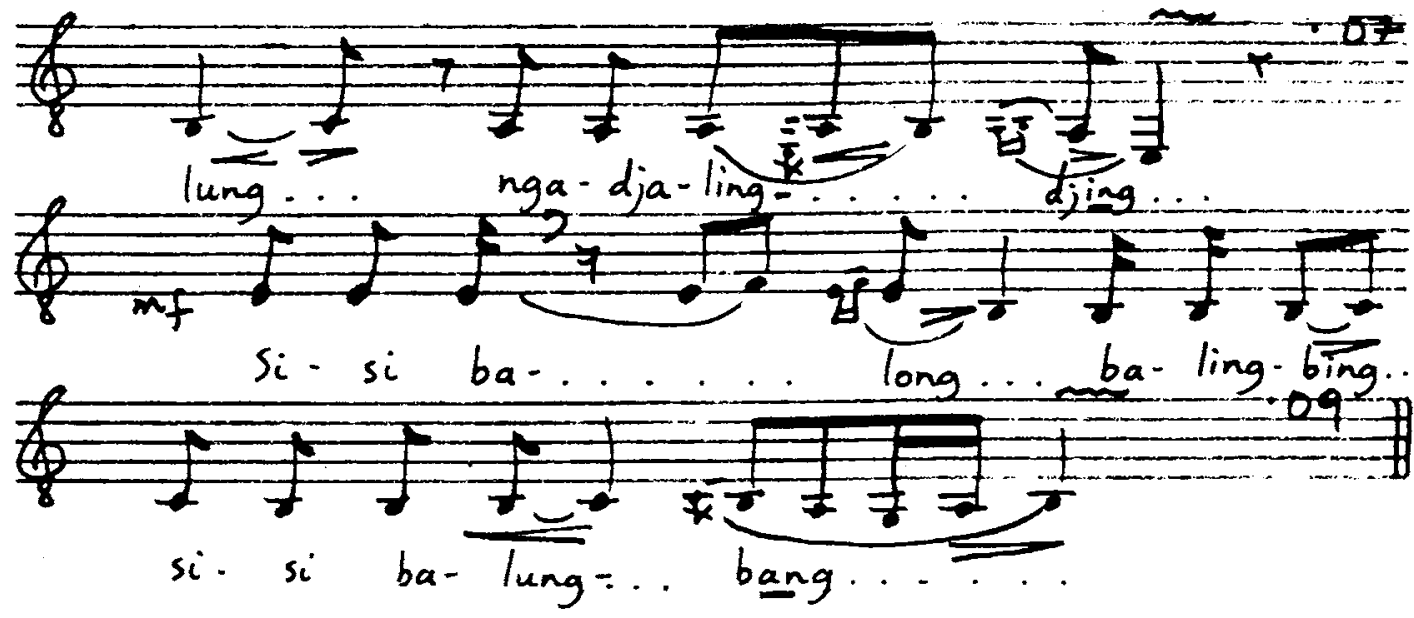


30. ASMARANDANA

SINGER: A. HAMID

T.L.: $0.39 \mathrm{~min}$.

O.P.: as below

$(d=112)$

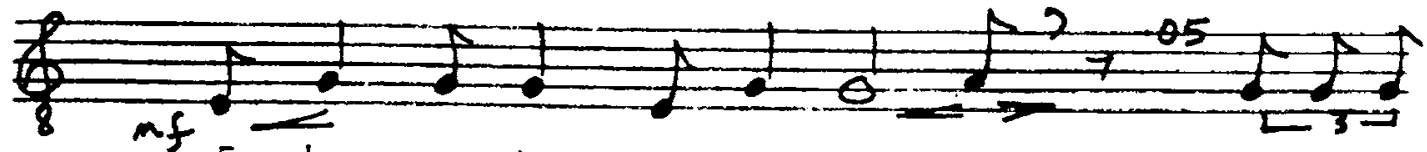

E- ling-e-ling mu- rang $k a-l \underline{h} \quad k_{u}-d u a-$

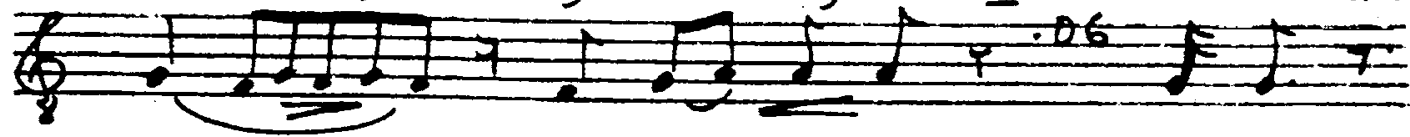

pik.... djeung ber:. se-ka $u$-lah

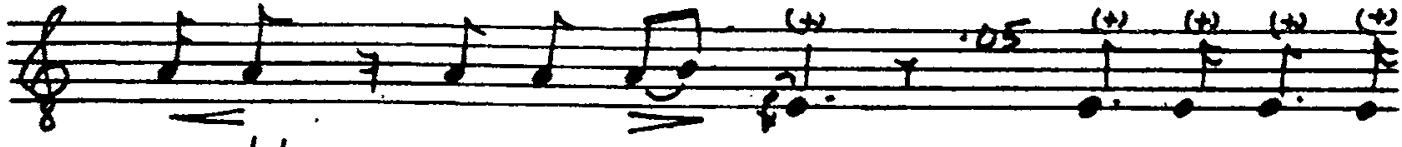

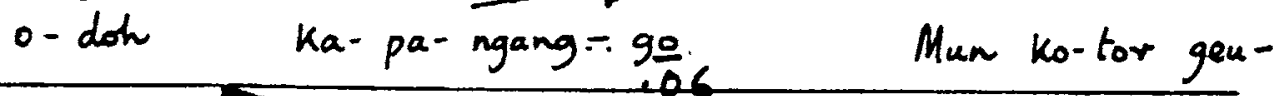

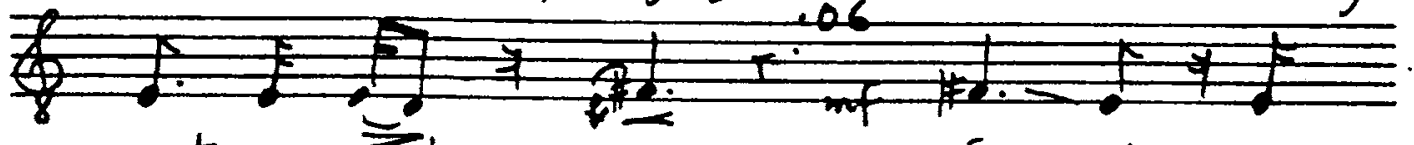

wat seu- sech.: an So- eh geu-

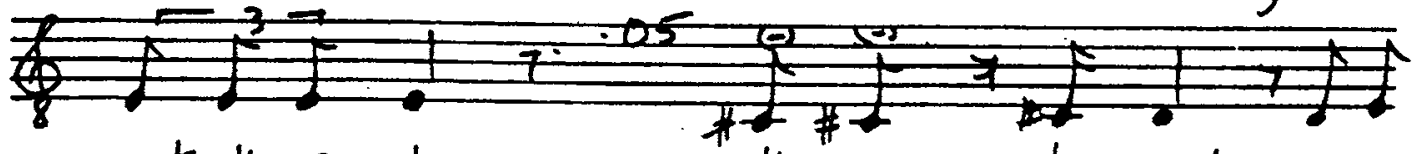

wat $k a-p u-\tan \quad k u-n u$ bu- ruk ma-sing

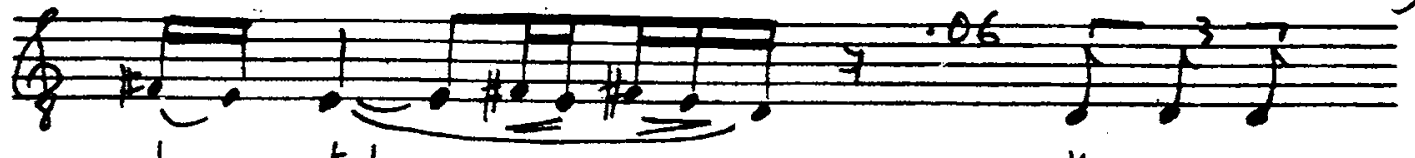

bu... twh ....... ku

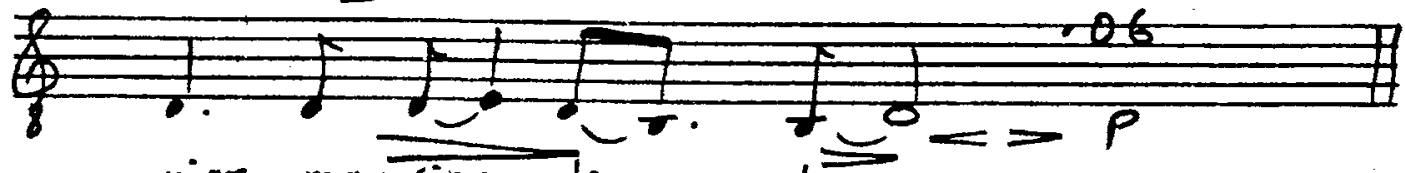

njar ma-sing...le-... bar :.. 


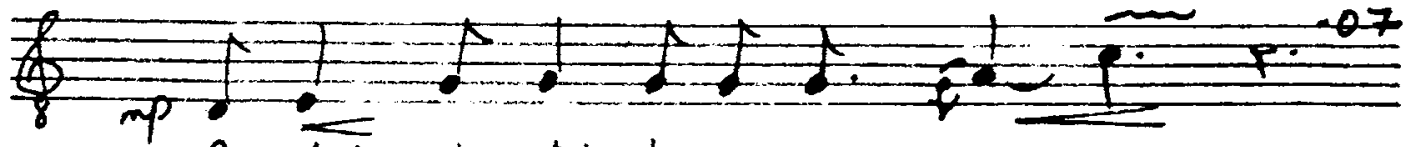
Bu- dak leu-tik bi-sa nga-pung

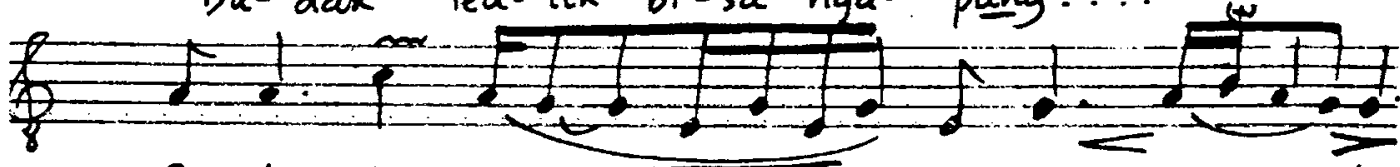
$\mathrm{Ba}-b_{a}-\mathrm{Ku}_{u}$ nga-... . pung-na peu-.. ting

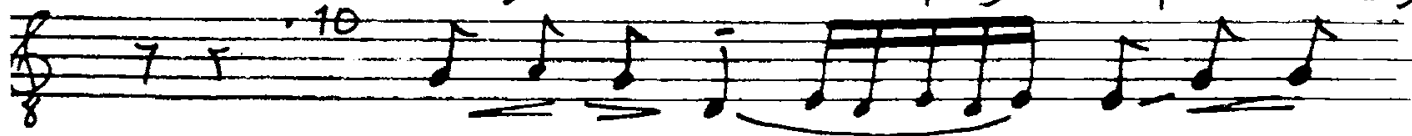
Ngu-ri. ling $k_{a}-\ldots \ldots k_{\alpha}-l_{\alpha-j a n g-}$

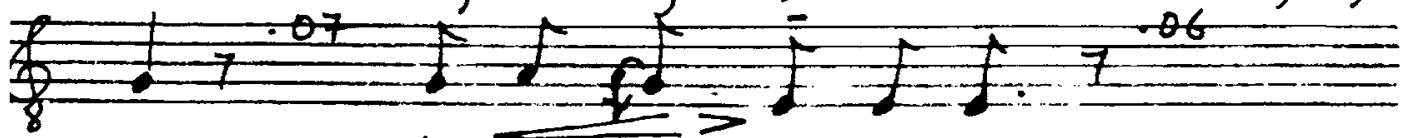
an $\quad N_{l}-\overline{a_{k g}-\alpha n}$ nue a-imis

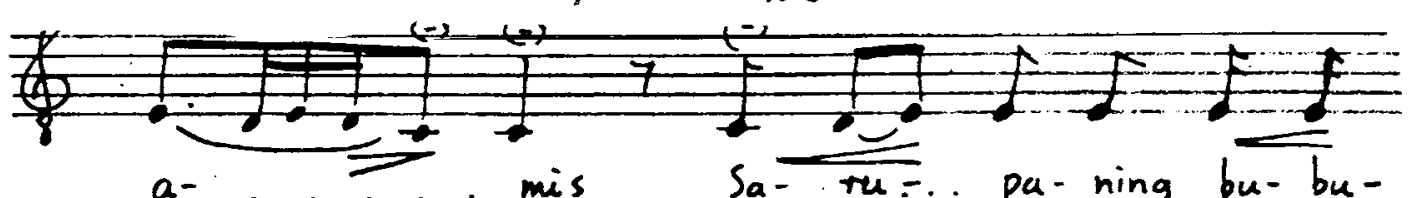
ah- an... mis Sa-rus pa-ning bu-bu$72-07=07$ pang..... gih 
32. MASKUMAMBANG

SINGER: A. HAMID

T.L.: $0.29 \mathrm{~min}$.

O.P.: as below

$(d=108)$

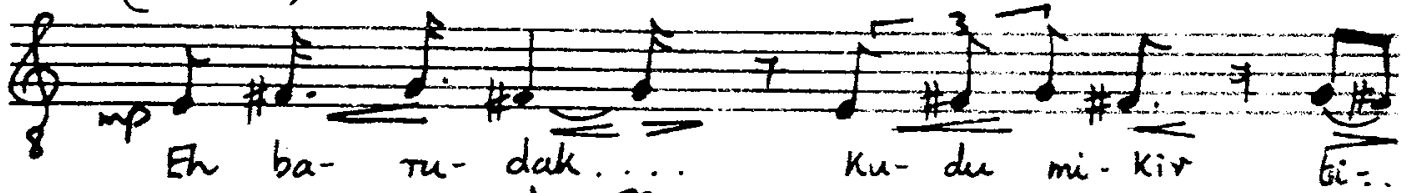
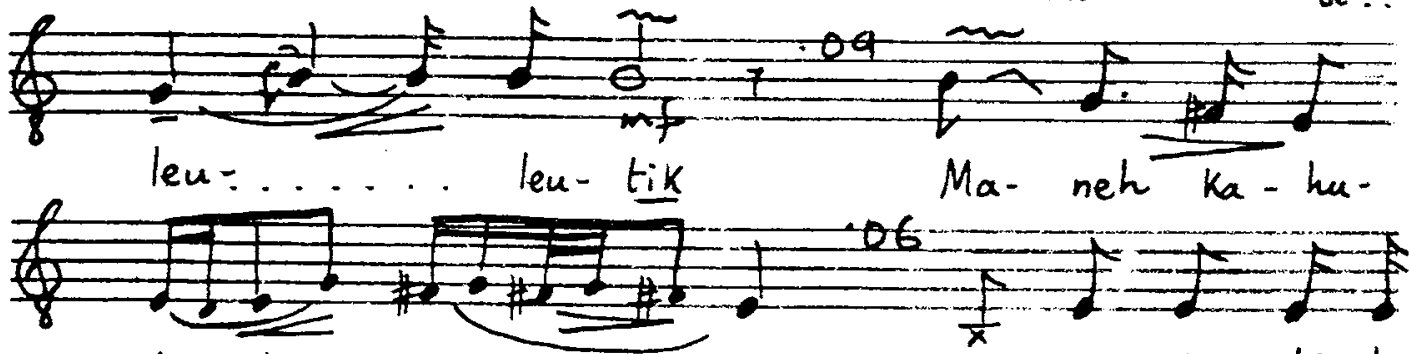

tang-... an.......... ku ko- lot ti ba

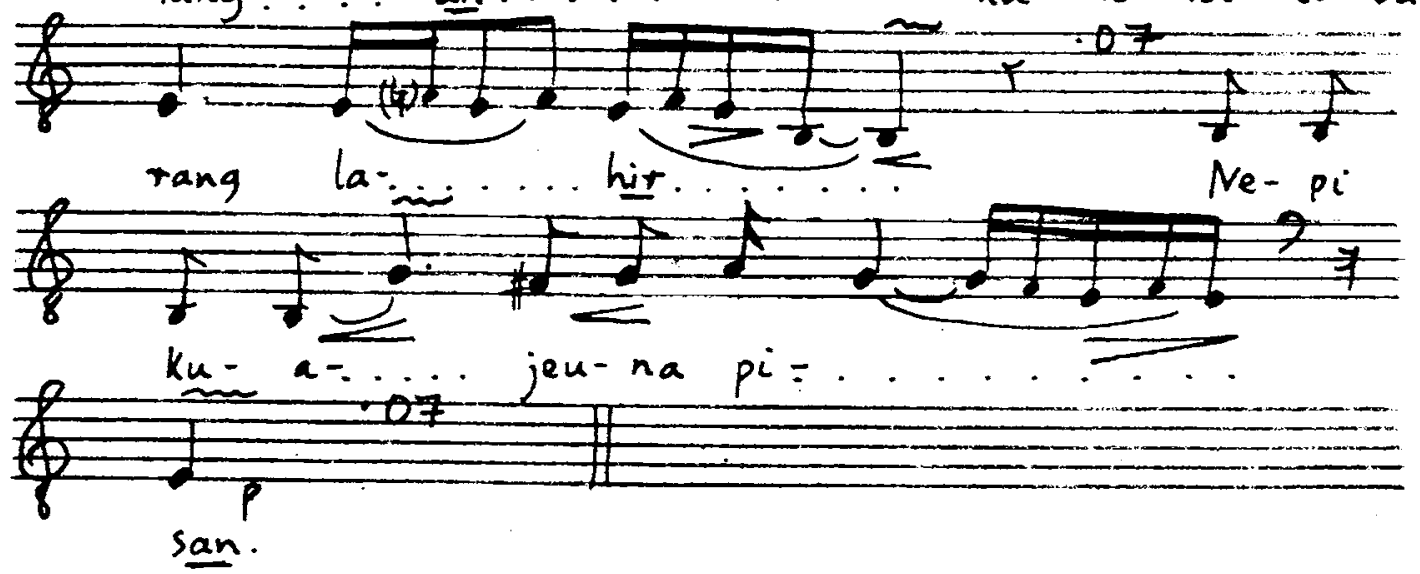


33. PANGKUR

SINGER: SJAMSUDDIN

HOME TOWN : SUMEDANG

T.L.: $0.40 \mathrm{~min}$.

O.P.: I tone lower

$(d=115)$
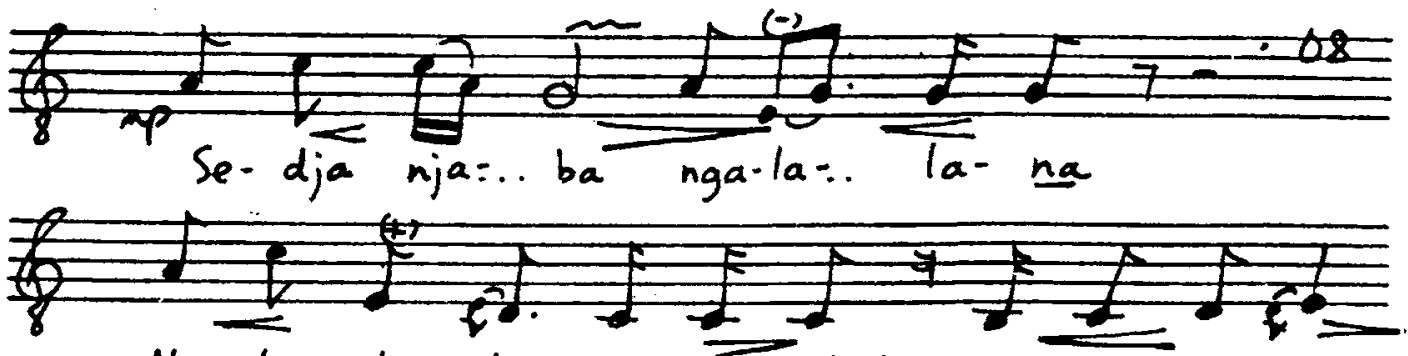

Ngi-tung lem- bur nga- $\overline{d_{j a}-d_{j a h}} M_{i}-$ lang-an $K_{0}-$
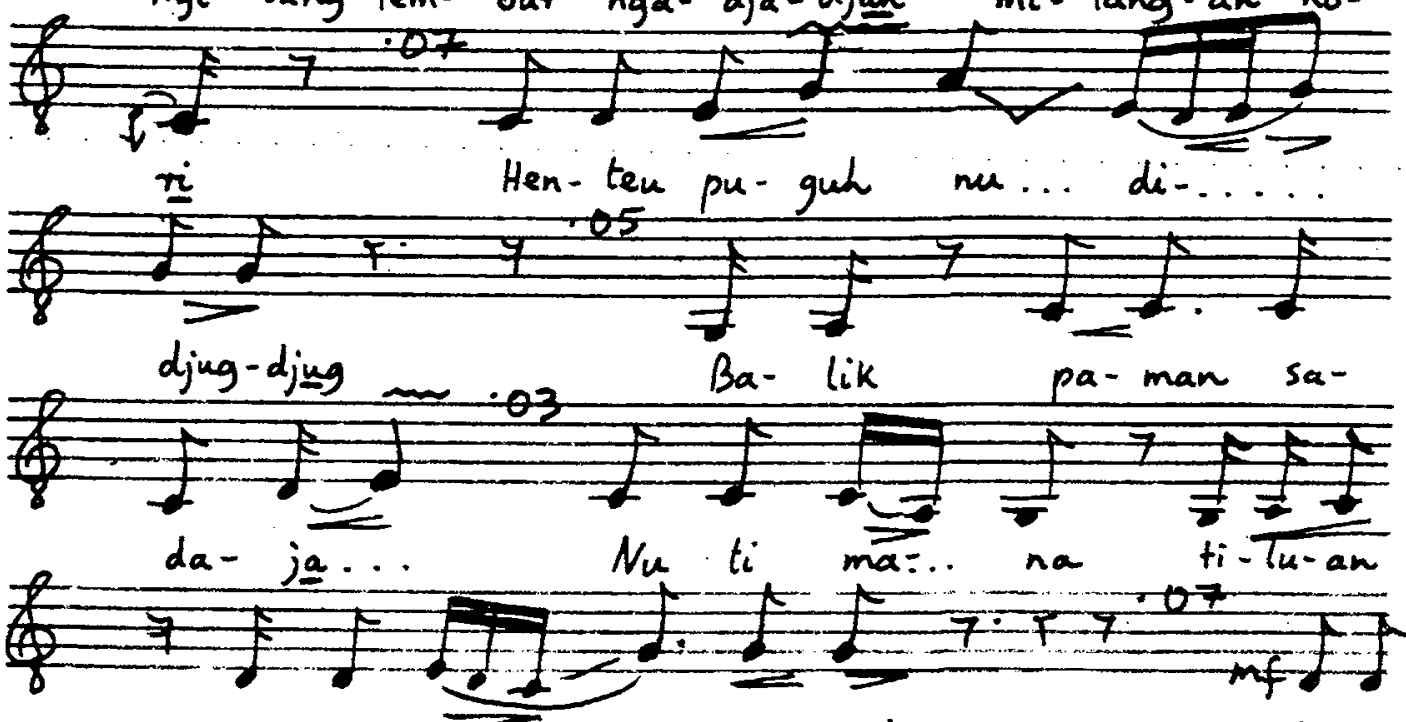

se-mu ra-.... ru-suh bu-rah

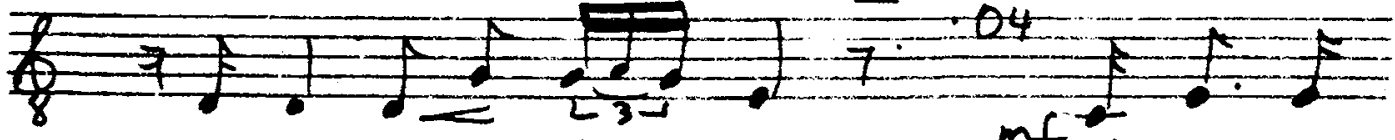
be-gal nga-wa-lon-... an $m f_{\alpha A}$ - ing nga-

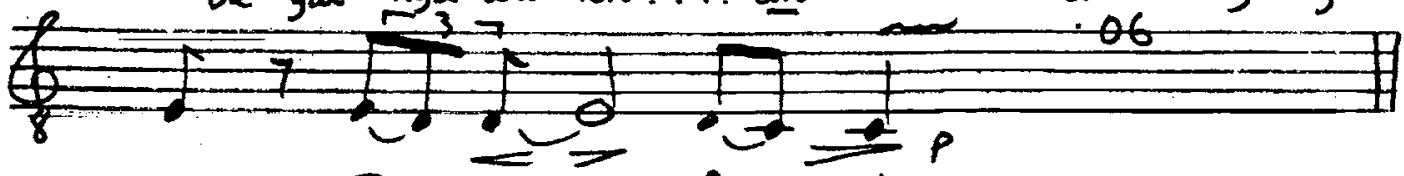

ran $D_{j a}-j_{a} \ldots P_{a}-t_{i}$. 
34. SINOM

SINGER: SJAMSUDDIN

T.L.: $0.55 \mathrm{~min}$.

O.P.: $2 \frac{1}{2}$ tones lower

\&20 War na... war-na lauk em-.. pang.... Seueur... nu sa-mi djeung ping-ping

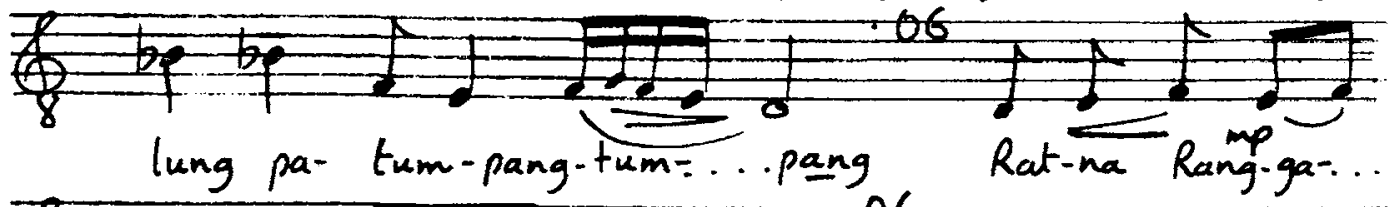

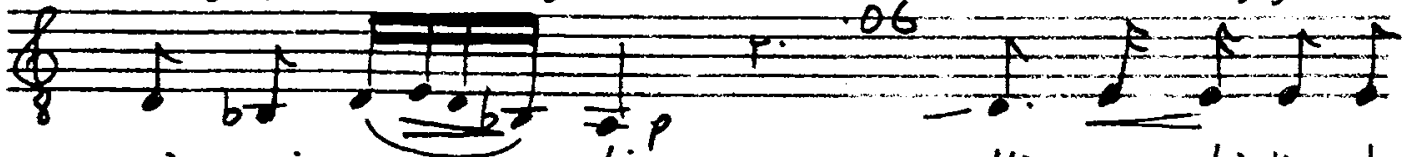
mis $n i-n g a-\ldots l l_{i}$ Ni. nga-li keun lauk

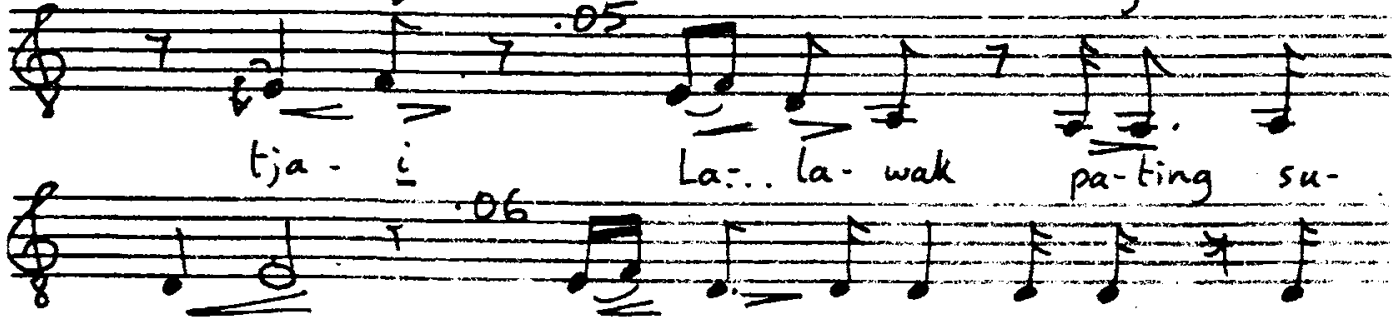
ru-wuk se ...pat pa-ting ka-ro- tjeD pat Do Dju-lung-dju-lung... nga- dja-ling-...

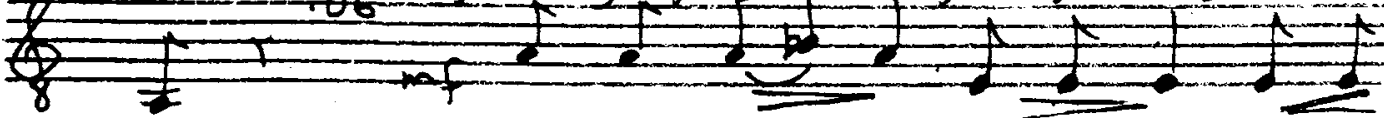
djing Si si bo ba-... long ba-ling-bing si-si

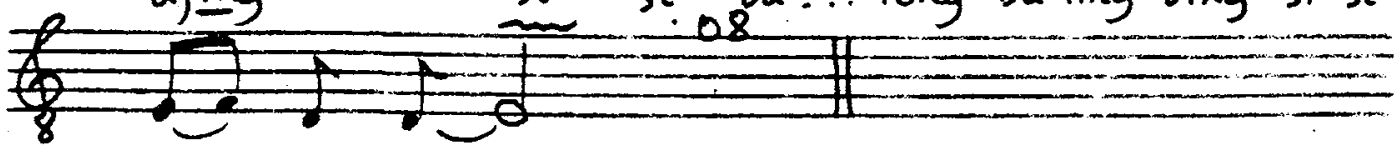
ba:... lung - bang. 
35. DURMA

SINGER: SJAMSUDDIN

T.I.: $0.36 \mathrm{~min}$.

O.P.: 2 tones lower

$(d=104)$

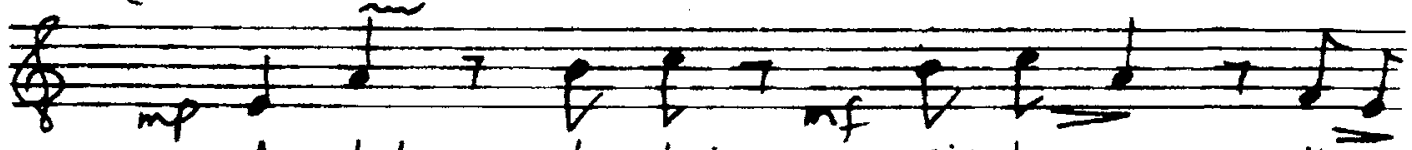

A. duch to bat si: ho-reng $k_{i}$-eu
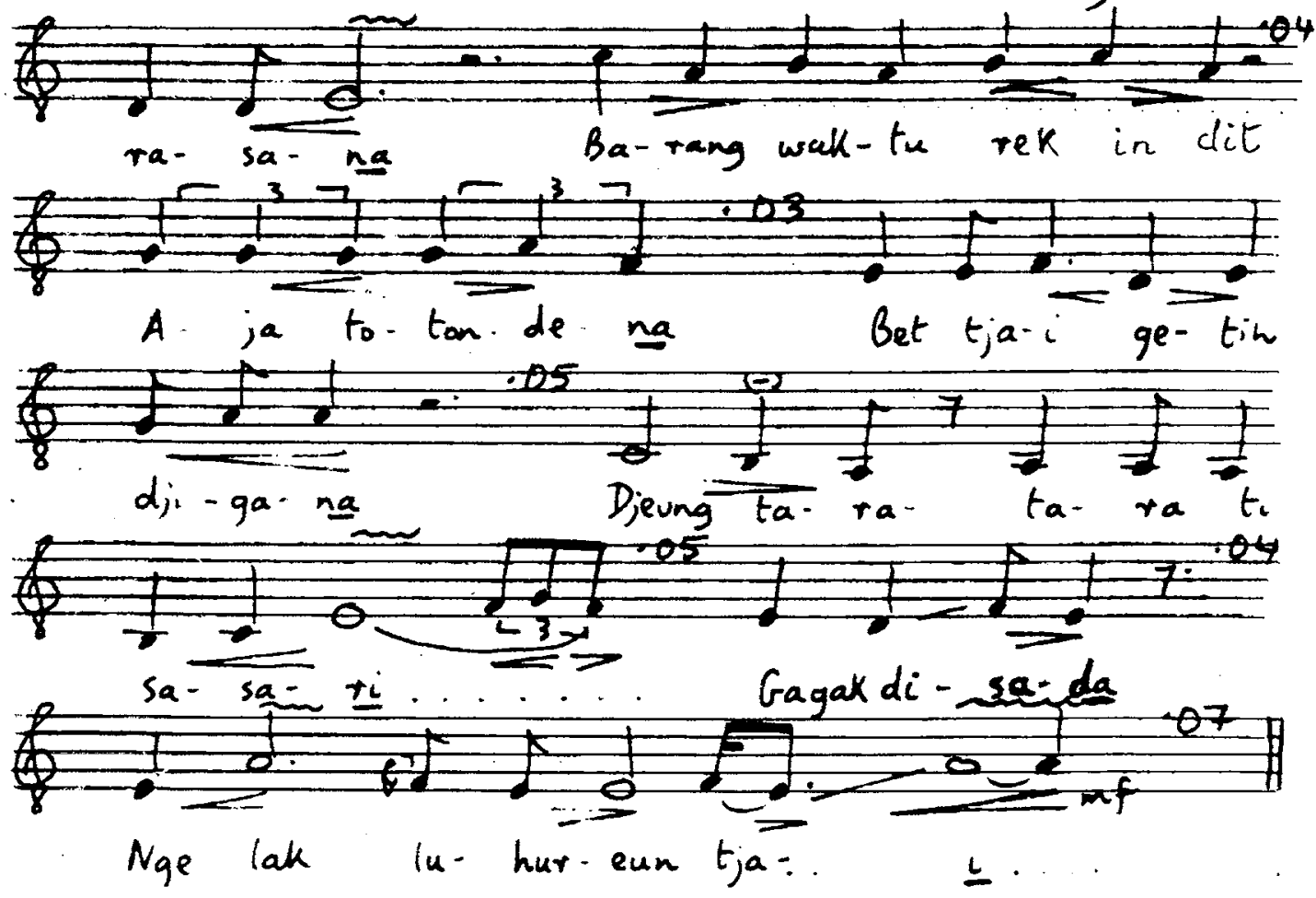
36. ASMARANDANA

SINGER: SJAMSUDDIN

T.I.: $0.37 \mathrm{~min}$.

O.P.: $\frac{1}{2}$ tone higher

$(d=137)$

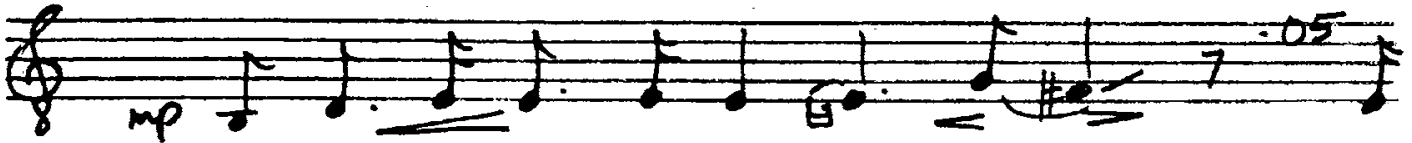

$E$ - ling-e-ling mu- rang $\mathrm{Ka}_{a}$ lih... $\mathrm{ku}$

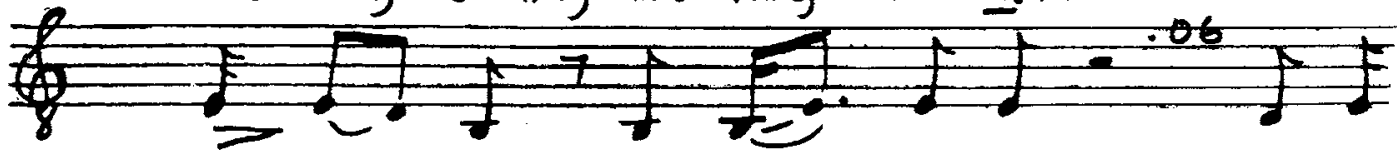

du a.... pik djeung ber:.. se-ke U-lah

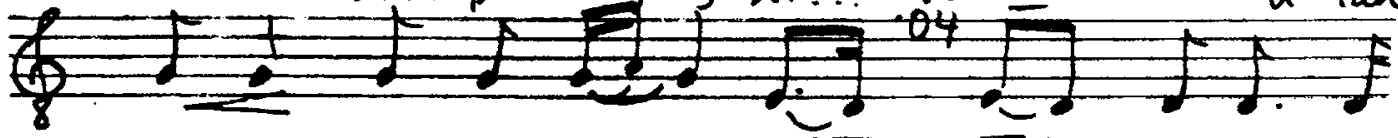

o- doh $K_{a}$ pa-ngang-.. go... $\bar{M}_{k n}{ }_{n}$.. ko-tor geu-

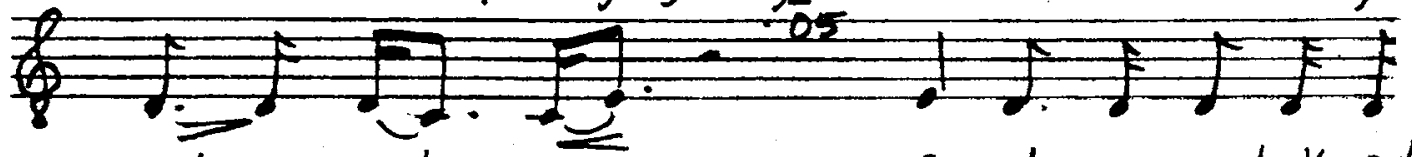
wat seu-sech-... an...
So-eh qu-wat Ka-put.
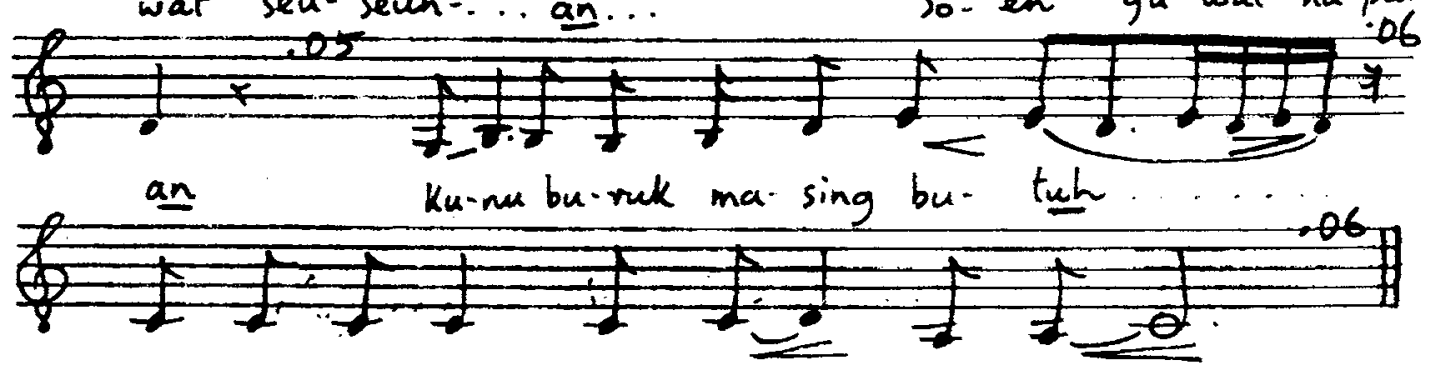

$k_{u}$ - mu a- njar ma- sing... le- bar 
$(d=87)$
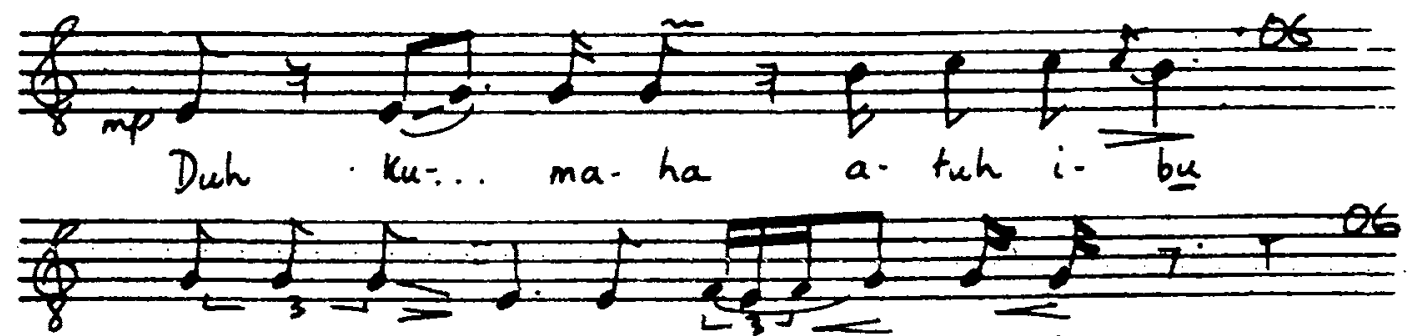
A. nu- nu
dju
se - nang.
ga. lih
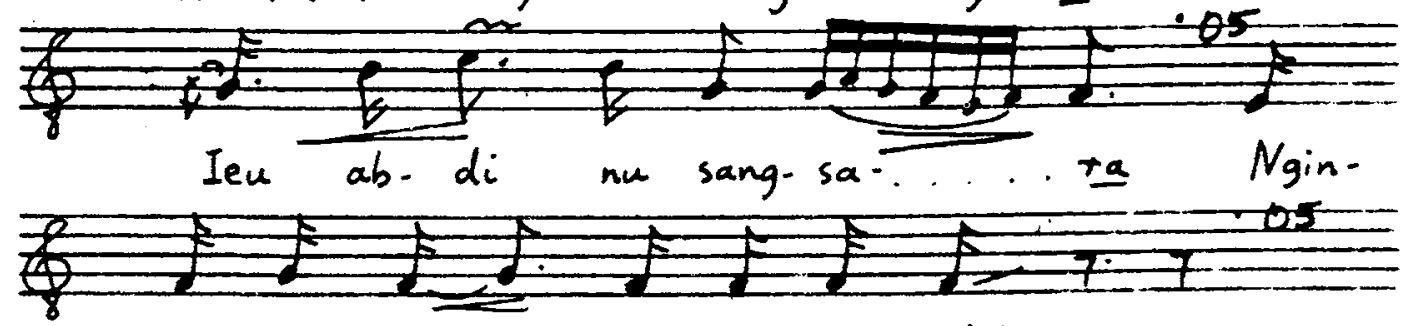

tun-keun se-.. trat sa- hi. dji
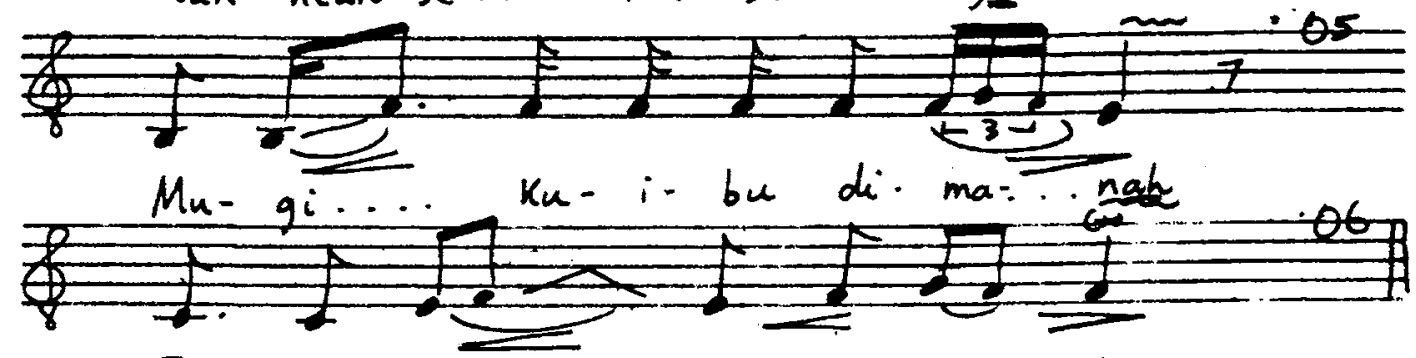

Ieu $p^{i}$ - hon......djuk $\sin a b=\ldots d i$. 
39. PUTJUNG

SINGER： SJAMSUDDIN

T.I.: $0.25 \mathrm{~min}$.

O.P.: I tone lower

$(d=125)$

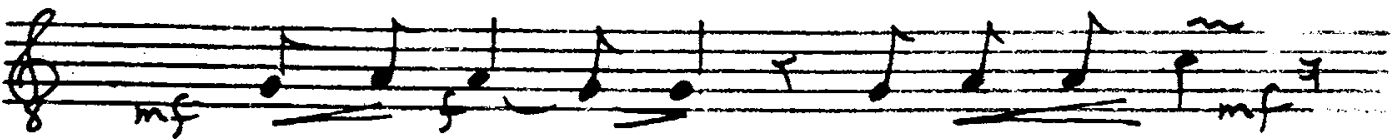

Ba-pak lu-... tjung ka-beu-ki- na

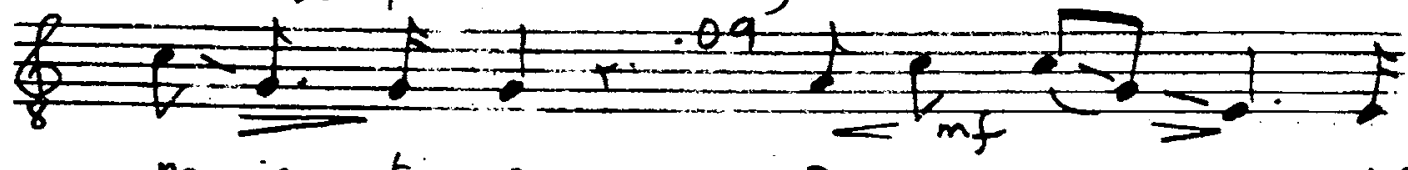

pa is ti-pung Dig ka- wa- rung men

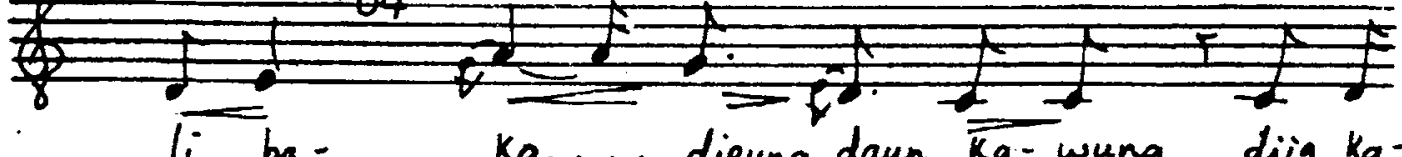

$l_{i}$ ba- ko.... djeung daun $\overline{k a-w u n g ~ d j i g ~} k_{a}$

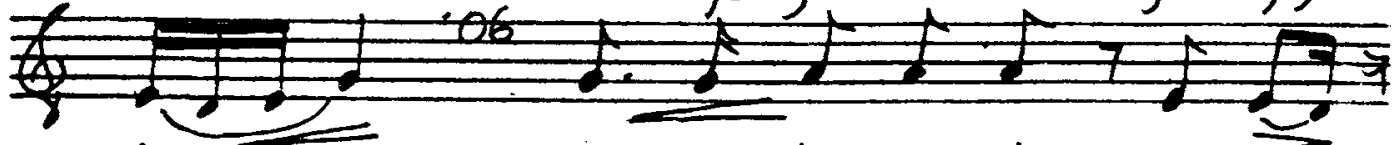

li... sung ma-ling ha-jam ke- $\overline{\text { keok- }}$

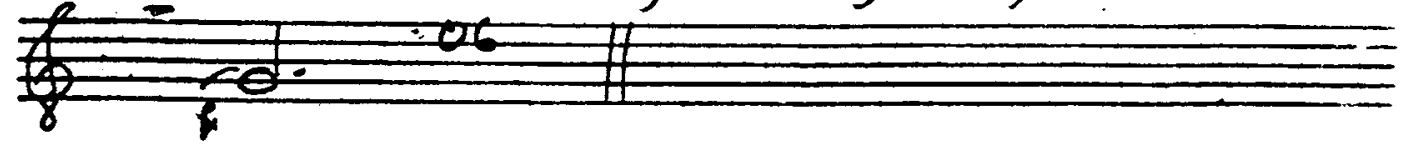

an. 
4I. KINANTI

$$
(d=136)
$$

SINGER: M. ROCHIM

HOME TOWN: BOGOR

T.L.: $0.28 \mathrm{~min}$.

O.P.: as below
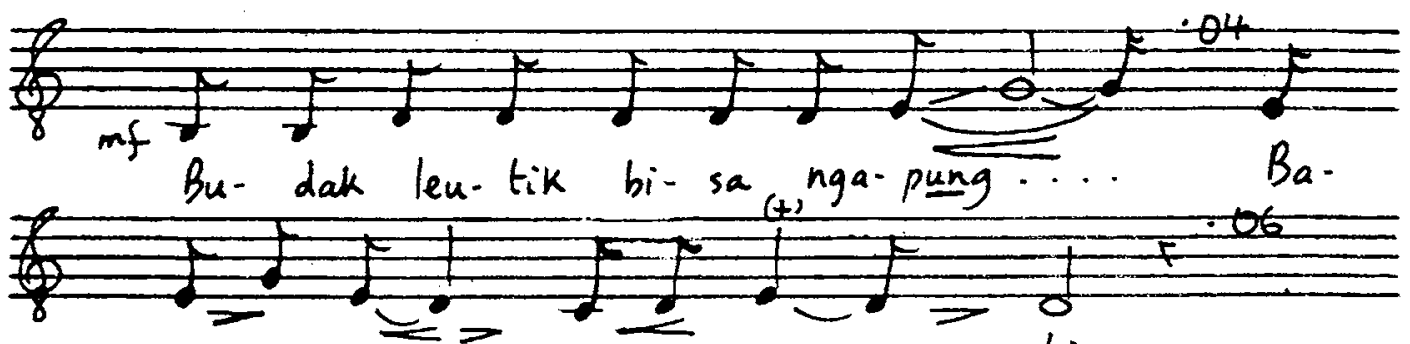

ba:ku inga: $:$ pungina peu.... ting
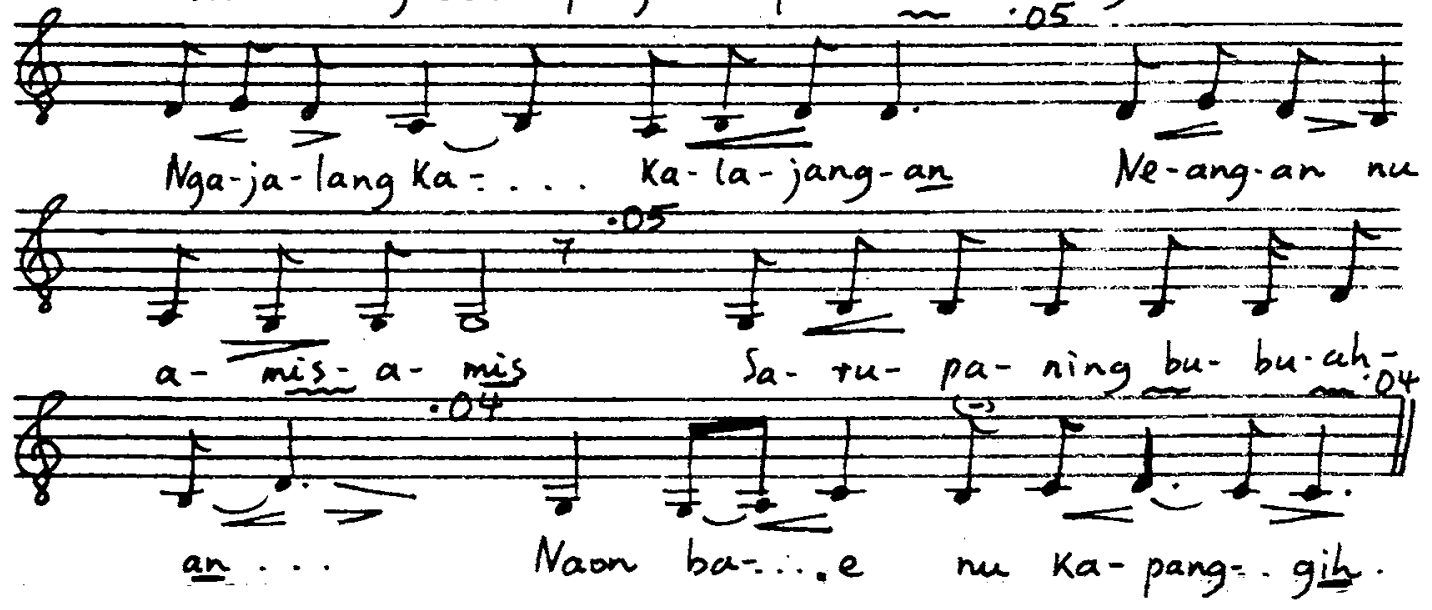
42. MASKUMAMBANG

SINGER: M. ROCHIM

T.L.: $0.24 \mathrm{~min}$.

O.P.: as below

\section{$(d=137)$}
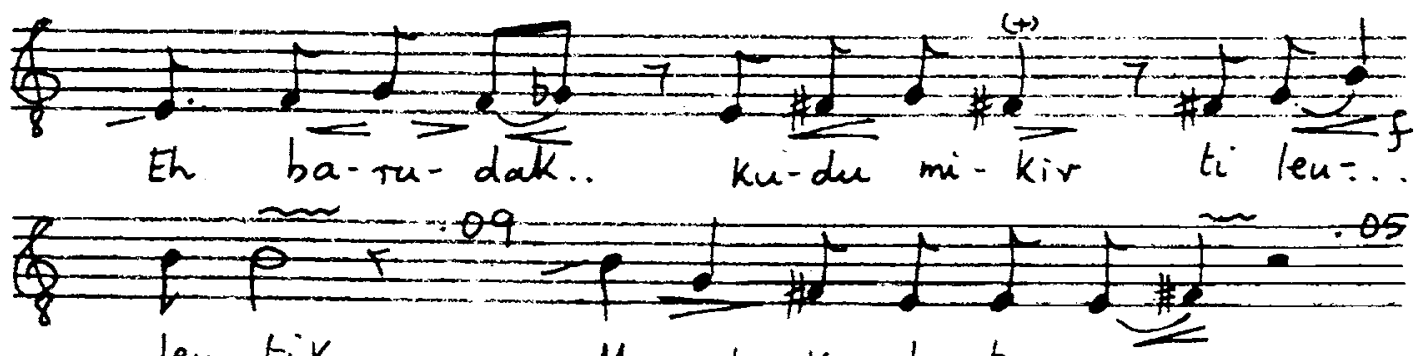

leu-tik Ma-neh Ka-hu-tang-an..

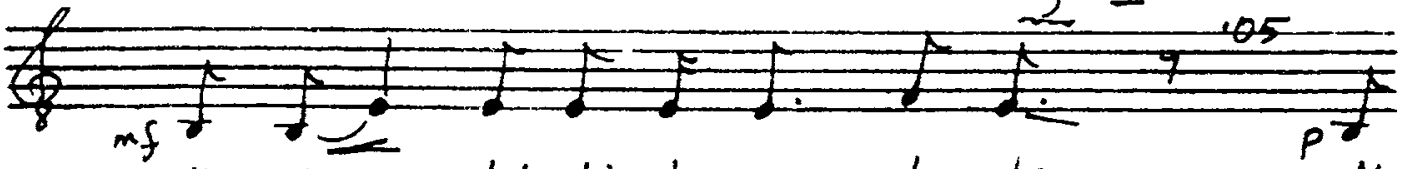

$k_{u} k_{0}=\ldots$ lot ti ba-rang la- hir ${ }$ Ne-

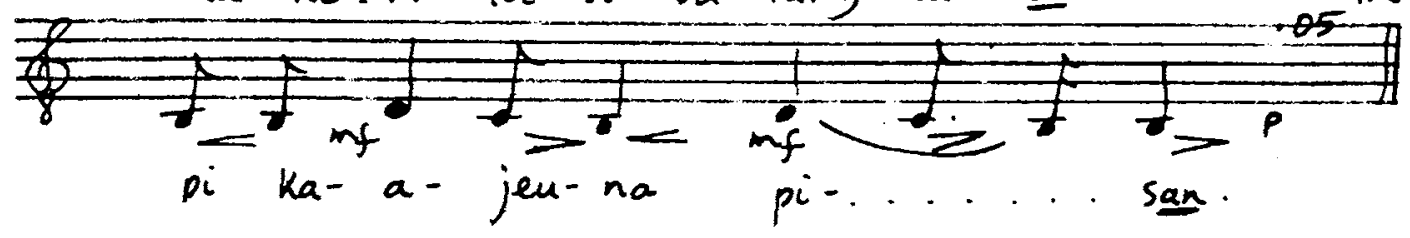


SINDANG-KEMPENG

T.L.: $0.32+0.34 \mathrm{~min}$.

O.P.: as below

$$
(d=112)
$$

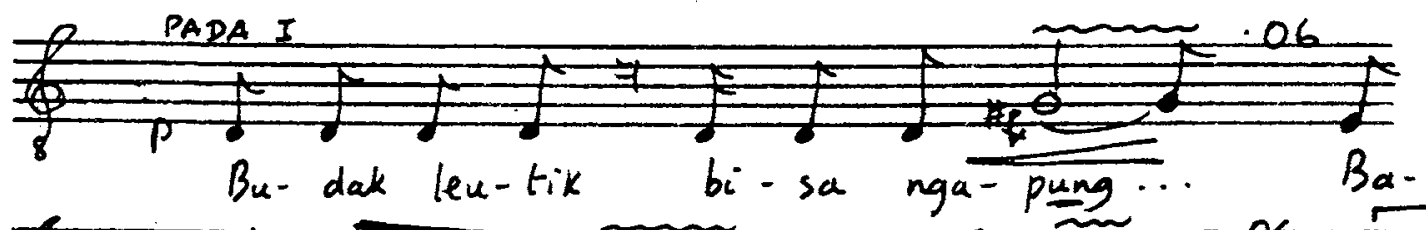
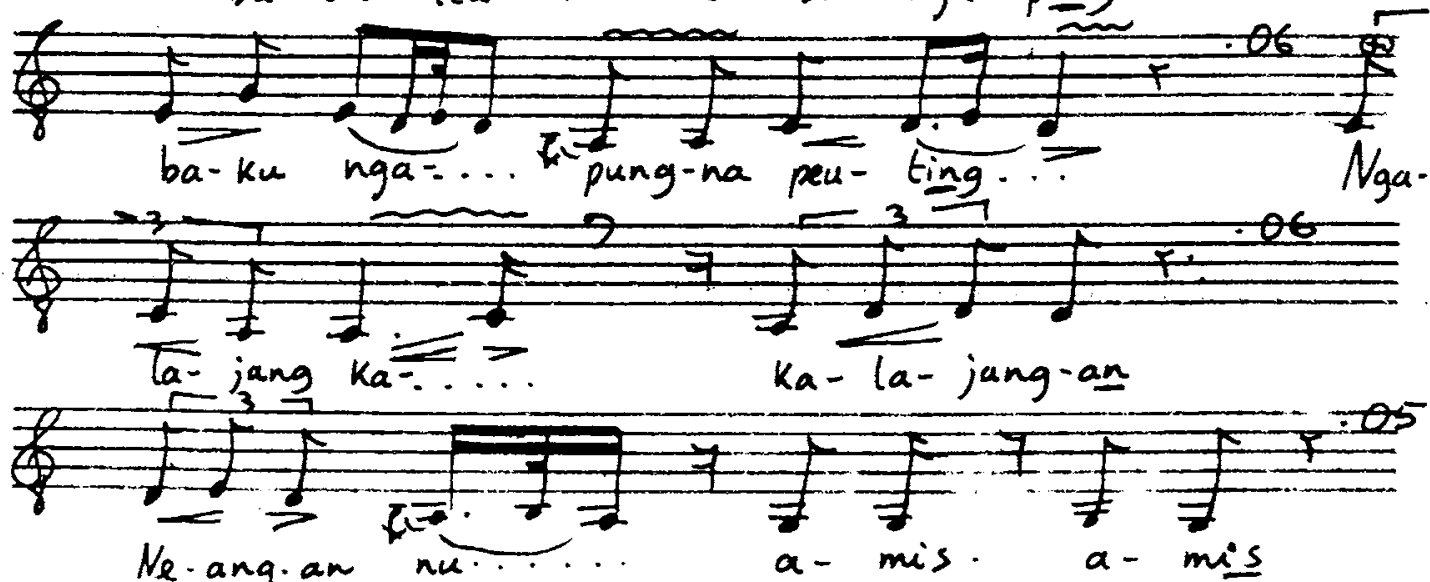

事

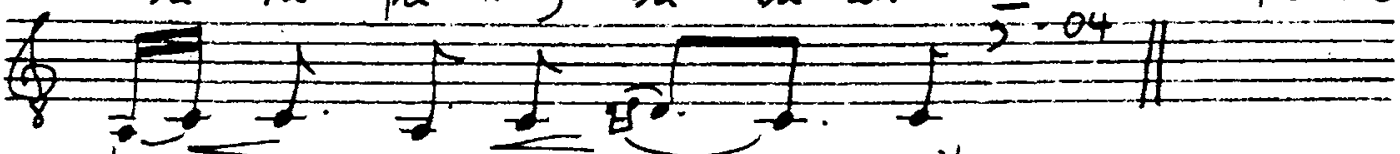

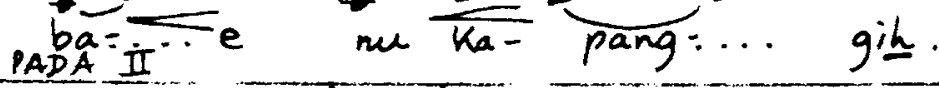

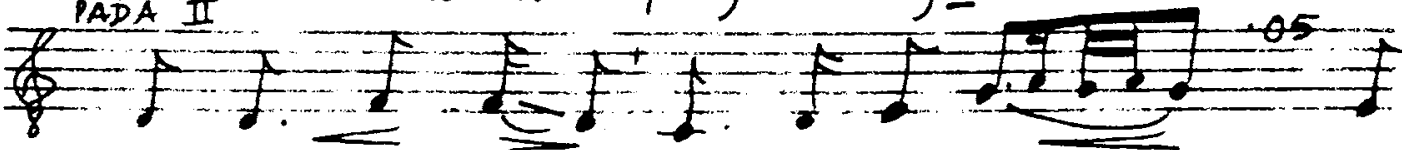

A.ri beu-rang. ting ga-ran-tung $N_{9066}$

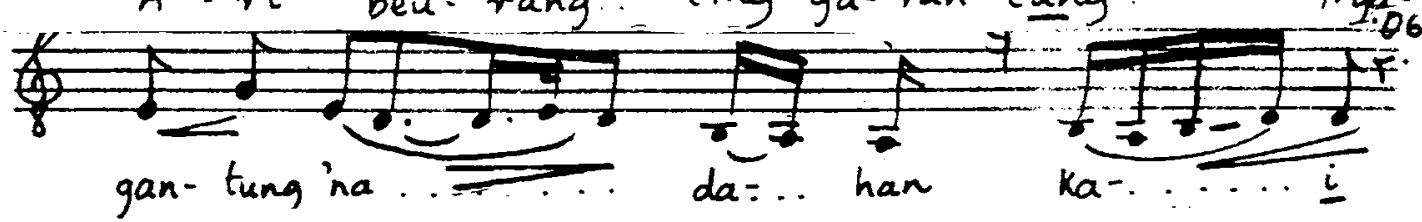




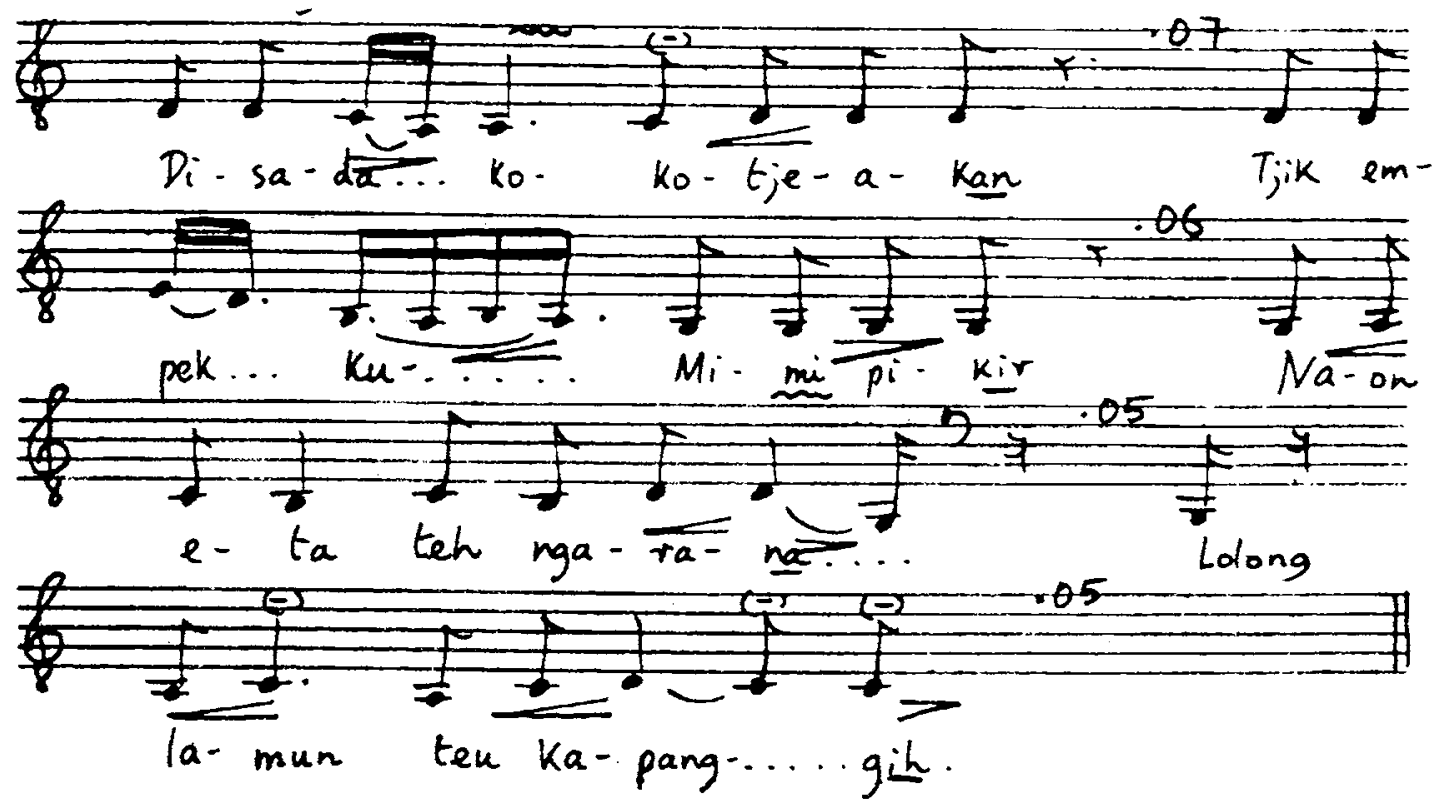


44. KINANTI

SINGER: A. SOPANDI

HOME TOWN: BANDUNG

T.L.: $0.24 \mathrm{~min}$.

O.P.: $\quad 1 \frac{1}{2}$ tones lower

$(d=125)$
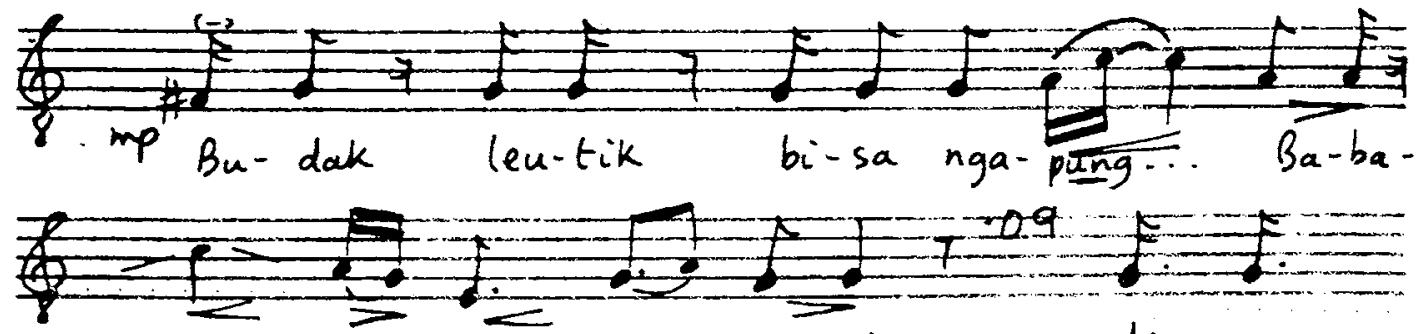

Ku nga: pung-na...pen-ting Ngu-ri-

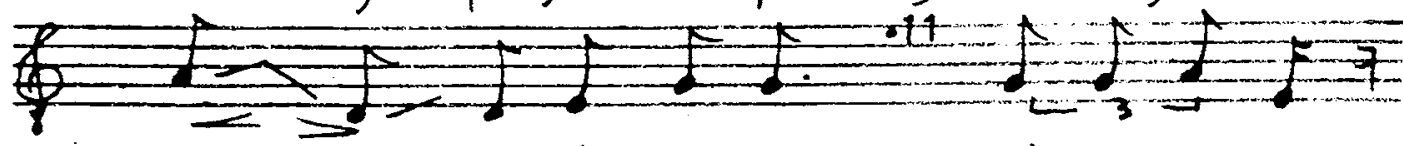

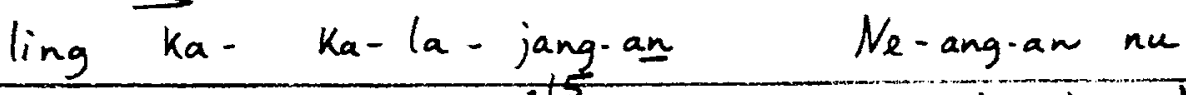

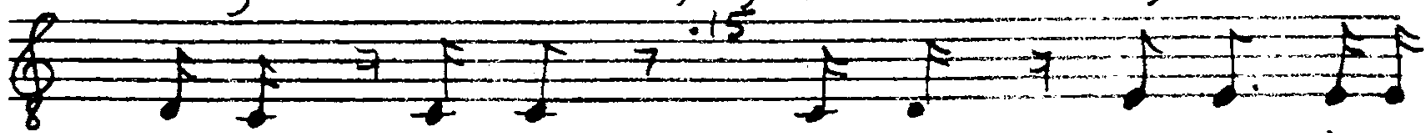

$a-m i s-\quad: a-m i s$

Sa-ru-

pa- ning bu-bu-

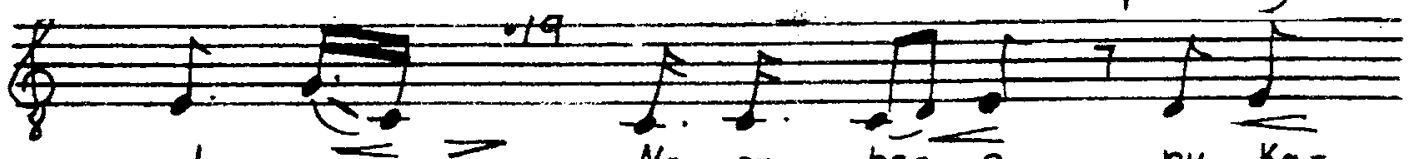

ah- an $\mathrm{Na}$ - on ba: $=\mathrm{e}$ nu $\mathrm{Ka}$ -

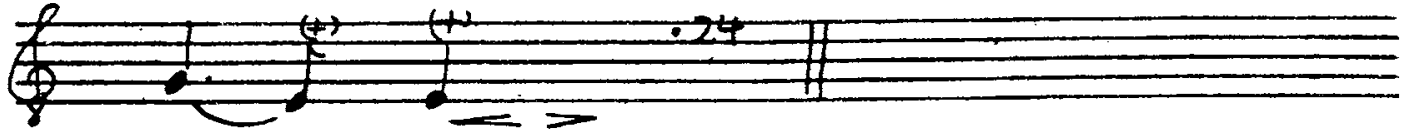

pang:... gih. 
45i. KINANTI

SINGER: A. SOPANDI

T.L.: $0.49 \mathrm{~min}$.

O.P.: as below

$(d=110)$

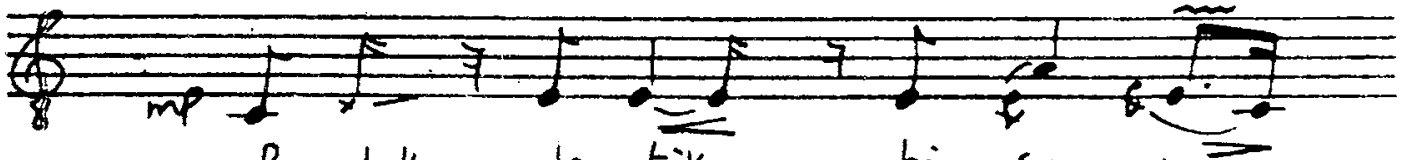
Bu-dak leu-tik.. bi sa nga
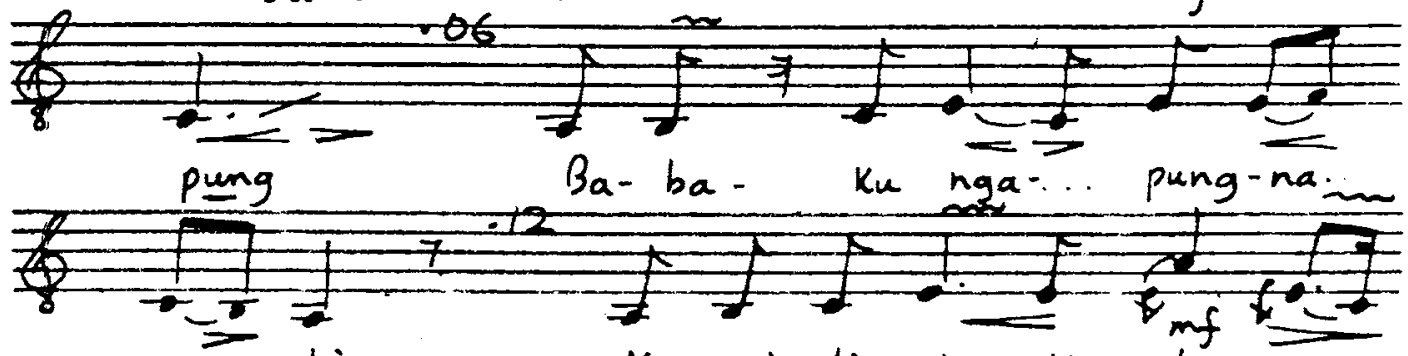

peus. ting Ngu- $+i-l i n g k a-k a-l a-j a n g=$.

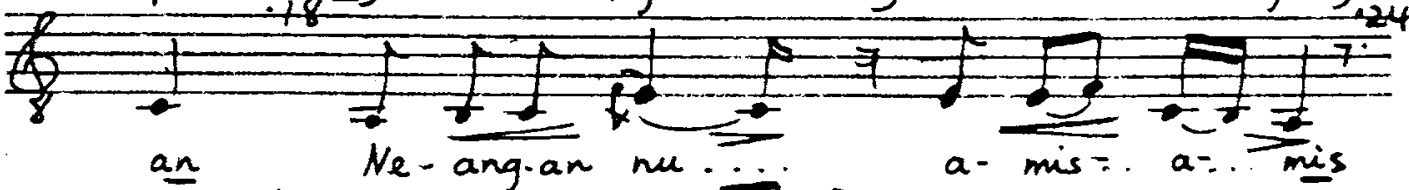

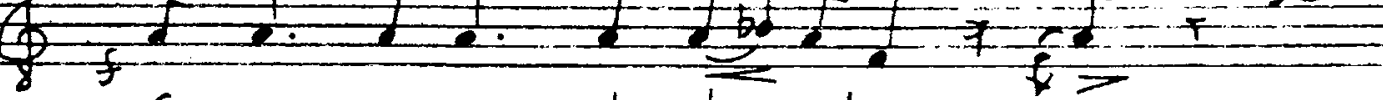
Sa- ru-pa-ning bu-bu=.. ah ..

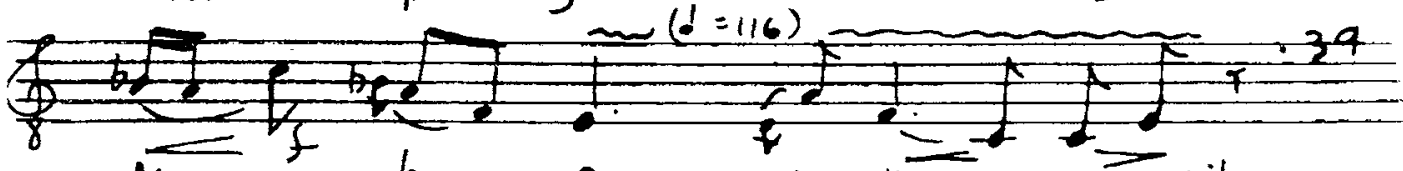
Naon... ba... e e the kang.gih

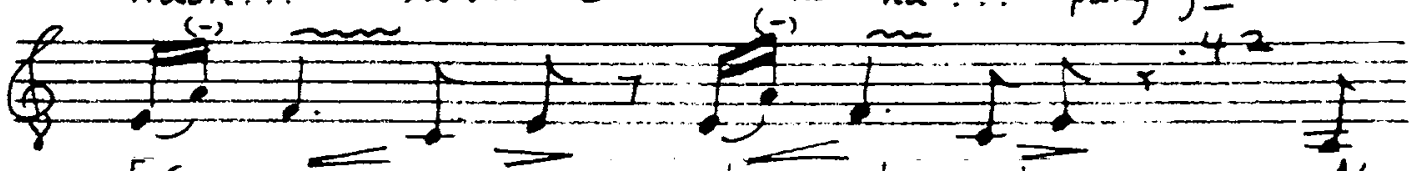

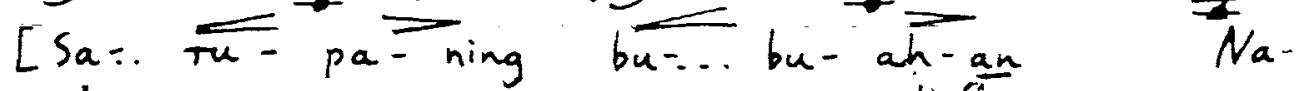

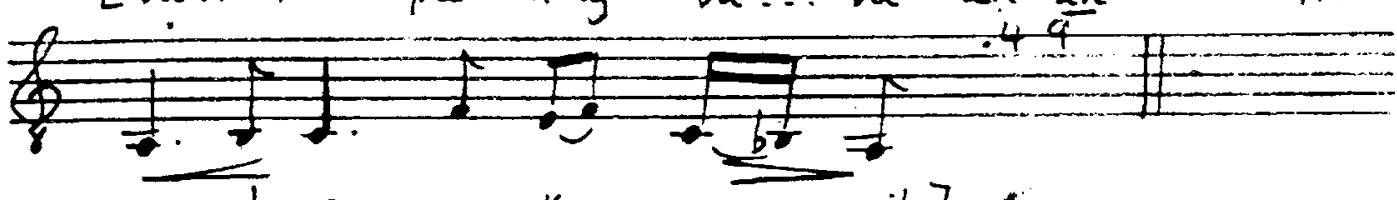
on ba-e nu ka... pang $\ldots$ gih]. 
46. ASMARANDANA

SINGER: A. SOPANDI

T.L. : $0.27 \mathrm{~min}$.

O.P.: $\frac{1}{2}$ tone lower

(d. =84)

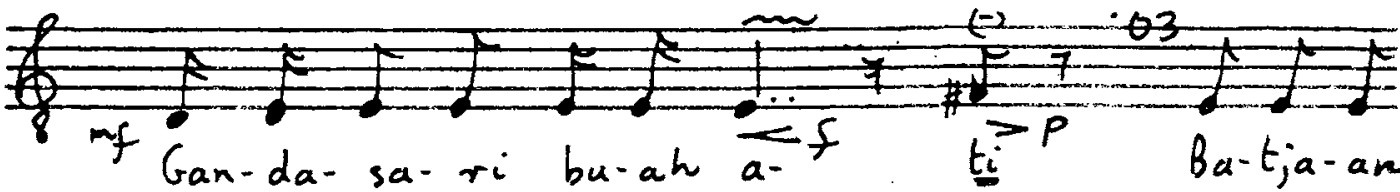
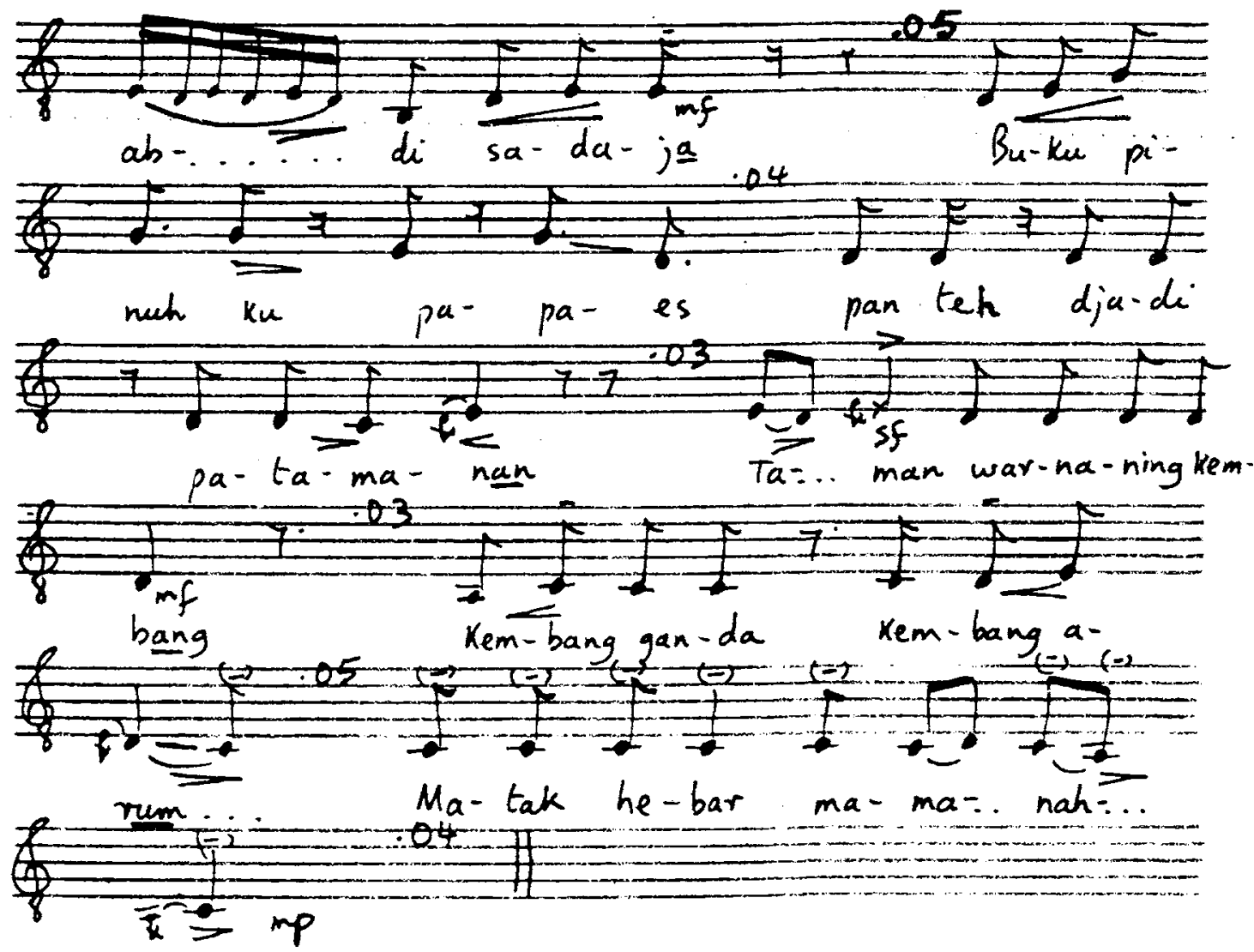
47. ASMARANDANA

SINGER: A. SOPANDI

T.L. : $0.65 \mathrm{~min}$.

O.P.: as below

$(d=102)$

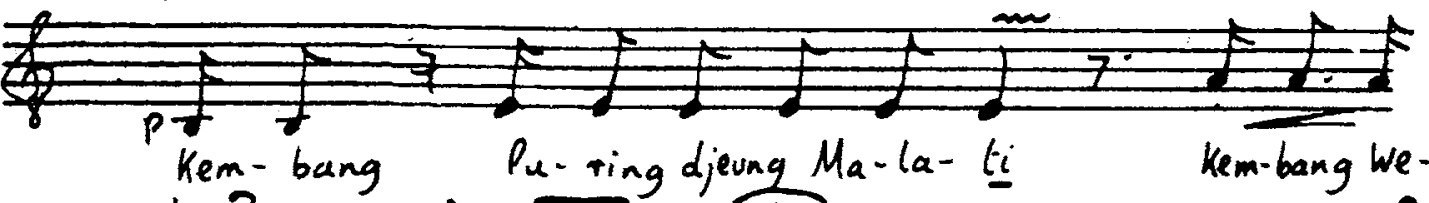

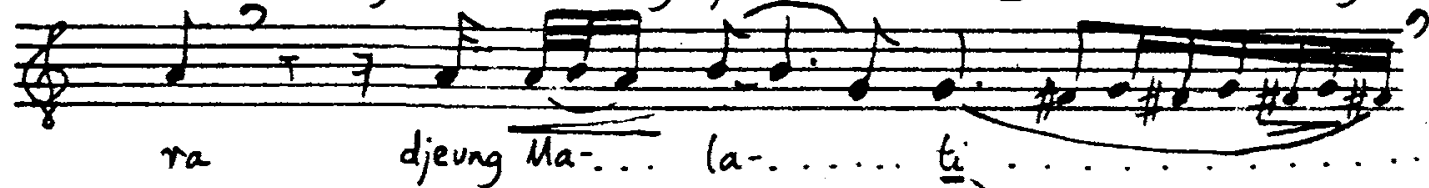

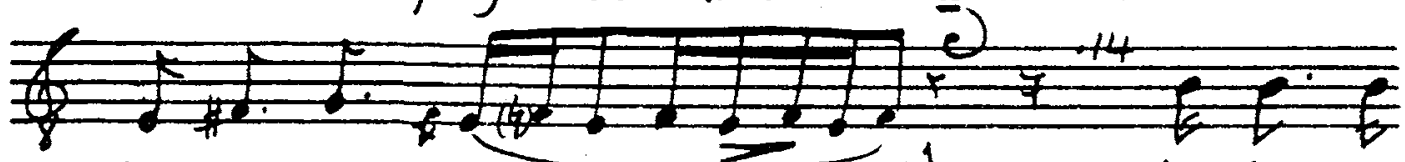

(a-duch am- pun........ kem-bang we -

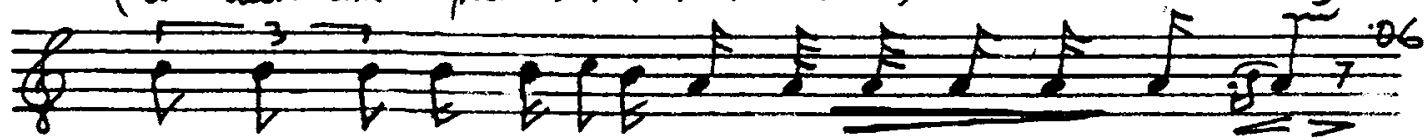

ra ros sok tu-ma.noska-ma-na $a-+i$ du-nung-an

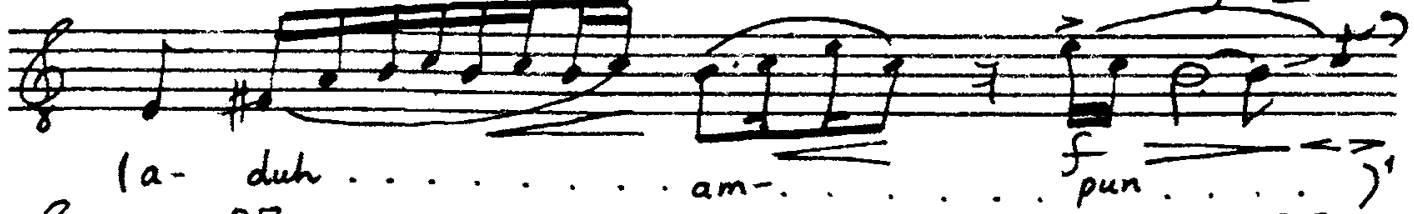
$\frac{f}{2}+08$ Du- nung-an nu mi-ka he-man..

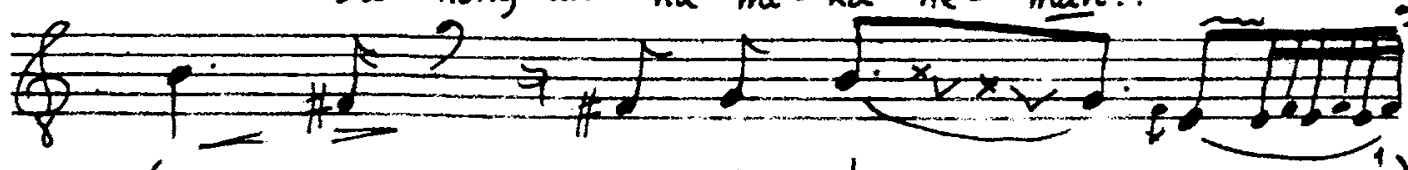
(nu.... $\operatorname{mi}-k_{a} h e=. .1$ man...

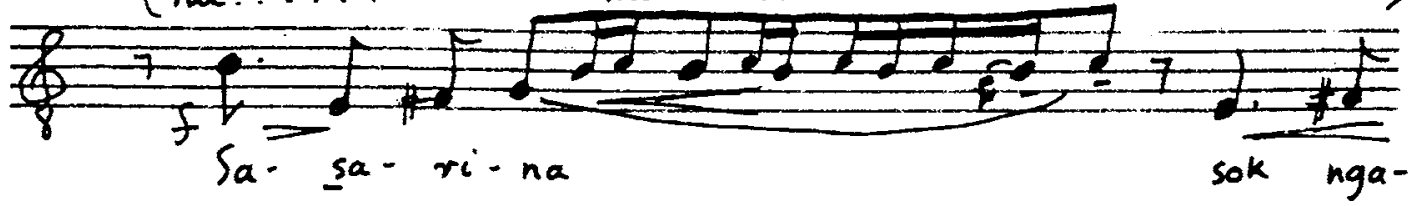



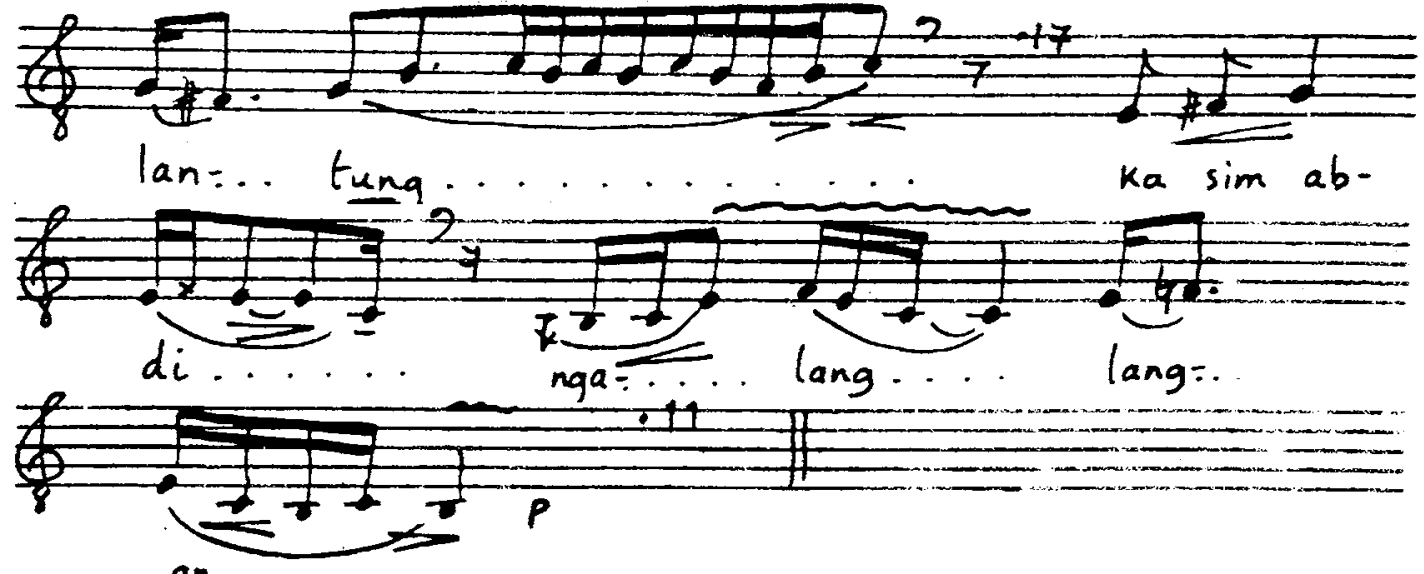

an 
448. SINOM BUHUN

SINGER: A. SOPANDI

T.L.: $0.56 \mathrm{~min}$.

O.P.: $\frac{1}{2}$ tone lower

$(1=113)$

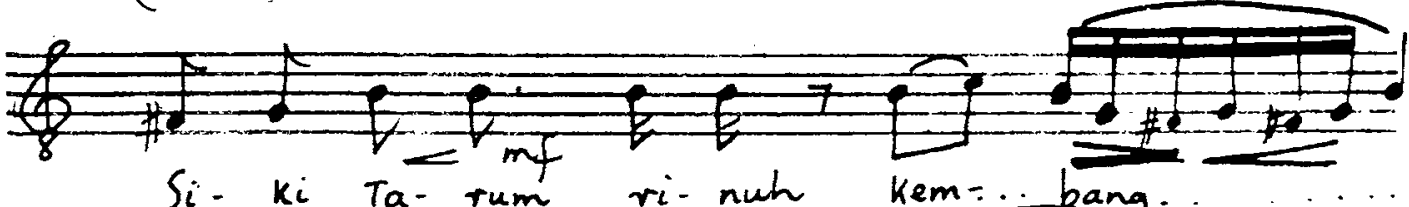

Si-ki Ta- rum ri-nuh kem $=.$. bang

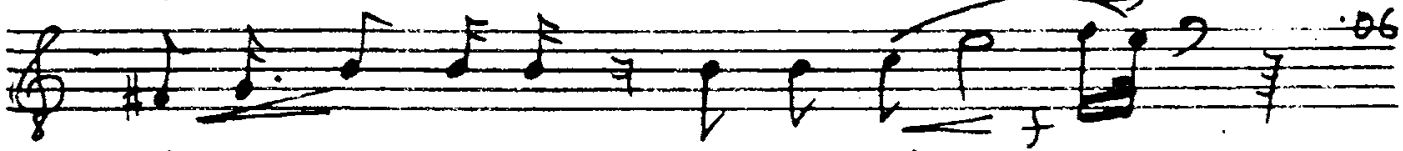

$B a-d o$-ang ma-nuk ba-do-ri.

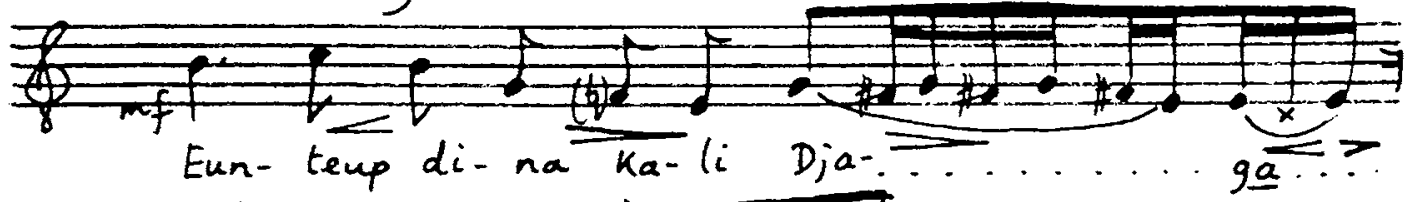

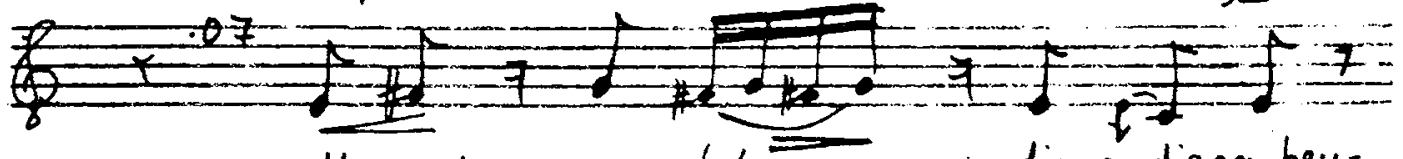
Ma-nuk wa-let:... djang-djang beu-

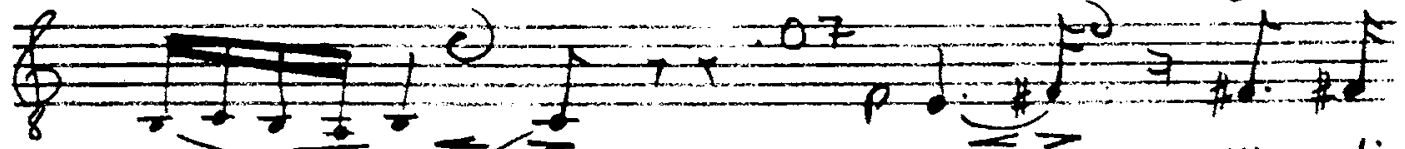

si... kith k. kir di.

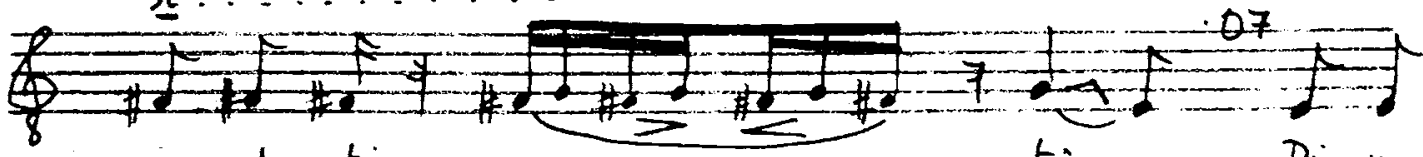

sa-da ti peu-.............. ting Di-na

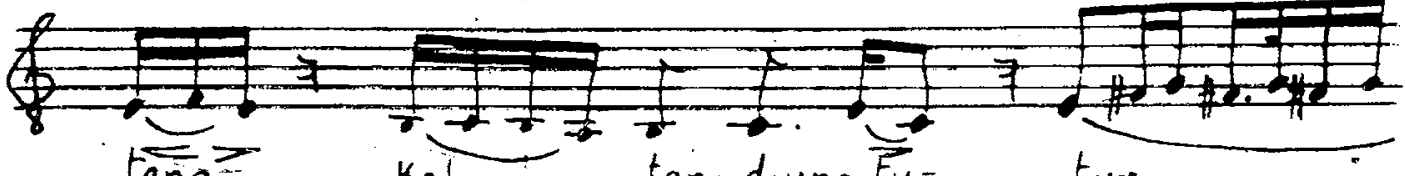

tang?-

Kal....tan d d ung $\overrightarrow{E_{u}}-\ldots$

tur

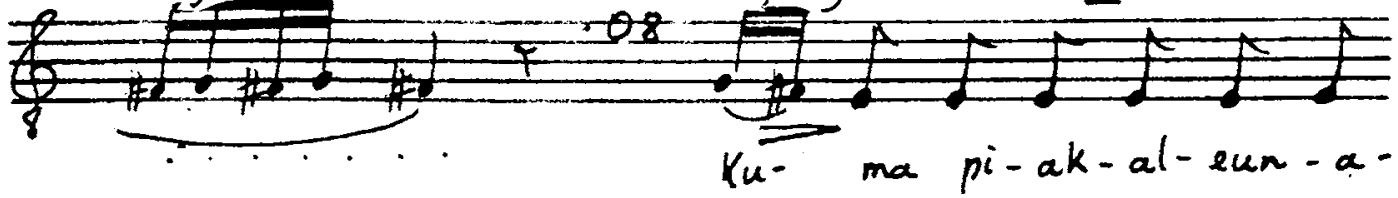




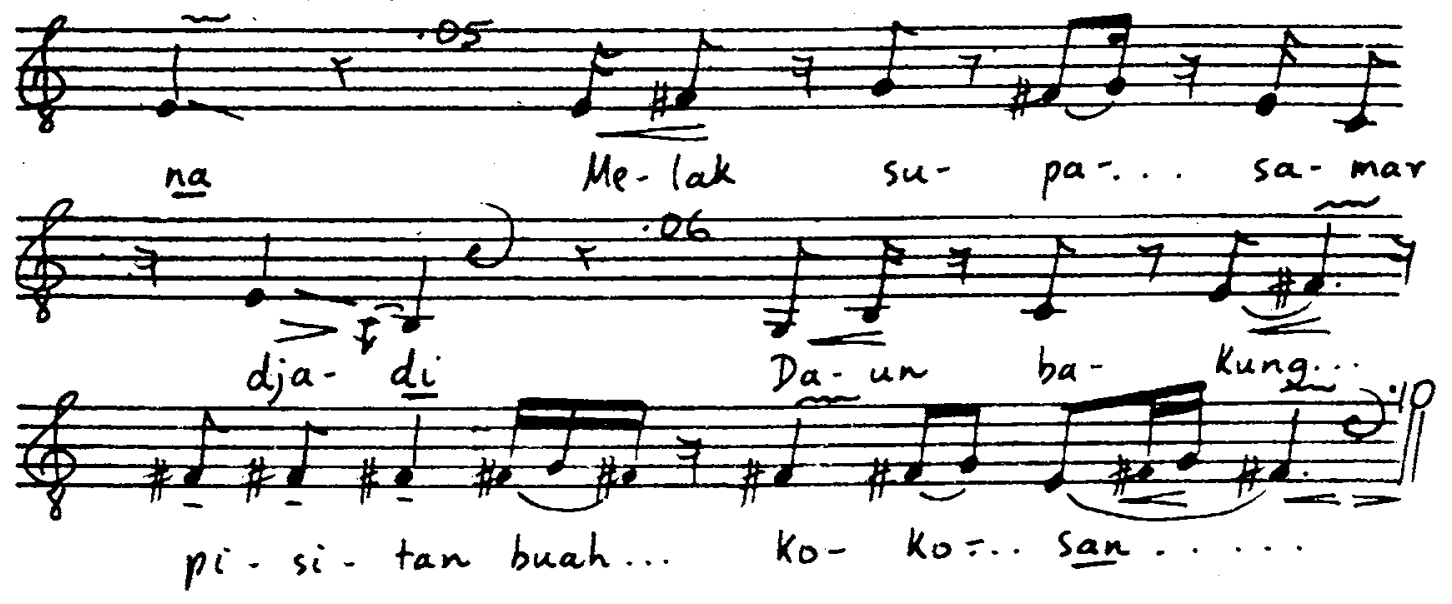


49. PUPUH SINOM

SINGER: A. SOPANDI

T.L.: $0.96 \mathrm{~min}$.

O.P.: $\frac{1}{2}$ tone higher

$(d=104)$

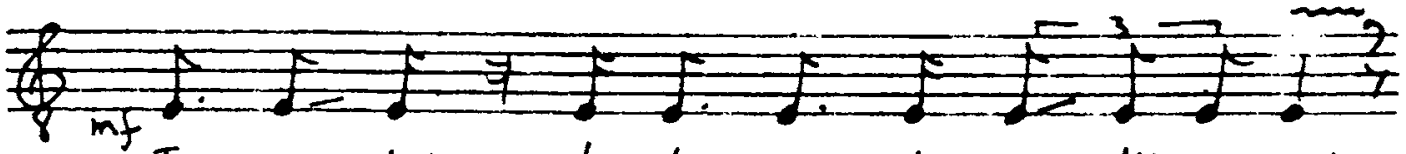
Tjing a-tuh bu-lan sing tja-ang Nja ma-neh

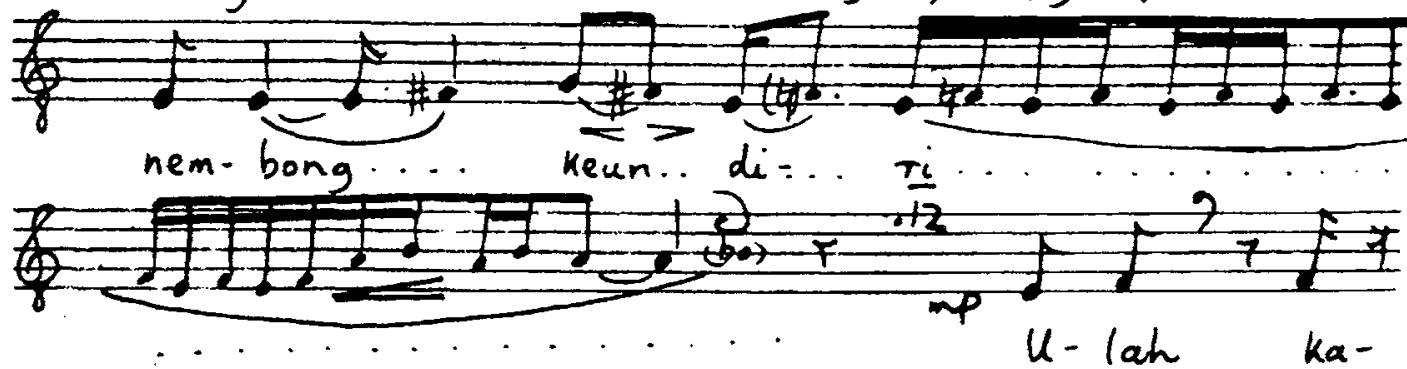

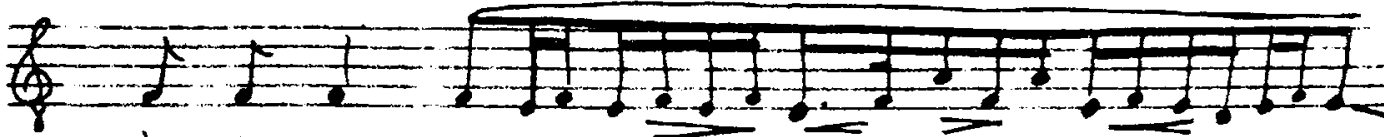
ha-lang-an me.............

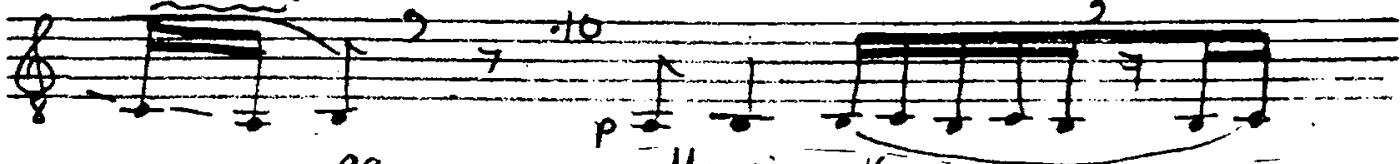

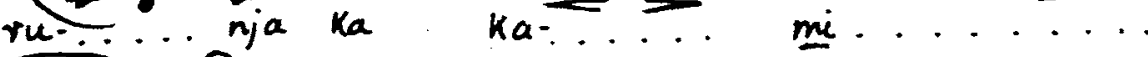

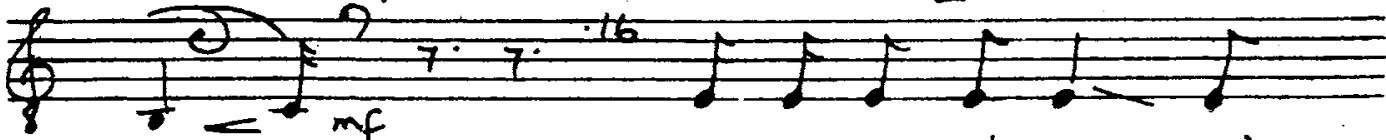

A - nu keur li-wung pi-

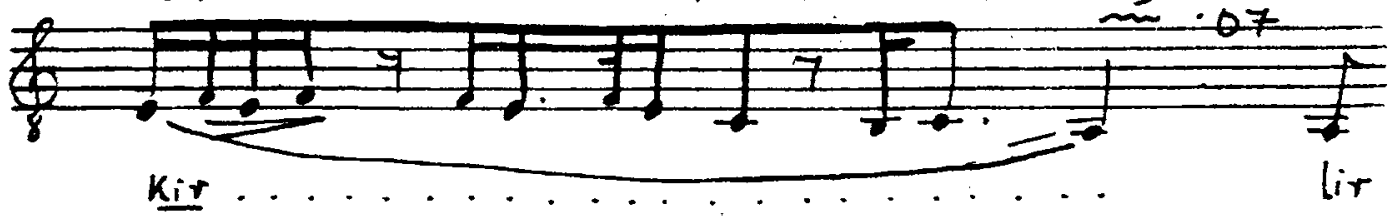



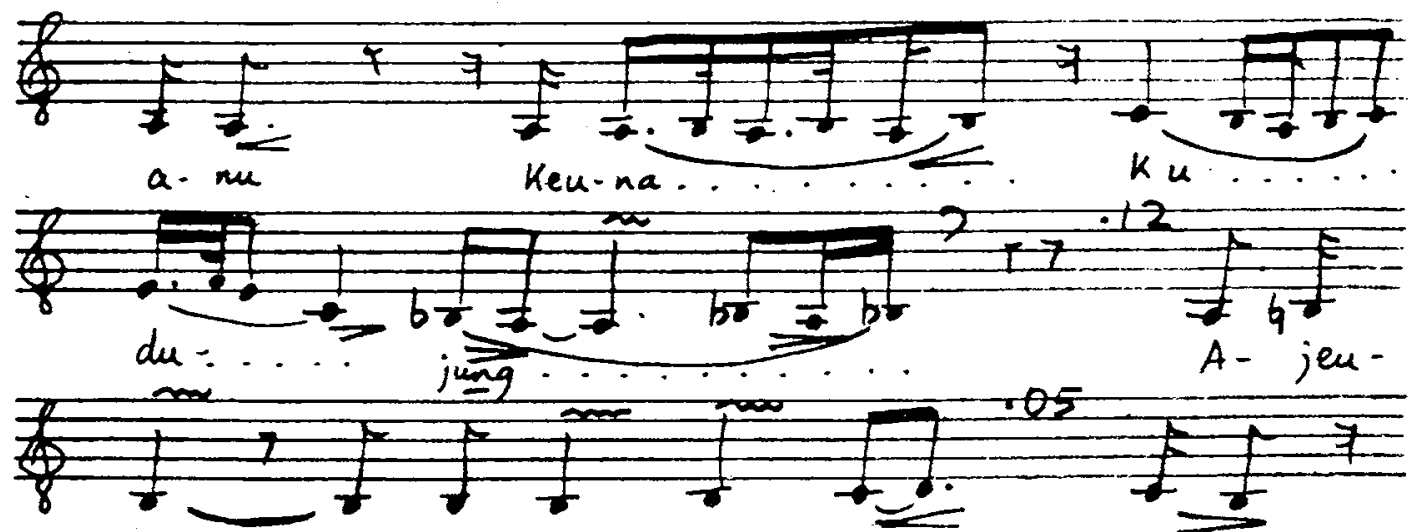
na . . .
rek
nga-bung-bang
Nga-Ian -
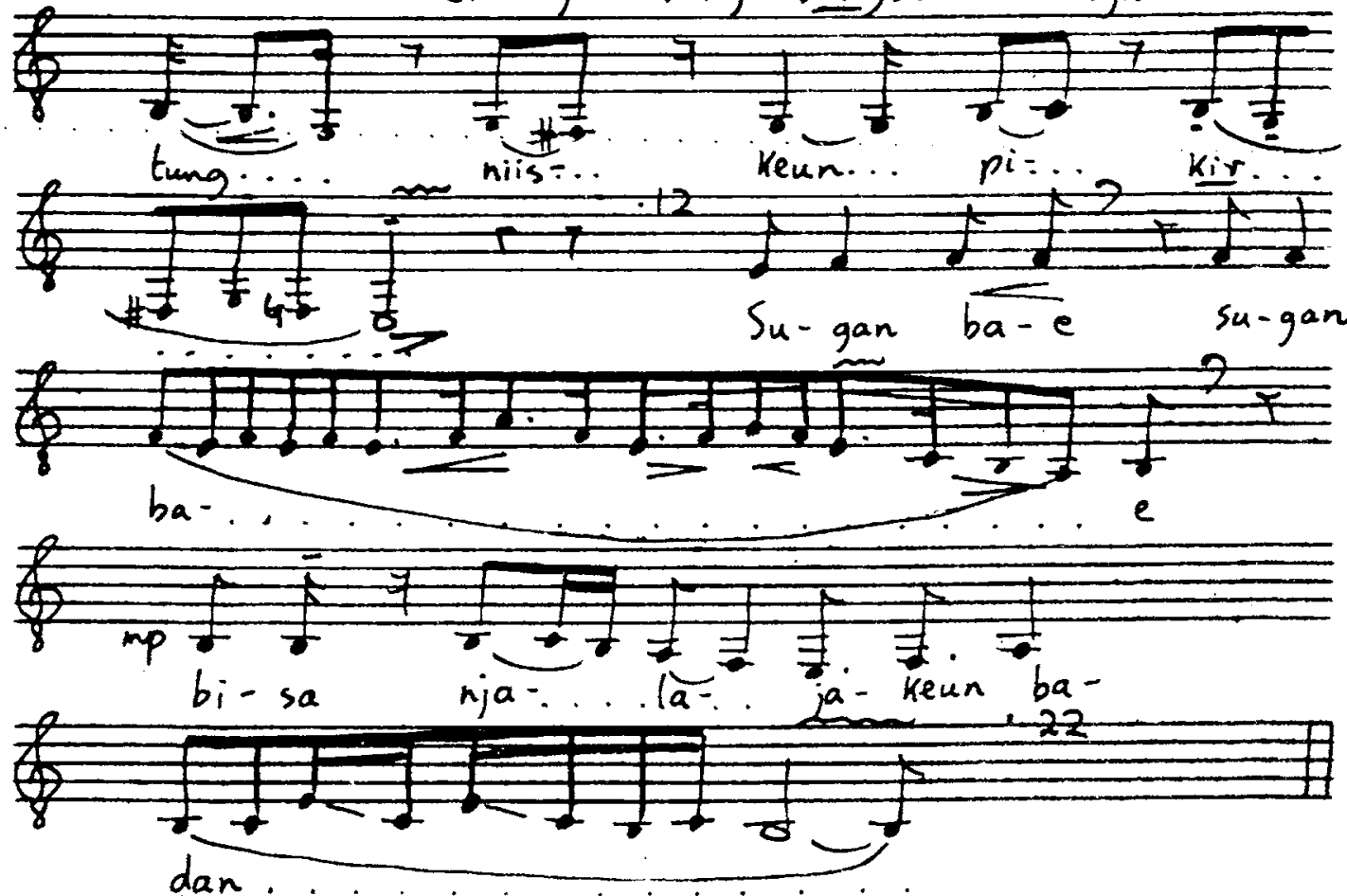
50. DANGDANGGULA BAJUBUD

SINGER: A. SOPANDI

T.L.: $1.16 \mathrm{~min}$.

O.P.: 1 tone lower

$(d=85)$

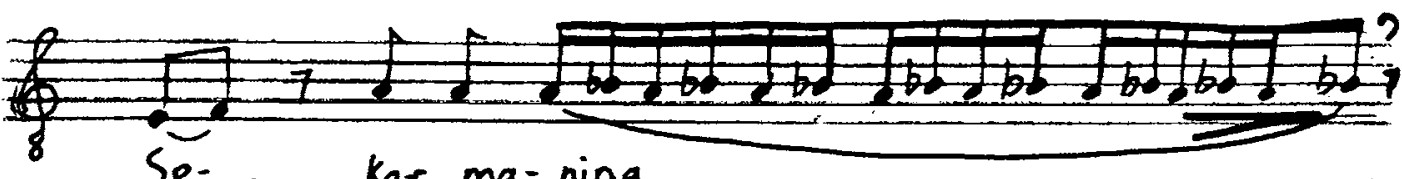

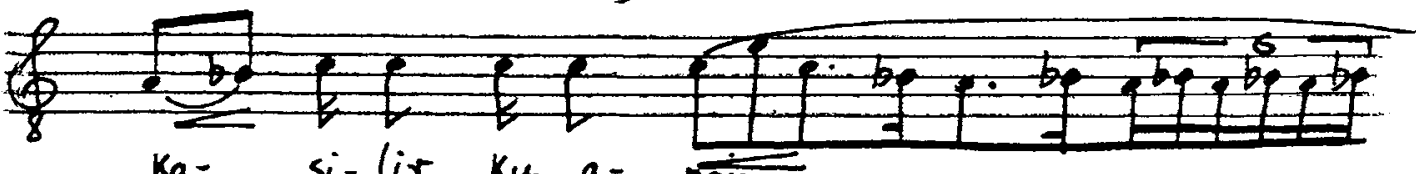
$k_{a}$... si-lir $k u$ a- nik.

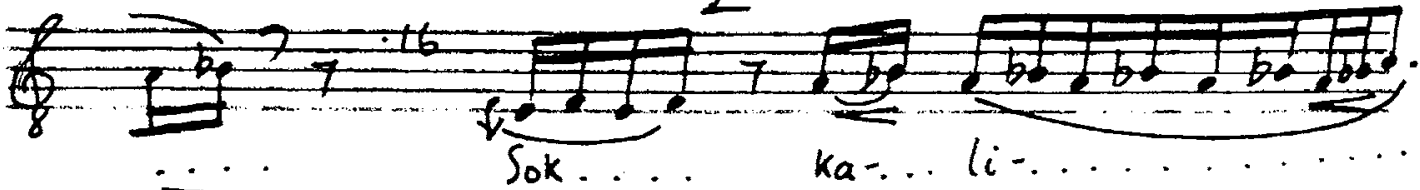

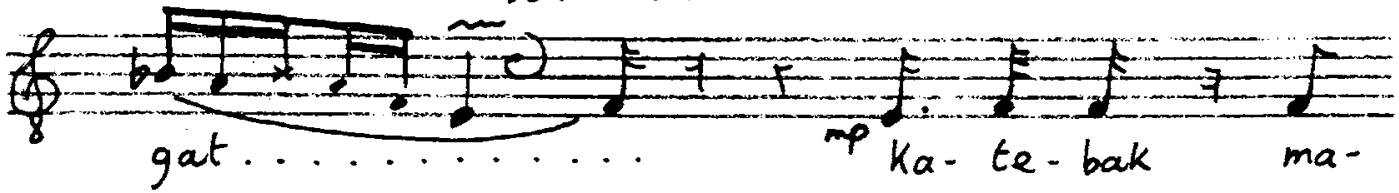

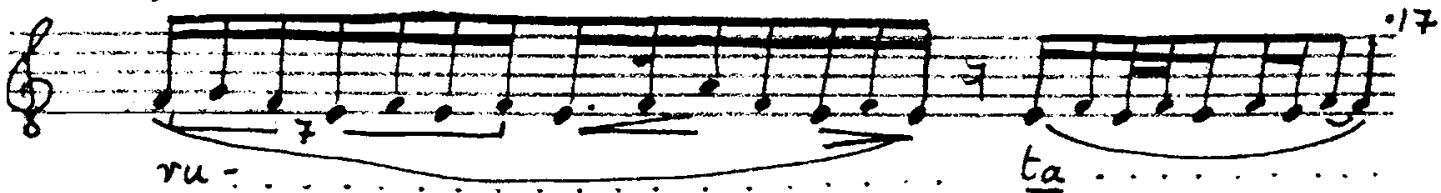

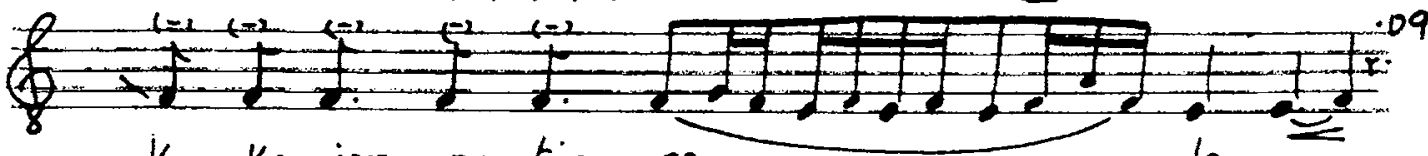

$k_{a}-k_{a}$-jon pa-ting pe .......... le-nong.

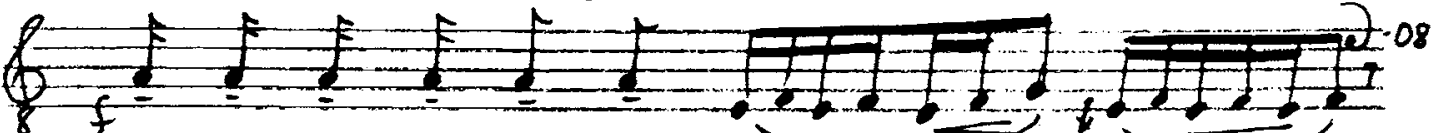

$D_{j i}$-ga nu nan-don keun $u-\ldots . .$. mur $\ldots$

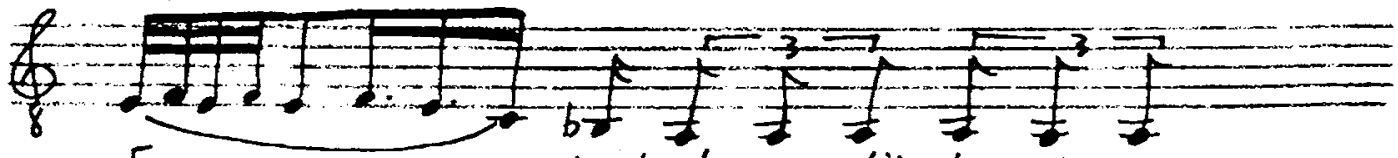

$E=\ldots \ldots$ breh di- na tjip-ta-ning a- 

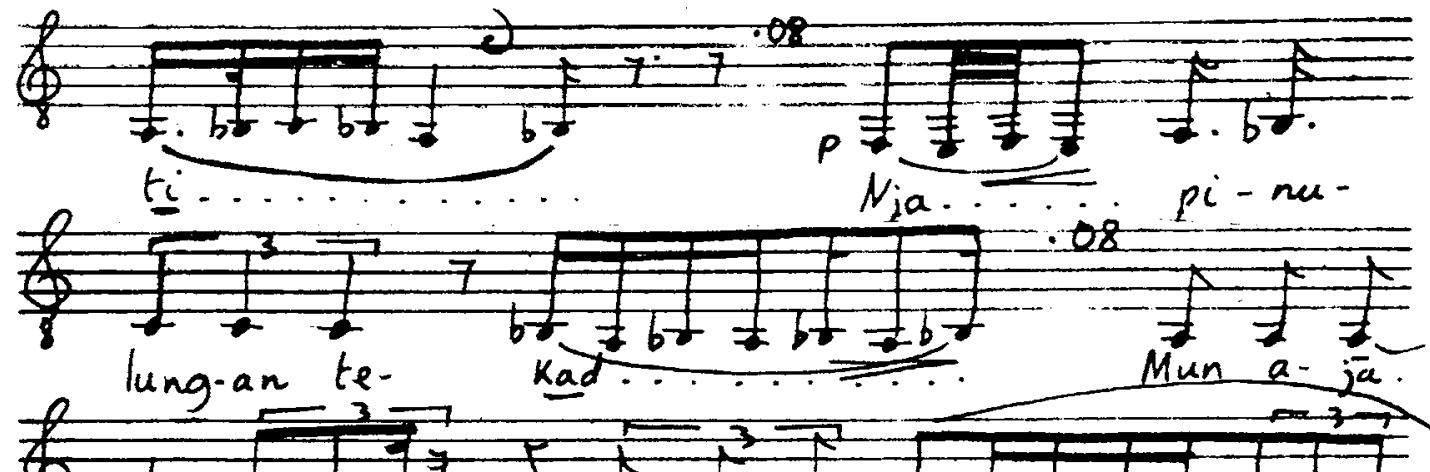

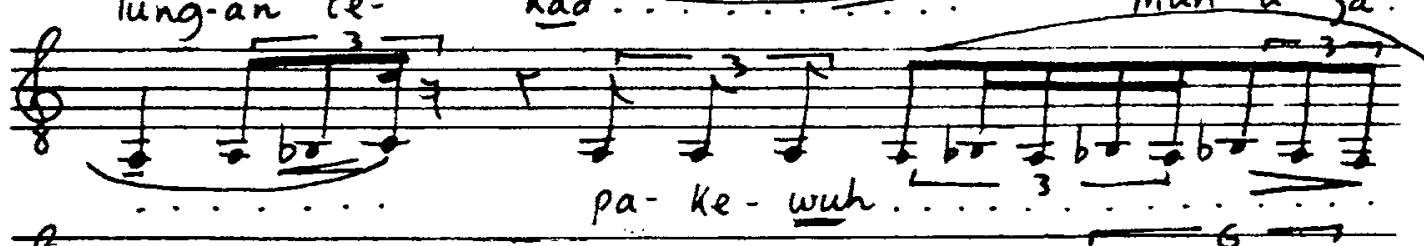

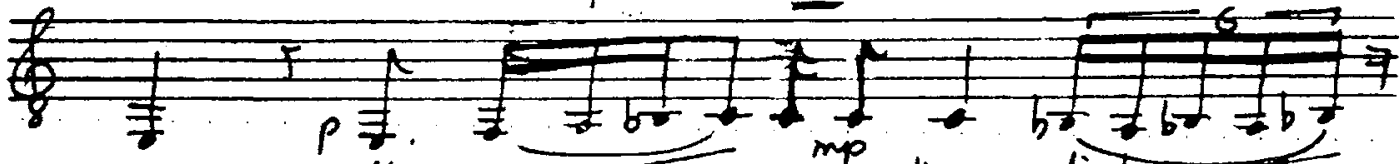

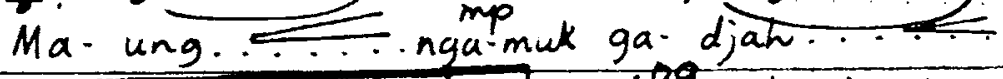
me.ta.
ta-as $i$-klas

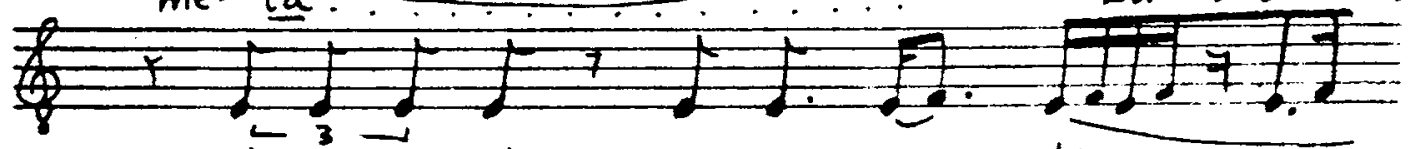

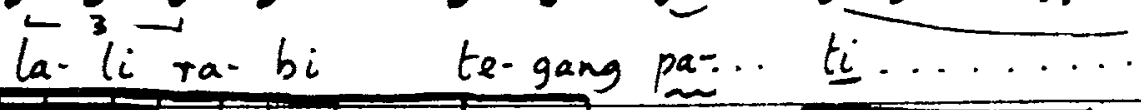

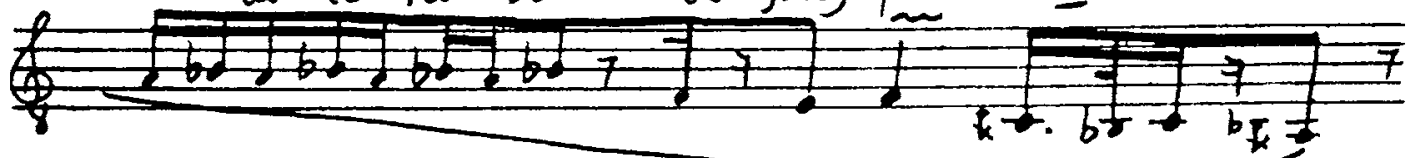

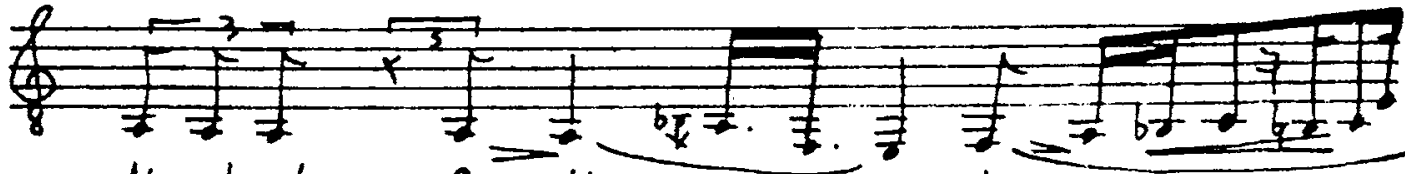

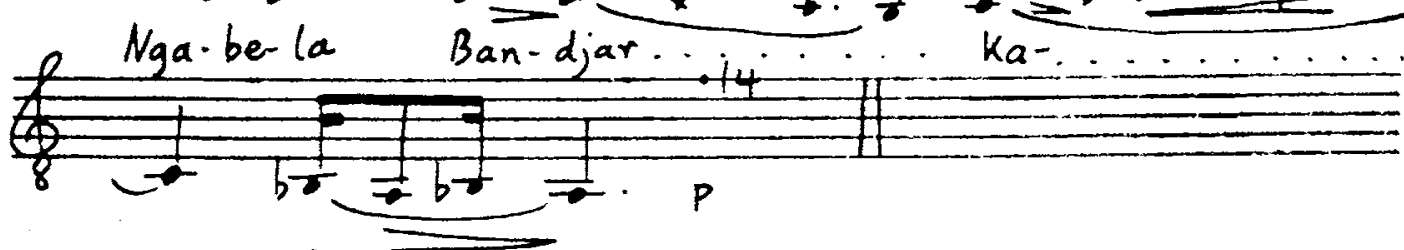


51.. PANGKUR

SINGER: A. SOPANDI

T.L.: $0.34 \mathrm{~min}$.

O.P.: 1 tone higher

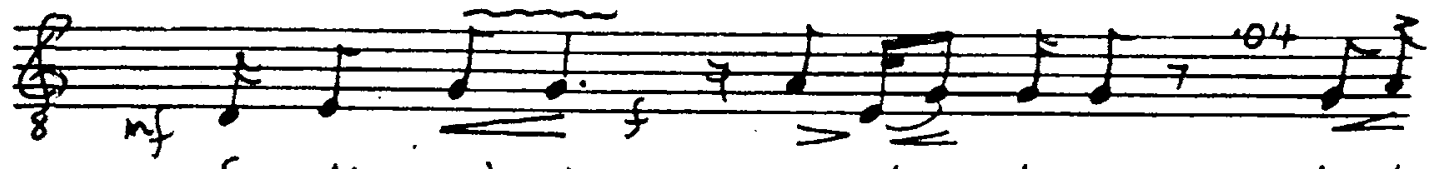

Se-dja nja-ba nga-la $\ldots$ la

Ngi-tung

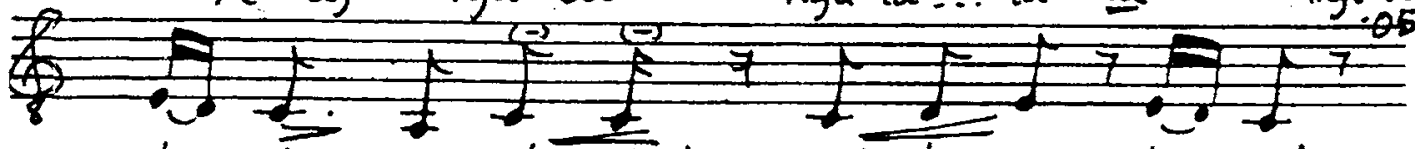

lem=. bur nga-dja-djah mi-lang-an $k_{0}=\ldots$ ri
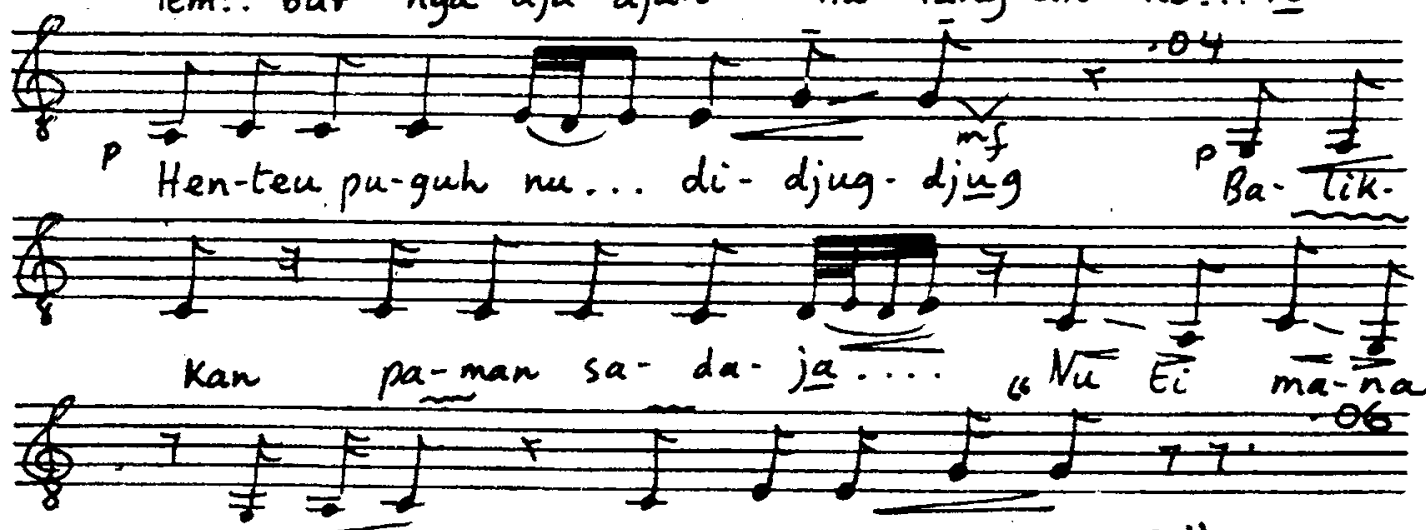

$t_{i}-\overline{l u-a n}$ se-mu $+\alpha-r u-\operatorname{seh}$ ?"
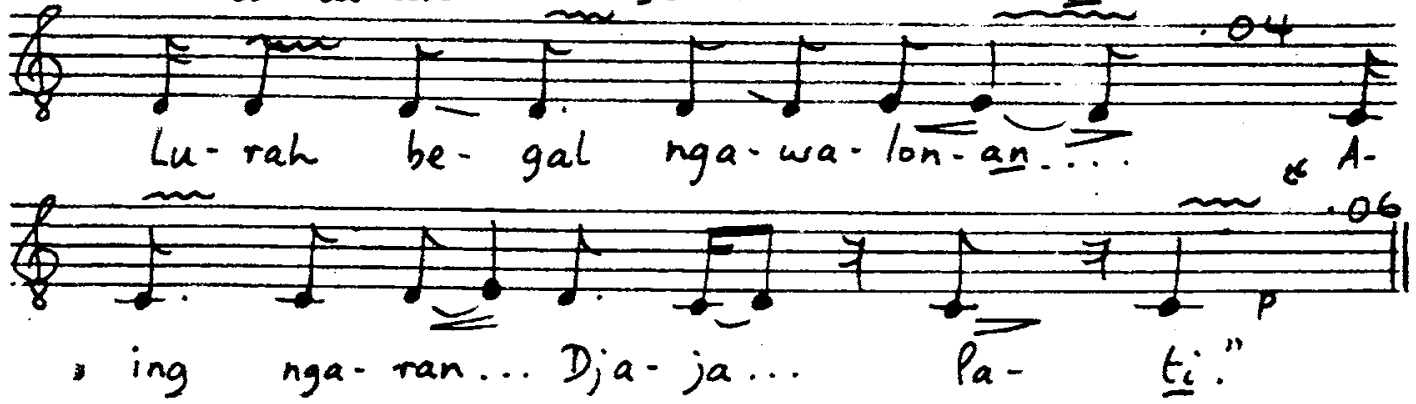
52. DURMA

SINGER: A. SOPANDI

T.L.: $0.32 \mathrm{~min}$.

O.P.: $I^{1 / \frac{1}{2}}$ tones higher

$(d=105)$

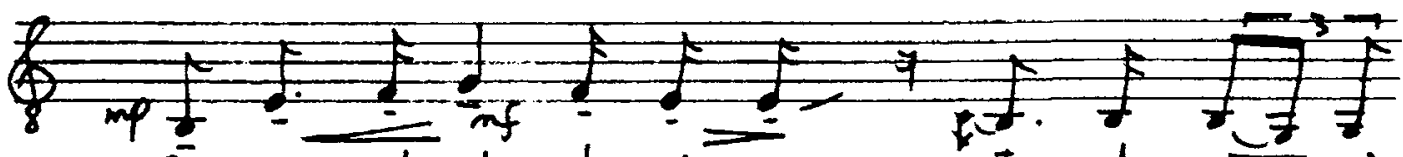

Beu-reum bo-das ban-de-ra In-do-

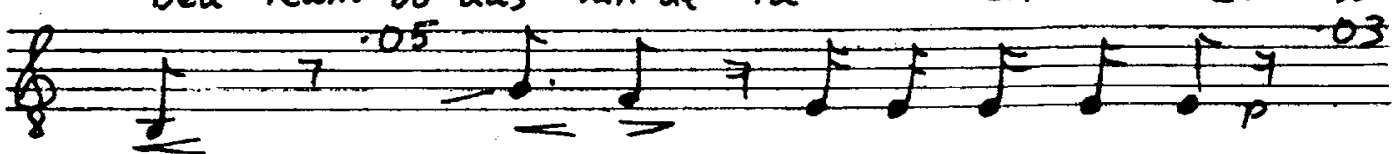

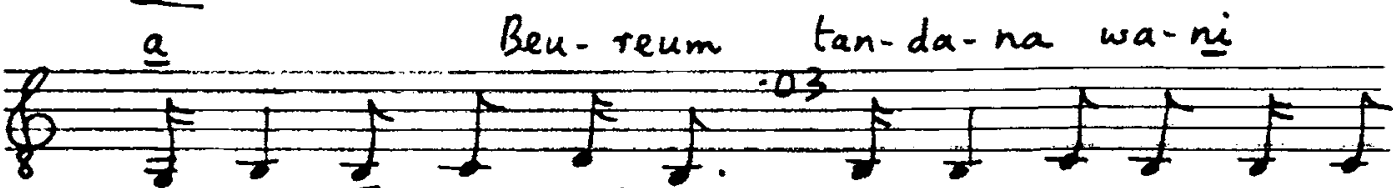
Bo-das $\mathrm{k}_{a}$ - su- $\bar{t}_{j i}-\mathrm{T}_{\mathrm{an}} \mathrm{Wa}_{\mathrm{n}} \mathrm{ni}$ sar-ta be-ner (2)

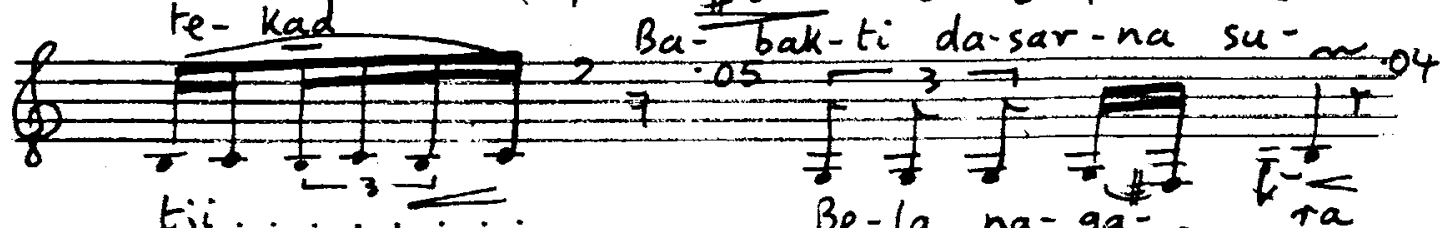

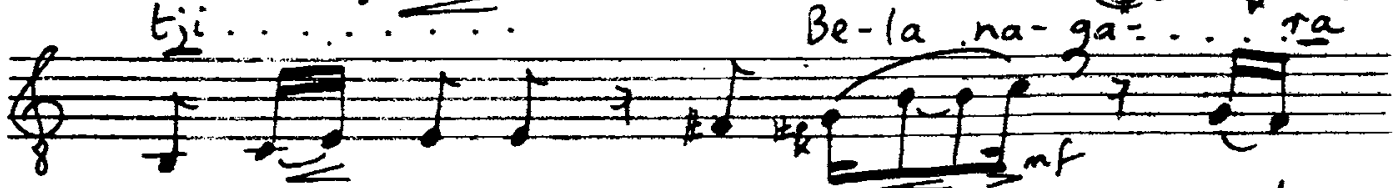
Ma-lar...mul-ja su-gih.... muk..

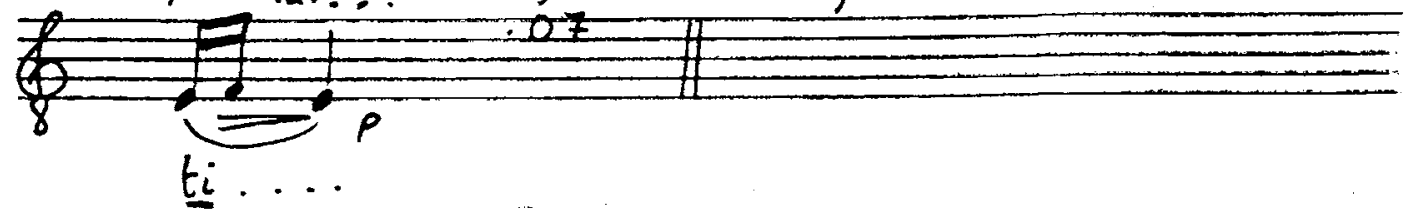


53. MASKIIMAMBANG

SINGER: A. SOPANDI

T.I.: 0.27 min.

O.P.: as below
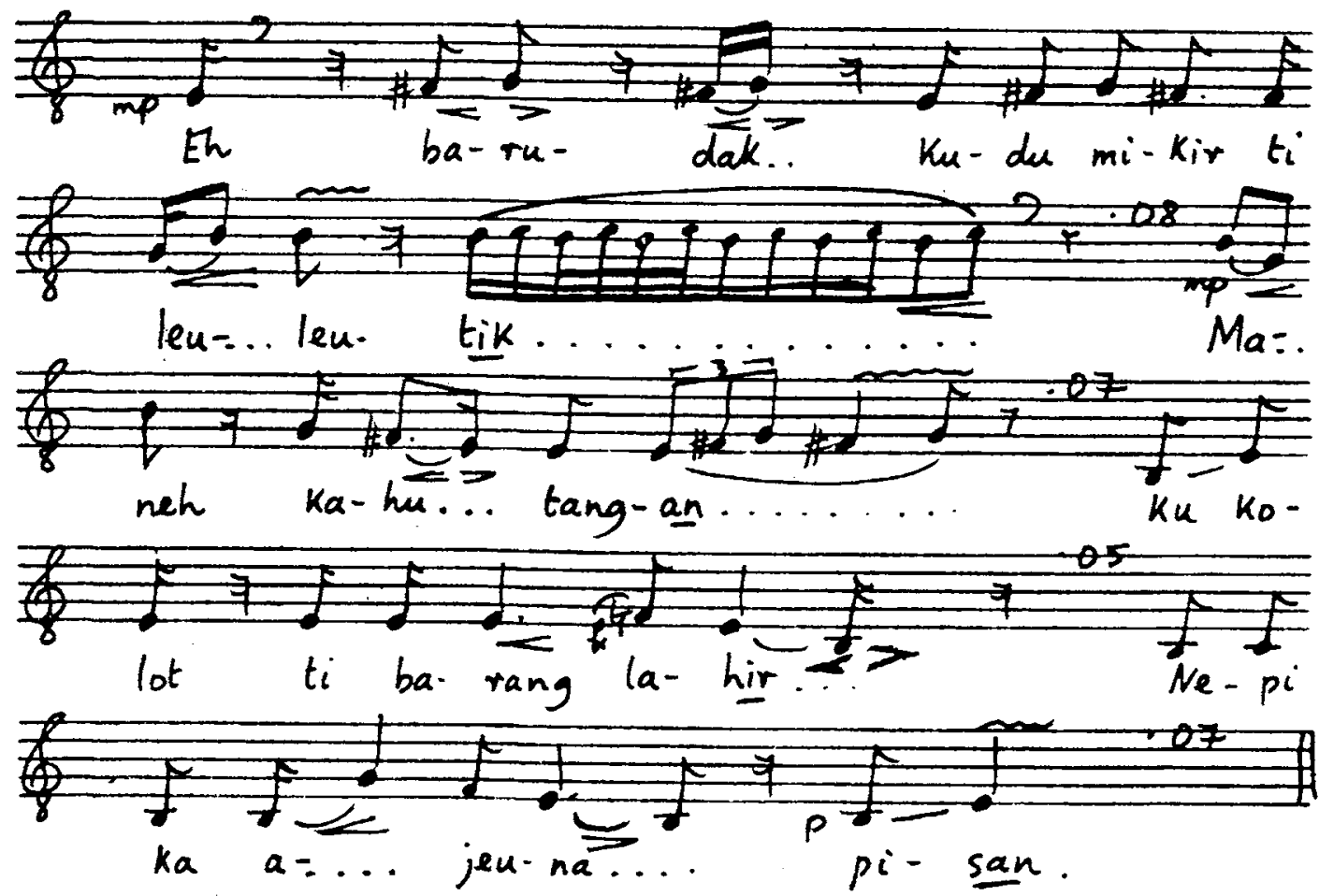
54. ASMARANDANA

SINGER: A. SOPANDI

T.I.: $0.32 \mathrm{~min}$.

O.P.: 1 tone lower

$(d=144)$

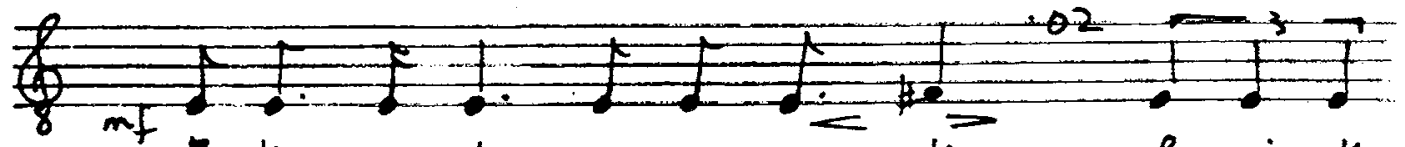

of $E-l i n g-e-l i n g$ mang. $k_{\alpha} e-\overrightarrow{l i n g} \quad R u-m i n g-k a n g$

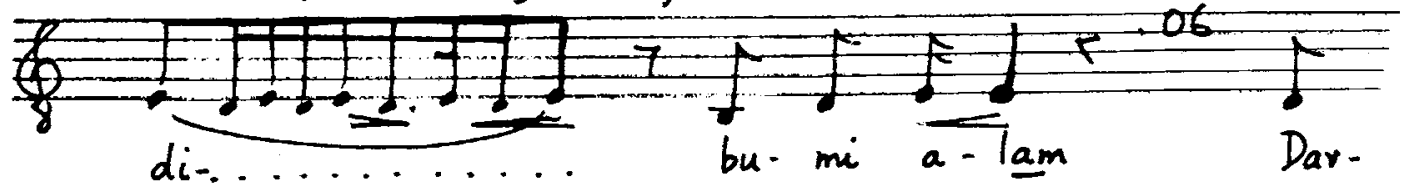

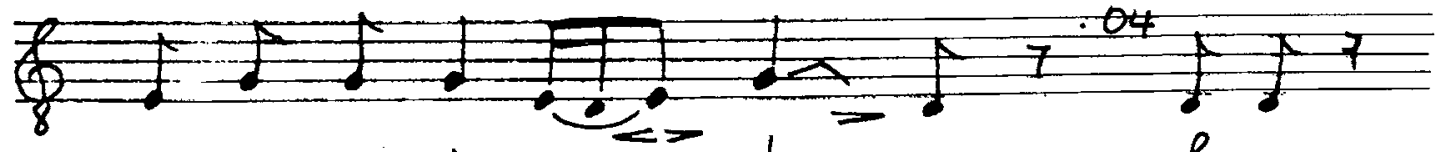
ma wa-wa-jang-an... ba- $e$ Ra-ga

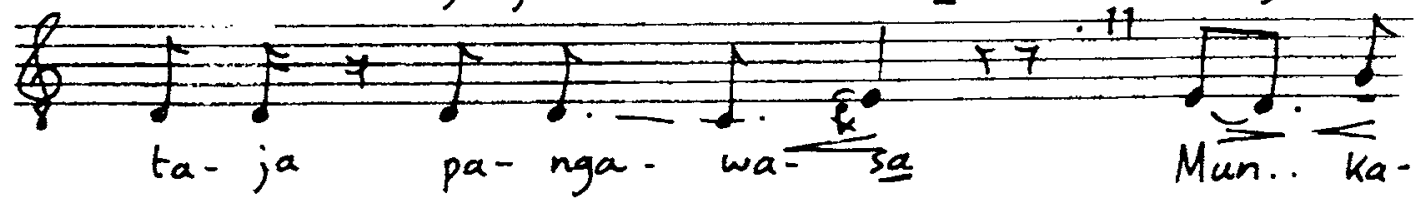

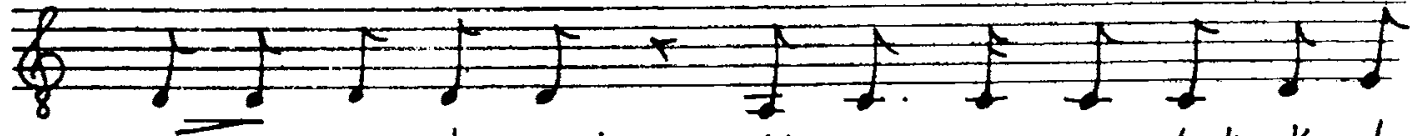
sa-sar nja lam-pah Nap-su nu ma-tak Ka-du-

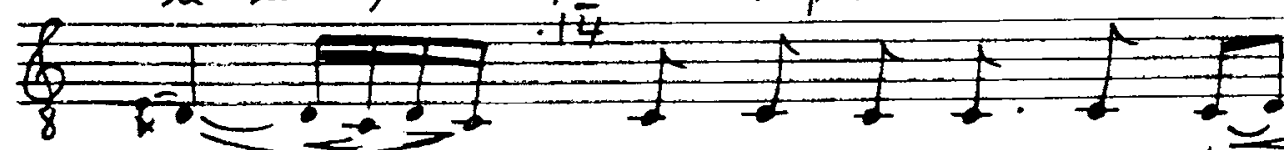

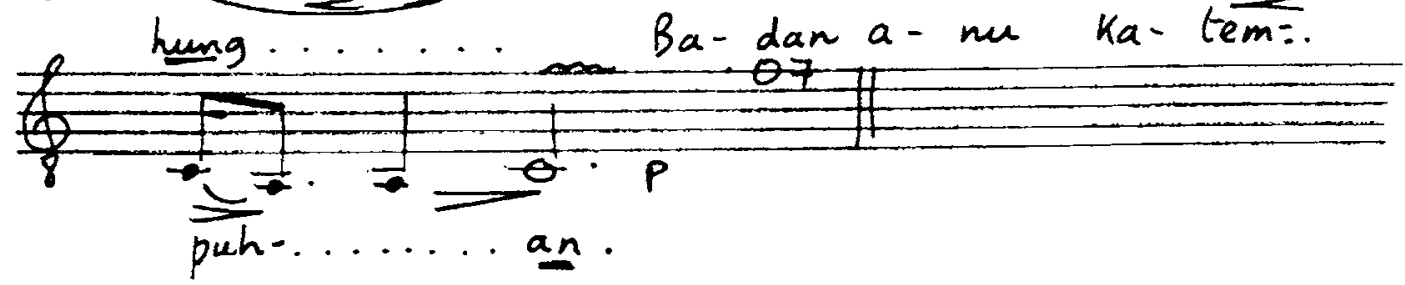


APPENDIX III

Literature about the Music of Java

Understandably enough, perhaps, the extremely attractive music of the gomelan and other smaller instrumental ensembles in the islands off Java and Bali has absorbed almost exclusively the attention of investigators of the music of these islands. Even after the gomelon's first European appearance of 1889 in the Exposition Universelle Paris, it left a lasting impact on French musical style, notably on that of Debussy, coinciding with a growing interest on the part of European (mainly Dutch) investigators, some of whom, expecially in the later colonial period, were instructed by the Dutch government to make a systematic study of the culture of 'The Indies'.

The attention of a wide body of research workers was directed to the art of instmument making, to the fascinating wealth of musical forms and instrumental combinations of gamelan and smaller ensembles, to the evidence of past musical culture in temple reliefs, archaeological excavations and literary inscriptions, to the vital role of music in wajong, dance, literature, mythology and functionary and ceremonial activities. However, as Mantle Hood points out as late as 1954, 'there has been one noticeable lacuna among the copious publications of Western and Eastern writers - a systematic study of the music itself'. ${ }^{1}$

Apart from short musical descriptions in early Dutch colonial reports, ${ }^{2}$ little scholarly interest in Javanese music was shown until the second half of the nineteenth century, during which, besides the appearance of articles on specific subjects, some nuclear themes of gending and melodic skeletons of songs were written down in Javanese and European notational systems and collected by Javanese and Dutch musicians. Early in the nineteenth century, however, following the brief period of British control in Java, the Englishmen T.S. Raffles ${ }^{3}$ and J. Crawfurd ${ }^{4}$ in their general 'histories' of Java each included a 
description of Javanese music which was a little more thorough and sympathetic than was common at the time, and even included some Europeanised 'transcriptions' of a few instrumental and vocal melodies, some translated matjapat and other song texts, and mention of some of the matjopat poetic regulations.

A.J. Ellis ${ }^{5}$ became the pioneer of the study of slendro and pelog scale structures in 1884, describing them with the aid of his pitch measurement system in cents. Useful early publications about Javanese music, sometimes including some musical transcriptions, were made among others by J. Groneman, ${ }^{6}$ J.P.N. Land, ${ }^{7}$ and C. Sachs.

Large numbers of publications about Javanese music have appeared in the twentieth century, including those in important periodicals about Javanese culture such as $D j j^{\circ} \dot{\circ}^{\circ},{ }^{9}$ which gradually accumulated information about a wide variety of aspects of the culture of Java and nearby islands.

Iinda Bandara's short article 'Über javanische Musik"IO serves as a general introduction to the field. Passing references were made to Javanese music by R. Lachmann ${ }^{11}$ and C. Sachs. ${ }^{12}$ E.M. Hornbostel ${ }^{13}$ wrote about the origins of Javanese tone systems. M.E. Bukofzer's The Evolution of Javanese Tone Systems appeared in 1944 (New York).

The musicological writings of J.S. Brandts Buys and his wife A. Brandts Buys-van Zijp (in Dutch) are valuable not only for their factual and descriptive information in articles about areas of music hardly touched by others, but also for their sympathetic attitude to and keen insight into the music of Java. Particularly valuable are Over de ontwikkelingsmogelijkheden der miziek op Java ${ }^{14}$ and De Toonkunst bij de Madoereezen. ${ }^{15}$ 
The basic work for all research into music in Java is Jaap Kunst's encyclopaedic Music in Java, its two volumes published in the second edition and translated into English in 1949. Besides writing various works and articles about music in various Indonesian regions (Bali, Flores, Nias, New Guinea etc.), Kunst delved into theories about Indonesian culture contacts with other parts of the world, the origin of the slendro and pelog scales, and the study of the musical instruments. About the very little studied music of West Java, he contributed three articles as well as the sections on the subject in Music in Java. In all, he contributed about sixty publications dealing with the music of the Indonesian archipelago.

In 1954, Mantle Hood published The Nuclear Theme as a Determinant of Patet in Javanese Music, which has the distinction of being the first systematic study of any one musical element of Javanese music. Limited to a study of patet in Central Javanese gending nuclear themes, it yielded valuable results. However, it does not and did not set out to say the last word on this difficult problem in all its musical and extra-musical characteristics, in its regional diversity and in its vocal and instrumental variations.

Several other mid-twentieth-century publications include discussions of historical and/or song-textual elements of Javanese music. ${ }^{16}$ Descriptive and analytical articles by Ernst Heins ${ }^{17}$ and N. Tirtaamidjaja $\mathrm{a}^{18}$ on Javanese instrumental music and dance are to be found in the periodical Indonesia, ${ }^{19}$ which has adopted the function of the older Dutch periodicals such as $D j j^{\circ}$ iv $a$ of distributing information by research workers on Indonesian culture, history, and society. Among Hood's recent articles, the most valuable from the point of view of research are, perhaps, 'The Javanese Rebab', 20 which is a partial result of the author having gained a proficiency in performing the instrument, and 'Sléndro and Pélog Redefined'. 21 
Various Javanese and Sundanese writers such as Ki Hadjar Dewantara, 22 R.M.A. Koes cemadinat $a^{23}$ and R. Ng. S. Probohardjono ${ }^{24}$ have written about musical theoretical subjects (theories of scales, patet, kembangon, descriptions of gending forms and song types etc.). Book One of R. Tedjohadisumarto's series Mbombong Manah ${ }^{25}$ presents factual information about the main aspects of tembong and gending in the Surakarta area. Various articles about modern Javanese theatre, music and musical instruments etc., have been published since the 1945 Revolution by Javanese and Sundanese writers, especially in

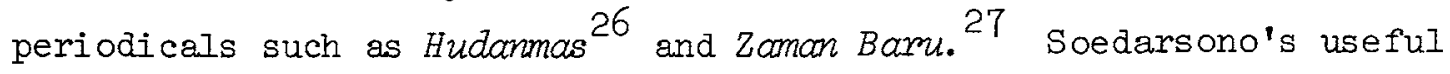
article entitled 'Classical Javanese Dance, History and Characterization' appeared in Ethnomusicology in 1969.

\section{Tembang Matjopat}

Despite its pervasive importance in Javanese life and culture, tembang matjopat has hardly been investigated at all in the half thous and or so publications about the music of the Indonesian archipelago. Indeed, very little research dealing with any type of song from Central, West or East Java or any other region has been attempted, whether it be on the Lagu dolanon (songs for children), the tembang gede (songs in 'great' Indian poetic metres) or the tembang tengahon (songs in 'midaling' autochthon metres). Linguistic and prosodic aspects of matjopat texts have been mentioned by some authors $^{28}$ and a few have included occasional transcriptions of song melodies. 29 Pages 122 to 126 of Jaap Kunst's Music in Java include a Iist of matjapat metres, reference to their generally accepted. content character and some comments about the manner of singing. R. Tedjohadisumarto's Mbombong Manah (Djilid I) contains facts about matjapat prosodic structure, poetic techniques, possible meanings of the metre titles, the usual content character of the metres and the desired manner of singing. References to songs in matjapat metres 
ias performed on the islands of Madura and Bali are contained in

'De Toonkunst bij de Madoereezen' by J.S. Brandts Buys and A. Brandts IBuys-van Zijp, ${ }^{30}$ De Toonkunst van Bali by Jaap Kunst and C.J.A. Kunst-van Wely ${ }^{31}$ and in Music in Bali by Colin McPhee. ${ }^{32}$

In recent times, some of the most popular matjapat texts (including some kidung) have been printed in pamphlet form for !popular use, as well as skeletal notations of some matjapat melodies. ${ }^{33}$ These are usually notated in their melodic outlines only in number script (a solfa-like system), and serve either to aid the memory of the singer or, in the case of a new song, to indicate the main melodic line around the tones of which a singer may improvise and give life to a melody in his own tembang style.

Recordings of unaccompanied matjapat songs are (to the author's jknowledge) not on the market, but disc recordings of musical works which include songs in matjapat metres, with or without gamelan accompaniment, are to be found. ${ }^{34}$ An example of Sundanese solo matjopat singing, accompanied by katjopi, can be found on the record Music of Indonesia, the song being entitled Udan Limis. 35 iSundanese songs in matjopat metres are sometimes performed in West Java to the accompaniment of the katjopi, pintjik and suling, as in the case of the disc BAM LD 110B, which includes recordings of Sinom Degung, Katineung (Asmarandana) and Kapati-pati (Sinom).

\section{Cultural History}

Some Javanese literary sources contain references to or descriptive passages on the musical life in the courts of the time in which they were written. Of the available sources, the three most significant from a musical point of view are Prapantja's description in the Nägarakertagama of instrumental and vocal music in the fourteenth-century Keraton of the great Madjopahit empire 
the Pararaton 37 of the Singasari period and the early nineteenth century Tjentini Romance ${ }^{38}$ compiled from earlier sources by Surakarta court scholars. 39

A number of mid-twentieth-century authors have dealt with problems of Javanese cultural history, religion, sociology and the development of theatre, all of which have bearing on general musical trends. ${ }^{40}$ A. Slamet, ${ }^{41}$ C. Geertz, ${ }^{42}$ J.I. Peacock, ${ }^{43}$ and others have written about the folk origins, popular content, and humour of Ludruk and other forms of modern Javanese theatre. Several writers have discussed the regression or 'involution 44 of Javanese culture in the last one and a half centuries or so and the tendency of the courts to become prototypes of classical culture.

Th. Pigeaud (1932) distinguished between court and folk art in Java, which he interpreted, however, as being only gradations in the cultivation of the one art field. In his Literature of Java (1967) he frequently related his conception of the history of Javanese literature to social, political and general artistic trends. W.F. Wertheim among others stressed the living source of Javanese court culture in the villages and the continual interaction throughout history between keraton (royal seat), desa (village), pasisir (coastal Moslem) and 'popular' culture. 45 Geertz, on the other hand, distinguished three art clusters in Java on the basis of sociological attitudes: the alus, the kasar and the national art complexes.

Various scholars have put forward hypotheses as to how JavaneseIndian culture contact could have taken place in the early centuries A.D. 47 In the last decades, several scholars (especially van Leur) have demoted the myth commoniy accepted in the colonial period that Indians imposed their high culture on a Javanese primitive society during the first few centuries of their contact with Java, this myth being based on a serious under-estimation of Javanese pre-Hindu civilisation. Active two-way culture contact between Java and India was emphasised by Schrieke (1955), Vlekke (1959) and Holt (1967). 
The impact of Islam on Javanese culture has been dealt with by Schrieke, van Leur, Vlekke, and others who discussed, among other things, the way Islamic power and teachings were consolidated in Java. Wertheim, stressed humanistic Islam as a symbol of resistance to the 'Hindu caste' and 'colonial caste' system 48 and the resulting Javanese tendency to make efforts to preserve the old culture. Pigeaud believed that certain ancient art forms such as gamelan and wajang were freed from religious taboos, spread and popularised in the early Islamic period. ${ }^{49}$ Schrieke, Jay and others mentioned the syncretism of Islamic and pre-Islamic concepts in Javanese religion, while Legge ${ }^{50}$ emphasised the social tensions between the elements that finally reached degrees of syncretism. Kunst mentions the slight Arabic influence on Javanese music, ${ }^{51}$ which consisted chiefly of some instances of Persian-Arabic instrumental borrowing. Wagner (1954) and others mentioned the regression of architectural and plastic arts but the rise of music, dance, and the decorative arts in the early Islamic period (especially under Sultan Agung - 16131645).

European art, which was regarded by the Javanese in the colonial period as being antagonistic to and possessing little common ground with their own culture, has been regarded by most scholars as having had a negligible influence upon classical Javanese art styles. The impact of Western art upon modern trends in Indonesian city art may, however, be of a more far-reaching nature. Clair Holt (1967) presents a detailed study of Indonesian art (especially the plastic arts, dance, and wajang) during the revolutionary and post-revolutionary periods within her broad and sympathetic examination of Indonesian artistic phenomena in their historic and pre-historic origins and development. 
NOTES

1. The Nuclear Theme as a Determinant of Patet in Javanese Music, Groningen, 1954, p. 3.

2. For a list of these, see Jaap Kunst, Music in Java (MJ), The Hague, 1949, pp. 5-6.

3. The History of Java, London, 1817, repr. Kuala Lumpur, 1965; about matjopat poetry pp. 399ff, about musical instruments, pp.469ff. 4. History of the Indion Archipe Lago, Edinburgh, 1820; about matjopat poetry see Vol. II,pp. 22ff: about musical instruments, see Vol. I, pp. 332ff.

5. Tonometrical Observations on some Existing Non-harmonic Musical Scales', Proceedings of the Royal Society, Vol. XXXVII, London, 1884, pp. 374ff. Über die Tonleitern verschiedener Volker, 1885. 6. De Gomelan te Jogjakarta, Amsterdam, 1890; with preface by J.P.N. Land, 'Over onze kennis der Javaansche Muziek'. 7. Über die Tonkunst der Javaner, in Vierteljahrschrift für Musikwissenschaft, 1889, pp. 193-215.

8. Die Musikinstmumente Indiens und Indonesiens, Berlin, 1923. 9. Tijdschrift van het Java-Instituut, Surakarta, 1921-39.

10. Die Musik, 1910, pp. 341-7.

11. Die Musik der auBereuropäischen Naturvölker, Potsdam, 1929.

12. References in his books about musical instruments and in the Rise of Music in the Ancient World, East and West, 1943.

13. 'Über ein akustisches Kriterium für Kulturzus ammenhänge', Zeitschrift für Ethnologie, 1911, pp. 601ff.

14. Djowà, Vol. 1, 1921, pp. 1-90.

15. Djơi̊a, Vol. 8, 1928, pp. 3-290.

16. For example, C. Geertz, The Religion of Java, Glencoe, Illinois, 1960.

17. 'Supplemental Note on a Recent Javanese Gamelan Record', Indonesia, April 1966, pp. 22-9. 'Music of the Serimpi, Anglir Mendung', Indonesia, Apri1 1968, pp. 135- 52. 
li8. 'A Bedaja Ketawang Dance Performance at the Court of Surakarta', Iindonesia, April 1968, pp. 31-61.

119. Benedict R. Anders on (ed.), New York, from April 1966.

230. Music, Libramies and Instmments, London, 1961.

2?I. Selected Reports of the Institute of Ethnomusicology, Vol. I, No. 1, Los Angeles, 1966, pp. $28 \mathrm{ff}$.

232. Ki Hadjar Dewantara and M.Ng. Najawitangka, 'Kawruh Gending D)jawa', Mardowa Lagu Djowa, Surakarta, 1957; Ki Hadjar Dewantara, Siari Swara, 1930.

233. R.M.A. Koesoemadinata's most comprehensive work is I Imu Seni Rraras, Djakarta, 1969.

24. Gending Djowa, 2 books, Surakarta, 1955-63.

25. This consists of 5 books, Djakarta, 1958. Books $2-5$ contain classical Javanese songs notated in number script.

26. Art magazine of the Konservatori Karowitan Surakarta.

27. Magazine of the Lekra cultural organisation (non-existent since October 1965.)

2.8. For instance, Th. Pigeaud, Literature of Java, Vol. 1, The Hague $11967, \mathrm{pp} .20,24$.

29. For instance, Kunst, MJ, App. 16, 19, 44, 46.

30. Djowåa, Vol. 8., 1928, pp. 3-290.

31. Weltevreden, 1925.

32. New Haven, London, 1966, pp. 298-303.

33. For instance, Mang Endang (collector), Pongadjaron Tembong Sunda, Bandung, 1968.

34. Songs in matjopat metres as performed in Javanese Wajong Orang theatre are recorded, for instance, on the Lokananta disc ALD-041, Gatotkatja Gandmang. Columbia disc GJ 60-65, Menakdjingga Lena has recordings of matjopat songs as performed in Langendrijan theatre. Odeon A 39562a contains the song Midjil Ketoprak with ketoprak accompaniment. A Sindenan Lampah sekar gending-style Kinonti Maduomurti performance is recorded on Odeon A 39603b. Other discs are listed in Kunst, M T $^{\top}$, pp. 576-8. 
35. Folkways disc FE4406, side 2.

36. For the translation of this poem into English, see Pigeaud, Java in the Fourteenth Century, VoI. III, The Hague, 1960-3.

37. Translated into Dutch by J.L.A. Brandes, 1896, 1920.

38. For references to this poem, see Pigeaud, Literature of Java,

p. 299 and various parts of MJ.

39. For other references, see General Index of Pigeaud's Literature of Java.

40. These include Jaap Kunst, 'The Cultural Background of Indonesian Music', Journal of the International Folk Music Council, Vol. I, Amsterdam, 1949; J.C. van Leur, Indonesian Trade and Society, The Hague, 1955; W.H. Rassers, Panji, the Culture Hero, The Hague, 1959;

B.H.M. Vlekke, Nusantara; a History of Indonesia, The Hague and Bandung, 1959; W.F. Wertheim, Indonesian Society in Transition, The Hague, 1959; F.A. Wagner, Indonesien, Die Kunst eines Inselreiches, Baden-baden, 1959; C. Geertz, The Religion of Java, Illinois, 1960; R.R. Jay, Religion and Politics in Rural Central Java, Yale University, 1963; Pigeaud, Java in the Fourteenth Century, The Hague, 1960 and Literature of Java, The Hague, 1967-70 (3 vols.) 41. 'Drama Daerah dan Penggarapannja', Zoman Baru 10/11, 1962. 42. 1960, pp. 261ff.

43. Rites of Modernization. Symbolic and Social Aspects of Indonesian Proletarian Drama, Chicago, 1968. 44. For a discussion of this term, see W.F. Wertheim, East-West Paralzels, The Hague, 1964, pp.254ff. 45. Indonesian Society in Transition, 1959.

46. The Reirgion of Java, pp. 261-2. 47. For instance, J.C. van Leur, Indonesian Trade and Society, The Hague, 1955; B. Schrieke, Indonesian Sociological Studies, Selected Writings of B. Schrieke, The Hague, 1955 and 1957; W.F. Wertheim, Indonesian Society in Transition, The Hague, 1959. 
48.. Indonesion Society, pp. 196-7.

49.. Literature of Java, p. 93.

50.. J.D. Legge, Indonesia, Englewood Cliffs, 1964, p. 50.

51.. In various parts of Kunst, MJ , 1949. 


\section{APPENDIX IV}

Number Scripts and Tone Names in Javanese and Sundanese Songs

The number-script method of musical notation and tone names used for slendro and pelog songs in Central Java is basically as follows:

[dji] nem pat lu ro dji [nem] [dji] nem pat lu ro dji [nem]

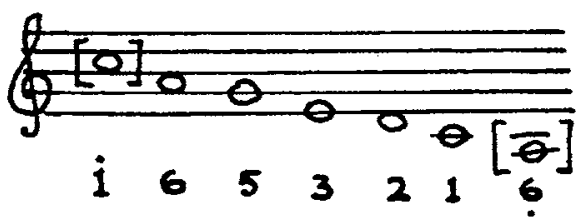

SLENDRO GENUS

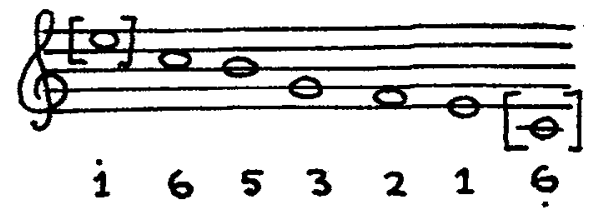

PELOG GENUS

$i$ means an octave above tone 1 and 6 means an octave below tone 6 .

In songs of the salendro genus and the pelog (degurg, sorog etc.) genus in West Java, the order of numbers, the tone names and octave designation is reversed:

[ha] da mi na ti la [da]

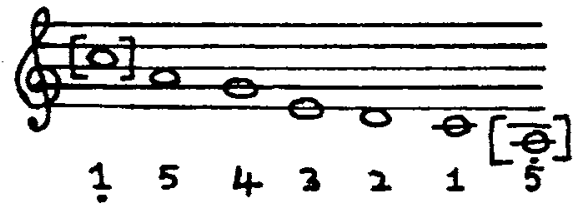

SALENDRO GENUS [ha] da mi na ti la [da]

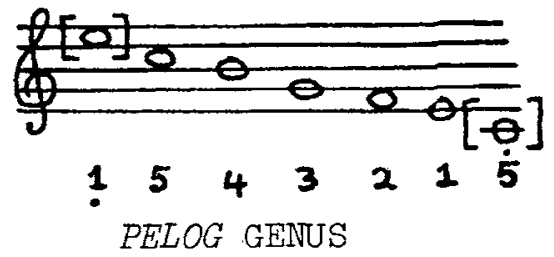

The numbering and tone names vary from patet to patet.

In this book, however, the Central Javanese method only is used, in order to avoid confusion on the part of the reader. 


\section{INDEX}

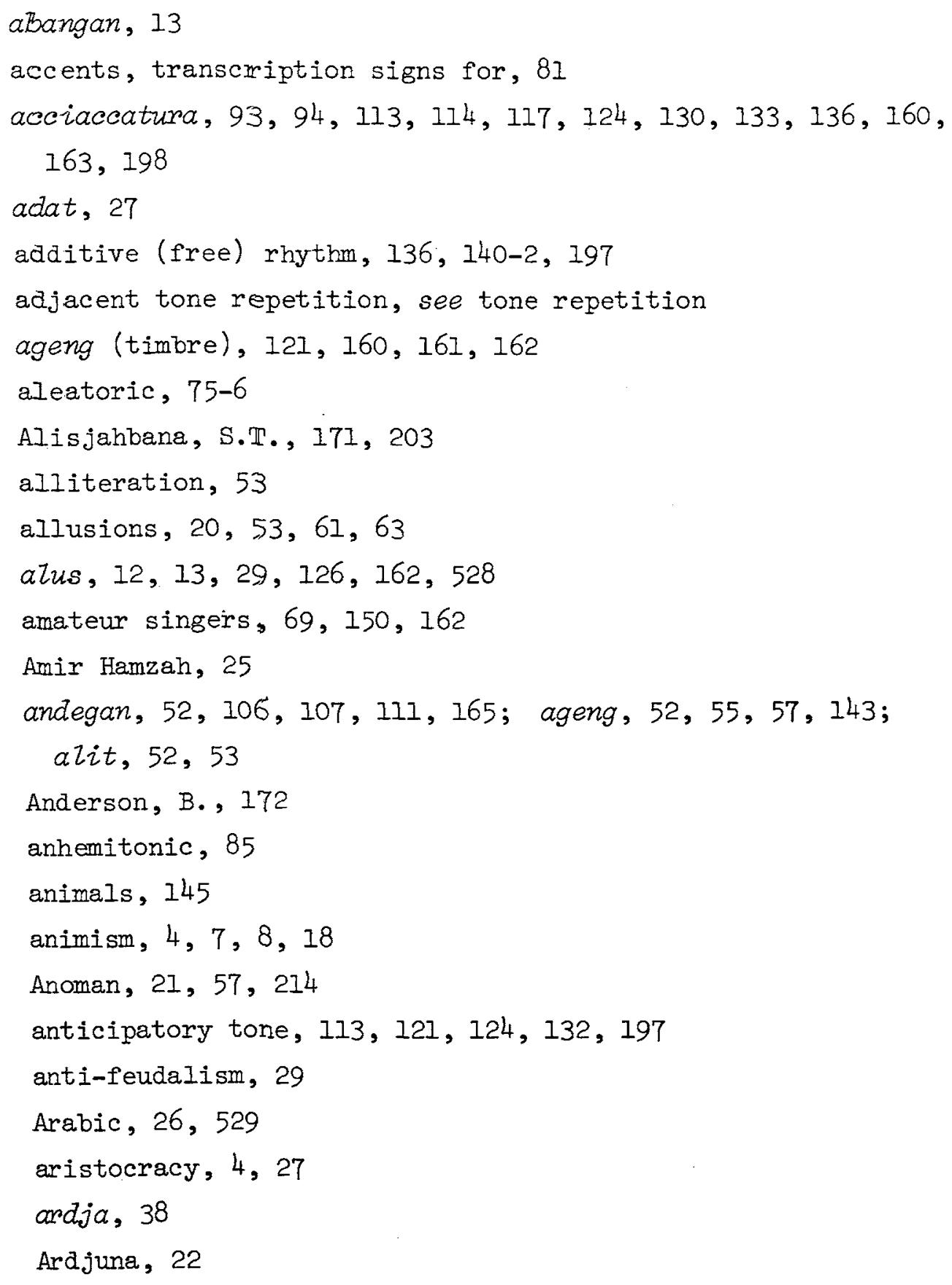


Ardjunawiwaha, Ardjuna Wiwaha, 21, 22

art clusters, 12-13

articulation, 125, 126, 131, 140, 161

Asmarandana, or Asmaradana, 25, 40, 45, 47-9, 58, 62, 63, 216, $219,231,338,240,242,244 ;$ Madenda, 54, 63

assonance, 53

auxiliary: scale, 89, 97, 147; tone, 124, 197

Babad, 5, 17, 25, 26

Balabak, 25

Bali, 38, 46, 47

Balinese matjapat metres, 172

Belkan, 85

balungan, 76,91

Bandara, L., 524

Bandjar, 68

Bandjarmasin, 38

Banjumas, 68

Bapak Putjung, 122, 123, 175

Barabudur, 21, 168

barang, 81, 146

barés, 43

Bartók, B. and Lord, A.B., 175, 203

batik, 3, 6, 7

bowa, 7

bem, 80,86

Berg, C.C., 170, 203

beulit, 180

Bharata Yuddha, 22

Bible, 14, 60

B.M.K.N., 34,172 
Bralhmanism, 18, 21

Bramdts Buys, J.S. and Brandts Buys-van Zijp, A., 174, 203, $4 \imath 25,526$

bubuka opaq-opaq, 180

Budiahism, 18, 19, 21, 24

Bukcofzer, M.E., 524

butca, see giants

cadential formula, 90, 197

caessura rules, 43

Cailendra, 21

Centini, 87

Central Java(nese), 5, 6, 8, 31, 38, 39, 43, 59, 108, 138-9,

$140,146-8,151-7,159 \mathrm{ff} ., 176$

Central Javanese period, 17,21

change in musical style, 13, 14, 15, 25, 35-7, 122

children, 9, 11, 12, 59,60,62, 64, 145

choir, 164

choral songs, $5,6,7,71,143,164$

Christian(ity), 4, 60, 122, 177

chromatic melody, 21

collective outlook, 4, 59

colonialism, colonial times, 26-8, 33, 35, 59

colotomy, 176,197

communalism, 4

court art, court culture, 20, 21, 26, 27, 29, 35

court matjapat singing, 6, 14

courts, $6,7,12,14,16,19,21,26-8,29,30,35,38,42$,

$69,70,126,162,527-8$

Crawfurd, J., 56, 174, 175, 204, 523

cultural identity, 14 
538

dada, 80,81

dalang, 5, 20, 28, 53, 142, 167, 217

Damar Wulan, 22, 30, 57, 211-12

dance, $4,12,21,23,26,27,28,29,30,31$

dance bands, 13

Dandang Gendis, 45

Dandanggula, 10, 25, 40, 45, 48, 49, 145, 150, 174, 211, 212,

$214,217,218,220,223,225,226,233,234,239 ;$ Bajubud, 136,

151; Palaran, 57; Tlutur, 58, 82, 115-18, 119, 128, 147, 185

Dandanggula Tumulare, 82, 102-18, 185

Dangdanggula, 42, 141, 150, 151, 239, 243; Bajubud, 151

dapur bener, 95

dapur Zuq, 95

dasar, 92, 107, 116, 124, 153

death, $58,63,145$

demung, 167

des $\alpha, 528$

descending formula, 179

deviating tones (miring), 87, 88, 115, 116, 118, 138, 140, 146, 198

Dewantara, Ki Hadjar, 172, 204

Dipa Negara, 27

Dipasieup, 129

'diphthong notes', 87, 125, 197

disc, 67; Lokananta AID-041, 71

divisive rhythm, 142, 197

djoman edan, 58

Djogjakarta, 26, 27, 30, 68, 69,70

Djumat Kliwon, 9

Djumideming, 25

dongding, 173

dongeng, 12 
Durma, 13, 14, 25, 40, 46, 48, 49, 51, 57, 58, 59, 62, 63, 69, $82,83,140,146,147,150,211,214,216,219,223,227,240$, 241,243

Duttch, 26, 27 dymamics (musical), 82, 112, 113, 117-18, 121, 125-6, 129, 132, $161-2,164-5$

East Java, 6, 14, 16, 17, 21, 31, 59

East Javanese period, 22 education, 10-11, 12, 15, 23, 27, 38, 48, 145 Ellis, A.J., 524 eluk, 3, 94-6, 109, 111, 113, 115, 117, 121, 125, 130, 133, $135-8,141,143,160,162,164,165$

employment, 31

'enemy tone', 89, $99,108,124,198$

equidistant interval, 86

exchange tones (sorog, sorogan), 85, 134, 146, 147, 148

feudalism, 3, 11, 18, 20, 22, 29, 34, 59

folk song, folk art, folklore, 17, 20, 23, 26, 28, 29, 56, 146; style, 160,161

food, 123

forecasting the future, 59, 102

formal unity, 84, 111

formula shape, 105, 107, 154

Gambuh, 25

gomelan, 3, 4, 5, 7, 12-13, 23, 24, 27, 28, 30, 31, 37, 42, 118, $120,121,129,142,143,164,167,523,527$

Getotkatja, 69, 129 
540

gatra, 40, 49, $51,53,54,70,71,76,80,84,85,87,88,164$

Gatutkatja: see Gatotkatja; Gandrung, 7, 71

Geertz, C., 6, 7, 11, 12-13, 167, 168, 204, 528

gender, $5,165,176$

gending, 4, 6, 7, 30, 32, 35, 37, 39, 71, 88, 90, 105, 121, 158, 236,523

Gending Beksan Gatutkatja Gandrung, 71

Gerong Gending Pangkur, 6

gerongan, 5, 71, 143, 236

giants, 13, 57

glissando, 87, 93, 111, 121, 133, 198

glottal stop, 93, 111, 113, 132, 136, 198

gong: ageng, 121 ; tone, 89,90

greediness, 59

Groneman, J., 524

gulu, $80,81,86$

Guru: Lagu, 40, 48, 52, 55; Petungan, 173; Wilangan, 40, 48, 52,

55; Witjalan, 173

Hadisoeseno, 171

Hamengku Buwana (Sultan), 6, 26, 27, 69, 70

happiness, 12

Hardjawiraga, R., 24, 173

harvest, 5

Hebrew, 176-7

Hersoebeno, 80

Hinajanaism, 18

Hinduism, 4, 19, 24

Hindu-Javanese, 8, 23, 24, 27

Hindu-Budahist, 24 
Holt, C., 528, 529

homesickness, 52

home town of singers, 68

Hood, M. , 80, 85, 89, 90, 91, 92, 105, 128, 153, 154, 156, 157,

$175,176,177,179,183,184,185,205,523,525$

hope, 50

humour, $13,15,30,50,56,170$

illness, 8, 59

Imam, 102, 111

improvisation, 93, 94

Independence, 32,33

India, 4, 16, 17, 18, 20, 21, 22, 528

Indonesian identity, 32

inggil (timbre), 126,160

intervals, 97, 104, 116, 129, 139, 163, 198

intonation, $67-8,1.18,126,134,135-6,140,146,148-9,159,198$

involution, 528

Is lam, 4, 10, 23-6, 27, 31, 40, 41, 60, 528

Jasadipura I, 174

Javanisation, 19

Jay, R.R., 529

jazz, 117

kakawihan barudak, 44

kakawin, 16, 17, 19, 21, 22, 23, 27, 47, 167

kaken, 52 
KaZasan (charter), 46

Kali Oja, 61

Kalimantan, 38

kalzovak, 47, 213

Kartomi, H., 112

kas, 225

kasar, 12, 13, 14, 528

Kasepuhan, 10

Kasuhunan, 32

KasuZtanan, 26, 27, 167

katjapi, 5, 164, 165, 527

$K^{\prime}$ 'owi, 46, 175

Kediri, 22, 45, 47, 170

kembangan, see ornamentation, melisma, eluk

kempyang, 76, 176

Ken Angrok, 45, 170

kenong, 76,176

keraton, see courts; Kasepuhan, 10

keris, 3, 6, 21, 95

Kertadjaja, 45

Ketowang Midjiz SuZastri, 6

Ketoprak, 4, 13, 14, 31, 32

ketuk, 76,176

Ki Hadjar Dewantara, 172

kidung, 5, 8, 9, 10, 16, 17, 23, 25, 27, 28, 40, 43, 44, 46, $56,69,158,527$

Kidung Sunda, 170

kidungan, 31

Kinanti, 25, 40, 43, 47, 48, 49, 50, 57, 58, 59, 60-4, 83, 138, $142,144-5,149-50,212,214,218,219,222,228,229,230$, 237, 238, 239, 241; Bares, 137; Djemplang Titi, 130, 131, 132-4; 
Djugag, 40, 49, 50, 54, 60,61, 144; Gondomastuti, 83, 118;

Lugu, 142, 143; Panembrama, 10; Paurkir, 121;Sandung, 52;

Subokastowo, 83, 118; Tembang Gending, 118, 120-3

kisaran, 38

knights, 13

Koesoemadinata, R.M.A., 88, 177-8, 526

Kolinski, M., 181, 184, 206

Konservatori Karawitan (KOKAR), 70, 86

Koran, 25

krama, 55, 175; inggil, 175

Kuningan, 42

Kunst, J., 40, 54, 85, 88, 89, 90, 97, 150, 167, 170, 171, 173,

$174,175,176,177,178,179,180,182,184,185,186,206$,

$525,527,529$

kupat, 58

Kurawa, 22

Lach, R., 182, 206

Lachmann, R., 88, 178, 206

Ladrang, 92, 235; Pangkur, 6, 7, 142; Wirogo, 179

lagu djondjang, 39; dolanan, 39, 526; gending, 43, 129

lakon, 5, 14, 20, 21, 30, 35, 37

Zompah, 40, 48, 49, 50, 51

Land, J.P.N., 7

landlordism, 31

Langenasmara, 41

Laingendrijan, 4, 14, 26, 30

Langerwanara, 4

laziness, 59

legato, 125

Legge, J., 171, 529 
544

Lekra, 34, 172

Leur, J.C. $\operatorname{van}, 169,206,528$

Level Shift, 99, 103, 115, 120, 123, 125-6, 130, 134, 135, 136, $140,145,181,198$

Iily, 58

lima, 80,81

List, G., 181-2, 207

I.K.N., 34, 172

Lombok, 38

Lontar, 16

love, $29,47,48,50,51,58,63,102,115,130,145$

Ludmk, 4, 12, 13, 14, 31, 32, 171, 528

Lugu, 9, 43

Lumh, 86

Madjapahit, 22, 23, 25, 46, 527

Madukusuma, K.R.T., 70, 167

Madura, 38, 47

Mahajanaism, 18

MaZom Kidungan, 8, 9, 44, 62, 110, 158

mamaos, 42

manangis, 150

mandala, 169

Mangkunegara IV (Sultan), 29

Mangkunegaran, 26, 30,69, 70, 126

Mangunwidjaja, M.Ng., 24

Manipol Usdek, 33

mantjapat, 44

Maruti, Retna, 160

Maskumambang, 25, 40, 47-9, 51, 60, 62, 64, 83, 134-6, 144, 150, $213,223,231,240$ 
Mataram, 26

matja-dji, 173

matja-lu, 173

matja-ro, 173

matjapat: poetic content, 55-66; prosody and metres, 40, 45-55,

524; symbolism, 7, 8; tembang, see tembang matjapat; title

meaning, 43, 45

McKinney, H.D. and Anderson, W.R., 176-7, 207

MacPhee, C., 172, 207, 527

McVey, R., 172, 207

Megatruh, 25

melisma, 93, 94-6, 107, 109, 111, 112, 113, 114-17, 120-5, 129, $130,132-4,136-9,140-5,158-9,161-4,181,199$

melodic: direction, 129, 130, 134, 137, 140, 141, 163; direction change, 102-3, 115, 118, 120, 123, 126, 130, 134, 135, 136, 137, 138, 139, 145, 160, 181, 199; formula, 84, 90-3, 105, 106, 107, $111,116,117,120,124,128,144,151-4,162,165,179,199$;

leaps, 104, 121, 124, 126, 128, 139; motive, 84, 111; range, $103,115,116,120,126,130,134,136,140,147,150-1,163$; shakes, 113, 117, 121, 124, 130, 133, 135, 136; variability, 71 melodies, 38,39 melos, 96, 97, 103, 105, 106, 107, 109, 116, 117, 119, 127-8, 129, $131,133-4,199$

Menakjjingga, 57, 213

Mendang Pramesan, 40

merchants, 20, 24 metre, 172, 199; characterisation, 48-52; musical, 120, 121, 129,

$139,142,143$; poetic, 38-55, 138, 145

Metro, 38

Midjil, 7, 40, 47-9, 50, 57, 59,60,61, 62, 82, 83, 100, 129-31, $138,144-5,147,150,212,214,216,218,222,224,226,227$, 235, 238; Ketoprak, 54 
miracles, 50, 59

miring: see deviating tones; scale, 88

modulation, $89,126-8,145,146,147,148,149,150,163,179$, 199

Mohammed, 25

monasteries, 20

monkeys, 57,236

moral advice, $4,11,23,26,31,38,50,51,52,59,60,63,145$

morality, 115, 125, 145

moonlit night, 115

motive, 84

musical: instruments, 25; notation, 16, 67, 71-6

Nägarakertāgama, 23, 46, 527

national art complex, 12, 13, 528

nationalism, $7,13,14,32,33,34,63$

nature, $29,48,51,57,60,61,63,129$

nem, 80,81

ngoko, 55, 175; madija, 175

nijaga, 93

Nini Towong, 8

nuclear theme, 199

number script, $118,122,128,146$

Old Javanese, 22

ornament signs, 81

ornamentation, 137, 158-60,162-3, 198, 199, 201 
pada, $40,50,51$

Paku Alam (Sultan), 26, 69

Paku Buwana IV (Sultan), 26, 69

pain, 52

Palembang, 21, 61, 213

Panalkawan, $13,29,46,170$

Pandawa, 22, 171

Pand ji, 4, 22, 46

Panembrama, 10, 61

Pangeran, P. Djatikoesoema, 42

Pangikur, 25, 40, 46-9, 51, 58, 59, 60, 61, 63, 82, 83, 138, 143,

$144-5,214,216,221,224,231,232,235,236,237$; Gerong

Gending, 6; Lugu, 44; Matjapat, 44, 138; Palaran, 82, 125-8

pantan, 44

Pararaton, 45

parents, 52, 60, 64, 134, 145

partando, 163,183

pasieup, 129,130

Pasisir, 5, 16, 23, 24, 26, 169, 528

patet, 5, 83, 85, 89-93, 105, 106, 107, 114, 116, 120, 127, 144,

$145,146-50,151-7,525-6$

patriotism, 145

patronage, 27

Peacock, J.L., 168, 207, 528

peasants, 18, 19, 20,28, 29, 59

pedotan, 43, 52, 54, 55

pelog, 102, 114, 123, 136, 139, 145, 147, 148, 149, 525; patet

(barang), 83, 92, 124, 147, 153, 155-7, 179, (bem), 178, (lima), 92, 105, 107, 152, 153, 154-7, (manjura), 92, (nem), 92, 124,

154-7, (tone), 146

pendapa, 8, 70 
548

pentatonic(ism), 129, 131, 135, 146, 147, 148, 149

Persian-Arabic, 31

Pigeaud, Th., 16, 22, 44, 45, 46, 47, 53, 169, 170, 173, 174, 207,528

pillar tone, $89,90-3,98,107,111,114,124,179,200$

pitch, 79-81, 200

pokok, 91

politics, 11, 12, 13, 14, 15, 24, 27, 30,31, 32, 33, 34, 50,

$58,63,145$

'popular': art, 13, 171, 528; theatre, 11

portamento, $82,113,117$

Prabu Bandjaransari, 40; Daniswara, 40

Prambanan, 21; Ballet Ramajana, 71

Prapantja, 257

Prawiroatmodjo, S., 44

principal scale, 89, 147, 183

priests, 18,30

prijaji, 12, 25, 27, 28

Prijambada, 61

Probohardjono, R. Ng. S., 173, 207

professional singers, 69, 126, 161, 162

prosody, 13, 15, 17, 19, 22, 28, 38, 39-42, 44

pudjangga, 16, 22, 23, 27, 28, 29, 172, 174

Pupuh Sinom, 63, 149

purwakanti, 53, 55; sastra, 53; swara, 53; tembang, 53

Purwaredja, 69

Putjung, 25, 40, 47-9, 51, 59,60,83, 143, 144-5, 147, 151,

213, 221, 222, 224, 226, 236, 237, 240, 241; Slendro, 122-5;

Pelog, 122, 125

puzzles, ridales, $47,51,58,60-1,64,123,145$ 
raclio, 9, 69; station $\mathrm{P} 2 \mathrm{SC}, 9$

raeham, 129

Rafffles, T.S., 26, 208, 523

Rama, 2I, 57

Ramgga Warsita, R. Ng. (Ranggawarsita), 29, 58, 173, 174, 208 Rassers, W.H., 3, 21, 95, 167, 170, 180, 208

ratta, 86

reßbab, $85,87,126,160,525$

regiomal styles, 68,159

religion, $11,12,13,14,15,18,22,23,25,26,29,46,50$,

60,62

$\operatorname{Reog}, 4$

rests, 109, 111, 125, 133

Revolution, 31, 32, 33, 34, 171

rhyme, 49, 50, 51

rhythm, 77-9, 108, 109, 111, 112, 118, 121, 129, 131, 134, 136,

$137,140-3$

rice cultivation, 23

ringkung, scale, 88

rintjik, 527

ritardando, 121, 143

mibato, 142

Rubinem, 69,160

Rusman, 69, 71, 121, 132, 142, 143

Sabar, 69, 112, 143, 158

Sachs, C. , 85, 208, 524

sadjen, 10

sadness, $12,50,59,138,145$ 
sagembyangan, 180

salah gamun, 180

samaran, 87

sandiasma, 54, 55

sandiwara, 4, 14, 31

Sang Marabangun, 61

Sanskrit, 19, 21, 22, 39, 44, 47

Saputra, P., 158

saron, 105,154

sastra, 3

Scheirmodulation, 179, 199

scholars, 16, 17, 20, 45

schools, 10, 11, 12, 64

Schrieke, B., 170, 171, 174, 208

Seeger, Ch., 176, 208

sekar, 23, 39, 42; ageng, 44; tandak, 42

senggak, 54

senggakan, 53

sengkalan, 54, 55

Serat: Kidungan, 8; Menak, 25; Pararaton, 28; Purwakanti, 170

Serimpi, 29

Shivaism, 18

Si Djuring, 168

Sigaluh, 40

sigrak, 86,163

siza, 9

Sinau Tembang Djowa, 14, 122

sinden, 5, 7, 69, 71, 76,77,87, 126, 142, 150, 160-2

Sindok, 46

Singasari, 22 
Sinom, 10, 25, 40, 45, 46, 48, 49, 50, 51, 53, 57-9, 62, 82-4, $137,145,147,150,211,213,220,221,223,225,232,233$, 239, 242, 527; Degung, 527; Lugu, 138; Paridjata, 82

Sinoman, 45

Sinta, 21, 57

Sjamsuddin, 69

Slamet, S., 171, 208, 528

slometan, 9, 10

slendang, 161

slendro, 5, 30,85-6, 88, 89,91,92,97,98, 100, 102, 104, $106-7,112,116,123,139,145,147-8,149,152,525$; patet manjura, 91, 92, 142-3, 155-7; patet nem, 128, 152-3, 155-7; patet sanga, 83, 92, 105, 114, 116, 120, 123, 124, 152-3, 155-7;

Scheinmodulation, 126, 179

sliring, 87, 104, 114, 146, 184, 198, 200

slurs, 125, 133, 135

Smara Dahana, 47

social criticism, 20,34

Soedarsono, 526

Soekarno, 14, 33, 35, 58

Soema Di Pradja, R. Hassan, 10, 168

Sopandi, A., 69

sorog, see exchange tones

sorogan, see exchange tones

spectograph, 182

splicing of motives, 84, 129

Srepegan: Dandanggula, 6; Rambangan, 167

Srikandi, 69, 160

Sriwidjaja, 21

Stockmann, D., 77, 176, 177, 209

study, knowledge, 102, 123, 125

Sudradjat, $130,136,158,161$ 
Sujitno, 80, 112

suling, 85, 87, 527

Sultan of Djogjakarta, 6, 26, 27, 69, 70

suluk, $5,17,25$

Szomarah, 14

Sumardjo, 69

Sunan: Bonang, 25; Geseng, 25; Giri, 25; Gunung Djati, 25;

Kalidjaga, 25; Madjaagung, 25; Murjapada, 25; Padjang, 25

Sunarta, 111

Sunda, see West Java

Sundanese Culture Area, 67

Sundanisation, 17

sunrise, $30,31,57$

Supardi, 111

Surabaja, 31

Surakarta, 26, 27,68,69,70,86,94,95, 167, 526

surupan, 150

Susuhunan, 6

Sutamdio, 80

syncretism, 22, 29

Taman Siswa, 172

tarian, see dance; tandak, 43

tatamitjingan, 64

Tawan, 46

Tedjohadisumarto, R., 12, 40, 45, 46, 47, 50-5, 91, 116, 173, $174,175,182,209,526$

tembang, 3, 5, 6, 10, 11, 12, 14, 28, 30, 35, 37, 39, 42, 43, 52, 526, 527; ardja, 38; asal, 144; buthin, 44; gede, 4, 6, $17,21,24,28,39,40,42,44,45,69,70,526$; gending, 39, $118,120-3,142,144,164,165$; kaajeunaan, 44; matjapat, 3-15, 
$16-17,21-5,27-32,36,38-45,67-71,82-3,94-6,102-36$, $137-65,526,527$; pendapa, 32; tengahan, 5, 17, 23, 25, 28, $39,40,43,44,524,526$; tjilik, 28, 39

temple reliefs, 21

tempo, 78, 125, 141, 142, 143

tengah (timbre), 160-1

theatre, 3-5, 11-14, 21, 23,26, 28, 30, 32, 126

theme, 105

tingkeban, 9

Tirip, 46

Tirtaamidjaja, N., 525

tjangkriman, see puzzles

Tjigugur, 42

Tjirebon, 10, 167

Tjukur Baji, 9

tzutur, $88,115,116,118,128,198$

Tobing, K., 158, 161

Togog, 46

tonal glottal stop, 82

tone: hierarchy, 89, 98; prominence, 98-9, 107, 116, 123-4, 128,

$134,151,156,157,180,181,183,201$; repetition, 101, 102, $103,107,108,109,120-3,124,126,130,133,134,135,136$, $137,138,139,141,143,160,181,201$; system, 85, 177, 201 trade, 24

transcription, $71-82,176$

Transcriptions (Javanese): (1), 57, 63, 69, 82, 89, 102, 103, 104, $106,107,108,109,111,112,113,115 ;(2), 58,59,69,88$, $138 ;(3), 13,58,63,69,146 ;(4), 62,69 ;(5), 60,63,69,82$;

(6) $, 69,83,122,142,143 ;(7), 60,62,69,122,123,125$;

$(8), 60,69,149,122,123,125,150 ;(9), 64,69,83,123,125$;

(10), 60,69, 83; (11), 13, 57,69, 82; (12), 62, 63, 69, 148;

$(13), 59,69,82,125,126,127-8,139,148,170 ;(14), 57,69$,

105,$150 ;(15), 57,58,64,69 ;(16), 58,60,69,82,88,95$, 
$115,116,117,118,119,147,176 ;(17), 7,69,82,150 ;(18)$, $82,138,149 ;$ (19), 82, 102, 103, 104, 105, 107, 109, 113, 117; (20), 63; (21), 82, 150; (22), 82, 138, 151; (23), 59, 82, 139, $155 ;(24), 54,72 ;(25), 123 ;(26), 83 ;(28), 147 ;(29), 137$; $(30), 83 ;(31), 83,137 ;(32), 83 ;(33), 58,69,82 ;(34), 69$, 82,$138 ;(35), 63,69,140 ;(36), 59,69,82,102,104 ;(37)$, 69,$123 ;(38), 69,82,102,103,105,106,107,114 ;(39), 69$, $83 ;(40), 69,83,123 ;(41), 83,119,120,150 ;(42), 82,126$, $148 ;(43), 64,69 ;(44), 7,69,82 ;(45), 7,69,83,118,119$, $120,121,123,142,144 ;(46), 7,63,69,83,118,119,120,121$, $142,143,144 ;(47), 58,63,69,82,99,102,103,104,106,107$, $111,113,114,137,170 ;(48), 60,69,83 ;(49), 63,69,82,147$, $149 ;(50), 63,69,82,83,151 ;(51), 14,58,69,168 ;(52), 63$, $69,83,168 ;(53), 60,69,82,146 ;(54), 69,82,96,102,104$, 123,$150 ;(55), 82,96,102,104,113,117 ;(56), 82 ;(57), 82$; $(58), 82,102,104,113,117 ;(59), 82,96 ;(60), 42,82,96$, $107 ;(61), 83 ;(62), 82 ;(63), 123 ;(64), 82,102 ;(65), 82$, 104,$140 ;(66), 82 ;(67), 116,123,147 ;(68), 82 ;(69), 58,82$, $88,115,116,117,118,119,123 ;(70), 54,58,82 ;(71), 58$; $(72), 60,82 ;(73), 59,60,83,125 ;(74), 123,124,125 ;(75)$, 7,$59 ;(76), 59,83 ;(77), 59,83 ;(78), 61,69,147 ;(80), 69$; $(81), 69,82,148,126 ;(83), 69,83,124,170 ;(85), 59,82$; $(86), 82,147,181,170 ;(87), 58 ;(89), 60,83,170 ;(90), 82$, $102,104,111 ;(92), 59 ;(93), 83,124 ;(95), 107 ; \quad(98), 58$, $82,115,116,117,118,119,155 ;(99), 57 ;(100), 57 ;$ (101), $60,83,125 ;(102), 60,83 ;(103), 60 ;(104), 60 ;(105), 60,61$; $(107), 58,82 ;(108), 82 ;(109), 58,82 ; \quad$ (110), 60; (111), $10,61,83$; (113), 60; (117), 59; (118), 83, 119, 120, 121, $122 ;(119), 83 ;(120), 60 ;(121), 10,61 ;(123), 58 ;$ (124), 60,$83 ;(125), 60,82 ;(126), 58,82,60 ;(127), 61 ;(130)$, 59 ; (131), 60, 82; (132), 59, 82, 102; (133), 61; (134), 71, $128 ;(136), 6,7,54,58,60,61,71,142 ;(137), 6 ;(138), 6$, $143 ;(139), 143 ;(140), 58 ;(141), 59 ;(142), 58 ;(144), 59$ 
'Transcriptions (Sundanese): (1), 83; (2), 83; (3), 83; (4), $83,129-31 ;(5), 83,141 ;(6), 83,141 ;(7), 83 ;(8), 83$, 149, 150; (11), 83; (12), 83; (13), 83; (14), 83, 150; (15), 83, 134-6; (16), 83, 129-31; (17), 83, 150; (18), 138, $149 ;(20), 130,132-4 ;(21), 83,150 ;(22), 83,138 ;(23)$, 139,$155 ; \quad(24), 83,134-6$; (25), 83, 129-31; (26), 83; (27), 83, 129-31; (28), 83, 141; (29), 39, 83; (30), 83; (31), 83; (32), 83, 134-6; (33), 83; (34), 83; (36), 83; (38), 83; (39), 83; (40), 83, 134-6; (41), 83, 150; (42), 83, 134-6; $(43), 83 ;(44), 83 ;(46), 83 ; \quad(49), 136,149 ; \quad(50), 151,83$; $(52), 14,83 ; \quad(53), 83,134-6 ; \quad(54), 83,150$ transposition, $78,89,106,107,116,151,156-7,201$ triads, 128, 139 triplet, 126 turns, 117, 121, 124, 201

Uhlenbeck, E.M., 170, 209 ujon-ujon, 6, 69 unity of arts, 3-4

Upatjara Mudun Lemah, 10 uran-uran, 7

variability, 107, 109, 118, 120, 127, 137, 140-1, 201 variants, $71,82,102,121,138,151,201$ versions, $82,102,122-36,138,151,201$ vibrato, $81,111,112,117,125,129,132,133,160,161,162$, 164,201 villages, $4,5,6,7,9,12,19,20,28,29,30,32,34-6$ Vishnuism, 18 
Vlekke, B.H.M., 528

vocal glottal stop, 81,113

vocal: style, 94, 96, 137, 160-1, 165, 186, 201; timbre, 112, 126,130 ; tones, $87,113-14,118,128,130,134-5,141,147-9$, 201

Wajang, 3, 12, 13, 20, 21, 23, 24, 27, 28, 29, 30, 37, 46, 53, 167, 523, 528-9; Kulit, 4, 8, 30, 32, 89, 152; Orang, 4, 7, $13,30,69,142,171$; Perdjuangan, 171

Wali, $24,25,41$

wangsalan, 53,174

war, $29,47,51,58$

weddings, 10

welcome to guests, 48

Wertheim, W.F., 169, 172, 209

West Java(nese), Sunda(nese), 5, 8, 9, 10, 11, 17, 31, 38, 39, $42-3,62-4,68-9,93,108,137,138,139,140,148-50,152$, $155,159,161,168,176$

wizah, 180

Wirangrong, 25

Wonogiri, 8,68 